\title{
Bioengineering of novel 3D scaffolds for cell-based therapy in heart failure and diabetes mellitus
}

Citation for published version (APA):

Sondermeijer, H. P. (2019). Bioengineering of novel 3D scaffolds for cell-based therapy in heart failure and diabetes mellitus. [Doctoral Thesis, Maastricht University]. Ridderprint. https://doi.org/10.26481/dis.20190517hs

Document status and date:

Published: 01/01/2019

DOI:

10.26481/dis.20190517hs

Document Version:

Publisher's PDF, also known as Version of record

\section{Please check the document version of this publication:}

- A submitted manuscript is the version of the article upon submission and before peer-review. There can be important differences between the submitted version and the official published version of record.

People interested in the research are advised to contact the author for the final version of the publication, or visit the DOI to the publisher's website.

- The final author version and the galley proof are versions of the publication after peer review.

- The final published version features the final layout of the paper including the volume, issue and page numbers.

Link to publication

\footnotetext{
General rights rights.

- You may freely distribute the URL identifying the publication in the public portal. please follow below link for the End User Agreement:

www.umlib.nl/taverne-license

Take down policy

If you believe that this document breaches copyright please contact us at:

repository@maastrichtuniversity.nl

providing details and we will investigate your claim.
}

Copyright and moral rights for the publications made accessible in the public portal are retained by the authors and/or other copyright owners and it is a condition of accessing publications that users recognise and abide by the legal requirements associated with these

- Users may download and print one copy of any publication from the public portal for the purpose of private study or research.

- You may not further distribute the material or use it for any profit-making activity or commercial gain

If the publication is distributed under the terms of Article $25 \mathrm{fa}$ of the Dutch Copyright Act, indicated by the "Taverne" license above, 
Bioengineering of novel 3D scaffolds for cell-based therapy in heart failure and diabetes mellitus.

Hugo P. Sondermeijer, 2019. 
Colophon.

Bioengineering of novel 3D scaffolds for cell-based therapy in heart failure and diabetes mellitus.

Hugo P. Sondermeijer, 2019.

All rights are reserved. No part of this publication may be reproduced, stored, or transmitted in any form or by any means, without the permission of the copyright owners.

ISBN/EAN: 978-90-829118-8-6

Layout by Hugo P. Sondermeijer

Printing: Ridderprint BV, www.ridderprint.nl

Illustrations by Hugo P. Sondermeijer

The printing of this thesis was kindly supported by Maastricht University.

Cover image: transverse section of infarcted and fibrotic left ventricle (blue, front cover) with 3D scaffold (red; back cover) patched to the epicardial surface of the heart (Masson's trichrome stain, 100x). Also see page 47.

Invitation page marker image: "Ring of Fire" - injected viable ring-shaped pancreatic islets, distributed in and around 3D scaffold, between right abdominal rectus muscles, visualized by PET. A plane of liver is also shown. Also see pages 62, 64 and 72 . 


\title{
BIOENGINEERING OF NOVEL 3D SCAFFOLDS FOR CELL-BASED THERAPY IN HEART FAILURE AND DIABETES MELLITUS
}

\author{
Proefschrift \\ ter verkrijging van de graad van doctor \\ aan de Universiteit Maastricht, \\ op gezag van de Rector Magnificus, \\ Prof. dr. Rianne M. Letschert \\ volgens het besluit van het College van Decanen, \\ in het openbaar te verdedigen \\ op vrijdag 17 mei 2019 \\ om 14.00 uur \\ door \\ Hugo Pieter Sondermeijer \\ geboren op 16 april 1975 \\ te Leiderdorp
}




\section{Promotores:}

Prof. dr. M.J. Post.

Prof. dr. A. van der Laarse, Leids Universitair Medisch Centrum, Leiden.

\section{Beoordelingscommissie:}

Prof. dr. T.M. Hackeng (voorzitter).

Prof. dr. H.B.J. Karperien, Universiteit Twente, Enschede.

Prof. dr. P. Habibovic.

Prof. dr. G.M.J. Bos.

The research described in this thesis was kindly supported by the following grants/foundations: European Society of Organ Transplantation (ESOT)/American Society of Transplantation (AST) Joint Exchange Grant, The Transplant Society (TTS) Leslie Brent Award, National Institutes of Health (NIDDK and NHLBI), multiple Leiden University Fund Grants, Dr. E. Dekker Dutch Heart Foundation Grant, Johannes Keur Fund, Schuurman Schimmel-van Outeren Foundation, Dr. Saal van Swanenberg Foundation, and Fundatie van de Vrijvrouwe van Renswoude Foundation. 
Table of Contents - 1

Chapter 1 General introduction, aims, hypothesis and thesis outline - 3

Part I - Bioengineered scaffolding for cell transplantation - 24

Chapter 2 Optimization of alginate purification using polyvinylidene difluoride membrane filtration: Effects on immunogenicity and biocompatibility of three-dimensional alginate scaffolds - 25

Chapter 3 RGDfK-peptide modified alginate scaffold for cell transplantation and cardiac neovascularization - 39

Chapter 4 Islet grafting and imaging in a bioengineered intramuscular space $-55$

Chapter 5 The long road to pancreatic islet transplantation - an intermezzo 69

\section{Part II - Mechanisms of stem cell mediated tissue repair - 74}

Chapter 6 CCR3- and CXCR4-mediated interactions regulate migration of CD $34^{+}$human bone marrow progenitors to ischemic myocardium and subsequent tissue repair - 75

Chapter 7 Downregulation of the CXC chemokine receptor 4/stromal cellderived factor 1 pathway enhances myocardial neovascularization, cardiomyocyte survival, and functional recovery after myocardial infarction - 87

\section{Part III - Discussion and summaries - 102}

Chapter 8 General discussion and future perspectives - 103

Chapter 9 Summary in English - 125

Chapter 10 Nederlandse samenvatting - 129

Part IV - Addenda - 132

Appendix 1 Mesenchymal lineage precursor cells induce vascular network formation in ischemic myocardium - 133

Appendix 2 Therapeutic effects of human STRO-3-selected mesenchymal precursor cells and their soluble factors in experimental myocardial ischemia - 139

Appendix 3 Effect of ex vivo-expanded recipient regulatory $\mathrm{T}$ cells on hematopoietic chimerism and kidney allograft tolerance across MHC barriers in cynomolgus macaques - 155

Appendix 4 Valorization addendum - patent - 169

Appendix 5 Acknowledgements, list of publications, curriculum vitae - 177 



\section{Chapter 1}

General introduction, aims, hypothesis and thesis outline. 


\section{GENERAL INTRODUCTION TO REGENERATIVE MEDICINE}

\subsection{GENERAL CLINICAL BACKGROUND}

Heart failure (HF) and insulin dependent diabetes mellitus (IDDM) pose major health threats in the Westernized world. While pharmacotherapy and solid organ transplantation are established interventions, their effectiveness and utility need improvement. Cell therapy and tissue engineering are novel approaches that may drastically change therapeutic options for millions of patients. This thesis focuses on applications of both cell therapy and tissue engineering in management of $\mathrm{HF}$ and IDDM.

\subsection{HF: CLINICAL DISEASE BACKGROUND}

In the past 30 years, major advances in therapeutic intervention in the developed world have resulted in decrease by more than two-thirds of patient mortality from acute myocardial infarction (AMI), uncontrolled hypertension, valvular heart disease, and congenital heart disease. Since mortality is reduced and HF develops in 1 out of every 10 men and 1 out of every 12 women over the age of 60 years, this results in more than 1 million hospitalizations at a cost greater than $\$ 40$ billion annually in the USA alone (1). Cardiac disease, frequently characterized by AMIs, is the main cause of death in the Western hemisphere (2). It is due primarily to insufficient blood supply to an identifiable part of the heart as a result of vascular narrowing. Depending on the severity and location of the vascular injury and/or narrowing, lack of blood supply results in death of variable sections of myocardial tissue (infarct). If the infarct is large and in a critical location, as in a major early blockage of the left anterior descending artery (LAD, also known as the "widow-maker"), the patient is likely to die acutely. With smaller damage or a less critical location, the infarct results in a scar which, depending on its size and location, may result in arrhythmias, contractile dysfunction, and/or lead to $\mathrm{HF}(3,4)$. Repair of the damaged part of the heart muscle depends on revascularization of the underperfused (ischemic) area, which can be achieved clinically by percutaneous coronary intervention (PCI), usually with, but also without stent placement. Alternatively, novel experimental approaches explore the application of stem cell populations or biomaterials with pro-angiogenic properties directly to the area of AMI. Replacement or repair of infarcted tissue by methods involving cell technology are being presently studied and evaluated in order to support contractile cardiac function and to normalize electrical conduction of the damaged areas of the heart.

\subsection{HF: PRECLINICAL MODELS}

Animal models of $\mathrm{HF}$ are required for testing of safety and efficacy of novel invasive therapeutic interventions such as stem cell therapy or tissue engineering. Since the 1970's, many HF models have been developed in various species, including mice, rats, dogs, cats, pigs, and monkeys. These usually artificial manipulated acute models include HF through valvular lesions such as stenosis or regurgitation, primary dilated cardiomyopathy due to genetic mutations in cytoskeletal, sarcolemmal, sarcomeric, and nuclear envelope proteins, secondary dilated cardiomyopathy due to coronary artery disease or hypertensive heart disease and restrictive cardiomyopathy due to underlying systemic conditions such as sarcoidosis. Large animal models are useful because they mimic human physiology better than small animal models and allow the use of clinical instrumentation. They are employed less frequently because of the high costs, and in case of (non-)human primates may raise ethical issues.

An example of one such model is AMI, produced by slow inflation of a balloon cuff placed around the LAD, which transiently stops coronary blood supply to the left ventricular (LV) myocardium. An alternative method is placement of an intraarterial balloon, which permits a less invasive percutaneous approach but requires radiographic imaging to visualize location of the balloon in the coronary artery. EKG tracings, implanted pressure recording devices, and echocardiography are subsequently used to qualify and quantify myocardial infarct size, location and expansion over time during balloon inflation, and collection of serial serum samples to confirm the presence of evolving cardiac damage. Genetically modified mice permit studies of the influence of cell therapy or tissue engineering interventions on the improvement of outcome and gain or loss of function of specific genes in response to these interventions (5). The disadvantage of small animal models is that the results this obtains are not always translatable to the human situation. The small size of the animals also makes some technical interventions more challenging. For example, the small animal AMI model is complicated by unwanted variability and difficulties in precise definition of injury since delicate operations, such as coronary artery ligation, are difficult in a small dynamic space (i.e. rapidly contracting LV) (6). Ultimately, consistent animal models are indispensable as there are no in vitro or in vivo alternatives that can mimic a multimodal disease such as HF in a sufficient number to yield statistically significant results in early stages of feasibility testing.

\subsection{IDDM: CLINICAL DISEASE BACKGROUND}

IDDM or diabetes mellitus type I is a lifelong, incapacitating disease affecting many organs. The total number of people with IDDM is projected to rise world-wide from 171 million in 2000 to 366 million in 2030 (7). IDDM is a chronic disorder that results from autoimmune destruction of the insulinproducing B-cells in pancreatic islets (8). The need for replacement of pancreatic islets either as a total pancreas or as islet replacement in patients with IDDM is critical for optimal continuous control of blood sugars not possible with insulin injections 
alone, even with a pump, regardless of which pumps or regimens are used. Optimal glucose control is needed to avoid frequently tragic consequences of inadequate control such as episodes of ketoacidosis, hypoglycemic unawareness with consequent syncope and accidents, blindness, peripheral vascular disease and neuropathy, amputations, renal failure, cardiac disease, strokes and a multitude of other problems associated with this disease. Almost all attempts at clinical transplantation of isolated human pancreatic islets from one donor of a single whole pancreas, and usually two pancreases from two donors, following Edmonton's Group protocol, have relied on intrahepatic percutaneous injection through portal vein access under fluoroscopic guidance (9). The advantage of such a location is that the islets are immediately vascularized and that released insulin passes through the liver first. The major disadvantage is that the transplanted islets are immediately attacked by an overwhelming inflammatory response resulting in up to $50 \%$ islet loss, frequently requiring two, and even more, islet transplantations (10). With the universal shortage of organ donors, and the very large number of diabetic recipients, this approach is clinically impractical. The present goal of islet transplantation is to find another easily accessible site, less injurious to islets and allowing allograft removal in case of for instance infection, cancer or hyperplasia. Intramuscular or subcutaneous and even intraperitoneal implantation is most attractive, as long as they are performed with minimal (i.e. laparoscopic) intervention and the integrity of the implantation site can be well controlled and monitored for islet number and survival. Insulin producing cells, either from autologous, allogeneic or xenogeneic pancreases, or derived from stem cells, in combination with tissue engineering and carrier materials, are being investigated by many groups around the world (11).

\subsection{IDDM: PRECLINICAL MODELS}

Similar to HF models, IDDM models exist in mouse, rat, rabbit, pig, and non-human primates (reviewed in $(12,13)$ ). Mouse models can provide important mechanistic insights, while pig models are generally favored due to the similarities to human anatomy, physiology (especially pancreatic islets), size, and, in contrast to non-human primates, greater availability, less cost and less ethical objection. Several techniques have been used to induce hyperglycemia and a diabetic phenotype: dietary intervention, chemical induction, and pancreatectomy and, in mice, genetic modification. Dietary intervention has led to variable and relatively unreliable results. Since pigs do not become diabetic spontaneously, a high caloric diet resulting in obesity has led to variable results not readily amenable to correction with pancreas or islet transplant (reviewed in (13-15)). Streptozotocin (STZ) and alloxan (ALX) are chemical agents commonly used to induce IDDM in swine, rodents, rabbits, and non-human primates. Both chemicals are toxic glucose analogues that are transported into cells via the GLUT2 transporter. ALX generates toxic free radicals, leading to pancreatic cell death via necrosis, whereas STZ, once it has entered the cell, is cleaved and generates free methylnitrosourea that induces DNA fragmentation and necrotic cell decay. Both chemicals lead to hyperglycemia resulting from insulin deficiency. Among the best rodent models, there are the nonobese diabetic (NOD) mice (16) and BioBreeding (BB) rats (17). NOD mice were developed at Shionogi Research Laboratories in Aburahi, Japan in the 1980's (18), and have a polygenic phenotype to spontaneous development of IDDM as a result of insulitis, a leukocytic infiltrate of the pancreatic islets. BB rats are inbred rats that also spontaneously develop IDDM, and have greatly contributed to the research of IDDM pathogenesis (19). Both NOD mice and $\mathrm{BB}$ rats also have inherent biological problems which have led to misconceptions and erroneous extrapolations, as well as false expectations with regard to the efficacy of immunotherapy (20); most recently diabetic mice became available, which are biologically very precisely defined and are insulin deficient as a result of transgenic modification. Among large animal models there are spontaneously diabetic dogs which are difficult to obtain and pigs or monkeys where total pancreatectomy is another approach in the production of recipients who have brittle diabetes and insulin deficiency $(21,22)$. The latter model has many animal welfare and clinical management issues as well as significant variability and mortality. Ethically, more acceptable models with a diabetic phenotype are transgenic pigs which express the mutant insulin $\mathrm{C} 94 \mathrm{Y}$ or transgenic pigs which express a dominant-negative GIP receptor (GIPRdn). Which model is best suited heavily depends on the research question. Large animal models are usually chosen to validate results obtained in small animal models prior to translating the findings to studies in humans, since large animal models usually mimic human physiology better than small animal models. In some experimental settings, large animal models allow for novel therapeutic interventions without interference of standard of care therapy, as we have shown in our non-human primate studies for tolerance induction using regulatory T-cell ( $\mathrm{T}_{\text {reg}}$ ) therapy ((23), Appendix 3). Such studies would not be possible in human subjects, because they would imply abandoning immunosuppressive therapy (i.e. standard of care) after kidney transplantation.

\section{THE MEDICAL NEED}

\subsection{DONOR ORGANS AND DONOR ORGAN SHORTAGES}

Organ and tissue transplantations are life-saving procedures for patients with acute and/or chronic organ failure. Between 2000 and 2017, 509,889 patients in the USA received a solid organ allograft (24), while 571 allogeneic islet transplants were performed between 1999 and 2009 (25). 
Unfortunately, as of June 2018, in the USA alone more than 125,000 patients are waiting for a donor organ, while shortage of their availability is great and on the rise. This has resulted in a very high risk of death in all patients on the waiting lists, even those on dialysis, and certainly much higher and faster risk of death when liver, lung, and heart transplantation are concerned. In addition, many patients on the renal or pancreatic waiting lists have reduced quality of life (QOL) in the absence of available donor organs. In 2017, the majority of organ transplantations in the USA included kidney $(n=19,849)$, liver $(n=8,082)$, heart $(n=3,244)$, lung $(n=2,449)$ and less frequently, pancreas $(n=213)$ (adapted from Organ Procurement and Transplantation Network (OPTN) (24) (Figure 1).

There are two major obstacles to successful organ transplantations. One, documented in great detail in several registries in the USA and in Europe such as UNOS (26), STRT (27) and Eurotransplant (28), is the limited number of available and appropriate (deceased or living) donors. The other is medicine's inability so far to treat end-stage organ failure adequately by other means than organ transplantation and our present lack of knowledge and inability to successfully transplant other than human organs, i.e. xenotransplants. Public campaigns and governmental support and encouragement in some countries (i.e. Spain, Belgium, and more recently, the Netherlands) have increased awareness and public willingness to participate in various donor programs by an opt-out approach, i.e. one is automatically an organ donor unless personally stated otherwise. Despite a variety of efforts in many countries, a major shortage of donor organs remains.

Most transplantation candidates could benefit from repair of donor organs or their regeneration which would most likely involve cell therapy or tissue engineering: (1) many heart transplants are performed in patients with endstage $\mathrm{HF}$ due to multiple MIs that might be repaired by cellular therapy; (2) many liver transplants, especially in children, are performed for metabolic liver deficiencies which might be corrected with appropriate hepatocyte transplants; (3) $25 \%$ of renal transplants are performed for endstage renal disease secondary to progressive IDDM which might have been prevented, or treated, by early pancreatic islet transplants.

\section{A SOLUTION TO DONOR ORGAN SHORTAGES: CELL THERAPY AND TISSUE ENGINEERING}

This thesis focuses on two possible therapies for several end-stage organ diseases, based on cellular transplantation and bioengineering, to complement, and in some instances replace, the use of a limited number of available donor organs. Beyond the scope of this discussion is the possibility to replace human damaged organs by xenogeneic grafts (most likely porcine), which would rapidly decompress the transplant waiting lists. We and others postulate that it may be advantageous and possible in the near future to treat patients with end-stage organ disease/failure, based on availability, with off-theshelf cellular products (isogenic, allogeneic, or xenogeneic) and/or tissue engineered organs. Such modern cell and biomaterial products and techniques may prove to be more effective and efficient than current approaches, in that cells and/or artificial organs could be mass-produced and supplied independently of donor derived organs. The first two approaches we investigated consist of the use of (progenitor) cell transplantation for: (1) organ and blood vessel repair and regeneration, and (2) for defective cell replacement in various metabolic disorders, including IDDM. The second series of approaches focus on various types of tissue engineering, including use of multipotent progenitor cells and appropriate biomaterial scaffolds with a milieu favorable for the introduced cells to form a structure that may partially or completely replace the organ.

The heart, bladder, esophagus and bone (29-32) are examples of such organs or tissues that have already been experimentally repaired or replaced. This innovation may become less urgent (i.e. for heart, kidney, pancreas, lung) when xenotransplantation based on recent progress in genetic engineering of donor pigs using CRISPR/Cas9 technology advances sufficiently to enter the clinical arena (33). Mutagenesis remains an important problem with different methods of genetic engineering, including CRISPR/Cas9 technology (34-36). Furthermore, an important challenge to successful cell and tissue transplantation is prevention of the host immune responses to avoid rejection of the transplanted cells or tissues, as well as prevention of reactions to any non-cellular biomaterial that is used. Rejection of whole organs is more difficult to prevent than prevention of rejection of cell and/or tissue transplants (which are easier to manipulate in vitro); the latter approach may therefore be more effective and safer. To further mitigate the risk of rejection, immunologic manipulation may be performed in vitro prior to cell transplantation or may be maintained in situ in direct contact with the allografted cells in an immunomodulated scaffold. Three-dimensional scaffolds can be chemically and biologically modified with certain immunomodulatory proteins or other compounds before implantation to abrogate local immune responses, as elegantly reviewed by Singh and Peppas (37). In another example of possible physical modification, treatment of rat dendritic cells, platelets, or islet allografts with ultraviolet B (UVB) irradiation in vitro completely abrogated their allostimulatory capacity (38). Furthermore, the use of transplantation of cells introduced with a scaffold may lead to improved engraftment in the target organ, such as the pancreas or the heart, as we suggest in our preliminary studies (Chapters 3-5, (39-41)). Hence, the choice of cells as well as biomaterials for the scaffold is pertinent. 


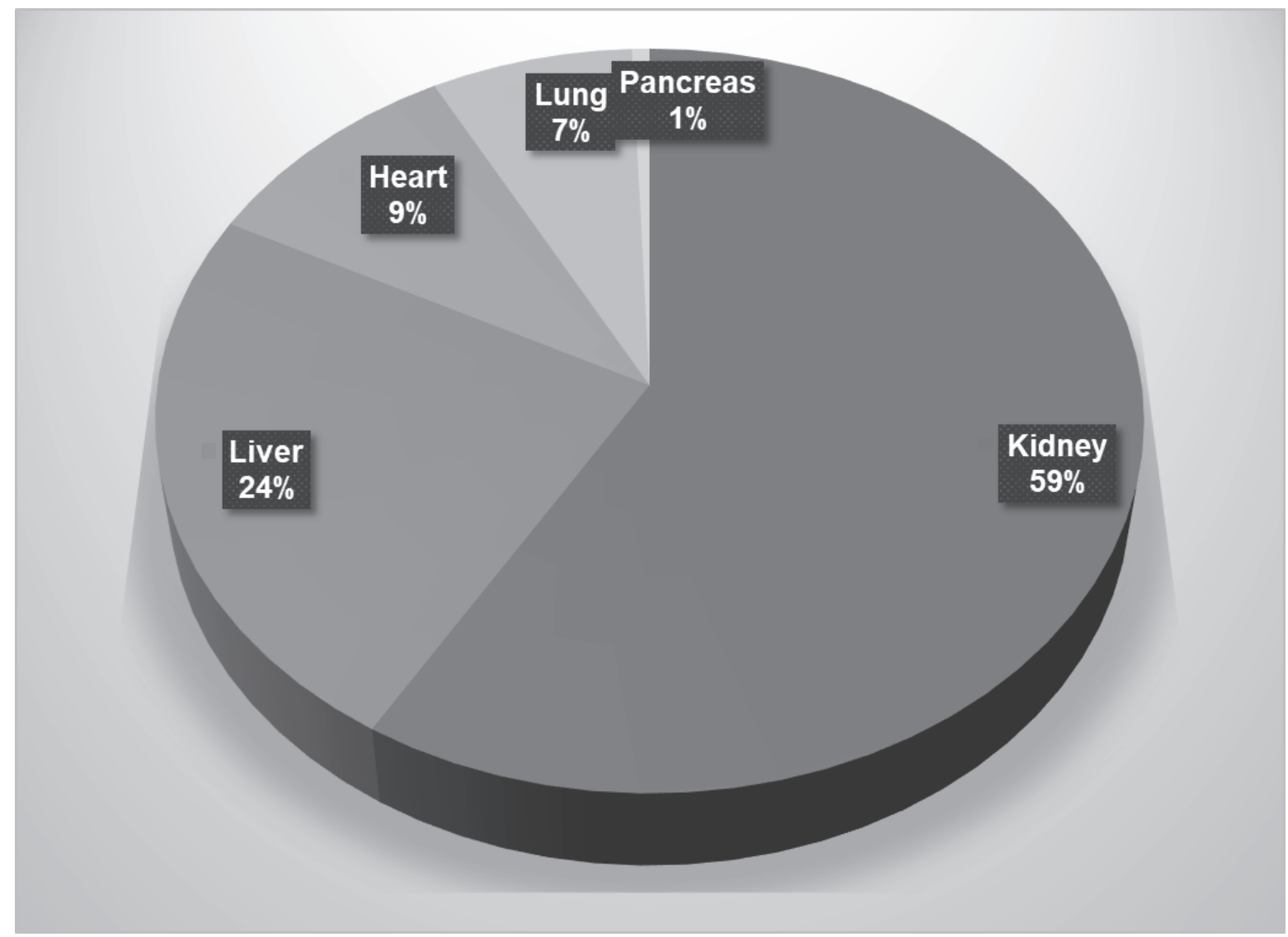

Figure 1. Solid organ transplantations including living and deceased donors in 2017. Obtained from Organ Transplant and Procurement Network (OPTN). Total number is 33837 (24).

\subsection{CELLS}

\subsubsection{CELL THERAPY AND THE ROLE OF CHEMOKINES IN CELL TRANSPLANTATION}

The first clinical bone marrow stem cell transplantation was performed by a French oncologist and immunologist, Georges Mathé, in November 1958. His efforts extended even to allogeneic bone marrow transplants in unrelated human beings (42). The whole field of cell and organ transplantation was finally honored when Edward Donnall Thomas, an American hematologist, and Joseph Edward Murray, an American plastic surgeon, shared the 1990 Nobel Prize in Physiology or Medicine for their discoveries concerning "organ and cell transplantation in the treatment of human disease". Back in 1957 Thomas, who has been called the father of bone-marrow transplantation, treated a patient with leukemia using high doses of totalbody irradiation to first eradicate the cancer, and then infused him with marrow cells from an identical twin (43). In 1954, Murray performed the first successful kidney transplantation between identical twins at the Peter Bent Brigham Hospital (later Brigham and Women's Hospital) (44).

Since then, stem cell research, stem cell therapy and transplantation medicine have made enormous progress. Since 1982, characterization and clinical use of various stem cell populations have been standardized and improved by the implementation of the cluster of differentiation (CD) protocols. The CD nomenclature was intended for the classification of monoclonal antibodies (mAbs) generated by several different laboratories around the world against cell surface epitopes of leukocytes, but has been extended to characterize tissue (stem) cells (45). Each CD epitope represents a specific cell surface molecule, for example a chemokine receptor on lymphocytes such as CD184, or the hematopoietic progenitor cell marker CD34. As of July 2018, 371 human CD epitopes have been described and many have been characterized.

Clinical cell-transplantation trials for tissue regeneration and/or repair have met with mixed results. In 2000, Shapiro and colleagues at the University of Alberta reported remarkable early success with clinical islet transplantation implanted into the liver using a steroid-free protocol with a median follow up of 11.9 months (9). This achievement has been successfully reproduced by a few, but not all centers. Hardy and colleagues at Columbia University Medical Center have had only two successful clinical transplants, and their efficacy lasted only 6 months (Chapter 5, (41)). Similarly disparate results have been reported with clinical bone marrow (stem) cell transplantation trials for treatment of congestive HF following AMI. Moderate improvement in cardiac function was achieved in one large clinical study (TOPCARECHD trial, (46)) while no success was noted in another (ASTAMI trial, (47)). The recent metaAnalysis of Cell-based CaRdiac stUdiEs (ACCRUE) 
of several bone marrow stem cell trials (ASTAMI, Aalst, BOOST, BONAMI, CADUCEUS, FINCELL, REGENT, REPAIR-AMI, SCAMI, SWISS-AMI, TIME, LATE-TIME, with a total number of $n=1252$ concluded that this approach provided no net benefit, in terms of clinical events or improvement of LV function (48). These discrepant results and uncertainties reflect differences in many variables affecting initial cellular engraftment starting with the number of donor cells needed. Other factors affecting outcomes include: 1) methods of cell preparation (e.g. use of phosphate buffered saline in the TOPCARE-CHD trial (46) vs. saline in the ASTAMI trial (47) to reconstitute bone marrow cells); 2) the site of transplantation (as in islets); 3) the type of immunosuppression or lack of it; and 4) many other conditions that may affect survival of cell isograft, allograft, or xenograft. Although metaanalyses may occasionally be misleading by providing a miscalculated or false representation of existing actual results (48), a lack of well-defined beneficial outcomes in treatment of ischemic heart disease strongly suggests that, at present, there is a lack of efficacy of intramyocardial bone marrow (stem) cell injection therapy, despite claims of some individual studies $(46,49)$.

Apart from the characterization of stem cells using CD molecules, homing of for example $\mathrm{CD} 4^{+}$hematopoietic stem cells following systemic administration or even local infusion to the correct site is a prerequisite for proper function. Bone marrow stromal tissue secretes specific proteins called chemokines that act as attractants to infused bone marrow stem cells (50). Amongst the numerous cytokines implicated in stem cell homing to the bone marrow are members of the CC, CXC and $\mathrm{C}$ family of chemokines. For example, bone marrow derived hematopoietic $\mathrm{CD}_{3} 4^{+}$progenitor cells migrate preferably towards a stromal derived factor 1 (SDF-1) gradient (51). Interestingly, CD $4^{+}$ and $\mathrm{CD}^{+} \mathrm{T}$-cells show migration patterns towards and away from an SDF-1 gradient in an inverted Ushape-like manner, moving optimally towards an SDF-1 concentration at $100 \mathrm{ng} / \mathrm{ml}$ (52). This effect was reversed at lower or higher doses, both in vitro and in vivo, indicating a pharmacodynamic doseeffect response. SDF-1, also known as CXCL-12, needs, in order to induce an effect, to bind to a cell surface receptor on target cells in order to perform its function. The surface receptor on CD $34^{+}$cells for SDF-1 is CXCR4, also known as CD184. We illustrate above how important is the identification of homing factors and their cell surface receptors in influencing the functions of the transplanted cells. Previously, it was found that SDF-1/CXCR4 plays an essential role in embryological blood vessel formation, and that CXCR4 deficient mice die in utero since they are defective in vascular development, hematopoiesis and cardiogenesis, suggesting a role for CXCR4 in endothelial cell biology and tissue (neo)vascularization (53). Subsequently, several groups, including ours, showed beneficial effects of bone marrow stem cell infusion on cardiac neovascularization and cardiac function following AMI in small animal models (Chapters 6 and 7, appendix 1 and 2, (54-57)), and (58-60)). In our models, manipulating chemokine and chemokine receptor signaling using blocking antibodies could redirect ${\mathrm{CD} 34^{+}}^{+}$ hematopoietic progenitor cells to the infarcted myocardium and enhance recovery of $\mathrm{LV}$ function $(54,55)$. These findings laid the foundation for several large clinical trials which are briefly described below. Blocking specific cell receptors which may have a role in stem cell migration by using small molecules or mAbs could inhibit homing or redirect injected cells to other tissues. For example, AMD3100 is a small molecule that blocks CXCR4 (CD184) which was developed to treat HIV infection, because HIV uses CXCR4 as a co-receptor to enter $\mathrm{CD}^{+}{ }^{+} \mathrm{T}$-cells (61). AMD3100 was later shown to also have an effect on bone marrow hematopoietic stem cell mobilization. This was based on the finding that blocking of CXCR4 disables its chemoattractant effects, and this subsequently results in a net release of $\mathrm{CD} 34^{+}$cells from bone marrow to the circulation (62).

\subsubsection{CELL THERAPY FOR CARDIAC CELL REPLACEMENT}

The following is a brief overview of cell therapy used for treatment of heart disease, including cardiac tissue-engineering approaches. As this is a very dynamic field, it is not feasible in this introduction to discuss, even briefly, every aspect of this expanding and exciting field. Cell therapy in the heart can be performed as cell injection or surgically implanted cardiac constructs consisting of cells and a biomaterial based scaffold. Figure 2 shows several scaffolds used for cardiac repair (reprinted with permission from (63)).

As described before, results of cell transplantation alone as a treatment for $\mathrm{HF}$ vary among different preclinical studies while few clinical trials have reported limited efficacy (64). Various types of cells have been used in these trials, including bone marrow stem cells, skeletal muscle stem cells, adipose tissue-derived cells and cardiac stem cells. Major problems with cell engraftment after intra-myocardial injections following myocardial injury are most likely due to a combination of factors, including 1) the unfavorable myocardial environment during infarction, 2) ischemia in the area, 3) shear stress within the myocardium due to regular or irregular contraction, 4) number and initial viability of introduced cells, 5) lack of electrical integration of the new cells with the host myocardium, and 6) remodeling of the area of injury. These difficulties are only a fraction of many others that have been previously mentioned. A large body of work currently exists in the experimental field of cell therapy for cardiac tissue regeneration (i.e. without the use of biomaterial scaffolds as a cell carrier). Based on studies as long ago as 1961, Mauro and colleagues discovered that the regenerative capacity of skeletal muscle resides in satellite cells (65). In contrast to skeletal muscle, general consensus dictates that the myocardium 


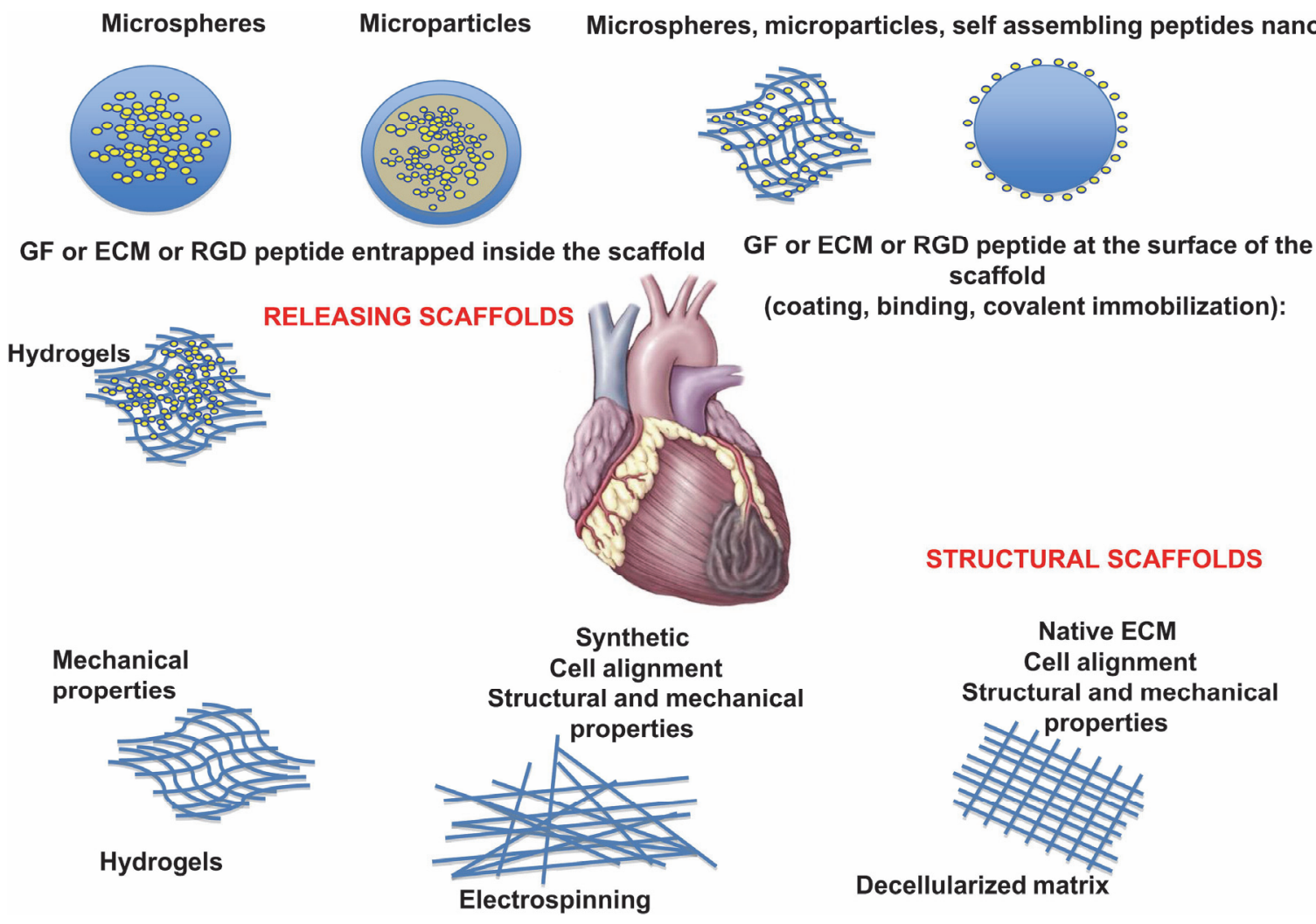

Figure 2. ECM scaffolds used for cardiac repair. With permission (63). GF=growth factor. $\mathrm{ECM}=$ extracellular matrix. RGD=Arg-Gly-Asp.

lacks a regenerative stem cell system: ventricular cardiomyocytes in the adult mammalian heart are permanently withdrawn from the cell cycle $(66,67)$. Cardiac myofiber loss due to trauma or disease is therefore considered to be irreversible. However, in 1993, Koh and colleagues showed that murine AT-1 cardiomyocytes, a differentiated tumor line derived from transgenic mice expressing an atrial natriuretic factor-simian virus $40 \mathrm{~T}$ antigen fusion gene, could be detected as long as 4 months postimplantation following direct grafting into the myocardium of syngeneic animals (68). One year later, the same group showed that murine embryonic stem cells could form nascent intercalated disks between grafted cells and host myocardium (69). Given technical and ethical issues with embryonic stem cells, alternative cell sources were promptly evaluated. Subsequently, a number of intriguing observations was published showing that 1) human cardiomyocytes may divide following AMI (70), 2) engrafted cardiomyocytes revealed chimerism following sex-mismatched cardiac transplantation (71), and 3) bone marrow-derived stem cells injected intravenously or directly into infarcted heart tissue resulted in cardiac regeneration $(58,59)$. These findings set off a frantic search for an intra- or extracardiac stem cell source that could be employed therapeutically in human subjects. A wide array of potential candidates, each with their own specific characteristics, has been discovered over the years, among them bone marrow-derived cells (hematopoietic $\mathrm{CD} 34^{+}$or non- hematopoietic mesenchymal stem/progenitor cells (MSCs/MPCs)), skeletal myoblasts, embryonic stem cells (ESCs), induced pluripotent stem cells (iPSCs), and endogenous cardiac stem cells (CSCs). A 2015 Cochrane review concluded that there is currently insufficient evidence for a beneficial effect of bone marrow cell therapy for AMI patients (72). Skeletal myoblasts are prone to cause cardiac arrhythmias and failed to show the expected beneficial effects in phase-II clinical trials (73). Very few trials (because of ethical issues) have been done with ESCs but those have shown some promising findings in nonhuman primates (74). IPSCs which can be derived from the same patient and subsequently transformed into cardiac lineages still need to be evaluated for clinical efficacy and safety. Endogenous CSCs can be identified based on their surface markers such as c-kit (CD117) or sca-1 (ly$6 \mathrm{~A} / \mathrm{E})(75,76)$, transcription factors such as the LIM-homeodomain transcription factor islet-1(isl-1) (77), and their anatomical location, for example the cardiac atrial appendage (78), or their capacity to extrude intracellular Hoechst 33342 dye using the Abcg2 transporter, so called side population (SP) cells (79). Several small clinical trials using CSCs have been performed, i.e. the SCIPIO trial, which triggered an expression of concern in the Lancet with respect to the integrity of the trial $(80)$, the CADUCEUS trial, and the ALCADIA trial (reviewed in (81)). Larger randomized controlled trials are required to assess efficacy and safety, ideal cell dose, time of infusion in regard to the 
primary injury, and frequency and route of administration. In spite of these hurdles, stem cell therapy for cardiac regeneration continues to be a highly dynamic field; a May 2018 Pubmed search on "stem cell therapy cardiac" resulted in more than 11,000 scientific papers.

MSCs/MPCs from bone marrow are cells of special interest. MSCs are characterized mainly by expression of CD44, CD90 and CD106, but not CD34, and have multilineage potential, and can differentiate into bone, cartilage, and fat tissue under appropriate conditions (82). MPCs are considered a more primitive MSC with similar multilineage potential, and are characterized by the expression of STRO-1 and/or STRO-3 $(83,84)$.

In order to identify the "optimal" cell type only limited direct comparisons have been done to compare different effects of several cell types on cardiac regeneration (85). Recently, three different bone marrow-derived stem cell sources have been evaluated following AMI, and found to have no effect on LV ejection fraction compared to standard treatment. However, a small but significant reduction of infarct size was found in cell treated groups (86). One trial sought to compare autologous vs. allogeneic bone marrow-derived MSCs in a small non-ischemic chronic HF trial using transendocardial injection, and surprisingly found a benefit of allogeneic cells compared to autologous cells (87). Mechanistically, one could speculate that allogeneic cells induce an immune response and therefore affect cardiac remodeling and cardiac function through modulation of the inflammatory response following AMI. The observation that some immunomodulatory paracrine factors improve cardiac function could explain why stem cell treatments might be effective, as we and others have shown (Appendix 2, (57)) and (88).

\subsubsection{CELL THERAPY FOR PANCREATIC ISLET CELL REPLACEMENT}

The source for the insulin-secreting cells, abundant in the human pancreas but not easily available as a donor organ, is another type of cells that is being studied by many groups. The most common and the only method used clinically is to isolate the islets from whole human pancreases. Islets are first depleted of adjoining acinar tissue by collagenase digestion and gradient sedimentation to avoid uncontrolled enzymatic secretion that may be injurious to islets and other tissues, and are then infused into the liver by percutaneous intraportal technique. The whole islet provides B-cells, a-cells and $\delta$-cells which interact and facilitate insulin function via internal controls. Investigators led by Dr. Pipeleers and Dr. Roep have attempted to reconstruct human islets for transplantation and studied the physiology of the interaction of both innate and adaptive auto- and allo-immunity with hESC-derived pancreatic progenitor cells and hESC-derived endocrine cells (89). As long as isografts, allografts, or even xenografts are used, whole islets will remain the source "organ". In the future, separate cell lineages for 6 -, $\alpha$-, and $\delta$-cells may be produced from stem cells or genetically engineered. Next, quantitative ratios of different types of cells will need to be determined and located with appropriate cell-to-cell contact - a prohibitive task when using intra-portal infusion. This type of approach could become feasible when compartmentalized three-dimensional biomaterial scaffolds are employed that allow spatial organization and appropriate orientation of several cell types through the action of various chemokines.

\subsection{BIOMATERIALS AND BIOMATERIAL SCAFFOLDS}

\subsubsection{BIOMATERIALS AND BIOENGINEERED SCAFFOLDS FOR CELL TRANSPLANTATION AND CELL ENGRAFTMENT}

To improve survival of engrafted cells following transplantation, a variety of biomaterials and processes of tissue engineering offer potential tools and opportunities for success. Most biomaterials which were known in the medical and engineering fields before tissue engineering was established, have reentered the field and have been investigated. Collagen, for example, has been, and continues to be used as a biological filler material in cosmetic surgery (90), and more recently has been used to build engineered heart tissue grafts (EHTs) (91). Polymerized fibrin (TISSEEL fibrin sealant or "fibrin glue") is used with variable results during surgery as an adhesive compound as well as repair of meningeal tears after head trauma (92), and of bronchopleural fistulas (93). Fibrin glue has also been used to achieve hemostasis after spleen (94) and liver (95) trauma. In addition, fibrin glue as injectable material has also been used as a carrier to transplant myoblasts to infarcted myocardium (96). Fibrin glue solidifies rapidly after mixing with thrombin and calcium ions and has proven useful for intramyocardial injections. Such fibrin glue carriers improved cell survival and helped to preserve cardiac function. Thus, collagen and fibrin glue have been successfully used as matrices to transplant cells into damaged tissues. Naturally occurring polymers such as collagen, either recombinant or derived from animals, and alginate obtained from seaweed, have proven to be suitable carriers for cell transplantation, but may induce undesirable immunological reactions $(97,98)$. This problem may be overcome by using material that is immunologically inert or sufficiently purified to diminish the risk of immunological rejection. Newer materials have been engineered to mimic properties of the extracellular matrix (ECM) through functional customization. In developing a new biomaterial, emphasis is placed on several characteristics; these include 1) injectability, 2) biocompatibility, 3) non-immunogenicity, 4) controllable resorption rates and 5) sufficient porosity to support in-growth of blood vessels, i.e. neovascularization. Biomaterials are either synthetic or of natural origin. Polylactic acid (PLA), for example, is synthetic polyester that degrades into lactic acid in the body, which is then easily 
metabolized, i.e. taken up by the liver where it is oxidized to form pyruvate.

The goal of tissue engineering is to overcome the limitations of established treatments based on experience with organ and cell transplantation and with implantation of biomaterials (99). In cases of organ repair, the three-dimensional (3D) lattice that houses replacement cells or tissues already exists in the extracellular spaces of the organ that is being repaired. For example, following AMI, contractile myocardium will be replaced by scar tissue, which can then be regenerated or replaced by injection of allogeneic iPSC-derived cardiomyocytes, as has been demonstrated in non-human primates (100). This approach does not support the creation of new organs designed to replace the existing ones and should be constructed from bottom up, starting with the matrix (scaffold) and then introducing cells which stimulate each other to align correctly.

One of the main methods used in tissue engineering involves growing the relevant cell(s) in vitro and then placing them on or in the threedimensional (3D) organ or tissue in vivo. Cells lack the ability to grow in favored 3D-orientations by themselves and thus are guided by the anatomical shape of the environment/tissue as well as by cellto-cell communications. Without such guidance and stimulation, most cells randomly migrate to form a two-dimensional (2D) layer of cells, while cells like fibroblasts may grow on top of each other creating a hill and valley pattern. Endothelial cells will start to form tubes, and cell mixtures in gel or fluid drops can form aggregates with self-organization of some cells to the outer layers while others prefer a central position. Since 3D-configurations are required for guidance of cell realignment, this is generally achieved by seeding the cells onto porous matrices known as scaffolds, to which the cells attach and which they subsequently colonize. The porous 3D scaffold, therefore, is a critical foundation necessary for tissue engineering. Recently, more emphasis has been placed on the importance of the architecture of the matrix, and this has led to the use of the ECM of entire organs as a 3D scaffold, by a process called decellularization $(101,102)$.

\subsubsection{BIOMATERIALS AND CELL TYPES} USED FOR CARDIAC TISSUE ENGINEERING

One of the emphasized problems with cell therapy in the heart is that the dynamic contraction and continuous mechanical shear stresses limits retention of intramyocardially injected cells (48). In order to improve cell retention and delivery to repair damaged myocardium, numerous biomaterial scaffold materials that retain cells have been investigated. 3D scaffolds with limited adhesive properties can be modified to enhance cell adhesion and retention. Scaffolds employed for cardiac repair were either engineered in vitro or in situ. In pioneering work almost 2 decades ago, 3Dpolyglycolic acid (PGA) scaffolds were studied by previously Massachusetts Institute of Technology's (MIT) and now Columbia University Medical
Center's (CUMC) Gordana Vunjak-Novakovic's bioengineering group to culture neonatal rat cardiomyocytes in a bioreactor system, and this resulted in interconnected contracting 3D structures (103). Around the same time, Smadar Cohen and Jonathan Leor applied 3D-alginate scaffolds seeded with fetal cardiomyocytes as an epicardial patch, which led to intense neovascularization, attenuation of LV dilatation, and improved LV function following AMI (104).

GFP-positive mouse embryonic stem cells suspended in Matrigel $^{\mathrm{TM}}$ (a protein mixture composed of laminin, entactin, collagen and heparan sulfate proteoglycans which remains liquid at $4^{\mathrm{O}} \mathrm{C}$ but polymerizes at body temperature) were shown to have beneficial effects on LV function after intramyocardial injection following $\mathrm{AMI}$ in $\mathrm{BALB} / \mathrm{c}$ mice (105). This method prevented distortion of the myocardium that can occur when a solid scaffold is used since it retains the geometry of the lateral LV wall. In other studies, injectable RGD-peptidemodified alginate that solidifies after mixing with calcium ions was used to generate an effective solid scaffold in situ by injecting it into infarcted myocardium together with endothelial cells (106).

We have previously shown in our studies that ex vivo engineered 3D cyclic RGD-peptidemodified alginate scaffolds seeded with adult human bone marrow-derived (MPCs) enhanced the vascular response in vivo when compared to unmodified alginate; it was therefore not surprising that cells carried by modified scaffolds improved LV function of rat hearts that were infarcted (39). MSCs/MPCs are of specific clinical interest in the treatment of cardiac disease due to their multipotential differentiation and relatively standardized and reliable expansion potential (82, 107). In addition, adipose tissue-derived MSC/MPCs have also become very attractive to various investigators due to their high availability and less invasive harvesting procedure, and the experience of their already successful use in clinical trials (108).

Other previously described scaffolds created ex vivo include engineered heart tissue constructs (EHTs) made by mixing type I collagen with neonatal rat cardiomyocytes which were then preconditioned on a stretch device (91). The resulting contractile coils were combined and transplanted epicardially in a rat AMI model. These EHTs formed thick cardiac muscle layers after implantation and showed immediate electrical coupling without inducing any arrhythmias. In addition, these constructs not only delayed further cardiac dilatation but also improved cardiac function much better than that found using control noncontractile constructs. More recent applications of EHT's include pre-clinical drug testing and iPSC differentiation studies (109).

Ex vivo treatment of heart tissue by detergents and enzymes to remove resident cells offers the advantage of retaining the whole myocardial extracellular architecture. This method was used to generate contractile cardiac patches 
and was employed experimentally to even evaluate cellular repopulation of complete functional hearts (101). Recellularization of these decellularized animal hearts with cardiac cells in vitro resulted in contracting tissue, albeit pump function was less effective than that found in the original heart.

An elegant method to prepare sheets of MSCs for epicardial transplantation is use temperature sensitive materials such as poly $(\mathrm{N}$ isopropylacrylamide) (PNIPAAM) (110). This material solidifies at body temperature, while it loses lipophilicity at a temperature of less than $20^{\circ} \mathrm{C}$. In previously described experiments in rodents, cells grown on this material were initially allowed to form an interconnected cell sheet in tissue culture incubators. By lowering the temperature, the cells were detached in the form of an intact sheet of cells. MSC monolayer sheets induced angiogenesis and improved cardiac function after epicardial transplantation to infarcted areas of mouse hearts (110). More recently, this technique was applied to generate in vitro multilayered constructs consisting of a combination of 12 layers of vascular cells and cardiac cells, which were subsequently implanted over the epigastric artery and vein in rats to create myocardial tubes in vivo (111). This technique was also applied to generate pancreatic islet cell sheets composed of a- and Bcells (112).

A direct comparison was made of intramyocardial injection of (1) human skeletal myoblast with the use of (2) human skeletal myoblast-seeded collagen scaffold, or with the use of (3) a fibrin-human myoblast bilayer cell sheet. The scaffolds or sheets were placed so as to overlay the surface of the infarcted lateral ventricular wall in rats. The results showed enhanced recovery of cardiac function in the groups transplanted with the sheet of two bilayer cells when compared with the use of myoblast injection alone (113). In this study, the human skeletal myoblast-seeded collagen scaffold was most effective in enhancing cardiac angiogenesis and reducing fibrosis when compared to human skeletal myoblast injection or to sham operations.

A small scale feasibility open-label clinical trial (MAGNUM) in $\mathrm{HF}$ patients using collagen scaffolds carrying bone marrow-derived cell transplants has been completed (114). It was found that this approach, in which a collagen patch seeded with bone marrow cells was transplanted onto the infarcted lateral LV wall, was feasible and safe. It also appeared to be more effective than were intramyocardial injections of bone marrow cells. The cell-seeded collagen matrix increased the fraction of viable tissue in the infarct scar and supported normalization of contractile performance in the injured regions, thus limiting LV remodeling and improving LV diastolic function.

The approaches which utilize tissueengineered scaffolds to transplant cells to infarcted myocardium appear to be safe and frequently effective in improving cardiac function in experimental animal models of AMI. They also appear to be a more effective method of cell transplantation when compared to direct injections of isolated cells alone. Clearly, we expect that optimal results will be achieved when appropriate cell carrying scaffolds are combined with the appropriate cell populations. This will require preliminary studies in small (rats and mice) and then large animals (pigs and non-human primates) prior to embarking on human trials. The latter may first focus on arterial limb reconstruction as blood vessels are relatively simple structures when compared to hearts and such experiments are relatively easier to perform. Once optimal outcomes are achieved in studies of regeneration of blood vessels, the subsequent evaluation of repair and alteration of more complex damaged organs such as the heart will be safer and more effective. Ideally, the optimal combination of materials and cell types for each clinical application needs to be identified and tested in appropriate animal models before their use in well designed and supervised clinical trials.

\subsubsection{BIOMATERIALS AND CELL TYPES USED FOR PANCREATIC TISSUE ENGINEERING}

We, and others, have investigated transplantation of $3 \mathrm{D}$ islet cell scaffolds into extra-hepatic sites, by evaluating several different materials and various implant sites. In 1996, for example, mouse islets were transplanted syngeneically under the kidney capsule (a preferred but hard to access site) and compared to subcutaneous and intraperitoneal sites using polyvinyl alcohol (PVA) and polyglycolic acid (PGA) scaffolds (115). These studies showed that subcutaneous islet transplantation using PGA polymers can improve the metabolic status and, in some cases, even cure diabetes in STZ-diabetic mice. In our initial studies, when RGD-modified alginate was used for intramuscular islet transplantation in rats, the prevascularized alginate scaffolds carrying pancreatic islet isografts (not individual cells) reversed permanently (120 days) hyperglycemia in STZ-induced diabetic rats, which maintained normoglycemia for 4 months and became diabetic when the islet loaded scaffolds were removed (40). Scaffold vascularization was induced by initially implanting the modified scaffolds subcutaneously for two weeks followed by injection of 400 islets into or onto the prevascularised scaffolds. The effectiveness of this approach depends on the use of prevascularised scaffolds (2 weeks). Secondly, it depends on employment of a site (intramuscular, subcutaneous or intraperitoneal) that does not favor an immediate high inflammatory reaction that could destroy the majority of the islets as it does in the intrahepatic location. Likewise, pancreatic islets enmeshed in poly(glycolide-L-lactide) copolymer fibers (Vicryl ${ }^{\mathrm{TM}}$ ) in combination with collagen/laminin gel (Matrige ${ }^{\mathrm{TM}}$ ) transplanted into the epididymal fat pad of diabetic mice also led to durable reversal of IDDM when compared to injection of "bare" islets transplanted under the kidney capsule (116). To achieve success by 


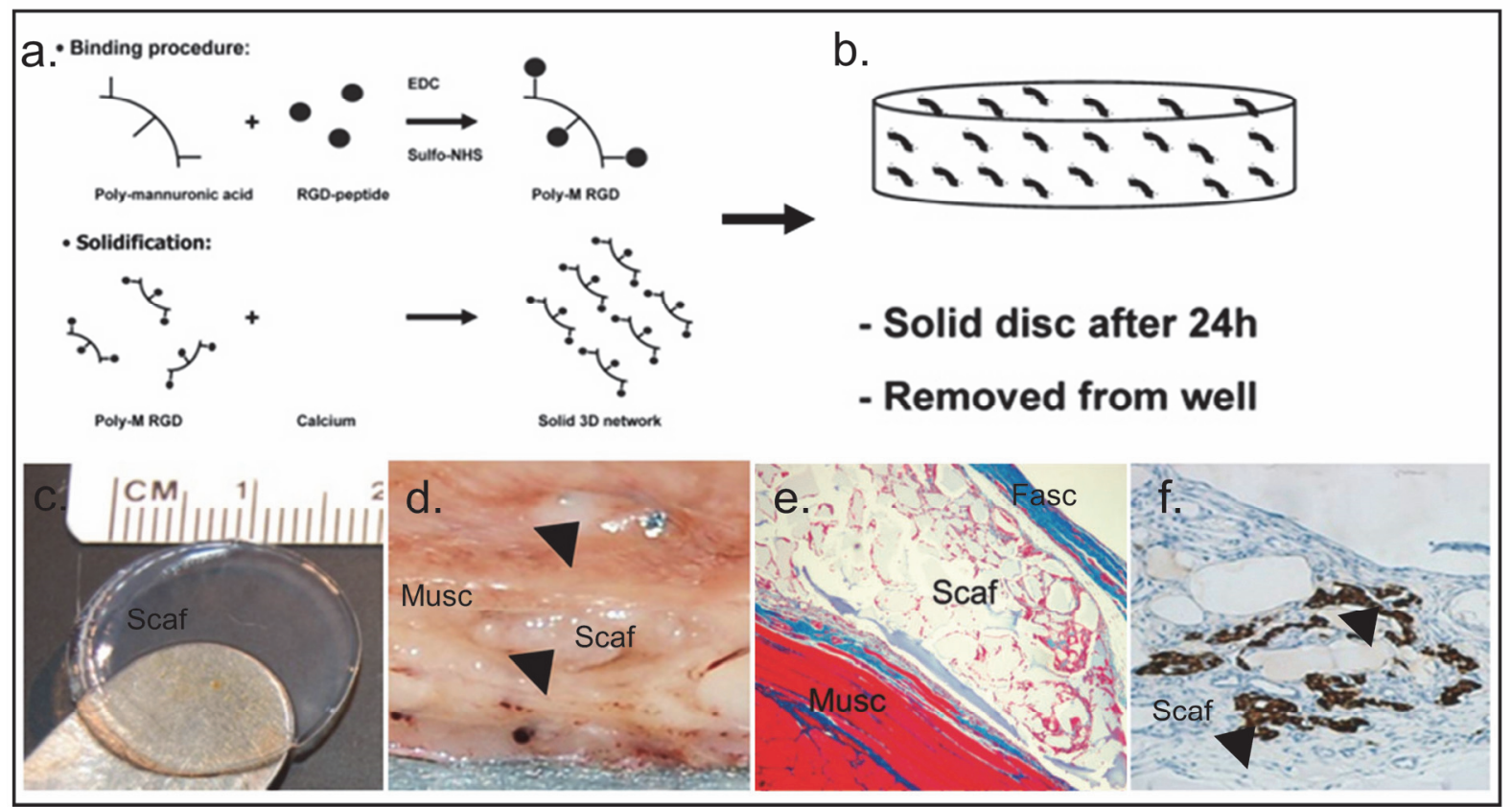

Figure 3. Schematic representation and in vivo application of alginate hydrogel scaffold for prevascularization and subsequent islet implantation. Purified sodium alginate solution (poly-mannuronic acid) was modified with cyclic RGDfK peptide (panel a.). $\mathrm{Ca}^{2+}$ was added to generate solid scaffolds in $15 \mathrm{~mm}$ transwells (panel b.) that mimic biological tissue, and promote islet survival and blood vessel growth. Circular translucent RGDfK-alginate scaffolds \pm PDGFbb and VEGF (panel c.) were implanted between abdominal muscles, injected with islets, and harvested 4 weeks later (panel d., black arrows indicate scaffold embedded between muscle). Histology showed scaffold between abdominal muscle with no signs of scar formation (panel e. Masson's trichrome stain, blue indicates connective/scar tissue). Viable islets (brown=insulin, black arrows) were detected inside scaffold material (panel f.) (Author's personal impression and $(40,41,120)($ Chapters 2,4 and 5). Scaf=scaffold. Musc=muscle. Fasc=abdominal fascia.

providing sufficient oxygen and nutrients to the graft, this method also relied on 1) a minimally inflammatory site, and 2) a well vascularized site. Islets supported by an FDA-approved absorbable composite biodegradable scaffold (Ethisorb ${ }^{\mathrm{TM}}$ Dura Patch), when implanted onto the omentum of diabetic Beagle dogs, reversed their IDDM and sustained normoglycemia without the use of any exogenous insulin in two-thirds of the test animals, whereas none of the control animals who received bare islet transplants without any scaffold became normoglycemic and all required exogenous insulin replacement (117).

In a similar study, the Ethisorb ${ }^{\mathrm{TM}}$ Dura Patch was used to transplant allogeneic islets into the omental pouch of diabetic cynomolgus monkeys. The results reinforced the critical value of the scaffolding in these experiments and reemphasized the importance of the implantation site in a more clinically relevant model. However, significantly more islets were needed in the omental pouch than were needed to achieve normoglycemia (lasting a whole year) for intrahepatic placement as bare islets via the portal vein (118). The outcome of these studies may be related to the initial need for revascularization of the omental pouch and to the relatively poor blood supply to the implanted islets placed in the omental site, since the scaffolds used were not prevascularised. The lack of a high inflammatory environment in the omental pouch in the peritoneum as compared to the intrahepatic site makes this approach clinically attractive and practically feasible with minimal interventional operation (i.e. by laparoscopy).

For this thesis, we have used porous and non-porous 3D RGD peptide-modified alginate scaffolds to enhance stem cell and endothelial cell adhesion using the RGD (Arg-Gly-Asp) peptide. The RGD sequence is an amino acid sequence that promotes (vascular) cell adhesion and is present throughout the extracellular matrix (119). We describe this in detail in Chapters 3, 4 and 5. Scaffold pre-cell transplant vascularization is critical as it provides nutrients and oxygen to implanted cells, removes waste products, and in case of pancreatic islets, transports glucose to and insulin from the graft. To provide improved neovascularity for our alginate scaffolds, we found that cyclic RGDfK peptides can be chemically and covalently linked to alginate to enhance adhesive properties of 3D RGDfK-alginate scaffolds, and thus make them particularly suitable to support blood vessel growth and cell survival. Additional impregnation of the RGDfK-alginate scaffolds with vascular growth factors further improved scaffold neovascularization in rats. Once scaffolds were prevascularised (we used two weeks prior to introducing pancreatic islets), we could place them 
in the most favorable site, i.e. the site that is least inflammatory, has readily available blood supply, allows easy placement, and can be easily approached both for insertion of the grafted cells and for their removal, if that becomes necessary. An intramuscular location was our first choice due to its high vascularity, easy accessibility, and need for only a minimally invasive procedure; we think that a subcutaneous location may be equally practical.

Our own studies revealed that we could effectively modify purified alginate with RGDpeptides, generate solid 3D-scaffolds, and safely transplant whole islets into intramuscular 3Dscaffolds following scaffold pre-vascularization for 2 weeks (Figure 3) $(40,41,120)$. Others have developed islet-like cells (selected for B-cells, and not including $\alpha$ - or $\delta$ - cells) from hESCs to reverse hyperglycemia in diabetic severe combined immunodeficient (SCID) mice. These cell-scaffolds could reverse hyperglycemia for 7 weeks, when compared to similar cells implanted under the kidney capsule (121). In other experiments, normal mouse islets that were cultured and maintained in PGA 3D scaffolds and subsequently suspended in a thermoreversible gelatin polymer (TGP) in vitro for 40 days were also able to reverse hyperglycemia when transplanted under the kidney capsule in STZ induced diabetic mice (122). The use of poly(lacticco-glycolic acid) (PLGA) scaffolds is an approach that focuses on the limited availability of human islets and on a possible method to replace them with genetically engineered cells. iPSC technology has also been used to generate insulin producing cells from human skin fibroblasts (mimicking B-cells) that respond to glucose stimulation. This could theoretically lead to cellular isografts to treat IDDM (123), and thus eliminate the concerns about availability of islets and rejection of human alloantigens of the donor. Recent studies showed that autologous iPSCs, i.e. cells developed from the same organism but genetically modified with transcription factors, unfortunately also possess immunogenic properties, albeit reportedly negligible (124-126). Such pseudo-8 cells alone may also not function properly without collaboration with $\alpha$ - and $\delta$ - cells as B-cells do in whole pancreas. Despite these many practical and theoretical difficulties, once cell replacement is indicated in reversal of IDDM, the use of scaffolds as carriers should be very useful and probably necessary.

\section{CONDITIONING}

Besides using various material for construction of scaffolds, there are several conditioning protocols for both donor cells, recipients and even scaffolds. Ex vivo pre-transplantation treatments of donor tissues, cells or organs and/or the pre-treatment of recipient animals or patients, in order to improve (stem) cell engraftment and/or donor cell or organ allograft acceptance are challenges that are difficult to overcome and which we will not discuss in detail. It is, however necessary to mention some of the concerns in preparation of the various cellular inoculae and touch on the possible solutions. In the case of cell pre-conditioning for application in ischemic cardiac disease, a variety of cytokines and growth factors (i.e. VEGF, angiogenin, Ang-1, HGF, IL-18 binding protein, TNFR1/2, FGF2), prosurvival factors, genetic modification, and physical stimuli have been used to increase overall cell survival following transplantation $(127,128)$.

Since the bone marrow niche offers a hypoxic environment, as recently shown by direct measurements (129), hypoxic preconditioning of bone marrow derived cells has been a well-known strategy to enhance MSC survival. This enhanced survival depends on the activation of the AKT signaling survival pathway during hypoxic conditions (130). Practically, this implies that MSCs/MPCs should be expanded in culture in a 1$2 \%$ oxygen environment before they are collected for transplantation from cell culture flasks. Genetic modification using retroviral transduction with AKT without preconditioning has also been shown to improve MSC survival. Such MSCs are four times more effective in preventing remodeling and restoring performance of infarcted hearts compared to mock-transfected MSCs (131).

Pancreatic islets do not proliferate in tissue culture environments. They are subject to significant loss during and following tissue culture treatments due to hypoxia and nutrient deprivation in vitro and in vivo (132). Therefore, several approaches to enhance islet cell survival during cell culture and after transplantation have been studied. For instance, treatment of rodent islets during isolation with a $\mathrm{PKC} \varepsilon$ activator blocking $\mathrm{Ca}^{2+}$ inflow with nifedipine improves islet viability, since it is involved in the regulation of B-cell survival through the activation of AKT in the phosphoinositide 3 (PI3)-kinase dependent pathway. Or, one can prevent ischemia-reperfusion damage with diazoxide by opening ATP-sensitive $\mathrm{K}^{+}$ channels during islet isolation (133-135). In addition, islet survival and graft function after transplantation could be enhanced by reducing $\mathrm{CD}_{11} \mathrm{~b}^{+}$cellular infiltration, decreasing islet apoptosis, and enhancing islet graft function by pretransplant knockdown of intraislet IKKB using siRNA against pro-inflammatory cytokine-induced NF-kB activation (136). Many other methods of improving islet survival during isolation have been tried and can be effectively combined under specific conditions.

Preconditioning of the recipient and of the donor cells or tissues has been described for heart, lung, kidney, liver, and pancreas, mostly in the context of ischemia and reperfusion injury (137). In contrast to preconditioning of donor cells, tissues or organs before transplantation, an alternative approach to enhance graft survival is to precondition the recipient. Regarding immunological pre-conditioning, we have recently shown that non-myeloablative treatment with total body irradiation, thymic irradiation, intravenous anti-CD154 mAb, followed by cyclosporin A with bone marrow transplantation and recipient $\mathrm{CD} 4^{+} \mathrm{CD} 25^{\text {high }}$ regulatory $\mathrm{T}$-cell $\left(\mathrm{T}_{\text {reg }}\right.$ ) intravenous 
infusion leads to prolonged hematopoietic chimerism and kidney allograft survival in cynomolgus macaques (23) and appendix 3 . This approach has been used successfully clinically but it remains laborious, expensive, and is not always effective or even completely safe due to use of ionizing radiation (138). Alternative recipient preconditioning approaches include targeting the hypoxia inducible factor 1 (HIF-1) pathway, which is activated during ischemia-reperfusion injury where it plays an important role in cardioprotection through ischemic preconditioning (139). Pharmacological heart transplant recipient treatment with HIF-a stabilizing prolyl hydroxylase inhibitors decreased macrophage infiltration in the cardiac allograft, mildly improving long-term allograft survival (140). Although preconditioning of the graft or of the host is promising, it is also highly complex and additional research is needed before such treatments can be translated into the clinic.

\section{HOST RESPONSE}

Both the host innate and acquired immune responses remain major obstacles to the acceptance of biomaterial implants. The responses are affected by biomaterial specific variables which include 1) the intended clinical application, 2) the source of the raw material/tissue from which the artificial ECM is harvested, and 3) the processing steps involved in the manufacture of an approved scaffold with allogeneic, xenogeneic, and/or biomaterial implants. The responses consist of either a direct response as in the case of foreign body responses (FBR) against implanted (bio)materials, or an indirect response against allogeneic cells or bioengineered tissues via cellular immunity such as Th1/Th2 lymphocyte responses or M1/M2 macrophage responses (141). Chapter 2 of this thesis focuses exclusively on generation of an immunotolerant biomaterial (sodium alginate) that allows fabrication of biocompatible $3 \mathrm{D}$ alginate scaffolds that induce limited immune responses. Our innovative purification technique based on PVDF membrane filtration removes mitogenic impurities, i.e. impurities that could lead to an activation of immune cells, that allow generation of $3 \mathrm{D}$ scaffolds from this purified material that do not induce any foreign body responses or scar tissue formation in vivo (120) (Chapter 2).

The FBR has been well characterized and embodies an immune-mediated reaction that can lead to the failure of implanted bioengineered scaffolds or medical devices as well as discomfort for the recipient (98). With the introduction of tissue engineering, new facets of the foreign body response need to be addressed. "Older" materials that have been previously used, such as total joint or artificial heart valve replacements, have been evaluated for several decades and their biocompatibility is well documented $(142,143)$. This also applies to host responses to metals and surgical sutures which have been studied in detail and are fully accepted (144-146). Newer (hydrogel) materials such as RGDmodified alginate $(39,40)$ (Chapters 3 -5) or self- assembling peptide-amphiphile nanofibers (147), that allow the fabrication of artificial 3D tissues, have specific properties whose immunogenicity depends on the antigenic composition and purity of the material. Any potential contamination of these novel materials may make them immunogenic. Extensive purification of manufactured foreign biomaterial which we emphasize in this thesis is therefore critical in reduction of host responses. Additionally, optimization of purification protocols is sometimes needed, for example in order to improve effectiveness and/or reduce waste, as described in (120) (Chapter 2).

The FBR ultimately leads to fibrotic encapsulation of implanted materials, gradual decrease in flux of nutrients and oxygen and eventually leads to loss of function. Broadly, the FBR consists of 5 phases: protein adsorption, acute inflammation, chronic inflammation, foreign body giant cell formation, and fibrous capsule formation $(148,149)$. Still, it is difficult to predict which phase will occur first and to what extent it will occur. This depends on many factors, some of which include the biomaterial source and composition of the biomaterial, its surface characteristics, and many others which we discuss in Chapter 2. The major or "key" cell in the FBR is the monocyte/macrophage; it is therefore not surprising that macrophage depletion in some animal models leads to a complete loss of fibrotic encapsulation after biomaterial implantation, but does not necessarily affect other macrophage functions such as wound healing, reactive oxygen species production and phagocytosis. The macrophages secrete several kinds of pro-inflammatory cytokines such as IL-1B and IL-6, and the anti-inflammatory cytokines TGF81 and IL-10 that play important roles during the FBR. Other cells that play an important role in inducing FBR are B-cells and T-cells (150). Recently, a role for colony stimulating factor-1 (CSF-1) and its receptor (CSF-1R) has been identified (151). Several 3D in vitro models have been developed to help elucidate which cells and cytokines play major roles during the different stages of the FBR $(152,153)$ in order to develop agents that may modify or prevent the undesirable reactions. Appropriate and effective modulation of the FBR could improve the efficacy of biomaterial devices. This could be accomplished, for example, by coating biomaterial with other biocompatible materials or coating with anti-inflammatory drugs, i.e. non-steroidal antiinflammatory (NSAID's), immunomodulatory biologicals and/or mAbs, such as CTLA-4-Ig or anti-CD40, or anti-proliferative agents such as rapamycin $(154,155)$ as has been done for many years in coronary artery stents.

It must be remembered that the FBR is a natural and useful reaction against foreign materials such as wood splinters, where monocytes/macrophages play an important role in phagocytosis of infectious agents. However, the FBR offers serious barriers to biomaterials and can lead to biomaterial device failure in tissue engineering applications. Systemic inhibition of the FBR 
however might have serious clinical side effects. Therefore, careful modulation of the FBR is mandatory and while this may offer a promising strategy to further enhance the efficacy of biomaterial applications in vivo, its natural function in host defenses must be preserved. In some tissue engineering applications, the natural FBR might actually be useful; the monocyte/macrophage/fibrotic response has been applied to generate tube-like structures to create tissue-engineered blood vessels (TEBV's) in vivo (156). Subcutaneous implantation of solid material rods results in their encapsulation by fibroblasts which then form a hollow tube consisting of autologous cells upon removal of the rod. Such tubes can subsequently be explanted and seeded with endothelial cells in vitro to form blood vessel-like structures; they provide the benefit of tissue elasticity and non-immunogenicity that is absent when synthetic polytetrafluoroethylene (PTFE) or Dacron vessel grafts are used. The technical problems that haunt this approach evolve around successful resurfacing of such tubes permanently with host endothelial cells to prevent thrombosis following exposure to blood.

\section{AIMS AND HYPOTHESES}

This thesis derives its main focus from the observation that direct injection of cells into tissues results in poor survival and retention of injected cells, while still exerting measurable outcomes. The author hypothesized that carrier materials that mimic the native environment of transplanted cells may be manipulated to enhance survival and functionality of transplanted cells. The author aims to demonstrate 1) that biomaterial purity is of paramount importance for its in vitro and in vivo biological application in combination with transplantable cells (120) (Chapter 2), 2) that biomaterial scaffold modification with adhesion factors is essential for survival and retention of cells residing inside the $3 \mathrm{D}$ structure $(39,40)$ (Chapters 3-5), 3) that modified scaffolds can also be used to transplant, stimulate neovascularization, and protect cells from immunologic and/or infectious injuries by binding appropriate prosurvival agents to the scaffold, and that such scaffolds can then be used for the treatment of HF and IDDM among other possible pathological processes $(39,40)$ (Chapters 3-5), 4) that specific chemokines and their receptors are involved in the migration/homing of bone marrow derived stem cells to the site of damaged cardiac tissue $(54,55)$ (Chapters 6-7), and 5) that stem cells produce certain chemokines and/or other paracrine factors that could attract other cells or act locally to regenerate damaged tissue (57) (Appendices 1-2). Finally, in order to prevent rejection of allogeneic cells and organs, additional studies were initiated to elucidate the role of autologous $\mathrm{CD} 4^{+} \mathrm{CD} 25^{\text {high }} \mathrm{T}_{\text {regs }}$ in kidney transplantation in monkeys following minimal pre-conditioning (23) (Appendix 3) as a guide for future incorporation of cells and factors that would stimulate donor-specific $\mathrm{T}_{\text {regs }}$ in cell allograft recipients.

\section{THESIS OUTLINE}

Part $I$ is the main part of the thesis, is divided into Chapters 1-5, and focuses on 1) the fabrication of an optimal starting material for (pre)clinical applications that consists of purified sodium alginate, that is easily manipulated in its shape, immunocompetency and biological properties, 2) optimal base material that is economical for large scale clinical application, and 3) optimal base material that is suitable for cell maintenance and growth, and cell transplantation. Chapter $\mathbf{1}$ is the current chapter which contains General Introduction, Rationale, Hypothesis, Aims and Thesis Outline. Chapter 2 describes our novel sodium alginate purification technique based on PVDF membrane filtration which results in a clinically useable immunotolerant biomaterial free of toxins or mitogens such as LPS, protein, DNA or RNA (120). Chapter 3 focuses on alginate modification with cyclic RGDfK-peptide and includes the construction of a "dry" porous freezegelled/freeze-extracted cyclic RGDfK-modified 3D scaffold that enhances stem cell and cardiac cell survival; it also describes the experimental use of the material in a HF model in rodents (39). Chapters 4 and 5 describe the use of a slightly different cyclic RGDfK-modified "wet" alginate hydrogel scaffold and its application in an experimental prevascularization model of pancreatic islet transplantation in STZ induced diabetic rodents $(40,41)$.

Part II of the thesis, Chapters 6 and 7, focuses on the mechanisms that support cell mediated tissue repair, especially the role of cytokines and chemokines and their roles in stem cell migration and homing, as well as their effects on cardiac neovascularization and immunomodulation. Chapter 6 summarizes the roles of specific chemokine receptors CCR3 (CD193) and CXCR4 (CD184) involved in $\mathrm{CD}^{+}$bone marrow derived precursor cell homing to damaged tissue following MI (54). Chapter 7 further addresses the roles of chemokine stromal derived factor 1 (SDF-1, also known as CXCL12) and its surface receptor CXCR4 (CD184) on homing mechanisms of bone marrow derived ${\mathrm{CD} 34^{+}}^{+}$ precursor cells to ischemic myocardium (55).

Chapter 8 presents the summary, discussion, and conclusion of this thesis, and explores future perspectives in regenerative medicine. Chapter 9 presents the thesis summary in English, Chapter 10 contains a summary in Dutch.

The thesis also contains Appendices 1-5, whose content mostly focuses on other studies/projects that served as precursors, exploration, pilot, or follow-up projects and were performed in parallel with the experiments that provide the foundations for this thesis. Appendix 1 describes the first application of STRO- $1^{+}$MPCs in AMI (56). Appendix 2 describes the cytokines and 
chemokines that STRO-3 ${ }^{+}$MPCs secrete, and their effects on cardiac remodeling following AMI (57). Appendix 3 describes the application of regulatory T-cell ( $\left.\mathrm{T}_{\mathrm{reg}}\right)$ therapy in the prevention of organ rejection in a kidney transplantation model in cynomolgus macaques, and was performed as a foundation for primate transplantation research at the Columbia Center for Translational Immunology (CCTI; http://www.cumc.columbia.edu/ccti/) (23). Appendix 4 is a valorization addendum that describes the cell/scaffold applications in this thesis for commercial purposes in a provisional patent application (157). Appendix $\mathbf{5}$ contains acknowledgements, financial support, curriculum vitae, list of publications and awards, followed by thesis propositions.

\section{REFERENCES}

1. E. Braunwald, Heart failure: an update. Clin Pharmacol Ther 94, 430 (Oct, 2013).

2. R. Madonna, L. W. Van Laake, S. M. Davidson, F. B. Engel, D. J. Hausenloy, S. Lecour, J. Leor, C. Perrino, R. Schulz, K. Ytrehus, U. Landmesser, C. L. Mummery, S. Janssens, J. Willerson, T. Eschenhagen, P. Ferdinandy, J. P. Sluijter, Position Paper of the European Society of Cardiology Working Group Cellular Biology of the Heart: cell-based therapies for myocardial repair and regeneration in ischemic heart disease and heart failure. European heart journal 37, 1789 (Jun 14, 2016).

3. C. W. Yancy, M. Jessup, B. Bozkurt, J. Butler, D. E. Casey, Jr., M. H. Drazner, G. C. Fonarow, S. A. Geraci, T. Horwich, J. L. Januzzi, M. R. Johnson, E. K. Kasper, W. C. Levy, F. A. Masoudi, P. E. McBride, J. J. McMurray, J. E. Mitchell, P. N. Peterson, B. Riegel, F. Sam, L. W. Stevenson, W. H. Tang, E. J. Tsai, B. L. Wilkoff, F. American College of Cardiology, G. American Heart Association Task Force on Practice, 2013 ACCF/AHA guideline for the management of heart failure: a report of the American College of Cardiology Foundation/American Heart Association Task Force on Practice Guidelines. $J$ Am Coll Cardiol 62, e147 (Oct 15, 2013).

4. C. W. Yancy, M. Jessup, B. Bozkurt, J. Butler, D. E. Casey, Jr., M. M. Colvin, M. H. Drazner, G. S. Filippatos, G. C. Fonarow, M. M. Givertz, S. M. Hollenberg, J. Lindenfeld, F. A. Masoudi, P. E. McBride, P. N. Peterson, L. W. Stevenson, C. Westlake, 2017 ACC/AHA/HFSA Focused update of the 2013 ACCF/AHA guideline for the Management of heart failure: A report of the American College of Cardiology/American Heart Association Task Force on clinical practice guidelines and the Heart Failure Society of America. Circulation 136, e137 (Aug 8, 2017).

5. S. R. Houser, K. B. Margulies, A. M. Murphy, F. G. Spinale, G. S. Francis, S. D. Prabhu, H. A. Rockman, D. A. Kass, J. D. Molkentin, M. A Sussman, W. J. Koch, C. o. C. C. American Heart Association Council on Basic Cardiovascular Sciences, G. Council on Functional, B. Translational, Animal models of heart failure: a scientific statement from the American Heart Association. Circ Res 111, 131 (Jun 22, 2012).

6. N. M. Degabriele, U. Griesenbach, K. Sato, M. J. Post, J. Zhu, J. Williams, P. K. Jeffery, D. M. Geddes, E. W. Alton, Critical appraisal of the mouse model of myocardial infarction. Experimental physiology 89, 497 (Jul, 2004).

7. S. Wild, G. Roglic, A. Green, R. Sicree, H. King, Global prevalence of diabetes: estimates for the year 2000 and projections for 2030. Diabetes Care 27, 1047 (May, 2004).

8. M. A. Atkinson, N. K. Maclaren, The pathogenesis of insulin-dependent diabetes mellitus. $N$ Engl J Med 331, 1428 (Nov 24, 1994).

9. A. M. Shapiro, J. R. Lakey, E. A. Ryan, G. S. Korbutt, E. Toth, G. L. Warnock, N. M. Kneteman, R. V. Rajotte, Islet transplantation in seven patients with type 1 diabetes mellitus using a glucocorticoid-free immunosuppressive regimen. $N$ Engl J Med 343, 230 (Jul 27, 2000).

10. C. R. van der Torren, J. S. Suwandi, D. Lee, E. T. Van't Wout, G. Duinkerken, G. Swings, A. Mulder, F. H. Claas, Z. Ling, P. Gillard, B. Keymeulen, P. In't Veld, B. O. Roep, Identification of donor origin and condition of transplantedi in situ in the liver of a type 1 diabetic recipient. Cell Transplant 26, 1 (Jan 24, 2017).

11. L. D. Amer, M. J. Mahoney, S. J. Bryant, Tissue engineering approaches to cell-based type 1 diabetes therapy. Tissue engineering. Part B, Reviews 20, 455 (Oct, 2014).

12. S. Renner, B. Dobenecker, A. Blutke, S. Zols, R. Wanke, M. Ritzmann, E. Wolf, Comparative aspects of rodent and nonrodent animal models for mechanistic and translational diabetes research. Theriogenology 86, 406 (Jul 01, 2016).

13. M. L. Graham, H. J. Schuurman, Validity of animal models of type 1 diabetes, and strategies to enhance their utility in translational research. Eur J Pharmacol 759, 221 (Jul 15, 2015).

14. S. J. Koopmans, T. Schuurman, Considerations on pig models for appetite, metabolic syndrome and obese type 2 diabetes: From food intake to metabolic disease. Eur J Pharmacol 759, 231 (Jul 15, 2015).

15. M. O. Larsen, B. Rolin, Use of the Gottingen minipig as a model of diabetes, with special focus on type 1 diabetes research. ILAR journal 45, 303 (2004).

16. L. K. Shoda, D. L. Young, S. Ramanujan, C. C. Whiting, M. A. Atkinson, J. A. Bluestone, G. S. Eisenbarth, D. Mathis, A. A. Rossini, S. E. Campbell, R. Kahn, H. T. Kreuwel, A comprehensive review of interventions in the NOD mouse and implications for translation. Immunity 23, 115 (Aug, 2005).

17. S. Ramanathan, P. Poussier, BB rat lyp mutation and Type 1 diabetes. Immunological reviews 184, 161 (Dec, 2001).

18. S. Makino, K. Kunimoto, Y. Muraoka, Y. Mizushima, K. Katagiri, Y. Tochino, Breeding of a non-obese, diabetic strain of mice. Jikken dobutsu. Experimental animals 29, 1 (Jan, 1980). 19. J. P. Mordes, R. Bortell, E. P. Blankenhorn, A. A. Rossini, D. L. Greiner, Rat models of type 1 diabetes: genetics, environment, and autoimmunity. ILAR journal 45, 278 (2004).

20. B. O. Roep, Are insights gained from NOD mice sufficient to guide clinical translation? Another inconvenient truth. Ann N Y Acad Sci 1103, 1 (Apr, 2007).

21. M. J. Truty, M. D. Sawyer, F. G. Que, Decreasing pancreatic leak after distal pancreatectomy: saline-coupled radiofrequency ablation in a porcine model. Journal of gastrointestinal 
surgery : official journal of the Society for Surgery of the Alimentary Tract 11, 998 (Aug, 2007).

22. X. Y. Huang, C. Wang, Y. Z. Liu, J. Z. Liu, H. C. Wang, Q. Jiao, Z. Yuan, K. X. Ai, Q. Zheng, Decreasing pancreatic leak after distal pancreatectomy: bovine pericardium wrapping stump in a porcine model. Digestive surgery $\mathbf{2 9}$ 457 (2012).

23. R. Duran-Struuck, H. P. Sondermeijer, L. Buhler, P. Alonso-Guallart, J. Zitsman, Y. Kato, A. Wu, A. N. McMurchy, D. Woodland, A. Griesemer, M. Martinez, S. Boskovic, T. Kawai, A. B. Cosimi, C. S. Wuu, A. Slate, M. Y. Mapara, S. Baker, R. Tokarz, V. D'Agati, S. Hammer, M. Pereira, W. I. Lipkin, T. Wekerle, M. K. Levings, M. Sykes, Effect of ex vivo-expanded recipient regulatory $\mathrm{T}$ cells on hematopoietic chimerism and kidney allograft tolerance across $\mathrm{MHC}$ barriers in cynomolgus macaques. Transplantation 101, 274 (Feb, 2017).

24. Organ Procurement and Transplantation Network; https://optn.transplant.hrsa.gov/.

25. B. US Department of Health and Human Services, Maryland, Collaborative islet transplant registry 9th annual report. (December 17th, 2015).

26. United network for organ sharing; www.unos.org.

27. Scientific registry for transplant recipients; www.strt.org.

28. Eurotransplant, www.eurotransplant.org.

29. Z. Lin, W. T. Pu, Strategies for cardiac regeneration and repair. Science translational medicine 6, 239rv1 (Jun 04, 2014).

$30 . \quad$ B. M. Sicari, J. P. Rubin, C. L. Dearth, M. T. Wolf, F. Ambrosio, M. Boninger, N. J. Turner, D. J. Weber, T. W. Simpson, A. Wyse, E. H. Brown, J. L. Dziki, L. E. Fisher, S. Brown, S. F. Badylak, An acellular biologic scaffold promotes skeletal muscle formation in mice and humans with volumetric muscle loss. Science translational medicine 6, 234ra58 (Apr 30, 2014).

31. S. Sjoqvist, P. Jungebluth, M. L. Lim, J. C. Haag, Y. Gustafsson, G. Lemon, S. Baiguera, M. A. Burguillos, C. Del Gaudio, A. B. Rodriguez, A Sotnichenko, K. Kublickiene, H. Ullman, H. Kielstein, P. Damberg, A. Bianco, R. Heuchel, Y. Zhao, D. Ribatti, C. Ibarra, B. Joseph, D. A Taylor, P. Macchiarini, Experimental orthotopic transplantation of a tissue-engineered oesophagus in rats. Nat Commun 5, 3562 (Apr 15, 2014).

32. S. Bhumiratana, J. C. Bernhard, D. M. Alfi, K. Yeager, R. E. Eton, J. Bova, F. Shah, J. M. Gimble, M. J. Lopez, S. B. Eisig, G. VunjakNovakovic, Tissue-engineered autologous grafts for facial bone reconstruction. Science translational medicine 8, 343ra83 (Jun 15, 2016).

33. K. Fischer, S. Kraner-Scheiber, B. Petersen, B. Rieblinger, A. Buermann, T. Flisikowska, K. Flisikowski, S. Christan, M. Edlinger, W. Baars, M. Kurome, V. Zakhartchenko, B. Kessler, E. Plotzki, I. Szczerbal, M. Switonski, J. Denner, E. Wolf, R. Schwinzer, H. Niemann, A. Kind, A. Schnieke, Efficient production of multi-modified pigs for xenotransplantation by 'combineering', gene stacking and gene editing. Scientific reports 6, 29081 (Jun 29, 2016).

34. K. A. Schaefer, W. H. Wu, D. F. Colgan, S. H. Tsang, A. G. Bassuk, V. B. Mahajan, Unexpected mutations after CRISPR-Cas9 editing in vivo. Nat Methods 14, 547 (May 30, 2017).

35. E. Haapaniemi, S. Botla, J. Persson, B. Schmierer, J. Taipale, CRISPR-Cas9 genome editing induces a p53-mediated DNA damage response. Nat Med, (Jun 11, 2018).

36. R. J. Ihry, K. A. Worringer, M. R. Salick, E. Frias, D. Ho, K. Theriault, S. Kommineni, J. Chen, M. Sondey, C. Ye, R. Randhawa, T. Kulkarni, Z. Yang, G. McAllister, C. Russ, J. Reece-Hoyes, W. Forrester, G. R. Hoffman, R. Dolmetsch, A. Kaykas, p53 inhibits CRISPRCas9 engineering in human pluripotent stem cells. Nat Med, (Jun 11, 2018).

37. A. Singh, N. A. Peppas, Hydrogels and scaffolds for immunomodulation. Advanced materials 26, 6530 (Oct, 2014).

38. H. Lau, K. Reemtsma, M. A. Hardy, Prolongation of rat islet allograft survival by direct ultraviolet irradiation of the graft. Science 223, 607 (Feb 10, 1984).

39. H. P. Sondermeijer, P. Witkowski, T. Seki, A. van der Laarse, S. Itescu, M. A. Hardy, RGDfKpeptide modified alginate scaffold for cell transplantation and cardiac neovascularization. Tissue Eng Part A 24, 740 (May, 2018).

40. P. Witkowski, H. Sondermeijer, M. A. Hardy, D. C. Woodland, K. Lee, G. Bhagat, K. Witkowski, F. See, A. Rana, A. Maffei, S. Itescu, P. E. Harris, Islet grafting and imaging in a bioengineered intramuscular space. Transplantation 88, 1065 (Nov 15, 2009).

41. M. A. Hardy, P. Witkowski, H. Sondermeijer, P. Harris, The long road to pancreatic islet transplantation. World J Surg 34, 625 (Apr, 2010)

42. G. Mathe, H. Jammet, B. Pendic, L. Schwarzenberg, J. F. Duplan, B. Maupin, R. Latarjet, M. J. Larrieu, D. Kalic, Z. Djukic, [Transfusions and grafts of homologous bone marrow in humans after accidental high dosage irradiation]. Revue francaise d'etudes cliniques et biologiques 4, 226 (Mar, 1959).

43. R. Storb, Edward Donnall Thomas (1920-2012). Nature 491, 334 (Nov 15, 2012).

44. W. R. Guild, J. H. Harrison, J. P. Merrill, J. Murray, Successful homotransplantation of the kidney in an identical twin. Transactions of the American Clinical and Climatological Association 67, 167 (1955).

45. Proceedings of the 9th International workshop on human leukocyte differentiation antigens. March 2010. Barcelona, Spain. Immunol Lett 134, 103 (Jan 30, 2011).

46. B. Assmus, J. Honold, V. Schachinger, M. B. Britten, U. Fischer-Rasokat, R. Lehmann, C. Teupe, K. Pistorius, H. Martin, N. D. Abolmaali, T. Tonn, S. Dimmeler, A. M. Zeiher, Transcoronary transplantation of progenitor cells after myocardial infarction. $N$ Engl J Med 355, 1222 (Sep 21, 2006).

47. K. Lunde, S. Solheim, S. Aakhus, H. Arnesen, M. Abdelnoor, T. Egeland, K. Endresen, A. Ilebekk, A. Mangschau, J. G. Fjeld, H. J. Smith, E. Taraldsrud, H. K. Grogaard, R. Bjornerheim, M. Brekke, C. Muller, E. Hopp, A. Ragnarsson, J. E. Brinchmann, K. Forfang, Intracoronary injection of mononuclear bone marrow cells in acute myocardial infarction. N Engl J Med 355, 1199 (Sep 21, 2006).

48. M. Gyongyosi, W. Wojakowski, P. Lemarchand, K. Lunde, M. Tendera, J. Bartunek, E. Marban, 
B. Assmus, T. D. Henry, J. H. Traverse, L. A. Moye, D. Surder, R. Corti, H. Huikuri, J. Miettinen, J. Wohrle, S. Obradovic, J. Roncalli, K. Malliaras, E. Pokushalov, A. Romanov, J. Kastrup, M. W. Bergmann, D. E. Atsma, A Diederichsen, I. Edes, I. Benedek, T. Benedek, H. Pejkov, N. Nyolczas, N. Pavo, J. Bergler-Klein, I. J. Pavo, C. Sylven, S. Berti, E. P. Navarese, G. Maurer, A. Investigators, Meta-Analysis of Cellbased CaRdiac stUdiEs (ACCRUE) in patients with acute myocardial infarction based on individual patient data. Circ Res 116, 1346 (Apr 10, 2015).

V. Schachinger, S. Erbs, A. Elsasser, W. Haberbosch, R. Hambrecht, H. Holschermann, J. Yu, R. Corti, D. G. Mathey, C. W. Hamm, T. Suselbeck, B. Assmus, T. Tonn, S. Dimmeler, A. M. Zeiher, R.-A. Investigators, Intracoronary bone marrow-derived progenitor cells in acute myocardial infarction. $N$ Engl $J$ Med 355, 1210 (Sep 21, 2006).

50. B. S. Youn, C. Mantel, H. E. Broxmeyer, Chemokines, chemokine receptors and hematopoiesis. Immunological reviews 177, 150 (Oct, 2000).

51. A. Aiuti, I. J. Webb, C. Bleul, T. Springer, J. C. Gutierrez-Ramos, The chemokine SDF-1 is a chemoattractant for human CD $34^{+}$hematopoietic progenitor cells and provides a new mechanism to explain the mobilization of CD34+ progenitors to peripheral blood. J Exp Med 185, 111 (Jan 06, 1997).

52. M. C. Poznansky, I. T. Olszak, R. Foxall, R. H. Evans, A. D. Luster, D. T. Scadden, Active movement of $\mathrm{T}$ cells away from a chemokine. Nat Med 6, 543 (May, 2000).

53. K. Tachibana, S. Hirota, H. Iizasa, H. Yoshida, K. Kawabata, Y. Kataoka, Y. Kitamura, K Matsushima, N. Yoshida, S. Nishikawa, T. Kishimoto, T. Nagasawa, The chemokine receptor CXCR4 is essential for vascularization of the gastrointestinal tract. Nature 393, 591 (Jun 11, 1998).

54. N. Bonaros, H. Sondermeijer, M. Schuster, R. Rauf, S. F. Wang, T. Seki, D. Skerrett, S. Itescu, A. A. Kocher, CCR3- and CXCR4-mediated interactions regulate migration of $\mathrm{CD} 34^{+}$human bone marrow progenitors to ischemic myocardium and subsequent tissue repair. $J$ Thorac Cardiovasc Surg 136, 1044 (Oct, 2008).

$55 . \quad$ N. Bonaros, H. Sondermeijer, D. Wiedemann, B. Schlechta, T. Schachner, M. Schuster, T. Seki, T. P. Martens, S. Itescu, A. A. Kocher, Downregulation of the CXC chemokine receptor 4/stromal cell-derived factor 1 pathway enhances myocardial neovascularization, cardiomyocyte survival, and functional recovery after myocardial infarction. J Thorac Cardiovasc Surg 142, 687 (Sep, 2011).

56. T. P. Martens, F. See, M. D. Schuster, H. P. Sondermeijer, M. M. Hefti, A. Zannettino, S. Gronthos, T. Seki, S. Itescu, Mesenchymal lineage precursor cells induce vascular network formation in ischemic myocardium. Nature clinical practice. Cardiovascular medicine $\mathbf{3}$ Suppl 1, S18 (Mar, 2006).

57. F. See, T. Seki, P. J. Psaltis, H. P. Sondermeijer, S. Gronthos, A. C. Zannettino, K. M. Govaert, M. D. Schuster, P. A. Kurlansky, D. J. Kelly, H Krum, S. Itescu, Therapeutic effects of human STRO-3-selected mesenchymal precursor cells and their soluble factors in experimental myocardial ischemia. Journal of cellular and molecular medicine 15, 2117 (Oct, 2011).

58. A. A. Kocher, M. D. Schuster, M. J. Szabolcs, S. Takuma, D. Burkhoff, J. Wang, S. Homma, N. M. Edwards, S. Itescu, Neovascularization of ischemic myocardium by human bone-marrowderived angioblasts prevents cardiomyocyte apoptosis, reduces remodeling and improves cardiac function. Nat Med 7, 430 (Apr, 2001).

59 D. Orlic, J. Kajstura, S. Chimenti, I. Jakoniuk, S. M. Anderson, B. Li, J. Pickel, R. McKay, B. Nadal-Ginard, D. M. Bodine, A. Leri, P. Anversa, Bone marrow cells regenerate infarcted myocardium. Nature 410, 701 (Apr 05, 2001).

$60 . \quad$ S. Tomita, R. K. Li, R. D. Weisel, D. A. Mickle, E. J. Kim, T. Sakai, Z. Q. Jia, Autologous transplantation of bone marrow cells improves damaged heart function. Circulation 100, II247 (Nov 09, 1999).

61. G. A. Donzella, D. Schols, S. W. Lin, J. A. Este, K. A. Nagashima, P. J. Maddon, G. P. Allaway, T. P. Sakmar, G. Henson, E. De Clercq, J. P. Moore, AMD3100, a small molecule inhibitor of HIV-1 entry via the CXCR4 co-receptor. Nat Med 4, 72 (Jan, 1998).

62. W. C. Liles, H. E. Broxmeyer, E. Rodger, B. Wood, K. Hubel, S. Cooper, G. Hangoc, G. J. Bridger, G. W. Henson, G. Calandra, D. C. Dale, Mobilization of hematopoietic progenitor cells in healthy volunteers by AMD3100, a CXCR4 antagonist. Blood 102, 2728 (Oct 15, 2003).

$63 . \quad$ J. P. Karam, C. Muscari, C. N. Montero-Menei, Combining adult stem cells and polymeric devices for tissue engineering in infarcted myocardium. Biomaterials 33, 5683 (Aug, 2012).

64 S. A. Fisher, C. Doree, D. P. Taggart, A. Mathur, E. Martin-Rendon, Cell therapy for heart disease: Trial sequential analyses of two Cochrane reviews. Clin Pharmacol Ther 100, 88 (Jul, 2016)

65. A. Mauro, Satellite cell of skeletal muscle fibers. J Biophys Biochem Cytol 9, 493 (Feb, 1961).

66. P. P. Rumyantsev, Interrelations of the proliferation and differentiation processes during cardiact myogenesis and regeneration. Int Rev Cytol 51, 186 (1977)

67. P. P. Rumyantsev, Reproduction of cardiac myocytes developing in vivo and its relationship to processes of differentiation. Growth and Hyperplasia of Cardiac Muscle Cells. Harwood Academic Press, New York., 70 (1991).

68 G. Y. Koh, M. H. Soonpaa, M. G. Klug, L. J. Field, Long-term survival of AT-1 cardiomyocyte grafts in syngeneic myocardium. Am J Physiol 264, H1727 (May, 1993).

69. M. H. Soonpaa, G. Y. Koh, M. G. Klug, L. J. Field, Formation of nascent intercalated disks between grafted fetal cardiomyocytes and host myocardium. Science 264, 98 (Apr 01, 1994).

70. A. P. Beltrami, K. Urbanek, J. Kajstura, S. M. Yan, N. Finato, R. Bussani, B. Nadal-Ginard, F. Silvestri, A. Leri, C. A. Beltrami, P. Anversa, Evidence that human cardiac myocytes divide after myocardial infarction. $N$ Engl J Med 344, 1750 (Jun 07, 2001).

71. F. Quaini, K. Urbanek, A. P. Beltrami, N. Finato, C. A. Beltrami, B. Nadal-Ginard, J. Kajstura, A. Leri, P. Anversa, Chimerism of the transplanted heart. N Engl J Med 346, 5 (Jan 03, 2002).

72. S. A. Fisher, H. Zhang, C. Doree, A. Mathur, E. Martin-Rendon, Stem cell treatment for acute 
myocardial infarction. Cochrane Database Syst Rev, CD006536 (Sep 30, 2015).

73. P. Menasche, O. Alfieri, S. Janssens, W. McKenna, H. Reichenspurner, L. Trinquart, J. T. Vilquin, J. P. Marolleau, B. Seymour, J. Larghero, S. Lake, G. Chatellier, S. Solomon, M. Desnos, A. A. Hagege, The Myoblast Autologous Grafting in Ischemic Cardiomyopathy (MAGIC) trial: first randomized placebo-controlled study of myoblast transplantation. Circulation 117, 1189 (Mar 04, 2008).

74. J. J. Chong, X. Yang, C. W. Don, E. Minami, Y. W. Liu, J. J. Weyers, W. M. Mahoney, B. Van Biber, S. M. Cook, N. J. Palpant, J. A. Gantz, J. A. Fugate, V. Muskheli, G. M. Gough, K. W. Vogel, C. A. Astley, C. E. Hotchkiss, A. Baldessari, L. Pabon, H. Reinecke, E. A. Gill, V. Nelson, H. P. Kiem, M. A. Laflamme, C. E. Murry, Human embryonic-stem-cell-derived cardiomyocytes regenerate non-human primate hearts. Nature 510, 273 (Jun 12, 2014).

75. A. P. Beltrami, L. Barlucchi, D. Torella, M Baker, F. Limana, S. Chimenti, H. Kasahara, M. Rota, E. Musso, K. Urbanek, A. Leri, J. Kajstura, B. Nadal-Ginard, P. Anversa, Adult cardiac stem cells are multipotent and support myocardial regeneration. Cell 114, 763 (Sep 19, 2003).

76. H. Oh, S. B. Bradfute, T. D. Gallardo, T. Nakamura, V. Gaussin, Y. Mishina, J. Pocius, L. H. Michael, R. R. Behringer, D. J. Garry, M. L. Entman, M. D. Schneider, Cardiac progenitor cells from adult myocardium: homing, differentiation, and fusion after infarction. Proc Natl Acad Sci U S A 100, 12313 (Oct 14, 2003).

$77 . \quad$ K. L. Laugwitz, A. Moretti, J. Lam, P. Gruber, Y. Chen, S. Woodard, L. Z. Lin, C. L. Cai, M. M. Lu, M. Reth, O. Platoshyn, J. X. Yuan, S. Evans, K. R. Chien, Postnatal isl1 $1^{+}$cardioblasts enter fully differentiated cardiomyocyte lineages. Nature 433, 647 (Feb 10, 2005).

78. R. Koninckx, A. Daniels, S. Windmolders, U. Mees, R. Macianskiene, K. Mubagwa, P. Steels, L. Jamaer, J. Dubois, B. Robic, M. Hendrikx, J. L. Rummens, K. Hensen, The cardiac atrial appendage stem cell: a new and promising candidate for myocardial repair. Cardiovasc Res 97, 413 (Mar 01, 2013)

79. A. M. Hierlihy, P. Seale, C. G. Lobe, M. A Rudnicki, L. A. Megeney, The post-natal heart contains a myocardial stem cell population. FEBS Lett 530, 239 (Oct 23, 2002).

80. E. The Lancet, Expression of concern: the SCIPIO trial. Lancet 383, 1279 (Apr 12, 2014).

81. M. H. Yacoub, J. Terrovitis, CADUCEUS, SCIPIO, ALCADIA: Cell therapy trials using cardiac-derived cells for patients with post myocardial infarction LV dysfunction, still evolving. Glob Cardiol Sci Pract 2013, 5 (2013).

82. M. F. Pittenger, A. M. Mackay, S. C. Beck, R. K. Jaiswal, R. Douglas, J. D. Mosca, M. A. Moorman, D. W. Simonetti, S. Craig, D. R. Marshak, Multilineage potential of adult human mesenchymal stem cells. Science 284, 143 (Apr 2, 1999).

83. S. Gronthos, S. E. Graves, S. Ohta, P. J. Simmons, The STRO-1+ fraction of adult human bone marrow contains the osteogenic precursors. Blood 84, 4164 (Dec 15, 1994).

84. S. Gronthos, S. Fitter, P. Diamond, P. J. Simmons, S. Itescu, A. C. Zannettino, A novel monoclonal antibody (STRO-3) identifies an isoform of tissue nonspecific alkaline phosphatase expressed by multipotent bone marrow stromal stem cells. Stem Cells Dev 16, 953 (Dec, 2007).

85. J. Ye, Y. Yeghiazarians, Cardiac stem cell therapy: Have we put too much hype in which cell type to use? Heart failure reviews 20, 613 (Sep, 2015)

86. J. A. San Roman, P. L. Sanchez, A. Villa, R. Sanz-Ruiz, M. E. Fernandez-Santos, F. Gimeno, B. Ramos, R. Arnold, A. Serrador, H. Gutierrez, F. Martin-Herrero, M. J. Rollan, F. FernandezVazquez, J. Lopez-Messa, P. Ancillo, G. PerezOjeda, F. Fernandez-Aviles, Comparison of different bone marrow-derived stem cell approaches in reperfused STEMI. A multicenter, prospective, randomized, open-labeled TECAM trial. J Am Coll Cardiol 65, 2372 (Jun 09, 2015).

87. J. M. Hare, D. L. DiFede, A. M. Castellanos, V. Florea, A. M. Landin, J. El-Khorazaty, A. Khan, M. Mushtaq, M. H. Lowery, J. J. Byrnes, R. C. Hendel, M. G. Cohen, C. E. Alfonso, K. Valasaki, M. V. Pujol, S. Golpanian, E. Ghersin, J. E. Fishman, P. Pattany, S. A. Gomes, C. Delgado, R. Miki, F. Abuzeid, M. Vidro-Casiano, C. Premer, A. Medina, V. Porras, K. E. Hatzistergos, E. Anderson, A. Mendizabal, R. Mitrani, A. W. Heldman, Randomized comparison of allogeneic vs. autologous mesenchymal stem cells for non-ischemic dilated cardiomyopathy: POSEIDON-DCM trial. $\mathrm{J} \mathrm{Am}$ Coll Cardiol, (Nov 14, 2016).

88. M. Gnecchi, H. He, O. D. Liang, L. G. Melo, F. Morello, H. Mu, N. Noiseux, L. Zhang, R. E. Pratt, J. S. Ingwall, V. J. Dzau, Paracrine action accounts for marked protection of ischemic heart by Akt-modified mesenchymal stem cells. Nat Med 11, 367 (Apr, 2005).

89. C. R. van der Torren, A. Zaldumbide, G. Duinkerken, S. H. Brand-Schaaf, M. Peakman, G. Stange, L. Martinson, E. Kroon, E. P. Brandon, D. Pipeleers, B. O. Roep, Immunogenicity of human embryonic stem cellderived beta cells. Diabetologia 60, 126 (Jan, 2017).

90. T. C. Kontis, Contemporary review of injectable facial fillers. JAMA facial plastic surgery 15, 58 (Jan, 2013).

91. W. H. Zimmermann, I. Melnychenko, G. Wasmeier, M. Didie, H. Naito, U. Nixdorff, A. Hess, L. Budinsky, K. Brune, B. Michaelis, S. Dhein, A. Schwoerer, H. Ehmke, T. Eschenhagen, Engineered heart tissue grafts improve systolic and diastolic function in infarcted rat hearts. Nat Med 12, 452 (Apr, 2006).

92. R. Gazzeri, M. Galarza, C. Fiore, G. Callovini, A. Alfieri, Use of tissue-glue-coated collagen sponge (TachoSil) to repair minor cerebral dural venous sinus lacerations: technical note. Neurosurgery 11 Suppl 2, 32 (Mar, 2015).

93. K. Ishikawa, T. Kato, M. Aragaki, R. Hase, T. Saikai, Y. Matsui, M. Kaji, Endobronchial closure of a bronchopleural fistula using a fibrin glue-coated collagen patch and fibrin glue. Ann Thorac Cardiovasc Surg 19, 423 (2013).

94. S. Olmi, A. Scaini, L. Erba, A. Bertolini, M. Guaglio, E. Croce, Use of fibrin glue (Tissucol) as a hemostatic in laparoscopic conservative treatment of spleen trauma. Surgical endoscopy 21, 2051 (Nov, 2007).

95. M. T. de Boer, J. M. Klaase, C. Verhoef, R. M. van Dam, T. M. van Gulik, I. Q. Molenaar, K. 
Bosscha, C. H. Dejong, E. J. Van der Jagt, R. J. Porte, F. T. Group, Fibrin sealant for prevention of resection surface-related complications after liver resection: a randomized controlled trial. Ann Surg 256, 229 (Aug, 2012).

96.

K. L. Christman, A. J. Vardanian, Q. Fang, R. E. Sievers, H. H. Fok, R. J. Lee, Injectable fibrin scaffold improves cell transplant survival, reduces infarct expansion, and induces neovasculature formation in ischemic myocardium. J Am Coll Cardiol 44, 654 (Aug 04, 2004).

97. J. M. Aamodt, D. W. Grainger, Extracellular matrix-based biomaterial scaffolds and the host response. Biomaterials 86, 68 (Apr, 2016).

98. A. J. Vegas, O. Veiseh, J. C. Doloff, M. Ma, H. H. Tam, K. Bratlie, J. Li, A. R. Bader, E. Langan, K. Olejnik, P. Fenton, J. W. Kang, J. HollisterLocke, M. A. Bochenek, A. Chiu, S. Siebert, K. Tang, S. Jhunjhunwala, S. Aresta-Dasilva, N. Dholakia, R. Thakrar, T. Vietti, M. Chen, J. Cohen, K. Siniakowicz, M. Qi, J. McGarrigle, S. Lyle, D. M. Harlan, D. L. Greiner, J. Oberholzer, G. C. Weir, R. Langer, D. G. Anderson, Combinatorial hydrogel library enables identification of materials that mitigate the foreign body response in primates. Nat Biotechnol 34, 345 (Mar, 2016).

99. R. Langer, J. P. Vacanti, Tissue engineering. Science 260, 920 (May 14, 1993).

100. Y. Shiba, T. Gomibuchi, T. Seto, Y. Wada, H. Ichimura, Y. Tanaka, T. Ogasawara, K. Okada, N. Shiba, K. Sakamoto, D. Ido, T. Shiina, M. Ohkura, J. Nakai, N. Uno, Y. Kazuki, M. Oshimura, I. Minami, U. Ikeda, Allogeneic transplantation of iPS cell-derived cardiomyocytes regenerates primate hearts. Nature 538, 388 (Oct 10, 2016).

101. H. C. Ott, T. S. Matthiesen, S. K. Goh, L. D. Black, S. M. Kren, T. I. Netoff, D. A. Taylor, Perfusion-decellularized matrix: using nature's platform to engineer a bioartificial heart. Nat Med 14, 213 (Feb, 2008)

102. J. P. Guyette, S. E. Gilpin, J. M. Charest, L. F. Tapias, X. Ren, H. C. Ott, Perfusion decellularization of whole organs. Nature protocols 9, 1451 (2014).

103. R. L. Carrier, M. Papadaki, M. Rupnick, F. J. Schoen, N. Bursac, R. Langer, L. E. Freed, G. Vunjak-Novakovic, Cardiac tissue engineering: cell seeding, cultivation parameters, and tissue construct characterization. Biotechnol Bioeng 64, 580 (Sep 05, 1999).

104. J. Leor, S. Aboulafia-Etzion, A. Dar, L. Shapiro, I. M. Barbash, A. Battler, Y. Granot, S. Cohen, Bioengineered cardiac grafts: A new approach to repair the infarcted myocardium? Circulation 102, III56 (Nov 7, 2000)

105. T. Kofidis, D. R. Lebl, E. C. Martinez, G. Hoyt, M. Tanaka, R. C. Robbins, Novel injectable bioartificial tissue facilitates targeted, less invasive, large-scale tissue restoration on the beating heart after myocardial injury. Circulation 112, I173 (Aug 30, 2005).

106. M. Shachar, O. Tsur-Gang, T. Dvir, J. Leor, S. Cohen, The effect of immobilized RGD peptide in alginate scaffolds on cardiac tissue engineering. Acta Biomater 7, 152 (Jan, 2011).

107. C. A. Gregory, J. Ylostalo, D. J. Prockop, Adult bone marrow stem/progenitor cells (MSCs) are preconditioned by microenvironmental "niches" in culture: a two-stage hypothesis for regulation of MSC fate. Science's STKE : signal transduction knowledge environment 2005, pe37 (Jul 26, 2005).

108. E. C. Perin, R. Sanz-Ruiz, P. L. Sanchez, J. Lasso, R. Perez-Cano, J. C. Alonso-Farto, E. Perez-David, M. E. Fernandez-Santos, P. W. Serruys, H. J. Duckers, J. Kastrup, S. Chamuleau, Y. Zheng, G. V. Silva, J. T. Willerson, F. Fernandez-Aviles, Adipose-derived regenerative cells in patients with ischemic cardiomyopathy: The PRECISE Trial. American heart journal 168, 88 (Jul, 2014).

109. A. Eder, I. Vollert, A. Hansen, T. Eschenhagen, Human engineered heart tissue as a model system for drug testing. Advanced drug delivery reviews 96, 214 (Jan 15, 2016).

110. Y. Miyahara, N. Nagaya, M. Kataoka, B. Yanagawa, K. Tanaka, H. Hao, K. Ishino, H. Ishida, T. Shimizu, K. Kangawa, S. Sano, T. Okano, S. Kitamura, H. Mori, Monolayered mesenchymal stem cells repair scarred myocardium after myocardial infarction. Nat Med 12, 459 (Apr, 2006).

111. K. Sakaguchi, T. Shimizu, T. Okano, Construction of three-dimensional vascularized cardiac tissue with cell sheet engineering. $J$ Control Release 205, 83 (May 10, 2015).

112. H. Shimizu, K. Ohashi, T. Saito, R. Utoh, K. Ise, M. Yamato, T. Okano, M. Gotoh, Topographical arrangement of alpha- and beta-cells within neoislet tissues engineered by islet cell sheet transplantation in mice. Transplant Proc 45, 1881 (Jun, 2013).

113. H. Hamdi, A. Furuta, V. Bellamy, A. Bel, E. Puymirat, S. Peyrard, O. Agbulut, P. Menasche, Cell delivery: intramyocardial injections or epicardial deposition? A head-to-head comparison. The Annals of thoracic surgery 87, 1196 (Apr, 2009).

114. J. C. Chachques, J. C. Trainini, N. Lago, M. Cortes-Morichetti, O. Schussler, A. Carpentier, Myocardial assistance by grafting a new bioartificial upgraded myocardium (MAGNUM trial): clinical feasibility study. The Annals of thoracic surgery 85, 901 (Mar, 2008).

115. J. H. Juang, S. Bonner-Weir, Y. Ogawa, J. P. Vacanti, G. C. Weir, Outcome of subcutaneous islet transplantation improved by polymer device. Transplantation 61, 1557 (Jun 15, 1996).

116. J. M. Dufour, R. V. Rajotte, M. Zimmerman, A. Rezania, T. Kin, D. E. Dixon, G. S. Korbutt, Development of an ectopic site for islet transplantation, using biodegradable scaffolds. Tissue Eng 11, 1323 (Sep-Oct, 2005).

117. T. Kin, J. J. O'Neil, R. Pawlick, G. S. Korbutt, A. M. Shapiro, J. R. Lakey, The use of an approved biodegradable polymer scaffold as a solid support system for improvement of islet engraftment. Artif Organs 32, 990 (Dec, 2008)

118. D. M. Berman, J. J. O'Neil, L. C. Coffey, P. C. Chaffanjon, N. M. Kenyon, P. Ruiz, Jr., A. Pileggi, C. Ricordi, N. S. Kenyon, Long-term survival of nonhuman primate islets implanted in an omental pouch on a biodegradable scaffold. Am J Transplant 9, 91 (Jan, 2009).

119. E. Ruoslahti, M. D. Pierschbacher, New perspectives in cell adhesion: RGD and integrins. Science 238, 491 (Oct 23, 1987).

120. H. P. Sondermeijer, P. Witkowski, D. Woodland, T. Seki, F. J. Aangenendt, A. van der Laarse, S. Itescu, M. A. Hardy, Optimization of alginate purification using polyvinylidene difluoride 
membrane filtration: Effects on immunogenicity and biocompatibility of three-dimensional alginate scaffolds. Journal of biomaterials applications 31, 510 (Oct, 2016).

121. G. H. Mao, G. A. Chen, H. Y. Bai, T. R. Song, Y. $\mathrm{X}$. Wang, The reversal of hyperglycaemia in diabetic mice using PLGA scaffolds seeded with islet-like cells derived from human embryonic stem cells. Biomaterials 30, 1706 (Mar, 2009).

122. S. Kodama, K. Kojima, S. Furuta, M. Chambers, A. C. Paz, C. A. Vacanti, Engineering functional islets from cultured cells. Tissue Eng Part A 15, 3321 (Nov, 2009).

123. K. Tateishi, J. He, O. Taranova, G. Liang, A. C. D'Alessio, Y. Zhang, Generation of insulinsecreting islet-like clusters from human skin fibroblasts. J Biol Chem 283, 31601 (Nov 14, 2008).

124. T. Zhao, Z. N. Zhang, Z. Rong, Y. Xu, Immunogenicity of induced pluripotent stem cells. Nature 474, 212 (May 13, 2011).

125. X. Wang, J. Qin, R. C. Zhao, M. Zenke, Reduced immunogenicity of induced pluripotent stem cells derived from Sertoli cells. PLoS One 9, e106110 (2014)

126. Q. Lu, M. Yu, C. Shen, X. Chen, T. Feng, Y. Yao, J. Li, H. Li, W. Tu, Negligible immunogenicity of induced pluripotent stem cells derived from human skin fibroblasts. PLoS One 9, e114949 (2014).

127. H. Haider, M. Ashraf, Strategies to promote donor cell survival: combining preconditioning approach with stem cell transplantation. $J$ Mol Cell Cardiol 45, 554 (Oct, 2008).

128. J. L. Herrmann, A. M. Abarbanell, B. R. Weil, M. C. Manukyan, J. A. Poynter, B. J. Brewster, Y. Wang, D. R. Meldrum, Optimizing stem cell function for the treatment of ischemic heart disease. J Surg Res 166, 138 (Mar, 2011).

129. J. A. Spencer, F. Ferraro, E. Roussakis, A. Klein, J. Wu, J. M. Runnels, W. Zaher, L. J. Mortensen, C. Alt, R. Turcotte, R. Yusuf, D. Cote, S. A. Vinogradov, D. T. Scadden, C. P. Lin, Direct measurement of local oxygen concentration in the bone marrow of live animals. Nature 508, 269 (Apr 10, 2014).

130. I. Rosova, M. Dao, B. Capoccia, D. Link, J. A. Nolta, Hypoxic preconditioning results in increased motility and improved therapeutic potential of human mesenchymal stem cells. Stem cells 26, 2173 (Aug, 2008).

131. A. A. Mangi, N. Noiseux, D. Kong, H. He, M. Rezvani, J. S. Ingwall, V. J. Dzau, Mesenchymal stem cells modified with Akt prevent remodeling and restore performance of infarcted hearts. Nat Med 9, 1195 (Sep, 2003).

132. M. Giuliani, W. Moritz, E. Bodmer, D. Dindo, P. Kugelmeier, R. Lehmann, M. Gassmann, P. Groscurth, M. Weber, Central necrosis in isolated hypoxic human pancreatic islets: evidence for postisolation ischemia. Cell Transplant 14, 67 (2005).

133. Z. Ma, N. Moruzzi, S. B. Catrina, I. Hals, J. Oberholzer, V. Grill, A. Bjorklund, Preconditioning with associated blocking of $\mathrm{Ca}^{2+}$ inflow alleviates hypoxia-induced damage to pancreatic beta-cells. PLoS One 8, e67498 (2013).

134. D. Hamilton, C. Rugg, N. Davis, M. Kvezereli, B. A. Tafti, S. Busque, M. Fontaine, A preconditioning regimen with a PKCvarepsilon activator improves islet graft function in a mouse transplant model. Cell Transplant 23, 913 (2014).

135. Y. Wang, S. Wang, T. Harvat, K. Kinzer, L. Zhang, F. Feng, M. Qi, J. Oberholzer, Diazoxide, a K(ATP) channel opener, prevents ischemiareperfusion injury in rodent pancreatic islets. Cell Transplant 24, 25 (2015).

136. J. S. Rink, K. M. McMahon, X. Zhang, X. Chen, C. A. Mirkin, C. S. Thaxton, D. B. Kaufman, Knockdown of intraislet IKKbeta by spherical nucleic acid conjugates prevents cytokineinduced injury and enhances graft survival. Transplantation 96, 877 (Nov 27, 2013).

137. H. K. Eltzschig, T. Eckle, Ischemia and reperfusion--from mechanism to translation. Nat Med 17, 1391 (Nov 07, 2011).

138. T. Kawai, A. B. Cosimi, T. R. Spitzer, N. TolkoffRubin, M. Suthanthiran, S. L. Saidman, J. Shaffer, F. I. Preffer, R. Ding, V. Sharma, J. A. Fishman, B. Dey, D. S. Ko, M. Hertl, N. B. Goes, W. Wong, W. W. Williams, Jr., R. B. Colvin, M. Sykes, D. H. Sachs, HLA-mismatched renal transplantation without maintenance immunosuppression. $N$ Engl J Med 358, 353 (Jan 24, 2008).

139. T. Eckle, D. Kohler, R. Lehmann, K. El Kasmi, H. K. Eltzschig, Hypoxia-inducible factor-1 is central to cardioprotection: a new paradigm for ischemic preconditioning. Circulation 118, 166 (Jul 08, 2008).

140. M. A. Keranen, R. Tuuminen, S. Syrjala, R. Krebs, G. Walkinshaw, L. A. Flippin, M. Arend, P. K. Koskinen, A. I. Nykanen, K. B. Lemstrom, Differential effects of pharmacological HIF preconditioning of donors versus recipients in rat cardiac allografts. Am J Transplant 13, 600 (Mar, 2013).

141. S. F. Badylak, T. W. Gilbert, Immune response to biologic scaffold materials. Semin Immunol 20, 109 (Apr, 2008).

142. F. Escalas, J. Galante, W. Rostoker, Biocompatibility of materials for total joint replacement. J Biomed Mater Res 10, 175 (Mar, 1976).

143. S. D. Bruck, Problems and challenges of biomaterials in cardiovascular applications: a status report. Biomaterials, medical devices, and artificial organs 11, 271 (1983).

144. A. McNamara, D. F. Williams, The response to the intramuscular implantation of pure metals. Biomaterials 2, 33 (Jan, 1981).

145. S. A. Wallace, K. L. Brown, Foreign body reaction to sutures and other materials. Texas state journal of medicine 44, 463 (Oct, 1948).

146. L. L. Hench, H. A. Paschall, Histochemical responses at a biomaterial's interface. J Biomed Mater Res 8, 49 (1974).

147. J. D. Hartgerink, E. Beniash, S. I. Stupp, Selfassembly and mineralization of peptideamphiphile nanofibers. Science 294, 1684 (Nov 23, 2001)

148. R. Klopfleisch, F. Jung, The pathology of the foreign body reaction against biomaterials. $J$ Biomed Mater Res A 105, 927 (Mar, 2017).

149. J. M. Anderson, A. Rodriguez, D. T. Chang, Foreign body reaction to biomaterials. Semin Immunol 20, 86 (Apr, 2008).

150. A. Rodriguez, S. R. Macewan, H. Meyerson, J. T. Kirk, J. M. Anderson, The foreign body reaction in T-cell-deficient mice. $J$ Biomed Mater Res A 90, 106 (Jul, 2009). 
151. J. C. Doloff, O. Veiseh, A. J. Vegas, H. H. Tam, S. Farah, M. Ma, J. Li, A. Bader, A. Chiu, A. Sadraei, S. Aresta-Dasilva, M. Griffin, S. Jhunjhunwala, M. Webber, S. Siebert, K. Tang, M. Chen, E. Langan, N. Dholokia, R. Thakrar, M. Qi, J. Oberholzer, D. L. Greiner, R. Langer, D. G. Anderson, Colony stimulating factor-1 receptor is a central component of the foreign body response to biomaterial implants in rodents and non-human primates. Nature materials, (Mar 20, 2017).

152. F. F. Damanik, T. C. Rothuizen, C. van Blitterswijk, J. I. Rotmans, L. Moroni, Towards an in vitro model mimicking the foreign body response: tailoring the surface properties of biomaterials to modulate extracellular matrix. Scientific reports 4, 6325 (Sep 19, 2014).

153. A. C. Parks, K. Sung, B. M. Wu, A threedimensional in vitro model to quantify inflammatory response to biomaterials. Acta Biomater 10, 4742 (Nov, 2014).

154. J. M. Morais, F. Papadimitrakopoulos, D. J. Burgess, Biomaterials/tissue interactions: possible solutions to overcome foreign body response. The AAPS journal 12, 188 (Jun, 2010).

155. M. Kastellorizios, F. Papadimitrakopoulos, D. J. Burgess, Prevention of foreign body reaction in a pre-clinical large animal model. $J$ Control Release 202, 101 (Mar 28, 2015).

156. W. J. Geelhoed, L. Moroni, J. I. Rotmans, Utilizing the foreign body response to grow tissue engineered blood vessels in vivo. $J$ Cardiovasc Transl Res, (Feb 15, 2017).

157. H. Sondermeijer, Witkowski, P., Hardy, M.A., (WO/2009/039185) Uses Of immunologically modified scaffold for tissue prevascularization and cell transplantation. (26.03.2009, 2009). 


\section{Part I}

Bioengineered scaffolding for cell transplantation. 


\section{Chapter 2}

Optimization of alginate purification using polyvinylidene difluoride membrane filtration: Effects on immunogenicity and biocompatibility of three-dimensional alginate scaffolds.

Journal of Biomaterials Applications, 2016 Oct; 31(4): 510-520.

Hugo P. Sondermeijer, Piotr Witkowski, David Woodland, Tetsunori Seki, Frank J. Aangenendt, Arnoud van der Laarse, Silviu Itescu, and Mark A. Hardy. 


\section{ABSTRACT}

Sodium alginate is an effective biomaterial for tissue engineering applications. Nonpurified alginate is contaminated with protein, lipopolysaccharide, DNA, and RNA, which could elicit adverse immunological reactions. We developed a purification protocol to generate biocompatible alginate based on (a) activated charcoal treatment, (b) use of hydrophobic membrane filtration (we used hydrophobic polyvinylidene difluoride membranes to remove organic contaminants), (c) dialysis, and finally (d) ethanol precipitation. Using this approach, we could omit pre-treatment with chloroform and significantly reduce the quantities of reagents used. Purification resulted in reduction of residual protein by $70 \%$ down to $0.315 \mathrm{mg} / \mathrm{g}$, DNA by $62 \%$ down to $1.28 \mathrm{\mu g} / \mathrm{g}$, and RNA by $61 \%$ down to less than $10 \mathrm{\mu g} / \mathrm{g}$, respectively. Lipopolysaccharide levels were reduced by $>90 \%$ to less than $125 \mathrm{EU} / \mathrm{g}$. Purified alginate did not induce splenocyte proliferation in vitro. Three-dimensional scaffolds generated from purified alginate did not elicit a significant foreign body reaction, fibrotic overgrowth, or macrophage infiltration 4 weeks after implantation. This study describes a simplified and economical alginate purification method that results in alginate purity, which meets clinically useful criteria.

\section{INTRODUCTION}

Sodium alginate is a naturally occurring polysaccharide extracted from marine plants (algae kelp) (1). It has been widely used for cell encapsulation and tissue engineering applications (2-8). Our group has recently described the use of a pro-angiogenic 3D alginate scaffold that was prevascularized for 2 weeks under the abdominal rodent rectus muscles, and subsequently used successfully as a carrier for pancreatic islets isografts in an extrahepatic, easily accessible site (9).

It is well known that non-purified sodium alginate is contaminated with various proteins, lipopolysaccharide (LPS), DNA, and RNA, each of which is capable of inducing host immune responses following implantation (10). Since impurities can induce fibrotic overgrowth that interferes with the diffusion of nutrients and oxygen (11), the use of alginate scaffolds or capsules has not yet achieved clinical application. The production of cytokines by attracted inflammatory cells leads to destruction of transplanted cells residing within the alginate matrix (12), and pancreatic islet viability has been shown to be directly related to the purity of the alginate used for implantation (13).

To minimize immune responses that interfere with the clinical usefulness of alginate scaffolds, several methods for alginate purification have been tested previously $(14,15)$. Industrial purification methods suffer from inefficiencies such as the need to use large quantities of organic solvents and/or time consuming extraction steps, and/or use of potentially harmful chemicals such as chloroform (16-18). Previous studies purified alginate with activated charcoal followed by dialysis and ethanol precipitation to remove gross contamination (19). These methods resulted in preparations which were still unacceptable due to the remaining levels of residual LPS and protein contamination that would continue to elicit immunological reactions (14).
To avoid the above pitfalls, we therefore evaluated materials that specifically bind organic contaminants without binding alginate. Several bioactive resins and filter membranes are known that meet these requirements (20), for example, aldehyde-based (21) or anhydride-based (22) chemistry. Unfortunately, these materials need to be activated using hazardous chemicals such as cyanuric chloride. Moreover, reactive aldehyde or anhydride groups on these materials are rapidly deactivated in water, making them less suitable for large volume treatment of aqueous solutions.

Polyvinylidene difluoride (PVDF) does not suffer from the previously mentioned disadvantages. PVDF is a hydrophobic polymer with high affinity for proteins via both hydrophobic and electrostatic interactions $(23,24)$. Hydrophobic PVDF membranes such as Immobilon-P (Millipore, Temecula, CA) have already been used for protein and LPS analyses $(25,26)$. These membranes have a thickness of $100-130 \mu \mathrm{m}$, a pore size of $0.45 \mu \mathrm{m}$,

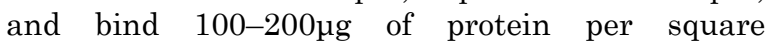
centimeter. We hypothesized that the use of a membrane filtration step would enhance the removal of contaminants from alginate by specifically binding residual contaminants. Using our optimal PVDF-based protocol, we could effectively increase the removal of protein, LPS, DNA, and RNA to levels that are clinically acceptable, while omitting pre-treatment with chloroform, which can be toxic to the cells. We could also significantly reduce the total quantities of reagents used compared with methods described earlier (17).

\section{MATERIALS}

Ultrapure water for dialysis was obtained from a Hydro Picopure (Millipore, Temecula, CA) purification system. Low viscosity alginate (MW $<35 \mathrm{kD}$ ) obtained from brown algae which consists of straight-chain, hydrophilic, colloidal, and polyuronic acid, which is composed primarily of anhydro-B-D- 
mannuronic and a-L-guluronic acid residues with $1 \rightarrow 4$ linkage (A0682) and a viscosity of $4-12 \mathrm{cP}, 1 \%$ at $25^{\circ} \mathrm{C}$, activated charcoal (C9157), monosodium phosphate monohydrate (71507), disodium phosphate heptahydrate (431478), hydrochloric acid (H1758), and sodium hydroxide (S8045) were all purchased from Sigma-Aldrich (St Louis, MO). Molecular biology grade water (Hyclone SH30538), neutralized carbon (C170), 50,000 MWCO dialysis tubing (Spectra/Por7, Spectrum Laboratories, Inc., Rancho Dominguez, CA, part \# 132130), 35mm standard closures (Spectrum Laboratories, Inc., Rancho Dominguez, CA, part \# 132736), 90mm Büchner funnel filter setup (Kontes Ultraware, Kimble-Chase, Vineland, NJ), micro-BCA kit (part \# 23235), and molecular biology grade ethanol 100\% (BP2818-4) were purchased from Thermo Fisher Scientific (Fairlawn, NJ). Hydrophobic Immobilon P membranes (IPVH 00010) with $0.45 \mu \mathrm{m}$ pore size, $90 \mathrm{~mm}$ glass membrane pre-filters (type AP15), and $0.45 \mu \mathrm{m}$ Stericup filter flasks (SCHVU05RE) were purchased from Millipore (Temecula, CA). Alpha minimum essential medium (MEM), fetal calf serum (FCS), and L-glutamine (GlutaMax ${ }^{\circledR}$ ) were purchased from Invitrogen/Gibco (Carlsbad, CA). Primocin was purchased from Invivogen (San Diego, CA).

Glassware was cleaned and detoxified by $24 \mathrm{~h}$ treatment with $0.5 \%$ hypochlorite followed by washing and baking for at least $120 \mathrm{~min}$ at $240^{\circ} \mathrm{C}$. LPS was measured using the Pyrosate kit according to the manufacturer's instructions (Cape Cod Inc., East Falmouth, MA). DNA and RNA were determined using the Qubit Quantitation Platform (Invitrogen, Carlsbad, CA). Spectrophotometric absorption was measured on a Shimadzu UV1700 PharmaSpec (Shimadzu Scientific Instruments, Somerset, NJ). Controls used for purification efficiency consisted of non-purified alginate (SigmaAldrich 0682) and pharmaceutical grade alginates; low viscosity, high mannuronic acid Pronova UP LVM (approx. MW 75-200kD, apparent viscosity 20-200cP), and low viscosity, high guluronic acid, Pronova UP LVG (approx. MW 75-200kD, apparent viscosity 20-200cP) (batch numbers FP-106-1 and FP-305-01, respectively, both were obtained from FMC Biopolymer/Novamatrix, Sandvika, Norway). Lyophilization was achieved using a BOC/Edwards 8 vacuum pump and cold trap (Tewkbury, MA) at 0.2 torr. $\mathrm{pHs}$ were determined using a digital $\mathrm{pH}$ meter (Accumet AB15+, Cole-Parmer, Vernon Hills, IL) calibrated with commercially available buffers (Thermo Fisher Scientific, Fairlawn, NJ).

\section{METHODS}

\subsection{ALGINATE PURIFICATION PROTOCOL (Chart 1)}

We investigated several conditions to optimize removal of mitogens and pyrogens by filtration. We employed a minimum $\mathrm{pH}$ of 5.5 due to precipitation of alginate at lower $\mathrm{pHs}$, which would result in unacceptable filtration rates. To determine the influence of ionic strength on degree of filtration and purification, we used sodium phosphate buffer concentrations of $10 \mathrm{mM}$ and $50 \mathrm{mM}$. In total, we produced 17 batches of purified alginate. Comparisons of residual organic contaminants are shown within the final most optimized batch.

\subsubsection{CHARCOAL TREATMENT}

After dissolving $1.5 \%$ alginate $(\mathrm{w} / \mathrm{w})$ in purified water without or with either $10 \mathrm{mM}$ or $50 \mathrm{mM}$ sodium phosphate, $1.5 \%$ neutralized carbon was added to the solution and $\mathrm{pH}$ was adjusted to 5.5 using 37\% hydrochloric acid at room temperature. The solution was subsequently stirred for $20 \mathrm{~h}$ at $50^{\circ} \mathrm{C}$ to prevent potential microbial growth and was then filtered through a glass pre-filter to remove charcoal and any particulate matter prior to collection in a $2 \mathrm{~L}$ depyrogenized Erlenmeyer flask. Following filtration, $1.5 \%$ of acidic activated charcoal was added to the suspension while stirring and $\mathrm{pH}$ adjusted at 5.5 at room temperature, followed by an additional $20 \mathrm{~h}$ of stirring at $50^{\circ} \mathrm{C}$. A second filtration step through a glass pre-filter to remove charcoal resulted in a filtrate with a yellowish gray color.

\subsubsection{HYDROPHOBIC PVDF TREATMENT}

Sheets $(90 \mathrm{~mm} \times 90 \mathrm{~mm})$ of PVDF were cut prior to their use in the $90 \mathrm{~mm}$ Büchner funnel setup. Membrane filters were immersed in methanol for $15 \mathrm{~s}$ to remove air, washed in ultrapure $\mathrm{H}_{2} \mathrm{O}$ and kept in sterile phosphate buffer solution at pH 5.5. Filtration was performed using a Büchner funnel setup and two alternating Erlenmeyer vacuum flasks. Prior to filtration, the $\mathrm{pH}$ of alginate solution was adjusted to 5.5. Using the in-house vacuum system in a laminar flow hood, the complete volume of alginate solution was filtered, the membrane filter was then replaced with a fresh filter and this step was repeated 20 times using a total of 20 filter membranes for $1 \mathrm{~L}$ of alginate solution. The price per single PVDF sheet used in this protocol was between US $\$ 3$ and US $\$ 4$.

\subsubsection{DIALYSIS}

After filtration, alginate solution was sterile filtered using $0.45 \mu \mathrm{m}$ Stericup filter flasks (Millipore, Temacula, CA). Filtered solution was transferred to pre-washed dialysis tubes (50,000 MWCO), closed with double clamps on each side, and dialyzed for $48 \mathrm{~h}$ against ultrapure $\mathrm{H}_{2} \mathrm{O}$ (1:100 volume) with one change of water after $24 \mathrm{~h}$ at room temperature. Following dialysis, the resulting purified solution was collected in $50 \mathrm{~mL}$ conical tubes (part \# 352070, BD Biosciences, Franklin Lakes, NJ), frozen at $-20^{\circ} \mathrm{C}$, lyophilized at 0.2 torr, and redissolved in ultrapure $\mathrm{H}_{2} \mathrm{O}$ at $2 \%$ weight/volume prior to use.

\subsubsection{ETHANOL PRECIPITATION}

To precipitate $20 \mathrm{~mL}$ alginate solution in $50 \mathrm{~mL}$ conical tubes, we used equal volumes of $100 \%$ ethanol and $2 \%$ alginate solution. After adding $20 \mathrm{~mL}$ ethanol, the solution was vortexed for $1 \mathrm{~min}$ at 3000rpm and subsequently spun at 4000rpm for $30 \mathrm{~min}$. Supernatants were removed and pellets 


\begin{tabular}{|c|c|}
\hline \multicolumn{2}{|r|}{ ALGINATE PURIFICATION PROCEDURE FLOW CHART } \\
\hline 1. & Sodium alginate $1.5 \%$ in $10 \mathrm{mM}$ phosphate buffer, pH 5.5 \\
\hline 2. & Neutralized carbon treatment \\
\hline 3. & Glass membrane pre-filter filtration \\
\hline 4. & Acid washed carbon treatment, readjust $\mathrm{pH}$ to 5.5 \\
\hline 5. & Glass membrane pre-filter filtration \\
\hline 6. & Serial hydrophobic PVDF membrane filtration, readjust $\mathrm{pH}$ to 5.5 \\
\hline 7. & Sterile filter, dialysis against $\mathrm{ddH}_{2} \mathrm{O}, 50,000 \mathrm{MWCO}, 48 \mathrm{~h}$ \\
\hline 8. & Lyophilize solution, redissolve at $2 \%$ in $\mathrm{ddH}_{2} \mathrm{O}$ \\
\hline 9. & Precipitation with $100 \%$ ethanol $1: 1$ \\
\hline 10. & Lyophilize precipitate, redissolve at $2 \%$ in $\mathrm{ddH}_{2} \mathrm{O}$, filter sterilize \\
\hline 11. & Purity analysis, further processing \\
\hline
\end{tabular}

Chart 1. Flow chart showing step-wise purification of raw alginate. Complete description is found in the "Materials" and "Methods" sections.

dried at 0.2torr. After drying, pellets were redissolved at $2 \%$ in ultrapure $\mathrm{H}_{2} \mathrm{O}$ and sterile filtered using $0.45 \mu \mathrm{m}$ Stericup filter flasks (Millipore, Temacula, CA) before analyzing the product for purity.

\subsection{DETERMINATION OF ALGINATE PURITY AND IMMUNOGENICITY}

\subsubsection{PROTEIN QUANTIFICATION}

In preparation for protein assay, alginate solutions were diluted $1: 10$ to $0.2 \%$ inultra-pure water, followed by $60 \mathrm{~min}$ incubation with BCA reagent according to the manufacturer's instructions. Protein concentrations were compared with standard curves obtained with bovine serum albumin included in the BCA kit. Absorption was read in $200 \mu \mathrm{L}$ plastic cuvettes at $562 \mathrm{~nm}$. Resulting protein content was converted to milligrams of protein per gram of dry alginate. Measurements were performed in triplicate.

\subsubsection{LPS QUANTIFICATION}

LPS levels were determined using the Pyrosate kit, which is based on the limulus amoebocyte lysate (LAL) assay. This kit has a sensitivity of $0.25 \mathrm{EU}$ LPS $/ \mathrm{mL}$. Alginate solutions were tested at $2 \%$ and $0.2 \%$ weight/volume ultrapure $\mathrm{H}_{2} \mathrm{O}$ after filtration through $0.45 \mu \mathrm{m}$ syringe filters (Millex-HV, 33mm diameter, Millipore, Temecula, CA). In brief, according to the manufacturer's instructions, $0.5 \mathrm{~mL}$ LAL reagent water and $0.5 \mathrm{ml}$ alginate solution were added to sample tubes, mixed, and dissolved, followed by transfer of $0.25 \mathrm{~mL}$ of each solution to the positive control tubes in duplicate. All tubes were incubated at $37^{\circ} \mathrm{C}$ for the time specified by the manufacturer. Formation of a clot was determined by visual inspection and inversion of tubes; test was considered valid if sample and positive controls showed clot formation and all negative controls absence of clots.

\subsubsection{DNA AND RNA QUANTIFICATION}

DNA and RNA concentrations in alginate solutions were determined using the Qubit Quant-iT quantitation system using the Qubit Fluorometer (Q32857) with the Quant-iT dsDNA HS (Q32854) and RNA HS (Q32852) assays (Invitrogen, Carlsbad, CA). In brief, non-purified and purified alginate (Sigma-Aldrich 0682) and Pronova LVM and LVG solutions were diluted to $0.2 \%$ in working solution as provided by the manufacturer. DNA and RNA concentrations were determined fluorometrically according to the manufacturer's instructions. Results are presented in micrograms DNA or RNA per gram dry alginate.

\subsubsection{ASSAY FOR IMMUNOGENIC ACTIVITY}


Rat splenocyte proliferation was used as an indicator for alginate immunogenicity, based on a modified protocol as previously described (17). Briefly, rat spleens were removed under sterile conditions and collected in alpha MEM supplemented culture medium containing $10 \%$ fetal calf serum (FCS), 2mM L-glutamine, and $100 \mu \mathrm{g} / \mathrm{mL}$ Primocin, minced and passed through a $100 \mu \mathrm{m}$ cell strainer (part \# 352360, BD Biosciences, Franklin Lakes, NJ) into $50 \mathrm{~mL}$ conical tubes. In all, $10^{5}$ splenocytes were incubated in $200 \mu \mathrm{L}$ alpha MEM and $10 \%$ FCS including various alginate solutions in 96-well flat bottom tissue culture plates (part \# 353072, BD Biosciences, Franklin Lakes, NJ). Splenocyte proliferation was serially measured at $48 \mathrm{~h}$ after incubation at $37^{\circ} \mathrm{C}$ and $5 \% \mathrm{CO}_{2}$. WST- 1 $(20 \mu \mathrm{L})$ (Roche Applied Science, Indianapolis, IN) was added $2 \mathrm{~h}$ prior to reading at $450-650 \mathrm{~nm}$ in a $\mathrm{V}_{\max }$ kinetic microplate reader (Molecular Devices, Sunnyvale, CA) to determine light absorption which directly correlates with the number of metabolically active cells in the culture. Obtained values were corrected for background absorbance, which was determined by measuring absorption in the medium without the presence of alginate or cells.

\subsubsection{ALGINATE VISCOSITY}

Following purification, alginate viscosity may increase to unpractical levels after processing due to excessive removal of short chain alginate molecules (14). Viscosity of purified alginate solution was measured using a stress controlled MCR 501 rheometer (Anton Paar GmbH, Graz, Austria) at $25^{\circ} \mathrm{C}$ using a maximum of 41 increasing shear rates at minimum torque of $1.0 \times 10-7 \mathrm{nM}$ at $2.5 \%$ and $1.2 \% \mathrm{w} / \mathrm{w}$ solutions. Measurements were done in triplicate and compared with previously reported data (14).

\subsection{ALGINATE BIOCOMPATIBILITY IN VIVO}

\subsubsection{IMPLANTATION OF ALGINATE SCAFFOLDS}

All animal studies were reviewed and approved by the Columbia University Institutional Animal Care and Use Committee (IACUC). Male Lewis rats were obtained from Harlan Sprague Dawley, Inc. (Indianapolis, IN) and weighed between $200 \mathrm{~g}$ and $250 \mathrm{~g}$. Three-dimensional scaffolds were fabricated by adding $400 \mu \mathrm{L}$ alginate to a $4.2 \mathrm{~cm}^{2}$ cell culture insert with transparent $0.4 \mu \mathrm{m}$ polyethylene terephthalate membranes (part \# 353090, BD Falcon, BD Biosciences, Franklin Lakes, NJ). Transparent membranes were found to generate optimal scaffolds with even surfaces. Loaded inserts were placed in six-well tissue culture plates (part \# 353046, BD Falcon, BD Biosciences, Franklin Lakes, NJ) and $3 \mathrm{~mL}$ of $4.3 \%$ calcium gluconate was added to each bottom well. Plates were maintained at $4^{\circ} \mathrm{C}$ for $24 \mathrm{~h}$ to solidify the alginate by diffusion of calcium ions through the insert membrane. Following solidification, scaffolds were removed from the culture inserts and washed 3 times in $3 \mathrm{~mL}$ of sterile ultrapure water to remove excess calcium gluconate and to keep them moist in sterile ultrapure water until implantation. Scaffolds were inserted between abdominal muscle layers of Lewis rats $(n=5)$ following anaesthesia with isoflurane gas (1-5\%). After shaving and sterilizing the rat's ventral surface, skin was incised in the midline and the underlying muscle was then carefully dissected just lateral to the midline down to the ventral fascia over the peritoneum. By blunt dissection, a pocket was created within the rectus muscle. The pocket was made large enough to accommodate a scaffold $\sim 10 \mathrm{~mm}$ in diameter. The pocket and skin were closed in separate layers after successful scaffold implantation. Four weeks after implantation, the animals were euthanized by exsanguation and the rectus muscles containing scaffolds were harvested. Tissues were fixed in $4 \%$ paraformaldehyde in PBS for $24 \mathrm{~h}$, transferred to $70 \%$ ethanol and sectioned. Sections $(5 \mu \mathrm{m})$ were stained with hematoxylin/eosin for general histological analyses, and Masson's trichrome for collagen and fibrosis. We examined all sections for the well described foreign body reaction, which consists of fusion of macrophages to multinucleated giant cells in response to immunogenic material (27). We quantitated numbers of multinucleated giant cells as number of cells per high power field (400× magnification) under a light microscope (Olympus BX41, Center Valley, PA) in five serial sections per animal. As a positive control for multinucleated giant cell formation, we used biodegradable polyglycolic acid sutures (VICRYL ${ }^{\circledR}$, Ethicon, Somerville, NJ) made from polyglycolic acid (PGA), a biodegradable material, which is known to induce a significant giant cell reaction (28). Suture material was placed at a different site at the time of scaffold implantation in the abdominal rectus muscle and that tissue was harvested at the same time as scaffold explantation to use as comparison control for the quantification of macrophage and giant cell reaction in the alginate scaffold material.

\subsection{STATISTICAL ANALYSES}

Student's t-test (unequal variance, two-tailed) was used to compare the results. A p value $<0.05$ was considered to be statistically significant. Results are presented as means \pm standard error of the mean (SEM).

\section{RESULTS}

To prepare $3-4 \mathrm{~g}$ of purified alginate from $15 \mathrm{~g}$ of non-purified alginate, we used a total volume of 105L of water, mostly due to alginate dialysis steps against water 1:100. We further used a total volume of $500 \mathrm{~mL}$ of ethanol and $500 \mathrm{~mL}$ of methanol, a significant reduction when compared with other methods such as that of Klöck et al $(17,29)$. Following purification, aforementioned methods yielded $1-2 \mathrm{~g}$ of purified alginate from $18 \mathrm{~g}$ raw starting material.

\subsection{QUANTIFICATION OF RESIDUAL ALGINATE CONTAMINATION}




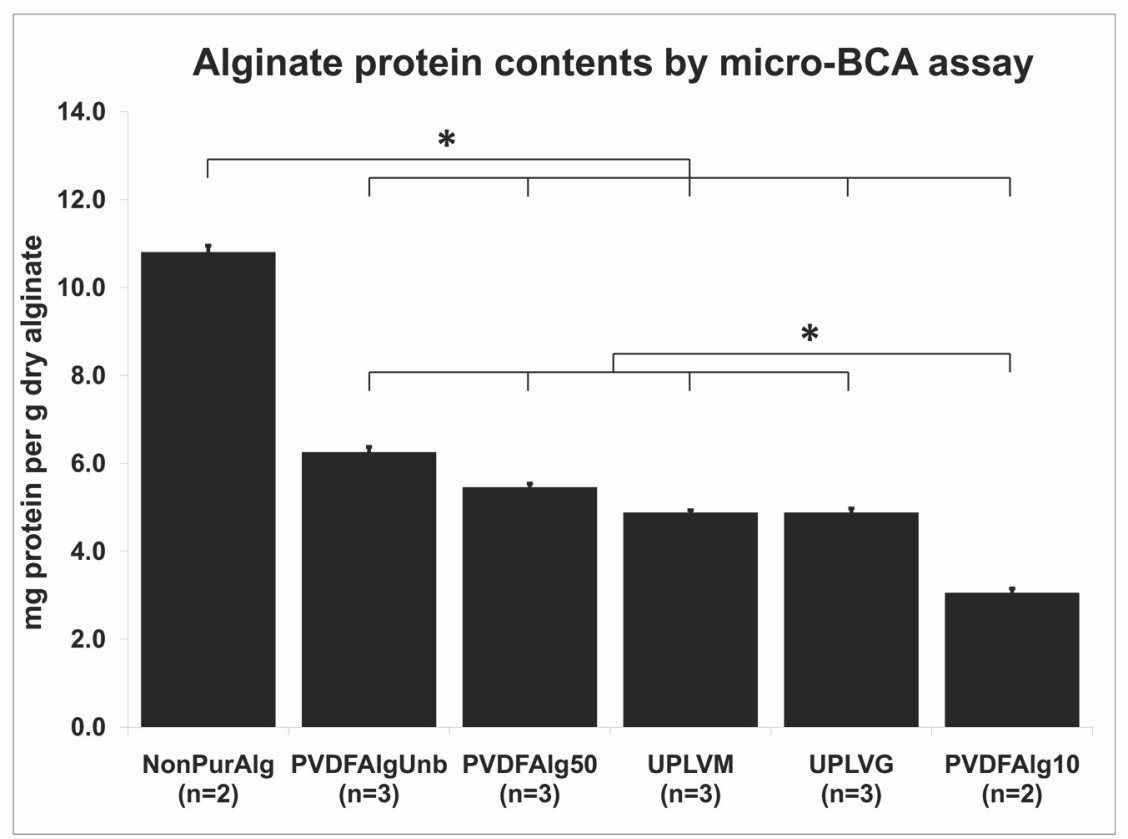

Figure 1. Quantitative evaluation of protein contamination in several different sodium alginate preparations. Results are presented in milligrams of protein per gram of dried alginate \pm SEM. Micro-BCA assay sensitivity is $0.5 \mu \mathrm{g} / \mathrm{mL}$. ${ }^{*} \mathrm{p}<0.05$. NonPurAlg: non purified Sigma A0682 alginate; PVDFAlgUnb: PVDF purified Sigma A0682 alginate in unbuffered solution; PVDFAlg50: PVDF purified Sigma A0682 alginate in 50mM phosphate buffer; UPLVM: Novamatrix Ultrapure low viscosity mannuronic acid; UPLVG: Novamatrix Ultrapure low viscosity guluronic acid; PVDFAlg10: PVDF purified Sigma A0682 alginate in $10 \mathrm{mM}$ phosphate buffer.

After purification of low molecular weight alginate (Sigma-Aldrich 0682) using our customized method, protein, DNA, RNA, and LPS contents were determined as described above. Controls included non-purified alginate and ultrapure LVM and LVG alginates (FMC Biopolymer/Novamatrix, Sandvika, Norway).

\subsubsection{PROTEIN CONTAMINATION}

We found filtration through hydrophobic PVDF membranes in $10 \mathrm{mM}$ phosphate buffer at $\mathrm{pH} 5.5$ (PVDFAlg10) to be optimal. As determined by the micro-BCA method, we could reduce protein contamination from $10.8 \pm 0.2 \mathrm{mg} / \mathrm{g}$ found in nonpurified alginate to $3.15 \pm 0.1 \mathrm{mg} / \mathrm{g}$ following filtration, a $72 \%$ reduction $(\mathrm{p}<0.05)$ (Figure 1$)$. This reduction was significantly less than when filtration was performed in unbuffered alginate solution (PVDFAlgUnb) or in 50mM phosphate buffer (PVDFAlg50). Control alginates Pronova Ultrapure LVM (UPLVM) and LVG (UPLVG) alginates both contained $4.9 \pm 0.1 \mathrm{mg} / \mathrm{g}$ protein, a $38 \%$ difference as compared with the alginate we purified $(\mathrm{p}<0.05)$. These results are summarized in Figure 1.

\subsubsection{DNA AND RNA CONTAMINATION}

Residual DNA and RNA contamination were determined after optimizing protein purification using PVDF membrane filtration. Non-purified alginate (Sigma-Aldrich 0682) contained $3.39 \pm 0.02 \mu \mathrm{gDNA}$ per gram of dry alginate and $32.48 \pm 2.78 \mu \mathrm{g}$ of RNA per gram of dry alginate.
Following purification, the residual amount of DNA was reduced to $1.28 \pm 0.01 \mu \mathrm{g}$ DNA per gram of dry alginate, a reduction by $62 \%(\mathrm{p}<0.01)$ (Figure 2 ). RNA content was too low following filtration to be detected using the Qubit system, which indicates that there was less than 10ug RNA per gram of dry alginate, a reduction by at least 69\% (Figure 3 ). Pronova LVM and LVG alginates contained less than $0.25 \mu \mathrm{g}$ DNA per gram of dry alginate and less than $10 \mu \mathrm{g}$ RNA per gram of dry alginate as shown in Figures 2 and 3.

\subsubsection{LPS}

The commercial Pyrosate assay to detect LPS has a detection level of $0.25 \mathrm{EU} / \mathrm{mL}$. PVDF purified alginate (Sigma-Aldrich 0682) and control alginates (Pronova UP LVM and UP LVG) at both $2 \%$ and $0.2 \%$ dilution did not induce gel clot formation, indicating LPS levels of $<125 \mathrm{EU} / \mathrm{g}$ dry alginate. Testing of non-purified alginate (Sigma-Aldrich 0682) resulted in gel clot formation at both $2 \%$ and $0.2 \%$ concentration, indicating that there was LPS contamination of $>125 \mathrm{EU} / \mathrm{g}$ dry unpurified alginate, and that there was at least a $90 \%$ reduction of LPS levels after PVDF purification.

\subsubsection{VISCOSITY}

Purified alginate displayed a mean viscosity of $328 \pm 55.6 \mathrm{cP}$ at $2.5 \% \mathrm{w} / \mathrm{w}$ solution and $32 \pm 2.4 \mathrm{cP}$ at $1.2 \% \quad \mathrm{w} / \mathrm{w}$ solution (Figure 4). These values correspond to previously reported pre- and postpurification viscosities and are within 


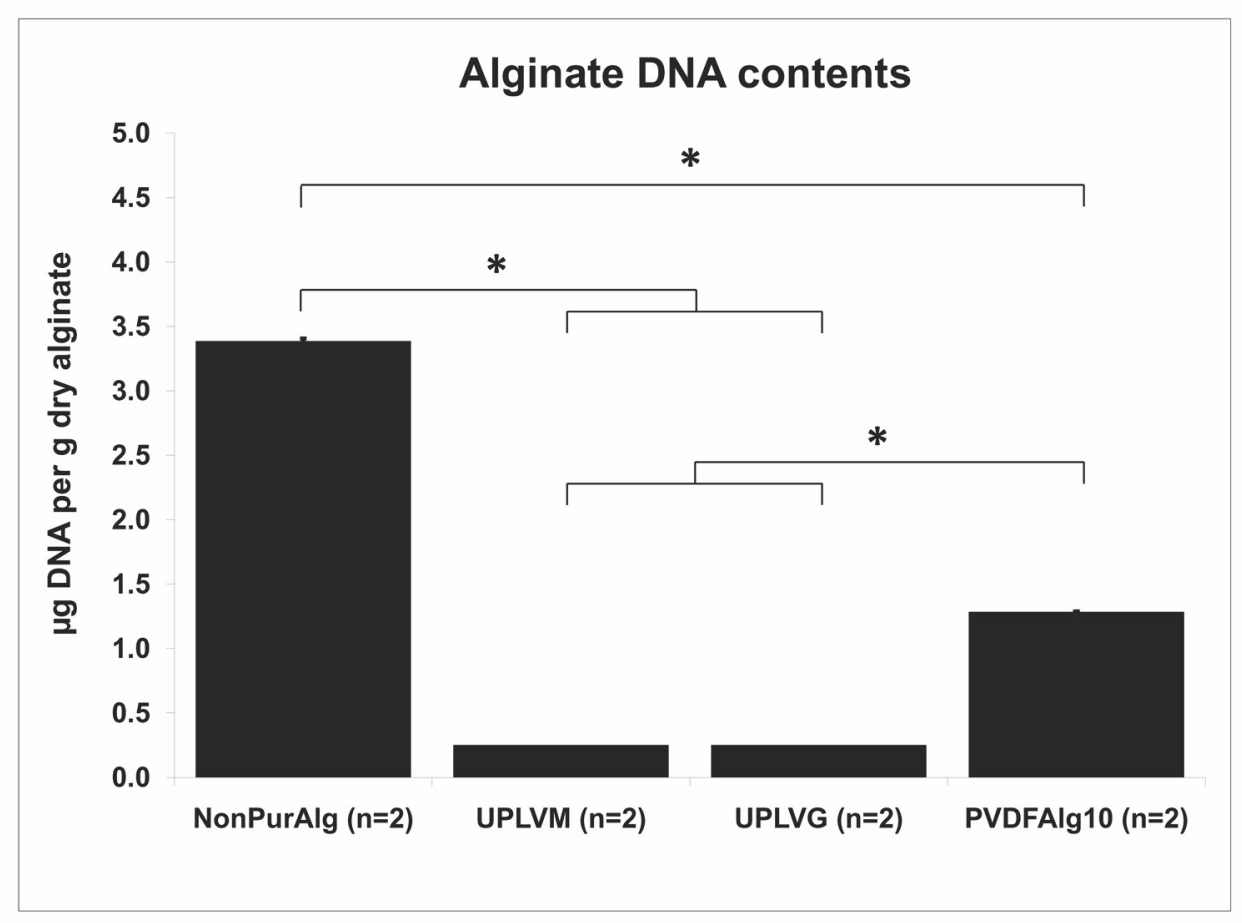

Figure 2. DNA content was determined using the Qubit quantitation system. The amount of DNA is represented in micrograms of DNA per gram of dry alginate \pm SEM. dsDNA assay sensitivity is $0.2-100 \mathrm{ng}$ per sample. ${ }^{*} \mathrm{p}<0.01$. NonPurAlg: non purified Sigma A0682 alginate; UPLVM: Novamatrix Ultrapure low viscosity mannuronic acid; UPLVG: Novamatrix Ultrapure low viscosity guluronic acid; PVDFAlg10: PVDF purified Sigma A0682 alginate in 10mM phosphate buffer.

range of the optimal viscosity of $200 \mathrm{cP}$ at $2.0 \%-2.5 \%$ for post-processing (i.e. alginate bead formation) procedures (14).

\subsection{SPLENOCYTE PROLIFERATION IN VITRO}

Stimulation with different alginate samples at $0.2 \%$ concentration of rat splenocyte proliferation after $48 \mathrm{~h}$ of incubation was determined by spectrophotometric assay of colored product in the Roche assay using WST-1 (Figure 5). Non-purified low molecular weight alginate (Sigma-Aldrich 0682) induced the highest degree of proliferation. The control alginates (Pronova Ultrapure LVM and Ultrapure LVG) induced a significantly lower degree of proliferation than non-purified alginate, but significantly higher than baseline, which was determined by unstimulated splenocyte proliferation in growth medium alone. Alginate purified by our newly described protocol did not induce proliferation above that found at unstimulated baseline. This result is consistent with the observation that alginates with a high mannuronic acid ratio (i.e. Pronova Ultrapure LVM) are reportedly more immunogenic than alginates with a high guluronic acid ratio (i.e. Pronova Ultrapure LVG) (29). However, since Sigma-Aldrich 0682 contains primarily mannuronic acid residues without induction of proliferation, it is possible that residual protein contamination or other contaminants may be more important for stimulation of immunogenicity of alginates than the composition of alginate itself. Results are presented in arbitrary absorbance units corrected for background absorbance by unstimulated cells at 450-650nm (Figure 5).

\subsection{IMMUNE RESPONSE IN VIVO}

To determine biocompatibility, purified alginate (Sigma-Aldrich 0682) scaffolds were implanted between the rectus muscles of male Lewis rats $(n=5)$. Scaffolds were well tolerated throughout the duration of all the experiments. One month following implantation, scaffold material was easily recovered with little evidence of adhesion or scarring. Histologically, fibrotic overgrowth as determined by blue staining using Masson's trichrome was limited when compared with fibrous overgrowth in the area of PGA suture material (Figure 6). Inflammatory reactions, as quantified by the number of multinucleated giant cells, were minimal, and significantly fewer than the number found at the site of PGA sutures $(p<0.05)$ (Figure 7 ). We did not implant unpurified alginate scaffolds as controls due to expected adverse reactions based on level of impurities and significant splenocyte proliferation in vitro, which could cause unnecessary distress in vivo.

\section{DISCUSSION}

We developed a practical and economical alginate purification protocol aimed at reducing residual protein and LPS contamination, which are typically found in many alginate preparations following various published purification protocols (14). Our method drastically reduced the quantities of organic 


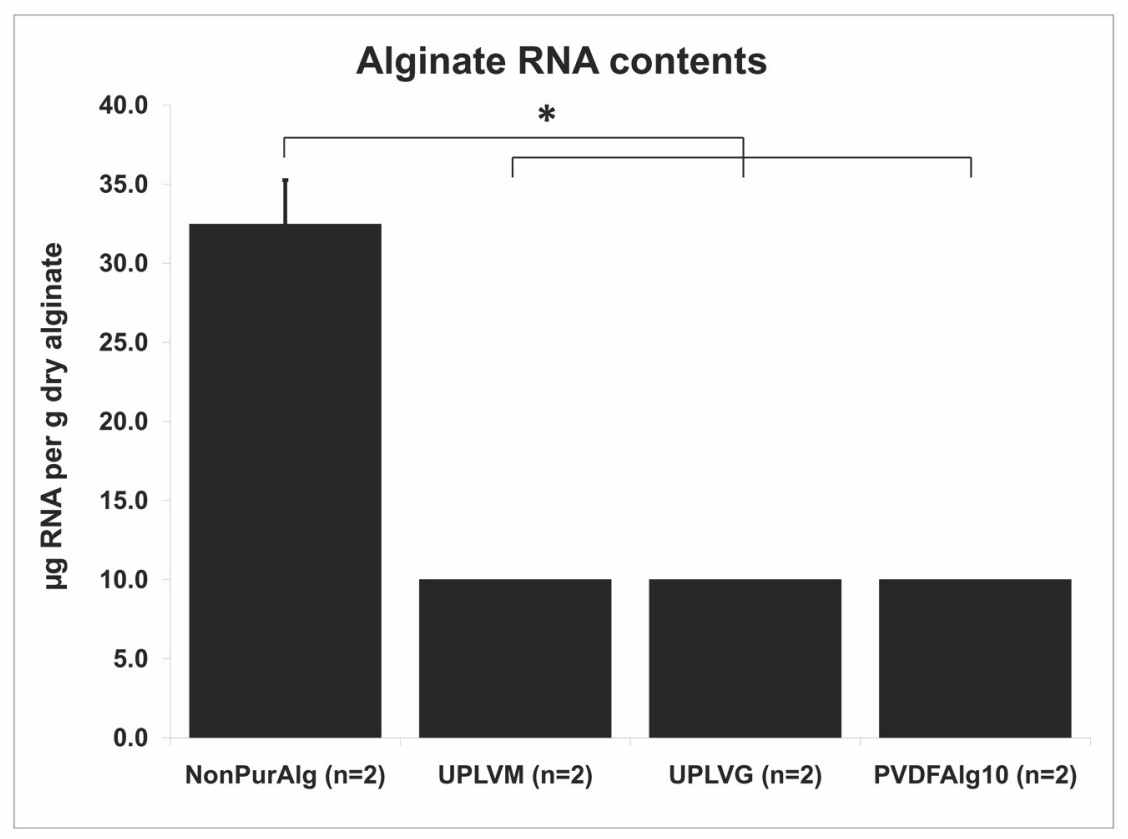

Figure 3. RNA content was determined using the Qubit quantitation system. The amount of RNA is represented in micrograms of RNA per gram of dry alginate \pm SEM. RNA assay sensitivity is 5-100ng per sample. ${ }^{*}$ p<0.01. NonPurAlg: non purified Sigma A0682 alginate; UPLVM: Novamatrix Ultrapure low viscosity mannuronic acid; UPLVG: Novamatrix Ultrapure low viscosity guluronic acid; PVDFAlg10: PVDF purified Sigma A0682 alginate in 10mM phosphate buffer.

reagents needed for the purification while being able to provide high levels of alginate purity. The only inorganic component that we employed was sodium phosphate in water (Flow chart 1).

We report here a novel alginate purification protocol, which leads to much less residual organic contamination of the final product when compared with either commercially available ultrapure alginates (i.e. Pronova UPLVM and UPLVG) or alginates purified by other existing purification protocols (14). Our protocol is based on the high affinity of hydrophobic PVDF for organic materials under specific buffer conditions. PVDF binds organic molecules through both hydrophobic and electrostatic interactions; we found that an alginate solution of low ionic strength, which is slightly acidic (10mM sodium phosphate buffer at $\mathrm{pH} 5.5)$ could optimally bind and therefore remove organic contaminants under flow-through conditions. Overall, approximately $70 \%-80 \%$ of alginate was lost, mostly due to charcoal treatment and ethanol precipitation, both of which are generally used for removal of gross organic contamination from nonpurified alginates and therefore considered unavoidable loss.

In devising this protocol, we reasoned that serial filtration through protein binding membranes would gradually reduce residual organic contaminants. We evaluated a range of conditions, such as $\mathrm{pH}$ and ionic strength of the alginate solution prior to settling on the optimal one for filtration. Alginate's $\mathrm{pKa}$ is approximately 3.2 , depending on the proportion of mannuronic and guluronic acid residues. We found that a $\mathrm{pH}$ of 5.5 in $10 \mathrm{mM}$ phosphate buffer was optimal when combined with filtration through hydrophobic PVDF membranes. We also tested activated membranes based on aldehyde chemistry (Pall Ultrabind, 66544, Pall Corporation, Ann Arbor, MI) or anhydride chemistry (Pall Immunodyne ABC, NBCHI3R, Pall Corporation, Ann Arbor, MI), which covalently bind organic molecules via amino groups at neutral or basic pHs. However, we were not able to achieve efficient removal of proteins using the latter membranes. It is possible that these activated membranes need longer exposure to proteincontaining solution or that proteins prefer to remain bound to alginate under the conditions necessary to optimally bind protein with the filters, i.e. $\mathrm{pH} \mathrm{8-9.}$ A more important disadvantage of such membranes is their high sensitivity to aqueous and humid environments, which rapidly inactivate the membrane's active protein binding groups. In contrast, hydrophobic PVDF membranes are highly stable, have low cost (approximately US\$ 0.04-US\$ 0.05 per $\mathrm{cm}^{2}$ ), and can be easily stored in a standard laboratory environment. The influence of ionic strength and $\mathrm{pH}$ in our purification method was striking. Using an aqueous unbuffered alginate solution at $\mathrm{pH} 5.5$ or $50 \mathrm{mM}$ phosphate buffer at $\mathrm{pH}$ 5.5 or 8.0, protein removal was not efficient. Hydrophobic PVDF interacts with organic molecules under a wide range of conditions through both hydrophobic and electrostatic interactions (24). The exact kinetics of these interactions are not known, however contaminating proteins may carry a different charge, which may favor binding to hydrophobic PVDF when compared with alginate placed in low ionic strength buffers. Of note, 


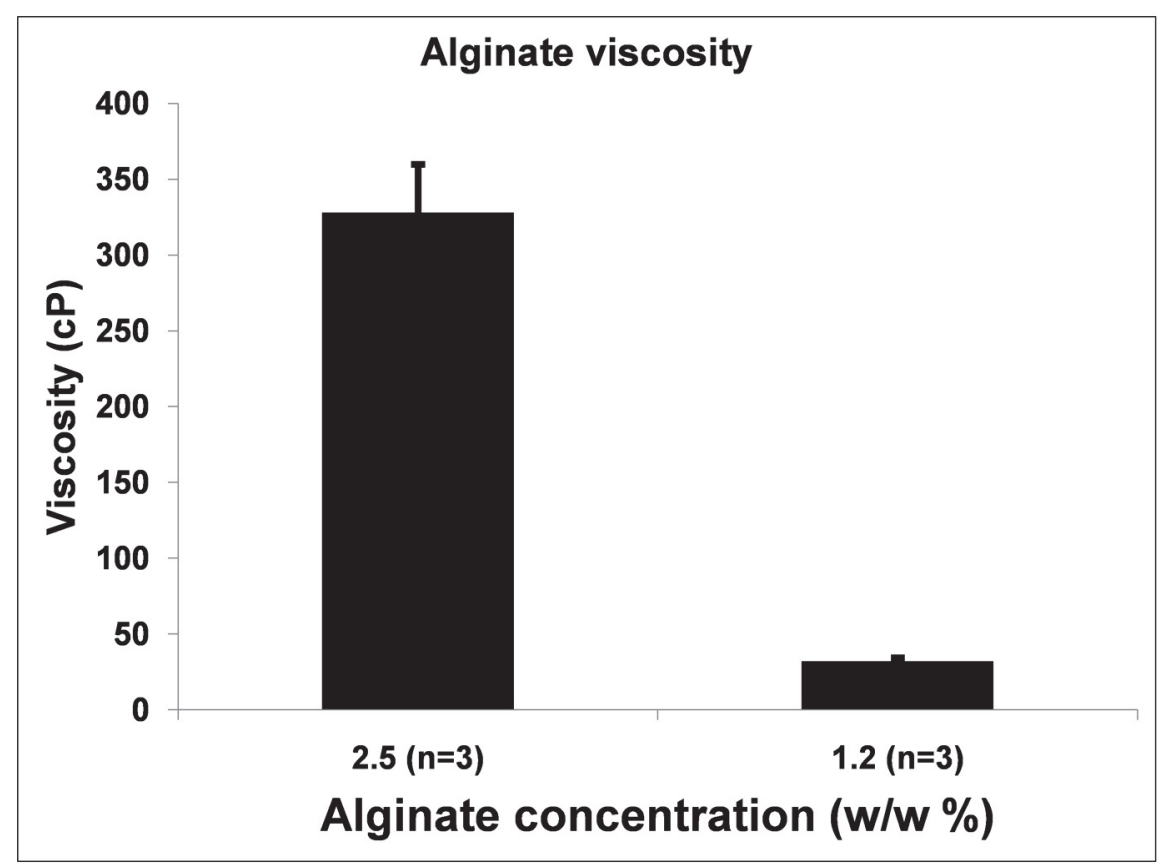

Figure 4. Alginate viscosity was measured using a rotational rheometer at two dilutions in triplicate \pm SEM. Minimum torque is $1 \mathrm{nNm}$.

residual DNA, while significantly reduced, remained higher compared with Pronova alginates. DNA is known to elicit immune responses and may warrant additional purification steps. Histologically, we compared purified alginate scaffolds to PGA suture material and found significantly more scarring and giant cells around PGA compared with alginate. Foreign body giant cell formation is the end-stage response of the inflammatory and wound healing process following implantation of biomaterials. Little fibrosis and low numbers of giant cells could implicate low immunogenicity or active suppression of an inflammatory response by alginate. We quantified average number of giant cells per high power field at 4 weeks. To get a better understanding of the regenerative process, multiple time point measurements may be desirable.

In 1994, Klöck et al. developed an alginate purification process based on free flow electrophoresis (FFE) (17). A comparable approach was performed more recently, by using size exclusion chromatography (SEC) (30). These methods resulted in highly purified alginate preparations, with residual protein contamination of only $0.05 \%$ of dry alginate weight, significantly less than $0.3 \%$ that is obtained with the chemical extraction protocol of Klöck et al. or the membrane filtration protocol described here. However, by adding a final dialysis step against saline instead of water in addition to the chemical extraction method of Klöck et al., Menard et al. recently showed that they could reduce protein contamination to $0.05 \%$ without the use of FFE or SEC. This accomplishment was probably due to reduction of electrostatic interaction between proteins and alginate in saline during dialysis (30). The addition of dialysis in saline instead of dialysis in water to step 7 (Flow chart 1) of our purification protocol should achieve a similarly high purity of alginate, using significantly lower volumes and number of organic reagents making the process more useful and practical.

Previously used methods such as FFE or SEC have been already shown to result in a product contaminated by residual protein that is responsible for immunogenicity of alginate. However, for large scale application, the disadvantages of such purification methods is high cost of equipment and that these procedures are highly labor-intensive. Whether alginate purity achieved regarding residual protein contamination using current methods is clinically acceptable remains to be determined in further trials, as there are no regulatory limits for residual protein contamination due to the number of variables involved, i.e. quality and quantity of contamination leaves it up to the manufacturer to determine safety. With regards to residual LPS, the Food and Drug Administration (FDA) accepts levels $<5 \mathrm{EU} / \mathrm{kg}$ for solutions or implantable devices to be used clinically. With a residual level of $<125 \mathrm{EU} / \mathrm{g}$ dry alginate following PVDF purification and potentially much lower, a quantity of $5 \mathrm{EU} / \mathrm{kg}$ in a $80 \mathrm{~kg}$ human would allow implantation of at least $3.2 \mathrm{~g}$ purified alginate before pyretic effects would ensue. At $2 \%$ w/w alginate solution, this would allow a volume of $160 \mathrm{ml}$, which is more than sufficient to generate relatively large size scaffolds for clinical use. For large scale clinical tissue-engineering applications, a combination of relatively high purity non-immunogenic alginate together with minimal systemic or local 


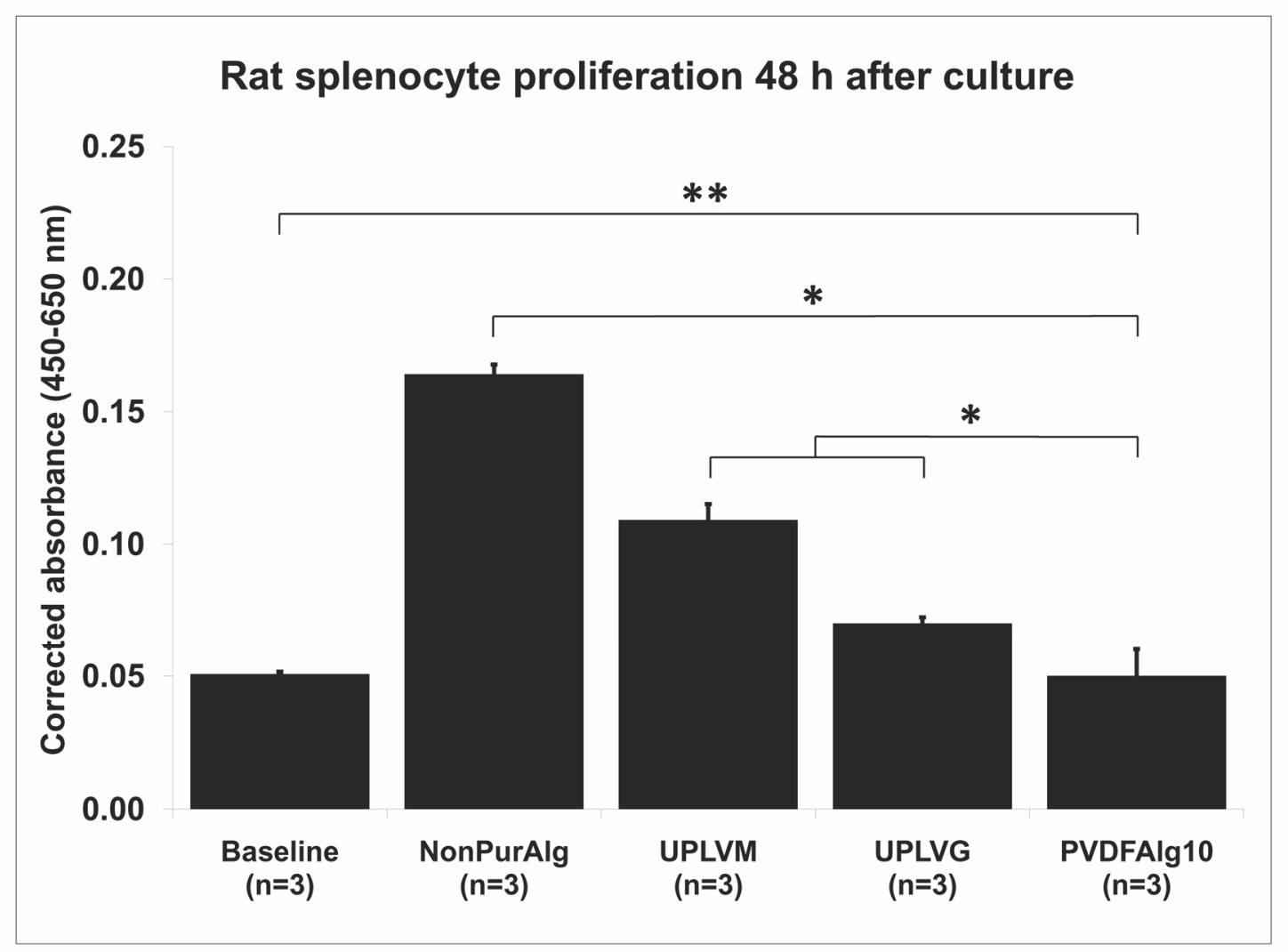

Figure 5. Splenocyte proliferation in the presence of different alginate preparations was determined by spectrophotometric assay \pm SEM. ${ }^{* *} \mathrm{p}=$ not significant; ${ }^{*} \mathrm{p}<0.05$. NonPurAlg: non purified Sigma A0682 alginate; UPLVM: Novamatrix Ultrapure low viscosity mannuronic acid; UPLVG: Novamatrix Ultrapure low viscosity guluronic acid; PVDFAlg10: PVDF purified Sigma A0682 alginate in 10mM phosphate buffer.

immunosuppression appears more desirable than the use of ultrahigh purity alginate, which comes with considerable cost and questionable immunologic value. Application of hydrophobic PVDF-based filtration would allow for significant up scaling of the alginate purification process by using reactors with large surface PVDF membranes or porous PVDF columns. Reconstitution of PVDF by elution of organic contaminants with sodium dodecyl sulfate (SDS) (23) would allow reuse of equipment for repeatable purifications.

Other polysaccharide biomaterials like chitosan or xanthan gum may also benefit from PVDF purification. However, several physical and chemical conditions apply to make the process useful. Polymer solutions should be aqueous and viscosity low enough for sufficient flow through. Buffer conditions should enhance affinity of organic contaminants for PVDF, while preventing the binding of polymers. The high chemical stability of PVDF membranes permits their use under different experimental conditions with appropriate polymers and buffers.

\subsection{CONCLUSIONS}

Because of its versatile nature and inertness (nonimmunogenicity), purified alginate remains one of the most attractive biomaterials for experimental applications in clinical tissue engineering. The development of large scale clinical tissue engineering trials will require standards for alginate purity that should be environmentally, economically, and biologically acceptable. We hereby describe a novel method of alginate preparation and purification based on PVDF membrane filtration that addresses these issues. The use of PVDF membrane filtration is an economical solution, which reduces waste and results in alginate with clinically acceptable purity levels while remaining non-immunogenic. With recent advances in regenerative medicine and tissue engineering, clinically useful and affordable biomaterials are desperately needed and will become of paramount importance for successful clinical progress.

\section{ACKNOWLEDGEMENTS}

We would like to acknowledge Fiona See, $\mathrm{PhD}$, for careful reading and correction of the manuscript.

\section{FUNDING}

NIH SCCOR \# 5P50HL077096-02 and NIH T32HL007854-19 (MAH)

\section{CONFLICT OF INTEREST}

Hugo P. Sondermeijer, Piotr Witkowski, and Mark A. Hardy are patent provisional holders of methods described in this manuscript, see valorization chapter and (31). 


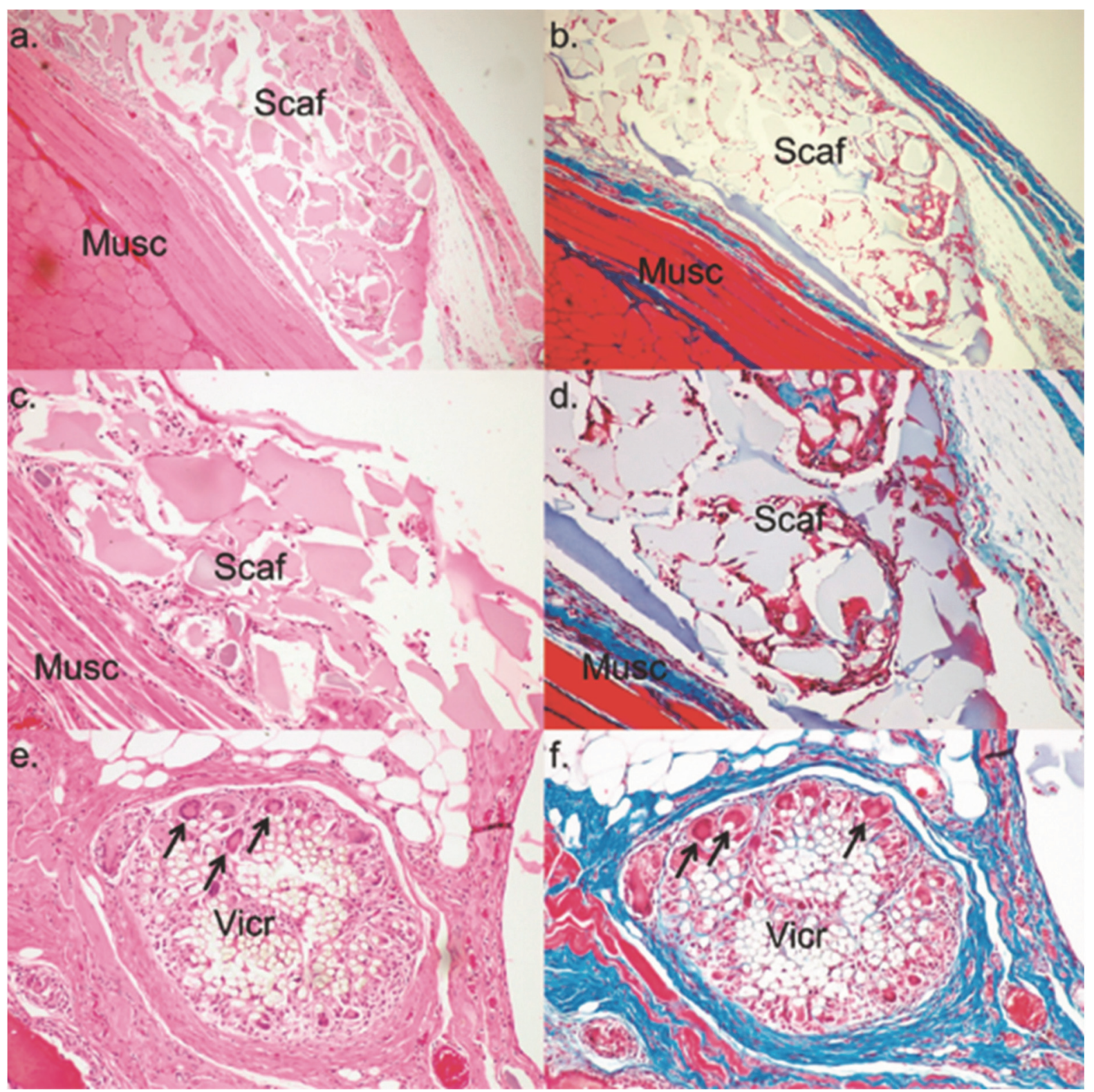

Figure 6. Scaffold histology 1 month after implantation. Scaffolds (Scaf) were implanted between abdominal muscle layers (Musc) of male Lewis rats $(n=5)$. H\&E shows histological characteristics with cellular invasion into scaffold material (panels a and c) and PGA (panel e). Masson's trichrome shows little fibrosis (blue) around scaffold material (panels b and d) compared with PGA/VICRYL® (Vic) (panel f), and significantly fewer giant cell phagocytic activity (arrows). This indicates scaffold material did not induce an immunological foreign body response. ( $\mathrm{a}$ and $\mathrm{b}$ at $40 \times, \mathrm{c}$ and $\mathrm{d}$ at $100 \times$, e and $\mathrm{f}$ at $200 \times$ ). We omitted implantation of unpurified scaffolds since in vitro experiments had already shown a significant proliferative response. 


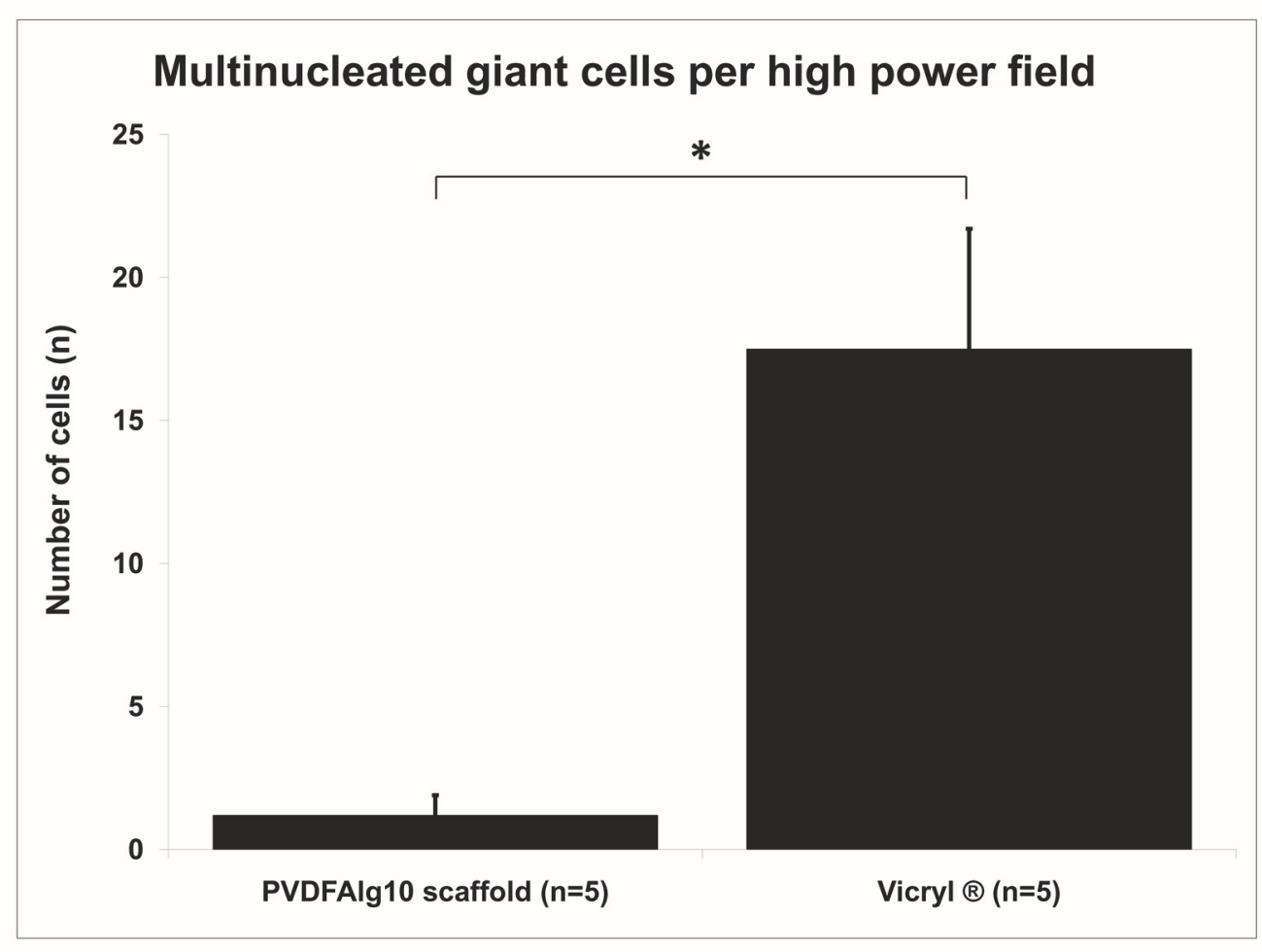

Figure 7. Quantification of giant cell numbers per high power field (400× magnification) in proximity to scaffold material or polyglycolic/VICRYL ${ }^{\circledR}$ sutures (positive control). Results are presented as number of cells \pm SEM. ${ }^{*} \mathrm{p}<0.05$. PVDFAlg10: PVDF purified Sigma A0682 alginate in $10 \mathrm{mM}$ phosphate buffer.

\section{REFERENCES}

1. F. A. Johnson, D. Q. Craig, A. D. Mercer, Characterization of the block structure and molecular weight of sodium alginates. $J$ Pharm Pharmacol 49, 639 (Jul, 1997).

2. $\quad$ P. Eiselt, J. Yeh, R. K. Latvala, L. D. Shea, D. J. Mooney, Porous carriers for biomedical applications based on alginate hydrogels. Biomaterials 21, 1921 (Oct, 2000).

3. E. Hill, T. Boontheekul, D. J. Mooney, Designing scaffolds to enhance transplanted myoblast survival and migration. Tissue Eng 12, 1295 (May, 2006)

4. J. Leor, S. Aboulafia-Etzion, A. Dar, L. Shapiro, I. M. Barbash, A. Battler, Y. Granot, S. Cohen, Bioengineered cardiac grafts: A new approach to repair the infarcted myocardium? Circulation 102, III56 (Nov 7, 2000).

5. F. Lim, A. M. Sun, Microencapsulated islets as bioartificial endocrine pancreas. Science 210, 908 (Nov 21, 1980).

6. T. A. Read, D. R. Sorensen, R. Mahesparan, P. O. Enger, R. Timpl, B. R. Olsen, M. H. Hjelstuen, O. Haraldseth, R. Bjerkvig, Local endostatin treatment of gliomas administered by microencapsulated producer cells. Nat Biotechnol 19, 29 (Jan, 2001).

7. O. Smidsrod, G. Skjak-Braek, Alginate as immobilization matrix for cells. Trends Biotechnol 8, 71 (Mar, 1990).

8. H. Zimmermann, S. G. Shirley, U. Zimmermann, Alginate-based encapsulation of cells: past, present, and future. Curr Diab Rep 7, 314 (Aug, 2007).

9. P. Witkowski, H. Sondermeijer, M. A. Hardy, D. C. Woodland, K. Lee, G. Bhagat, K. Witkowski, F. See, A. Rana, A. Maffei, S. Itescu, P. E. Harris, Islet grafting and imaging in a bioengineered intramuscular space. Transplantation 88, 1065 (Nov 15, 2009).

$10 . \quad$ S. K. Tam, J. Dusseault, S. Polizu, M. Menard, J. P. Halle, L. Yahia, Impact of residual contamination on the biofunctional properties of purified alginates used for cell encapsulation. Biomaterials 27, 1296 (Mar, 2006).

11. G. Orive, A. M. Carcaboso, R. M. Hernandez, A. R. Gascon, J. L. Pedraz, Biocompatibility evaluation of different alginates and alginatebased microcapsules. Biomacromolecules 6, 927 (Mar-Apr, 2005).

12. R. Robitaille, J. Dusseault, N. Henley, K. Desbiens, N. Labrecque, J. P. Halle, Inflammatory response to peritoneal implantation of alginate-poly-L-lysine microcapsules. Biomaterials 26, 4119 (Jul, 2005).

13. G. Langlois, J. Dusseault, S. Bilodeau, S. K. Tam, D. Magassouba, J. P. Halle, Direct effect of alginate purification on the survival of islets immobilized in alginate-based microcapsules. Acta Biomater 5, 3433 (Nov, 2009).

14. J. Dusseault, S. K. Tam, M. Menard, S. Polizu, G. Jourdan, L. Yahia, J. P. Halle, Evaluation of alginate purification methods: effect on polyphenol, endotoxin, and protein contamination. J Biomed Mater Res A 76, 243 (Feb, 2006).

15. A. R. Kim, J. H. Hwang, H. M. Kim, H. N. Kim, J. E. Song, Y. I. Yang, K. H. Yoon, D. Lee, G. Khang, Reduction of inflammatory reaction in the use of purified alginate microcapsules. Journal of biomaterials science. Polymer edition 24, 1084 (2013).

16. P. De Vos, B. J. De Haan, G. H. Wolters, J. H. Strubbe, R. Van Schilfgaarde, Improved biocompatibility but limited graft survival after purification of alginate for microencapsulation of 
pancreatic islets. Diabetologia 40, 262 (Mar, 1997).

17. G. Klock, H. Frank, R. Houben, T. Zekorn, A Horcher, U. Siebers, M. Wohrle, K. Federlin, U. Zimmermann, Production of purified alginates suitable for use in immunoisolated transplantation. Appl Microbiol Biotechnol 40, 638 (Jan, 1994)

18. K. H. Liao, Y. M. Tan, R. B. Conolly, S. J. Borghoff, M. L. Gargas, M. E. Andersen, H. J. Clewell, 3rd, Bayesian estimation of pharmacokinetic and pharmacodynamic parameters in a mode-of-action-based cancer risk assessment for chloroform. Risk Anal 27, 1535 (Dec, 2007).

19. A. Prokop, T. G. Wang, Purification of polymers used for fabrication of an immunoisolation barrier. Ann N Y Acad Sci 831, 223 (Dec 31, 1997).

20. L. R. Castilho, F. Birger Anspach, W. D. Deckwer, Comparison of affinity membranes for the purification

of immunoglobulins. Journal of Membrane Science 207, 253 (2002).

21. M. A. Krysteva, B. I. Shopova, L. Y. Yotova, M. I. Karasavova, Covalent binding of enzymes to synthetic membranes containing acrylamide units, using formaldehyde. Biotechnology and applied biochemistry 13, 106 (Feb, 1991).

22. S. De Saeger, F. Dumoulin, C. Van Peteghem, Quantitative determination of ochratoxin A in kidneys by liquid chromatography/mass spectrometry. Rapid communications in mass spectrometry : RCM 18, 2661 (2004).

23. J. Mozdzanowski, D. W. Speicher, Microsequence analysis of electroblotted proteins. I. Comparison of electroblotting recoveries using different types of PVDF membranes. Anal Biochem 207, 11 (Nov $15,1992)$.
24.

D. F. Reim, D. W. Speicher, Microsequence analysis of electroblotted proteins. II. Comparison of sequence performance on different types of PVDF membranes. Anal Biochem 207, 19 (Nov 15, 1992).

25. T. Choli, U. Kapp, B. Wittmann-Liebold, Blotting of proteins onto Immobilon membranes. In situ characterization and comparison with highperformance liquid chromatography. $J$ Chromatogr 476, 59 (Aug 4, 1989).

26. M. A. Stein, S. A. McAllister, K. H. Johnston, D. L. Diedrich, Detection of lipopolysaccharides blotted to polyvinylidene difluoride membranes. Anal Biochem 188, 285 (Aug 1, 1990).

27. J. M. Anderson, A. Rodriguez, D. T. Chang, Foreign body reaction to biomaterials. Semin Immunol 20, 86 (Apr, 2008).

28. E. A. Bakkum, R. A. Dalmeijer, M. J. Verdel, J. Hermans, C. A. van Blitterswijk, J. B. Trimbos, Quantitative analysis of the inflammatory reaction surrounding sutures commonly used in operative procedures and the relation to postsurgical adhesion formation. Biomaterials 16, 1283 (Nov, 1995).

29. G. Klock, A. Pfeffermann, C. Ryser, P. Grohn, B. Kuttler, H. J. Hahn, U. Zimmermann, Biocompatibility of mannuronic acid-rich alginates. Biomaterials 18, 707 (May, 1997).

30. M. Menard, J. Dusseault, G. Langlois, W. E. Baille, K. T. S, L. Yahia, X. X. Zhu, J. P. Halle, Role of protein contaminants in the immunogenicity of alginates. J Biomed Mater Res B Appl Biomater 93, 333 (May).

31. H. Sondermeijer, Witkowski, P., Hardy, M.A., (WO/2009/039185) Uses of immunologically modified scaffold for tissue prevascularization and cell transplantation. (26.03.2009, 2009). 



\section{Chapter 3}

\section{RGDfK-peptide modified alginate scaffold for cell transplantation and cardiac neovascularization.}

Tissue Engineering Part A. 2018 May; 24(9-10):740-751.

Hugo P. Sondermeijer, Piotr Witkowski, Tetsunori Seki, Arnoud van der Laarse, Silviu Itescu, and Mark A. Hardy. 


\section{ABSTRACT}

Cell implantation for tissue repair is a promising new therapeutic strategy. Although direct injection of cells into tissue is appealing, cell viability and retention are not very good. Cell engraftment and survival following implantation are dependent on a sufficient supply of oxygen and nutrients through functional microcirculation as well as a suitable local microenvironment for implanted cells. In this study, we describe the development of a porous, biocompatible, three-dimensional (3D) alginate scaffold covalently modified with the synthetic cyclic RGDfK (Arg-Gly-Asp-D-Phe-Lys) peptide. Cyclic RGDfK peptide is protease resistant, highly stable in aqueous solutions, and has high affinity for cellular integrins. Cyclic RGDfK-modified alginate scaffolds were generated using a novel silicone sheet sandwich technique in combination with freezegelation, resulting in highly porous nonimmunogenic scaffolds that promoted both human and rodent cell survival in vitro, and neoangiogenesis in vivo. Two months following implantation in abdominal rectus muscles in rats, cyclic RGDfK-modified scaffolds were fully populated by host cells, especially microvasculature without an overt immune response or fibrosis, whereas unmodified control scaffolds did not show cell ingrowth. Importantly, modified scaffolds that were seeded with human mesenchymal precursor cells and were patched to the epicardial surface of infarcted myocardium induced myocardial neoangiogenesis and significantly improved cardiac function. In summary, purified cyclic RGDfK peptide-modified 3D alginate scaffolds are biocompatible and nonimmunogenic, enhance cell viability, promote angiogenesis, and may be used as a means to deliver cells to myocardial infarct areas to improve neovascularization and cardiac function.

\section{INTRODUCTION}

Cell therapy is emerging as a promising strategy for tissue repair in a variety of diseases, including heart disease (reviewed in (1)). Cells can be (1) delivered directly into damaged tissue by injection (2) at orthotopic (heart and liver) or heterotopic sites (parathyroids and islets), (2) administered intravenously (3), in combination with biocompatible materials (4), or (3) prepared for implantation following in vitro culture, for example by using cell sheet monolayers (5) or biodegradable scaffolds (6).

Direct cell delivery by injection is an attractive method due to its minimally invasive character. This approach, however, has been frequently hampered by a lack of long-term cell survival due to insufficient cell oxygenation, lack of sufficient nutrients, and inadequacy of a suitable microenvironment, which usually consists of neighboring cells and the extracellular matrix (ECM), or stem-cell niche $(7,8)$. It is also suspected that delivery of cellular inoculate by needle injection may lead to an uneven cell distribution or formation of cell "islands" within tissue, further complicating both nutrient and oxygen delivery to individual cells, thereby interfering with therapeutic effects (9).

Numerous experimental tissue engineering approaches to tissue repair and regeneration have been previously attempted with mixed success. These have included for example, grafting of monolayered or multilayered cell sheets cultured ex vivo (5) or cell-seeded scaffolds (10) in animal models of tissue degenerative diseases. Clinically, a bioengineered stem cell-seeded trachea was successfully implanted in a patient with tracheal cancer (11). The application of various tissue engineering methods generally led to more efficient and better repair of damaged tissue when compared to direct needle injection-based therapies (12).

Biomaterial carriers have a variety of biological properties, which are either beneficial or potentially harmful to viable cells. Several have been previously used in (pre)clinical applications. Some of these include, for example, PGA (13) and collagen and hyaluronic acid (14). We chose alginate as a basic biomaterial because it has several advantages over those previously mentioned: it is plant derived, and therefore avoids the risk of pathogen (i.e., prion) transfer, it is biologically inert when sufficiently purified, and readily available in large quantities. Purified unmodified alginate has already been approved previously for several clinical applications, especially for wound dressing (15).

Recent studies showed that intracoronary alginate injection was safe and prevented left ventricular (LV) enlargement after myocardial infarction (MI) in swine (16), and clinical trials are being conducted to investigate effects of an aqueous mixture of sodium alginate and calcium gluconate for the prevention of remodeling of the ventricle and congestive heart failure after acute MI (ClinicalTrials.gov No. NCT01226563). Another advantage of alginate is its carboxyl groups, which permit covalent (i.e., irreversible) modifications with biologically active peptides that contain free amino groups, by carbodiimide crosslinking.

We previously developed an alginate purification protocol that results in a highly purified, biocompatible poly-mannuronic acid 
containing alginate (17). Alginate purification for cell transplantation application is of paramount importance for survival of transplanted cells, since raw alginate is contaminated with mitogens such as proteins, DNA, RNA, and lipopolysaccharides.

To enhance the biologically functional properties of alginate, we hypothesized that modification of purified alginate with covalently attached cyclic RGDfK (Arg-Gly-Asp-D-Phe-Lys) peptides will lead to more effective cell survival compared to controls, since cyclic RGDfK peptides are protease resistant and stable in aqueous solution (18). RGD is an abundant peptide sequence found in the ECM as part of vitronectin, fibronectin, and collagen (19). The RGD peptide sequence binds to cell surface integrins $a_{v} b_{3}$ and $\alpha_{5} b_{1}$, where it signals into the cell, thereby promoting cell adhesion and formation of cell viability factors (20).

More specifically, cyclic RGDfK is a synthetic RGD peptide that has been shown to enhance cell adhesion and cell survival after covalent immobilization on two-dimensional (2D) surfaces (21). Therefore, we hypothesized that a purified three-dimensional (3D) alginate scaffold dressed with cyclic RGDfK peptide would enhance cell retention and survival within the scaffold.

\section{EXPERIMENTAL SECTION}

\subsection{MATERIALS}

Solutions were prepared using purified water from an in-house Hydro Picopure (Millipore, Temecula, CA) purification system. Molecular biology grade $\mathrm{ddH}_{2} \mathrm{O}$ (No. SH30529.02), EDC (1ethyl-3-[3-dimethylaminopropyl] carbodiimide hydrochloride, No. 22980), sulfo-NHS (Nhydroxysulfosuccinimide, No. 24510), hydroxylamine (No. 26103), MES buffer (No. $28390)$, dialysis membranes $(3.5 \mathrm{kDa}$ membrane, SnakeSkin, No. 88244), EDTA (No. 17892), and TrypLE Select (No. 12604013) were purchased from Thermo Scientific (Rockford, IL). All glassware was cleaned and detoxified by 24 -h treatment with $0.5 \%$ hypochlorite followed by washing and baking for at least $120 \mathrm{~min}$ at $240^{\circ} \mathrm{C}$. Pyrex ${ }^{\circledR}$ glass plates $(100 \times 15 \mathrm{~mm})$ were purchased from Corning (New York, NY; No. 3160-101).

Low molecular weight (MW) sodium alginate (No. A0682) obtained from brown algae consisting of straight-chain, hydrophilic, colloidal polyuronic acid, which is composed primarily of anhydro-B-d-mannuronic acid residues with $1 \rightarrow 4$ linkage, calcium chloride (No. C2661), bovine serum albumin (BSA; cell culture grade, No. A9418), collagenase $(\geq 125$ collagen digestion U/mg, No. C5138), gelatin type A (No. G9136), and DNase I (grade II, from bovine pancreas, No. 10104159001) were purchased from Sigma-Aldrich (St. Louis, $\mathrm{MO})$.

Cyclic RGDfK peptide (No. PCI-3661-PI) and cyclic RADfK (negative control peptide; No. PCI-3883-PI) were purchased from Peptides International, Inc. (Louisville, KY). Nonreinforced vulcanized gloss/gloss silicone sheets (hardness 40 durometer, thickness $750 \mu \mathrm{m})$ were purchased from Specialty Manufacturing, Inc. (Saginaw, MI). Ten millimeters Acu-Punch skin punchers were purchased from Acuderm, Inc. (Fort Lauderdale, FL). Alpha minimum essential medium (a-MEM), fetal calf serum (FCS), l-glutamine (GlutaMax $\left.{ }^{\circledR}\right)$, and recombinant human vascular endothelial growth factor (VEGF-A, No. PHG0145) were purchased from Invitrogen (Carlsbad, CA). Human platelet-derived growth factor-bb (PDGF-BB No. GF018) was purchased from Chemicon/Millipore (Billerica, MA).

Human mesenchymal precursor cells (hMPCs) were a kind gift of Mesoblast, Ltd. (New York, NY). Primocin was purchased from InvivoGen (San Diego, CA). Osteogenic, chondrogenic, and adipogenic MSC differentiation kits (Nos. PT-3002, PT-3003, PT-3004) were purchased from Lonza (Walkersville, MD). WST-1 was purchased from Roche Applied Science (Indianapolis, IN). Factor VIII-related antigen monoclonal antibodies (mAb; No. A0082) were purchased from Dako (Carpinteria, CA). Rat a-smooth muscle actin (aSMA) mAb was purchased from Biogenex (Fremont, CA). mAb against CD163/ED-2, a rat macrophage marker, was purchased from Santa Cruz Biotechnology (Dallas, TX). The Vectastain ABC kit was purchased from Vector Laboratories (Burlingame, CA).

\subsubsection{SODIUM ALGINATE PURIFICATION}

We previously described our alginate purification protocol in detail (17). In brief, $1.5 \%$ sodium alginate solution was treated with activated charcoal before serial polyvinylidene difluoride (PVDF) membrane filtration in $10 \mathrm{mM}$ phosphate buffer at $\mathrm{pH}$ 5.5, followed by dialysis and ethanol precipitation. Resulting precipitate was freeze-dried and redissolved in molecular biology grade $\mathrm{ddH}_{2} \mathrm{O}$ at $2 \% \mathrm{w} / \mathrm{w}$ before further processing.

\subsection{STUDY 1: EX VIVO STUDIES}

\subsubsection{CYCLIC RGDfK PEPTIDE CONJUGATION, FABRICATION, AND CHARACTERIZATION OF CYCLIC RGDfK- MODIFIED ALGINATE SCAFFOLDS}

We applied carbodiimide chemistry based on EDC and sulfo-NHS in MES buffer using a modified protocol as previously described $(22,23)$ (Fig. 1a). Cyclic RGD peptide RGDfK and negative control peptide cyclic RADfK were covalently attached to alginate according to protocol with slight modifications. Cyclic RADfK peptide differs from cyclic RGDfK peptide, in that one glycine $(G)$ is replaced with alanine (A), abolishing its effects through lack of binding capacity to integrin receptors on cell surfaces (24).

Briefly, 8.82, 17.65 , and $35.30 \mathrm{mM}$ peptide (equivalent to 5, 10, and 20mg cyclic RGDfK) per gram alginate (estimated MW alginate $=194 \mathrm{D} / \mathrm{mannuronic}$ acid residue) in a $1 \%$ solution was incubated for $20 \mathrm{~h}$ at room temperature with EDC and sulfo-NHS to achieve theoretical activation of $10 \%$ of total mannuronic acid 
monomers. The reaction was subsequently quenched with hydroxylamine and the solution was dialyzed for 5 days against decreasing $\mathrm{NaCl}$ concentrations; it was then lyophilized at 0.2 torr, redissolved in molecular biology grade $\mathrm{dd}_{2} \mathrm{O}$ at $2 \%$ $\mathrm{w} / \mathrm{w}$, and sterile filtered.

\subsubsection{CELL ADHESION TO 2D CYCLIC RGDfK-MODIFIED ALGINATE SCAFFOLDS}

To determine covalent cyclic RGDfK modification, solid 2D scaffolds were produced as previously described. In brief, cyclic RGDfK-modified alginate was placed in cell culture insert top wells and allowed to solidify with $100 \mathrm{mM} \mathrm{CaCl} 2$ in bottom wells at $4^{\circ} \mathrm{C}$ overnight. Following solidification, scaffolds were washed thrice in molecular biology grade $\mathrm{ddH}_{2} \mathrm{O}$ to remove excess $\mathrm{CaCl}_{2}$ and placed in a full medium consisting of a-MEM supplemented with $10 \%$ FCS, $0.5 \%$ BSA, $0.1 \mu \mathrm{M}$ ascorbic acid, $0.05 \mu \mathrm{M} 2$-mercaptoethanol, and $0.2 \%$ Primocin. For each batch of cyclic RGDfK-modified alginate, $50,000 \mathrm{hMPCs}$ were seeded on $2 \mathrm{D}$ scaffold surface and allowed to adhere for $24-48 \mathrm{~h}$ in a humidified incubator at $37^{\circ} \mathrm{C}, 5 \% \mathrm{CO}_{2}$. The degree of adhesion was compared to that found in controls using unmodified alginate scaffolds (Fig. 1e, f).

\subsubsection{FABRICATION OF 3D FREEZE-GELLED CYCLIC RGDfK ALGINATE SCAFFOLDS}

Rectangular strips $(15 \times 40 \mathrm{~mm})$ of silicone sheeting $(0.75 \mathrm{~mm}$ thickness) were cut. Three circular wells with a diameter of $10 \mathrm{~mm}$ were punched in each strip (Fig. 2a.i). Circular silicone sheets $(90 \mathrm{~mm}$ diameter) (Fig. 2a.ii) were cut out and transferred to sterile glass petri dishes $(100 \times 15 \mathrm{~mm})$ (Fig. 2a.iii). Punched silicone strips were placed on silicone sheets, while assuring that no air remained between

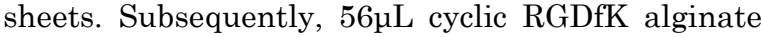
solution per well was cast in the circular wells and carefully layered with a third rectangular silicone strip $(15 \times 40 \mathrm{~mm})$, making sure that the alginate solution remained sandwiched between the silicone layers in the wells.

Alginate-containing plates were subsequently frozen at $-20^{\circ} \mathrm{C}$ overnight. Then, $25 \mathrm{~mL} 1.1 \% \mathrm{CaCl}_{2}$ in $70 \%$ ethanol/molecular biology grade $\mathrm{ddH}_{2} \mathrm{O}$ solution precooled at $-20^{\circ} \mathrm{C}$ was added to the petri dishes, and top strips were removed. This exposed frozen alginate scaffolds to ethanol/molecular biology grade $\mathrm{ddH}_{2} \mathrm{O}$ and the plates were placed back at $-20^{\circ} \mathrm{C}$ for at least $4 \mathrm{~h}$. By using this freeze-gelation approach as previously described (25), we were able to generate highly porous scaffolds, without the use of lyophilization, by simultaneous liquefaction of the frozen cyclic RGDfK alginate solution, while solidifying it by binding calcium ions.

Following freeze-gelation, plates were warmed to room temperature and sterilely washed thrice in molecular biology grade $\mathrm{ddH}_{2} \mathrm{O} ; 10 \mathrm{~mm}$ diameter circular scaffolds were removed from the plate, air dried, and stored dry at $-20^{\circ} \mathrm{C}$ until further use.

\subsubsection{SCANNING ELECTRON MICROSCOPY}

Scaffolds were dehydrated through an ethanol gradient, then dried using a Bal-Tec Critical Point Dryer (Bal-Tec, Balzers, Liechtenstein), sputter-coated with $15 \mathrm{~nm}$ of Gold-Palladium with a Cressington Manual Sputter Coater (Cressington, Watford, United Kingdom), and imaged with a Hitachi 4700 scanning electron microscope (Hitachi Medical Systems, Twinsburg, OH) (Fig. 2b-d).

\subsubsection{CELL CULTURE}

hMPCs were isolated from whole human bone marrow by magnetic bead separation using a novel mAb against STRO-3 as previously described (26). This antibody isolates an hMPC population expressing Stro-1, CD44, CD90, and CD106 by flow cytometric analysis. First, we confirmed the ability of these cells to differentiate into osteoblasts, adipocytes, and mature chondrocytes according to the manufacturer's instructions (27), followed by staining with Alizarin Red S, Oil Red O, and Alcian Blue, respectively.

Next, hMPCs were allowed to proliferate in T75 flasks with the full medium. For passage or cell usage, cells were lifted from flasks after incubation with $0.1 \%$ collagenase for $30 \mathrm{~min}$ followed by TrypLe Select treatment for 5min, and resuspended in phosphate-buffered saline (PBS) with $10 \%$ FCS and DNase I $(1 \mathrm{mg} / \mathrm{mL})$ to prevent cell clumping. Passage 2-5 hMPCs were used for all studies. Neonatal rat cardiomyocyte and neonatal rat cardiac fibroblast viability in vitro were assessed in separate experiments (Supplementary Data; Supplementary Data are available online at www.liebertpub.com/tea).

\subsubsection{SCAFFOLD SEEDING}

Dry scaffolds were placed in $35 \mathrm{~mm}$ tissue culturetreated dishes (Fig. 2b). Cells were suspended at $10^{7} / \mathrm{mL}$ followed by application of $1 \times 10^{6}$ cells $(100 \mu \mathrm{L})$ in the full medium directly onto the dry scaffold (Fig. 2c). Due to highly porous and hydroscopic nature of scaffolds, cells were quickly absorbed and retained inside the scaffold pores. $2.9 \mathrm{~mL}$ of full medium was subsequently added to each scaffold containing dish and they were placed on a shaker for $30 \mathrm{~min}$ at $20 \mathrm{rpm}$ to complete seeding. Dishes with scaffolds were subsequently transferred to a humidified incubator at $37^{\circ} \mathrm{C}$ and $5 \% \mathrm{CO}_{2}$ until further use (Fig. 2d).

\subsubsection{VIABILITY STUDIES}

Scaffolds seeded with hMPCs were cultured in full a-MEM and maintained for 7 days at $37^{\circ} \mathrm{C}$ and $5 \%$ $\mathrm{CO}_{2}$. The medium was replaced daily. After culture, scaffolds were removed from the medium and placed in citrate/EDTA buffer to liquefy alginate by $\mathrm{Ca}^{2+}$ chelation and permit collection of cells for viability studies. Removal of calcium by chelation through the citrate/EDTA buffer resulted in rapid degradation of the calcium alginate 3D structure.

Subsequently, cells were washed in $1 \mathrm{~mL}$ PBS/10\% FCS solution. After washing, cells were resuspended in collagenase $0.1 \%$ solution for $30 \mathrm{~min}$ 
at $37^{\circ} \mathrm{C}$ followed by treatment in TrypLe Selekt (Invitrogen) to facilitate cell disaggregation. Cells were then washed in $1 \mathrm{~mL}$ DNase $\mathrm{I}(1 \mathrm{mg} / \mathrm{mL})$ supplemented with 10\% FCS. Cell viability was assessed by counting live and dead cells using trypan blue exclusion (28). Studies were done thrice in duplicate. Additional viability studies using rodent cells were conducted (Supplementary Data).

\subsection{STUDY 2: SCAFFOLDS IMPLANTED INTO THE ABDOMINAL MUSCLES}

\subsubsection{INTRAMUSCULAR IN VIVO APPLICATION OF CYCLIC RGDfK- MODIFIED ALGINATE SCAFOLDS}

Proof-of-concept studies were performed by intramuscular scaffold implantation as previously described (6). All animal studies were reviewed and approved by the Columbia University Institutional Animal Care and Use Committee (IACUC).

Male Lewis rats weighing between 200 and 250g were obtained from Harlan Sprague Dawley, Inc. (Indianapolis, IN). Rats were anesthetized with isoflurane and after incising the abdominal skin, the rectus muscle was dissected to the peritoneum. A newly created pocket accommodated a $10 \mathrm{~mm}$ scaffold. Based on our previous studies (6), scaffolds were pretreated with recombinant VEGF-A $100 \mathrm{ng} / \mathrm{mL}$ and recombinant PDGF-BB $100 \mathrm{ng} / \mathrm{mL}$ to induce a vascular response and then implanted in the newly created space before reapproximating the muscle over the space and closing the incision in separate layers.

Sixty days after implantation, muscle plus scaffolds were harvested in toto and fixed in $2 \%$ paraformaldehyde for further analyses. In some animals, muscle was sectioned through the scaffold to optically inspect scaffold material at the time of harvest. Paraffin tissue sections were stained with Gill's hematoxylin/eosin (H\&E) and factor VIIIrelated antigen $\mathrm{mAb}$, diluted 1 in 200, according to the manufacturer's instructions, to examine vascularity of the tissue. Vessels within five separate high-power fields at 400× magnification were counted.

\subsection{STUDY 3: SCAFFOLDS TO REPAIR MI}

\subsubsection{EPICARDIAL IN VIVO APPLICATION OF CYCLIC RGDfK-MODIFIED ALGINATE SCAFFOLDS}

Epicardial scaffold implantation was performed as previously described (29). Rowett (rnu/rnu) athymic nude rats (225-250g; Harlan Sprague Dawley, Inc.) were used according to an IACUC-approved protocol. Rats were anesthetized with inhaled isoflurane (2-3\%), endotracheally intubated, and mechanically ventilated. The heart was exposed through a left thoracotomy. Following opening of the pericardium, the left anterior descending artery (LAD) was ligated with 7-0 Prolene (Ethicon, Somerville, NJ) suture $2-3 \mathrm{~mm}$ below the edge of the left atrium, and $48 \mathrm{~h}$ later, an engineered scaffold was placed onto the epicardial surface of the infarcted area. The pericardium was not closed thereafter.

Three types of engineered scaffolds were implanted: (1) cyclic RGDfK-modified scaffolds without hMPCs $(\mathrm{n}=11)$; (2) cyclic RGDfK-modified scaffolds with $1 \times 10^{6} \mathrm{hMPCs}(\mathrm{n}=14)$; and (3) cyclic RGDfK-modified scaffolds with $3 \times 10^{6}$ hMPCs $(\mathrm{n}=6)$. We did not use unmodified scaffolds in in vivo heart failure studies, since hMPC viability in such scaffolds was shown to be limited. We further opted to not pretreat epicardial hMPC-seeded scaffolds with VEGF-A/PDGF-BB, as we did in the intramuscular studies, since our data showed that hMPCs secrete several proangiogenic factors such as VEGF and MCP-1 that induce vasculogenesis in infarcted myocardium (26). Seven days after scaffold implantation, hearts were harvested, sectioned at the mid-LAD level, imaged, and fixed in $2 \%$ paraformaldehyde for further histological analyses.

\subsubsection{EFFECTS OF SCAFFOLD IMPLANTATION ON LV FUNCTION}

Rats were scanned in a parasternal short-axis view under inhaled isoflurane (2\%) anaesthesia, with $2 \mathrm{D}$ and M-mode echocardiographic imaging using a Sonos 5500 System (Philips Medical Systems, Framingham, MA) and a broadband high-frequency $(12 \mathrm{MHz})$ transducer (S12). Left ventricular fractional shortening (LVFS) was used to assess cardiac function based on its reported reproducibility and lower variability compared to other cardiac parameters following MI using LAD ligation in rats $(30,31)$.

LVFS was calculated using the formula LVFS $(\%)=(\mathrm{LV}$ diastolic diameter $[\mathrm{LVDd}]-\mathrm{LV}$ systolic diameter [LVDs])/LVDd $\times 100$. The maximum and minimum values of LVDd and LVDs in one cardiac cycle were obtained after tracing the endocardial LV border. To address echocardiographic data variability, interquartile range (IQR) analysis was performed. Outliers were defined as observations that fall below Q1-1.5×IQR or above Q3+1.5×IQR.

\subsection{TISSUE ANALYSES}

\subsubsection{HISTOLOGICAL ANALYSES}

Sections were stained with mAbs directed against rat factor VIII-like protein, rat aSMA, and CD163/ED-2, a rat macrophage marker. Arterioles were differentiated from large capillaries by the presence of a smooth muscle layer, identified by staining with a mAb against aSMA. Staining was performed using immunoperoxidase, an avidinbiotin blocking kit, a rat-absorbed biotinylated antimouse IgG, and a peroxidase conjugate. Histological sections from three or four animals per group were analyzed by a blinded investigator at $40 \times$ magnification by image processing (using 24-48 fields of view) to determine (1) factor VIII-positive vessels ( $\mathrm{n}=4$ animals per group) and (2) aSMApositive vessels ( $n=4$ animals per group). 

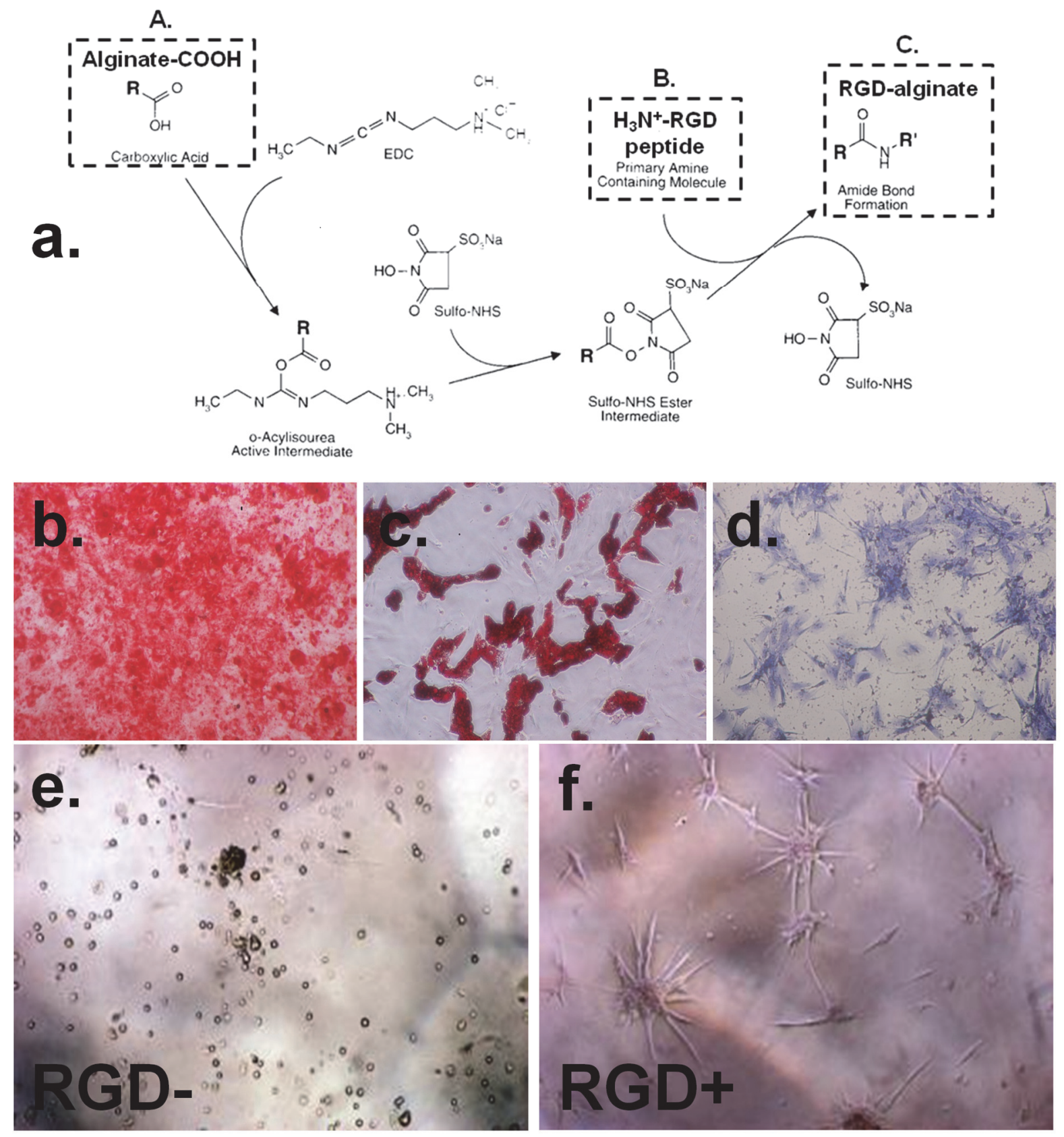

Figure 1. Schematic reaction scheme of covalent coupling of alginate-COOH groups (a.A) to cyclic RGDfK peptide $-\mathrm{NH}^{+}$groups (a.B) to yield cyclic RGDfK coupled alginate (a.C). Sulfo-NHS intermediary activation of alginate was used to increase efficiency of coupling reaction (adapted from Hermanson (23)). hMPC adhesion to tissue culture plates and subsequent differentiation into osteoblasts, adipocytes, and mature chondrocytes was shown by Alizarin Red (b), Oil Red O (c), and Alcian Blue (d) stains, respectively. Cyclic RGDfK incorporation was evaluated using 2D cell adhesion assays with hMPCs. Unmodified alginate showed no cell adhesion (e), with rounded cells on the alginate surface. Modified alginate showed cell adhesion with a nerve cell-like phenotype (f) comparable to tissue culture plate-adherent hMPCs (d). 2D, two dimensional; hMPC, human mesenchymal precursor cell; NHS, N-hydroxysulfosuccinimide; RGDfK, Arg-Gly-Asp-D-Phe-Lys.

\subsection{STATISTICAL ANALYSIS}

Groups were compared by Student's t-test or Welch's analysis of variance with Bonferroni correction, as indicated in figure legends. A p-value $<0.05$ was considered statistically significant. Bar graphs represent mean value \pm standard error of the mean (SEM) or, in case of box plots for echocardiographic analysis, medians with $\mathrm{IQR}_{\mathrm{S}} \pm$ minimum and maximum values. Calculations were performed using Microsoft Excel with the Real Statistics Add-In (www.real-statistics.com). 



Figure 2. One hundred millimeter glass dishes (a.ii) were used with a $90 \mathrm{~mm}$ bottom layer of silicone sheeting (a.iii). Three silicone strips (a.i) with $3 \times 10 \mathrm{~mm}$ circular wells each were layered on primary sheet (a.iii). Resulting wells were filled with modified alginate solution $(56 \mu \mathrm{L})$ before freezing at $-20^{\circ} \mathrm{C}$. Following freeze-gelation, scaffold seeding and culture are shown in (b-d). Black arrowheads indicate scaffolds in wells. Scanning electron microscopy images show sponge-like scaffold following freeze-gelation in (e) (magnification $1 \times$ ) and scaffold surface (f) (magnification 1000×). Note the highly porous structure of freezegelled scaffold without need for lyophilization. hMPC-seeded light microscopic scaffolds are shown in (g) $(40 \times)$ and (h) (200×). hMPC viability data (i) inside scaffolds following 1 week culture in vitro are shown. Cyclic RGDfK modification of alginate significantly enhanced hMPC viability compared to control (cyclic RADfK-modified or RADfK-unmodified scaffolds) at $20 \mathrm{mg} / \mathrm{g}$. Student's t-test, two-way, equal variance. Bars represent mean \pm SEM. ${ }^{*} \mathrm{p}<0.05$. SEM, standard error of the mean.

\section{RESULTS}

\subsection{ALGINATE PURIFICATION}

We used a novel purification protocol based on a modified protocol by Prokop and Wang with additional steps to improve removal of contaminants (32). The approach was based on our in-house developed protocol using hydrophobic PVDF membrane filtration. This method increased the final purity of poly-mannuronic acid threefold to fivefold compared to commercially available pharmaceutical grade poly-mannuronic/guluronic acid (17).

\subsection{CHARACTERIZATION OF STRO-3} SELECTED, CULTURE EXPANDED HMPCS

hMPCs were immunoselected from fresh bone marrow aspirates as previously described (26). Flow cytometric analysis of passage $5 \mathrm{hMPCs}$ indicated that $\sim 95 \%$ of the population was positive for the
Stro-1 antigen, which has been shown to be an important marker of clonogenic bone marrow stroma. Stro-1-positive hMPCs coexpressed a number of common MSC surface markers, namely CD13, CD29, CD44, CD90, and CD146, but were negative for the endothelial precursor marker, CD34, were plastic adherent, and displayed a fibroblastic morphology, which was retained following multiple passages (up to 5) (data not shown). These cells were confirmed to be clonogenic in fibroblastic colony-forming unit assays. Moreover, culture-expanded hMPCs were multipotent, as evidenced by their ability to differentiate along osteogenic, adipogenic, and chondrogenic lineages in the presence of previously defined inductive stimuli (Fig. 1b-d). The isolated hMPCs secreted several chemokines and growth factors, notably IL-6, MCP1 , and VEGF (data not shown). 

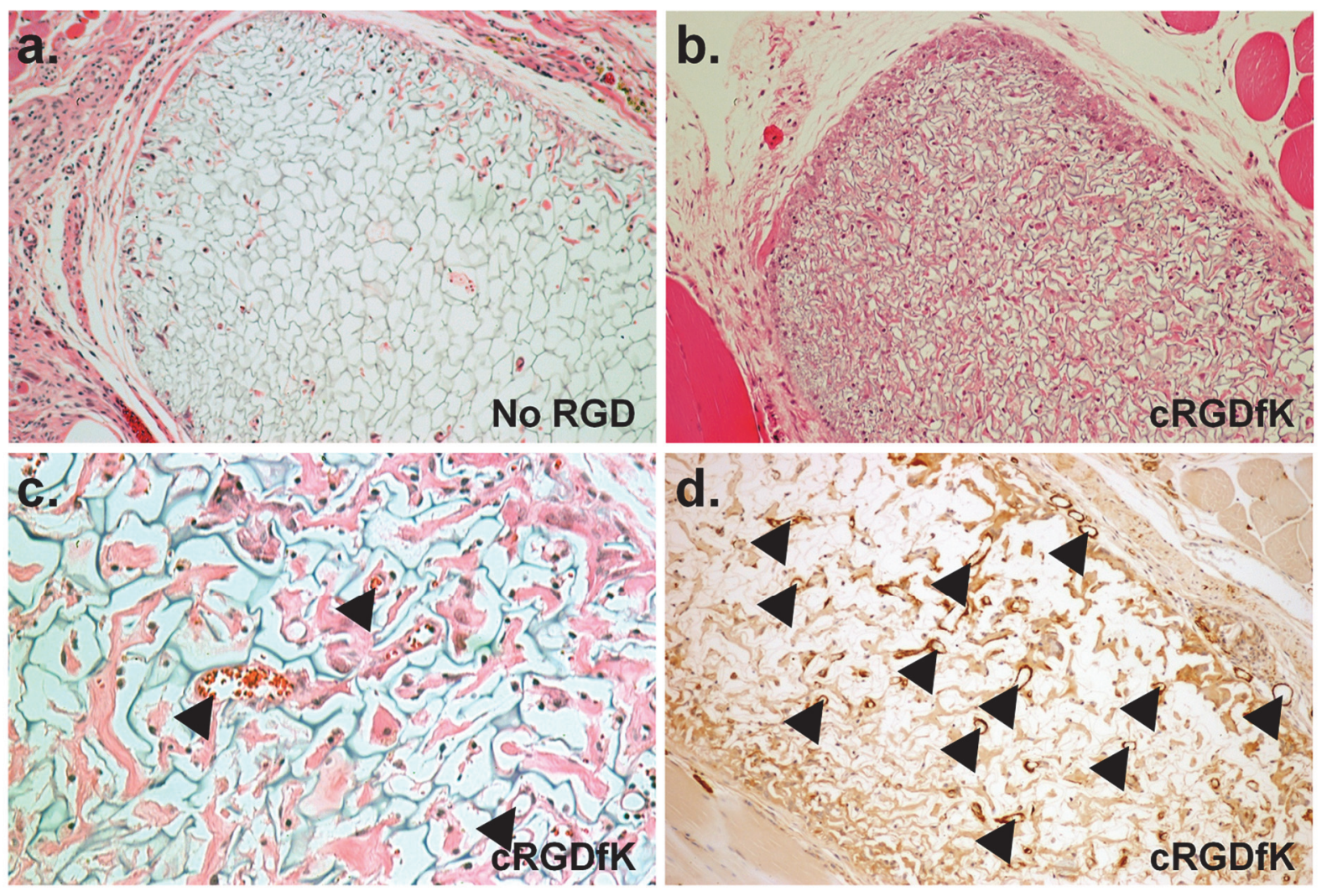

Figure 3. Alginate scaffolds with and without cyclic RGDfK peptide modification. Note virtual absence of cellularization of unmodified scaffold (a) (H\&E, 40×). Note scaffold cellularization throughout scaffold material of cyclic RGDfK modified scaffold (b) (H\&E, 40×). Note vascularization and functional blood vessels filled with erythrocytes inside cyclic RGDfK modified scaffolds (arrows, c) (H\&E, 200×). Cyclic RGDfK modified scaffold plus PDGF-BB and VEGF-A showed abundant vessel formation inside scaffold by von Willebrand factor-like protein staining (arrows, d) (40×). H\&E, hematoxylin/eosin; PDGF-BB, plateletderived growth factor-bb; VEGF, vascular endothelial growth factor.

\subsection{CYCLIC RGDfK CONJUGATION AND EFFECT ON HMPC ADHESION}

Following covalent cyclic RGDfK modification, 2D cyclic RGDfK-modified scaffolds were produced and then evaluated for hMPC adhesion as determined by cell spreading. The spreading of hMPCs seeded on cyclic RGDfK-modified alginate scaffolds (Fig. 1f) was comparable to spreading on $2 \mathrm{D}$ tissue culture plates (Fig. 1b-d). Unmodified scaffolds did not show any hMPC adhesion, but instead, hMPCs rounded up indicating no adhesion (Fig. 1e).

\subsection{FREEZE-GELATION AND SCAFFOLD STRUCTURE}

Scanning electron microscopy photographs of the highly porous structure of scaffolds produced using freeze-gelation are shown in Figure 2e and $f$. Figure 2 e shows $1 \times$ magnification, whereas Figure $2 \mathrm{f}$ shows $1000 \times$ magnification. As opposed to lyophilization, freeze-gelation did not result in the formation of an impenetrable surface, thus allowing retention of the highly porous structure throughout the scaffold (images not shown). Pore sizes ranged between 40 and $100 \mu \mathrm{m}$, as estimated using scanning electron microscopy imaging.

\subsection{EX VIVO STUDIES}

\subsubsection{HMPC RETENTION AND VIABILITY USING 3D FREEZE-GELLED SCAFFOLD}

Interestingly, retention of cells inside scaffolds was significantly higher in cyclic RGDfK-modified scaffolds than in unmodified scaffolds (data not shown). Figure $2 \mathrm{~g}$ and $\mathrm{h}$ show light microscopic images of hMPCs seeded inside cyclic RGDfKmodified scaffolds at $40 \times$ and $200 \times$ modification, respectively. After seeding, there was a significant difference in cell viability between those being placed on the cyclic RGDfK-modified scaffolds and those being placed on unmodified scaffolds (Fig. 2i and Supplementary Fig. S1).

Furthermore, the higher the cyclic RGDfK concentration, the higher the cell viability or cell number (Supplementary Fig. S1 and Fig. 2i). For hMPCs, 20mg/g cyclic RGDfK was associated with $38.3 \% \pm 2.7 \%$ viable cells versus $17.9 \% \pm 2.1 \%$ and $14.1 \% \pm 1.1 \%$ at $20 \mathrm{mg} / \mathrm{g}$ negative control cRADfK peptide and $0 \mathrm{mg} / \mathrm{g}$ cyclic RGDfK after 7 days of culture, respectively $(\mathrm{p}<0.05)$ (Fig. 2i). Additional data can be found in the Supplementary Data. 


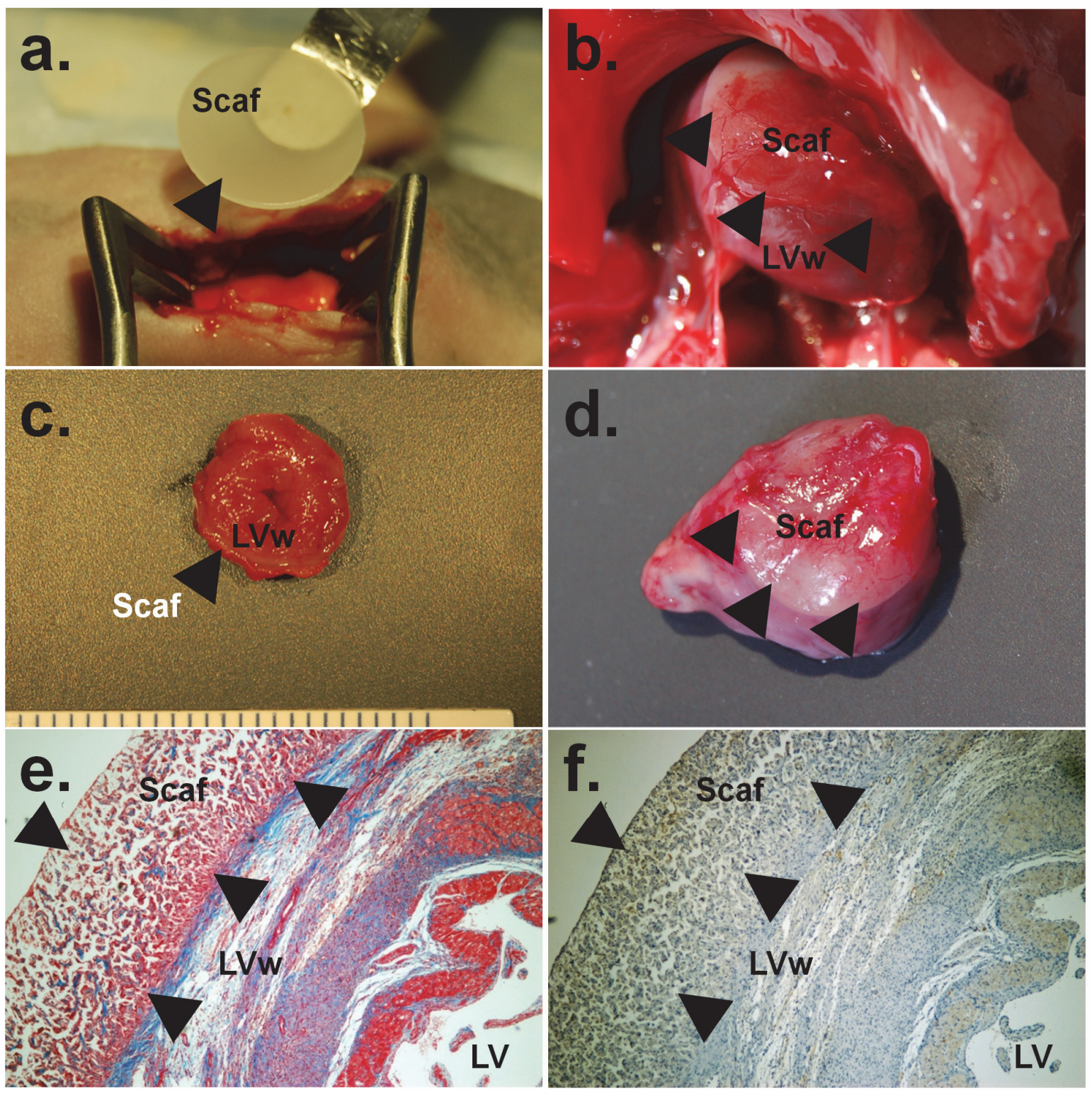

Figure 4. Scaffold application to epicardial surface. Scaffolds-cells were applied $48 \mathrm{~h}$ following MI through thoracotomy (a). Scaffolds sufficiently adhered to myocardial surface without sutures (b, d, arrows) and remained in place for the duration of the study (c, arrow). Hearts were harvested for histology 1 week after transplantation (c, d). Masson's trichrome staining for fibrosis (e) showed Scaf cellularization with minimal fibrosis in the scaffold, but significant fibrosis in the myocardium (blue). (f) Shows CD163/ED-2 staining for rat macrophages. There was no evidence of foreign body reaction against the scaffold material at 1 week following implantation. LVw, left ventricular wall; MI, myocardial infarction; Scaf, scaffold.

\subsection{IN VIVO STUDIES}

\subsubsection{SCAFFOLD IMPLANTED INTO THE ABDOMINAL MUSCLES}

Preliminary safety studies showed that all animals tolerated intramuscular scaffold implantation. There were no clinical signs of distress or infection/inflammation in general or at the implantation site. Sixty days following implantation, abdominal tissues were harvested. Scaffolds could be identified optically in situ. H\&E sections showed no scaffold cellularization of unmodified scaffolds (Fig. 3a). Scaffolds modified with cyclic RGDfK or cyclic RGDfK+100ng VEGF-
A+100ng PDGF-BB showed robust cellularization and vascularization (Fig. 3b, c), which was confirmed by factor VIII-like protein staining (Fig. 3d).

\subsubsection{EPICARDIAL SCAFFOLD IMPLANTATION IN RATS WITH MI}

Epicardial scaffolds were also well tolerated. Scaffolds remained in situ for 7 days (Fig. 4a-d). Following explantation, tissue analyses showed minimal scaffold fibrosis (Fig. 4e) and no CD163 ${ }^{+} / \mathrm{ED}-2$ macrophage or fibroblast infiltration (Fig. 4f), indicating absence of foreign body 


\section{Erythrocyte filled blood vessel count per high power field}
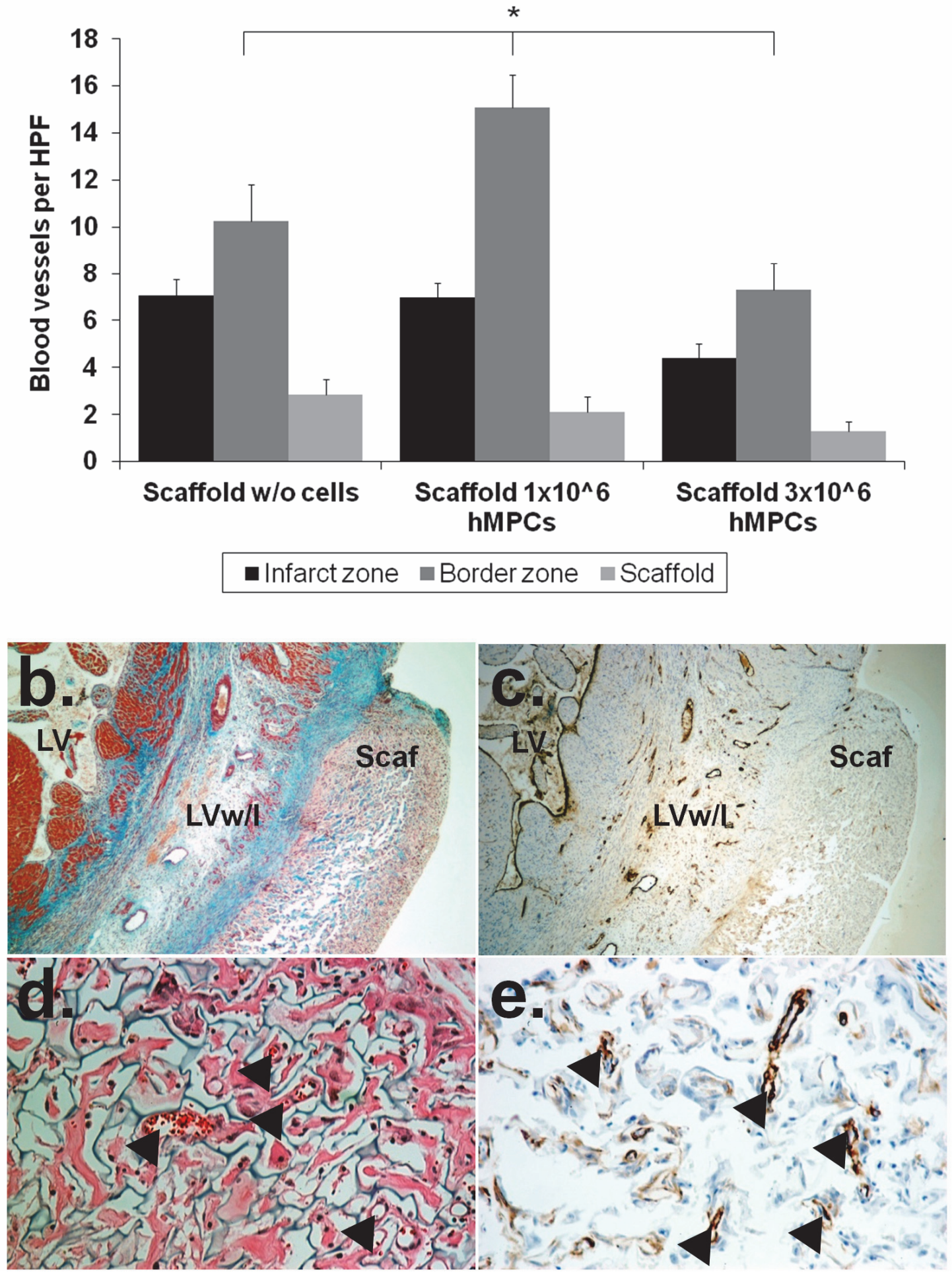

Figure 5. Numbers of erythrocyte filled blood vessels in infarct zone, border zone, and scaffold shown in (a). Blood vessels in the border zone of the MI showed significantly increased numbers in animals treated with scaffolds $+1 \times 10^{6} \mathrm{hMPCs}$ compared to animals that were treated with scaffolds only or with scaffolds $+3 \times 10^{6}$ hMPCs. (b, c) Show scaffold on epicardial surface using Masson's trichrome (b) and aSMA staining (c) at 40×. (d) Shows Masson's trichrome stain with erythrocyte-filled arterioles (arrows; blue is interstitial connective tissue) inside scaffold at 400×; (e) shows aSMA-positive vasculature (brown) inside scaffold at $400 \times$ (arrows). Scaf designates scaffold. LVw/I is left ventricular wall with infarction. Welch's ANOVA. Bars represent means \pm SEM. *p<0.05. aSMA, a-smooth muscle actin; ANOVA, analysis of variance. 
responses. Scaffolds seeded with $1 \times 10^{6} \mathrm{hMPCs}$ showed significantly more vascularization at the infarct border zone (Fig. 5) than scaffolds without cells.

Surprisingly, scaffolds seeded with a higher dose of hMPCs $\left(3 \times 10^{6}\right)$ did not show increased vascularization, but rather a trend to decreased vascularization at either border or infarct zone, perhaps on the basis of cell "crowding," resulting in lesser viability due to lack of nutrients when using a higher concentration of cells per scaffold (Fig. 5a).

\subsubsection{EPICARDIAL SCAFFOLDS AND EFFECT ON CARDIAC FUNCTION}

Following epicardial scaffold application in the $1 \times 10^{6}$ hMPC group, we found a slight, but significant positive effect of $4.7 \%$ on LVFS when day 0 (scaffold implantation) means were compared to means on day 7 (Fig. 6a, white diamonds). No effect on LVFS was observed in the group with unseeded scaffolds, nor in the group with scaffolds seeded with $3 \times 10^{6} \mathrm{hMPCs}$, compared to saline injection. Data for each individual animal are shown (Fig. 6be) and summarized in Figure $6 a$.

When comparing medians on day 0 versus 7 , decrease in fractional shortening was $-22.58 \%$ in saline control group, $-24.54 \%$ in scaffold without cells group, $-11.79 \%$ in $1 \times 10^{6} \mathrm{hMPC}$ group, and $-17.14 \%$ in $3 \times 10^{6}$ hMPC group (Fig. 6a, white lines).

For medians, IQR assessment was performed to address outlier and variability in the LVFS change data. For all groups, data fell between $\mathrm{Q} 1-1.5 \times \mathrm{IQR}$ and $\mathrm{Q} 3+1.5 \times \mathrm{IQR}$ (ranges $-71.8 \%$ to $19.2 \%$ for saline, $-80.2 \%$ to $57.2 \%$ for control scaffold, $-101.0 \%$ to $106.4 \%$ for $1 \times 10^{6} \mathrm{hMPC}$ group, and $-64.6 \%$ to $25.0 \%$ for $3 \times 10^{6}$ hMPC group).

\section{DISCUSSION}

We used a patented method for sodium alginate purification, which resulted in the production of nonimmunogenic material (17). The purified alginate could be covalently modified with cyclic RGDfK peptides and we were able to produce $3 \mathrm{D}$ scaffolds of this material. Scaffolds produced from cyclic RGDfK peptide-modified alginate significantly improved cell viability of a variety of cells, when compared with unmodified or negative control cyclic RADfK-modified alginate. Moreover, hMPC-seeded cyclic RGDfK peptide-modified scaffolds showed robust cellularization and neovascularization upon implantation in the abdominal wall or pericardially. No adverse immune response was observed.

In the heart, our results show that implantation of cyclic RGDfK-modified alginate scaffolds seeded with $1 \times 10^{6} \mathrm{hMPC}$ resulted in a mean $4.7 \%$ increase in LVFS compared to saline controls (Fig. 6a, white diamonds). Regarding median changes, fractional shortening decreased $\sim 50 \%$ less in the $1 \times 10^{6} \mathrm{hMPC}$ scaffold-treated group compared to saline control or scaffold without cells groups: $-22.58 \%$ in saline control group, $-24.54 \%$ for scaffold without cells group, $-11.79 \%$ for $1 \times 10^{6} \mathrm{hMPC}$ scaffold group, and $-17.14 \%$ in $3 \times 10^{6} \mathrm{hMPC}$ scaffold group (Fig. 6a, white lines). These results suggest a protective effect of epicardial application of hMPC-seeded cyclic RGDfK-modified alginate scaffolds on deterioration of cardiac function following acute MI. Of note, we did not test unmodified scaffolds in MI studies, since our preliminary data showed that unmodified scaffolds did not become vascularized and exerted a deleterious effect on hMPC viability. The enhanced in vitro viability of cells in cyclic RGDfK peptide-modified alginate is likely due to enhanced stability of cyclic RGDfK peptide, which is less susceptible to proteolytic degradation than linear Gly-Arg-Gly-Asp-Ser-Pro (GRGDSP) peptide (18). This would make cyclic RGDfK peptide more readily available to bind to cellular integrins on the cell surface.

In addition, cyclic RGDfK peptides bind to cellular integrin receptors with high affinity (21), which may further enhance signaling to maintain cell survival. Further optimization of cell survival with these peptide modifications, for instance by spacing the cyclic RGDfK moieties (33) or using multivalent cyclic RGDfK derivatives (34), may be required.

Cell death inside scaffolds may contribute to deleterious effects on tissue regeneration and therefore be counterproductive (35). Since scaffolds are generally not vascularized at the time of implantation, oxygen and nutrients to cells seeded inside scaffolds are initially delivered by diffusion. Cyclic RGDfK modification may enhance vessel growth by recruiting endothelial cells into scaffolds and promoting endothelial cell adhesion and proliferation. A preexisting vascular network, either by implanting a vascular growth factor containing scaffold before introducing cells or grown ex vivo using bioreactors, would be more desirable, may decrease cell death, and enhance regenerative effects $(36,37)$. This is suggested by our studies with islet cell transplantation where the modified scaffolds were implanted between the abdominal rectus muscle and subsequently injected with pancreatic $B$-cells after a prevascularization period of 2 weeks $(6)$.

Scaffolds seeded with $1 \times 10^{6} \quad$ hMPCs increased blood vessel formation in the border zone of the myocardial infarct and augmented cardiac function. The functional improvement of cardiac function upon treatment with a variety of bone marrow-derived precursor cells has generally been attributed to paracrine stimulation and stimulated neovascularization (38). Surprisingly, this effect was not observed using scaffolds with the higher dose of $3 \times 10^{6}$ hMPCs. This finding may be explained by "overcrowding" of cells, which is related to levels of paracrine factors (i.e., cytokines) that hMPCs secrete, such as IL-6 and MCP-1.

Clinical dose escalation trials using direct intramyocardial mesenchymal stem cell injection have found similar dose-dependent effects (39). Local excess cytokine concentrations may be toxic to cardiomyocytes and abolish the beneficial effects of transplanted cells. Alternatively, a high number of cells inside scaffolds may lead to accelerated cell death in vivo due to an initial lack of oxygen and 

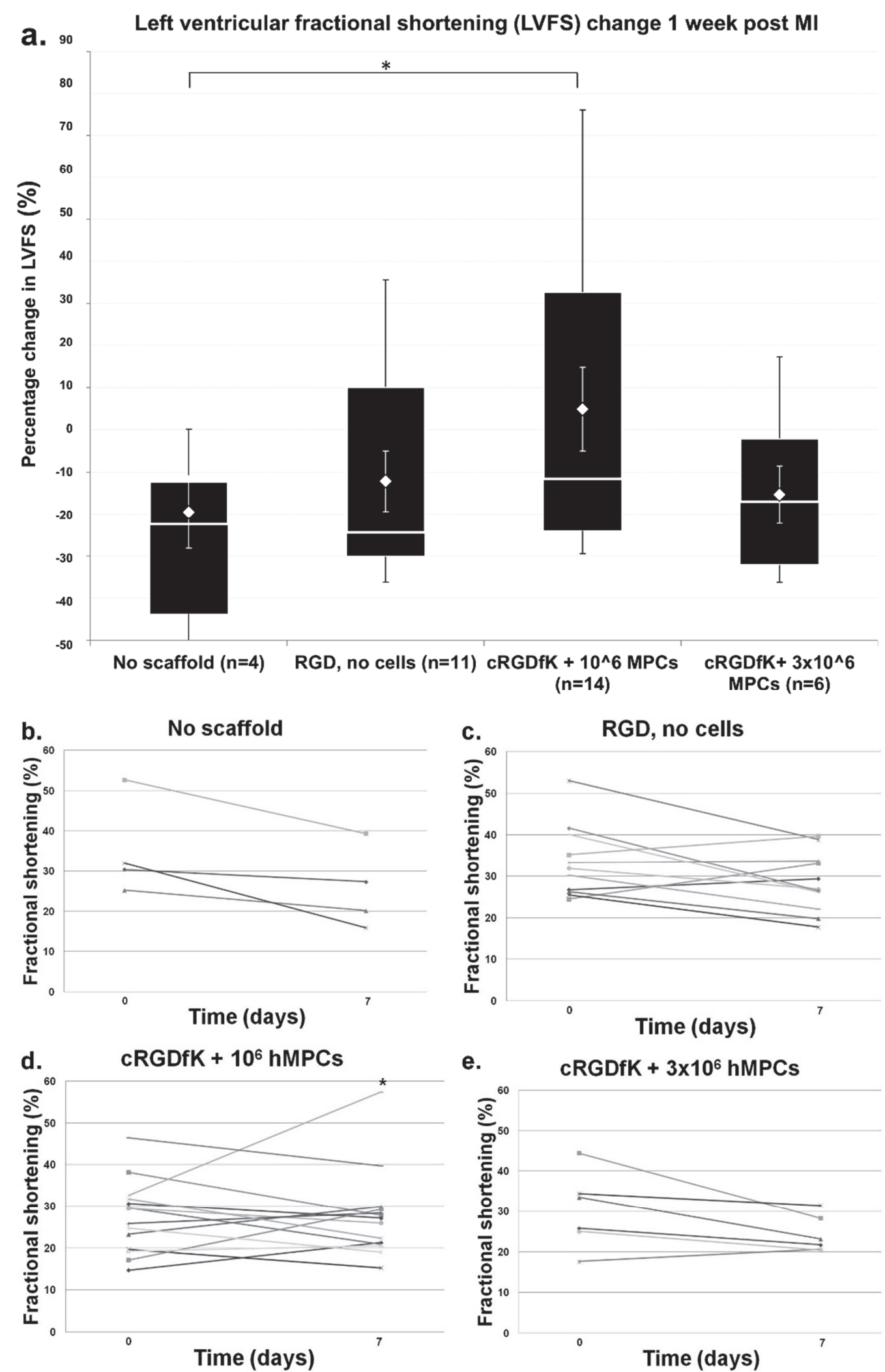

Figure 6. LVFS by echocardiography showed significant increase in cardiac function 1 week following epicardial application of cyclic RGDfK scaffolds seeded with $1 * 10^{6}$ hMPCs (d) compared to saline injection (b). This effect was not observed using scaffolds without cells (c) or scaffolds seeded with $3 \times 10^{6} \mathrm{hMPCs}$ (e).Mean (white diamonds) and median change in LVFS (white horizontal lines) are summarized in (a). For means, white error bars show SEM. Black bars represent IQR, black whiskers represent minimum and maximum values. Horizontal white lines inside bars show medians. Welch's ANOVA with Bonferroni correction. ${ }^{*} \mathrm{p}=0.047$. cRGDfK, cyclic RGDfK; IQR, interquartile range; LVFS, left ventricular fractional shortening. 
nutrients, abrogating their beneficial effects. The efficacy of cell delivery in scaffolds can be maximized since cell dose can be controlled to a greater extent and cell loss by a lower extent compared to direct cell injection (40).

Limitations to echocardiographic assessment of rat hearts following MI are well known (31). Variability in measurements of ejection fraction in rats without MI in different studies have been reported to be $60 \%, 75 \%$, and $91 \%$, and the corresponding values for LVFS were $48 \%, 41 \%$, and $56 \%$. We used LVFS due to its reported lower variability compared to other parameters such as stroke volume or cardiac output; however, more advanced techniques such as magnetic resonance imaging may yield more accurate results (41).

One animal's fractional shortening in the $1 \times 10^{6} \mathrm{hMPC}$ group normalized from $32.7 \%$ on day 0 to $57.4 \%$ on day 7 , a $75.9 \%$ increase (Fig. $6 \mathrm{~d}$ ). We deemed this change to be plausible; another animal showed an increase in LVFS from $17.1 \%$ to $29.3 \%$, a $71.0 \%$ increase; hence, we included the data point as part of the primary data of overall LVFS change, which was within the Q3+1.5 $\times \mathrm{IQR}$ range of 106.4 (Fig. 6a). Of note, the animal's LVFS (i.e., infarct size) on day 0 did not differ significantly from the other animals' "LVFS," which is relevant in this setting since initial degree of functional impairment of infarcted myocardium has been shown to affect functional outcome following intramyocardial cell transplantation (42).

Grubbs' outlier detection test (43) showed that both overall primary and normalized LVFS change data did not contain statistically significant outliers (not shown). It would need to be established whether animals in the $1 \times 10^{6} \mathrm{hMPC}$ group were either good responders, for instance due to genetic polymorphisms, or whether other causes (i.e., data variability) are responsible for the results. Given the relatively low data base numbers, additional animal studies would add to robustness of the data and increased statistical validity.

Many natural and synthetic materials are being evaluated in combination with a number of growth factors and/or cell types for clinical applications in cardiac tissue engineering and cell transplantation (44). This study sought to evaluate an economical, practical, and clinically feasible scaffold material that promotes cell survival without provoking adverse immunological reactions. Cyclic RGDfK-modified alginate is such a biomaterial that meets these properties.

Estimated material retail costs to produce 1 cyclic RGDfK-modified alginate scaffold suitable for clinical use (size $100 \times 0.75 \mathrm{~mm}$ using $2 \%$ cyclic RGDfK-modified alginate) would be approximately US $\$ 1500$, excluding cells and cell culture materials. Financial modeling would be needed to calculate whether this is an acceptable price in addition to standard treatments. It would add to the costs of direct cell injection by percutaneous coronary intervention (PCI) or coronary artery bypass grafting. Depending on effectiveness and efficacy, and assuming scaffolds would not need replacement frequently, scaffold treatment could offer an alternative cost-effective approach.

\section{CONCLUSION}

Purified cyclic RGDfK peptide-modified 3D alginate scaffolds are biocompatible and nonimmunogenic, enhance cell viability, promote angiogenesis, and may be used as a means to deliver cells to myocardial infarct areas to improve neovascularization and cardiac function.

\section{DISCLOSURE STATEMENT}

H.P.S., P.W., and M.A.H. are provisional patent holders of the procedures described in this article (patent application No. 20100196441). S.I. is Executive Director of Mesoblast Limited and holds several patents on HMPC technology. All other authors have no competing financial interests. 

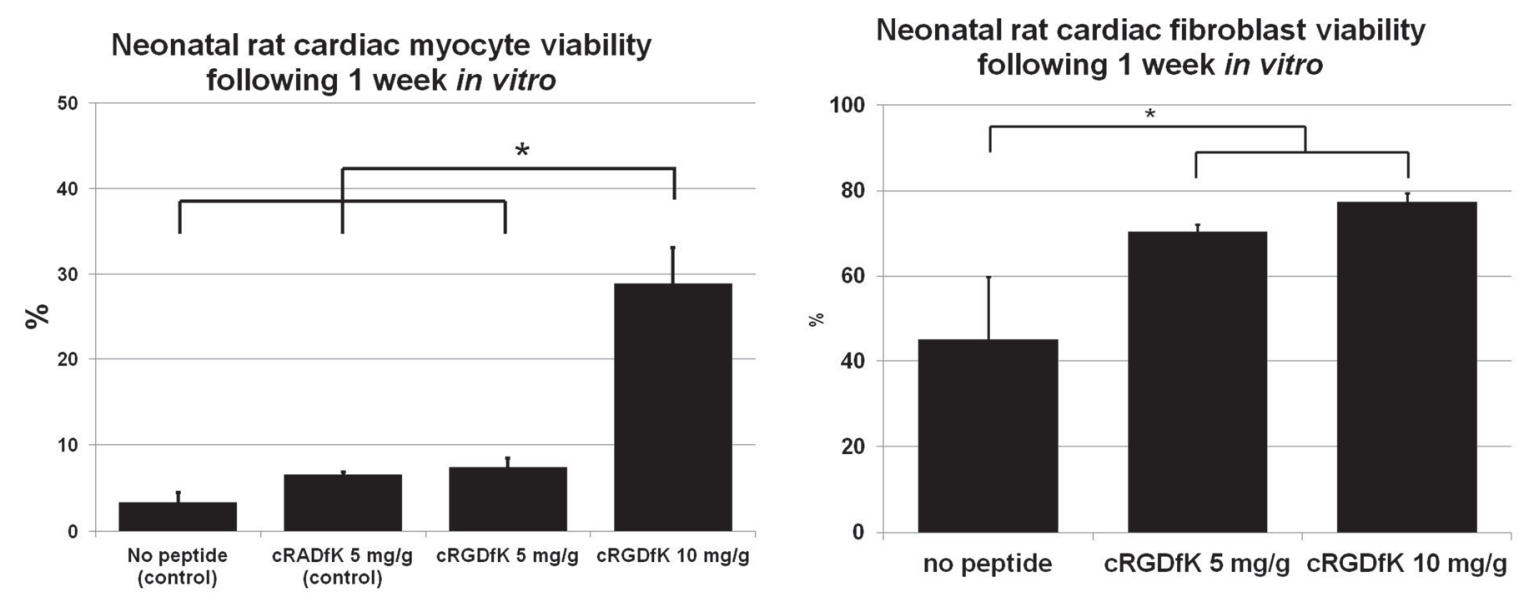

Supplementary figure S1. Neonatal rat cardiac myocyte (a) and neonatal rat cardiac fibroblast (b) viability inside scaffolds after 7 days of culture depend on cRGDfK concentrations used for alginate modification in a dose-dependent manner. Alginate scaffolds modified with $10 \mathrm{mg} / \mathrm{g}$ cyclic RGDfK and pretreated with gelatin significantly increased neonatal rat cardiac myocyte viability compared to scaffolds modified with $5 \mathrm{mg} / \mathrm{g}$ cyclic RGDfK peptide or $5 \mathrm{mg} / \mathrm{g}$ cyclic negative control RADfK peptide, or no peptide modification. Neonatal rat cardiac fibroblast viability increased in both 5 and $10 \mathrm{mg} / \mathrm{g}$ modified scaffolds compared to no peptide control scaffolds. Bars represent means \pm SEM. *p<0.05. RGDfK, Arg-Gly-Asp-d-PheLys; SEM, standard error of the mean.

\section{SUPPLEMENTARY DATA}

\subsection{EXPERIMENTAL SECTION}

\subsubsection{EX VIVO CELL VIABILITY INSIDE SCAFFOLDS}

For additional viability studies, neonatal rat cardiomyocytes and neonatal cardiac fibroblasts were isolated from 1-to 3-day-old neonatal SpragueDawley rats and cultured in Dulbecco's modified Eagle's medium: nutrient mixture F-12 medium with $5 \%$ horse serum for 7 days at $37^{\circ} \mathrm{C}$ and $5 \% \mathrm{CO}_{2}$ as previously described until use 25 . For rat cardiomyocytes, scaffolds were precoated with gelatin $0.1 \%$ in molecular biology grade $\mathrm{ddH}_{2} \mathrm{O}$ for 4 h. Cells were suspended at $10^{7} / \mathrm{mL}$ followed by application of $1 \times 10^{6}$ cells $/ 100 \mu \mathrm{L}$ ) in full medium per dry scaffold.

\subsection{RESULTS}

\subsubsection{EX VIVO VIABILITY INSIDE SCAFFOLDS}

The increase in percentage of live cells was also dependent on the dose of cyclic RGDfK (Arg-GlyAsp-d-Phe-Lys). After 7 days in culture, the dependence of cyclic RGDfK concentration (no peptide vs. $10 \mathrm{mg} / \mathrm{g}$ ) on cell viability was 2 -fold for rat cardiac fibroblasts $(45 \% \pm 14.9 \%$ vs. $77.4 \% \pm 2.2 \%$ viable) and 10 -fold for rat neonatal cardiomyocytes $(2.1 \% \pm 1.2 \%$ vs. $28.9 \% \pm 4.2 \%$ viable $)$

\section{REFERENCES}

1. N. Pavo, S. Charwat, N. Nyolczas, A. Jakab, Z. Murlasits, J. Bergler-Klein, M. Nikfardjam, I. Benedek, T. Benedek, I. J. Pavo, B. J. Gersh, K. Huber, G. Maurer, M. Gyongyosi, Cell therapy for human ischemic heart diseases: Critical review and summary of the clinical experiences. J Mol Cell Cardiol 75C, 12 (Jul 3, 2014).
2. P. P. Young, R. Schafer, Cell-based therapies for cardiac disease: a cellular therapist's perspective. Transfusion 55, 441 (Feb, 2015).

3. M. E. Reinders, J. W. de Fijter, H. Roelofs, I. M. Bajema, D. K. de Vries, A. F. Schaapherder, F. H. Claas, P. P. van Miert, D. L. Roelen, C. van Kooten, W. E. Fibbe, T. J. Rabelink, Autologous bone marrow-derived mesenchymal stromal cells for the treatment of allograft rejection after renal transplantation: results of a phase I study. Stem cells translational medicine 2, 107 (Feb, 2013).

4. S. B. Seif-Naraghi, J. M. Singelyn, M. A. Salvatore, K. G. Osborn, J. J. Wang, U. Sampat, O. L. Kwan, G. M. Strachan, J. Wong, P. J. Schup-Magoffin, R. L. Braden, K. Bartels, J. A. DeQuach, M. Preul, A. M. Kinsey, A. N. DeMaria, N. Dib, K. L. Christman, Safety and efficacy of an injectable extracellular matrix hydrogel for treating myocardial infarction. Science translational medicine 5, 173ra25 (Feb 20, 2013)

5. K. Matsuura, R. Utoh, K. Nagase, T. Okano, Cell sheet approach for tissue engineering and regenerative medicine. J Control Release 190C, 228 (Sep 28, 2014).

6. P. Witkowski, H. Sondermeijer, M. A. Hardy, D. C. Woodland, K. Lee, G. Bhagat, K. Witkowski, F. See, A. Rana, A. Maffei, S. Itescu, P. E. Harris, Islet grafting and imaging in a bioengineered intramuscular space. Transplantation 88, 1065 (Nov 15, 2009).

7. J. Dow, B. Z. Simkhovich, L. Kedes, R. A. Kloner, Washout of transplanted cells from the heart: a potential new hurdle for cell transplantation therapy. Cardiovasc Res 67, 301 (Aug 1, 2005).

8. M. Zhang, D. Methot, V. Poppa, Y. Fujio, K. Walsh, C. E. Murry, Cardiomyocyte grafting for cardiac repair: graft cell death and anti-death strategies. J Mol Cell Cardiol 33, 907 (May, 2001).

9. J. Leor, S. Gerecht, S. Cohen, L. Miller, R. Holbova, A. Ziskind, M. Shachar, M. S. Feinberg, E. Guetta, J. Itskovitz-Eldor, Human embryonic 
stem cell transplantation to repair the infarcted myocardium. Heart 93, 1278 (Oct, 2007).

$10 . \quad$ S. J. Hollister, Porous scaffold design for tissue engineering. Nature materials 4, 518 (Jul, 2005).

11. P. Jungebluth, E. Alici, S. Baiguera, K. Le Blanc, P. Blomberg, B. Bozoky, C. Crowley, O. Einarsson, K. H. Grinnemo, T. Gudbjartsson, S. Le Guyader, G. Henriksson, O. Hermanson, J. E. Juto, B. Leidner, T. Lilja, J. Liska, T. Luedde, V. Lundin, G. Moll, B. Nilsson, C. Roderburg, S Stromblad, T. Sutlu, A. I. Teixeira, E. Watz, A Seifalian, P. Macchiarini, Tracheobronchial transplantation with a stem-cell-seeded bioartificial nanocomposite: a proof-of-concept study. Lancet 378, 1997 (Dec 10, 2011).

12. H. Hamdi, A. Furuta, V. Bellamy, A. Bel, E. Puymirat, S. Peyrard, O. Agbulut, P. Menasche, Cell delivery: intramyocardial injections or epicardial deposition? A head-to-head comparison. The Annals of thoracic surgery 87, 1196 (Apr, 2009).

13. Q. Fu, C. L. Deng, R. Y. Zhao, Y. Wang, Y. Cao, The effect of mechanical extension stimulation combined with epithelial cell sorting on outcomes of implanted tissue-engineered muscular urethras. Biomaterials 35, 105 (Jan, 2014).

14. T. C. Kontis, Contemporary review of injectable facial fillers. JAMA facial plastic surgery 15, 58 (Jan, 2013).

15. P. J. Terrill, R. C. Goh, M. J. Bailey, Splitthickness skin graft donor sites: a comparative study of two absorbent dressings. $J$ Wound Care 16, 433 (Nov, 2007).

16. J. Leor, S. Tuvia, V. Guetta, F. Manczur, D. Castel, U. Willenz, O. Petnehazy, N. Landa, M. S. Feinberg, E. Konen, O. Goitein, O. Tsur-Gang, M. Shaul, L. Klapper, S. Cohen, Intracoronary injection of in situ forming alginate hydrogel reverses left ventricular remodeling after myocardial infarction in Swine. $J$ Am Coll Cardiol 54, 1014 (Sep 08, 2009).

17. H. P. Sondermeijer, P. Witkowski, D. Woodland, T. Seki, F. J. Aangenendt, A. van der Laarse, S Itescu, M. A. Hardy, Optimization of alginate purification using polyvinylidene difluoride membrane filtration: Effects on immunogenicity and biocompatibility of three-dimensional alginate scaffolds. Journal of biomaterials applications 31, 510 (Oct, 2016).

18. S. J. Bogdanowich-Knipp, S. Chakrabarti, T. D. Williams, R. K. Dillman, T. J. Siahaan, Solution stability of linear vs. cyclic RGD peptides. The journal of peptide research: official journal of the American Peptide Society 53, 530 (May, 1999).

19. E. Ruoslahti, M. D. Pierschbacher, New perspectives in cell adhesion: RGD and integrins. Science 238, 491 (Oct 23, 1987).

20. L. Y. Koo, D. J. Irvine, A. M. Mayes, D. A. Lauffenburger, L. G. Griffith, Co-regulation of cell adhesion by nanoscale RGD organization and mechanical stimulus. Journal of cell science 115, 1423 (Apr 1, 2002).

21. M. Kantlehner, P. Schaffner, D. Finsinger, J. Meyer, A. Jonczyk, B. Diefenbach, B. Nies, G. Holzemann, S. L. Goodman, H. Kessler, Surface coating with cyclic RGD peptides stimulates osteoblast adhesion and proliferation as well as bone formation. Chembiochem 1, 107 (Aug 18, 2000).

22. J. A. Rowley, G. Madlambayan, D. J. Mooney, Alginate hydrogels as synthetic extracellular

matrix materials. Biomaterials 20, 45 (Jan, 1999).

23.

24 Edition. p169 (1996).

C. Ryppa, H. Mann-Steinberg, M. L. Biniossek, R. Satchi-Fainaro, F. Kratz, In vitro and in vivo evaluation of a paclitaxel conjugate with the divalent peptide E-[c(RGDfK)2] that targets integrin alpha $\mathrm{v}$ beta 3 . Int $J$ Pharm 368, 89 (Feb 23, 2009).

25. M. H. Ho, P. Y. Kuo, H. J. Hsieh, T. Y. Hsien, L. T. Hou, J. Y. Lai, D. M. Wang, Preparation of porous scaffolds by using freeze-extraction and freeze-gelation methods. Biomaterials 25, 129 (Jan, 2004).

26. F. See, T. Seki, P. J. Psaltis, H. P. Sondermeijer, S. Gronthos, A. C. Zannettino, K. M. Govaert, M. D. Schuster, P. A. Kurlansky, D. J. Kelly, H. Krum, S. Itescu, Therapeutic effects of human STRO-3-selected mesenchymal precursor cells and their soluble factors in experimental myocardial ischemia. Journal of cellular and molecular medicine 15, 2117 (Oct, 2011).

27. Lonza, Document \# AA-2501-16 07/11. www.lonza.com, (2011).

28. W. Strober, Trypan blue exclusion test of cell viability. Current protocols in immunology 111, A3 B 1 (Nov 02, 2015).

29. A. F. Godier-Furnemont, T. P. Martens, M. S. Koeckert, L. Wan, J. Parks, K. Arai, G. Zhang, B. Hudson, S. Homma, G. Vunjak-Novakovic, Composite scaffold provides a cell delivery platform for cardiovascular repair. Proc Natl Acad Sci U S A 108, 7974 (May 10, 2011).

30. G. H. Wasmeier, I. Melnychenko, J. U. Voigt, W. H. Zimmermann, T. Eschenhagen, N. Schineis, U. Reulbach, F. A. Flachskampf, W. G. Daniel, U. Nixdorff, Reproducibility of transthoracic echocardiography in small animals using clinical equipment. Coronary artery disease 18, 283 (Jun, 2007).

31. R. Esmaeili, A. Sadeghpour, A. Darbandi-Azar, A. K. Majidzadeh, A. Vajhi, M. Sadeghizadeh, Echocardiographic assessment of myocardial infarction: comparison of a rat model in two strains. Iranian journal of veterinary research 18, 30 (Winter, 2017).

32. A. Prokop, T. G. Wang, Purification of polymers used for fabrication of an immunoisolation barrier. Ann N Y Acad Sci 831, 223 (Dec 31, 1997)

33. E. Hill, T. Boontheekul, D. J. Mooney, Designing scaffolds to enhance transplanted myoblast survival and migration. Tissue Eng 12, 1295 (May, 2006).

34 R. J. Kok, A. J. Schraa, E. J. Bos, H. E. Moorlag, S. A. Asgeirsdottir, M. Everts, D. K. Meijer, G. Molema, Preparation and functional evaluation of RGD-modified proteins as alpha(v)beta(3) integrin directed therapeutics. Bioconjug Chem 13, 128 (Jan-Feb, 2002).

35. X. Wang, T. Zhao, W. Huang, T. Wang, J. Qian, M. Xu, E. G. Kranias, Y. Wang, G. C. Fan, Hsp20-engineered mesenchymal stem cells are resistant to oxidative stress via enhanced activation of Akt and increased secretion of growth factors. Stem cells 27, 3021 (Dec, 2009).

36. M. J. Post, N. Rahimi, V. Caolo, Update on vascularization in tissue engineering. Regenerative medicine 8, 759 (Nov, 2013).

37. M. W. Laschke, M. D. Menger, Prevascularization in tissue engineering: 
Chapter 3 - RGDfK-peptide modified alginate scaffold for cell transplantation.

Current concepts and future directions. Biotechnology advances 34, 112 (Mar-Apr, 2016).

38. M. Gnecchi, H. He, O. D. Liang, L. G. Melo, F. Morello, H. Mu, N. Noiseux, L. Zhang, R. E. Pratt, J. S. Ingwall, V. J. Dzau, Paracrine action accounts for marked protection of ischemic heart by Akt-modified mesenchymal stem cells. Nat Med 11, 367 (Apr, 2005).

39. J. M. Hare, J. E. Fishman, G. Gerstenblith, D. L. DiFede Velazquez, J. P. Zambrano, V. Y. Suncion, M. Tracy, E. Ghersin, P. V. Johnston, J. A. Brinker, E. Breton, J. Davis-Sproul, I. H. Schulman, J. Byrnes, A. M. Mendizabal, M. H Lowery, D. Rouy, P. Altman, C. Wong Po Foo, P. Ruiz, A. Amador, J. Da Silva, I. K. McNiece, A. W. Heldman, R. George, A. Lardo, Comparison of allogeneic vs autologous bone marrow-derived mesenchymal stem cells delivered by transendocardial injection in patients with ischemic cardiomyopathy: the POSEIDON randomized trial. Jama 308, 2369 (Dec 12, 2012).

40. C. Le Visage, O. Gournay, N. Benguirat, S. Hamidi, L. Chaussumier, N. Mougenot, J. A Flanders, R. Isnard, J. B. Michel, S. Hatem, D. Letourneur, F. Norol, Mesenchymal stem cell delivery into rat infarcted myocardium using a porous polysaccharide-based scaffold: a quantitative comparison with endocardial injection. Tissue Eng Part A 18, 35 (Jan, 2012).

41. J. D. Richardson, A. G. Bertaso, L. Frost, P. J. Psaltis, A. Carbone, B. Koschade, D. T. Wong, A. J. Nelson, S. Paton, K. Williams, S. Azarisman, M. I. Worthley, K. S. Teo, S. Gronthos, A. C. Zannettino, S. G. Worthley, Cardiac magnetic resonance, transthoracic and transoesophageal echocardiography: a comparison of in vivo assessment of ventricular function in rats. Laboratory animals 47, 291 (Oct, 2013).

42. B. Pouzet, J. T. Vilquin, A. A. Hagege, M. Scorsin, E. Messas, M. Fiszman, K. Schwartz, P. Menasche, Factors affecting functional outcome after autologous skeletal myoblast transplantation. The Annals of thoracic surgery 71, 844 (Mar, 2001).

43. F. E. Grubbs, Procedures for detecting outlying observations in samples. Technometrics 11, 1 (1969).

44. A. A. Rane, K. L. Christman, Biomaterials for the treatment of myocardial infarction: a 5-year update. J Am Coll Cardiol 58, 2615 (Dec 13, 2011). 


\section{Chapter 4}

\section{Islet grafting and imaging in a bioengineered intramuscular space.}

Transplantation. 2009 Nov 15; 88(9): 1065-1074.

Piotr Witkowski, Hugo P. Sondermeijer, Mark A. Hardy, David C. Woodland, Keagan Lee, Govind Bhagat, Kajetan Witkowski, Fiona See, Abbas Rana, Antonella Maffei, Silviu Itescu, and Paul E. Harris. 


\section{ABSTRACT}

Background: Since the hepatic portal system may not be the optimal site for islet transplantation, several extrahepatic sites have been studied. Here we examine an intramuscular transplantation site, bioengineered to better support islet neovascularization, engraftment, and survival, and demonstrate that at this novel site, grafted beta cell mass may be quantitated in a real time non-invasive manner by PET imaging. Methods: Streptozotocin induced rats were pretreated intramuscularly with a biocompatible angiogenic scaffold received syngeneic islet transplants 2 weeks later. The recipients were monitored serially by blood glucose and glucose tolerance measurements and by PET imaging of the transplant site with $\left[{ }^{11} \mathrm{C}\right]$-dihydrotetrabenazine. Parallel histopathologic evaluation of the grafts was done using insulin staining and evaluation of microvasularity. Results: Reversal of hyperglycemia by islet transplantation was most successful in recipients pretreated with bioscaffolds containing angiogenic factors as compared to those who received no bioscaffolds or bioscaffolds not treated with angiogenic factors. PET imaging with $\left[{ }^{11} \mathrm{C}\right]$-dihydrotetrabenazine, insulin staining and microvascular density patterns were consistent with islet survival, increased levels of angiogenesis, and with reversal of hyperglycemia. Conclusions: Induction of increased neovascularization at an intramuscular site significantly improves islet transplant engraftment and survival compared to controls. The use of a non hepatic transplant site may avoid intrahepatic complications and permit the use of PET imaging to measure and follow transplanted beta-cell mass in real time. These findings have important implications for effective islet implantation outside of the liver, and offer promising possibilities for improving islet survival, monitoring, and even prevention of islet loss. Keywords: Islet transplantation, Imaging, Bioengineering.

\section{INTRODUCTION}

Although the application of steroid-free immunosuppression protocols and improvements in islet isolation and dosing, developed by the Edmonton group resulted in a great resurgence of optimism for clinical islet transplantation (1), the long term clinical outcomes have been disappointing since insulin independence at one year of $100 \%$ fell to less than $10 \%$ at five years (2).

The current standard for clinical islet transplant is intraportal infusion of purified islets from one to three donor pancreata (3). Multiple sites for transplantation have been explored, including the kidney capsule, splenic capsule, omentum, testes, and peritoneal cavity, but the intraportal site remains most popular as it presents the least invasive alternative and produces normoglycemia with the fewest number of transplanted islets $(4,5)$. Problems with the intraportal site, however, indicate that it is far from optimal. Intraportal islets are subject to substantially higher concentrations of toxic immunosuppressants $(6,7)$, activation of complement and coagulation cascades the so-called instant blood-mediated inflammatory reaction (IBMIR) (8), and exposure to inflammatory mediators released during activation of alloimmune rejection pathways (9). These problems complicate the already inefficient islet engraftment process (10) and suggest that new more efficient sites and methods for islet allografting are needed.

In this report we tested intramuscular islet implantation using a highly purified biocompatible alginate scaffold to form a microenvironment conducive to islet survival. Besides offering malleability and freedom from many of the conditions that imperil intraportal islets, the intramuscular site offers other advantages. First, the intraportal embolization procedure itself carries significant risk of perihepatic hematoma, portal branch thrombosis and hemorrhage $(2,11)$. Comparatively, an intramuscular implantation would be less invasive. Second, once infused, intraportal islets are accessible only by systemic therapy. In contrast, local interventions could potentially be made in the clinic at an intramuscular site.

Finally, monitoring islet grafts after infusion remains a problem. Metabolic tests only detect graft dysfunction when substantial islet mass has already been lost, after which graft-saving intervention is no longer possible. Attempts to develop other markers for early detection of rejection have been unsuccessful (12). Intramuscular implantation offers the opportunity to biopsy allografts or, alternatively, allow use of a beta cell imaging technique which relies on PET detection of a $\left[{ }^{11} \mathrm{C}\right]$-dihydrotetrabenazine (DTBZ) radioligand bound to vesicular monoamine transporter type 2 (VMAT2), a biomarker of beta cell mass $(\mathrm{BCM})(13,14)$. This technique shows promise for in situ islet imaging in man (15) but has never been tested in an extrapancreatic site. Therefore we tested the feasibility of this approach in our model of intramuscular islet transplantation. 
Chapter 4 - Islet grafting and imaging in a bioengineered intramuscular space.

\begin{tabular}{|c|c|c|c|c|}
\hline Group & Group & Day -14 & Day -4 & Day 0 \\
\hline 1 & $\begin{array}{c}\mathrm{Gel}^{\mathrm{a}}+\mathrm{VEGF} / \\
\mathrm{PDGF}\end{array}$ & $\begin{array}{l}\text { Implantation of bioscaffold containing } \\
\text { RGD peptide, VEGF and PDGF }\end{array}$ & STZ & Islet transplant \\
\hline 2 & Gel & $\begin{array}{c}\text { Bioscaffold containing RGD peptide, no } \\
\text { VEGF, no PDGF }\end{array}$ & STZ & Islet transplant \\
\hline 3 & Sham & $\begin{array}{c}\text { Intramuscular space opened and closed } \\
\text { surgically without any scaffold } \\
\text { implantation }\end{array}$ & STZ & Islet transplant \\
\hline 4 & No surgery & $\begin{array}{l}\text { No pretreatment surgery was } \\
\text { performed }\end{array}$ & STZ & Islet transplant \\
\hline 5 & No islets & $\begin{array}{c}\text { No pretreatment surgery was } \\
\text { performed and no islets were } \\
\text { transplanted }\end{array}$ & STZ & No islet transplant \\
\hline
\end{tabular}

Table 1. Experimental grouping as per pretransplantation procedures. ${ }^{a}$ Gel: alginate scaffold with cyclic arginine-glycine-aspartic acid RGD peptide; RGD: repeated arginine-glycine-aspartic acid peptide motif; Tx: transplant; VEGF: vascular endothelial-derived growth factor; PDGF: platelet-derived growth factor; STZ: streptozotocin.

\section{MATERIALS AND METHODS}

\subsection{ANIMALS AND STUDY DESIGN}

All animal studies were reviewed and approved by the Columbia University Institutional Animal Care and Use Committee. Male Lewis rats were obtained from Harlan Sprague Dawley, Inc (Indianapolis, Indiana) weighing between $200 \mathrm{~g}$ and $250 \mathrm{~g}$ and served as islet donors and transplant recipients in this study. Briefly, rats were divided into 5 groups of 12 rats each depending on the treatment they would receive (Table 1). Two weeks prior to scheduled transplantation (transplant day -14), groups one and two underwent surgery for implantation of scaffolds and group three underwent a sham operation. Four days prior to transplantation (day -4), all animals were rendered chemically diabetic with streptozotocin (STZ, Sigma Aldrich, St. Louis, Missouri) at a dose of $50 \mathrm{mg} / \mathrm{kg}$ via the penile vein under isoflurane anaesthesia. Animals were considered diabetic if blood glucose values were greater than $300 \mathrm{mg} / \mathrm{dL}$ for three consecutive days. Finally, on day 0, animals were transplanted with syngeneic islets unto the submuscular scaffold.

The principle outcome measure used in these studies was the four-hour fasting blood glucose levels. These measurements were performed throughout the post transplant period day +5 to day +60 . Islet implantation success was defined as reversal of diabetes with fasting glucose $<110 \mathrm{mg} / \mathrm{dL}$ on day +5 through +60 . Islet implantation success rate was defined as the percentage of animals in each group who could maintain a fasting blood glucose $<110 \mathrm{mg} / \mathrm{dL}$ throughout the post transplantation period. Statistical significance of the differences in blood glucose levels among the different treatment groups was determined by a repeated measure ANOVA with Tukey's HSD posthoc testing using the blood glucose measurements obtained during the two month post transplant window.

\subsection{SCAFFOLD PREPARATION AND IMPLANTATION}

Three-dimensional scaffolds were prepared from purified low molecular weight alginate (Sigma, 0682, St. Louis, Mo). High M Alginate was purified using a modified protocol based on charcoal extraction, serial filtration, dialysis, and alcohol precipitation (16). Subsequently, alginate was modified with $2 \mathrm{mg}$ cyclic RGDfK peptide per gram alginate using sulfo-NHS and EDC cross-linker according to a modified protocol (17). Cyclic RGDfK ( $\mathrm{f}=\mathrm{D}$-phenylalanine $)$ is a synthetic, protease resistant, $\alpha_{v} b_{3}$ and $\alpha_{5} B_{1}$ integrin selective peptide (18). Resulting cRGDfK-alginate was re-dissolved at $2 \%$ in sterile distilled water. To generate scaffolds, $400 \mu \mathrm{l}$ cRGDfK-alginate was loaded in a $4.2 \mathrm{~cm}^{2}$ cell culture insert $(0.4 \mu \mathrm{m}$ pores, pore density of $1.6 \times 10^{6} / \mathrm{cm}$, polyethylene terephthalate membrane) (BD number 353090, BD Falcon, BD Biosciences, New Jersey, USA). Loaded inserts were placed in 6well tissue culture plates and $3 \mathrm{ml}$ of $4.3 \%$ calcium gluconate was added to each bottom well. Plates were placed at $4^{\circ}$ Celsius for 24 hours to solidify cRGDfK-alginate by diffusion of calcium ions through the insert membrane. Following solidification, scaffolds were washed 3 times in $3 \mathrm{ml}$ sterile distilled water to remove excess calcium gluconate and kept moist in sterile distilled water until implantation.

Growth factor enriched scaffolds were prepared following the same protocol, with the addition of $100 \mathrm{ng} / \mathrm{ml}$ recombinant human VEGF165 (PHG0145, Invitrogen, Carlsbad, USA) and 100 ng/ml recombinant human PDGF-BB (P3201, Sigma Aldrich, St Louis, USA) to cRGDfK alginate, calcium gluconate and sterile distilled water solutions.

On day -14 , animals in groups 1,2 , and 3 were given isoflurane gas anesthesia and after opening the skin the muscle was dissected to the peritoneum. A newly created pocket accommodated a $10 \mathrm{~mm}$ scaffold. Scaffold was then implanted in 
animals in groups one and two before closing the pocket and skin in separate layers. Animals in group three (sham) were closed without scaffold implantation.

\subsection{ISLET ISOLATION}

On transplant day 0, fresh islets were isolated from Lewis donor rats using collagenase digestion and Ficoll separation, as previously described (19).

\subsection{ISLET YIELD AND VIABILITY}

Islet yield was quantified by hand counting of a dithizone-stained islet isolate (19). Islet viability was assessed with double staining with SYTO 13/Ethidium bromide (EB) as previously described (20).

\subsection{INSULIN STIMULATION INDEX}

Retrospectively, islet quality was confirmed with insulin stimulation index as previously described by Eizirik et al (21). Briefly, 200 isolated, hand-picked islets were washed twice with low-glucose $(1.7 \mathrm{mM})$ media (no glucose added RPMI 1640 w/o phenol red, supplemented with $0.1 \%$ BSA and glucose). From those, 5 groups of 20 islets measuring 100 to $150 \mu \mathrm{M}$ in diameter were placed in separate $6 \mathrm{ml}$ polypropylene tubes. Next, islets were sequentially pre-incubated with low-glucose media $(1.67 \mathrm{mM})$, incubated with low-glucose media, and incubated with high-glucose media $(16.7 \mathrm{mM})$. After each incubation $(1 \mathrm{hr})$, the media was removed from the islets and frozen for ELISA analysis.

\subsection{ISLET IMPLANTATION}

After isolation, approximately 2400 islets were resuspended from the final centrifugation pellets into volumes of approximately $0.4-0.5 \mathrm{~mL}$ of HBSS. High islet quality was confirmed before each injection by measurement of viability (>90\%) and retrospectively by examination of insulin stimulation indices (all greater than 4). After anaesthesia with isofluorane, the midline skin of study animals was dissected away from the abdominal musculature and in animals in groups 1 and 2, scaffolds were identified by sight and palpation. Islets with approximate purity of $90 \%$ were injected onto scaffolds in an intramuscular wheal via an 18-gauge needle. Animals from groups 3 and 4, which had not been pre-implanted with scaffolds, had islets injected intramuscularly in a similar fashion. Group 5, as a control, received no islets.

\subsection{GRAFT MONITORING: METABOLIC FUNCTION AND HISTOLOGIC EXAMINATION}

Transplanted animals were weighed biweekly and were monitored with daily blood glucose measurements (four-hour fasting) over the first two weeks after transplantation followed by bi-weekly measurements thereafter. Six out of twelve animals from each treatment group were sacrificed on transplant day 0 for histopathologic examinations of the scaffolds and neovascularization. Sections were obtained through the scaffold for animals in groups 1 and 2 and through muscle for animals in groups 3 , 4 and 5. Paraffin tissue sections were stained with Gill's hematoxilin/eosin (H\&E) and factor VIII related antigen (A0082, Dako, USA) 1 in 200 using the Vectastain ABC kit (Vector Laboratories, USA) according to the manufacturer's instructions in order to examine vascularity of the tissue. Vessels within five separate high-power fields at $400 \times$ magnification were counted.

\subsection{INSULIN STAINING}

From the remaining six animals in each group, tissue samples were obtained in a similar fashion at two months after transplantation. Those samples were additionally stained for insulin (I2018, Dako, USA) 1 in 1000 using the ABC kit to demonstrate the presence of islets.

\subsection{IPGTT}

Intraperitoneal glucose tolerance testing (IPGTT) was conducted on study rats two months after transplantation and prior to removal of the scaffolds after which fasting blood glusoce levels were repeated. Glucose boluses of $1 \mathrm{~g}$ glucose $/ \mathrm{kg}$ body weight were administered to unanesthetized animals, and blood glucose was measured at 0, 30, 60,90 , and 120 minutes after injection. Area under the curve (AUC) for glucose excursion was calculated by the trapezoidal rule for comparisons of the extent of diabetes.

\subsection{BETA CELL IMAGING}

For BCM imaging of islet transplants, stereochemically resolved (+)-9-O-desmethyl-adihydrotetrabenazine precursor of $\left[{ }^{11} \mathrm{C}\right] \mathrm{DTBZ}$ was obtained from MonomerChem Laboratories (RTP, NC). (+)- $\alpha-\left[{ }^{11} \mathrm{C}\right]-D T B Z$ was synthesized by $\left[{ }^{11} \mathrm{C}\right]$ methylation of the appropriate precursor and the product purified by HPLC (22). The purity of $\left[{ }^{11} \mathrm{C}\right]-$ DTBZ preparations varied from 98.5 to $99.9 \%$ of the desired (+) product. Specific activities of carbon-11 labeled radiotracers were $>2000 \mathrm{mCi} / \mu \mathrm{mol}$ at time of injection.

Prior to gel implantation and STZ treatment, two control rodents were imaged using a Concorde microPET-R4 (Siemens, CTI Molecular Imaging, Knoxville, TN, USA). Four additional rodents were imaged 2-4 weeks after STZ treatment followed with islets transplant, two of them pretreated with VEGF/PDGF-BB scaffold implantation and remaining two pretreated with a sham operation. PET scanning and image reconstruction was performed as previously described (23). Region of interest analysis was performed with PMOD software (Zurich, Switzerland). Regions of interest were placed using coronal, transverse, and sagittal reconstructions. Reconstructed PET images were used to identify and measure the time course of radioligand activity within each region of interest.

The concentration of VMAT2, as biomarker of $\mathrm{BCM}$, in the region of interest was estimated by calculation of a distribution volume ratio (DVR) 
using the Logan reference region method (24) and PMOD software. In previous studies we identified the kidney cortex as an appropriate VMAT2 free reference regions to which ligand uptake in the pancreas could be compared $(14,23,25)$. For islet transplants to the intramuscular space, we found that the kidney cortex overestimated non specific binding in the muscle and substituted a ROI contralateral to the islet transplant within the abdominal muscle wall.

\section{RESULTS}

\subsection{RESTORATION OF NORMOGLYCEMIA AND ISLET IMPLANTATION SUCCESS}

The goal of islet transplantation is not only the survival of islets in a new environment but also resumption of function and restoration of normoglycemia in otherwise hyperglycemic and diabetic animals. Measurements of fasting blood glucose levels were performed throughout the post transplant period and are presented in Figure 1A. The islet implantation success was defined as fasting glucose $<110 \mathrm{mg} / \mathrm{dL}$ on day +5 through +60 post implantation. Islet implantation success rate was defined as the percentage of animals in each group with fasting blood glucose $<110 \mathrm{mg} / \mathrm{dL}(\mathrm{N}=6)$ (Figure 1B). That correction of hyperglycemia was associated with islet transplantation was confirmed by the observation that when the scaffolds were removed on day 60 , all animals reverted to hyperglycemia. As all recipients received syngeneic grafts, not allografts, there was some improvement in hyperglycemia in animals that received the syngeneic grafts without a scaffold or a nonmodulated scaffold, but not in sham operated or untransplanted controls. Successful reversal was achieved in all animals (6/6) transplanted with islets into the fully enriched scaffold (group 1: gel + VEGF/PDGF) but in partial reversal in only $50 \%$ (3/6) of animals with the same scaffold but without VEGF or PDGF (Gel alone, group 2); and partial reversal in only $33 \%(2 / 6)$ of animals that received syngeneic islet grafts without surgical pretreatment (group 4). All control animals (sham operated group 3; or not transplanted - group 5) remained fully hyperglycemic $(\mathrm{p}<0.05)$ as expected.

As a more sensitive metric of restoration of islet mass and function, we measured the glucose excursions following glucose challenge by IPGTT (Figure 2A). Calculation of area under the curve (AUC) of blood glucose excursion showed that the AUC was significantly lower for the gel+VEGF/PDGF group than for the other groups $(2-4$ fold) (Figure 2B). Animals in the gel+VEGF/PDGF group also gained weight significantly better than animals in the other groups. This confirms that islet function and overall anabolic control were better in Group 1 animals $(\mathrm{p}<0.05)$ (Figure 3C).

\subsection{DEVELOPMENT OF FIBROVASCULAR TISSUE AND ROBUST VASCULATURE AT THE IMPLANTATION "BED"}

We hypothesized that success of islet engraftment and their functional capacity depends on proper neovascularization at the time of implantation and afterwards. Therefore, we evaluated the development of the vascular bed in the transplant site just before islet implantation. Scaffolds were surgically removed and evaluated for vessel development 2 weeks after their implantation, just before islet transplantation would have occurred. Figure 3, Top and Middle rows, shows hemotoxylin and eosin stained tissue containing fibrovascular tissue penetrating scaffolds placed between muscular layers. Preserved tissue was then stained for factor VIII related antigen, which is specific for endothelial cells and identifies blood vessels (Figure 4A). The number of capillaries stained with factor VIII related antigen per high power field was significantly higher in the gel+VEGF/PDGF group compared to the other groups by $2-5$ fold, $\mathrm{p}<0.05$ (Figure 4B). These histopathologic results, along with functional success, confirm the significance of neovascularization within the implantation "bed."

\subsection{CONFIRMATION OF THE PRESENCE AND FUNCTION OF ISLETS 2 MONTHS AFTER IMPLANTATION}

To confirm the role of the grafted islets in glucose control, on day 60 after transplantation, all tissue and scaffolds were removed and the normoglycemic animals promptly became hyperglycemic and diabetic. When the tissue was stained for insulin (Figure 3, bottom row) cells staining positively for insulin are seen within the scaffold, especially in proximity to vessels at the scaffold-muscle interface which suggests preferential islet engraftment in proximity to the blood vessels. We did not evaluate the direct neovascularization of the beta cells in this study.

\subsection{VISUALIZATION OF THE IMPLANTED ISLETS BY PET}

Since vesicular monoamine transporter type 2 (VMAT2) has been proposed as a biomarker for beta cells as it is highly expressed relative to other cells in the pancreas (13) we used PET imaging to quantitate VMAT2 at islet transplant site. This method, effective for imaging rodent beta cells in situ (14), cannot be applied to islets infused into the liver because liver and bile are routes of DTBZ excretion and have a high background signal (Figure 5).

Following intramuscular islet transplantation, PET scans with $\left[{ }^{11} \mathrm{C}\right]-\mathrm{DTBZ}$ demonstrated that the transplanted and viable beta cell mass can be visualized and quantified. Successful transplantation, defined by restoration of normoglycemia, was visualized in rodents in the gel+VEGF/PDGF group (Figure 5- A2, B2, C2). As a measure of VMAT2 density in tissue and by inference, beta cell mass, we calculated a distribution volume ratio (DVR), which is a linear function of VMAT2 target availability. The DVR presented in Panel D, was higher for the rodent from gel+VEGF/PDGF group (D2) in the islet 


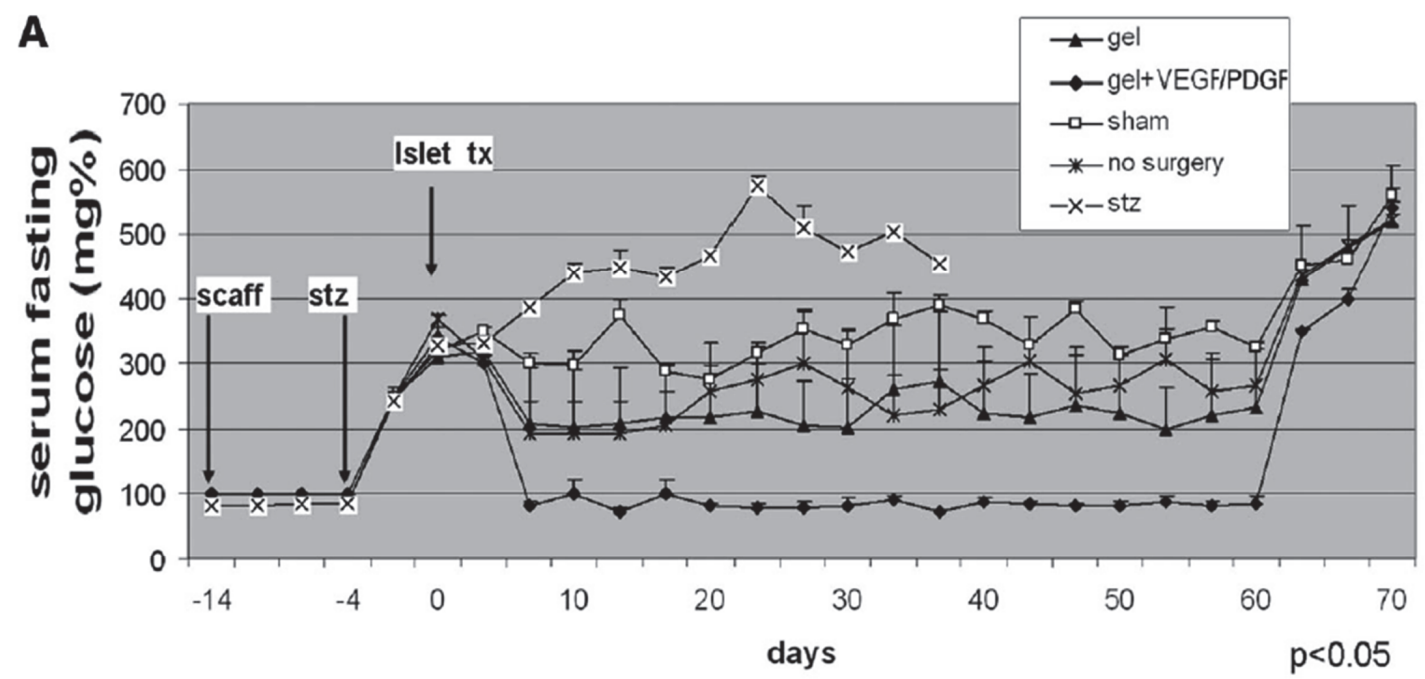

B

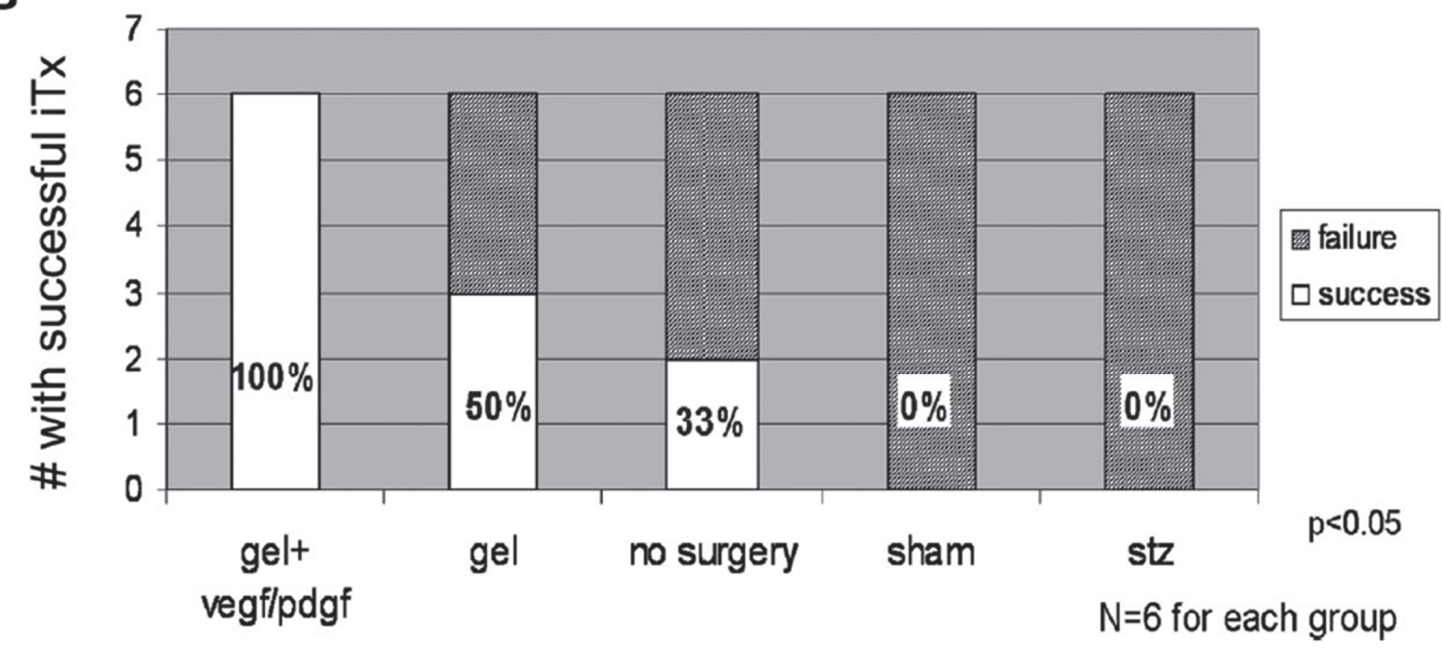

Figure 1. Blood Glucose Levels in Transplanted Rodents. (A) Figure presents mean fasting serum glucose level in animals within the 60 days follow-up. Mean fasting glucose level oscillates below $110 \mathrm{mg} / \mathrm{dL}$ for animals from group 1 (gel + VEGF/PDGF), whereas in other groups it was statistically higher, ANOVA, $\mathrm{p}<0.05$. As an additional control, removal of the scaffolds in normoglycemic animals from the gel + VEGF/PDGF group on day +60 led to prompt return of diabetes and hyperglycemia. Error bars represent S.E.M. (B) Islet grafting success rate. Number of animals out of six total achieving euglycemia following syngeneic islet transplantation is shown on the Y axis. Euglycemia was defined as four-hour fasting glucose $<110 \mathrm{mg} / \mathrm{dL}$ on post-transplant days +5 through +60 . The statistical significance of the differences in grafting success rate among the different treatment groups is shown and was determined by ANOVA using the blood glucose measurements obtained in the 55 day post-transplant window.

transplant site in comparison to the control shown in D1. In contrast, transplanted islets in the animals in the sham group, which remained hyperglycemic due to unsuccessful transplant, were not visible on any intramuscular plane (Figure 5A3) while the DVR (D3) in the region of interest, was much lower than for viable islets (D2), and as low as the corresponding region in controls without islets (D1).

Imaging results were correlated to the islets' ability to maintain normoglycemia (Figure 5 A2 vs A3). The native pancreas in animals treated with STZ had lower tracer binding, as revealed by the time-activity curves and calculation of the distribution volume ratios relative to the control animal prior to treatment with STZ (Figure 5- C2 and $\mathrm{C} 3$ versus control $\mathrm{C} 1$ and $\mathrm{D} 2$ and $\mathrm{D} 3$ versus control D1). These measurements additionally suggest that reversal of hyperglycemia was not due to residual beta cell mass in the native pancreas of the rodent with islet transplanted into the scaffold and confirm STZ induced impairment of native pancreas in animals with a functional islet transplant which is critical in maintenance of normoglycemia. 


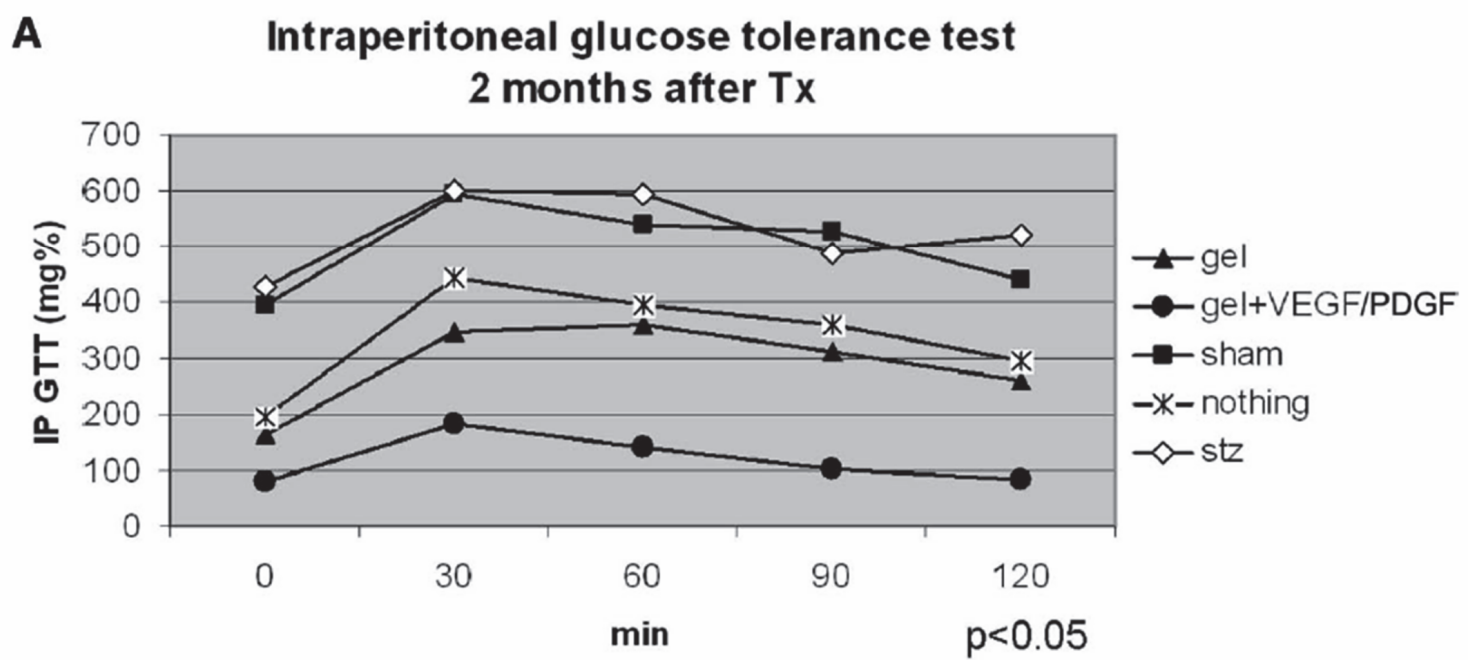

\section{B Intraperitoneal glucose tolerance test}

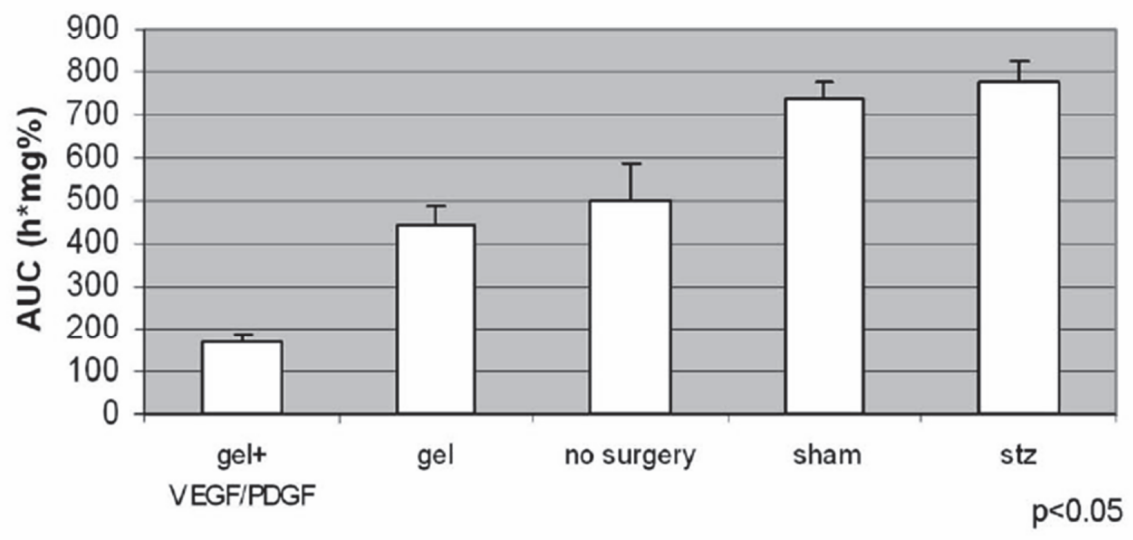

C Body weight after islet Tx

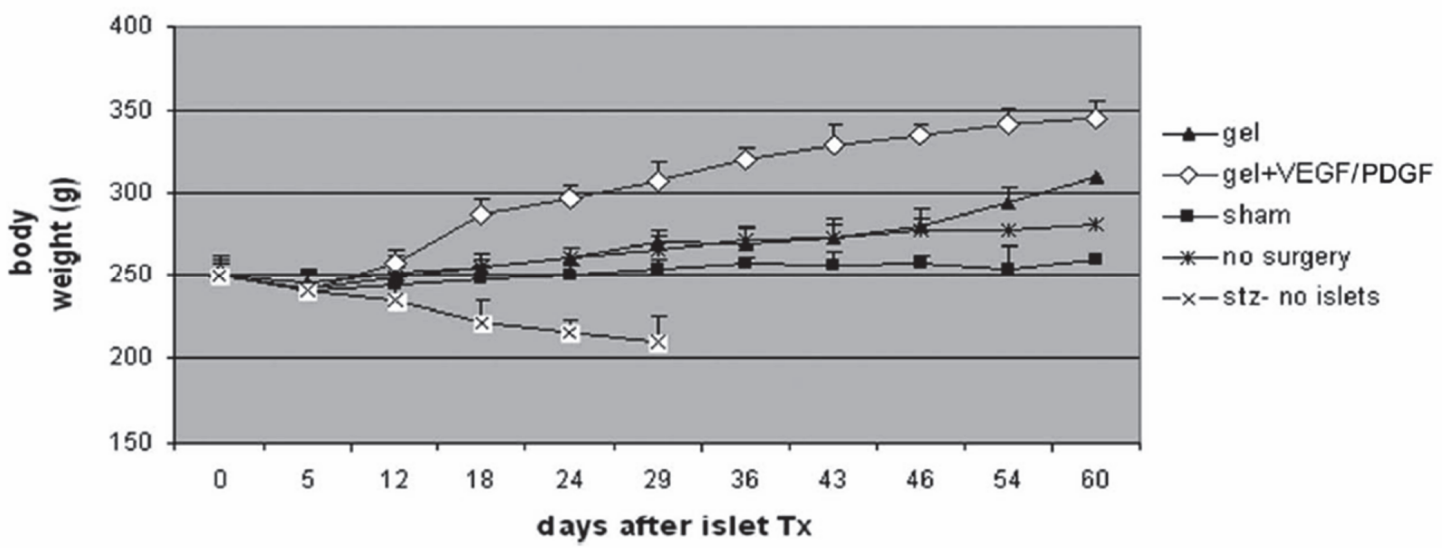

Figure 2. Restoration of glucose metabolism following islet transplantation; IPGTT testing and weight measurements. Panels A and B, Animals with islets transplanted into scaffolds containing vascular growth factors (Gel+VEGF/PDGF) had a smaller glucose excursion in GIPTT than animals in other four groups. Area under the curve was 2-4 times smaller than in other groups (ANOVA, $p<0.05$ ). The areas under the curve were determined using the trapezoid rule. Panel C, Body weight after Islet Tx. Rodents in the Gel+VEGF/PDGF group gained significantly more weight $(\mathrm{p}<0.01)$ than other groups as determined by repeated measure ANOVA and Tukey's post-hoc analysis. 

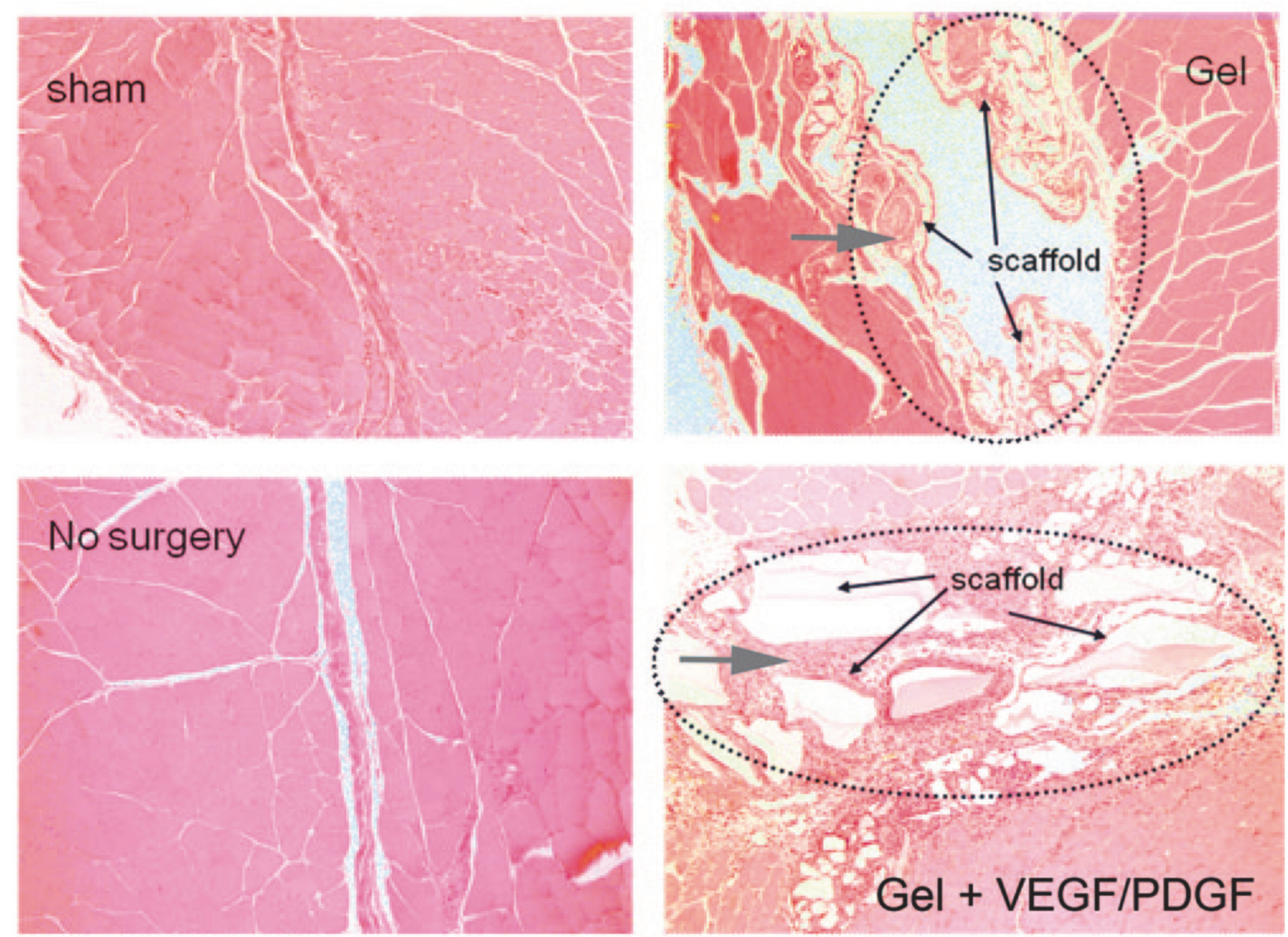

\section{ANTI INSULIN}
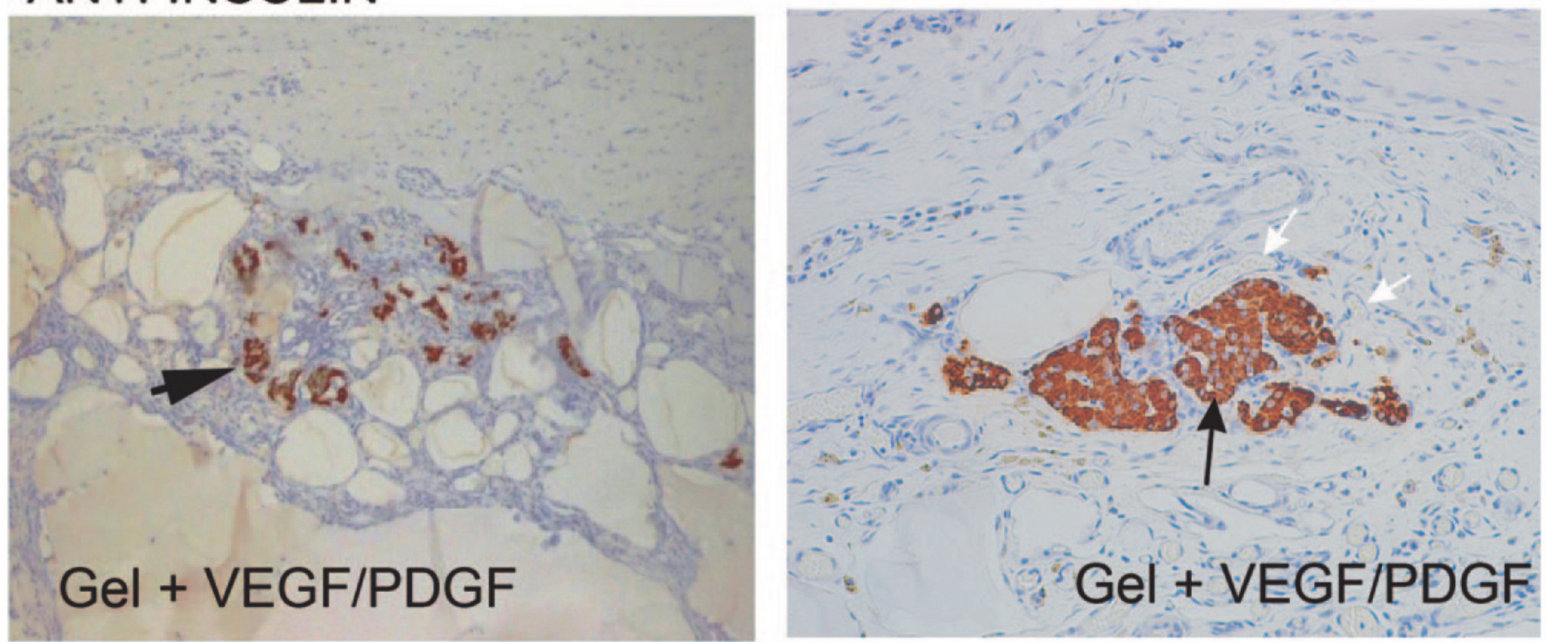

Figure 3. Histology of the tissue containing the scaffold on day 0, just before islet transplant. Top and middle row. The development of the vascular bed in the transplant site was evaluated microscopically just before islet implantation in our experimental animals. Scaffolds were surgically removed and tissues removed for preparation of paraffin sections. Hemotoxylin and eosin stained tissue containing fibrovascular tissue penetrating scaffolds placed between muscular layers (Figures labelled Gel and Gel+VEGF/PDGF) is shown with the grey arrows. Normal muscular tissue anatomy was seen in Figures labeled "No surgery" and "Sham" slides. Magnification 400×. Bottom row. Sections of the rectus muscle with the scaffold containing RGD peptide, VEGF and PDGF 60 days after islet transplantation was examined by H\&E and insulin staining. Islets staining positive for insulin (shown by black arrows) were found within the scaffolds containing VEGF and PDGF in animals which reverted from hyperglycemia after islet transplantation providing another proof for successful islets implantation and function. The majority of the islet were found in the proximity of the border between muscle and the VEGF/PDGF, the same location were rich vascularization was found (Figure 4). 


\section{A Staining for capillaries w/ factor VIII related antigen}
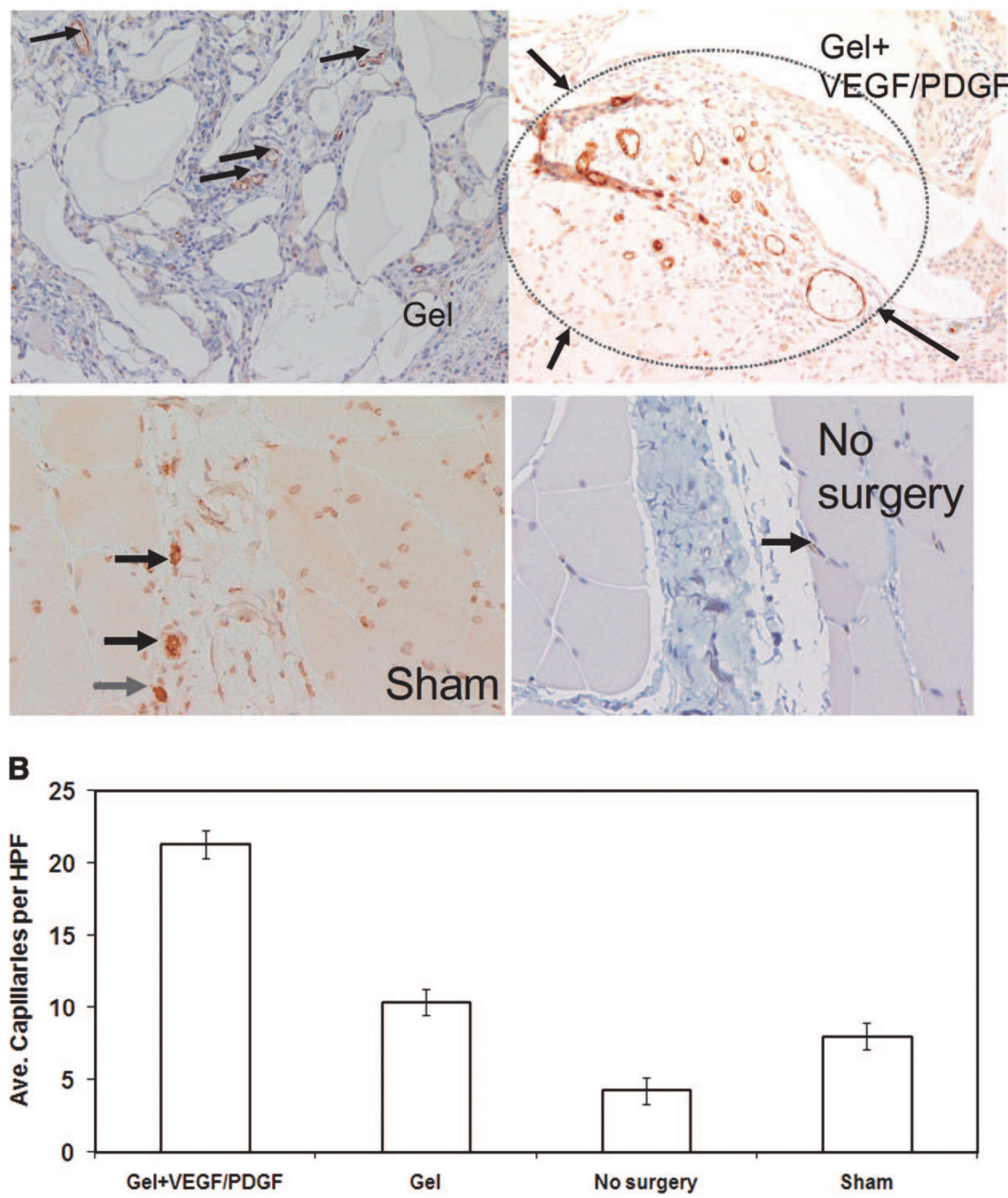

Figure 4. Evaluation of the vascularization within the tissue based on histology and staining for factor VIII related antigen. Panel A. Tissue containing scaffold was surgically removed 2 weeks after the implantation just before islet injection. In order to identify endothelium in blood vessels histological were stained for factor VIII related antigen. Panel B. The average number of capillaries stained positively was quantified per high power field (magnification 400×) and was significantly (2-5 fold) higher in the gel+VEGF/PDGF group compared to the other groups as determined by a repeated measure ANOVA and Tukey's post-hoc analysis $(p<0.01)$. The error bars represent the standard error of the mean. 

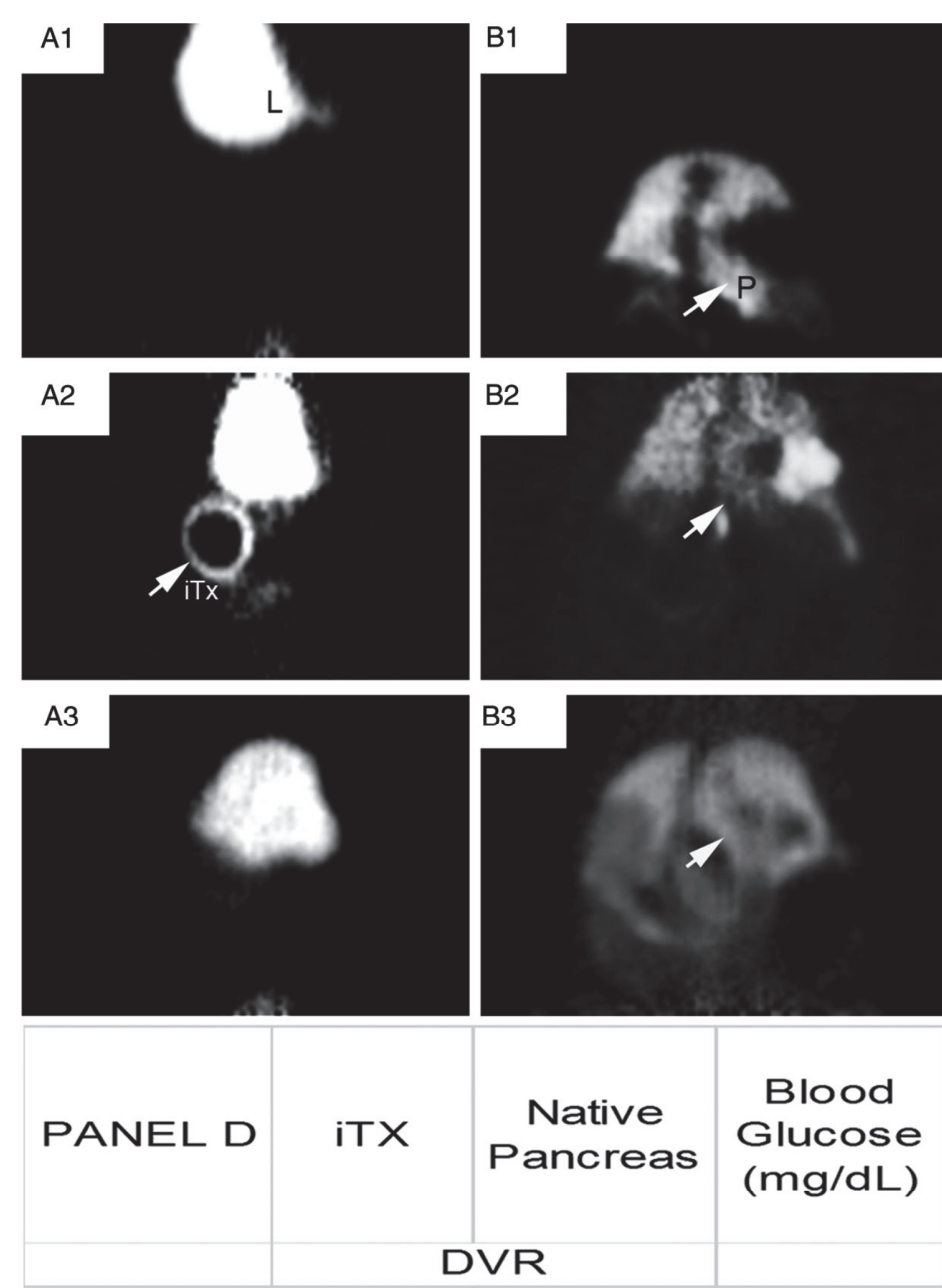

\begin{tabular}{|l|l|l|l|}
\hline $\mathrm{D} 1$ & 1.00 & 3.10 & 109 \\
\hline $\mathrm{D} 2$ & 2.91 & 1.27 & 108 \\
\hline $\mathrm{D} 3$ & 1.00 & 1.53 & 308 \\
\hline
\end{tabular}

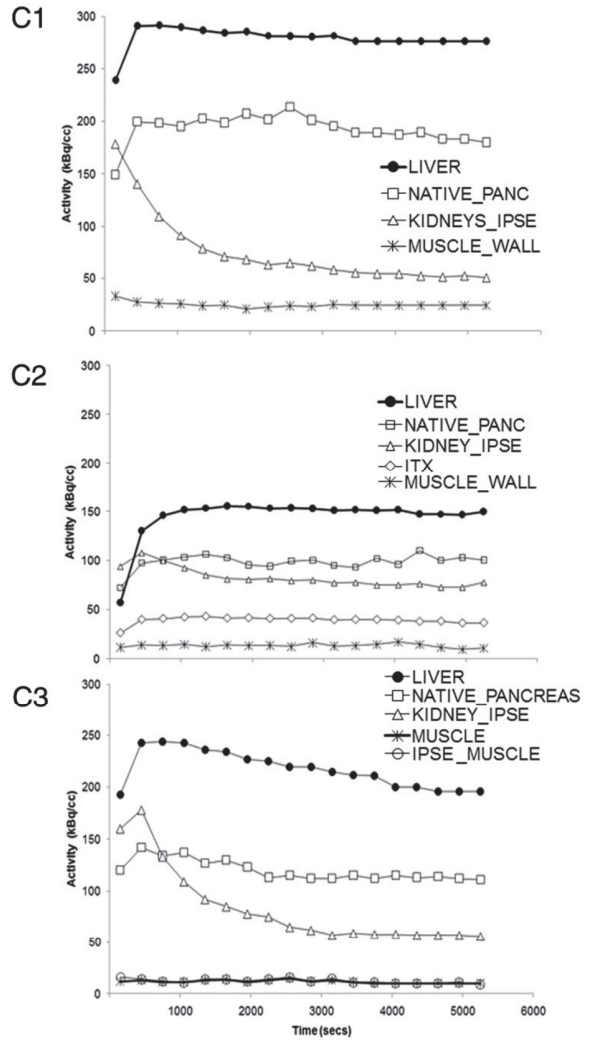

Blood Glucose $(\mathrm{mg} / \mathrm{dL})$

Figure 5. Imaging of native pancreas and islet transplants with $\left[{ }^{11} \mathrm{C}\right]-\mathrm{DTBZ}$. Rodents were imaged prior to or following islet transplantation to the intramuscular space. Dynamic PET data obtained from each scan was reconstructed and representative abdominal coronal plane images from transplanted animals are shown. Display ranges of images are not equivalent. A Panels are abdominal images from: (A1)- control rodent from group 5, prior to STZ treatment, no islet tx; (A2)- rodent from group 1 STZ pretreated, with implanted scaffold containing VEGF and PDGFa, and islet isograft; (A3)- rodent from sham group (3) treated with STZ and an islet isograft. A plane of liver, an organ of $\left[{ }^{11} \mathrm{C}\right]-\mathrm{DTBZ}$ catabolism, is shown with the letter "L" on $\mathrm{A} 1$, and the islet tissue isograft, distributed around the gel insert is visualized by PET scans with $\left[{ }^{11} \mathrm{C}\right]-\mathrm{DTBZ}$ and marked by a white arrow labeled with the letters "iTx" on A2. B Panels are more dorsal abdominal coronal planes showing the native pancreas, indicated by a white arrow or the letter "P" (B1), from the same series of rodents shown in A Panels: (B1) animal from Group 5, prior to STZ treatment; (B2) animal from Gel+VEGF/PDGF group (Group 1); (B3) rodent after islet transplant from sham group (Group 3). C Panels show the time activity curves of $\left[{ }^{11} \mathrm{C}\right]-D T B Z$ uptake in Liver, Kidney (the native pancreas reference region), native pancreas, islet transplant (iTx) and muscle wall and ipsilateral (to pancreas) muscle wall (iTx reference regions)from the same series of animal that in Panel A and B: (C1)group 5, (C2)- group 1, (C3)- group 3 animals. D Panel shows quantitation of VMAT2 density in the islet tissue transplanted to intramuscular space of the abdominal wall (iTx) as well as that measured in the native pancreas for the rodents imaged in Panels A, B, and C. Measurements are expressed as distribution volume ratios (DVR). Blood glucose concentrations on the day of imaging are shown in the last column. 


\section{DISCUSSION}

Our use of synthetic scaffolds and an intramuscular islet transplantation site is not without precedent. Weber et al (26) and Axen et al (27) validated the potential use of the intramuscular site over twentyfive years ago. Subsequent studies, however, showed poor function attributable to inadequate vascularization as well as dispersal of the intramuscular grafts $(28,29)$. To address these problems, we impregnated scaffolds with growth and anti-anoikosis factors. Specifically, we used vascular endothelial-derived growth factor (VEGF) and platelet-derived growth factor (PDGF) in combination to promote ingrowth of functionally sound vessels (30). In addition to these, we covalently modified alginate with cyclic extracellular matrix signaling molecule modeled after the repeated arginine-glycine-aspartic acid peptide motif (RGD) recognized in fibronectin molecules (cyclic-RGD). This peptide has been shown to enhance cellular adhesion and prevent transmembrane apoptotic signaling via integrins (31-33).

Synthetic scaffolds have been successfully used as transplanted-cell carriers that maintain cell viability and function (34). When scaffolds are prepared from highly purified polysaccharides like alginate, they are endotoxin, pathogen and mitogen free allowing for long-term cell survival in the absence of acute or chronic foreign body reactions (FBR). Alginate capsules have been widely used as inert material for encapsulated islet protection from inflammatory and immunological response of the body after implantation $(35,36)$.

The alginate used for the preparation of three dimensional scaffolds in the current study consists of cRGDfK-modified poly-mannuronic acid chains cross-linked with $\mathrm{Ca}^{2+}$ for solidification. Polymannuronic acid was used due to its favorable physical properties such as low viscosity and high biocompatibility after sufficient purification (35). Physical stability of cross-linked alginate, such as that used in capsules or scaffolds, depends on many different factors such as mannuronic acid and guluronic ratio, cation used for cross-linking (i.e. $\mathrm{Ca}^{2+}, \mathrm{Ba}^{2+}$ ), local $\mathrm{pH}$, presence of a protective polyL-lysine layer and local concentration of cation chelators (37). Thus, alginate capsules, stabilized with poly-L-lysine, can be stable in vivo for periods longer than 1 year after intraperitoneal implantation (38).

In contrast, we observed degradation of the scaffold over the follow-up period. We believe that $\mathrm{Ca}^{2+}$ leeches out of the scaffold or is actively absorbed by invading vasculature, leading to changes in three dimensional structures. Stability of cross-linked alginate can be altered by modifying aforementioned factors. In the current system, degradability is a desired property that promotes further in growth of blood vessels creating the fibrovascular tissue "bed" for transplanted islets which permits improved supply of oxygen and nutrients compared to unmodified muscle. Scaffold degradation could also be due to the use of cRGDfK- modified alginate in combination with vascular growth factors. After implantation of the modified scaffold, fibrovascular tissue is stimulated by locally released vascular growth factors which penetrate the space within the scaffold leading to neovascularization. Although we did not measure the persistence of the slowly released angiogenic factors in this study, it is probable that their persistence is not necessary, once they trigger the use of local host growth factors in the area. This process is additionally enhanced by the presence of the cRGDfK peptide supporting adherence and migration of endothelial cells. Increase in neovascularization may additionally enhance $\mathrm{Ca}^{2+}$ resorption and scaffold disintegration which permits further penetration by new endothelial cells (Figure 3). Islets infused into such milieu may be offered more optimal conditions for engraftment. Although we did not identify directly neovascularization of the transplanted islets, after 2 months we found islets lodged in proximity of the vessels and predominantly at the border of the scaffold, surrounding muscular tissue where the concentration of the vessels was the highest.

The selection of anti-anoikis peptides and growth factors in our scaffolds was based on a group of findings from the cell therapy and transplantation literature. Growth factors such as basic fibroblast growth factor (bFGF), VEGF and platelet derived growth factor (PDGF), when gradually released from synthetic scaffolds, synergistically enhance neovascularization of the transplant site thereby improving engraftment of the cells (39-42). This approach has been effective in vivo for transplants of hepatocytes, myocytes, and stem cells within subcutaneous and intramuscular sites $(42-44)$

Other groups have successfully utilized similar approaches in induction of angiogenesis (29, $35)$. Inoue et al $(45,46)$ and Weir et al $(47)$ used bFGF and VEGF respectively to improve neovascularization for use with devices. In our system, VEGF 165 and PDGF-BB were integrated with cRGDfK-modified alginate via electrostatic interaction during the solidification phase. In our experiments we used the initial concentration of vascular growth factors (both $100 \mathrm{ng} / \mathrm{ml}$ ) based on physiologically active concentrations (1-10ng/ml) and the gradual release gradient. These growth factors not only stimulate development of new vessels but also augment the islets' own vasculature $(35,42)$.

It has been shown in vitro that extracellular signaling with arginine-glycineaspartic acid (RGD) peptides efficiently prevents apoptosis of islets after isolation from the pancreas (48). Scaffolds synthesized with RGD peptide also provide extracellular signaling necessary for proper angiogenesis (39). Linear GRGDSP peptides are less stable and prone to proteolytic degradation. Therefore, we used a protease resistant cyclic RGDfK peptide in all scaffolds to enhance islet survival. 
Since in our study we used an intramuscular space which is already abundant in a rich blood supply, the addition of the slowly released factors synergistically potentiated neovascularization. Histologic examination at the time of transplantation showed a 6 -fold increase in vascularity of the tissue surrounding VEGF/PDGFenriched scaffolds as compared to controls. Islets transplanted onto such neovascularized scaffolds were most effective in converting the animals to normoglycemia.

At the same time as we tested the feasibility of bioengineering an extrahepatic site for islet transplantation, we also evaluated if this approach allowed application of a non invasive beta cell imaging method which we developed for evaluation of islets in-situ $(14,15,23,25)$. Our results suggest that, while there is a need for further optimization of the "bioengineering" phases of the protocol, the use of an extrahepatic site has the potential to overcome many of the shortcomings of intrahepatic islet transplantation. In the current study we purposely used a relatively high number of islets to reverse hyperglycemia because we wished to also test the beta cell imaging protocol. The parameters which need to be optimized in the future will include the concentration of vascular growth factors, size and density of the scaffold, timing of the islet injection after scaffold implantation, and determination of the lowest number of islets needed to restore normoglycemia as compared to that needed for the intraportal route.

The selection of an intramuscular space and use of a bioscaffold for islet implantation may have additional advantages. Future clinical applications of this approach might include monitoring of the transplanted BCM in real time using PET imaging with quantitation of VMAT2, which may permit modulation of immunosupression and early diagnosis of allograft rejection. Allogeneic islet transplantation, at least in the near term, will continue to be hampered by the shortage of donor tissue and allograft rejection. It has been demonstrated that adult beta cells have some selfrenewal potential (49). Scaffolds such as those employed in our study might be useful depots for cocktails of beta cell specific growth factors. Lastly, these scaffolds seem to be ideal locations for delivery of targeted immune intervention, such as co-stimulatory blockade or antisense RNA. Here only a small region will be affected and might preempt the need for traditional high-dose systemic immunosuppression.

\section{FUNDING}

This work was supported by the NIH, NIDDK, 5 RO1 DK63567 and NHLBI 5T32H2007874-11.

\section{ABBREVIATIONS}

$\begin{array}{ll}\text { BCM } & \text { Beta cell mass } \\ \text { DVR } & \text { Distribution Volume Ratio } \\ \text { Dithizone } & \text { Diphenylthiocarbazone } \\ \text { DTBZ } & \text { Dihydrotetrabenazine } \\ \text { EB } & \text { Ethidium bromide }\end{array}$

$\begin{array}{ll}\text { EDC } & \text { Diethylcarbamate } \\ \text { ELISA } & \text { Enzyme linked immunoassay } \\ \text { H\&E } & \text { Gill's hematoxilin/eosin } \\ \text { HBSS } & \text { Hanks balanced salt solution } \\ \text { IBMIR } & \begin{array}{l}\text { Instant blood-mediated } \\ \text { inflammatory reaction }\end{array} \\ \text { IPGTT } & \text { Intraperitoneal glucose tolerance } \\ & \text { testing } \\ \text { PBS } & \text { Phosphate buffered salt solution } \\ \text { PDGF } & \text { Platelet-derived growth factor } \\ \text { PET } & \text { Positron emission tomography } \\ \text { RGD } & \text { Repeated arginine-glycine-aspartic } \\ & \text { acid peptide motif } \\ \text { STZ } & \text { Streptozotocin } \\ \text { Sulfo-NHS } & \text { Sulfo N-hydroxysuccinamide } \\ \text { VEGF } & \text { Vascular } \\ & \text { growth factor } \\ \text { VMAT2 } & \text { Vesicular monoamine transporter } \\ & \text { type 2 }\end{array}$

\section{REFERENCES}

1. A. M. Shapiro, J. R. Lakey, E. A. Ryan, G. S. Korbutt, E. Toth, G. L. Warnock, N. M. Kneteman, R. V. Rajotte, Islet transplantation in seven patients with type 1 diabetes mellitus using a glucocorticoid-free immunosuppressive regimen. $N$ Engl J Med 343, 230 (Jul 27, 2000).

2. E. A. Ryan, B. W. Paty, P. A. Senior, D. Bigam, E. Alfadhli, N. M. Kneteman, J. R. T. Lakey, A. M. J. Shapiro, Five-year follow-up after clinical islet transplantation. Diabetes 54, 2060 (2005/06/27, 2005).

3. B. J. Hering, R. Kandaswamy, J. D. Ansite, P. M. Eckman, M. Nakano, T. Sawada, I. Matsumoto, S. H. Ihm, H. J. Zhang, J. Parkey, D. W. Hunter, D. E. Sutherland, Single-donor, marginal-dose islet transplantation in patients with type 1 diabetes. Jama 293, 830 (Feb 16, 2005).

4. A. S. Narang, Biological and biomaterial approaches for improved islet transplantation. Pharmacological Reviews 58, 194 (2006/06/01, 2006).

5. R. P. Robertson, Islet transplantation as a treatment for diabetes - A work in progress. New England Journal of Medicine 350, 694 (2004/02/12, 2004).

6. N. M. Desai, J. A. Goss, S. Deng, B. A. Wolf, E. Markmann, M. Palanjian, A. P. Shock, S. Feliciano, F. C. Brunicardi, C. F. Barker, A. Naji, J. F. Markmann, Elevated portal vein drug levels of sirolimus and tacrolimus in islet transplant recipients: local immunosuppression or islet toxicity? Transplantation 76, 1623 (Dec 15, 2003).

7. A. M. J. Shapiro, H. Gallant, E. Hao, J. Wong, R. Rajotte, R. Yatscoff, N. Kneteman, Portal vein immunosuppressant levels and islet graft toxicity. Transplantation Proceedings 30, 641 (1998/03, 1998).

8. W. Bennet, B. Sundberg, C. G. Groth, M. D. Brendel, D. Brandhorst, H. Brandhorst, R. G. Bretzel, G. Elgue, R. Larsson, B. Nilsson, O. Korsgren, Incompatibility between human blood and isolated islets of Langerhans: a finding with implications for clinical intraportal islet transplantation? Diabetes 48, 1907 (1999/10/01, 1999).

9. J. M. Dufour, R. V. Rajotte, M. Zimmerman, A. Rezania, T. Kin, D. E. Dixon, G. S. Korbutt, 
Development of an ectopic site for islet transplantation, using biodegradable scaffolds. Tissue Eng 11, 1323 (Sep-Oct, 2005).

10. A. Pileggi, L. Cobianchi, L. Inverardi, C. Ricordi, Overcoming the challenges now limiting islet transplantation: A sequential, integrated approach. Annals of the New York Academy of Sciences 1079, 383 (2006/10/01, 2006).

11. P. Bucher, Z. Mathe, D. Bosco, C. Becker, L. Kessler, M. Greget, P. Y. Benhamou, A. Andres, J. Oberholzer, L. Buhler, P. Morel, T. Berney, Morbidity associated with intraportal islet transplantation. Transplantation Proceedings 36, 1119 (2004/05, 2004).

12. A. M. Shapiro, E. G. Hao, J. R. Lakey, W. J. Yakimets, T. A. Churchill, P. G. Mitlianga, G. K. Papadopoulos, J. F. Elliott, R. V. Rajotte, N. M. Kneteman, Novel approaches toward early diagnosis of islet allograft rejection. Transplantation 71, 1709 (Jun 27, 2001).

13. Y. Saisho, P. E. Harris, A. E. Butler, R. Galasso, T. Gurlo, R. A. Rizza, P. C. Butler, Relationship between pancreatic vesicular monoamine transporter 2 (VMAT2) and insulin expression in human pancreas. Journal of Molecular Histology 39, 543 (2008/09/13, 2008).

14. N. R. Simpson, F. Souza, P. Witkowski, A. Maffei, A. Raffo, A. Herron, M. Kilbourn, A Jurewicz, K. Herold, E. Liu, M. A. Hardy, R. Van Heertum, P. E. Harris, Visualizing pancreatic beta-cell mass with [11C]DTBZ. Nucl Med Biol 33, 855 (Oct, 2006)

15. R. Goland, M. Freeby, R. Parsey, Y. Saisho, D. Kumar, N. Simpson, J. Hirsch, M. Prince, A. Maffei, J. J. Mann, P. C. Butler, R. Van Heertum, R. L. Leibel, M. Ichise, P. E. Harris, 11C-dihydrotetrabenazine PET of the pancreas in subjects with long-standing type 1 diabetes and in healthy controls. Journal of Nuclear Medicine 50, 382 (2009/02/17, 2009).

16. A. Prokop, T. G. Wang, Purification of polymers used for fabrication of an immunoisolation barriera. Annals of the New York Academy of Sciences 831, 223 (2006/12/17, 2006).

17. J. A. Rowley, G. Madlambayan, D. J. Mooney, Alginate hydrogels as synthetic extracellular matrix materials. Biomaterials 20, 45 (1999/01, 1999).

18. M. Kantlehner, P. Schaffner, D. Finsinger, J. Meyer, A. Jonczyk, B. Diefenbach, B. Nies, G. Hölzemann, S. L. Goodman, H. Kessler, Surface coating with cyclic RGD peptides stimulates osteoblast adhesion and proliferation as well as bone formation. Chembiochem : a European journal of chemical biology 1, 107 (2000/08/18, 2000).

19. A. Ali, M. Garrovillo, M. X. Jin, M. A. Hardy, S. F. Oluwole, Major histocompatibility complex class I peptide-pulsed host dendritic cells induce antigen-specific acquired thymic tolerance to islet cells. Transplantation 69, 221 (Jan 27, 2000).

20. M. J. Barnett, D. McGhee-Wilson, A. M. J. Shapiro, J. R. T. Lakey, Variation in human islet viability based on different membrane integrity stains. Cell Transplantation 13, 481 (2004/07, 2004).

21. D. L. Eizirik, G. S. Korbutt, C. Hellerström, Prolonged exposure of human pancreatic islets to high glucose concentrations in vitro impairs the beta-cell function. Journal of Clinical Investigation 90, 1263 (1992/10/01, 1992).
M. Kilbourn, L. Lee, T. V. Borght, D. Jewett, K. Frey, Binding of a-dihydrotetrabenazine to the vesicular monoamine transporter is stereospecific. European Journal of Pharmacology 278, 249 (1995/05, 1995)

23. F. Souza, N. Simpson, A. Raffo, C. Saxena, A. Maffei, M. Hardy, M. Kilbourn, R. Goland, R. Leibel, J. J. Mann, R. Van Heertum, P. E. Harris, Longitudinal noninvasive PET-based beta cell mass estimates in a spontaneous diabetes rat model. J Clin Invest 116, 1506 (Jun, 2006).

24. J. Logan, Graphical analysis of PET data applied to reversible and irreversible tracers. Nuclear Medicine and Biology 27, 661 (2000/10, 2000).

25. M. Freeby, R. Goland, M. Ichise, A. Maffei, R. Leibel, P. Harris, VMAT2 quantitation by PET as a biomarker for B-cell mass in health and disease. Diabetes, Obesity and Metabolism 10, 98 (2008/11, 2008).

26. C. J. Weber, M. A. Hardy, F. Pi-Sunyer, E. Zimmerman, K. Reemtsma, Tissue culture preservation and intramuscular transplantation of pancreatic islets. Surgery 84, 166 (Jul, 1978).

27. K. V. Axen, F. X. Pi-Sunyer, Long-term reversal of streptozotocin-induced diabetes in rats by intramuscular islet implantation. Transplantation 31, 439 (Jun, 1981).

28. J. H. Juang, B. R. S. Hsu, C. H. Kuo, Islet transplantation at subcutaneous and intramuscular sites. Transplantation Proceedings 37, 3479 (2005/10, 2005).

$29 . \quad$ C. J. Simeonovic, D. P. Dhall, J. D. Wilson, K. J. Lafferty, A comparative study of transplant sites for endocrine tissue transplantation in the pig. The Australian journal of experimental biology and medical science 64 ( Pt 1), 37 (Feb, 1986).

$30 . \quad$ T. P. Richardson, M. C. Peters, A. B. Ennett, D. J. Mooney, Polymeric system for dual growth factor delivery. Nat Biotechnol 19, 1029 (Nov, 2001).

31. U. Hersel, C. Dahmen, H. Kessler, RGD modified polymers: biomaterials for stimulated cell adhesion and beyond. Biomaterials 24, 4385 (2003/11, 2003).

32. M. D. Pierschbacher, E. Ruoslahti, Cell attachment activity of fibronectin can be duplicated by small synthetic fragments of the molecule. Nature 309, 30 (1984/05, 1984).

33. R. N. Wang, L. Rosenberg, Maintenance of betacell function and survival following islet isolation requires re-establishment of the islet-matrix relationship. J Endocrinol 163, 181 (Nov, 1999).

34. A. Kedem, A. Perets, I. Gamlieli-Bonshtein, M. Dvir-Ginzberg, S. Mizrahi, S. Cohen, Vascular endothelial growth factor-releasing scaffolds enhance vascularization and engraftment of hepatocytes transplanted on liver lobes. Tissue Engineering 11, 715 (2005/05, 2005).

35. G. Klöck, A. Pfeffermann, C. Ryser, P. Gröhn, B. Kuttler, H.-J. Hahn, U. Zimmermann, Biocompatibility of mannuronic acid-rich alginates. Biomaterials 18, 707 (1997/05, 1997).

36. P. de Vos, M. M. Faas, B. Strand, R. Calafiore, Alginate-based microcapsules for immunoisolation of pancreatic islets. Biomaterials 27, 5603 (2006/11, 2006).

37 A. L. Dainty, K. H. Goulding, P. K. Robinson, I. Simpkins, M. D. Trevan, Stability of alginateimmobilized algal cells. Biotechnology and Bioengineering 28, 210 (1986/02, 1986). 
Chapter 4 - Islet grafting and imaging in a bioengineered intramuscular space.

38.

R. P. Lanza, R. Jackson, A. Sullivan, J. Ringeling, C. McGrath, W. Kuhtreiber, W. L. Chick, Xenotransplantation of cells using biodegradable microcapsules. Transplantation 67, 1105 (Apr 27, 1999).

39. R. R. Chen, E. A. Silva, W. W. Yuen, D. J. Mooney, Spatio-temporal VEGF and PDGF delivery patterns blood vessel formation and maturation. Pharmaceutical Research 24, 258 (2006/12/27, 2006).

40. A. Kidszun, D. Schneider, D. Erb, G. Hertl, V. Schmidt, M. Eckhard, K. T. Preissner, G. Breier, R. G. Bretzel, T. Linn, Isolated pancreatic islets in three-dimensional matrices are responsive to stimulators and inhibitors of angiogenesis. Cell Transplantation 15, 489 (2006/07, 2006).

41. S. T. M. Nillesen, P. J. Geutjes, R. Wismans, J. Schalkwijk, W. F. Daamen, T. H. van Kuppevelt, Increased angiogenesis and blood vesse maturation in acellular collagen-heparin scaffolds containing both FGF2 and VEGF. Biomaterials 28, 1123 (2007/02, 2007).

B. Vasir, L. P. Aiello, K. H. Yoon, R. R. Quickel, S. Bonner-Weir, G. C. Weir, Hypoxia induces vascular endothelial growth factor gene and protein expression in cultured rat islet cells. Diabetes 47, 1894 (1998/12/01, 1998).

43. C. Danielsson, S. Ruault, A. Basset-Dardare, P. Frey, Modified collagen fleece, a scaffold for transplantation of human bladder smooth muscle cells. Biomaterials 27, 1054 (2006/03, 2006).

44. J. Elisseeff, A. Ferran, S. Hwang, S. Varghese, Z. Zhang, The role of biomaterials in stem cell differentiation: Applications in the musculoskeletal system. Stem cells and development 15, 295 (2006/06, 2006).

45. A. N. Balamurugan, Y. Gu, Y. Tabata, M. Miyamoto, W. Cui, H. Hori, A. Satake, N. Nagata, W. Wang, K. Inoue, Bioartificial pancreas transplantation at prevascularized intermuscular space: Effect of angiogenesis induction on islet survival. Pancreas 26, 279 (2003/04, 2003).

46. Y. Gu, Y. Tabata, Y. Kawakami, A. N. Balamurugan, H. Hori, N. Nagata, A. Satake, W. Cui, M. Qi, Y. Misawa, M. Toma, M. Miyamoto, M. Nozawa, K. Inoue, Development of a new method to induce angiogenesis at subcutaneous site of streptozotocin-induced diabetic rats for islet transplantation. Cell Transplant 10, 453 (2001).

47. N. Trivedi, G. M. Steil, C. K. Colton, S. BonnerWeir, G. C. Weir, Improved vascularization of planar membrane diffusion devices following continuous infusion of vascular endothelial growth factor. Cell Transplantation 9, 115 (2000/01, 2000).

48. G. G. Pinkse, W. P. Bouwman, R. Jiawan-Lalai, O. T. Terpstra, J. A. Bruijn, E. de Heer, Integrin signaling via RGD peptides and anti-beta1 antibodies confers resistance to apoptosis in islets of Langerhans. Diabetes 55, 312 (Feb, 2006)

49. T. Nir, D. A. Melton, Y. Dor, Recovery from diabetes in mice by $B$ cell regeneration. Journal of Clinical Investigation 117, 2553 (2007/09/04, 2007). 


\section{Chapter 5 \\ The long road to pancreatic islet transplantation - an intermezzo.}

World Journal of Surgery. 2010 Apr; 34(4): 625-627.

Mark A. Hardy, Piotr Witkowski, Hugo Sondermeijer, and Paul Harris. 


\section{ABSTRACT}

Some of us (MAH) have known Dr. Eric Rose when he was a resident, a fellow in cardiothoracic surgery, the director of heart transplantation program, the director of Cardiothoracic Division, and finally as Valentine and Johnson and Johnson Professor and Chairman of Department of Surgery at Columbia University for the last 15 years. Having this long relationship with Dr. Rose, I was not sure where or how to begin this tribute to my former resident, colleague, collaborator, and eventually director. It was as an innovative and courageous Chairman that Dr. Rose had a major impact on me when he appointed me as a Residency Program Director and through his remarkable interest and support of educational changes led to a rebirth and growth of the surgical residency at Columbia NY Presbyterian Hospital to one of the leading programs in the country. But the greatest inspiration that Dr. Rose brought to the Department of Surgery was his fearless and relentless support of ventures into the unknown. When faced with heart transplantation as a junior faculty member, he went on to lay the foundation for the largest heart transplant program in the world; when challenged by development and lack of acceptance of Left Ventricular Assist Devices, he guided their approval following appropriate multi-institutional studies which led to their adoption as standard of care. His influence extended to the support of a Pancreatic Islet Transplantation Program, originally inspired by his predecessor and mentor, Dr. Keith Reemtsma. Doctor Rose invested and encouraged both the clinical and experimental development of this program under my guidance as part of his dedication to innovation.

\section{CLINICAL ISLET TRANSPLANTATION}

Following the remarkable early success of Edmonton's group with steroid free protocol for clinical pancreatic islet transplantation, 10 other units, including ours, attempted to duplicate this effort with the support of NIH. With Dr. Rose's support, and of colleagues in other departments, The Regional Columbia Pancreatic Islet Center joined the initial NIH Consortium (1). Our success was limited to only two successful clinical transplants, and this treatment lasted only 6 months. As we learned that others who transplanted more patients had limited success in having their recipients stay off insulin for more than 4 to 5 years (2) we returned to experimental work on development of a site for islet implantation other than intrahepatic to avoid early islet destruction by an inflammatory storm, poor engraftment, and possible intense exposure to higher toxic levels of immunosuppressive drugs in the liver. Our experiments focused again (3) on the intramuscular route of islet implantation, but this time using preconditioning of the recipients with three dimensional alginate scaffolds modified with vascular endothelial-derived growth factor (VEGF) and platelet-derived growth factor (PDGF-BB) in combination to promote ingrowth of functionally sound vessels (4). In addition to these, we modified alginate with cyclic extracellular matrix signaling molecule arginine-glycine-aspartic acid peptide motif (RGD) which has been shown to enhance cellular adhesion and prevent transmembrane apoptotic signaling via integrins (5-7). The intent was to improve islet engraftment through avoidance low level of neovascularization. The choice of intramuscular site mimicked that of parathyroid autotransplantation and we felt was safer and more easily monitored without biopsies. It also offered the possibility of eventual local immunosuppression either with co-stimulatory blockade with monoclonal antibodies attached to the scaffold or with the use of immature dendritic cells cotransplanted with the islets (8-10).

The aims of the initial experiments was to separately study the efficacy of islet isografts with the use of scaffolds and on development of new methods of monitoring pancreatic islet survival using PET scanning techniques with available ligands. We then combined the experiments since such monitoring is best done intramuscularly and is not practical when the islets are in the liver because of the overwhelming background noise from the ligand.

The preliminary transplantation experiments using pancreatic islet isografts (2400 islets/recipient) into streptozotocin induced diabetic Lewis rat recipient primarily addressed the issues of neovascularization and engraftment at an intramuscular site. The islets were $>90 \%$ pure. The relatively newer methods, published elsewhere (1113) and modified by us, submitted elsewhere for publication (14), included priming of the alginate scaffolds with VGEF, PDGF, and with RGD prior to intramuscular implantation in the abdominal wall of each diabetic recipient of two scaffolds, either modified or unmodified (controls) 14 days before islet transplantation. This was to permit the area to be neovascularized before islet transplantation on day 0 .

Detailed analysis of neovascularization at the transplant site just before islet implantation and at 2 weeks after their implantation with immunostaining revealed fibrovascular tissue penetrating scaffolds and a significantly higher 


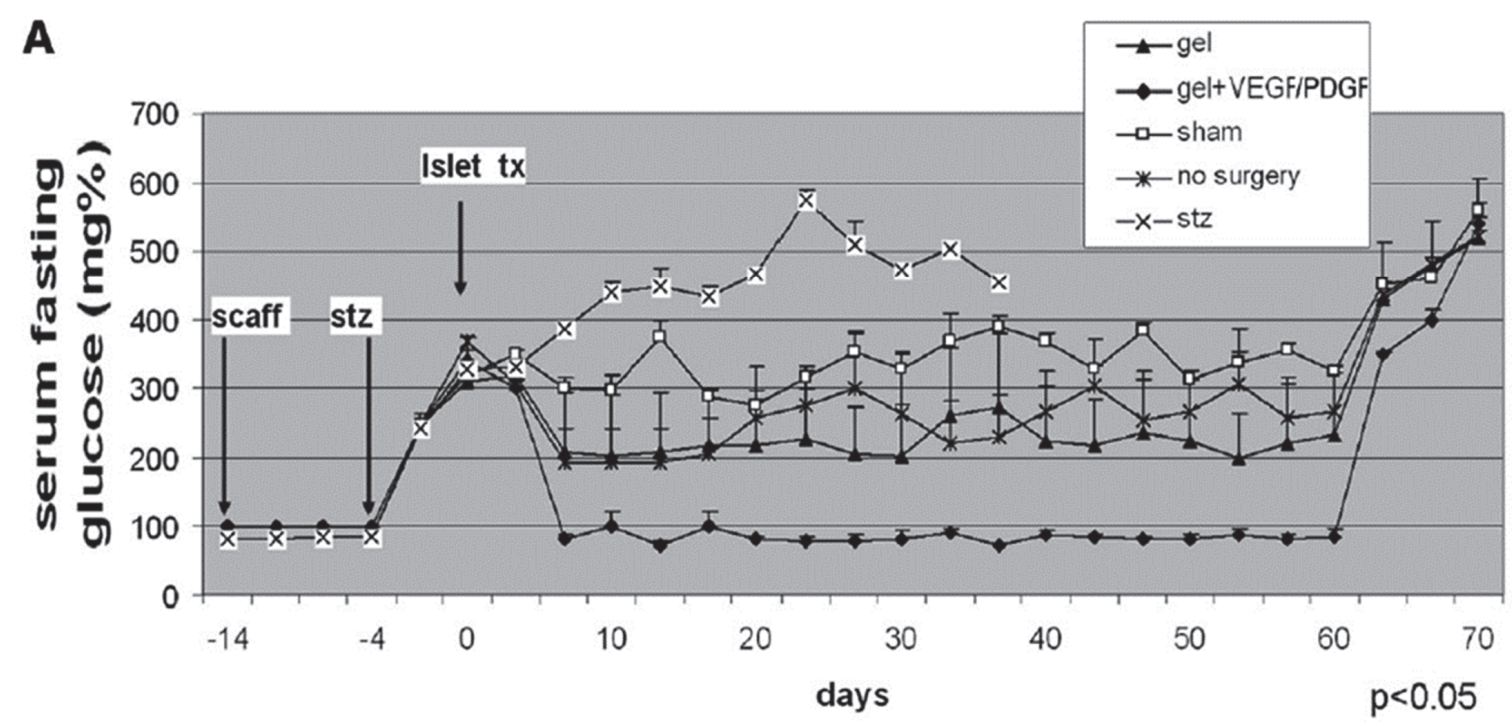

\section{B}

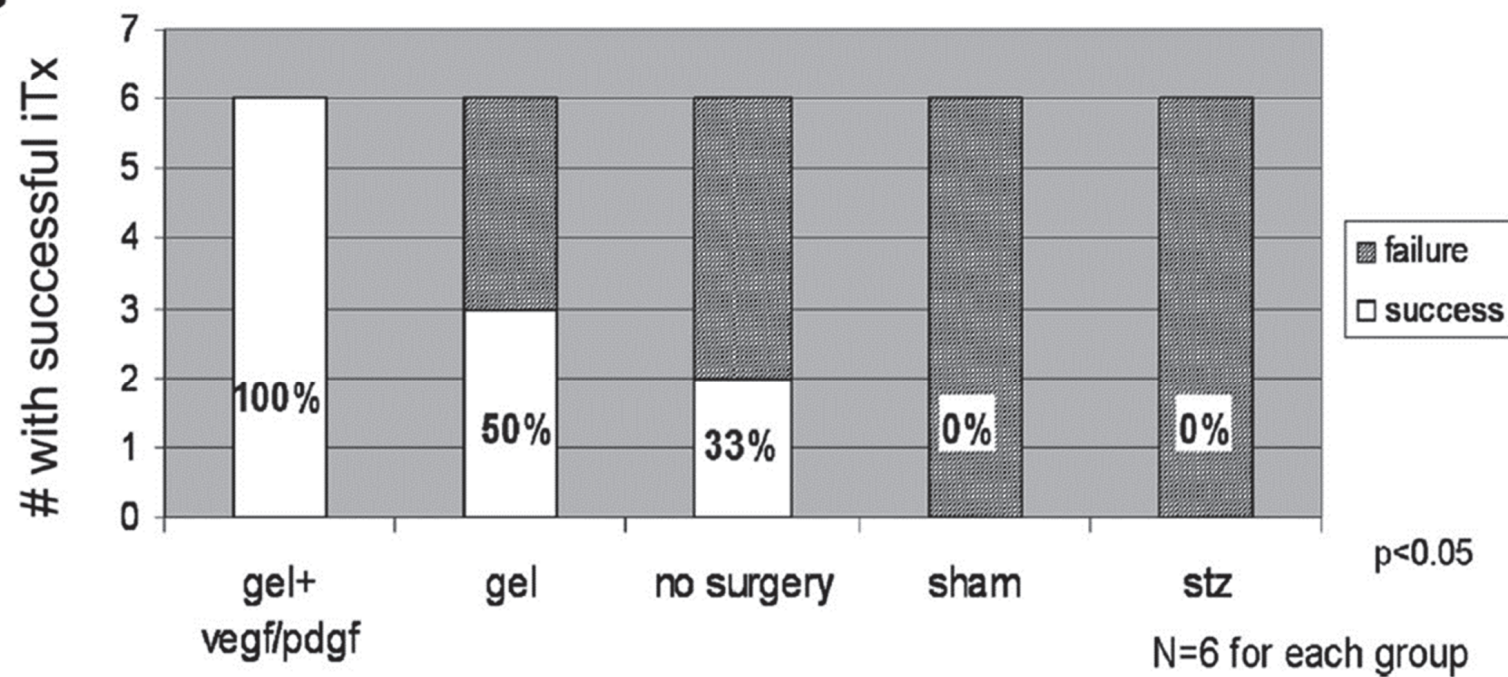

Figure 1. Blood Glucose Levels in Transplanted Rodents (A) Figure presents mean fasting serum glucose level in animals within the 60 days follow-up. Mean fasting glucose level oscillates below $110 \mathrm{mg} / \mathrm{dL}$ for animals from group 1 (gel+VEGF/PDGF), whereas in other groups it was statistically higher, ANOVA, $\mathrm{p}<0.05$. As an additional control, removal of the scaffolds in normoglycemic animals from the gel+VEGF/PDGF group on day +60 led to prompt return of diabetes and hyperglycemia. Error bars represent S.E.M. (B) Islet grafting success rate. Number of animals out of six total achieving euglycemia following syngeneic islet transplantation is shown on the $\mathrm{Y}$ axis. Euglycemia was defined as four-hour fasting glucose $<110 \mathrm{mg} / \mathrm{dL}$ on post-transplant days +5 through +60 . The statistical significance of the differences in grafting success rate among the different treatment groups is shown and was determined by ANOVA using the blood glucose measurements obtained in the 55 day post-transplant window.

number of capillaries stained with factor VIII related antigen per high power field in the scaffold containing VEGF/PDGF group compared to the other groups by $2-5$ fold, $\mathrm{p}<0.05$. Islet isograft survival for more than 2 months, as measured by normalized FBS and weekly GTT, was striking $(100 \%)$ in the neovascularized groups preconditioned with modified scaffolds as compared to controls, some of which (20-40\%) maintained improved, but not normalized blood glucose, since the islets were isografts and therefore were not rejected. When scaffolds were removed at 2 months, the animals reverted to being fully diabetic again
(Figure 1). The details of these experiments, including the methodology, immunopathology, and results have been submitted for publication elsewhere (14). Due to our expanding activities in clinical islet transplantation we, under the leadership of one of the co-authors (P.H.), also turned our attention to the issue of non-invasive monitoring of islet function after transplantation or after the onset of diabetes. Currently, islet allografts are monitored by metabolic measures which only detect graft dysfunction after substantial islet mass has already been lost (15) The noninvasive beta cell imaging technique that we 


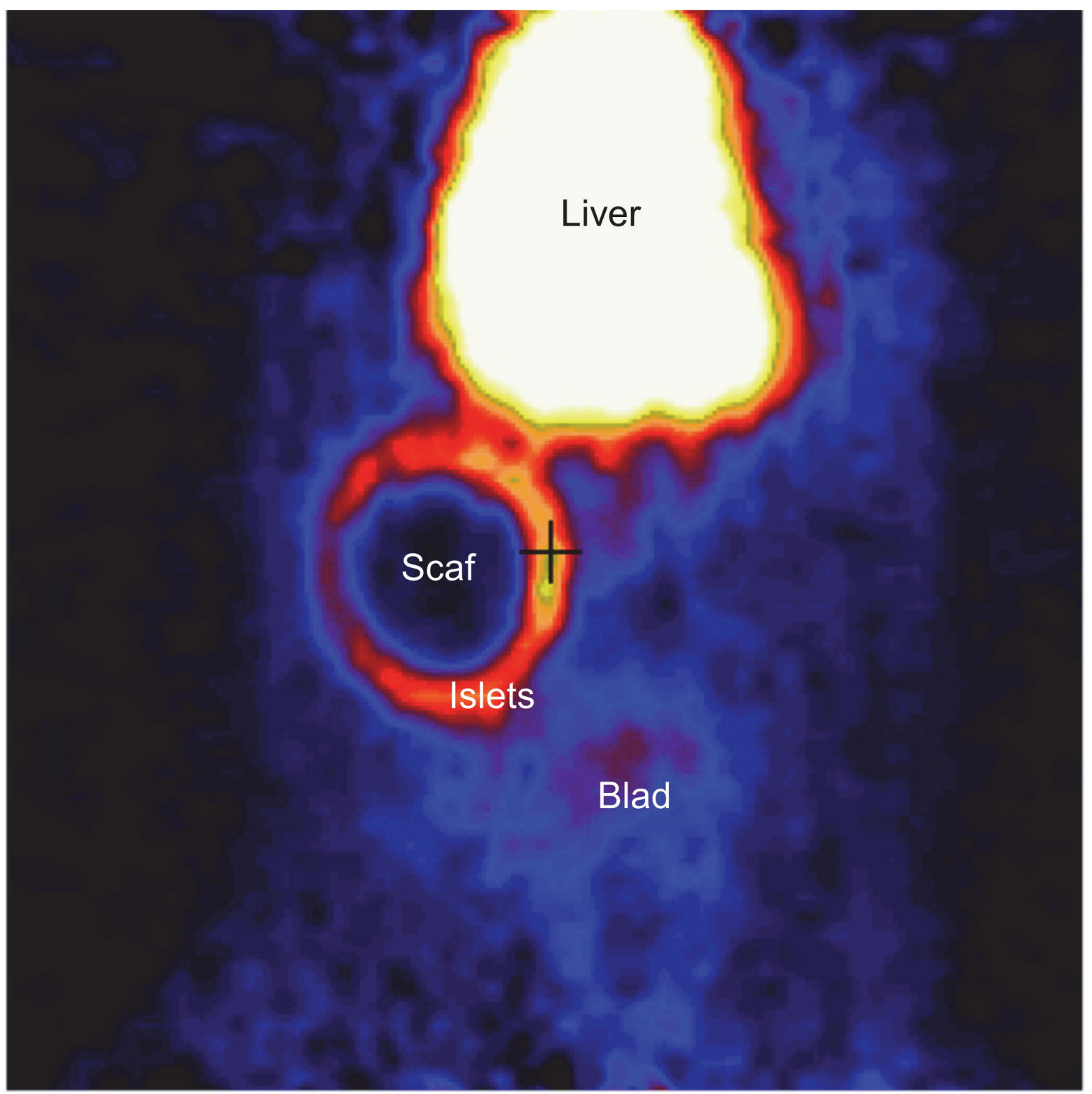

Figure 2. Representative coronal plane of abdomen of Lewis rats transplanted with allogeneic islets. Rats were imaged (90min) dynamically with $250 \mu \mathrm{Ci}\left[{ }^{11} \mathrm{C}\right]-\mathrm{DTBZ}$ and a Concorde microPET scanner. The large high uptake area in the top center of the figure is a plane of the liver, an organ of $\left.{ }^{11} \mathrm{C}\right]-\mathrm{DTBZ}$ catabolism. Radioligand uptake in the form of a ring corresponds to the location of the transplanted islets. Following imaging, the presence of insulin staining cells in this location was confirmed by preparing paraffin embedded sections of the tissue and insulin staining by immunohistochemistry. Scaf=scaffold. Blad=bladder.

recently developed relies on the use of PET with $\left[{ }^{11} \mathrm{C}\right]$-dihydrotetrabenazine (DTBZ) as means to quantitate vesicular monoamine transporter type 2 (VMAT2). VMAT2 is highly expressed relative to other cells in the beta cells of pancreas as it is located closely to insulin vesicles. This method cannot be applied to islets infused into the liver because liver and bile are routes of DTBZ excretion and have a high background signal. This approach originated by using gene profiling of purified human islets which grew out of our islet transplantation program (16).

Following islet transplantation to the intramuscular space, the PET scans with [ $\left.{ }^{11} \mathrm{C}\right]-$ DTBZ demonstrated that the transplanted and viable beta cell mass can be visualized and quantified. The transplanted islets were visualized in animals that had gel+VEGF/PDGF/RGD modified scaffolds and that were normoglycemic, while those in the sham operated controls were not visible. It was interesting to also note that the native pancreas in STZ-treated animals had lower tracer binding that confirms that reversal of hyperglycemia was not due to residual beta cell mass in the native pancreas. This approach has now been used in humans and is detailed in previous publications $(17,18)$.

We have here briefly described the most recent experimental studies on islet transplantation performed in our laboratory, based on our 
unsuccessful attempts at long term or permanent reversal of diabetes mellitus in patients, where Dr. Rose played an important catalytic role. In line with his major interest in translational research, the studies that we have described have a great translational potential both for cellular transplantation and for development of a tool for diagnosis of disease progression or prevention in diabetes mellitus and of pancreatic islet allograft survival following transplantation.

\section{FUNDING}

Supported in part by: NIH T32 HL 007854, NIH NIDDK 5RO1 DK63567-03.

Supported in Part by: NIH grant HL007854-12 (MAH).

\section{REFERENCES}

1. J. S. Kaddis, B. J. Olack, J. Sowinski, J. Cravens, J. L. Contreras, J. C. Niland, Human pancreatic islets and diabetes research. Jama 301, 1580 (Apr 15, 2009).

2. E. A. Ryan, B. W. Paty, P. A. Senior, D. Bigam, E. Alfadhli, N. M. Kneteman, J. R. T. Lakey, A. M. J. Shapiro, Five-year follow-up after clinical islet transplantation. Diabetes 54, 2060 (2005/06/27, 2005).

3. C. J. Weber, M. A. Hardy, F. Pi-Sunyer, E Zimmerman, K. Reemtsma, Tissue culture preservation and intramuscular transplantation of pancreatic islets. Surgery 84, 166 (Jul, 1978).

4. T. P. Richardson, M. C. Peters, A. B. Ennett, D. J. Mooney, Polymeric system for dual growth factor delivery. Nature Biotechnology 19, 1029 (2001/11, 2001)

5. U. Hersel, C. Dahmen, H. Kessler, RGD modified polymers: biomaterials for stimulated cell adhesion and beyond. Biomaterials 24, 4385 (2003/11, 2003)

6. M. D. Pierschbacher, E. Ruoslahti, Cell attachment activity of fibronectin can be duplicated by small synthetic fragments of the molecule. Nature 309, 30 (1984/05, 1984).

7. R. N. Wang, L. Rosenberg, Maintenance of betacell function and survival following islet isolation requires re-establishment of the islet-matrix relationship. J Endocrinol 163, 181 (Nov, 1999).

8. H. A. DePaz, O. O. Oluwole, A. O. Adeyeri, P. Witkowski, M.-X. Jin, M. A. Hardy, S. F. Oluwole, Immature rat myeloid dendritic cells generated in low-dose granulocyte macrophagecolony stimulating factor prolong donor-specific rat cardiac allograft survival. Transplantation 75, $521(2003 / 02,2003)$

9. S. F. Oluwole, O. O. Oluwole, H. A. DePaz, A. O. Adeyeri, P. Witkowski, M. A. Hardy, CD4 $4^{+} \mathrm{CD} 25^{+}$ regulatory $\mathrm{T}$ cells mediate acquired transplant tolerance. Transplant Immunology 11, 287 (2003/07, 2003).

10. D.-F. Yang, W.-H. Qiu, H.-F. Zhu, P. Lei, X. Wen, H. Dai, W. Zhou, G.-X. Shen, CTLA4-Ig-modified dendritic cells inhibit lymphocyte-mediated alloimmune responses and prolong the islet graft survival in mice. Transplant Immunology 19, 197 (2008/07, 2008).

11. A. Kedem, A. Perets, I. Gamlieli-Bonshtein, M. Dvir-Ginzberg, S. Mizrahi, S. Cohen, Vascular endothelial growth factor-releasing scaffolds enhance vascularization and engraftment of hepatocytes transplanted on liver lobes. Tissue Engineering 11, 715 (2005/05, 2005).

12. R. R. Chen, E. A. Silva, W. W. Yuen, D. J. Mooney, Spatio-temporal VEGF and PDGF delivery patterns blood vessel formation and maturation. Pharmaceutical Research 24, 258 (2006/12/27, 2006)

13. G. G. M. Pinkse, W. P. Bouwman, R. JiawanLalai, O. T. Terpstra, J. A. Bruijn, E. de Heer, Integrin signaling via RGD peptides and anti-B1 antibodies confers resistance to apoptosis in islets of Langerhans. Diabetes 55, 312 (2006/01/27, 2006).

14. P. Witkowski, H. Sondermeijer, M. A. Hardy, D. C. Woodland, K. Lee, G. Bhagat, K. Witkowski, F. See, A. Rana, A. Maffei, S. Itescu, P. E. Harris, Islet grafting and imaging in a bioengineered intramuscular space. Transplantation 88, 1065 (Nov 15, 2009).

15. A. M. Shapiro, E. G. Hao, J. R. Lakey, W. J. Yakimets, T. A. Churchill, P. G. Mitlianga, G. K. Papadopoulos, J. F. Elliott, R. V. Rajotte, N. M. Kneteman, Novel approaches toward early diagnosis of islet allograft rejection. Transplantation 71, 1709 (Jun 27, 2001).

16. A. Maffei, Z. Liu, P. Witkowski, F. Moschella, G. D. Pozzo, E. Liu, K. Herold, R. J. Winchester, M. A. Hardy, P. E. Harris, Identification of tissuerestricted transcripts in human islets. Endocrinology 145, 4513 (2004/10, 2004).

17. R. Goland, M. Freeby, R. Parsey, Y. Saisho, D. Kumar, N. Simpson, J. Hirsch, M. Prince, A. Maffei, J. J. Mann, P. C. Butler, R. Van Heertum, R. L. Leibel, M. Ichise, P. E. Harris, ${ }^{11} \mathrm{C}$-dihydrotetrabenazine PET of the pancreas in subjects with long-standing type 1 diabetes and in healthy controls. Journal of Nuclear Medicine 50, 382 (2009/02/17, 2009).

18. F. Souza, N. Simpson, A. Raffo, C. Saxena, A. Maffei, M. Hardy, M. Kilbourn, R. Goland, R. Leibel, J. J. Mann, R. Van Heertum, P. E. Harris, Longitudinal noninvasive PET-based beta cell mass estimates in a spontaneous diabetes rat model. J Clin Invest 116, 1506 (Jun, 2006). 


\section{Part II}

Mechanisms of stem cell mediated tissue repair. 


\section{Chapter 6}

CCR3- and CXCR4-mediated interactions regulate migration of CD34+ human bone marrow progenitors to ischemic myocardium and subsequent tissue repair.

The Journal of Thoracic and Cardiovascular Surgery. 2008 Oct;136(4):1044-53.

N. Bonaros\#, H. Sondermeijer\#, M. Schuster, R. Rauf, S. F. Wang, T. Seki, D. Skerrett, Itescu, MD, and A. A. Kocher (" ${ }^{*}$ contributed equally). 


\section{ABSTRACT}

Objective: Hematopoietic progenitor cells are able to induce neovascularization of ischemic myocardium, inhibit apoptosis, and prevent heart failure. They express functional CC chemokine-binding receptor 3 (CCR3) and CXC chemokine-binding receptor 4 (CXCR4); however, the role of those receptors in migration of progenitor cells into the ischemic myocardium is unknown. Methods: Myocardial infarction was surgically induced in athymic nude rats, and human bone marrow-derived CD $34^{+}$cells or saline was injected into the tail vein. Cell chemotaxis was studied in vitro using chemotaxis chambers with or without concomitant stimulation with eotaxin or stromal cell-derived factor-1. Cell migration into ischemic myocardium was evaluated by immunohistochemistry. CCR3 and CXCR4 antibodies or local injections of stromal cellderived factor-1 were used to investigate the role of chemokine expression in the migration capacity of the injected cells. Morphologic analysis included evaluation of apoptosis and capillary density in the ischemic myocardium. Results: Ischemic rat myocardium demonstrated induced messenger RNA expression for the CCR3-binding chemokines eotaxin, RANTES (regulated on activation, normal $\mathrm{T}$ expressed and secreted), and monocyte chemotactic protein-3, but not the CXCR4-binding chemokine stromal cell-derived factor-1. Migration of human angioblasts to ischemic rat myocardium was inhibited by a blocking anti-CCR3 monoclonal antibody, but not by a blocking anti-CXCR4 monoclonal antibody, which instead inhibited migration to bone marrow. Finally, intramyocardial injection of stromal cell-derived factor-1 redirected migration of human angioblasts to ischemic rat hearts, resulting in augmented neovascularization, enhanced cardiomyocyte survival, and functional cardiac recovery. Conclusions: CCR3-dependent chemokine interactions regulate endogenous migration of $\mathrm{CD}_{3} 4^{+}$progenitors from bone marrow to ischemic but not to normal myocardium. Manipulating CXCR4-dependent interactions could enhance the efficacy of cell therapy after myocardial infarction.

\section{INTRODUCTION}

In normal adult animals, CD34 ${ }^{+}$hematopoietic progenitors continuously migrate between the bone marrow and the intravascular compartment (1). Bone marrow homing and retention of ${\mathrm{CD} 34^{+}}^{+}$ hematopoietic progenitors in adult mammals are processes controlled by a number of adhesive interactions $(2,3)$, including those between the CXC chemokine stromal cell-derived factor-1 (SDF-1), which is constitutively produced by bone marrow stromal cells, and its receptor, CXCR4 $(4,5)$. Disruption of bone marrow SDF-1/CXCR4 interactions (6), as occurs after activation of neutrophil proteases by systemic administration of granulocyte-colony stimulating factor (G-CSF), results in transient egress of hematopoietic progenitors from the bone marrow into the peripheral circulation, a phenomenon termed mobilization (7). These observations form the basis of clinical protocols enabling large scale harvesting of bone marrow $\mathrm{CD}^{+} 4^{+}$progenitors for autologous stem cell transplantation in certain hematologic disorders.

Bone marrow-derived $\mathrm{CD}^{+} 4^{+}$progenitors are capable of giving rise to cells of nonhematopoietic lineage, including hepatocytes (8), epithelial cells (9), and endothelial cells (10). We (10) have reported that G-CSF-mobilized human adult bone marrow elements contain $\mathrm{CD}^{+} 4^{+}$ progenitors with phenotypic and functional characteristics of embryonic angioblasts that, when transplanted into animal models of acute myocardial infarction, home to ischemic myocardium, induce neovascularization, and result in improved cardiac outcome. Similar results have been obtained with autologous bone marrow cells in humans with acute myocardial ischemia $(11,12)$. Collectively, these studies suggest that a general mechanism by which endogenous repair of damaged tissues occurs is redirected migration of $\mathrm{CD}^{+}$ progenitors from the bone marrow to sites of acute injury, including the heart.

In adult mice, bone marrow progenitors capable of hematopoietic reconstitution have been reported to constitutively express several chemokine receptors, including $\mathrm{CXC}$ chemokine-binding receptor 4 (CXCR4) and $\mathrm{CC}$ chemokine-binding receptor 3 (CCR3), but to demonstrate restricted chemotactic responses only to SDF-1 (13). In contrast, human CD34 ${ }^{+}$bone marrow and cord blood cells, which contain both hematopoietic and nonhematopoietic progenitors, demonstrate robust chemotactic responses to diverse chemokines in addition to SDF-1, including migration to nonhematopoietic sites in response to the CCR3binding CC chemokine eotaxin $(14,15)$. In this study, we investigated the nature of the endogenous chemotactic signals provided by ischemic myocardium that result in migration of human bone marrow-derived angioblasts to the heart to identify 
strategies to enhance cell migration into the ischemic myocardium.

\section{METHODS}

\subsection{PURIFICATION AND CHARACTERIZATION OF CYTOKINE MOBILIZED HUMAN CD34 ${ }^{+}$CELLS}

Single-donor leukopheresis products were obtained from humans treated with recombinant G-CSF $10 \mu \mathrm{g} / \mathrm{kg}$ (Amgen, Thousand Oaks, Calif) subcutaneously daily for 4 days after approval by the ethical committee of Columbia University. Mononuclear cells were separated by FicollHypaque, and highly purified $\mathrm{CD}^{+} 4^{+}$cells $(>98 \%$ positive) were obtained using magnetic beads coated with anti-CD34 monoclonal antibody (mAb) (Miltenyi Biotech, Auburn, Calif). Purified CD34 cells were stained with fluorescein-conjugated mAbs against CD34 and CD117 (Becton Dickinson, Franklin Lakes, NJ), AC133 (Miltenyi Biotech), CD54 (Immunotech, Fullerton, Calif), CD62E (BioSource, Inc, Worcester, Mass), vascular endothelial growth factor receptor-2 (VEGFR-2), Tie-2, von Willebrand factor, endothelial nitric oxide synthase, CXCR1, CXCR2, and CXCR4 (all Santa Cruz Biotech, Santa Cruz, Calif), and analyzed by four-parameter fluorescence using FACScan (Becton Dickinson). Cells positively selected for CD34 expression were also stained with phycoerythrinconjugated anti-CD117 mAb (Becton Dickinson) and sorted for bright and dim fluorescence using a Facstar Plus (Becton Dickinson) and a phycoerythrin filter.

\subsection{INDIUM-111 LABELING OF BONE MARROW-DERIVED CD34 ${ }^{+}$PROGENITORS}

G-CSF-mobilized cells were immunoselected for $\mathrm{CD}_{3}{ }^{+}$expression and resuspended in medium containing $20 \mu \mathrm{Ci}$ of ${ }^{111} \mathrm{In} 8$-oxyquinoline (oxine) per $10^{8}$ cells as described before (16). After washing, $2 \times 10^{6}{ }^{111} \mathrm{In}$ 8-oxyquinoline (oxine) labeled CD34 ${ }^{+}$ cells were infused intravenously into the nude rats $24 \mathrm{~h}$ after myocardial infarction or into noninfarcted animals. Twenty-four hours later, animals were humanely killed and organs were harvested. Indium-111 counts in each tissue were measured with a gamma spectrometer and calibrated as desintegration per minute per gram tissue using the counter efficiency. Postlabeling viability exceeded $80 \%$ and preliminary experiments demonstrated adequate cell tracking.

\subsection{CHEMOTAXIS OF HUMAN BONE MARROW DERIVED HEMATOPOIETIC PROGENITORS}

Highly purified $\mathrm{CD} 34^{+} \mathrm{CD} 117^{+}$cells $(>98 \%$ purity) were plated in 48-well chemotaxis chambers fitted with membranes (8- $\mu \mathrm{m}$ pores) (Neuro-Probe, Inc, Gaithersburg, Md). After incubation for $2 \mathrm{~h}$ at $37^{\circ} \mathrm{C}$, chambers were inverted and cells were cultured for $3 \mathrm{~h}$ in medium containing eotaxin or SDF-1 at concentrations of $0.2,1.0$, and $5.0 \mu \mathrm{g} / \mathrm{mL}$. Stem cell factor (SCF) was used as negative control in chemotaxis assays at $0.1 \mu \mathrm{g} / \mathrm{mL}$, a biologically active concentration that induced 2 -fold proliferation of CD $34^{+}$CD $117^{\text {bright }}$ cells after culture for $96 \mathrm{~h}$. The membranes were fixed with methanol and stained with Leukostat (Fischer Scientific, Pittsburgh, $\mathrm{Pa}$ ). Chemotaxis was calculated by counting migrating cells in 10 high-power fields.

\subsection{ANIMALS, SURGICAL PROCEDURES, AND INJECTION OF HUMAN CELLS}

Rowett (rnu/rnu) athymic nude rats (Harlan Sprague Dawley, Inc, Indianapolis, Ind) were used in studies approved by the Columbia University Institute for Animal Care and Use Committee. After anesthesia, a left thoracotomy was performed, the pericardium was opened, and the left anterior descending (LAD) coronary artery was ligated. Sham-operated rats had a similar surgical procedure without having a suture placed around the coronary artery. For studies on cellular migration, $2.0 \times 10^{6}$ DiI-labeled CD34 ${ }^{+}$cells obtained from a single donor after G-CSF mobilization were injected into the tail vein $48 \mathrm{~h}$ after LAD ligation in the presence or absence of mAbs with known

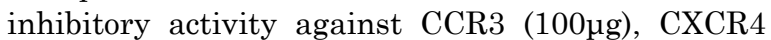

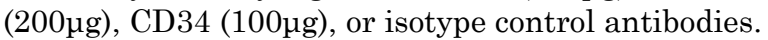
Inhibiting antibodies were injected in the ischemic area using 3 to 5 injections. Control animals received saline after $\mathrm{LAD}$ ligation, and $2.0 \times 10^{6}$ CD $34^{+}$human cells were also injected into the tail vein of sham-operated or LAD-ligated rats receiving three intramyocardial injections of $1.0 \mu \mathrm{g} / \mathrm{mL}$ eotaxin, SDF-1, VEGF, SCF, or saline.

\subsection{QUANTITATION OF CELLULAR MIGRATION INTO TISSUES}

After intravenous injection of human cells, quantitative analysis of the proportion of human cells in rat bone marrow and heart was performed by assessment of both DiI fluorescence and expression of major histocompatibility complex (MHC) class I proteins in rats humanely killed 2 days after injection. Single cell suspension of rat bone marrow was stained with fluoresceinconjugated mAbs against human CD34 and MHC class I beta2 microglobulin (Accurate Chemical \& Scientific Corporation, Meriden, Conn) and analyzed by multiparameter fluorescence using FACScan (Becton Dickinson,), as described previously (17). The proportion of human cells in rat heart tissue was expressed as the number of DiIpositive cells per high-power field (minimum 5 fields examined per sample) and as the proportion of cells staining positive for human MHC class I B2 microglobulin (Accurate Chemical \& Scientific Corporation). Cardiac tissue was stained by immunoperoxidase technique using an Avidin/Biotin Blocking Kit, a rat-absorbed biotinylated antimouse immunoglobulin G, and a peroxidase-conjugate (all Vector Laboratories, Burlingame, Calif). The human origin of the detected cells was confirmed by staining against the human-mitochondrial epitope S-100 (S1-61; Santa Cruz Biotech). 


\subsection{MEASUREMENT OF RAT MYOCARDIAL CHEMOKINE MESSENGER RNA (MRNA) EXPRESSION}

Total RNA was isolated from heart tissues of 3 normal and 12 LAD-ligated rats using the RNAqueous kit from Ambion (Austin, Tex) and was converted to complementary DNA with SuperScript First Strand Synthesis System for RT-PCR from Invitrogen (Carlsbad, Calif). Reverse-transcriptase polymerase chain reaction was used to quantify myocardial expression of rat eotaxin, regulated on activation, normal $\mathrm{T}$ expressed and secreted (RANTES), monocyte chemotactic protein-3 (MCP3 ), and SDF-1 mRNA at baseline, and at $6,12,24$, and $48 \mathrm{~h}$ after LAD ligation after normalizing for rat RNA content using rat ribosomal protein L32 (RPL32) mRNA expression. Primer sequences for rat SDF-1 alpha were $5^{\prime}$ CTGTTGTGCTTACTTGTTTAAGGCTTTGTC- $3^{\prime}$ for forward primer and 5'-GACGCCAAGGTCGTCGGT$3^{\prime}$ for reverse primer. For rat ribosomal protein L32, primers were 5'-CCCTTCGGCCTCTGGTGAAGC-3' for forward primer and $5^{\prime}$ GAACACAAAAACAGGCACACAAGCCATC- $3^{\prime}$ for reverse primer. Primer sequences for rat MCP-3 5'TTTCACCGTGCACGTGTGGG-3' for forward primer and 5'-GTCTTCAGGGCTTTGGAGTTG-3' for reverse primer. Primer sequences for rat RANTES were 5'-ACCTGCCTCCCCATATGGCT-3' for forward primer and $5^{\prime}$ GTATTCTTGAACCCACTTCTTC-3' for reverse primer. Primer sequences for rat eotaxin were $5^{\prime}$ TTCTATTCCTGCTGCTCA-3' for forward primer and 5'-CCTGGACCCACTTTTTCT-3' for reverse primer. PCR was performed with the GeneAmp PCR System 9700 (ABI, Foster City, Calif). Amplification was for $1 \mathrm{~min}$ at 94 cycles, 27 cycles (RPL32) or 32 cycles (SDF-1, RANTES, MCP-3) with 30 seconds at 94 cycles and 1 minute at 68 cycles, followed by $5 \mathrm{~min}$ at 68 cycles. PCR products were analyzed on agarose gel stained with ethidium bromide. Reverse-transcriptase polymerase chain reaction products were scanned and quantified by UN-SCAN-IT software from Silk Scientific Inc (Orem, Utah). Values of eotaxin, RANTES, MCP-3, and SDF-1 expression were calculated relative to the values of RPL32 expression. Data were expressed as the means obtained from three independent rats for each time point.

\subsection{QUANTITATION OF CAPILLARY DENSITY}

To quantitate capillary density and species origin of the capillaries, we stained additional sections with mAbs directed against rat or human CD31 (AbD Serotec, Oxford, United Kingdom, and Research Diagnostics, Inc, Flanders, NJ, respectively), factor VIII (Dako, Carpinteria, Calif), and rat or human MHC class I (Accurate \& Scientific Corporation), as described before (17).

\subsection{MEASUREMENT OF MYOCYTE APOPTOSIS BY DNA END LABELING OF PARAFFIN TISSUES}

For in situ detection of apoptosis at the single cell level, we used the terminal deoxynucleotidyl transferase-mediated dUTP nick end labeling method of DNA end labeling mediated by dexynucleotidyl transferase (Boehringer Mannheim, Mannheim, Germany), as previously described (17).

\subsection{QUANTIFICATION OF INFARCT SIZE}

A Masson trichrome stain was performed to evaluate collagen content. This enabled measurement of the size of the myocardial scar using a digital image analyzer. Infarct area was measured with a planimeter digital image analyzer and expressed as a percentage of the total ventricular circumference.

\subsection{ANALYSES OF MYOCARDIAL FUNCTION}

Echocardiographic studies were performed with a high-frequency linear array transducer (SONOS 5500, Hewlett Packard, Andover, MA). Twodimensional images were obtained at midpapillary and apical levels. End-diastolic (EDV) and endsystolic (ESV) left ventricular volumes were obtained by biplane area-length method, and percent left ventricular ejection fraction was calculated as $([\mathrm{EDV}-\mathrm{ESV}] / \mathrm{EDV}) \times 100$.

\subsection{8-FLUORO-2-DEOXY-D-GLUCOSE (FDG) POSITRON EMISSION TOMOGRAPHY}

Imaging studies were performed in rats using a Concorde R4 $\mu \mathrm{PET}$ small animal positron emission tomography imaging system after administration of FDG as described in a previous publication (17).

\section{RESULTS}

\subsection{G-CSF MOBILIZED HUMAN BONE MARROW ANGIOBLASTS SELECTIVELY MIGRATE TO ISCHEMIC MYOCARDIUM IN VIVO}

In the absence of ischemia, the majority of intravenously injected human cells were trapped in the rat liver, spleen, and lungs, with only $3.2 \%$ migrating to the nonischemic heart. In contrast, after LAD ligation, $23 \%$ of the intravenously injected human cells were present in the heart $24 \mathrm{~h}$ after injection $(\mathrm{P}<0.01)$. Moreover, the heart was the only rat organ demonstrating a significant increase in migration of human cells after acute myocardial ischemia, with 7.1-fold increase in the indium-111 desintegration per minute count relative to nonischemic myocardium $(\mathrm{P}<0.01)$ (Figure 1). A detailed examination of cell migration to the heart revealed that $69.1 \%$ and $25.4 \%$ of the cells were detected at the infarction area and the periinfarct zone, respectively. Detection of injected cells at nonischemic myocardium accounted for less than $5 \%$.

\subsection{G-CSF MOBILIZED HUMAN BONE MARROW ANGIOBLASTS EXPRESS CCR AND CXCR4 CHEMOKINE RECEPTORS}


To identify potential chemokine receptor-ligand interactions involved in chemotaxis of G-CSFmobilized angioblasts to the ischemic myocardium, we examined the $\mathrm{CD} 34^{+} \mathrm{CD} 117^{\text {bright }}$ human angioblasts for surface expression of chemokine receptors, specifically the CCR3, which binds the CC chemokines eotaxin, RANTES, and MCP-3, and the CXCR4, which binds the CXC chemokine SDF-1. Shown in Figure 2, A, is CD117 expression on GCSF-mobilized human CD $34^{+}$cells, identifying the dual staining CD117 bright population previously shown to contain the angioblast fraction. The CD $34^{+}$CD $117^{\text {bright }}$ population expressed both CCR3 and CXCR4 receptors.

\subsection{LIGATION OF CCR3 AND CXCR4 CHEMOKINE RECEPTORS INDUCES IN VITRO MIGRATION OF G-CSF-MOBILIZED HUMAN BONE MARROW ANGIOBLASTS}

To examine the functional activity of CCR3 and CXCR4 receptors on the angioblasts, we measured in vitro chemotaxis of $\mathrm{CD} 34^{+} \mathrm{CD} 117$ bright human bone marrow cells after triggering these receptors with their specific ligands, respectively, eotaxin and SDF-1. As shown in Figure 2, B, human angioblasts demonstrated significant in vitro chemotactic responses to both eotaxin and SDF-1. In contrast, SCF, used as a negative control, was not chemotactic for this cellular population at a biologically active concentration, which induced 2fold proliferation of $\mathrm{CD} 34^{+} \mathrm{CD} 117^{\text {bright }}$ cells after culture for $96 \mathrm{~h}$.

\subsection{ACUTE MYOCARDIAL ISCHEMIA IS ASSOCIATED WITH INCREASED MRNA EXPRESSION OF CCR3-BINDING CHEMOKINES BUT NOT CXCR4-BINDING CHEMOKINES}

Next, we examined rat myocardial tissue at various time-points after LAD ligation to determine whether there was induced mRNA expression of the CCR3-binding CC chemokines eotaxin, RANTES, and MCP-3, and of the CXCR4-binding CXC chemokine SDF-1. As shown in Figure 3, A, after LAD ligation, rat myocardium demonstrated a timedependent increase in eotaxin mRNA expression, with 3 -fold induction above baseline being seen at $12 \mathrm{~h}$, and elevated levels returning to normal by $48 \mathrm{~h}$ $(\mathrm{P}<0.001)$. Induced expression of RANTES and MCP-3 mRNA was also noted, with maximal levels by $12 \mathrm{~h}$ (Figure $3, \mathrm{~B}$ and $\mathrm{C}$; both $\mathrm{P}<.01$ ). In contrast, by $12 \mathrm{~h}$ after acute myocardial ischemia, SDF-1 mRNA expression in the heart decreased by a mean of $43 \%(\mathrm{P}<.01$; Figure $3, \mathrm{D})$.

\subsection{CCR3-BINDING CHEMOKINES REGULATE MIGRATION OF HUMAN CD34 ${ }^{+}$ PROGENITORS TO ISCHEMIC MYOCARDIUM WHEREAS CXCR4 BINDING REGULATES MIGRATION TO BONE MARROW}

We next sought to directly demonstrate that interactions between myocardial CCR3-binding chemokines and CCR3 receptors on human CD34 ${ }^{+}$ progenitors contributed to myocardial homing of bone marrow angioblasts in LAD-ligated rats.

As shown in Figure 4, A, co-administration of a blocking mAb against CCR3 reduced myocardial trafficking of intravenously injected human bone marrow-derived $\mathrm{CD} 34^{+}$progenitors at $48 \mathrm{~h}$ by a mean of $60 \%$ relative to isotype control antibodies $(\mathrm{P}<0.01)$. In contrast, mAbs directed to other surface receptors present on these cells, such as CD34 or VEGF-R, as well as against CXCR4, did not inhibit migration to the ischemic myocardium. Moreover, anti-CXCR4 mAb inhibited migration of human $\mathrm{CD}_{34}^{+}$progenitors to rat bone marrow by a mean of $80 \% \quad(\mathrm{P}<0.01)$, whereas isotype control antibodies were without effect (Figure $4, \mathrm{~B}$ ).

\subsection{MANIPULATING CCR3- AND CXCR4- DEPENDENT INTERACTIONS INCREASES MIGRATION OF HUMAN CD34 ${ }^{+}$ PROGENITORS TO MYOCARDIAL TISSUE}

To definitively prove that CCR3-dependent interactions could redirect human $\mathrm{CD}_{3} 4^{+}$bone marrow progenitors to the heart in vivo, we injected human recombinant eotaxin at $1.0 \mu \mathrm{g} / \mathrm{mL}$ into noninfarcted rat hearts concomitantly with intravenous injection of human angioblasts. As shown in Figure 4, C, this resulted in 2.3-fold increases in myocardial infiltration by human $\mathrm{CD}^{+} 4^{+}$progenitors at $48 \mathrm{~h}(\mathrm{P}<0.01)$, whereas SCF and VEGF, used as negative controls, had little effect. Intramyocardial injection of SDF-1 of $1.0 \mu \mathrm{g} / \mathrm{mL}$ was also effective, inducing a 2.5 -fold increase in angioblast chemotaxis to normal rat hearts $(\mathrm{P}<0.01)$. However, no increase in myocardial neovascularization was observed at 2 weeks after eotaxin or SDF-1 injection (data not shown), suggesting that additional factors produced under ischemic conditions are necessary for angioblast differentiation into mature hematopoietic cells and subsequent new blood vessel formation.

\subsection{INTRAMYOCARDIAL SDF-1 AUGMENTS NEOVASCULARIZATION, PROTECTS AGAINST CARDIOMYOCYTE APOPTOSIS, AND INDUCES FUNCTIONAL RECOVERY}

We finally examined whether increasing myocardial expression of SDF-1 could result in increased angioblast homing to the ischemic heart and augment angioblast-dependent neovascularization and cardiomyocyte survival after acute ischemia. As shown in Figure 5, A and B, co-administration of intramyocardial SDF-1 induced 2-fold greater myocardial neovascularization accompanying intravenous angioblast injection $(\mathrm{P}<0.01)$ and induced $76 \%$ further reduction in cardiomyocyte apoptosis $(\mathrm{P}<0.01)$. Moreover, co-administration of intramyocardial SDF-1 together with intravenous angioblasts resulted in an almost 3 -fold greater improvement in left ventricular ejection fraction as compared with intravenous injection of angioblasts alone (Figure 5, C; $\mathrm{P}<0.01$ ). Quantification of the infarct size showed a $32 \%$ reduction in animals treated with both local SDF-1 application and injection of $\mathrm{CD}^{+} 4^{+}$cells, as compared with a $19 \%$ 

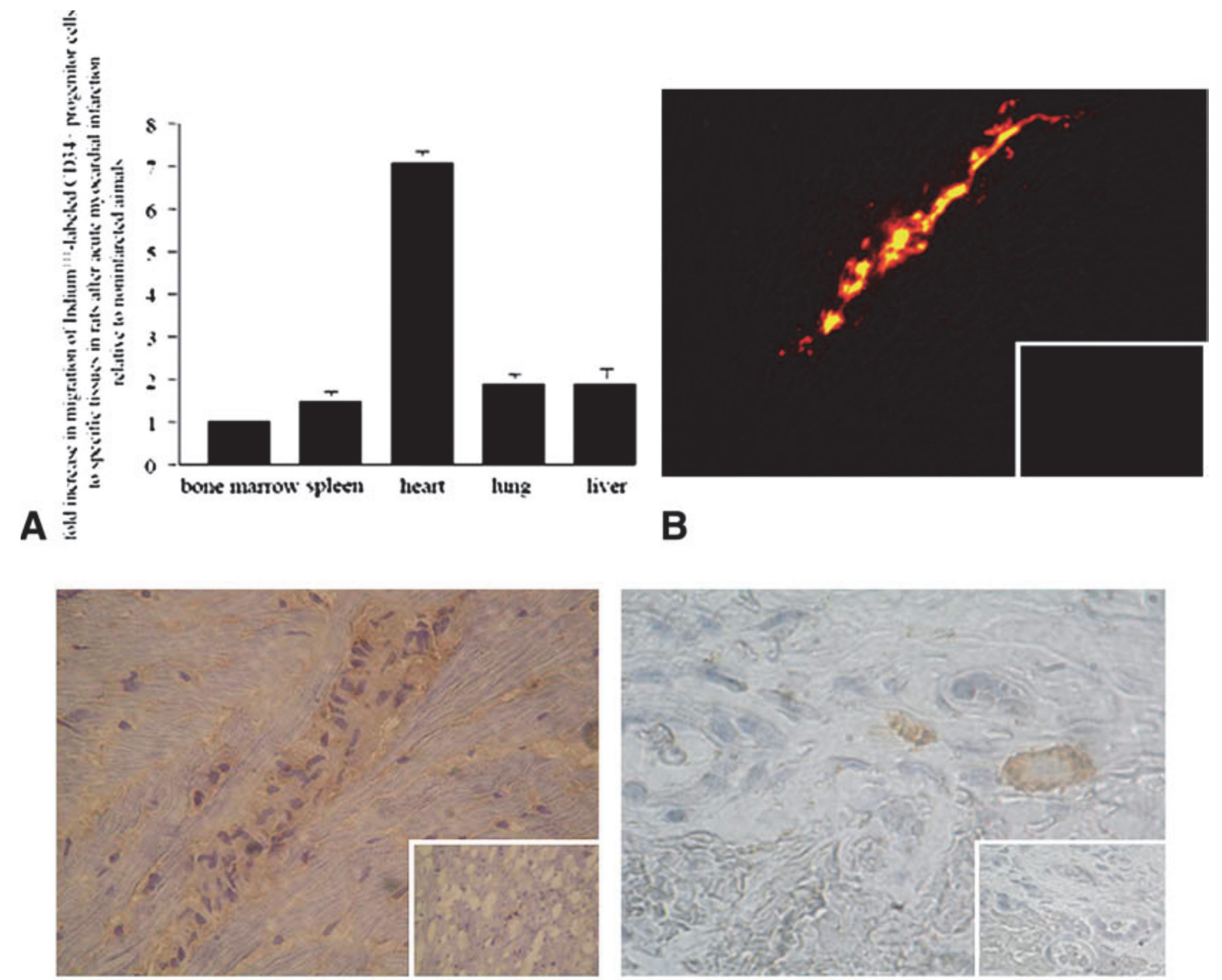

C

D

Figure 1. G-CSF mobilized human bone marrow $\mathrm{CD}_{3} 4^{+}$progenitors selectively migrate to ischemic myocardium in vivo. A, Detection of indium 111-labeled human bone marrow CD34 ${ }^{+}$progenitors at different organs. B, Fluorescence microscopy shows positive cell engraftment in the infarct area as detected by DiI fluorescence (the side panel represents a negative control). C, Verification of cell engraftment by detection of MHC class I B-2 microglobulin in the ischemic area by means of immunohistochemistry (the side panel represents a negative control). D, The human origin of the cells was confirmed by staining against the human mitochondrial epitope S-100.

reduction detected after single $\mathrm{CD} 34^{+}$cell injections $(\mathrm{P}=0.031)$. In addition, myocardial perfusion studies using FDG uptake showed a significantly improved tissue perfusion after combined treatment as

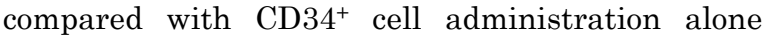
$(\mathrm{P}=0.004)$ (Figure 6).

\section{DISCUSSION}

Chemokine receptor-ligand interactions play a major role in leukocyte traffic and recruitment to sites of tissue damage or inflammation $(18,19)$. In this study, we have shown that human CD $34^{+}$bone marrow progenitors, which include CD117 bright angioblasts or hematopoietic progenitor cells, use two alternative chemokine receptor-ligand pairs to migrate to bone marrow or ischemic myocardium. The site of directed migration was primarily dependent on the specificity of locally induced chemokines, rather than alterations in chemokine receptor expression. Migration to the bone marrow was CXCR4-dependent in response to constitutive expression of the CXCR4-binding chemokine SDF-1 at this site. In contrast, migration to ischemic rat myocardium was CCR3- but not CXCR4-dependent, in response to induced mRNA expression of the CCR3-binding chemokines eotaxin, RANTES, and MCP-3, but not SDF-1. However, intramyocardial injection of SDF-1 redirected migration of human angioblasts to ischemic rat hearts, resulting in augmented neovascularizarion, enhanced cardiomyocyte survival, and functional cardiac recovery. These results demonstrate the feasibility of manipulating chemokine receptor-ligand interactions for therapy of cardiovascular disease and suggest that augmenting CXCR4-dependent interactions at extrahematopoietic sites could provide a general paradigm for enhancing hypoxic or ischemic tissue repair by bone marrow-derived hematopoietic progenitors. Our study elaborated on the role of CCR3- and CXCR4-mediated 

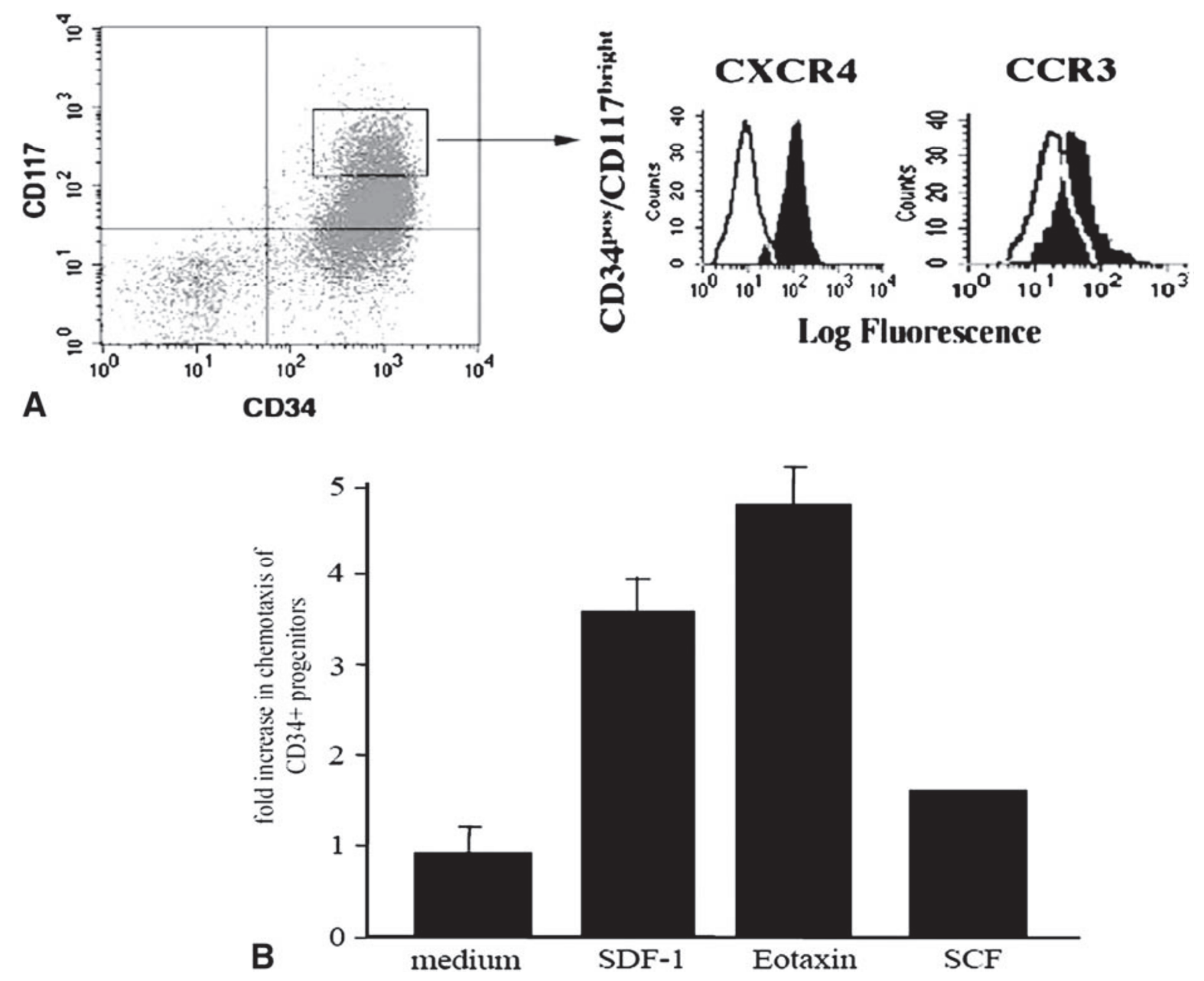

Figure 2. G-CSF mobilized human bone marrow-derived angioblasts express chemokine receptors CCR3 and CXCR4, and demonstrate in vitro chemotactic responses to their ligands, eotaxin and SDF-1. A, Fourparameter flow cytometric phenotypic characterization of GCSF-mobilized bone marrow-derived cells obtained by leukopharesis from a representative human donor adult. Only live cells were analyzed, as defined by 7-AAD staining. For each marker used, open areas represent background log fluorescence relative to isotype control antibody. The angioblast fraction has previously been characterized to reside in the minor $\mathrm{CD}_{3} 4^{+}$population expressing CD117 brightly. The CD34+CD117 bright angioblast subset expresses CXCR4 and CCR3. The injected CD34 ${ }^{+}$cells had a purity of greater than $98 \%$; $90 \%$ to $95 \%$ co-expressed the hematopoietic lineage marker CD45, 60\% to 80\% co-expressed the SCF receptor CD117, and less than $1 \%$ co-expressed the monocyte/macrophage lineage marker CD14. B, Results of in vitro chemotaxis of human angioblasts in response to various conditions using a 48-well chemotaxis chamber (Neuro Probe, Inc, Gaithersburg, Md). Chemotaxis is defined as the number of migrating cells per high-power field after examination of 10 high-power fields per condition tested. Chemotaxis is increased in response to eotaxin and SDF-1 (both $\mathrm{P}<0.01$ ), but not SCF (results are expressed as mean \pm SEM of 3 separate experiments).

chemoattraction in the early phase after acute myocardial infarction, and data on the midterm and long-term cell survival in ischemic myocardium were not included.

Homing and retention of hematopoietic progenitors in mammalian bone marrow are processes controlled by a number of adhesive interactions between stromal cells and hematopoietic progenitors $(2,3)$. Binding of SDF-1 to its ligand, CXCR4, results in augmented interactions between integrin receptor-ligand pairs, including very late antigen-4 and vascular cell adhesion molecule (VCAM-1)/CD106 (18), which serve to tether and retain very late antigen-4 expressing progenitors to VCAM-1/CD106 positive stromal cells in the bone marrow. Systemic treatment with G-CSF induces activation of neutrophil precursors in the bone marrow and their subsequent secretion of neutrophil proteases, which directly cleave the N-terminal regions of SDF-1 and CXCR4, as well as VCAM-1 $(6,7)$. Inasmuch as this results in egress of hematopoietic progenitors from the bone marrow into the peripheral circulation, GCSF administration may facilitate myocardial migration of $\mathrm{CD}^{+} 4^{+} \mathrm{CD} 117^{\text {bright }}$ angioblasts in response to CCR3-binding chemokines induced in the ischemic heart.

Eotaxin is principally produced by smooth muscle cells and fibroblasts in subendothelial tissue locations (20), and its expression is typically 


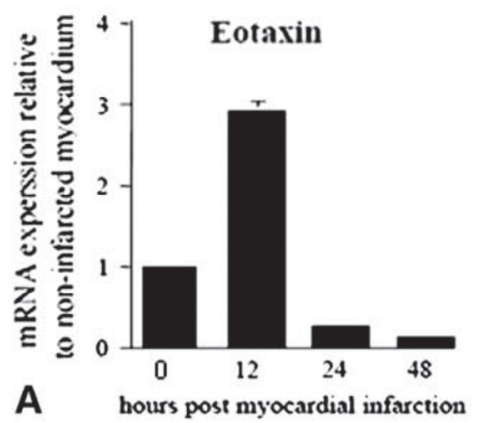

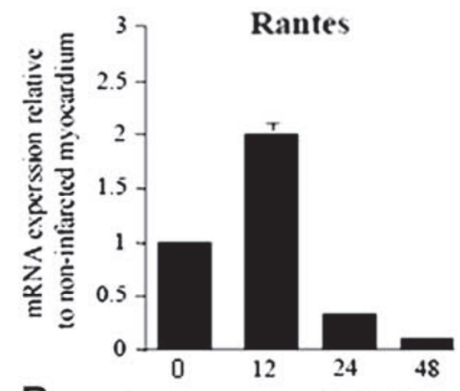

$\mathbf{B}$

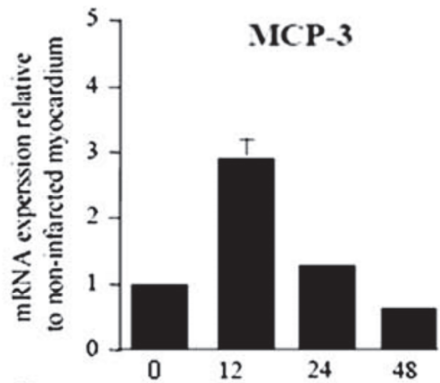

C hours post myocardial infarction

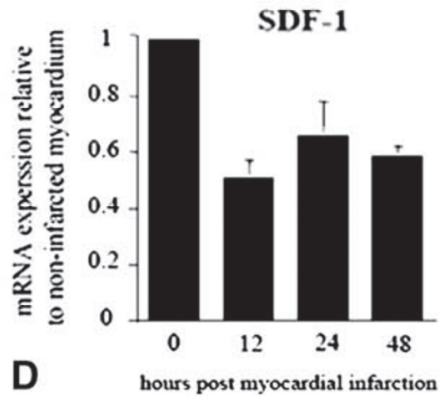

Figure 3. Increased myocardial mRNA expression of CCR3-binding chemokines, but not CXCR4-binding chemokines, after acute ischemia. A to D, Chemokine mRNA expression in rat myocardial tissue examined at various time-points after LAD ligation relative to constitutive expression of RPL32 to determine whether there was induced mRNA expression of the CCR3-binding CC chemokines eotaxin, RANTES, and MCP-3, and of the CXCR4-binding CXC chemokine SDF-1. Induced expression of eotaxin, RANTES, and MCP-3 mRNA was noted, with maximal mRNA levels by 6 to $12 \mathrm{~h}$ (all $\mathrm{P}<0.01$ ). In contrast, by $12 \mathrm{~h}$ after acute myocardial ischemia, SDF-1 mRNA expression decreased by a mean of $43 \%$ in cardiac tissue $(\mathrm{P}<.01)$ (results are expressed as mean \pm SEM of 3 separate experiments).

associated with the recruitment of eosinophils and basophils to inflamed tissues and their accumulation during certain inflammatory processes, such as allergy and asthma (21). The eotaxin receptor, CCR3, is expressed on eosinophils, basophils, mast cells, and the Th2 subset of T cells, and also binds the chemokines RANTES and MCP-3 with high affinity, but not other CC or CXC chemokines (22-24). Increased levels of eotaxin in autoimmune myocardial inflammation and during rejection episodes of transplanted heart confirm its crucial role as chemoattractant in myocardial tissue $(25,26)$.

These observations suggest that CCR3-dependent chemokine interactions direct migration of bone marrow-derived leukocyte progenitors away from the marrow to distal sites of tissue damage and inflammation. In support of these conclusions, CCR3-deficient mice demonstrate altered migration of eosinophils and mast cells, respectively, to the intestine and lungs (24). Our results extend these observations to migration of human CD $34^{+} \mathrm{CD} 117^{\text {bright }}$ bone marrow progenitors to the site of myocardial ischemia where expression of eotaxin, RANTES, and MCP-3 mRNA was induced. Moreover, since hypoxia is a stimulus for induction of eotaxin mRNA (27), we hypothesize that CCR3directed chemotaxis of human $\mathrm{CD}^{+} 4^{+} \mathrm{CD} 117^{\text {bright }}$ angioblasts or hematopoietic progenitors contributes to neovascularization of hypoxic or damaged tissues throughout the body.
Constitutive expression of CCR3 has also been reported by human and mouse bone marrow progenitors as well as dendritic cells $(14,15)$. However, whereas CD34+ eosinophil and dendritic bone marrow-derived progenitors demonstrate CCR3-dependent chemotactic responses (23-25), mouse hematopoietic stem cells that home to the bone marrow and recapitulate hematopoiesis do not (13).

SDF-1, a biologically active chemotactic factor for human endothelial progenitors (28), augmented angioblast-dependent myocardial chemotaxis, neovascularization, cardiomyocyte survival, and functional cardiac recovery when directly injected into the ischemic myocardium. Together with results from adult humans in whom SDF-1 expression at extrahematopoietic sites is accompanied by aberrant neovascularization (28), our data demonstrate that SDF-1 expression at sites outside the bone marrow can play a major role in induction of tissue neovascularization by bone marrow-derived hematopoietic progenitors. These conclusions are supported by recent studies using SDF-1 in an animal model of reduced hind limb perfusion (29) and in genetically engineered skeletal myoblasts implanted into ischemic myocardium (30).

Together, our results suggest that redirected migration of $\mathrm{CD} 34^{+}$progenitors from the bone marrow to sites of acute injury may represent a general mechanism by which endogenous repair of 

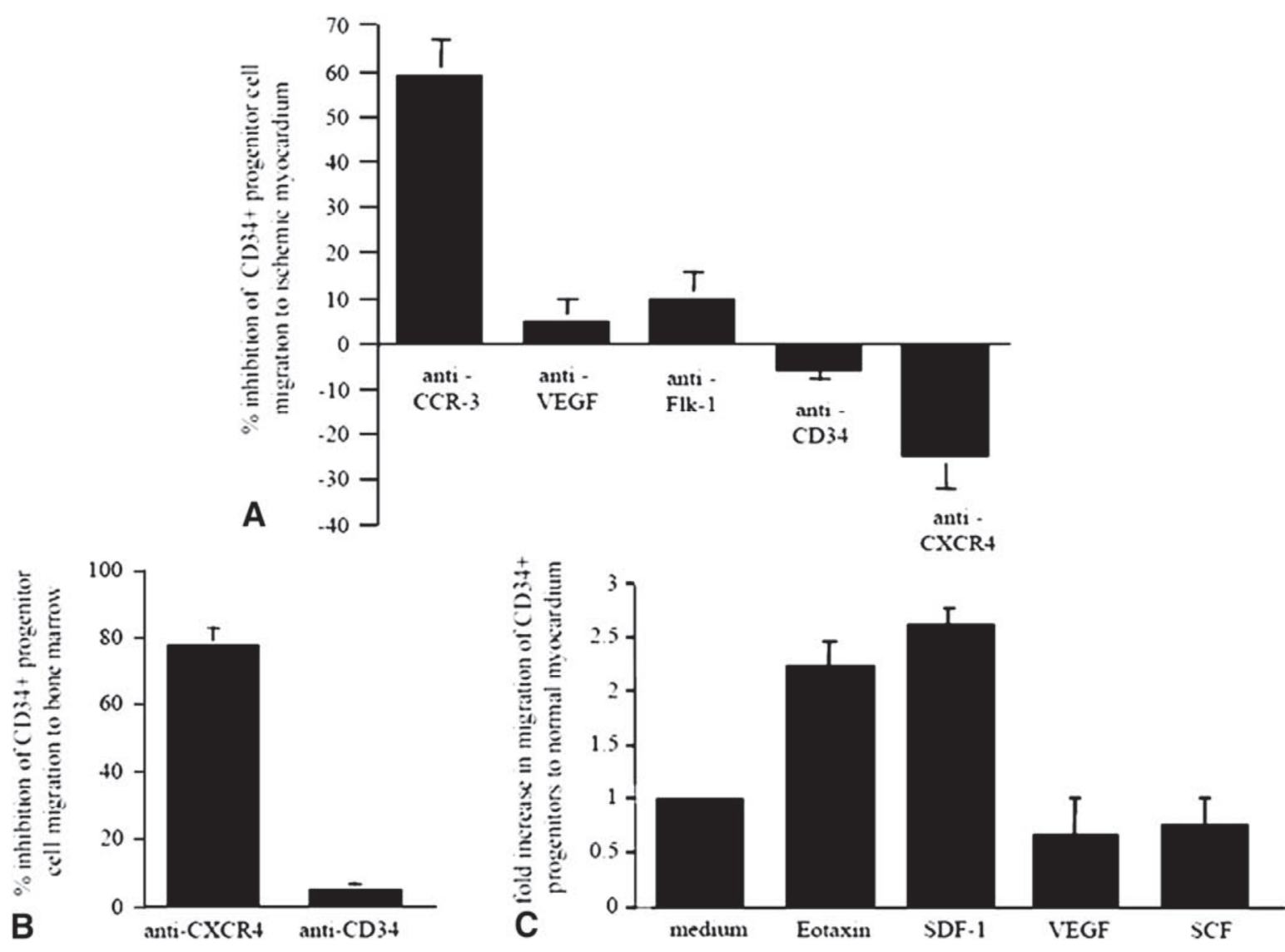

Figure 4. CCR3-binding chemokines regulate migration of human $\mathrm{CD} 34^{+}$progenitors to ischemic myocardium, whereas CXCR4-binding regulates migration to bone marrow. A, Migration of human angioblasts to ischemic rat myocardium at 2 days after intravenous injection is inhibited by antihuman CCR3 mAb $(\mathrm{P}<0.01)$, but not by mAbs against CXCR4, Flk-1, or isotype control (results are expressed as mean \pm SEM of 3 separate experiments). B, the proportion of human CD34 ${ }^{+} \mathrm{CD} 117^{\text {bright }}$ angioblasts in rat bone marrow at 2 days after intravenous injection is significantly decreased by co-administration of antiCXCR $4 \mathrm{mAb}$ (results are expressed as mean $\pm \mathrm{SEM}$ of bone marrow studies in 3 animals at each time point). c, Intracardiac injection of eotaxin or SDF-1 at $1 \mathrm{mg} / \mathrm{mL}$ significantly increases in vivo chemotaxis of DiIlabeled human angioblasts (98\% CD34+ purity) into nonischemic rat myocardium in comparison with injection of saline or ( $\mathrm{SCF}$, both $\mathrm{P}<0.01$ (results are expressed as mean $\pm \mathrm{SEM}$ of 3 separate experiments). Below are shown representative examples of DiI fluorescence microscopy in nonischemic rat hearts after intravenous angioblast administration accompanied by intracardiac injection with eotaxin or SDF-1.

damaged tissues occurs, and that the specificity of the migratory pattern is governed by the induced chemokine profile in a given injured tissue. Moreover, our results suggest that it may be possible to selectively activate CXCR4- or CCR3dependent chemotactic pathways to direct migration of $\mathrm{CD}_{3} 4^{+}$progenitors to sites of tissue ischemia or damage and induce therapeutic neovascularization for tissue repair. The effect of this combined approach using autologous cells injections in immunocompetent hosts is required to address the question of clinical applicability.

\section{ABBREVIATIONS AND ACRONYMS}

CCR3

CXCR4

FDG
G-CSF

LAD

Mab

MCP-3

MHC

RANTES

RPL32

SCF

SDF-1

VCAM-1

VEGF

VEGFR-2
Granulocyte-colony stimulating factor

Left anterior descending coronary artery

Monoclonal antibody

Monocyte chemotactic protein-3

Major histocompatibility complex

Regulated on activation, normal $\mathrm{T}$ expressed and secreted Ribosomal protein L32

Stem cell factor

Stromal cell-derived factor-1

Vascular cell adhesion molecule Vascular endothelial growth factor Vascular endothelial growth factor receptor-2 


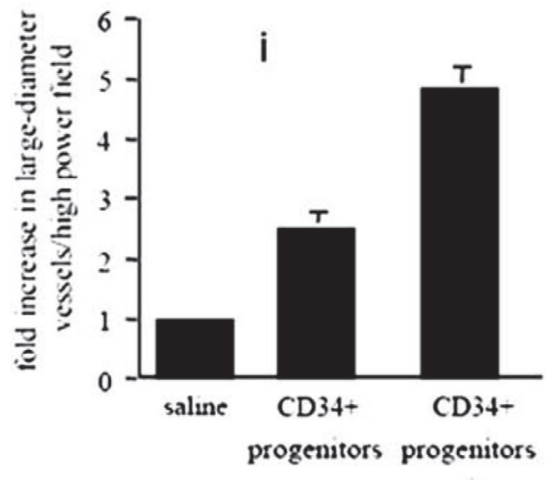

A
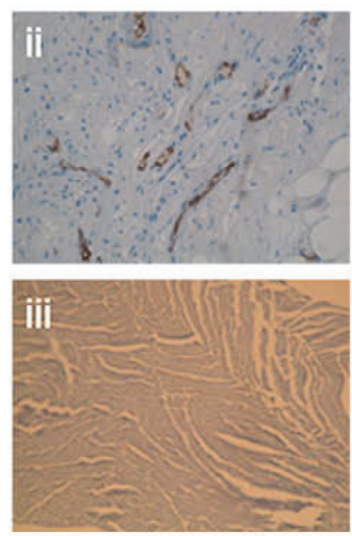

B SDF-1

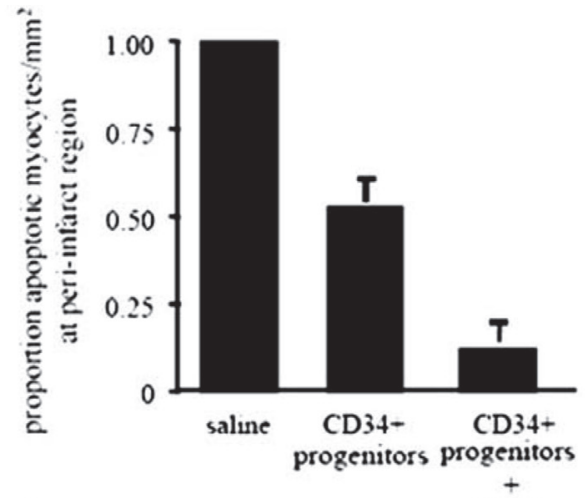

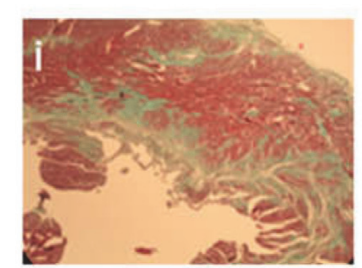

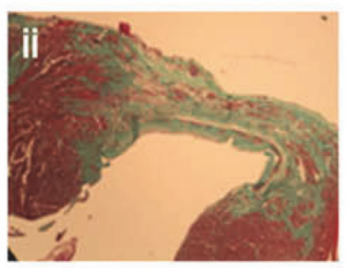

C

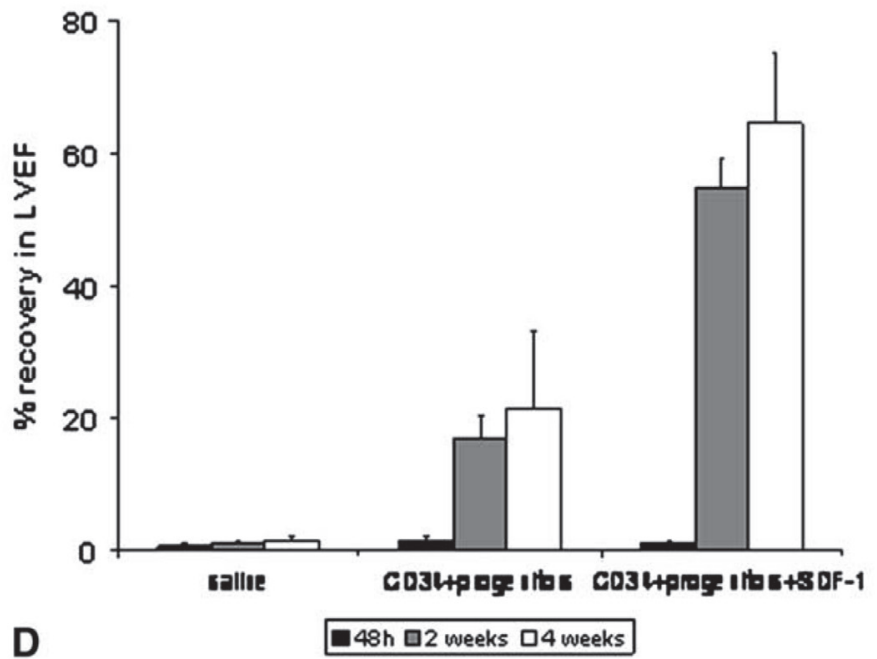

Figure 5. Intramyocardial injection of SDF-1 increases angioblast chemotaxis to ischemic myocardium, augmenting neovascularization, cardiomyocyte survival, and functional cardiac recovery. Intracardiac injection of SDF-1 into infarcted rat hearts in combination with intravenously-injected CD $34^{+}$human bone marrow cells resulted in a further 2-fold increase in capillary numbers (A), in a further reduction in cardiomyocyte apoptosis of $76 \%$ (B), and in a further reduction in infarct size (C) as compared with intravenously-injected angioblasts alone (all $\mathrm{P}<0.001$ ). The results of vascular density are expressed as mean \pm SEM of 3 separate experiments. Large diameter vessels include vessels built by more than 6 nuclei and with a diameter greater than $20 \mathrm{~mm}$. Representative staining against factor VIII and Masson trichrome stain shows increased vasculary density and reduced infarct scar, respectively, in treated animals (i) as compared with controls (ii). (D). Intracardiac co-administration of SDF-1 results in 4-fold greater improvement in left ventricular ejection fraction, determined by echocardiography, compared with intravenous injection of $\mathrm{CD}^{+} 4^{+}$human bone marrow cells alone $(\mathrm{P}<0.01)$. Results are expressed as mean \pm SEM of 3 separate experiments. 


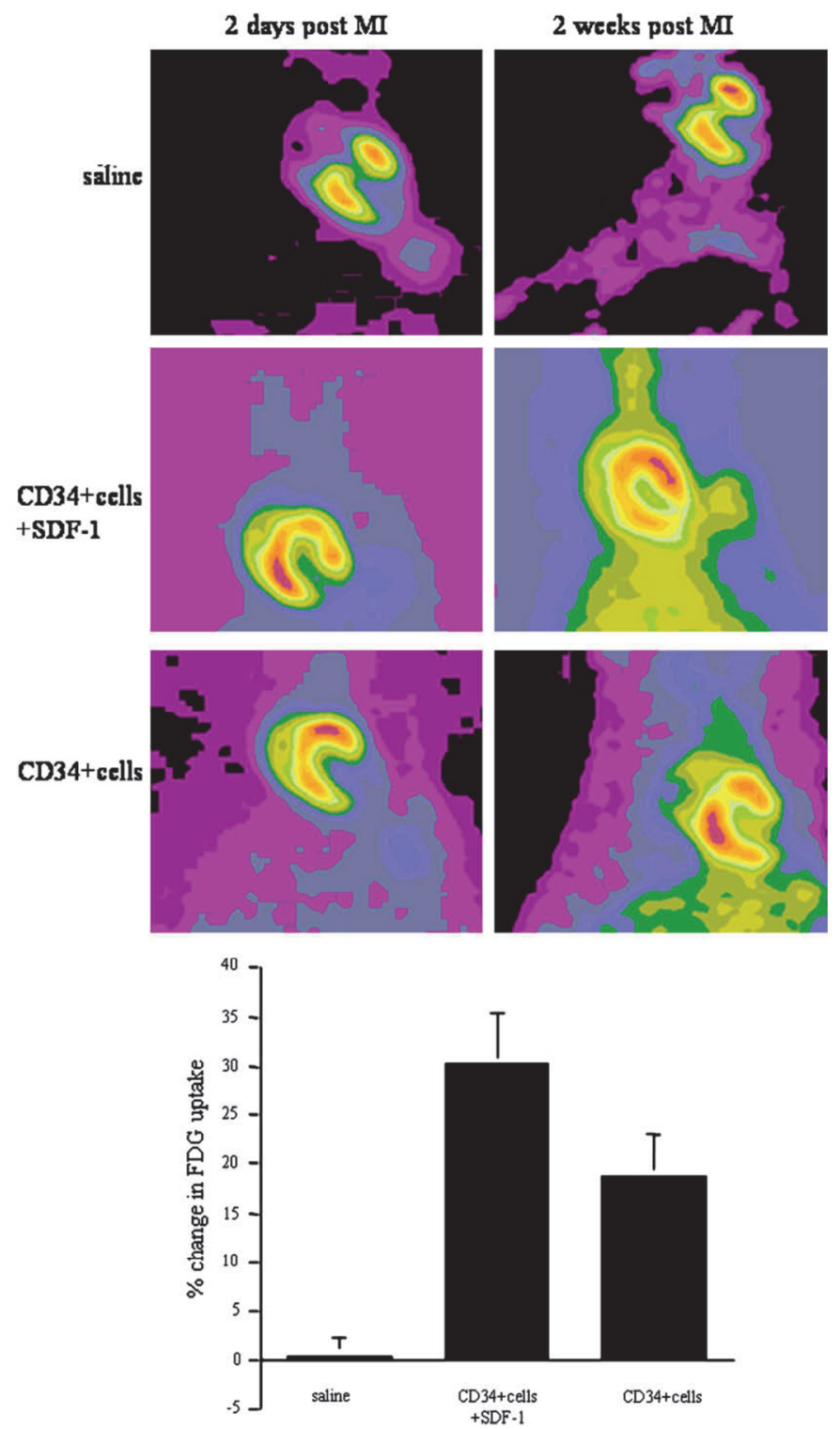

Figure 6. Emission tomography shows that intracardiac administration of SDF-1 results in an almost 2 fold increase of FDG uptake in animals treated with local administration of SDF-1 and injection of CD34 ${ }^{+}$ cells, as compared with animals subjected to injection of $\mathrm{CD} 34^{+}$cells alone $(\mathrm{P}<0.01)$.

\section{REFERENCES}

1. D. E. Wright, Physiological migration of hematopoietic stem and progenitor cells. Science 294, 1933 (2001/11/30, 2001).

2. P. S. Frenette, S. Subbarao, I. B. Mazo, U. H. von Andrian, D. D. Wagner, Endothelial selectins and vascular cell adhesion molecule-1 promote hematopoietic progenitor homing to bone marrow. Proceedings of the National Academy of Sciences 95, 14423 (1998/11/24, 1998).

3. C. M. Verfaillie, Adhesion receptors as regulators of the hematopoietic process. Blood 92, 2609 (Oct 15, 1998).

4. R. Mohle, F. Bautz, S. Rafii, S. Rafii, M. A. S. Moore, W. Brugger, L. Kanz, Regulation of transendothelial migration of hematopoietic progenitor cells. Annals of the New York Academy of Sciences 872, 176 (1999/04, 1999).

5. M. Honczarenko, Y. Le, M. Swierkowski, I. Ghiran, A. M. Glodek, L. E. Silberstein, Human bone marrow stromal cells express a distinct set of biologically functional chemokine receptors. Stem cells 24, 1030 (2006/04, 2006).

6. J. P. Levesque, J. Hendy, Y. Takamatsu, P. J. Simmons, L. J. Bendall, Disruption of the CXCR4/CXCL12 chemotactic interaction during hematopoietic stem cell mobilization induced by GCSF or cyclophosphamide. J Clin Invest 111, 187 (Jan, 2003).

7. I. Petit, M. Szyper-Kravitz, A. Nagler, M. Lahav, A. Peled, L. Habler, T. Ponomaryov, R. S. Taichman, F. Arenzana-Seisdedos, N. Fujii, J. Sandbank, D. Zipori, T. Lapidot, Erratum: GCSF induces stem cell mobilization by decreasing bone marrow SDF-1 and up-regulating CXCR4. Nature Immunology 3, 687 (2002/06/17, 2002).

8. E. Lagasse, H. Connors, M. Al-Dhalimy, M. Reitsma, M. Dohse, L. Osborne, X. Wang, M. Finegold, I. L. Weissman, M. Grompe, Purified hematopoietic stem cells can differentiate into hepatocytes in vivo. Nature medicine 6, 1229 (2000/11, 2000). 
9. D. S. Krause, N. D. Theise, M. I. Collector, O. Henegariu, S. Hwang, R. Gardner, S. Neutzel, S. J. Sharkis, Multi-organ, multi-lineage engraftment by a single bone marrow-derived stem cell. Cell 105, 369 (2001/05, 2001).

10. A. A. Kocher, M. D. Schuster, M. J. Szabolcs, S. Takuma, D. Burkhoff, J. Wang, S. Homma, N. M. Edwards, S. Itescu, Neovascularization of ischemic myocardium by human bone-marrowderived angioblasts prevents cardiomyocyte apoptosis, reduces remodeling and improves cardiac function. Nature medicine 7, 430 (2001/04, 2001).

11. V. Schächinger, B. Assmus, M. B. Britten, J. Honold, R. Lehmann, C. Teupe, N. D. Abolmaali, T. J. Vogl, W.-K. Hofmann, H. Martin, S. Dimmeler, A. M. Zeiher, Transplantation of progenitor cells and regeneration enhancement in acute myocardial infarction. Journal of the American College of Cardiology 44, 1690 (2004/10, 2004)

12. C. Stamm, B. Westphal, H.-D. Kleine, M. Petzsch, C. Kittner, H. Klinge, C. Schümichen, C. A. Nienaber, M. Freund, G. Steinhoff, Autologous bone-marrow stem-cell transplantation for myocardial regeneration. The Lancet 361, 45 (2003/01, 2003).

13. D. E. Wright, E. P. Bowman, A. J. Wagers, E. C. Butcher, I. L. Weissman, Hematopoietic stem cells are uniquely selective in their migratory response to chemokines. The Journal of Experimental Medicine 195, 1145 (2002/05/06, 2002).

14. B. Lamkhioued, S. G. Abdelilah, Q. Hamid, N. Mansour, G. Delespesse, P. M. Renzi, The CCR3 receptor is involved in eosinophil differentiation and is up-regulated by Th2 cytokines in CD34+ progenitor cells. The Journal of Immunology 170, 537 (2003/01/01, 2003).

15. J. J. Lataillade, D. Clay, C. Dupuy, S. Rigal, C. Jasmin, P. Bourin, M. C. Le Bousse-Kerdiles, Chemokine SDF-1 enhances circulating CD34 cell proliferation in synergy with cytokines: possible role in progenitor survival. Blood 95, 756 (Feb 1, 2000).

16. B. B. Chin, Y. Nakamoto, J. W. Bulte, M. F. Pittenger, R. Wahl, D. L. Kraitchman, ${ }^{111}$ In oxine labelled mesencymal stem cell SPECT after intravenous administration in myocardial infarction. Nuclear Medicine Communications 24, 1149 (2003/11, 2003).

17. A. A. Kocher, M. D. Schuster, N. Bonaros, K. Lietz, G. Xiang, T. P. Martens, P. A. Kurlansky, H. Sondermeijer, P. Witkowski, A. Boyle, Myocardial homing and neovascularization by human bone marrow angioblasts is regulated by IL-8/Gro CXC chemokines. Journal of molecular and cellular cardiology 40, 455 (2006/04, 2006).

18. W. Shen, L. J. Bendall, D. J. Gottlieb, K. F. Bradstock, The chemokine receptor CXCR4 enhances integrin-mediated in vitro adhesion and facilitates engraftment of leukemic precursor-B cells in the bone marrow. Experimental Hematology 29, 1439 (2001/12, 2001).

19. S. Vandervelde, M. Vanluyn, R. Tio, M. Harmsen, Signaling factors in stem cellmediated repair of infarcted myocardium.
Journal of molecular and cellular cardiology 39, $363(2005 / 08,2005)$.

20. L. M. Teran, M. Mochizuki, J. Bartels, E. L. Valencia, T. Nakajima, K. Hirai, J.-M. Schröder, Th1- and Th2-Type cytokines regulate the expression and production of eotaxin and RANTES by human lung fibroblasts. American Journal of Respiratory Cell and Molecular Biology 20, 777 (1999/04, 1999).

21. E. A. Garcia-Zepeda, M. E. Rothenberg, R. T. Ownbey, J. Celestin, P. Leder, A. D. Luster, Human eotaxin is a specific chemoattractant for eosinophil cells and provides a new mechanism to explain tissue eosinophilia. Nature medicine $\mathbf{2}$, 449 (1996/04, 1996).

22. B. L. Daugherty, Cloning, expression, and characterization of the human eosinophil eotaxin receptor. Journal of Experimental Medicine 183, $2349(1996 / 05 / 01,1996)$.

23. F. Sallusto, C. R. Mackay, A. Lanzavecchia, Selective expression of the eotaxin receptor CCR3 by human T helper 2 cells. Science $\mathbf{2 7 7}$, 2005 (1997/09/26, 1997).

24 A. A. Humbles, B. Lu, D. S. Friend, S. Okinaga, J. Lora, A. Al-garawi, T. R. Martin, N. P. Gerard, C. Gerard, The murine CCR3 receptor regulates both the role of eosinophils and mast cells in allergen-induced airway inflammation and hyperresponsiveness. Proceedings of the National Academy of Sciences 99, 1479 (2002/02/05, 2002).

25. S. Goser, M. Andrassy, S. J. Buss, F. Leuschner, C. H. Volz, Ottl, R., Zittrich, S., N. Blaudeck, S. E. Hardt, G. Pfitzer, N. R. Rose, H. A. Katus, Z. Kaya, Cardiac troponin I but not cardiac troponin $\mathrm{T}$ induces severe autoimmune inflammation in the myocardium. Circulation 114, 1693 (2006/10/17, 2006).

26. M. Melter, A. Exeni, M. E. J. Reinders, J. C. Fang, G. McMahon, P. Ganz, W. W. Hancock, D. M. Briscoe, Expression of the chemokine receptor CXCR3 and its ligand IP-10 during human cardiac allograft Rejection. Circulation 104, 2558 (2001/11/20, 2001).

27. M. Moayeri, D. Haines, H. A. Young, S. H. Leppla, Bacillus anthracis lethal toxin induces TNF-a-independent hypoxia-mediated toxicity in mice. Journal of Clinical Investigation 112, 670 (2003/09/01, 2003).

28. M. A. S. Moore, K. Hattori, B. Heissig, J. H. Shieh, S. Dias, R. G. Crystal, S. Rafii, Mobilization of endothelial and hematopoietic stem and progenitor cells by adenovectormediated elevation of serum levels of SDF-1, VEGF, and Angiopoietin-1. Annals of the New York Academy of Sciences 938, 36 (2006/01/25, 2006).

29. J. Yamaguchi, K. F. Kusano, O. Masuo, A. Kawamoto, M. Silver, S. Murasawa, M. BoschMarce, H. Masuda, D. W. Losordo, J. M. Isner, T. Asahara, Stromal cell-derived factor-1 effects on ex vivo expanded endothelial progenitor cell recruitment for ischemic neovascularization. Circulation 107, 1322 (Mar 11, 2003).

30. A. T. Askari, S. Unzek, Z. B. Popovic, C. K. Goldman, F. Forudi, M. Kiedrowski, A. Rovner, S. G. Ellis, J. D. Thomas, P. E. DiCorleto, E. J. Topol, M. S. Penn, Effect of stromal-cell-derived factor 1 on stem-cell homing and tissue regeneration in ischaemic cardiomyopathy. The Lancet 362, $697 \quad$ (2003/08, 2003). 


\section{Chapter 7}

\section{Downregulation of the CXC chemokine receptor 4/stromal cell-derived factor 1 pathway enhances myocardial neovascularization, cardiomyocyte survival, and functional recovery after myocardial infarction.}

The Journal of Thoracic and Cardiovascular Surgery. 2011 Sep; 142(3):687-96.

Nikolaos Bonaros", Hugo P. Sondermeijer", Dominik Wiedemann, Bernhard Schlechta, Thomas Schachner, Michael Schuster, Tetsunori Seki, Timothy P. Martens, Silviu Itescu, and Alfred A. Kocher (\#contributed equally). 


\section{ABSTRACT}

Objectives: Although adequate numbers of hematopoietic progenitor cells reside in the human bone marrow, the extent of endogenous neovascularization after myocardial infarction remains insufficient. The aim of this study was to identify the role of the CXC chemokine receptor 4/stromal cell-derived factor 1 axis in the mobilization and homing of hematopoietic progenitor cells in the ischemic heart. Methods: Human bone marrowderived hematopoietic progenitor cells or saline were injected systemically into athymic nude rats 48 hours after myocardial infarction. Myocardial and bone marrow expression of stromal cell-derived factor 1 and chemotaxis of hematopoietic progenitor cells were measured in vitro in the presence or absence of stromal cell-derived factor 1 . The role of the CXC chemokine receptor 4/stromal cell-derived factor 1 axis was investigated by means of antibody blockade or systemic administration of granulocyte colonystimulating factor. Morphologic analysis included measurement of the infarct area, capillary density, and apoptosis, whereas left ventricular function was measured by means of echocardiographic analysis. Results: Expression of postinfarct stromal cellderived factor 1 was increased by $67 \%$ in the bone marrow and decreased by $43 \%$ in myocardium. Disruption of bone marrow stromal cell-derived factor 1/CXC chemokine receptor 4 interactions by antibody blockade resulted in a redirection of human hematopoietic progenitor cells from the bone marrow to the ischemic heart and augmented neovascularization and cardiomyocyte survival. Similarly, systemic administration of granulocyte colony-stimulating factor to block CXC chemokine receptor 4/stromal cell-derived factor 1 interaction resulted in increased mobilization and homing of hematopoietic progenitor cells to the ischemic heart, which translated to augmented myocardial neovascularization, prevention of apoptosis, and improved cardiac function. Conclusions: Bone marrow stromal cell-derived factor 1 upregulation after myocardial ischemia prevents mobilization of endogenous hematopoietic progenitor cells. We provide evidence that disruption of stromal cell-derived factor 1/CXC chemokine receptor 4 interactions allows redirection of hematopoietic progenitor cells to ischemic myocardium and enhances recovery of left ventricular function.

\section{INTRODUCTION}

Although development of neovascularization is an integral component of the remodeling process after myocardial infarction (MI) (1), it is insufficient to keep pace with the tissue growth required for contractile compensation and is unable to support the greater demands of the hypertrophied but viable myocardium. Transplantation of ex vivo isolated hematopoietic progenitor cells (HPCs) after acute ischemia results in myocardial neovascularization, enhanced myocardial perfusion, and improved functional recovery in both animal models and human subjects (2-5). A combination of mechanisms enabling egress or migration of HPCs from the bone marrow to the heart and transplantation of HPCs in the myocardium might improve the results of cardiac neovascularization after MI.

Homing and retention of $\mathrm{HPCs}$ in mammalian bone marrow are controlled by interactions between stromal cells and hematopoietic progenitors $(6,7)$. The CXC chemokine stromal cell-derived factor 1 (SDF-1), which is constitutively produced by bone marrow stromal cells, appears to be essential for homing and engraftment of HPCs $(8,9)$. Systemic treatment with granulocyte colony-stimulating factor (G-CSF) results in transient egress of HPCs from the bone marrow into the peripheral circulation $(10,11)$. This phenomenon, termed bone marrow mobilization, is due to G-CSF-mediated induction and activation of neutrophil precursors in the bone marrow and their subsequent secretion of neutrophil proteases, which directly cleave the $\mathrm{N}$-terminal regions of SDF-1 and CXC chemokine receptor 4 (CXCR4) $(12,13)$, as well as the $\mathrm{N}$-terminal regions of vascular cell adhesion molecule 1 (14).

We have previously shown that manipulating CCR3- and CXCR4-dependent interactions increases migration of human CD34 ${ }^{+}$ progenitors to myocardial tissue. In the present study we tested whether in vivo disruption of CXCR4/SDF-1 interactions could redirect migration of human bone marrow-derived HPCs to ischemic myocardial tissue and whether this intervention has any influence on cardiac recovery.

\section{MATERIALS AND METHODS}

\subsection{PURIFICATION AND \\ CHARACTERIZATION OF G-CSF-MOBILIZED HUMAN CD34 ${ }^{+}$CELLS}

Cell isolation, purification, and characterization have been described elsewhere (15). Briefly, singledonor leukapheresis products were obtained from human subjects treated with recombinant G-CSF

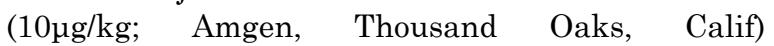


administered subcutaneously daily for 4 days. Mononuclear cells were separated by using FicollHypaque, and highly purified $\mathrm{CD}^{+} 4^{+}$cells $(>98 \%$ positive) were obtained by using magnetic beads coated with anti-CD34 monoclonal antibody (mAb; Miltenyi Biotech, Auburn, Calif).

\subsection{CHEMOTAXIS OF HUMAN BONE MARROW-DERIVED HPCS}

Highly purified $\mathrm{CD} 34^{+} \mathrm{CD} 117^{\text {bright }}$ cells were plated in 48-well chemotaxis chambers fitted with membranes (8- $\mu \mathrm{m}$ pores; Neuro Probe, Gaithersburg, Md). After incubation for 2 hours at $37^{\circ} \mathrm{C}$, cells were cultured for 3 hours in medium containing SDF-1a/B, vascular endothelial growth factor (VEGF), and stem cell factor (SCF), all at a concentration of $1.0 \mu \mathrm{g} / \mathrm{mL}$. Chemotaxis was calculated by counting migrating cells in 10 highpower fields.

\subsection{MYOCARDIAL INFARCTION AND CELL INJECTIONS}

Rowett (rnu/rnu) athymic nude rats (Harlan Sprague-Dawley, Indianapolis, Ind) were used in studies approved by the Columbia University Institute for Animal Care and Use Committee. Permanent surgical ligation of the left anterior descending coronary artery (LAD) and injection of human cells have been described previously (15). For studies on cellular migration, saline or $2.0 \times 10^{6}$ DiI-labeled CD $34^{+}$cells obtained from a single donor after G-CSF mobilization were injected into the tail vein 48 hours after LAD ligation in the presence or absence of mAbs against human CXCR4 and CD34 (ImmunoLaboratories, Takasaki, Japan) and rat SDF-1 (R\&D Systems, Minneapolis, Minn) or isotype controls $(n=6-10)$. Quantitation of cell homing was performed by means of assessment of DiI fluorescence in myocardium and flow cytometric and reverse transcriptase-polymerase chain reaction (RT-PCR) analysis of HLA class I-positive cells in the bone marrow. The results were confirmed by means of immunohistochemistry staining against the human mitochondrial epitope S-100 (S1-61; Santa Cruz Biotechnology, Santa Cruz, Calif), which is not expressed in rat tissues.

\subsection{DISRUPTION OF BONE MARROW CXCR4/SDF-1 INTERACTIONS}

To investigate the effect of the CXCR4/SDF-1 pathway on retention of HPCs in the bone marrow and on homing to the myocardium, antibody blockade of human CXCR4 or rat SDF-1 or systemic administration of G-CSF was used (Figure E1).

\subsection{MEASUREMENT OF RAT MYOCARDIAL AND BONE MARROW SDF-1 MRNA EXPRESSION}

RT-PCR was used to quantify myocardial expression of rat SDF-1 mRNA at baseline and at 6 , 12,24 , and 48 hours after MI by using the following primer sequences: rat SDF-1 a, 5'CTGTTGTGCTTACTTGTTTAAGGCTTTGTC-3' (forward primer) and $5^{\prime}$
GACGCCAAGGTCGTCGGT-3' (reverse primer); rat ribosomal protein L32 (RPL32), 5'CCCTTCGGCCTCTGGTGAAGC-3' (forward primer) and 5'GAACACAAAAACAGGCACACAAGCCATC-3'

(reverse primer). Polymerase chain reaction (PCR) was performed with the GeneAmp PCR System 9700 (Applied Biosystems, Foster City, Calif). PCR products were analyzed on agarose gel stained with ethidium bromide. RT-PCR products were quantified by using UN-SCAN-IT software from Silk Scientific, Inc (Orem, Utah). Values of SDF-1 expression were calculated relative to the values of RPL32 expression. Data were expressed as the means obtained from 3 independent rats for each time point.

\subsection{MEASUREMENT OF INFARCT SIZE AND CAPILLARY DENSITY AND QUANTIFICATION OF APOPTOSIS}

Masson trichrome stain was used to quantify the size of the MI, as described previously (15). Quantification of capillary density was performed by means of antibody staining against rat or human CD31 (Serotec, Kidlington, United Kingdom, and Research Diagnostics, Flanders, NJ, respectively), factor VIII (Dako, Carpinteria, Calif), and rat or human major histocompatibility complex (MHC) class I (Accurate Chemicals, Westbury, NY), as described previously. For in situ detection of apoptosis at the single-cell level, we used the TUNEL method of DNA end-labeling mediated by deoxynucleotidyl transferase (Roche Diagnostics, Mannheim, Germany), as previously described (16). All histological studies were performed at 2 and 15 weeks after MI by a pathologist blinded to the study group.

\subsection{ECHOCARDIOGRAPHIC ANALYSIS OF MYOCARDIAL FUNCTION}

Transthoracic echocardiographic analysis was performed by using a high-frequency liner array transducer (SONOS 5500; Hewlett Packard, Andover, Mass). Two-dimensional images were obtained at the midpapillary and apical levels. Enddiastolic (EDV) and end-systolic (ESV) left ventricular volumes were obtained by using the biplane area-length method, and percentage of left ventricular ejection fraction was calculated as follows: [(EDV - ESV)/EDV] $\times 100$.

\subsection{STATISTICAL ANALYSIS}

Statistical analysis was performed with SPSS 17 software (SPSS, Inc, Chicago, Ill). Continuous variables are presented as means \pm standard deviations. Group means were compared by using the Student's test and 1-way analysis of variance with the post-hoc Bonferroni correction. For further information regarding the study methodology, see the online-only "Materials and Methods." 

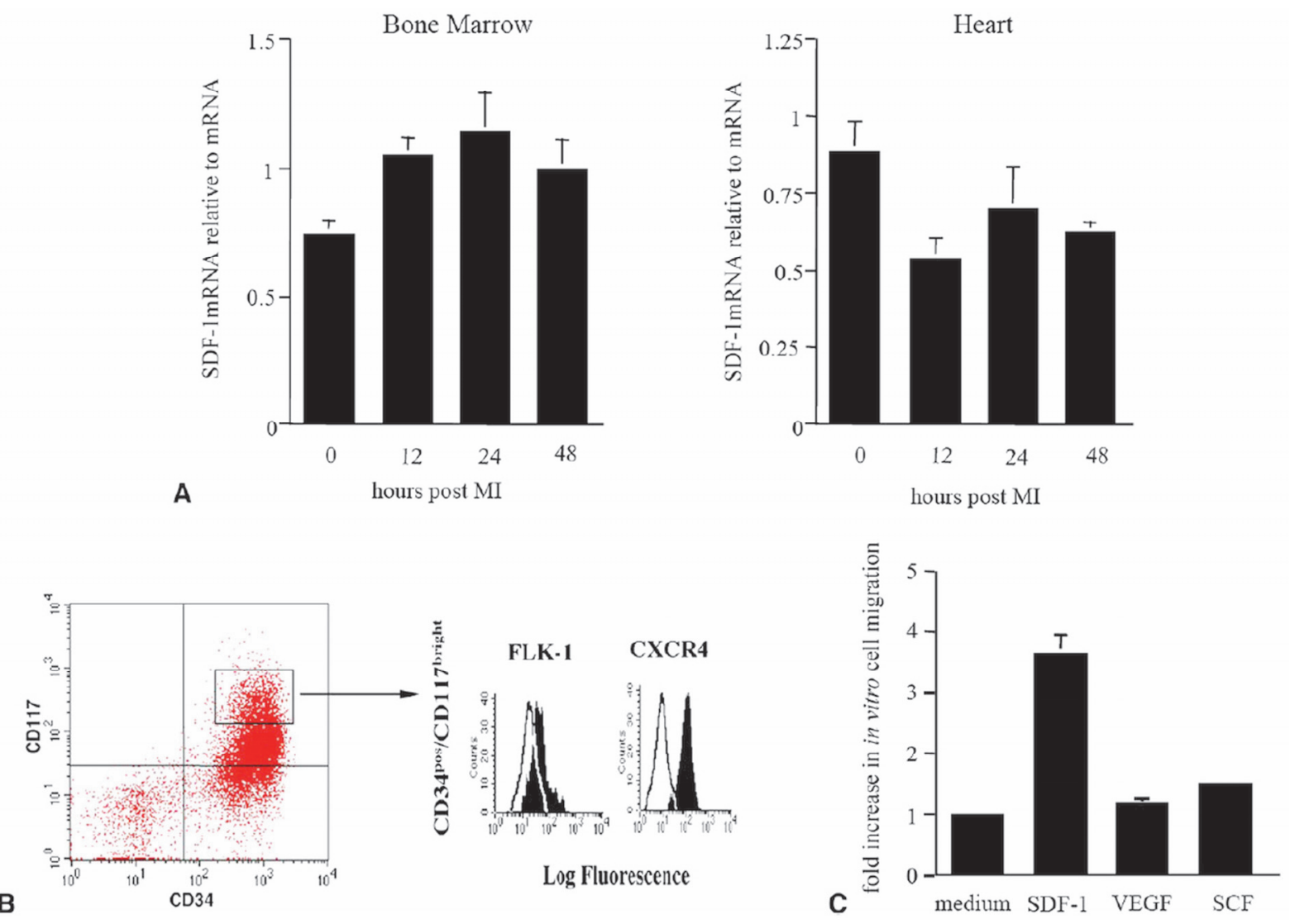

Figure 1. Stromal cell-derived factor 1 (SDF-1) expression is increased in bone marrow after acute myocardial ischemia and induces chemotaxis of hematopoietic progenitor cells. A, Time-dependent changes in SDF-1 mRNA expression relative to that of a constitutively expressed control gene in rat myocardium and bone marrow after myocardial infarction (MI; means \pm standard errors of the mean). B, Four-parameter flow cytometric phenotypic characterization of granulocyte colony-stimulating factor-mobilized bone marrow-derived cells obtained by means of leukapheresis from a representative adult human donor. Only live cells were analyzed, as defined by 7 -aminoactinomycin D staining (vitality $>90 \%$ ). For each marker used, open areas represent background log fluorescence relative to isotype control antibody. The angioblast fraction has previously been characterized to reside in the minor CD34+ population expressing CD117 brightly. The CD34 ${ }^{+} \mathrm{CD} 117^{\text {bright }}$ angioblast subset expresses CXC chemokine receptor 4 (CXCR4) but not flk. The injected CD $34^{+}$cells had a purity of greater than $98 \%$. Ninety percent to $95 \%$ coexpressed the hematopoietic lineage marker CD45, 60\% to 80\% coexpressed the stem cell factor receptor CD117, and less than 1\% coexpressed the monocyte/macrophage lineage marker CD14. C, In vitro chemotaxis of human hematopoietic progenitor cells (mean \pm standard error of the mean). VEGF, Vascular endothelial growth factor; SCF, stem cell factor.

\section{RESULTS}

\subsection{MYOCARDIAL AND BONE MARROW SDF- 1 EXPRESSION AFTER ACUTE MI}

Although the ratio of SDF-1 mRNA expression relative to that of a constitutively expressed control gene was similar in the myocardium and bone marrow of normal rats, by $12 \mathrm{~h}$ after $\mathrm{MI}$, this ratio decreased by a mean of $43 \%$ in cardiac tissue and increased by a mean of $67 \%$ in the bone marrow, representing a 2.3-fold net increase in the bone marrow/cardiac SDF-1 mRNA expression ratio $(\mathrm{P}<0.01)$. These changes persisted for at least 48 hours after LAD ligation (Figure 1).

\subsection{SDF-1 INDUCES IN VITRO CHEMOTAXIS OF BONE MARROW HPCS}

After mobilization by G-CSF, CD $34^{+}$CD $117^{\text {bright }}$ cells constitutively expressed the SDF-1 CXCR4, as well as the VEGF-binding receptor Flk-1 (Figure 1, B). To examine whether SDF-1 was a chemoattractant for $\mathrm{CD} 34^{+} \mathrm{CD} 117^{\text {bright }}$ cells, positively selected CD $34^{+}$ cells were cultured in RPMI medium for $12 \mathrm{~h}$ before in vitro chemotactic assays to reacquire CXCR4 epitopes that were lost after G-CSF treatment and were necessary for conferring SDF-1 affinity. Although SDF-1 induced significant in vitro chemotaxis of $\mathrm{CD} 34^{+} \mathrm{CD} 117^{\text {bright }}$ cells, neither VEGF nor SCF induced greater chemotaxis than medium alone (Figure 1, C). The concentrations of both VEGF and SCF used were sufficient to induce a more than 2 -fold increase in proliferation of HPCs in culture for 96 hours. 

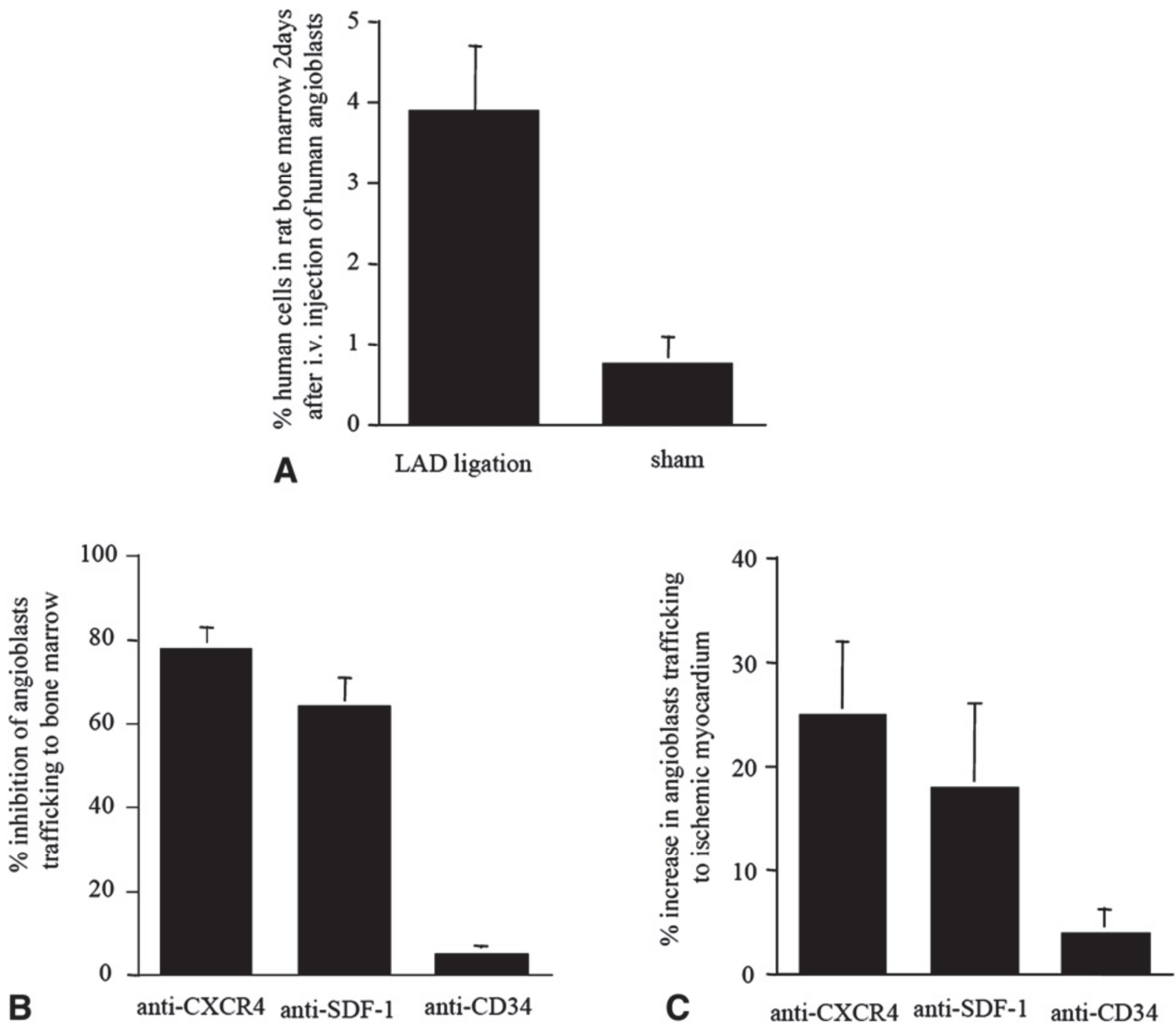

Figure 2. Induced expression of stromal cell-derived factor 1 (SDF-1) increases bone marrow retention of hematopoietic progenitor cells, and disrupting CXC chemokine receptor 4 (CXCR4)/SDF-1 interactions redirects them to ischemic myocardium. A, Detection of human cells in rat bone marrow 2 days after intravenous injection. LAD, Left anterior descending coronary artery. B, Bone marrow retention of hematopoietic progenitor cells after coadministration of monoclonal antibodies against CXCR4 or SDF-1 (mean \pm standard error of the mean). C, Coadministration of anti-CXCR4 or anti-SDF-1 monoclonal antibody significantly increased migration of hematopoietic progenitors to ischemic myocardium, whereas anti-CD34 monoclonal antibody had no effect (mean \pm standard error of the mean).

\subsection{POST-MI SDF-1 EXPRESSION IN THE BONE MARROW RESULTS IN INCREASED RETENTION OF HPCS}

CD $34^{+} \mathrm{CD} 117^{\text {bright }}$ human HPCs were cultured in RPMI medium for $12 \mathrm{~h}$ before in vivo use to reacquire CXCR4 epitopes lost after G-CSF treatment (data not shown). Two days after intravenous injection of cultured cells, bone marrow from LAD-ligated rats contained 5-fold higher levels of human $\mathrm{CD} 34^{+} \mathrm{CD} 117^{\text {bright }}$ cells compared with bone marrow from control subjects 2 days after intravenous injection of cultured cells $(\mathrm{P}<0.01$; Figure 2, A) . Coadministration of $\mathrm{mAbs}$ against either human CXCR4 or rat SDF-1 significantly reduced migration of intravenously administered human HPCs to ischemic rat bone marrow compared with anti-CD34 control antibody (both $\mathrm{P}<0.01$; Figure 2, B). Together, these results indicate that the increased expression of SDF-1 in bone marrow of ischemic rats directly augments HPC retention at this site. Comparative studies on detection of DiI and MHC class I positive cells revealed no difference between the 2 detection methods (Table E1).

\subsection{DISRUPTION OF BONE MARROW CXCR4/SDF-1 INTERACTIONS REDIRECTS HUMAN HPCS FROM THE BONE MARROW TO THE ISCHEMIC HEART}

Next we investigated whether disrupting CXCR4/SDF-1 interactions could reduce HPC retention in the bone marrow and increase homing to the myocardium in rats with acute MI. Myocardial trafficking of human HPCs increased by $24 \%$ and $17 \%$, respectively, after coadministration of mAbs against either human CXCR4 or rat SDF-1, respectively (both $\mathrm{P}<0.01$; Figure 2, C). 


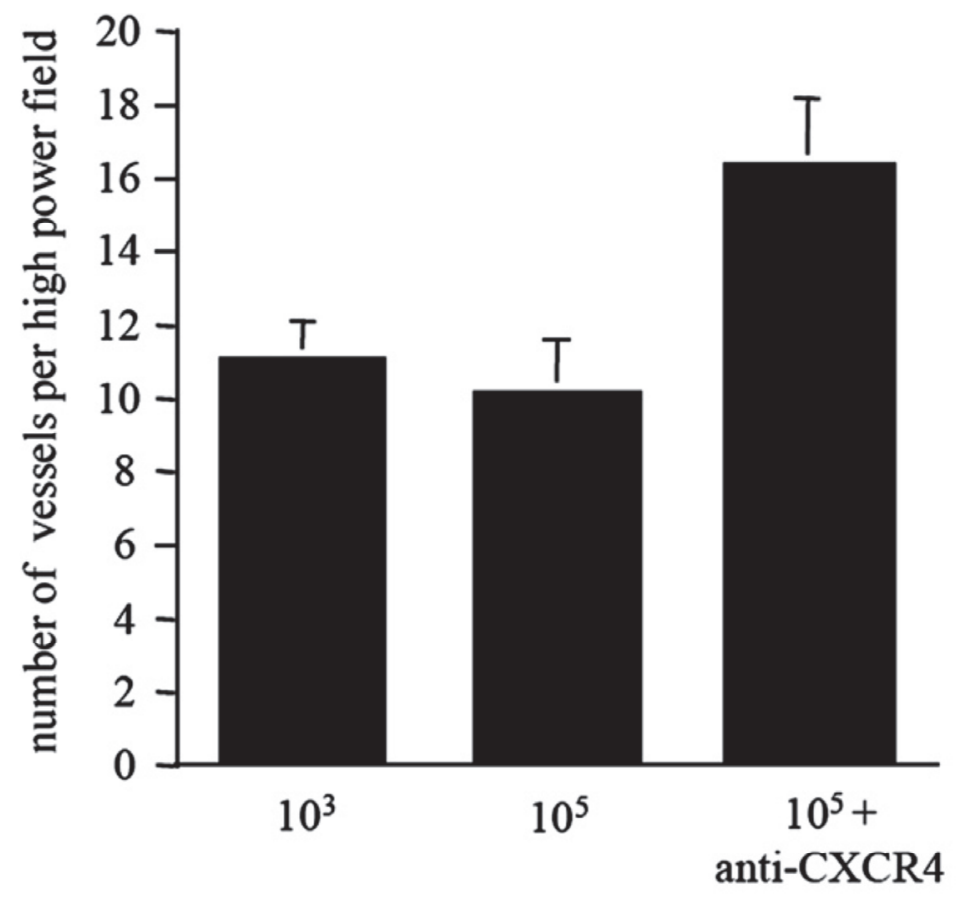

A number of angioblasts injected
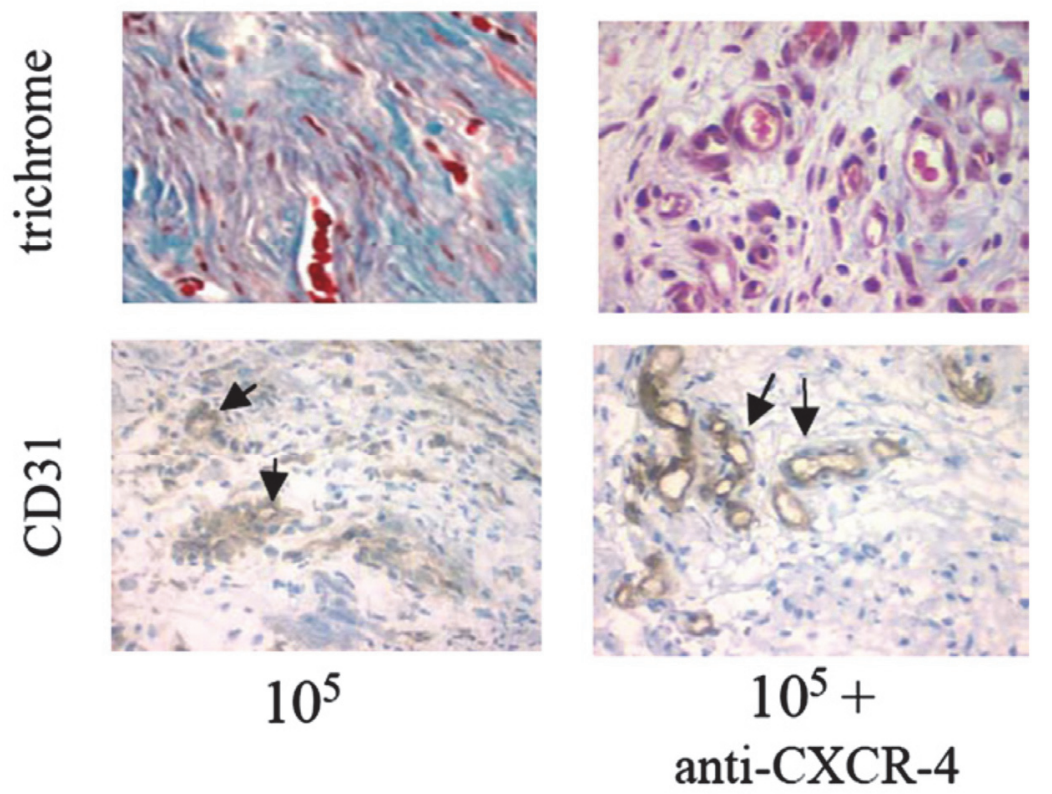

B number of angioblasts injected

Figure 3. Disruption of CXC chemokine receptor 4 (CXCR4)/stromal cell-derived factor 1 interactions after acute myocardial ischemia redirects migration of human hematopoietic progenitors to the ischemic heart and induces neovascularization. A, Relationship between the number of human hematopoietic progenitors injected intravenously $\left(10^{3}, 10^{5}\right.$, and $10^{5}$ plus anti-CXCR4 monoclonal antibody) and development of rat peri-infarct neovascularization at 2 weeks defined as the mean number of capillaries/highpower field. Results are expressed as the mean \pm standard error of the mean of at least 15 high-power fields $(n=3)$. B, Myocardial infarct bed 2 weeks after left anterior descending coronary artery ligation from representative animals in each group stained with Masson's trichrome (upper panel) or immunoperoxidase after binding of CD31 monoclonal antibody (lower panel). The infarct zones of rats receiving either $10^{3}$ or $10^{5}$ angioblasts show myocardial scars composed of paucicellular, dense fibrous tissue stained blue by trichrome $(\times 400)$. In contrast, the infarct zones of rats injected with $10^{5}$ hematopoietic progenitors plus anti-CXCR4 mAb show significant increase in cellularity of granulation tissue, minimal matrix deposition and fibrosis, and numerous medium-sized capillaries of human origin. 

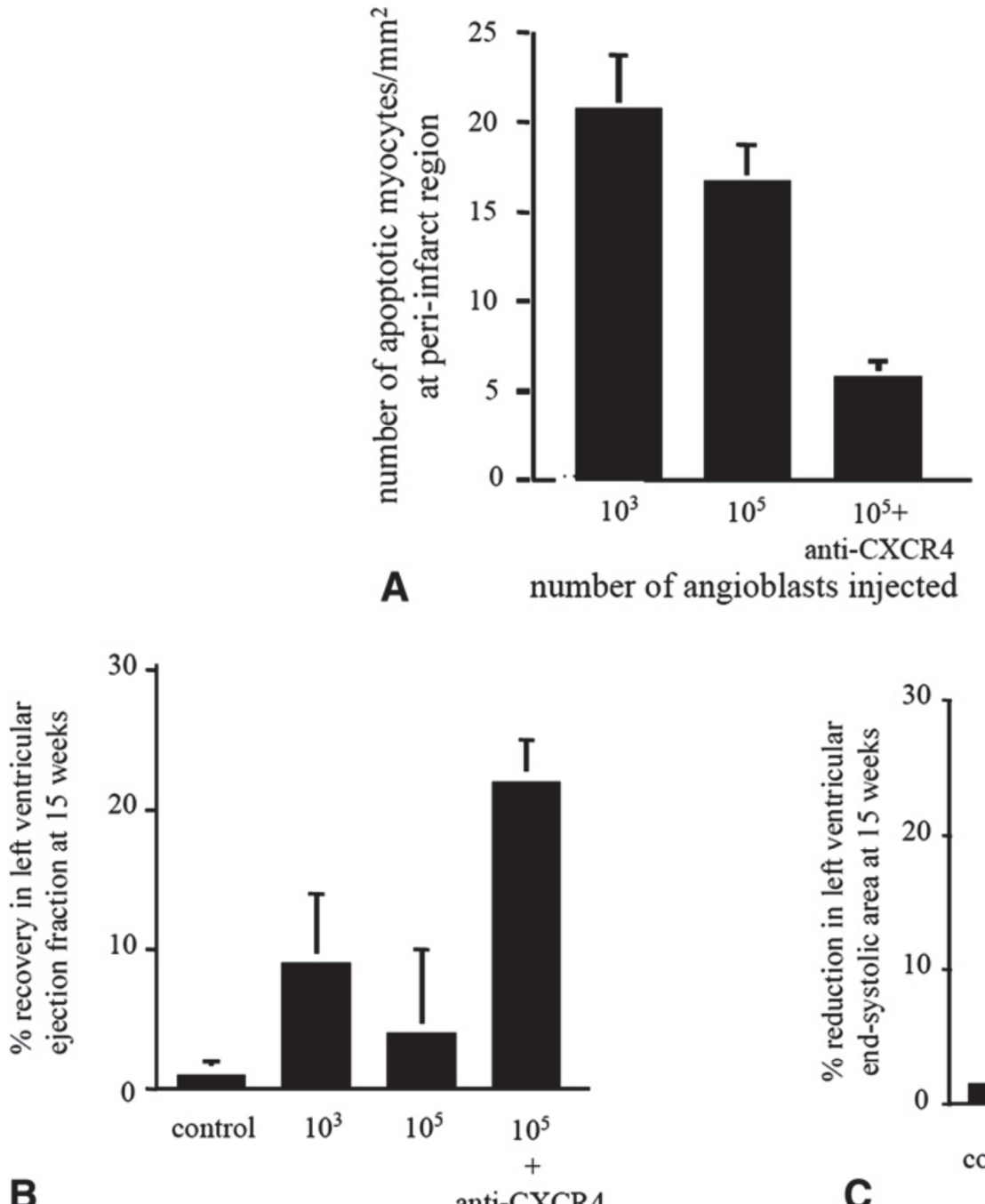

number of angioblasts injected

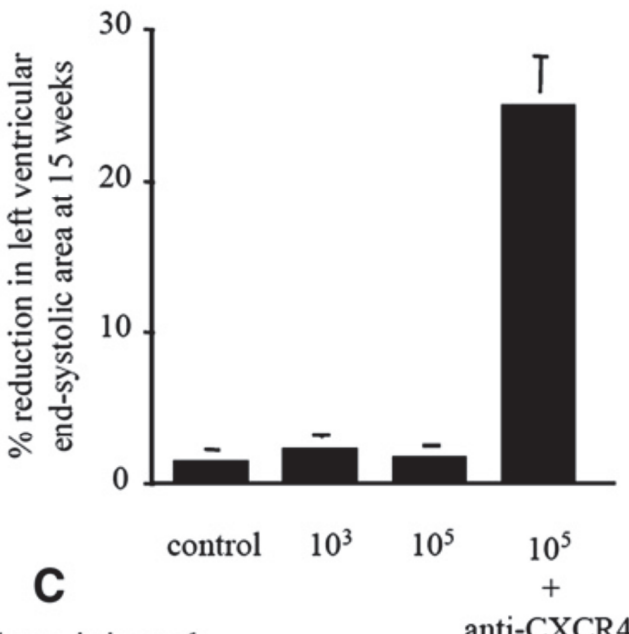

Figure 4. Disruption of $\mathrm{CXC}$ chemokine receptor 4 (CXCR4)/stromal cell-derived factor 1 (SDF-1) interactions after acute myocardial ischemia prevents cardiomyocyte apoptosis and improves cardiac function. A, Reduction of cardiomyocyte apoptosis at the peri-infarct rim in rats receiving $10^{5}$ hematopoietic progenitors (HPCs) together with anti-CXCR4 monoclonal antibody in comparison with rats receiving $10^{3}$ or $10^{5}$ HPCs alone (mean \pm standard error of the mean, $\mathrm{n}=3, \mathrm{P}<0.01$ ). B and $\mathrm{C}$, Relationship between the number of hematopoietic progenitors injected intravenously $\left(10^{3}, 10^{5}\right.$, and $10^{5}$ plus anti-CXCR4 mAb) and improvement in left ventricular ejection fraction at 15 weeks (B) and mean reduction in left ventricular endsystolic area $(\mathrm{C}$; mean \pm standard error of the mean, both $\mathrm{P}<0.001)$.

\subsection{DISRUPTION OF BONE MARROW CXCR4/SDF-1 INTERACTIONS AUGMENTS CARDIAC NEOVASCULARIZATION AFTER ACUTE ISCHEMIA}

Two days after LAD ligation, animals received $2 \times 10^{6}$ human $\mathrm{HPCs}$ reconstituted with varying proportions of $\mathrm{CD}^{+} \mathrm{CD} 117^{\mathrm{bright}}$ angioblasts $\left(10^{3}\right.$, $10^{5}$, and $10^{5}$ plus anti-CXCR4 mAb). The group receiving $10^{5}$ HPCs plus anti-CXCR4 mAb demonstrated greater numbers of capillaries compared with the other 2 groups $(16.4 \pm 1.86$ vs $10.25 \pm 1.43$ and $11.19 \pm 1.01$, respectively; $\mathrm{P}<0.01$; Figure 3, A). Induction of neovascularization was accompanied by a significant increase in the cellularity of granulation tissue and minimal matrix deposition and fibrosis (Figure 3, B).

\subsection{DISRUPTION OF BONE MARROW CXCR4/SDF-1 INTERACTIONS AUGMENTS CARDIOMYOCYTE SURVIVAL AND FUNCTIONAL RECOVERY AFTER ACUTE ISCHEMIA}

Rats receiving $10^{5} \mathrm{HPCs}$ plus anti-CXCR4 mAb demonstrated a significant reduction in the number of apoptotic myocytes at the peri-infarct region compared with that seen in the groups receiving either $10^{3}$ or $10^{5}$ HPCs alone (both $\mathrm{P}<0.001$ ), but in the groups receiving $10^{3}$ or $10^{5} \mathrm{HPCs}$, abundant numbers of apoptotic cells in the peri-infarct region were observed (Figure 4, A). On the contrary, no improvement in these parameters was observed in the groups receiving $10^{3}$ or $10^{5} \mathrm{HPCs}$ in comparison with those seen in rats receiving saline alone. Animals receiving $10^{5} \mathrm{HPCs}$ plus anti-CXCR4 $\mathrm{mAb}$ 

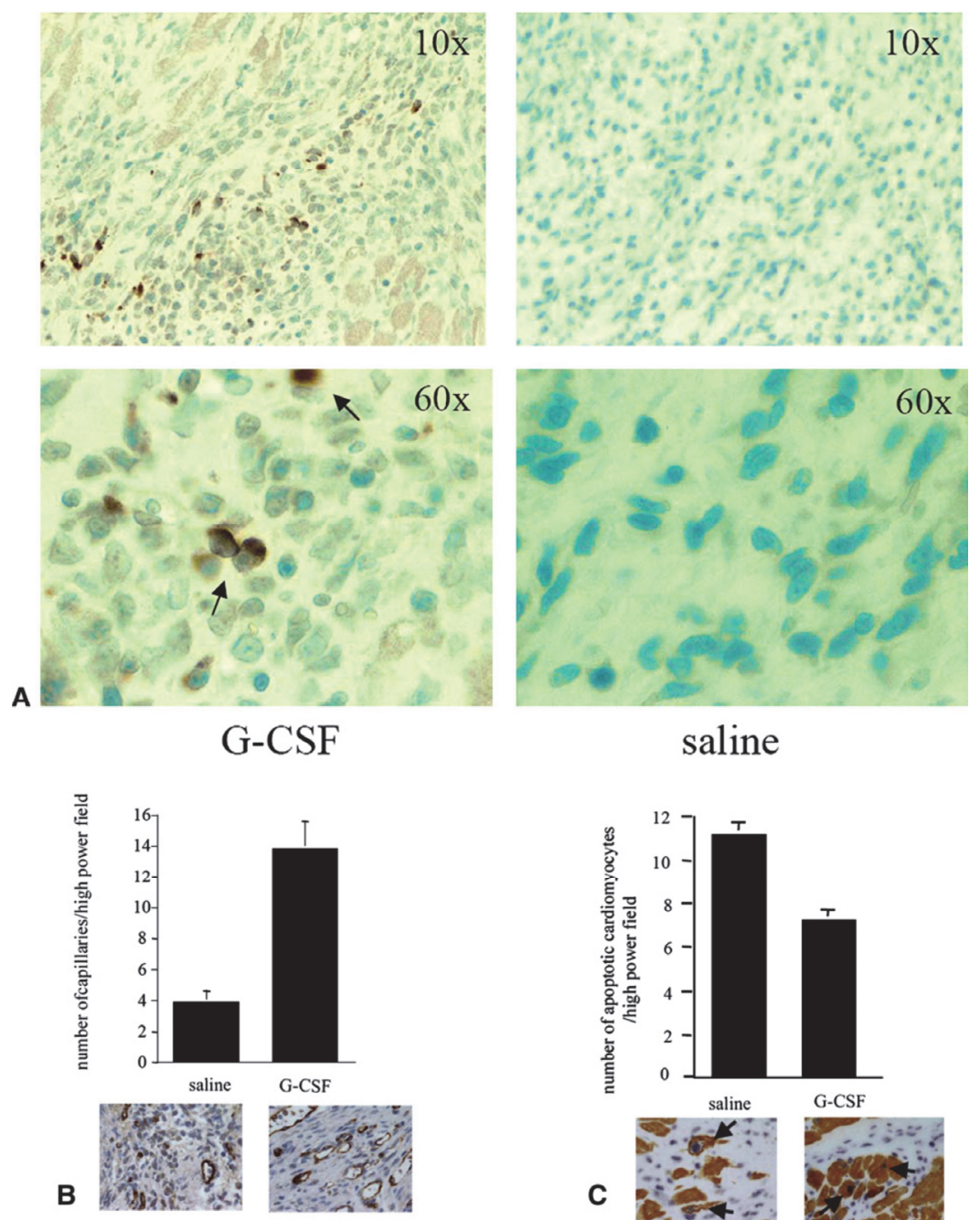

\section{saline}
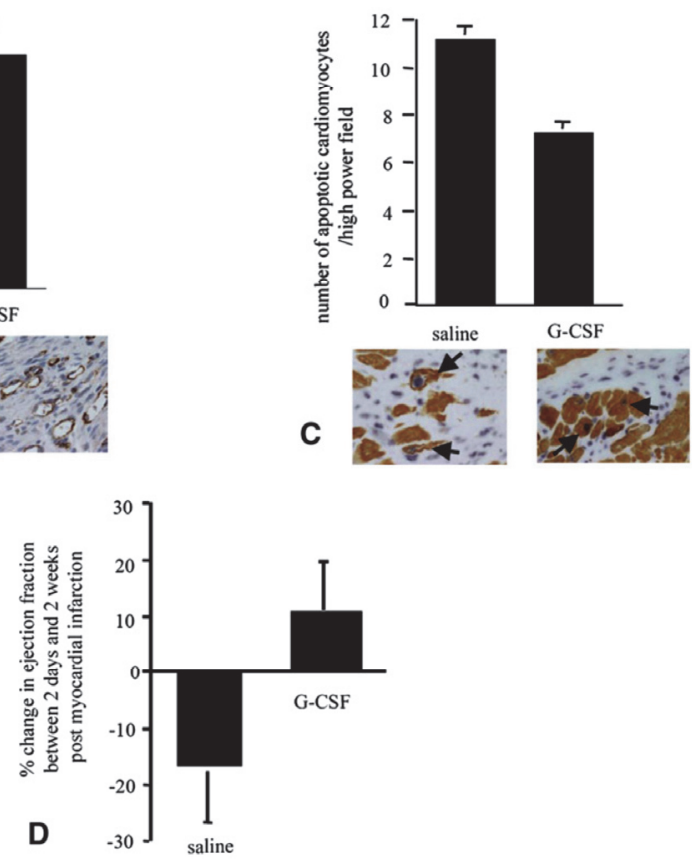

Figure 5. Granulocyte colony-stimulating factor (G-CSF) administration after acute myocardial ischemia induces neovascularization, prevents cardiomyocyte apoptosis, and improves cardiac function. A, Detection of human hematopoietic progenitor cells (HPCs; arrows) stained positive for human MHC class I b2microglobulin at the peri-infarct region after G-CSF treatment. B, Increase in total blood vessel count at the peri-infarct region 2 weeks after administration of human G-CSF $(\mathrm{P}<0.01$, mean \pm standard error of the mean, $n=3$ ). C, Quantitative analysis of cardiomyocyte apoptosis at the peri-infarct region 2 weeks after treatment (mean \pm standard error of the mean, $\mathrm{P}<0.01$ ). Arrows show cells with apoptotic nuclei. $\mathrm{D}$, changes in ejection fraction between 2 days and 2 weeks after myocardial infarction in G-CSF-treated animals and saline-treated control animals (mean \pm standard error of the mean, $\mathrm{P}<0.01$ ).

demonstrated a significant improvement in left ventricular ejection fraction $(22 \% \pm 2 \%, \quad \mathrm{P}<0.001$; Figure $4, \mathrm{~B})$ and a reduction left ventricular endsystolic diameter $(24 \% \pm 4 \%, \mathrm{P}<0.001$; Figure $4, \mathrm{C}$; see also Table E2).

\subsection{SYSTEMIC ADMINISTRATION OF G-CSF TO DISRUPT BONE MARROW CXCR4/SDF-1}

\section{INTERACTIONS RESULTS IN MOBILIZATION AND HOMING OF HPCS TO ISCHEMIC MYOCARDIUM}

To investigate whether disruption of bone marrow CXCR4/SDF-1 interactions provides a general paradigm for improving cardiac outcome after acute infarction, LAD-ligated rats were treated systemically with G-CSF. G-CSF administration 
induced a 2- to 3-fold increase in circulating neutrophil and monocyte/macrophage lineage cell numbers, indicating successful mobilization. Histologic examination of heart tissue from ischemic rats treated with $\mathrm{G}-\mathrm{CSF}$ at $10 \mu \mathrm{g} / \mathrm{kg}$ for 4 days starting $48 \mathrm{~h}$ after LAD ligation revealed a high infiltration grade of polymorphonuclear leukocytes and cells of the macrophage lineage in the periinfarct region. In addition, numerous $\mathrm{CD} 117^{+}$ mononuclear cells were detected in the peri-infarct regions of animals treated with G-CSF (Figure 5, A). This indicated myocardial homing of HPCs after GCSF mobilization. G-CSF administration resulted in a 3.5 -fold increase in total blood vessel count in the peri-infarct region $(13.85 \pm 1.79$ vs $3.96 \pm 0.69, \mathrm{P}<0.01$; Figure 5, B), in a $36 \% \pm 16 \%$ reduction in cardiomyocyte apoptosis at the peri-infarct region $(\mathrm{P}<0.01$; Figure 5, C), and in an improvement in left ventricular ejection fraction (Figure 5, D), all compared with corresponding measurements in rats treated with saline.

\section{DISCUSSION}

Binding of the CXC chemokine SDF-1 to its ligand, CXCR4, is essential for homing and retention of HPCs in mammalian bone marrow $(9,10)$. Our results indicate that the increase in bone marrow SDF-1 expression observed after MI serves to prevent mobilization of HPCs, which could otherwise induce neovascularization of the myocardium and improve outcome (3-5). Disrupting bone marrow CXCR4/SDF-1 interactions resulted in enhanced myocardial neovascularization, decreased apoptosis levels, and improved myocardial function.

Cellular activation, chemotaxis, and bone marrow retention are mediated by the N-terminus of SDF-1, which binds to CXCR4 (17). These activities are lost on exposure to dipeptidyl peptidase IV (CD26) (18), neutrophil cathepsin G (19), and elastase (20), as well as tissue metalloproteinases, including matrix metalloproteinases 2 and 9 (21), all of which cleave the $\mathrm{N}$-terminal residues to generate a truncated and nonfunctional chemokines (22). SDF-1-mediated redirection of stem cell migration is based on a low to high SDF-1 gradient. Given the fact that HPCs can secrete high concentrations of SDF-1, one could argue that the beneficial effects of bone marrow stem cell-based therapy could be associated with a change in the SDF-1 gradient (23). Moreover, cell therapy was found to increase the number of stem cells in the remodeled myocardium and significantly improved cardiac function (24). The finding of a concomitant increase in $\mathrm{CD} 34^{+}, \mathrm{CD} 117^{+}$, and STRO$1^{+}$cells in the myocardium, resulting in more capillary density, improved cardiac function, and a decrease in infarct size, is consistent with our results (25). The decrease in myocardial SDF-1 production after the first peak can theoretically be explained by increased and sustained myocardial apoptosis, which affects cell-secreting function.

The rationale of SDF-1 pretreatment of the ischemic area is based on the indispensable improvement of the myocardial matrix to augment the potential of cardiac regeneration (26). In our hands intramyocardial injections of SDF-1 in cases of acute myocardial ischemia induced a 2-fold greater myocardial neovascularization. Accompanying intravenous angioblast injection induced $76 \%$ further reduction in cardiomyocyte apoptosis and resulted in a 3-fold greater improvement of left ventricular ejection fraction compared with injections of HPCs alone (15). Other authors have used a local delivery approach either by means of direct injection of SDF-1 in the ischemic area $(27,28)$ or by implanting an SDF-1seeded patch for controlled SDF-1 release in the neighboring myocardium (29). Both techniques led to less cell death and increased homing of transplanted cell angiogenesis within the hypoxic tissue, ultimately leading to reduced scarring and improved cardiac function. Explanations of the observed effects of SDF-1 include increased phosphorylation of Akt and upregulation of VEGF in response to SDF-1. Other authors used injections of transfected cells with ex vivo delivered SDF-1 to prove the same concept. Likewise, SDF-1expressing cell transplantation augmented stem and progenitor cell migration to the heart, activated cell survival signaling, and enhanced angiomyogenesis $(30,31)$.

Although an SDF-1 gradient to enable homing of mobilized HPCs is a crucial step in myocardial regeneration, this is not sufficient in the absence of myocardial injury $(31,32)$. Our ability to redirect migration of human bone marrow-derived CD117 bright cells to ischemic myocardium through disruption of CXCR4/SDF-1 interactions after either administration of G-CSF or specific mAbs provides further evidence that bone marrow SDF-1 is a biologically active chemotactic factor for this cell lineage (16).

Consistent with our results is the observation that subcutaneous injections of G-CSF in patients with acute MI led to increased mobilization of HPCs into the ischemic myocardium (33). However, the functional activity of the endothelial progenitor cells, as assessed based on the migratory response to VEGF and SDF-1, as well as the surface expression of the functionally active CXCR4 receptor $6 \mathrm{H} 8$, were significantly reduced after G-CSF treatment. Because cells mobilized by G-CSF lose N-terminal residues on CXCR4 molecules, which are absolutely necessary for SDFmediated chemotaxis (13), and because we observed reduced SDF-1 expression in the ischemic heart relative to that seen in nonischemic control hearts, it is likely that homing of G-CSF-mobilized HPCs to the ischemic heart was due to local production of chemotactic factors other than SDF-1. In this regard we have recently shown that myocardial expression of the interleukin 8 (IL-8)/Gro chemokine family is significantly induced after acute ischemia and that interactions between IL-8/Gro and CXCR1/2 on GCSF-mobilized HPCs play a major role in their homing to the ischemic heart (34). These results are supported by recent clinical trials using G-CSF for treatment of patients with acute MI; demonstrating 
no effect of G-CSF on functional improvement might support this assumption (35). Whether this G-CSF mobilization-induced impairment of functional capacities of HPCs indeed leads to an attenuation of improvement in cardiac function in patients after cell therapy remains to be elucidated. The use of other mobilizing substances, which lack a negative influence on the migratory capacity of circulating HPCs, might be a preferred option for future treatment of ischemic disease.

Although we have found that IL-8/Gro-a mRNA and protein expression increases by more than 8- to 10-fold within 12 hours of acute myocardial ischemia in rats, these levels return to baseline by 2 weeks. The transient nature of these myocardial chemotactic signals suggest that strategies to disrupt CXCR4/SDF-1 interactions might not, by themselves, be effective for myocardial homing of bone marrow HPCs at times more remote from the acute ischemic event. CXCR4/SDF-1 interactions in the ischemic myocardium appear to be complicated because this axis is influenced by production of a variety of chemokines, which change over time after MI (36). Upregulation of both chemokines in cases of acute ischemia explains why transplantation of SDF-1- or CXCR-4-overexpressing mesenchymal cells could enhance mesenchymal cell therapy $(37,38)$. However, the upregulation of SDF-1 and CXCR4 is not a simultaneous process. A multivariate analysis of the Reinfusion of Enriched Progenitor Cells and Infarct Remodeling in Acute Myocardial Infarction (REPAIR-AMI) trial (39) showed that when magnitude of SDF-1 migration was included as a variable, treatment time after MI was no longer a predictor of response to therapy. These data suggest that the bone marrow alters its responsiveness to SDF-1 over time, indicating that bone marrow stem cells might be more responsive to SDF-1 4 to 7 days after MI than at baseline. One strategy would include a temporal alignment of SDF-1 and cardiomyocyte CXCR4 expression, whereas a second strategy would take into consideration secretion of other chemokines. Other growth factors, such as fibroblast growth factor 2, can lead to synergistic upregulation of CXCR4 in the setting of hypoxia (40). An additional improvement of the matrix milieu has also been suggested because upregulation of matrix metalloproteinases has been found to enhance the ability of transplanted or mobilized cells to generate new myocytes (41). Additionally, as described in a previous study, increased homing of progenitors into the ischemic myocardium might imply the involvement of alternate mechanisms, such as IL-8/Gro-CXCR1/2 (16) which have not been addressed in this study.

Another study limitation is the artificial environment of xenogeneic cell transplantation in nude rats. Although the model used is a widely accepted in investigational studies of cardiac regeneration, extrapolation of the results in endogenous or autologous cells might be limited.

We provide evidence that bone marrow

SDF-1 upregulation after $\mathrm{MI}$ is a negative regulatory factor for mobilization of HPCs and prevents their homing in ischemic myocardium. Because disruption of bone marrow CXCR4-SDF-1 interactions resulted in increased neovascularization, our results suggest a general paradigm by which myocardial recovery can be enhanced after acute ischemia. The use of additional cell therapeutic techniques should only be considered under the prism of concomitant improvement of the extracellular environment to which the cells are expected to adhere and proliferate. Myocardial cell-specific disruption of CXCR4/SDF-1 interactions could prove helpful in improvement of the extracellular milieu and enhance the results of cell transplantation (40).

\section{ACKNOWLEDGEMENTS}

We acknowledge the contribution of Douwe Atsma and Arnoud van der Laarse from the Department of Cardiology, Leiden University Medical Center, for critical reading and correction of the manuscript. 
A

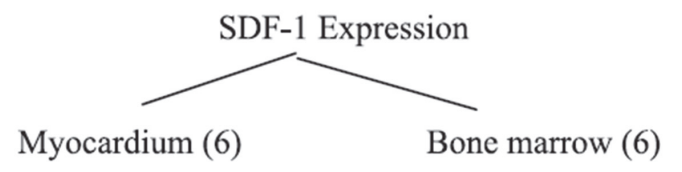

B

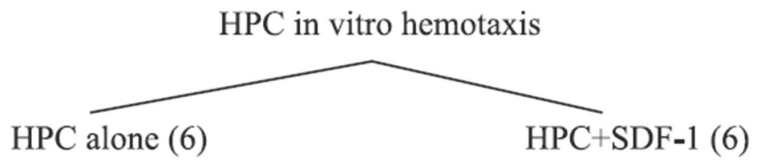

C

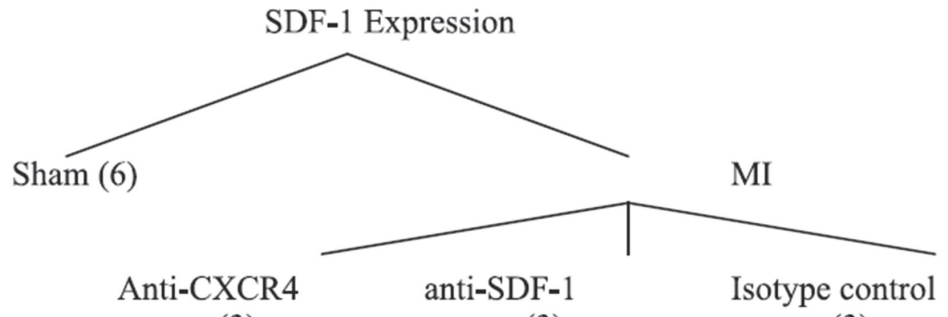

(3)

(3)

(3)

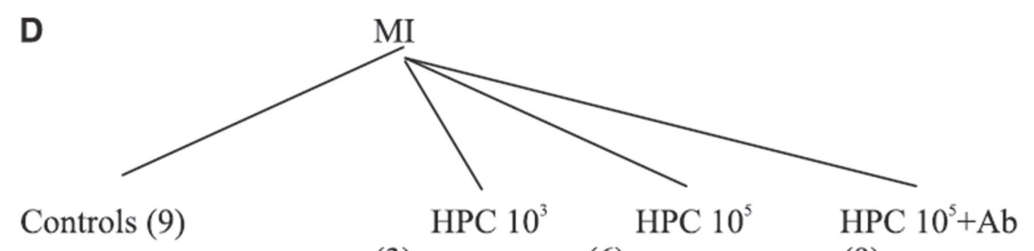

(3)

(6)

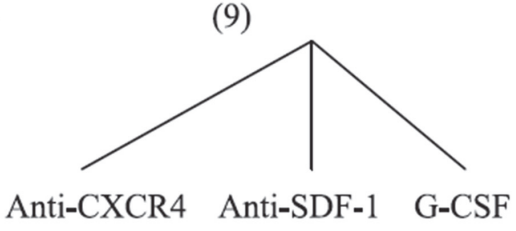

(3)

(3)

(3)

Figure E1. A-D. Workflow of experiments to investigate CXCR4/SDF-1 interactions after myocardial infarction and transplantation of G-CSF-mobilized hematopoietic progenitors. CXCR4, CXC chemokine receptor 4; SDF-1, stromal cell-derived factor 1; G-CSF, granulocyte colony-stimulating factor; HPC, hematopoietic progenitor cell.

\section{E-MATERIALS AND METHODS}

\subsection{QUANTITATION OF CELLULAR MIGRATION INTO TISSUES}

After intravenous injection of human cells, quantitative analysis of the proportion of human cells in rat bone marrow and heart tissue was performed by means assessment of both DiI fluorescence and expression of MHC class I proteins. A single-cell suspension of rat bone marrow was stained with fluorescein-conjugated mAbs against human CD34 and MHC class I 82microglobulin (Accurate Chemicals, New Haven, Conn) and analyzed by means of multiparameter fluorescence with FACScan (Becton Dickinson, Mountain View, Calif), as described previously (16). The proportion of human cells in rat heart tissue was expressed as the number of DiI-positive cells per high-power field (minimum of 5 fields examined per sample) and as the proportion of cells staining positive for human MHC class I b2-microglobulin. Staining of cardiac tissue was performed by using an immunoperoxidase technique with an Avidin/Biotin Blocking Kit, a rat-absorbed biotinylated anti-mouse IgG, and a peroxidase conjugate (all Vector Laboratories, Burlingame, Calif). The human origin of the detected cells was confirmed by staining against the human mitochondrial epitope S-100 (S1-61, Santa Cruz Biotechnology). 
Chapter 7 - Downregulation of the CXC chemokine receptor 4/stromal cell-derived factor 1.

TABLE E1. Comparison of DiI-positive and human MHC class I $\beta_{2}$-positive cells in rat myocardium

\begin{tabular}{lcc}
\hline & DiI & MHC class I \\
\hline Cells in rat bone marrow 2 d after injection (\%) & $3.6 \pm 0.7$ & $3.9 \pm 0.8$ \\
Inhibition of HPC trafficking to bone marrow (\%) & & .27 \\
Anti-CXCR4 & $76.2 \pm 2.1$ & $78.9 \pm 2.4$ \\
anti-SDF-1 & $64.8 \pm 3.6$ & $64.1 \pm 4.1$ \\
Anti-CD34 & $3.6 \pm 0.5$ & $4 \pm 0.4$ \\
Increase of HPC trafficking to ischemic myocardium & & .39 \\
Anti-CXCR4 & $22.9 \pm 5.3$ & $24.8 \pm 6.3$ \\
Anti-SDF-1 & $20.5 \pm 6.3$ & $18.1 \pm 8.6$ \\
Anti-CD34 & $3.2 .6 \pm 1.6$ & $3.9 \pm 1.4$ \\
\hline
\end{tabular}

DiI, 1,1'-dioctadecyl-3,3,3',3'-tetramethylindocarbocyanine perchlorate; $M H C$, major histocompatibility complex; $H P C$, hematopoietic progenitor cell; $C X C R 4, C X C$ chemokine receptor 4; SDF-1, stromal cell-derived factor 1 .

TABLE E2. Echocardiographic results after systemic injections of hematopoietic progenitors 48 hours after myocardial infarction

\begin{tabular}{|c|c|c|c|c|}
\hline & Control & HPC $10^{3}$ & HPC $10^{5}$ & HPC $10^{5}+$ anti-CXCR4 \\
\hline \multicolumn{5}{|l|}{ Baseline } \\
\hline LVEF $(\%)$ & 37.3 & 38.5 & 39.1 & 36.7 \\
\hline $\operatorname{LVESD}(\mathrm{cm})$ & 0.46 & 0.41 & 0.44 & 0.47 \\
\hline $\operatorname{LVEDD}(\mathrm{cm})$ & 0.73 & 0.67 & 0.72 & 0.74 \\
\hline \multicolumn{5}{|l|}{$15 \mathrm{wk}$} \\
\hline $\operatorname{LVEF}(\%)$ & 38.7 & 47.1 & 43.5 & 57.4 \\
\hline
\end{tabular}




\section{REFERENCES}

1. C. Dubois, X. Liu, P. Claus, G. Marsboom, P. Pokreisz, S. Vandenwijngaert, H. Dépelteau, W. Streb, L. Chaothawee, F. Maes, O. Gheysens, Z. Debyser, H. Gillijns, M. Pellens, T. Vandendriessche, M. Chuah, D. Collen, E. Verbeken, A. Belmans, F. Van de Werf, J. Bogaert, S. Janssens, Differential effects of progenitor cell populations on left ventricular remodeling and myocardial neovascularization after myocardial infarction. Journal of the American College of Cardiology 55, 2232 (2010/05, 2010).

2. C. Kalka, H. Masuda, T. Takahashi, W. M. Kalka-Moll, M. Silver, M. Kearney, T. Li, J. M. Isner, T. Asahara, Transplantation of ex vivo expanded endothelial progenitor cells for therapeutic neovascularization. Proceedings of the National Academy of Sciences 97, 3422 (2000/03/28, 2000).

3. A. A. Kocher, M. D. Schuster, M. J. Szabolcs, S. Takuma, D. Burkhoff, J. Wang, S. Homma, N. M. Edwards, S. Itescu, Neovascularization of ischemic myocardium by human bone-marrowderived angioblasts prevents cardiomyocyte apoptosis, reduces remodeling and improves cardiac function. Nature medicine 7, 430 (2001/04, 2001)

4. B. Assmus, J. Honold, V. Schächinger, M. B. Britten, U. Fischer-Rasokat, R. Lehmann, C. Teupe, K. Pistorius, H. Martin, N. D. Abolmaali, T. Tonn, S. Dimmeler, A. M. Zeiher, Transcoronary transplantation of progenitor cells after myocardial infarction. New England Journal of Medicine 355, 1222 (2006/09/21, 2006).

5. C. Stamm, H.-D. Kleine, Y.-H. Choi, S. Dunkelmann, J.-A. Lauffs, B. Lorenzen, A. David, A. Liebold, C. Nienaber, D. Zurakowski, M. Freund, G. Steinhoff, Intramyocardial delivery of CD133+ bone marrow cells and coronary artery bypass grafting for chronic ischemic heart disease: Safety and efficacy studies. The Journal of Thoracic and Cardiovascular Surgery 133, 717 (2007/03, 2007).

6. A. G. Arroyo, D. Taverna, C. A. Whittaker, U. G. Strauch, B. L. Bader, H. Rayburn, D. Crowley, C. M. Parker, R. O. Hynes, In vivo roles of integrins during leukocyte development and traffic: Insights from the analysis of mice chimeric for 5 , v, and 4 Integrins. The Journal of Immunology 165, 4667 (2000/10/15, 2000).

7. P. S. Frenette, S. Subbarao, I. B. Mazo, U. H. von Andrian, D. D. Wagner, Endothelial selectins and vascular cell adhesion molecule-1 promote hematopoietic progenitor homing to bone marrow. Proceedings of the National Academy of Sciences 95, 14423 (1998/11/24, 1998).

8. W. Hiesinger, J. R. Frederick, P. Atluri, R. C. McCormick, N. Marotta, J. R. Muenzer, Y. J. Woo, Spliced stromal cell-derived factor-1alpha analog stimulates endothelial progenitor cell migration and improves cardiac function in a dose-dependent manner after myocardial infarction. J Thorac Cardiovasc Surg 140, 1174 (Nov, 2010).

9. A. Peled, I. Petit, O. Kollet, M. Magid, T. Ponomaryov, T. Byk, A. Nagler, H. Ben-Hur, A. Many, L. Shultz, O. Lider, R. Alon, D. Zipori, T. Lapidot, Dependence of human stem cell engraftment and repopulation of NOD/SCID mice on CXCR4. Science 283, 845 (Feb 5, 1999).

10. M. Delgaudine, B. Lambermont, P. Lancellotti, V. Roelants, S. Walrand, J.-L. Vanoverschelde, L. Pierard, A. Gothot, Y. Beguin, Effects of granulocyte-colony-stimulating factor on progenitor cell mobilization and heart perfusion and function in normal mice. Cytotherapy 13, 237 (2011/02, 2011).

11. S. Fruehauf, M. R. Veldwijk, T. Seeger, M. Schubert, S. Laufs, J. Topaly, P. Wuchter, F. Dillmann, V. Eckstein, F. Wenz, H. Goldschmidt, A. D. Ho, G. Calandra, A combination of granulocyte-colony-stimulating factor (G-CSF) and plerixafor mobilizes more primitive peripheral blood progenitor cells than G-CSF alone: results of a European phase II study. Cytotherapy 11, 992 (2009/01, 2009).

12. J.-P. Lévesque, J. Hendy, Y. Takamatsu, P. J. Simmons, L. J. Bendall, Disruption of the CXCR4/CXCL12 chemotactic interaction during hematopoietic stem cell mobilization induced by GCSF or cyclophosphamide. Journal of Clinical Investigation 111, 187 (2003/01/15, 2003).

13. I. Petit, M. Szyper-Kravitz, A. Nagler, M. Lahav, A. Peled, L. Habler, T. Ponomaryov, R. S. Taichman, F. Arenzana-Seisdedos, N. Fujii, J. Sandbank, D. Zipori, T. Lapidot, Erratum: GCSF induces stem cell mobilization by decreasing bone marrow SDF-1 and up-regulating CXCR4. Nature Immunology 3, 687 (2002/06/17, 2002).

14. J.-P. Lévesque, J. Hendy, Y. Takamatsu, B. Williams, I. G. Winkler, P. J. Simmons, Mobilization by either cyclophosphamide or granulocyte colony-stimulating factor transforms the bone marrow into a highly proteolytic environment. Experimental Hematology 30, 440 (2002/05, 2002).

15. N. Bonaros, H. Sondermejer, M. Schuster, R. Rauf, S. F. Wang, T. Seki, D. Skerrett, S. Itescu, A. A. Kocher, CCR3- and CXCR4-mediated interactions regulate migration of $\mathrm{CD} 34^{+}$human bone marrow progenitors to ischemic myocardium and subsequent tissue repair. The Journal of Thoracic and Cardiovascular Surgery 136, 1044 (2008/10, 2008).

16. A. A. Kocher, M. D. Schuster, N. Bonaros, K. Lietz, G. Xiang, T. P. Martens, P. A. Kurlansky, H. Sondermeijer, P. Witkowski, A. Boyle, Myocardial homing and neovascularization by human bone marrow angioblasts is regulated by IL-8/Gro CXC chemokines. Journal of molecular and cellular cardiology 40, 455 (2006/04, 2006).

17. M. P. Crump, J. H. Gong, P. Loetscher, K. Rajarathnam, A. Amara, F. Arenzana-Seisdedos, J. L. Virelizier, M. Baggiolini, B. D. Sykes, I. Clark-Lewis, Solution structure and basis for functional activity of stromal cell-derived factor1; dissociation of CXCR4 activation from binding and inhibition of HIV-1. EMBO J 16, 6996 (Dec 1, 1997).

18. I. De Meester, S. Korom, J. Van Damme, S. Scharpé, CD26, let it cut or cut it down. Immunology Today 20, 367 (1999/08, 1999).

19. M. B. Delgado, I. Clark-Lewis, P. Loetscher, H. Langen, M. Thelen, M. Baggiolini, M. Wolf, Rapid inactivation of stromal cell-derived factor1 by cathepsin G associated with lymphocytes. European Journal of Immunology 31, 699 (2001/03, 2001). 
20. A. n. Valenzuela-Fernández, T. Planchenault, F Baleux, I. Staropoli, K. Le-Barillec, D. Leduc, T. Delaunay, F. Lazarini, J.-L. Virelizier, M. Chignard, D. Pidard, F. Arenzana-Seisdedos, Leukocyte elastase negatively regulates stromal cell-derived factor-1 (SDF-1)/CXCR4 binding and functions by amino-terminal processing of SDF-1 and CXCR4. Journal of Biological Chemistry 277, 15677 (2002/02/26, 2002).

21. G. A. McQuibban, G. S. Butler, J.-H. Gong, L. Bendall, C. Power, I. Clark-Lewis, C. M. Overall, Matrix metalloproteinase activity inactivates the CXC chemokine stromal cell-derived factor-1. Journal of Biological Chemistry 276, 43503 (2001/09/24, 2001).

22 D. C. Link, Mechanisms of granulocyte colonystimulating factor-induced hematopoietic progenitor-cell mobilization. Seminars in Hematology 37, 25 (2000/01, 2000).

$23 . \quad$ B.-C. Lee, H.-C. Hsu, W.-Y. I. Tseng, C.-Y. Chen, H.-J. Lin, Y.-L. Ho, M.-J. Su, M.-F. Chen, Cell therapy generates a favourable chemokine gradient for stem cell recruitment into the infarcted heart in rabbits. European Journal of Heart Failure 11, 238 (2009/02/26, 2009).

24 D. K. Jin, K. Shido, H.-G. Kopp, I. Petit, S. V. Shmelkov, L. M. Young, A. T. Hooper, H. Amano, S. T. Avecilla, B. Heissig, K. Hattori, F. Zhang, D. J. Hicklin, Y. Wu, Z. Zhu, A. Dunn, H. Salari, Z. Werb, N. R. Hackett, R. G. Crystal, D. Lyden, S. Rafii, Cytokine-mediated deployment of SDF-1 induces revascularization through recruitment of CXCR4 $4^{+}$hemangiocytes. Nature medicine 12, 557 (2006/04/30, 2006).

25. A. Abbate, R. Bussani, G. G. Biondi-Zoccai, R. Rossiello, F. Silvestri, F. Baldi, L. M. Biasucci, A. Baldi, Persistent infarct-related artery occlusion is associated with an increased myocardial apoptosis at postmortem examination in humans late after an acute myocardial infarction. Circulation 106, 1051 (Aug 27, 2002).

26. A. Kortesidis, A. Zannettino, S. Isenmann, S. Shi, T. Lapidot, S. Gronthos, Stromal-derived factor-1 promotes the growth, survival, and development of human bone marrow stromal stem cells. Blood 105, 3793 (May 15, 2005).

27. A. Saxena, J. E. Fish, M. D. White, S. Yu, J. W. P. Smyth, R. M. Shaw, J. M. DiMaio, D. Srivastava, Stromal cell-derived factor-1 is cardioprotective after myocardial infarction. Circulation 117, 2224 (2008/04/29, 2008).

28. A. T. Askari, S. Unzek, Z. B. Popovic, C. K. Goldman, F. Forudi, M. Kiedrowski, A. Rovner, S. G. Ellis, J. D. Thomas, P. E. DiCorleto, E. J. Topol, M. S. Penn, Effect of stromal-cell-derived factor 1 on stem-cell homing and tissue regeneration in ischaemic cardiomyopathy. The Lancet 362, 697 (2003/08, 2003).

29. G. Zhang, Y. Nakamura, X. Wang, Q. Hu, L. J Suggs, J. Zhang, Controlled release of stromal cell-derived factor-1 alpha in situ increases Ckit $^{+}$cell homing to the infarcted heart. Tissue Engineering 13, 2063 (2007/08, 2007).

30. I. Elmadbouh, H. K. Haider, S. Jiang, N. M. Idris, G. Lu, M. Ashraf, Ex vivo delivered stromal cell-derived factor-1a promotes stem cell homing and induces angiomyogenesis in the infarcted myocardium. Journal of molecular and cellular cardiology 42, 792 (2007/04, 2007).

31. J. Yamaguchi, K. F. Kusano, O. Masuo, A. Kawamoto, M. Silver, S. Murasawa, M. BoschMarce, H. Masuda, D. W. Losordo, J. M. Isner, T.
Asahara, Stromal cell-derived factor-1 effects on ex vivo expanded endothelial progenitor cell recruitment for ischemic neovascularization. Circulation 107, 1322 (Mar 11, 2003).

32. J. D. Abbott, Y. Huang, D. Liu, R. Hickey, D. S. Krause, F. J. Giordano, Stromal cell-derived factor-1alpha plays a critical role in stem cell recruitment to the heart after myocardial infarction but is not sufficient to induce homing in the absence of injury. Circulation 110, 3300 (Nov 23, 2004)

33. Y. J. Woo, T. J. Grand, M. F. Berry, P. Atluri, M. A. Moise, V. M. Hsu, J. Cohen, O. Fisher, J. Burdick, M. Taylor, S. Zentko, G. Liao, M. Smith, S. Kolakowski, V. Jayasankar, T. J. Gardner, H. L. Sweeney, Stromal cell-derived factor and granulocyte-monocyte colony-stimulating factor form a combined neovasculogenic therapy for ischemic cardiomyopathy. The Journal of Thoracic and Cardiovascular Surgery 130, 321 (2005/08, 2005).

34. J. Honold, R. Lehmann, C. Heeschen, D. H. Walter, B. Assmus, K. Sasaki, H. Martin, J. Haendeler, A. M. Zeiher, S. Dimmeler, Effects of granulocyte colony simulating factor on functional activities of endothelial progenitor cells in patients with chronic ischemic heart disease. Arterioscler Thromb Vasc Biol 26, 2238 (Oct, 2006).

35. A. Abdel-Latif, R. Bolli, E. K. Zuba-Surma, I. M. Tleyjeh, C. A. Hornung, B. Dawn, Granulocyte colony-stimulating factor therapy for cardiac repair after acute myocardial infarction: A systematic review and meta-analysis of randomized controlled trials. American Heart Journal 156, 216 (2008/08, 2008).

36. M. S. Penn, Importance of the SDF-1:CXCR4 Axis in Myocardial Repair. Circulation research 104, 1133 (2009/05/21, 2009).

37. M. Zhang, N. Mal, M. Kiedrowski, M. Chacko, A. T. Askari, Z. B. Popovic, O. N. Koc, M. S. Penn, SDF-1 expression by mesenchymal stem cells results in trophic support of cardiac myocytes after myocardial infarction. The FASEB Journal 21, 3197 (2007/10, 2007).

38. D. Zhang, G.-C. Fan, X. Zhou, T. Zhao, Z. Pasha, M. Xu, Y. Zhu, M. Ashraf, Y. Wang, Overexpression of CXCR4 on mesenchymal stem cells augments myoangiogenesis in the infarcted myocardium. Journal of molecular and cellular cardiology 44, 281 (2008/02, 2008).

39. V. Schächinger, S. Erbs, A. Elsässer, W. Haberbosch, R. Hambrecht, H. Hölschermann, J. Yu, R. Corti, D. G. Mathey, C. W. Hamm, T. Süselbeck, B. Assmus, T. Tonn, S. Dimmeler, A. M. Zeiher, Intracoronary bone marrow-derived progenitor cells in acute myocardial infarction. New England Journal of Medicine 355, 1210 (2006/09/21, 2006).

40. X. Hu, S. Dai, W. J. Wu, W. Tan, X. Zhu, J. Mu, Y. Guo, R. Bolli, G. Rokosh, Stromal cell derived factor-1 confers protection against myocardial ischemia/reperfusion injury: Role of the cardiac stromal cell derived factor-1 CXCR4 axis. Circulation 116, 654 (2007/08/07, 2007).

41. O. Kollet, S. Shivtiel, Y.-Q. Chen, J. Suriawinata, S. N. Thung, M. D. Dabeva, J. Kahn, A. Spiegel, A. Dar, S. Samira, P. Goichberg, A. Kalinkovich, F. ArenzanaSeisdedos, A. Nagler, I. Hardan, M. Revel, D. A. Shafritz, T. Lapidot, HGF, SDF-1, and MMP-9 are involved in stress-induced human CD34+ 
Chapter 7 - Downregulation of the CXC chemokine receptor 4/stromal cell-derived factor 1.

stem cell recruitment to the liver. Journal of 2003)

Clinical Investigation 112, $160 \quad(2003 / 07 / 15$, 


\section{Part III}

Discussion and summaries. 


\section{Chapter 8 \\ General discussion and future perspectives.}




\section{GENERAL DISCUSSION AND FUTURE PERSPECTIVES}

Cardiovascular disease (CVD) and subsequent heart failure (HF), and type I diabetes mellitus (IDDM), and its complications, are two major health threats to an ageing Western population $(1,2)$. Cell and (structural) tissue loss due to ischemia and/or autoimmunity are the main reasons for these events. Therefore, cell and/or tissue engineering, regeneration, and replacement offer novel treatment options to reverse or even cure CVD, HF, and IDDM. The research described in this thesis was designed to better understand the functions that various approaches which utilize cell transplantation and tissue engineering can play in tissue degenerative diseases such as $\mathrm{CVD} / \mathrm{HF}$ or IDDM. We plan to discuss in this section the main conclusions and implications of our findings, and future perspectives for this novel area of investigations.

This thesis consists of two parts; the first part emphasizes the role of biomaterials and bioengineering upon which effective stem cell and Bcell transplantation relies, while the second part focuses on the application and mechanisms of hematopoietic stem cells in cardiac tissue repair without the use of biomaterials. The studies on cardiac repair provide a deeper analysis into the homing mechanisms that could influence stem cell mediated regeneration.

The main findings of this thesis which are outlined in greater detail in corresponding chapters are:

a. Raw sodium alginate derived from brown seaweed can be highly purified using specific buffer conditions in combination with hydrophobic polyvinylidene difluoride (PVDF) membrane filtration. The resulting alginate surpasses purity in terms of protein content and immunogenicity, compared to commercially available "ultra pure" alginates (Chapter 2) and Table 1. Table 1 summarizes the results of alginate purification by PVDF membrane filtration, and compares relative efficiencies of contamination removal by application of different purification processes used by different commercial parties.

b. Custom purified alginate can be covalently (i.e. irreversibly) modified with synthetic cyclic RGDfK peptides, which bind to specific cell surface receptors (i.e. integrins) on the outside of cell membranes. Such modified alginate can be subsequently used in downstream applications, as in fabrication of either hydrogel or solid 3Dscaffolds. Such 3D-scaffolds when seeded with different cell types were shown to enhance STRO-1 ${ }^{+}$ mesenchymal precursor cell (MPC) adhesion and their survival; they could therefore be used to transplant MPCs to create new blood vessels and to improve cardiac function in $\mathrm{HF}$ (Chapter 3). By carrying pancreatic $B$-cells, such $3 \mathrm{D}$-scaffolds could also successfully treat IDDM (Chapters 4 \& 5), in experimental animal models. c. The "homing" of hematopoietic stem cells to damaged tissues (i.e. infarcted myocardial tissue) is mediated by specific pathways that play a role in cytokine/chemokine signaling, i.e. eotaxin/CCL11, RANTES/CCL5, MCP3/CCL7 and their receptor CD193 (CCR3), and SDF-1/CXCL12 and its receptor CD184 (CXCR4). Modulation of these chemokinereceptor axes by blocking antibodies against CD193, CD184, or SDF-1, by local cardiac administration of eotaxin or SDF-1, or systemic administration of G$\mathrm{CSF}$, can redirect stem cells to other locations (i.e. damaged organs) following tissue injury and thereby exert a reparative effect (Chapters 6 and 7).

\section{ALGINATE BASED BIOMATERIALS AS A VERSATILE TOOL IN TISSUE ENGINEERING APPLICATIONS TO TREATMENT OF HF AND IDDM (CHAPTERS 2, 3, 4 \& 5)}

Sodium alginate, mainly derived from brown seaweed, offers a wide range of applications, starting as beer foam stability enhancer and extending to its use as acid reflux inhibitor and 3Dprinter ink material (3-5). The usefulness of sodium alginate as a material useful in cell transplantation for pancreatic islets was shown in 1980 by Lim and Sun in their search for methods to safely encapsulate islets to protect them from immunological reactions (6). The islets in this case were encapsulated in small spheres with a semipermeable alginate-poly-L-lysine-alginate membrane that permitted diffusion of glucose and insulin but prevented entry of immune cells into the sphere. Unfortunately, the stability of such spheres remains limited in vivo and since there is no neovasculature following transplantation, the islets are initially dependent only on diffusion of nutrients and oxygen for their survival, and on glucose and catecholamines for their function.

To complicate the matters, we have shown that seaweed derived sodium alginate is heavily contaminated with several biological components such as protein, DNA, RNA and endotoxin, each of which could elicit an unwanted immune response to the material itself which can then act almost as an adjuvant in the reaction of the enclosed or carried cells. To avoid this problem, we were able to remove almost all contamination by implementing a newly developed purification protocol based on hydrophobic PVDF membrane filtration at $\mathrm{pH} 5.5$ (7). The resulting purified sodium alginate could then be used in further downstream applications, such as 1) covalent (i.e. irreversible binding) modification with bioactive peptides, 2) generation of biocompatible 3D scaffolds as cell carriers, and for 3) neovascularization, in vivo or potentiating growth of new vascular networks (as described in chapters 2, 3, 4 \& 5).

\section{MODIFICATION OF ALGINATE USING ARG-GLY-ASP (RGD), OTHER PEPTIDES AND PROTEINS, AND ITS APPLICATIONS IN TISSUE ENGINEERING (CHAPTERS 2 \& 3)}




\begin{tabular}{|c|c|c|c|c|}
\hline & $\begin{array}{l}\text { Sigma-Aldrich } \\
\text { unpurified } \\
\text { sodium } \\
\text { alginate } \\
\text { (Sigma0682, } \\
\text { LVM) }\end{array}$ & $\begin{array}{l}\text { Commercial } \\
\text { Ultrapure } \\
\text { alginate } \\
\text { NovaMatrix LVM }\end{array}$ & $\begin{array}{l}\text { Commercial } \\
\text { Ultrapure } \\
\text { alginate } \\
\text { NovaMatrix LVG }\end{array}$ & $\begin{array}{l}\text { Custom purified } \\
\text { alginate } \\
\text { Sondermeijer } \\
\text { (Sigma-Aldrich } \\
\text { 0682, LVM) }\end{array}$ \\
\hline $\begin{array}{l}\text { Protein (per } \\
\text { gram dry } \\
\text { alginate) }\end{array}$ & $11 \mathrm{mg}$ & $5 \mathrm{mg}$ & $5 \mathrm{mg}$ & $3 \mathrm{mg}$ \\
\hline $\begin{array}{l}\text { DNA (per gram } \\
\text { dry alginate) }\end{array}$ & $3 \mu \mathrm{g}$ & $<0.25 \mu \mathrm{g}$ & $<0.25 \mu \mathrm{g}$ & $1 \mu \mathrm{g}$ \\
\hline $\begin{array}{l}\text { RNA (per gram } \\
\text { dry alginate) }\end{array}$ & $32 \mu \mathrm{g}$ & $<10 \mu \mathrm{g}$ & $<10 \mu \mathrm{g}$ & $<10 \mu \mathrm{g}$ \\
\hline $\begin{array}{l}\text { Endotoxin (per } \\
\text { gram dry } \\
\text { alginate) }\end{array}$ & $>125 \mathrm{EU}$ & $<125 \mathrm{EU}$ & $<125 \mathrm{EU}$ & $<125 \mathrm{EU}$ \\
\hline $\begin{array}{l}\text { Immune } \\
\text { activation } \\
\text { (compared to } \\
\text { baseline) }\end{array}$ & +++ & + & ++ & - \\
\hline $\begin{array}{l}\text { Organic } \\
\text { solvents used } \\
\text { for } \\
\text { purification }\end{array}$ & N/A & $\begin{array}{l}\text { Chloroform, } \\
\text { ethanol, ethyl } \\
\text { ether, butanol }\end{array}$ & $\begin{array}{l}\text { Chloroform, } \\
\text { ethanol, ethyl } \\
\text { ether, butanol }\end{array}$ & Ethanol \\
\hline $\begin{array}{l}\text { Inorganic } \\
\text { solvents used } \\
\text { for } \\
\text { purification }\end{array}$ & N/A & $\begin{array}{l}\text { Sodium hydroxide, } \\
\text { sodium citrate, } \\
\text { acetic acid, EDTA, } \\
\text { EGTA }\end{array}$ & $\begin{array}{l}\text { Sodium hydroxide, } \\
\text { sodium citrate, } \\
\text { acetic acid, EDTA, } \\
\text { EGTA }\end{array}$ & Sodium phosphate \\
\hline
\end{tabular}

Table 1. Comparison of several commercially available alginates before and after purification. LVM = low viscosity mannuronic acid. $\mathrm{LVG}=$ low viscosity guluronic acid. EDTA= ethylenediaminetetraacetic acid. EGTA=egtazic acid. The far right column shows results of our novel purification protocol applied in chapter 2. Relative efficiencies of purification of different sodium alginate products are shown, represented as residual contamination following purification of protein, DNA, RNA and endotoxin content, immunogenicity, and solvents (i.e. waste) used for purification.

Legend: = low efficiency, = = intermediate efficiency, = high efficiency

Sodium alginate's main advantage lies in its saccharide monomers, each containing carboxyl ($\mathrm{COOH})$ groups, which are readily available to react with amino $\left(-\mathrm{NH}_{2}\right)$ groups using various crosslinkers (8-11) in aqueous solution. When the polysaccharide becomes solid in aqueous solutions following addition of divalent ions (i.e. $\mathrm{Ca}^{2+}, \mathrm{Ba}^{2+}$ ), the level of rigidity of the $\mathrm{Ca}^{2+}$-or $\mathrm{Ba}^{2+}$-alginate matrix can be controlled based on the amount/concentration of added divalent ions (Figure 1).

There are many different sodium alginate formulations. Sodium alginate generally consists of mannuronic or guluronic acid monomers (12). The molecular weight (MW) of monomers is 194D (13). Sodium alginate polymers can reach lengths with masses over $250 \mathrm{kD}$, which results in high viscosity at $1-2 \% \quad \mathrm{w} / \mathrm{w}$ aqueous solution (14); sodium alginate's viscosity in aqueous solution therefore can vary and is dependent on the ratio of guluronic to mannuronic acid monomers which can be manipulated, and on the polymer chain length (13). Heating sodium alginate in aqueous solutions, and/or ionizing irradiation, can result in chain breakdown and result in lower viscosities in solution (15). To minimize alginate's effects on cells and their immunological properties, variation of viscosity can be beneficial (16). For mesenchymal stem cells (MSCs) or STRO-1+/STRO-3 ${ }^{+}$MPCs, which are purified MSCs using the proprietary antiSTRO-1 or anti-STRO-3 mAb $(17,18)$ and considered to be more primitive MSCs, and pancreatic islets, optimal viscosities are determined by the consistency of the alginate solution (in case of islet encapsulation (19)) or scaffold rigidity (in case of 3D scaffolds (20)).

For the studies on which this thesis is based, we were able to generate purified alginate that surpasses commercially available pharmaceutical grade alginate formulations (Figure 1). Our approach was based on filtration through hydrophobic PVDF membranes (7). Subsequently, we managed to modify the purified alginate with the cyclic RGDfK peptide using carbodiimide and sulfo-NHS crosslinking in aqueous solution $(10,11)$. This peptide has been previously used as an antiangiogenic agent, in the setting of blood vessel growth inhibition in malignancies. It inhibits angiogenesis by acting as an antagonist of endothelial cell adhesion by blocking $\alpha_{v} b_{3}$ and $\alpha_{5} b_{1}$, which are two main integrin receptors on endothelial cells (21). In contrast, it is also used as a radioactive imaging agent in tissues that are actively undergoing vascular remodeling (i.e. malignant tumor tissue or metastases) by specifically binding to proliferating endothelial cells, 


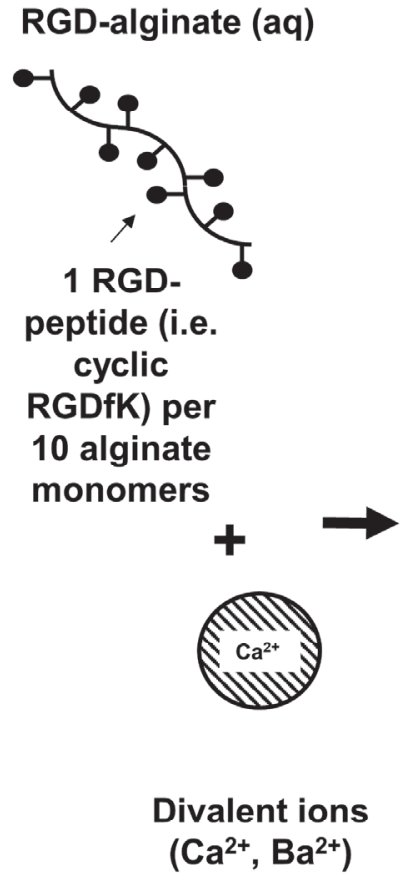

Step 1

\author{
Solid calcium- \\ RGD-alginate \\ scaffold in \\ typical tilted \\ "egg-box" \\ conformation
}

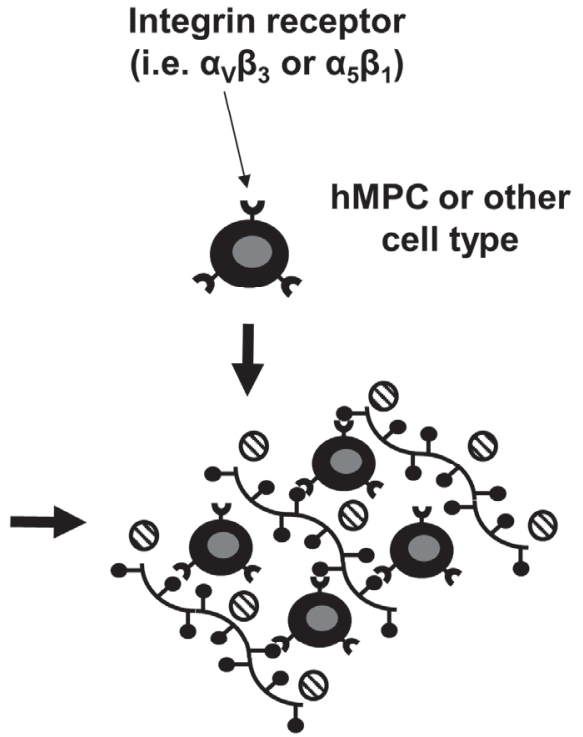

hMPC loaded porous 3D calcium-

RGD-alginate scaffold (not to scale)

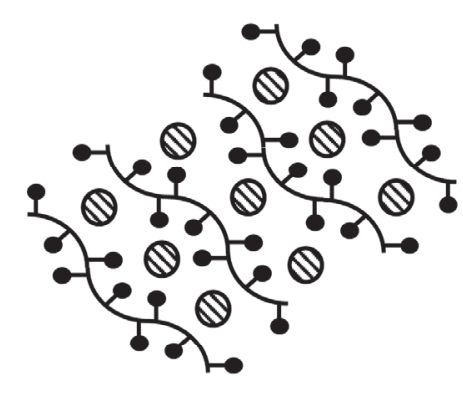

\begin{abstract}
Figure 1. Schematic representation of calcium-RGD-alginate scaffold generation, including cell loading. Step 1 shows the mixing of aqueous RGD-alginate (up to $2 \% \mathrm{w} / \mathrm{w}$, depending on viscosity and chain length) with divalent ions $\left(\mathrm{Ca}^{2+}, \mathrm{Ba}^{2+}\right.$, typically $\left.\sim 1 \% \mathrm{w} / \mathrm{w}\right)$ in aqueous solution. Step 2 shows the arrangement of RGD-alginate chains with divalent ions in the hypothetical "tilted egg-box" conformation (25). Step 3 shows addition of hMPCs expressing integrin receptors (i.e. avb3) which attach with high specificity to immobilized RGD in the 3D RGD-alginate matrix. Note that in aqueous solutions such as used in hydrogels and chapters 2, 4 and 5, ratios of alginate/RGD-alginate: $\mathrm{Ca}^{2+}: \mathrm{H}_{2} \mathrm{O}$ (i.e. 2:1:98) are not shown to scale. In solid lyophilized RGD-alginate scaffold applications, such as used in chapter 3, densities of RGD-alginate and $\mathrm{Ca}^{2+}$ would be higher (25).
\end{abstract}

in order to visualize tumor blood vessel proliferation (22). Conversely, the immobilization of cyclic RGDfK peptide on alginate polymers chains, as we have done, creates a solid substrate for endothelial cells and other cells with integrin receptors such as MSCs/MPCs to adhere and to spread, therefore enhancing survival and preventing "anoikis", i.e. programmed cell death after detachment, of RGDalginate bound cells (23).

Thus, RGD-peptides have been used in many other therapeutic applications (24). RGDpeptides in solution have been mostly used as blockers of cell adhesion, which could be useful in anti-proliferative/anti-cancer/anti-metastasis therapy. Radiolabeled RGDfK peptides have been used for PET-imaging studies, mostly in oncology, since solid tumors express high levels of integrins such as $\alpha_{v} b_{3}$ and $\alpha_{5} b_{1}$ at high levels (26).

\section{OPTIMIZATION OF ALGINATE MODIFICATION USING CROSS-LINKER TECHNOLOGY (CHAPTER 3, 4 \& 5)}

As mentioned before, the attractiveness of sodium alginate is its modifiable carboxy (-COOH)-groups. These groups can be "activated" so as to react with other activated groups such as amino $\left(\mathrm{NH}_{2}-\right)$-groups,
SH-groups, or others. We used (1-ethyl-3-(3dimethylaminopropyl)carbodiimide hydrochloride) (EDC) and N-hydroxysulfosuccinimide (sulfo-NHS) chemistry to covalently attach RGD peptides to sodium alginate (27). EDC/sulfo-NHS is a combination of zero-length cross-linkers, which implies that they will not introduce any spacer molecules between the two molecules that are coupled (in this case alginate and RGDfK peptide) (9). Other cross-linkers introduce spacer arm atoms that may provide enhanced access of integrins to coupled RGDfK peptides. Other known cross-linkers are homo-bifunctional cross- linker reagents that have the same reactive group at both ends of the spacer arm, i.e. $\mathrm{NH}_{2}-\mathrm{NH}_{2}$ reactive (28); while hetero-bifunctional cross-linkers have different reactive groups on each end of a spacer arm, i.e. $\mathrm{SH}-\mathrm{NH}_{2}$ reactive (29). Cross-linker chemistry is commonly used in several areas and is therefore an important tool in this field. It has been used in 1) conjugation or labeling of antibodies in reporter assays $(30), 2$ ) covalent crosslinking of proteins to solid surfaces (31), or 3) study of protein-protein interactions in disease (32), as well as in other manipulations. 
In our studies, we used exact molar concentrations that would theoretically activate $10 \%$ of the $-\mathrm{COOH}$ groups in any given alginate polymer chain $(10,11)$. We hypothesized that based on the proposed hypothetical 3D egg-box structure of calcium alginate (25) sufficient RGDfK peptides would be available to bind to cells with surface integrin receptors (Figure 1). By modifying the concentration of cyclic RGDfK bound to alginate we showed a dose-dependent cell survival; the higher the amount of cyclic RGDfK peptide used, the higher the percentage of live cells inside scaffolds after 1 week of in vitro culture (10).

Since the covalent attachment of cyclic RGDfK to alginate monomers theoretically is $1: 1$, the increased survival of cells could be explained by 1) complexes of cyclic RGDfK clustered together on 1 carboxy-group by covalent peptide-to-peptide interaction, 2) the concentration range used still fell in the non-saturation domain, or 3) the theoretical percentage of $-\mathrm{COOH}$ activation was exceeded. Indeed, for tumor imaging studies, soluble $99 \mathrm{~m} \mathrm{Tc}$ and ${ }^{111}$ In radiolabeled RGDfK polymer chains have been used to enhance binding to tumor cells (26). In other studies, the spacing of the RGD sequence and its molecular distance from the alginate polymer chain may enhance availability in the 3D conformational space of RGD to integrin receptors on the surface of cells, which has been shown by modifying alginate with a GGGGRGDSP $\left(\mathrm{G}_{4} \mathrm{RGDSP}\right)$ peptide compared to GRGDSP peptide modification, where $4 \mathrm{x}$ glycine $(\mathrm{G})$ acts as a spacer amino acid chain (33).

Apart from RGD, which is an important part of many extracellular matrix proteins such as fibronectin, collagen and vitronectin $(34,35)$, other peptide sequences may be considered to create a 3D alginate scaffold with additional properties other than enhancing cell survival. For example, the peptide sequence $\mathrm{FN}-\mathrm{C} / \mathrm{H}-\mathrm{V}$ in fibronectin (residues Gln1892 to Gly1910) has been shown to promote adhesion, spreading, as well as motility of certain cell types (36). Whereas RGD enhances cell adhesion via integrins such as avb3, RGD by itself is not known to be indispensable for cell motility and cell migration, which in dense tissue seems to be integrin independent and based on actomyosinmediated protrusion and contraction (37). Cell division (mitosis) needs additional (intracellular) integrin signaling (38). Thus, an RGD-only modified scaffold may not be the optimal environment if one is to generate a proliferating tissue system. Other peptides in fibronectin such as Leu-Asp-Val (LDV) and Arg-Glu-Asp-Val (REDV) have been shown to bind to other integrins such as integrin $\alpha_{4} B_{1}$ and thereby enhance vascular cell spreading (39). If one considers using otherwise inert biomaterials such as alginate or hyaluronic acid, it may therefore be critical to incorporate into such biomaterials several different peptide sequences to create a fully functional 3D-environment that promotes cell adhesion (i.e. survival), migration, and division.

\section{HOMING OF BONE MARROW DERIVED STEM CELLS BY CHEMOKINES AND THEIR ROLES IN TISSUE DEGENERATIVE DISEASES (CHAPTERS 7 \& 8)}

Bone marrow transplantation remains the therapy of choice for hematological malignancies. The mechanisms of bone marrow stem cell homing are quite well established (40). Homing of leukocytes to sites of inflammation or infection is also well described (41). The application of bone marrow stem cells or other tissue derived stem cells to sites of tissue damage is a relatively new concept, especially in case of organs that were previously considered to have no regenerative capabilities such as the human heart $(42,43)$. In the case of the heart, one needs to understand that ischemia will induce an inflammatory response $(44,45)$, which will attract immune cells such as macrophages, innate lymphoid cells, and mast cells (46). Bone marrow derived cells such as monocytes/macrophages play key roles in inflammation as they are needed to generate new vasculature (47) and clean up dead tissue debris following ischemia/infarction (48). Indeed, macrophage depletion impairs wound healing and left ventricular remodeling and increases mortality following myocardial infarction in mice, probably via TGF-B and VEGF-A signaling pathways (49).

The migration of such immune cells to sites of inflammation should not be confused with a specific regenerative response by stem cells. Interestingly, cytokines and chemokines that are produced by damaged tissue such as SDF-1 or CCL3/CCL4 (also known as MIP1a/MIP1B) are not only capable of attracting immune cells such as monocytes/ macrophages through its respective receptors CXCR4 and CCR5 (50), but these chemokines also attract bone marrow derived CD $34^{+}$stem cells, as we and other have shown (51, 52). Stromal derived factor 1 (SDF-1) is produced by bone marrow stromal cells and attracts hematopoietic stem cells via their receptor CXCR4 which is abundantly expressed on CD34 ${ }^{+}$ hematopoietic stem cells. Surface receptors of such cells are used as markers of putative stem cells, not just stem cells from the bone marrow, but also from other tissues, for example vascular endothelium (53). The identification of CD34 on circulating mononuclear cells led to the early hypothesis that bone marrow derived stem cells might circulate in the blood stream and regenerate tissues with damaged vasculature such as the heart following MI. This has resulted in an extensive search for other cell surface receptors and cytokines/chemokines that play roles in regeneration of tissues. For example, c-kit/CD117, a tyrosine-protein kinase type III and the receptor for stem cell factor (SCF), is a cell surface protein on hematopoietic stem cells, but was also found in the heart (54). This led to the hypothesis that the heart may contain intrinsic cardiac stem cells (CSCs) that potentially could repair cardiac damage after MI. (54). It was later found that cardiac mast cells also express c-kit/CD117 (55), hence additional research 
is ongoing to characterize the (stem cell) phenotype of c-kit ${ }^{+} \mathrm{CD} 117^{+}$cardiac cells.

Given the apparent overlap between proinflammatory and pro-regenerative signals, the question arises if one should separate an inflammatory immune response from a specific stem cell-based tissue repair response, and if so, how? Therapeutic intervention will be more specific if the regenerative response is enhanced without triggering an inflammatory reaction, but there are also examples where inflammation may facilitate homing and engraftment of stem cells. In the case of bone marrow transplantation for example, not every transplant results in successful engraftment, indicating that the interaction between donor bone marrow stem cells and the host bone marrow is subject to specific signals and cellular interactions within a well-defined matrix (56). Indeed, such interaction is highly complex, and involves not only the cell homing capacity, but also the immune status of the recipient, age of donor and host, and many other variables. Total body irradiation (TBI) of the bone marrow recipient, also known as conditioning, enhances the efficacy of stem cell engraftment after bone marrow transplantation. The theory here is to create "space" in the recipient's bone marrow niche for donor cells by killing resident bone marrow, in some cases even without irradiation (57). However, ionizing irradiation also induces bone marrow inflammation, which may provide signals for immune cells but also for infused stem cells to home to bone marrow and engraft (58). In addition, it has been shown that local irradiation enhances the homing and engraftment of human MSCs to the irradiated tissue in NOD/SCID mice models due to radioinduced tissue damage (59). Thus, the differences between inflammation and stem cell repair frequently have a common outcome.

An acute MI induces an acute inflammatory response (44). In the heart, just as in bone marrow, this inflammation stimulates homing of leukocytes and stem cells to the myocardium, which can be shown non-invasively, for example by PET imaging (60), or in combination with Cre-loxassisted cell fate mapping (61). Whether such stem cells are ultimately responsible for the observed tissue repair in animal models is subject of intense discussions. Following MI, one can measure stem cell homing signals such as SDF-1 in the heart, as we and others have shown $(51,62,63)$, but the question remains whether such signals lead to mobilization of primarily inflammatory and/or of dedicated reparative stem cells, or to both. It is likely that the homing signals for inflammation and/or repair may be synergistic, rather than mutually exclusive. Indeed, in skeletal muscle it was shown that the micro-environment of the injury site can have profound effects on wound healing in vivo (64). For instance prolonged hypoxia had an immediate anti-inflammatory effect and resulted in significant $\mathrm{Pax}^{+}$satellite stem cell proliferation. Conversely, inhibition of hypoxia by lowering mitochondrial oxygen consumption induced inflammation and reduced the number of proliferating $\mathrm{Pax}^{+}$satellite stem cells. These differential effects were regulated by hypoxiainducible factor $1 \alpha$ (HIF1a), a polypeptide and transcriptional activator of vascular endothelial growth factor (VEGF). In the heart, an increase in the level of HIF1a is an early response to myocardial ischemia or infarction (65). HIF1a has further been shown to modulate the expression of several chemokine receptors on white blood cells, notably CCR1, -2 , and -4 (66), which could affect homing behavior of WBCs. In mice, continuous expression of HIF1a by inhibiting its degradation by prolyl hydroxylase (PHDs) inhibitors resulted in tissue regeneration (67). Thus, the net outcome of a tissue injury response (i.e. regeneration or scar formation/fibrosis) is at least partially regulated by tissue oxygen levels.

Adoptive transfer of MSCs after MI is considered to be a therapeutic strategy to repair damaged cardiac tissue. MSCs migrate in response to homing signals and express cell surface receptors involved in stem cell homing. However, in chronic HF models, application of labeled sheets of MSCs as an epicardial patch did not result in the migration of these cells into the myocardial infarct scar (68). In chronic $\mathrm{HF}$ models however, homing signals may be lacking due to a subsided inflammatory response. In our own studies, G-CSF mobilized purified human $\mathrm{CD} 4^{+}$bone marrow cells injected directly into the myocardial infarct scars of nude rats 4 weeks after an MI (considered to be a chronic HF condition) did not alter cardiac function (Master Thesis H.P. Sondermeijer, not published). Thus, the healing effects seen in animal models may be dependent on stem cells, but homing and/or attractant signals seem to be essential for an overall effect (i.e. cell retention, cell proliferation) in the damaged tissue, where, in addition, a suitable environment must be present and which is essential for successful engraftment of such cells in the target organ that needs repair.

It must also be considered that alone, the injection of stem cells into the circulation after an MI would not automatically signify that such stem cells migrate to the damaged heart. The bone marrow produces low levels of SDF-1 (69), hence i.v. injected stem cells may also migrate to many other locations. Indeed, T-cells seem to react to specific concentration gradients of SDF-1 in vitro, and either migrate towards or away from such gradients (70). Modulating the homing properties of CD34 ${ }^{+}$ hematopoietic progenitor cells can, as we have shown, be achieved by specifically blocking chemokine receptors (i.e. CCR3/CD193), or by injection of chemokines such as SDF-1 into ischemic myocardium after acute $\mathrm{MI}(51,63)$.

The interplay between stem cells and their homing factors is a highly complex process which is not fully understood. New cell surface receptors and cytokines/chemokines and their interactions are still being discovered and described (71). Therefore, one needs to be cautious in the assessment of (stem) cell homing studies and conclusions must be guarded as 
to the mechanisms and observed effects of such cells in the physiology of repair of the injured organs. Further experiments are needed to answer some of these questions. This can be achieved by thorough scientific design, for example by a combination of cell membrane staining, radioactive labeling for non-invasive (PET) imaging, or sex mismatched donor-recipient animal pairing for precise identification of reparative cell types (61). Unfortunately, even the latter approach has led to false positive conclusions because donor cells have been shown to fuse at the cell membrane level with recipient organ resident end-differentiated cells (i.e. cardiac myocytes). This resulted in misinterpretation that labeled donor cells differentiated into cardiac muscle cells, which could be prevented by fluorescent in situ hybridization (FISH) techniques, which distinguishes cells based on differences in (sex) chromosome content. Indeed, it was shown in human sex-mismatched heart transplant patients where male recipients received a female heart, approximately $7-10 \%$ of the cells (i.e. myocytes, coronary arterioles, capillaries) in the female heart contained cells with a Y chromosome and were highly proliferative compared to control hearts (72), raising the intriguing question whether the heart is able to regenerate via external stem cell recruitment and transdifferentiation. However, chimeric animals did not show evidence of such phenomenon, at least not in non-hematopoietic tissues, including brain, kidney, gut, liver, and muscle (73). Up till today, the debate as to whether the heart possesses regenerative capacities continues (74).

\section{TISSUE RESPONSE AND MECHANISMS OF TISSUE REPAIR (CHAPTERS 3, 4, 7 \& 8, APPENDIX 3)}

The injection of (stem) cells into damaged tissues has provoked extensive discussion and research regarding their role in the mechanisms of tissue repair, from transdifferentiation and paracrine effects (75, 76) (Appendix 2), modulation of extracellular matrix proteins (77), telomere shortening (78), and effects of so called exosomes, small vesicles secreted by injected cells (79). In the case of an experimental MI, one can measure objective improvement in cardiac function following injection of stem cells by using accepted parameters measured by various methods. These include echocardiography, MRI and PET imaging (80). The proposed mechanisms of such improvement range from induction of angiogenesis (81), the selective migration and subsequent support of injected stem cells to damaged cardiac muscle (82), or activation of endogenous cardiac stem cells in response to injected cells (83). For each mechanism, there is supporting scientific evidence, however, since there is a risk of misinterpretation, one needs to be cautious in formulating any definite clinical conclusions based on reported results in animal experiments. For example, in animal experiments, including our own (Chapters 3, 7 \& 8; appendix 3 ), one can measure virtual normalization of cardiac function following the application of human MSCs (75) or MSC seeded scaffolds (10). However, in human clinical trials with whole bone marrow which contains MSCs as well as $\mathrm{CD}^{+}$cells, intracoronary injection has not consistently shown a durable beneficial effect on cardiac function $(42,43$, 84). Meta-analyses (i.e. ACCRUE) have resulted in similar conclusions (85), though one needs to be careful with statements regarding lack of efficacy, even when based on meta-analyses.

Similarly, in IDDM studies, although there are many successful experimental treatments in various animal models, including the NOD/SCID mouse model, translation to the clinic has not yet been successful (86-88). To achieve translational clinical success we need to carefully consider many factors. This initially includes the animal model used, the type of therapeutic intervention, the methods to measure differences from baseline, as well as methods of islet isolation and location of islet placement. It is this latter consideration where we think major progress can, and is being made (89) using various forms of encapsulation and scaffold formation, as we have done using cyclic RGDfKpeptide modified alginate scaffolds (Chapters 4 \& 5 and (11)). The inefficiencies of translation from small animal models to human clinical studies are based, not only on quantitative consideration of size differences, but more importantly in case of pancreatic islets on qualitative differences on acceptance, longevity, immunologic tolerance to both biomaterial and their islet contents, and physiologic function and responses of islets within a new environment.

In the field of cardiac regeneration the use of microscopic techniques can be misleading in identifying the mechanism of efficacy of the transplanted stem cells by falsely identifying differentiation of one cell type into another by the use of inappropriate techniques. The issue in this particular case lies in the staining of stem cells for tracking purposes (90). An investigator could falsely conclude that a cell has acquired a new phenotype and has transdifferentiated into another cell type, even from another germ layer, when instead two different cells have fused. This can occur when cells are tracked by cell membrane staining or species specific cell surface markers such as the major histocompatibility complex (MHC), cell membranes including membrane surface antigens can be exchanged in vivo between cells of different species in a process called trogocytosis (91), therefore giving the false impression one cell has changed into another. This phenomenon could also be demonstrated in co-culture experiments in vitro (92). While biologically and even evolutionary this is a remarkable observation, there has been remarkably little attention to this mechanism in the field of stem cell therapy.

So, which mechanism has been proven to be more likely than transdifferentiation? Immunomodulation of the inflammatory response following acute tissue injury such as $\mathrm{MI}$ is a plausible explanation, as shown by the acute 
cardiovascular protective effects of antiinflammatory corticosteroids (93). Cardiac ischemic injury causes an intense proinflammatory cytokine response, notably by release of TNF-a, IL-6 and IL$1 \mathrm{Ra}$, which can lead to Systemic Inflammatory Response Syndrome (SIRS) (94). Systemic injection of stem cells or direct injection into acutely injured tissue may cause changes in the cardiac remodeling response by decreasing levels of circulating pro-and antiinflammatory cytokines, which could result in a net positive outcome with regards to cardiac function. Indeed, in a recent clinical trial using canakinumab, a therapeutic monoclonal antibody targeting interleukin-18, subcutaneous administration every 3 months led to a significantly lower rate of recurrent cardiovascular events than placebo in patients with atherosclerotic disease, independent of lipid-level lowering (95). Immunomodulatory effects may explain why the beneficial outcomes of stem cell injections or of other interventions, such as scaffold application in acute MI, when the inflammatory response is still "fresh", appears to be more pronounced than intervention in the established chronic HF model (author's observation).

Regardless of the underlying mechanism of tissue repair, modulating the immune response could be a novel approach to treat acute MI and other tissue degenerative diseases $(96,97)$. Several studies have addressed this observation, as for example by studying the anti-inflammatory actions of statins (98). Others, using newer experimental approaches employing antibodies and/or immunomodulatory biological, for example monoclonal antibodies against interleukin-1B (95), or known small antiinflammatory molecules such as methotrexate, have also addressed this problem (99). In this thesis, we used several different approaches based on the assumption that cell transplantation of human bone marrow derived $\mathrm{CD}_{34}{ }^{+}$cells or $\mathrm{hMPCs} \pm$ biomaterial would enhance tissue regeneration by proliferation and/or differentiation of transplanted cells into cardiovascular tissue (Chapters 3, 6, 7, and appendix $2(10,51,63,75))$. Since we did not find major human derived structures (i.e. replacement tissue, vascular structures, or contracting cardiac muscle) in the hearts of our animal models of HF, and could not detect any human RNA 24 hours after hMPC injection into rat MIs (75), it is likely that the effects that were seen on cardiac remodeling were most likely caused by other mechanism such as immunomodulation. In the case of hMPCs in our experiments, the injection of $\mathrm{hMPC}$ conditioned medium (i.e. concentrated cell growth medium collected after hMPC culture without the cells) into hearts of animals with acute MI improved cardiac function to a similar extent as direct intramyocardial cell injection (75). Since hMPCs are known to secrete a number of immunomodulatory cytokines, notably IL-6, and express a distinct panel of chemokine receptors (100) that could consume locally produced or systemically circulating chemokines, it is likely that these factors contribute to the observed positive functional effects that we measured on cardiac remodeling following an MI in these experimental models.

\section{CELL THERAPY OR TISSUE ENGINEERING: WHAT TO PREFER IN REGENERATIVE MEDICINE?}

The field of tissue engineering and cell therapy for tissue repair is relatively young. Initially, based on animal models, regenerative cell therapy showed great promise in several diseases such as cardiovascular disease, IDDM, and others $(81,101$, 102). Many cell types have been isolated, expanded, identified, and functionally evaluated in an effort to facilitate tissue and organ repair and regeneration. Concomitantly, many biologic and bioengineering efforts to combine different biomaterials with different cell types has followed suit. Table 2 and table 3 provide an overview of major biomaterials which have been evaluated in combination with cell types in experiments focused on treating MIs and IDDM. Although the tables are incomplete due to almost daily progress in this new field, already a pattern in the progress can be identified. Most studies of MIs to date include the use of decellularized tissues, sodium alginate scaffolds, and fibrin based scaffolds. In studies of IDDM, there was predominant use of sodium alginate and polylactide (i.e. PGA) based materials. Since sodium alginate, fibrin and poly-lactide based materials are FDA-approved for clinical use, it is logical to use such materials as a starting point. Decellularized scaffolds may be less desirable for clinical application due to potential pathogen transfer such as prions, or contamination with host derived DNA that could lead to immune responses.

It remains to be seen whether bioengineered scaffolds, "natural" decellularized carriers or cell transfers themselves are the most efficient; this may well depend on the target organ treated. Clinical trials will eventually decide which approaches are most feasible and hold greatest promise for the future. Cell therapy by direct injection is more practical, however cell survival and hence efficacy and longevity may be a problem. For more complex tissues, biomaterials and tissue engineering seem to have an advantage over cell sheets or cell injections. On another note, financial issues must also be taken into account. Pharmaceutical companies may be hesitant to invest in a single therapeutic intervention (i.e. an autologous stem cell \pm biomaterial transplantation) that "cures" a disease. The discussion as how to finance tissue engineering and cell therapy investigations and clinical trials deserves additional attention $(154,155)$. 
Chapter 8 - General discussion and future perspectives.

\begin{tabular}{|c|c|c|c|c|}
\hline Scaffold material & Cell types & Model organism & Primary endpoints & References \\
\hline Sodium alginate & $\begin{array}{l}\text { Rodent FCMs, } \\
\text { hESCs, hMSCs, } \\
\text { CSCs, acellular }\end{array}$ & $\begin{array}{l}\text { Rodent permanent } \mathrm{Ml} \text {, } \\
\text { human } \mathrm{HF} \text {, } \\
\text { porcine ischemia/reperfusion }\end{array}$ & $\begin{array}{l}\text { Cell proliferation/retention/fate, } \\
\text { cardiac neovascularization, } \\
\text { LV function }\end{array}$ & $(103-108)$ \\
\hline $\begin{array}{l}\text { Fibrin glue } \\
\text { (Tisseel }{ }^{\mathrm{TM}} \text { ) }\end{array}$ & $\begin{array}{l}\text { SMCs, MSCs, } \\
\text { hiPSCs, } \\
\text { acellular }\end{array}$ & $\begin{array}{l}\text { Rodent ischemia reperfusion, } \\
\text { permanent ligation, porcine MI }\end{array}$ & Cell retention, LV function & $(109-114)$ \\
\hline PGA/PLA & $\begin{array}{l}\text { Rodent ESCs, } \\
\text { human DFBs, } \\
\text { rodent BMNCs }\end{array}$ & Rodent MI, swine MI & LV function, angiogenesis & $(115-118)$ \\
\hline $\begin{array}{l}\text { Acellular } \\
\text { (synthetic) }\end{array}$ & N/A & $\begin{array}{l}\text { Rodent } \mathrm{MI} \text {, porcine ischemia } \\
\text { reperfusion, human VSD }\end{array}$ & LV function, angiogenesis & $(119-121)$ \\
\hline $\begin{array}{l}\text { Decellularized } \\
\text { (biological) }\end{array}$ & $\begin{array}{l}\text { Rodent CPCs, } \\
\text { rodent MSCs, } \\
\text { human DFBs, } \\
\text { humans MPCs }\end{array}$ & $\begin{array}{l}\text { Rodent permanent MI, } \\
\text { porcine Ml, dog Ml }\end{array}$ & LV function, angiogenesis & $(122-128)$ \\
\hline Collagen & $\begin{array}{l}\text { Rodent BMNCs, } \\
\text { rodent MSCs, } \\
\text { human CAECs, } \\
\text { human BMNCs }\end{array}$ & $\begin{array}{l}\text { Rodent Ml, } \\
\text { human phase I trial }\end{array}$ & $\begin{array}{l}\text { Remodeling, angiogenesis, } \\
\text { LV function }\end{array}$ & $(107,129-132)$ \\
\hline $\begin{array}{l}\text { Self-assembling } \\
\text { peptides }\end{array}$ & $\begin{array}{l}\text { Human iPSCs, } \\
\text { murine CPCs }\end{array}$ & Rodent MI, & LV function, angiogenesis & $(133,134)$ \\
\hline PNIPAAM & $\begin{array}{l}\text { Rodent MSCs, } \\
\text { rodent NCMs }\end{array}$ & Rodent permanent $\mathrm{Ml}$ & Cell migration, LV function & $(68,135,136)$ \\
\hline $\begin{array}{l}\text { Gelatin, } \\
\left.\text { (Gelfoam }^{\mathrm{TM}}\right)\end{array}$ & $\begin{array}{l}\text { Rodent MSCs, } \\
\text { rodent NCMs, } \\
\text { human iPSCs }\end{array}$ & Rodent $\mathrm{Ml}$, in vitro & $\begin{array}{l}\text { LV function, electrical } \\
\text { integration } \\
\text { electrical integration }\end{array}$ & $(137-139)$ \\
\hline
\end{tabular}

Table 2. Select cells and materials in tissue engineering approaches for cardiac regeneration. Nonexhaustive list of commonly used biomaterials for 3D cell culture and subsequent in vivo application in models of HF. Legend: FCM=fetal cardiomyocytes, ESC=embryonic stem cell, MSC=mesenchymal stem cell, $\mathrm{CSC}=$ cardiac stem cell, $\mathrm{SMC}=$ smooth muscle cell, iPSC=induced pluripotent stem cell, $\mathrm{DFB}=\mathrm{dermal}$ fibroblast, $\mathrm{BMNC}=$ bone marrow mononuclear cell, $\mathrm{CPC}=$ cardiac progenitor cell, $\mathrm{MPC}=$ mesenchymal progenitor cell, $\mathrm{CAEC}=$ cardiac arterial endothelial cell, $\mathrm{NCM}=$ neonatal cardiomyocytes, $\mathrm{MI}=\mathrm{myocardial}$ infarction, $\mathrm{HF}=$ heart failure, $\mathrm{LV}=$ left ventricle. 
Chapter 8 - General discussion and future perspectives.

\begin{tabular}{|l|l|l|l|l|}
\hline Scaffold material & Cell types & Model organism & Primary endpoints & References \\
\hline Sodium alginate & $\begin{array}{l}\text { Rodent islets, } \\
\text { human islets }\end{array}$ & $\begin{array}{l}\text { Rodent STZ } \\
\text { Rodent STZ }\end{array}$ & Glucose tolerance, islet survival & $(6,11,140)$ \\
\hline Fibrin-based & $\begin{array}{l}\text { Rodent islets, } \\
\text { human islets }\end{array}$ & Rodent STZ & Islet viability & $(141,142)$ \\
\hline PGA, PLA, PLG & $\begin{array}{l}\text { Rodent islets, } \\
\text { monkey islets, } \\
\text { human islets }\end{array}$ & Rodent STZ, monkey STZ & $\begin{array}{l}\text { Glucose tolerance, islet survival } \\
\text { implant site survival }\end{array}$ & $(143-146)$ \\
\hline $\begin{array}{l}\text { Decellularized } \\
\text { (biological) }\end{array}$ & $\begin{array}{l}\text { Rodent islets, } \\
\text { porcine islets }\end{array}$ & Rodent STZ & Cell survival, glucose tolerance & $(147,148)$ \\
\hline Collagen based & Rodent islets & Rodent STZ & Implant site, retrievability & $(149)$ \\
\hline $\begin{array}{l}\text { Self-assembling } \\
\text { peptides }\end{array}$ & $\begin{array}{l}\text { Human islets, } \\
\text { INS1 cell line }\end{array}$ & In vitro & Cell proliferation, differentiation & $(150,151)$ \\
\hline PNIPAAM & Rodent islets & Rodent STZ & Implant site, glucose tolerance & $(152)$ \\
\hline Gelatin & Rodent islets & In vitro & Cytocompatibility & $(153)$ \\
\hline
\end{tabular}

Table 3. Select cells and tissue engineering approaches for pancreatic regeneration. Non-exhaustive list of commonly used biomaterials for 3D cell culture and subsequent in vivo application in models of T1DM. Legend: STZ=streptozotocin, PGA=ploy-glycolic acid, PLA=poly-lactic acid. PLG=poly(lactide-co-glycolide), PNIPAAM=poly $(\mathrm{N}$-isopropylacrylamide $)$. INS1= insulin secreting B-cell derived line. 


\section{TARGET PATIENTS}

The decision on how to identify patients who would benefit from cell therapy and/or the application of tissue engineered organs will be a major undertaking once the field of regenerative medicine enters the clinical realm, as it already has to a minor extent in pancreatic islet auto-and allotransplantation (89). While BMT for hematological malignancies has been practiced for many decades, management approaches to specific clinical scenarios vary widely (156). This variation is caused by the rapid developments in these emerging fields, both in specific outcomes, and especially in the use of new immunosuppressive agents. This is further dictated by local preferences of new treatment modalities which may result in similar patients being offered different transplant and treatment procedures.

When it comes to patient selection, we can define several criteria: 1) safety of the therapy with regards to reversibility, location, or no option patients, 2) translation to the real population (randomized controlled clinical trials versus patient registries), and 3) mechanistic considerations, i.e. are we interested in elucidation of mechanisms or would if suffice to prove efficacy of the regenerative therapy regardless of mechanistic background.

The choice of patients for new clinical studies will need to follow the same pattern as has been used in all other clinical studies, adhering closely to both regulatory and ethical principles that have been described and practiced by others over more than 50 years. The patients will need to be restricted to treatment of one very specifically defined condition with known outcomes without, or with, specific accepted treatment. The patients will need to be volunteers who understand the implications, including potential complications, of the proposed treatment. They must accept the potential risk/benefit ratio, agree to follow-up studies, and to be initially randomized if the experimental design demands it. They must also understand that they may drop out of the study at any time or that the study may be terminated at any time by the investigator.

In the new field of regenerative medicine, different diseases with shared mechanistic backgrounds may benefit from similar cell therapies. For example, due to their immunomodulatory properties, MSCs have been used in clinical trials to treat multiple sclerosis (157) as well as IDDM (158). It is clear that such studies will need to be conducted separately with different patients. Since (stem) cell therapy and tissue engineered organs are considered to be medical devices, regulations as to their application to humans differ from those applied to pharmacotherapeutics. This could in some instances be advantageous for patients and clinicians, since less restrictive regulation on devices could simplify and accelerate the introduction of specific cell types and/or biomaterial treatments for previously studies and well characterized patient populations. However, there is serious concern that this new field may not be regulated sufficiently to prevent the risk of rise of "clinical cowboy medicine" and of problems with commercial conflicts of interest (159, 160). While free enterprise may be laudable, it may include risks and side effects that are uncertain and severe. When these occur unexpectedly, they could arrest and even reverse innovation in this novel field of scientific inquiry due to public mistrust and resistance, either in a commercial or academic environment. This problem was brought dramatically to the fore in a case in which a patient with ataxia telangiectasia received intracerebellar and intrathecal (i.e. into the spinal canal) injections of human fetal neural stem cells and subsequently developed a donor derived brain tumor (161).

Thorough basic research and diligent supervised and well-designed clinical trials should be conducted and be successful before cell and regenerative medicine therapies move from the experimental to the clinical phase and subsequently, commercially (162). Once there is consensus on a particular regenerative medicine therapy, such multicenter studies would need to be designed to further develop the field by minimizing the undesirable side effects and improve outcomes while identifying the most eligible patients. Currently, the field of regenerative medicine is so new, that emphasis is primarily on many questions regarding cell types, biomaterials and diseases for which cellular treatment may be most suitable and most needed before any clinical trials are designed. Therefore, this field needs careful but rapid nurturing by multidisciplinary investigators to focus on identifying which novel cellular treatment is most suitable for which patient while remaining safe. This is well illustrated by the progress being made in islet transplantation since year 2000 when the Edmonton protocol was introduced (163). After a recent period of "stem cell hypes" (164-166), the field is slowly moving from the "trough of disillusionment" into the "slope of enlightenment" (167), while investigators have realized that "plain" cell injections into damaged tissues is ineffective unless a suitable microenvironment (i.e. extracellular matrix) in which cells can thrive (168) is provided in the form of custom-designed scaffolds.

An "artificial pancreas" was recently approved by the FDA for treatment of IDDM (169). This device consists of electrodes that measure glucose levels and secrete insulin based on subcutaneous sensor data. Like the LVAD, the device does not contain any living cells or tissues (yet). Previous trials have used intraportal islet infusion in IDDM patients, with limited long-term effectiveness (163). When alginate-poly-L-lysine capsules loaded with human pancreatic islets were previously evaluated as a treatment in IDDM, longterm capsule stability as well as intracapsular islet survival were found to be limited (170). Although electronic medical devices appear to be suitable to control IDDM, regenerative strategies, although promising and logical, need further development, consistency, experimental and clinical evaluation. 
Overall, therapeutic bioengineering and regenerative medicine may in the near future become critical in the treatment in the ageing populations where degenerative diseases are a major cause of morbidity and mortality. Cell replacement of aging and dying cells appears to be a sorely needed therapeutic intervention and a logical future development. New technologies such as personalized "printing" of 3D organs may further add to the efficacy of biomaterial and cellular applications (171) in novel therapeutic interventions. The dynamic nature of the field will certainly lead to many new advances in the decades to come as the clinical applications of bioengineering and regenerative medicine reach new levels in clinical practice.

\section{FUTURE PERSPECTIVES}

Regenerative medicine and tissue engineering hold great promise in the field of future precision medicine. Current biological techniques facilitate and permit the development and precise deep characterization of different subsets of tissue resident stem cells which may provide reparative therapeutic functions. At the same time, on the materials side, many new biomaterials are currently being evaluated for their use in clinical applications, extending from bone scaffolds to artificial pancreases.

The question remains which cell type, in combination with which biomaterial, would give an optimal therapeutic benefit, without too many side effects, to correct specific organ damage and/or insufficiency. The interplay between engineers, biologists and medical doctors will play a crucial role in advancing this exciting field into the clinic.

The new field requires mutual understanding by physicians of what is technically possible on the materials side, and by engineers of whether a specific (bio)material would hold up in the field of medical device approval by the relevant authorities. An integrated approach would prevent the development of tissue engineered devices or organs that would look promising on paper or in the laboratory, but would not be clinically useful. That being said, the medical and pharmaceutical professions/industries should remain integrated with academic institutions to encourage unrestricted new developments and innovation in tissue engineering and regenerative medicine, some of which may actually reduce their perceived relevance and/or financial revenue, for example a replacement organ that "cures" a certain disease. Health care authorities should be aware of these issues, especially in the current environment of competition for (public) funding and free market ideology.

Apart from regulatory issues, the creation of new tissues and organs is still a relatively new undertaking. Rapid progress is being made in the design of artificial organs and integration of different scientific areas is occurring in a systematic way, starting with the establishment of new consortia that bring together in the same physical space numerous expert scientists by integrating their biological and technical laboratories into single units. Additional integration by creating spaces where senior clinicians would interact directly with basic scientists on a daily basis would further facilitate progress in this complex new field of regenerative medicine.

This section is called "Future Perspectives". However, one needs to be guarded in ever suggesting that regenerative medicine is going to offer many cures. Similar claims were previously made with regards to gene therapy and stem cell therapy. Despite continuing to see many exciting new developments in the field of medical science and therapy, this complex field, including regenerative medicine, needs to remain aware of many potential pitfalls, hype-creation and minimal longevity. Thorough mechanistic approaches are more valuable in the long-term than efficacy. For example, the clustered regularly interspaced short palindromic repeats-associated protein 9 (CRISPRCas9) gene editing technology was initially discovered in a microbiology laboratory while studying the "immune system" of bacteria against bacteriophages, notably by a group working at a Danish bio-based company with activities in food production, enzymes and other bioproducts (172). Only later it was shown how such highly basic scientific studies can have such major impact and influence on development of new treatments in medicine, i.e. by facilitating insertion or deletion of specific genes to treat diseases, for example HIV/AIDS (173), muscular dystrophy (174) or sickle cell disease (175). Unfortunately, it was found that CRISPR-Cas9 technology can induce p53 dependent mutagenic mutations, making it less attractive for direct clinical application (176, 177), and emphasizing the need for thorough pre-clinical studies before moving to the clinic.

An exciting approach to circumvent aforementioned direct mutagenicity risks was recently applied by combining 4 different regenerative medicine strategies: somatic nuclear cell transplant (SCNT), induced human pluripotent stem cells (ihPSCs), pre-implantation blastocyst chimerism, and CRISPR/Cas9 genetic modification technologies. The therapeutic idea for this combination would be to generate a human pancreas (or any other organ) in a carrier species such as the sheep, pig or cow, by creating an embryo in utero that contains cells derived both from a patient (i.e. ihPSCs from a patient with IDDM) and the carrier species. Proof-of-principle was first shown in rodents, which allowed the growth of ratderived pancreases in mice that were genetically modified. This was done by first preventing mouse pancreas development in the embryo stage by disabling a specific gene called PDX1 using CRISPR/Cas9 technology. At the same time, rat iPSCs were injected into the mouse embryo. By stochastic selection, some mice turned out to grow rat iPSC-derived pancreases, basically generating a rat-mouse chimera. 
In large animals, the same strategy was not so successful when rodent PSCs were injected into pig embryos, but surprisingly and useful, successful engraftment in porcine and bovine preembryonic (i.e. blastocyst) stages was achieved up to $80 \%$ with human naïve PSCs $(178,179)$. In these pigs however, further growth of human-porcine chimeras was less evident, and the levels of pancreatic chimerism from all hiPSCs in pig embryos were much lower when compare to the ratmouse chimeras. Subsequently, the same groups moved to sheep, disabled the PDX1 gene, which resulted in sheep without a pancreas (180). The next step would obviously be to repeat the same approach in sheep, i.e. inject human iPSCs into preembryonic (i.e. blastocyst) stage sheep. In viable embryos, by stochastic selection, this could lead to sheep embryos with human iPSC derived pancreases. Human pancreases could be generated this way using autologous cells, i.e. human iPSCs derived from patients with IDDM, using the sheep as a bioreactor. This would open the road to rejection-free transplantation of autologous whole pancreas or isolated islets grown in sheep. This would both be safer for patients as it would prevent mutagenesis, as well as avoid the ethical issues that come with use of human embryos. Nevertheless, there is no guarantee that sheep antigens or pathogens will be absent in iPSC derived pancreatic tissue grown this way, either by contamination or processes such as trogocytosis (i.e. the exchange of cell membrane antigens between host and donor cells as explained in paragraph 6).

There is no doubt that tissue engineering will become an important addition to the tools that clinicians will eventually have to consider in treatment of many diseases. Before 2000, no clinical tissue engineering trials were registered (www.clinicaltrials.gov, accessed 10 July 2018, query "tissue engineering" or "bioengineering"), from 2000-2010 this number increased to 17 , while since 2010 there are 43 trials listed, and this number is likely going to continue to increase. There are still many breakthroughs that are needed and that will undoubtedly be made. Many will focus on the optimization of tissue engineered graft survival, which, in contrast to organ transplants, are not initially connected to the recipient's circulation, and are therefore dependent on diffusion of oxygen and nutrients for their function. Another area of focus is the immune and tissue response to foreign cells and/or materials, which could also affect survival and function. Perhaps it might be necessary, just as in the case of bone marrow transplantation, to evaluate specific pre-conditioning protocols that would enhance biomaterial function and/or therefore tissue engineered graft survival.

\section{FINAL CONCLUSIONS}

Regenerative medicine is a relatively novel field that intersects with the borders of medicine, cell biology, and engineering. In order to improve current therapies for tissue degenerative diseases such as HF and IDDM progress in regenerative medicine must embrace all these disciplines. Our studies presented in this thesis have contributed small advances in this field. Cell therapy, as a strategy, has the potential to replace and/or heal damaged tissues by direct cell injection or infusion (i.e. bone marrow transplantation) as we showed in our human bone marrow derived $\mathrm{CD}^{+} 4^{+}$cell transplantation studies $(51,63)$. Biomaterials can further enhance the efficacy of cell transplantation by creating a suitable microenvironment for transplanted cells, either by providing survival signals or creating an immunoprotective "bed" for the cells, as we showed in our bioengineering studies with $3 \mathrm{D}$ cyclic RGDfK-modified alginate scaffolds $(10,11)$. Cell therapy has been approved for certain diseases such as bone marrow malignancies. Newer forms of cell therapy for other diseases are being evaluated intensively, with primary goals of enhancing its effectiveness. Cell survival and immunological cell rejection by the recipient are major hurdles after cell application or infusion into a recipient that need to be overcome to make cell therapy an acceptable "mainstream" therapy.

We have further demonstrated in this thesis that sodium alginate, an FDA-approved biomaterial, can be used as a carrier scaffold to transplant stem cells or pancreatic B-cells in $\mathrm{HF}$ and IDDM, respectively. The simple modification and biocompatibility of sodium alginate make it a versatile choice for tissue engineering strategies. 3D alginate scaffold optimization for the "right" disease application poses several challenges for physicians, biologists, and tissue engineers. Other biomaterials are also available and are being evaluated in preclinical and clinical settings.

The optimal cells, the right biomaterials, or a combination of both need to be determined to generate artificial tissues or create organs for regeneration. It is critical when everything else is considered, that the ultimate aim of all our efforts to design and test constructs is to benefit the patient who suffers with HF, IDDM, or other lifealtering disease. 


\section{REFERENCES}

1. E. Braunwald, Heart failure: an update. Clin Pharmacol Ther 94, 430 (Oct, 2013).

2. S. Wild, G. Roglic, A. Green, R. Sicree, H. King, Global prevalence of diabetes: estimates for the year 2000 and projections for 2030. Diabetes Care 27, 1047 (May, 2004).

3. I. M. Ferreira, K. Jorge, L. C. Nogueira, F. Silva, L. C. Trugo, Effects of the combination of hydrophobic polypeptides, iso-alpha acids, and malto-oligosaccharides on beer foam stability. Journal of agricultural and food chemistry $\mathbf{5 3}$ 4976 (Jun 15, 2005).

4. M. Tighe, N. A. Afzal, A. Bevan, A. Hayen, A. Munro, R. M. Beattie, Pharmacological treatment of children with gastro-oesophageal reflux. The Cochrane database of systematic reviews, CD008550 (Nov 24, 2014)

5. J. Jia, D. J. Richards, S. Pollard, Y. Tan, J. Rodriguez, R. P. Visconti, T. C. Trusk, M. J. Yost, H. Yao, R. R. Markwald, Y. Mei, Engineering alginate as bioink for bioprinting. Acta biomaterialia 10, 4323 (Oct, 2014).

6. F. Lim, A. M. Sun, Microencapsulated islets as bioartificial endocrine pancreas. Science 210, 908 (Nov 21, 1980).

7. H. P. Sondermeijer, P. Witkowski, D. Woodland, T. Seki, F. J. Aangenendt, A. van der Laarse, S. Itescu, M. A. Hardy, Optimization of alginate purification using polyvinylidene difluoride membrane filtration: Effects on immunogenicity and biocompatibility of three-dimensional alginate scaffolds. J Biomater Appl 31, 510 (Oct, 2016).

8. J. Sun, H. Tan, Alginate-based biomaterials for regenerative medicine applications. Materials $\mathbf{6}$ 1285 (Mar 26, 2013).

9. G. T. Hermanson, Bioconjugate Techniques 1st Edition. p169 (1996)

10. H. P. Sondermeijer, P. Witkowski, T. Seki, A. van der Laarse, S. Itescu, M. A. Hardy, RGDfKpeptide modified alginate scaffold for cell transplantation and cardiac neovascularization. Tissue Eng Part A 24, 740 (May, 2018).

11. P. Witkowski, H. Sondermeijer, M. A. Hardy, D. C. Woodland, K. Lee, G. Bhagat, K. Witkowski, F. See, A. Rana, A. Maffei, S. Itescu, P. E. Harris, Islet grafting and imaging in a bioengineered intramuscular space. Transplantation 88, 1065 (Nov 15, 2009).

12. G. Klock, A. Pfeffermann, C. Ryser, P. Grohn, B. Kuttler, H. J. Hahn, U. Zimmermann, Biocompatibility of mannuronic acid-rich alginates. Biomaterials 18, 707 (May, 1997).

13. D. M. Sperger, S. Fu, L. H. Block, E. J. Munson, Analysis of composition, molecular weight, and water content variations in sodium alginate using solid-state NMR spectroscopy. Journal of pharmaceutical sciences 100, 3441 (Aug, 2011).

14. S. Duggirala, P. P. Deluca, Rheological characterization of cellulosic and alginate polymers. PDA journal of pharmaceutical science and technology 50, 290 (Sep-Oct, 1996).

15. W. J. Leo, A. J. McLoughlin, D. M. Malone, Effects of sterilization treatments on some properties of alginate solutions and gels. Biotechnology progress 6, 51 (Jan-Feb, 1990).

16. J. Dusseault, S. K. Tam, M. Menard, S. Polizu, G. Jourdan, L. Yahia, J. P. Halle, Evaluation of alginate purification methods: effect on polyphenol, endotoxin, and protein contamination. Journal of biomedical materials research. Part A 76, 243 (Feb, 2006).

17. S. Gronthos, S. Fitter, P. Diamond, P. J. Simmons, S. Itescu, A. C. Zannettino, A novel monoclonal antibody (STRO-3) identifies an isoform of tissue nonspecific alkaline phosphatase expressed by multipotent bone marrow stromal stem cells. Stem cells and development 16, 953 (Dec, 2007).

18. S. Gronthos, S. E. Graves, S. Ohta, P. J. Simmons, The STRO-1+ fraction of adult human bone marrow contains the osteogenic precursors. Blood 84, 4164 (Dec 15, 1994).

19. P. De Vos, B. De Haan, G. H. Wolters, R. Van Schilfgaarde, Factors influencing the adequacy of microencapsulation of rat pancreatic islets. Transplantation 62, 888 (Oct 15, 1996).

20. H. J. Kong, M. K. Smith, D. J. Mooney, Designing alginate hydrogels to maintain viability of immobilized cells. Biomaterials 24, 4023 (Oct, 2003).

21. C. Ryppa, H. Mann-Steinberg, M. L. Biniossek, R. Satchi-Fainaro, F. Kratz, In vitro and in vivo evaluation of a paclitaxel conjugate with the divalent peptide E-[c(RGDfK)2] that targets integrin alpha $\mathrm{v}$ beta 3 . International journal of pharmaceutics 368, 89 (Feb 23, 2009).

22. B. C. Lee, H. J. Sung, J. S. Kim, K. H. Jung, Y. S. Choe, K. H. Lee, D. Y. Chi, Synthesis of Tc-99m labeled glucosamino-Asp-cyclic(Arg-Gly-Asp-dPhe-Lys) as a potential angiogenesis imaging agent. Bioorganic \& medicinal chemistry 15, 7755 (Dec 15, 2007).

23. S. M. Frisch, K. Vuori, E. Ruoslahti, P. Y. ChanHui, Control of adhesion-dependent cell survival by focal adhesion kinase. The Journal of cell biology 134, 793 (Aug, 1996).

24. M. A. Rubtsov, M. S. Syrkina, G. Aliev, RGDbased therapy: Principles of selectivity. Current pharmaceutical design 22, 932 (2016).

25. M. Borgogna, G. Skjak-Braek, S. Paoletti, I. Donati, On the initial binding of alginate by calcium ions. The tilted egg-box hypothesis. The journal of physical chemistry. B 117, 7277 (Jun 20, 2013)

$26 . \quad$ M. L. Janssen, W. J. Oyen, I. Dijkgraaf, L. F. Massuger, C. Frielink, D. S. Edwards, M. Rajopadhye, H. Boonstra, F. H. Corstens, O. C. Boerman, Tumor targeting with radiolabeled alpha(v)beta(3) integrin binding peptides in a nude mouse model. Cancer Res 62, 6146 (Nov 1, 2002).

27. J. A. Rowley, G. Madlambayan, D. J. Mooney, Alginate hydrogels as synthetic extracellular matrix materials. Biomaterials 20, 45 (Jan, 1999).

28. F. Agou, M. Veron, In vivo protein cross-linking. Methods in molecular biology 1278, 391 (2015)

29. A. Zhu, M. Zhang, J. Wu, J. Shen, Covalent immobilization of chitosan/heparin complex with a photosensitive hetero-bifunctional crosslinking reagent on PLA surface. Biomaterials 23, 4657 (Dec, 2002).

30. W. Mahmoud, G. Rousserie, B. Reveil, T. Tabary, J. M. Millot, M. Artemyev, V. A. Oleinikov, J. H. Cohen, I. Nabiev, A. Sukhanova, Advanced procedures for labeling of antibodies with quantum dots. Analytical biochemistry 416, 180 (Sep 15, 2011).

31. D. A. Puleo, R. A. Kissling, M. S. Sheu, A technique to immobilize bioactive proteins, including bone morphogenetic protein-4 (BMP-4), 
on titanium alloy. Biomaterials 23, 2079 (May, 2002).

32. D. Price, I. Park, H. Avraham, Methods for the study of protein-protein interactions in cancer cell biology. Methods in molecular biology 218, 255 (2003).

33. E. Hill, T. Boontheekul, D. J. Mooney, Designing scaffolds to enhance transplanted myoblast survival and migration. Tissue engineering 12, 1295 (May, 2006).

34. K. R. Gehlsen, W. S. Argraves, M. D Pierschbacher, E. Ruoslahti, Inhibition of in vitro tumor cell invasion by Arg-Gly-Asp-containing synthetic peptides. The Journal of cell biology 106, 925 (Mar, 1988)

35. E. Ruoslahti, M. D. Pierschbacher, New perspectives in cell adhesion: RGD and integrins. Science 238, 491 (Oct 23, 1987).

$36 . \quad$ D. L. Mooradian, J. B. McCarthy, A. P. Skubitz, J. D. Cameron, L. T. Furcht, Characterization of FN-C/H-V, a novel synthetic peptide from fibronectin that promotes rabbit corneal epithelial cell adhesion, spreading, and motility. Investigative ophthalmology \& visual science $\mathbf{3 4}$, 153 (Jan, 1993).

37. M. G. Overstreet, A. Gaylo, B. R. Angermann, A. Hughson, Y. M. Hyun, K. Lambert, M. Acharya, A. C. Billroth-Maclurg, A. F. Rosenberg, D. J. Topham, H. Yagita, M. Kim, A. Lacy-Hulbert, M. Meier-Schellersheim, D. J. Fowell, Inflammation-induced interstitial migration of effector $\mathrm{CD} 4^{+} \mathrm{T}$ cells is dependent on integrin alphaV. Nature immunology 14, 949 (Sep, 2013).

38. S. E. LaFlamme, B. Nieves, D. Colello, C. G. Reverte, Integrins as regulators of the mitotic machinery. Current opinion in cell biology 20, 576 (Oct, 2008).

$39 . \quad$ S. P. Massia, J. A. Hubbell, Vascular endothelial cell adhesion and spreading promoted by the peptide REDV of the IIICS region of plasma fibronectin is mediated by integrin alpha 4 beta 1. The Journal of biological chemistry 267, 14019 (Jul 15, 1992).

40. T. Lapidot, A. Dar, O. Kollet, How do stem cells find their way home? Blood 106, 1901 (Sep 15, 2005).

41. K. Ley, C. Laudanna, M. I. Cybulsky, S. Nourshargh, Getting to the site of inflammation: the leukocyte adhesion cascade updated. Nature reviews. Immunology 7, 678 (Sep, 2007).

42. B. Assmus, J. Honold, V. Schachinger, M. B. Britten, U. Fischer-Rasokat, R. Lehmann, C. Teupe, K. Pistorius, H. Martin, N. D. Abolmaali, T. Tonn, S. Dimmeler, A. M. Zeiher, Transcoronary transplantation of progenitor cells after myocardial infarction. $N$ Engl J Med 355, 1222 (Sep 21, 2006).

43. K. Lunde, S. Solheim, S. Aakhus, H. Arnesen, M. Abdelnoor, T. Egeland, K. Endresen, A. Ilebekk, A. Mangschau, J. G. Fjeld, H. J. Smith, E. Taraldsrud, H. K. Grogaard, R. Bjornerheim, M. Brekke, C. Muller, E. Hopp, A. Ragnarsson, J. E. Brinchmann, K. Forfang, Intracoronary injection of mononuclear bone marrow cells in acute myocardial infarction. $N$ Engl J Med 355, 1199 (Sep 21, 2006).

44. S. D. Prabhu, N. G. Frangogiannis, The biological basis for cardiac repair after myocardial infarction: From inflammation to fibrosis. Circulation research 119, 91 (Jun 24, 2016).
B. Chen, N. G. Frangogiannis, Immune cells in repair of the infarcted myocardium. Microcirculation 24, (Jan, 2017).

46. R. Gentek, G. Hoeffel, The innate immune response in myocardial infarction, repair, and regeneration. Advances in experimental medicine and biology 1003, 251 (2017).

47. S. Rafii, D. Lyden, Therapeutic stem and progenitor cell transplantation for organ vascularization and regeneration. Nature medicine 9, 702 (Jun, 2003).

48. P. Dutta, M. Nahrendorf, Monocytes in myocardial infarction. Arteriosclerosis, thrombosis, and vascular biology 35, 1066 (May, 2015).

49. M. J. van Amerongen, M. C. Harmsen, N. van Rooijen, A. H. Petersen, M. J. van Luyn, Macrophage depletion impairs wound healing and increases left ventricular remodeling after myocardial injury in mice. The American journal of pathology 170, 818 (Mar, 2007).

50. B. Lee, M. Sharron, L. J. Montaner, D. Weissman, R. W. Doms, Quantification of CD4, CCR5, and CXCR4 levels on lymphocyte subsets, dendritic cells, and differentially conditioned monocyte-derived macrophages. Proceedings of the National Academy of Sciences of the United States of America 96, 5215 (Apr 27, 1999).

51. N. Bonaros, H. Sondermeijer, M. Schuster, R. Rauf, S. F. Wang, T. Seki, D. Skerrett, S. Itescu, A. A. Kocher, CCR3- and CXCR4-mediated interactions regulate migration of $\mathrm{CD} 34^{+}$human bone marrow progenitors to ischemic myocardium and subsequent tissue repair. $J$ Thorac Cardiovasc Surg 136, 1044 (Oct, 2008).

52. A. Aiuti, I. J. Webb, C. Bleul, T. Springer, J. C. Gutierrez-Ramos, The chemokine SDF-1 is a chemoattractant for human CD34+ hematopoietic progenitor cells and provides a new mechanism to explain the mobilization of CD34+ progenitors to peripheral blood. The Journal of experimental medicine 185, 111 (Jan 6, 1997).

53. T. Asahara, T. Murohara, A. Sullivan, M. Silver, R. van der Zee, T. Li, B. Witzenbichler, G. Schatteman, J. M. Isner, Isolation of putative progenitor endothelial cells for angiogenesis. Science 275, 964 (Feb 14, 1997).

54. A. P. Beltrami, L. Barlucchi, D. Torella, M. Baker, F. Limana, S. Chimenti, H. Kasahara, M. Rota, E. Musso, K. Urbanek, A. Leri, J. Kajstura, B. Nadal-Ginard, P. Anversa, Adult cardiac stem cells are multipotent and support myocardial regeneration. Cell 114, 763 (Sep 19, 2003).

55. A. Ngkelo, A. Richart, J. A. Kirk, P. Bonnin, J. Vilar, M. Lemitre, P. Marck, M. Branchereau, S. Le Gall, N. Renault, C. Guerin, M. J. Ranek, A. Kervadec, L. Danelli, G. Gautier, U. Blank, P. Launay, E. Camerer, P. Bruneval, P. Menasche, C. Heymes, E. Luche, L. Casteilla, B. Cousin, H. R. Rodewald, D. A. Kass, J. S. Silvestre, Mast cells regulate myofilament calcium sensitization and heart function after myocardial infarction. The Journal of experimental medicine 213, 1353 (Jun 27, 2016).

56. P. A. Taylor, M. J. Ehrhardt, M. M. Roforth, J. M. Swedin, A. Panoskaltsis-Mortari, J. S. Serody, B. R. Blazar, Preformed antibody, not primed $\mathrm{T}$ cells, is the initial and major barrier to bone marrow engraftment in allosensitized recipients. Blood 109, 1307 (Feb 1, 2007). 
57. K. N. Cosgun, S. Rahmig, N. Mende, S. Reinke, I. Hauber, C. Schafer, A. Petzold, H. Weisbach, G. Heidkamp, A. Purbojo, R. Cesnjevar, A. Platz, M. Bornhauser, M. Schmitz, D. Dudziak, J. Hauber, J. Kirberg, C. Waskow, Kit regulates HSC engraftment across the human-mouse species barrier. Cell stem cell 15, 227 (Aug 7, 2014).

58. S. A. Lorimore, P. J. Coates, G. E. Scobie, G. Milne, E. G. Wright, Inflammatory-type responses after exposure to ionizing radiation in vivo: a mechanism for radiation-induced bystander effects? Oncogene 20, 7085 (Oct 25, 2001).

59. S. Francois, M. Bensidhoum, M. Mouiseddine, C. Mazurier, B. Allenet, A. Semont, J. Frick, A. Sache, S. Bouchet, D. Thierry, P. Gourmelon, N. C. Gorin, A. Chapel, Local irradiation not only induces homing of human mesenchymal stem cells at exposed sites but promotes their widespread engraftment to multiple organs: a study of their quantitative distribution after irradiation damage. Stem cells 24, 1020 (Apr, 2006).

60. M. Hofmann, K. C. Wollert, G. P. Meyer, A. Menke, L. Arseniev, B. Hertenstein, A. Ganser, W. H. Knapp, H. Drexler, Monitoring of bone marrow cell homing into the infarcted human myocardium. Circulation 111, 2198 (May 3, 2005).

61. M. Thunemann, B. F. Schorg, S. Feil, Y. Lin, J. Voelkl, M. Golla, A. Vachaviolos, U. Kohlhofer, L. Quintanilla-Martinez, M. Olbrich, W. Ehrlichmann, G. Reischl, C. M. Griessinger, H. F. Langer, M. Gawaz, F. Lang, M. Schafers, M. Kneilling, B. J. Pichler, R. Feil, Cre/lox-assisted non-invasive in vivo tracking of specific cell populations by positron emission tomography. Nature communications 8, 444 (Sep 5, 2017).

62. R. Ascione, J. Rowlinson, E. Avolio, R. Katare, M. Meloni, H. L. Spencer, G. Mangialardi, C. Norris, N. Krankel, G. Spinetti, C. Emanueli, P. Madeddu, Migration towards SDF-1 selects angiogenin-expressing bone marrow monocytes endowed with cardiac reparative activity in patients with previous myocardial infarction. Stem cell research \& therapy 6, 53 (Apr 11, 2015).

63. N. Bonaros, H. Sondermeijer, D. Wiedemann, B. Schlechta, T. Schachner, M. Schuster, T. Seki, T. P. Martens, S. Itescu, A. A. Kocher, Downregulation of the CXC chemokine receptor 4/stromal cell-derived factor 1 pathway enhances myocardial neovascularization, cardiomyocyte survival, and functional recovery after myocardial infarction. J Thorac Cardiovasc Surg 142, 687 (Sep, 2011).

64. S. Jash, S. Adhya, Effects of transient hypoxia versus prolonged hypoxia on satellite cell proliferation and differentiation in vivo. Stem cells international 2015, 961307 (2015).

65. S. H. Lee, P. L. Wolf, R. Escudero, R. Deutsch, S. W. Jamieson, P. A. Thistlethwaite, Early expression of angiogenesis factors in acute myocardial ischemia and infarction. $N$ Engl $J$ Med 342, 626 (Mar 2, 2000).

66. F. Dong, M. Khalil, M. Kiedrowski, C. O'Connor, E. Petrovic, X. Zhou, M. S. Penn, Critical role for leukocyte hypoxia inducible factor-1alpha expression in post-myocardial infarction left ventricular remodeling. Circulation research 106, 601 (Feb 19, 2010).
67. Y. Zhang, I. Strehin, K. Bedelbaeva, D. Gourevitch, L. Clark, J. Leferovich, P. B. Messersmith, E. Heber-Katz, Drug-induced regeneration in adult mice. Science translational medicine 7, 290ra92 (Jun 3, 2015).

68. Y. Miyahara, N. Nagaya, M. Kataoka, B. Yanagawa, K. Tanaka, H. Hao, K. Ishino, H. Ishida, T. Shimizu, K. Kangawa, S. Sano, T. Okano, S. Kitamura, H. Mori, Monolayered mesenchymal stem cells repair scarred myocardium after myocardial infarction. Nature medicine 12, 459 (Apr, 2006)

69. R. Mohle, F. Bautz, S. Rafii, M. A. Moore, W. Brugger, L. Kanz, The chemokine receptor CXCR-4 is expressed on CD $34^{+}$hematopoietic progenitors and leukemic cells and mediates transendothelial migration induced by stromal cell-derived factor-1. Blood 91, 4523 (Jun 15, 1998).

70. M. C. Poznansky, I. T. Olszak, R. Foxall, R. H. Evans, A. D. Luster, D. T. Scadden, Active movement of $\mathrm{T}$ cells away from a chemokine. Nature medicine 6, 543 (May, 2000).

71. P. von Hundelshausen, S. M. Agten, V. Eckardt, X. Blanchet, M. M. Schmitt, H. Ippel, C. Neideck, K. Bidzhekov, J. Leberzammer, K. Wichapong, A. Faussner, M. Drechsler, J. Grommes, J. P. van Geffen, H. Li, A. Ortega-Gomez, R. T. Megens, R. Naumann, I. Dijkgraaf, G. A. Nicolaes, Y. Doring, O. Soehnlein, E. Lutgens, J. W. Heemskerk, R. R. Koenen, K. H. Mayo, T. M. Hackeng, C. Weber, Chemokine interactome mapping enables tailored intervention in acute and chronic inflammation. Science translational medicine 9, (Apr 5, 2017).

72. F. Quaini, K. Urbanek, A. P. Beltrami, N. Finato, C. A. Beltrami, B. Nadal-Ginard, J. Kajstura, A. Leri, P. Anversa, Chimerism of the transplanted heart. $N$ Engl J Med 346, 5 (Jan 3, 2002).

73. A. J. Wagers, R. I. Sherwood, J. L. Christensen, I. L. Weissman, Little evidence for developmental plasticity of adult hematopoietic stem cells. Science 297, 2256 (Sep 27, 2002).

74. T. Moccetti, A. Leri, P. Anversa, Controversy in myocardial regeneration. Regenerative medicine 10, 921 (Nov, 2015).

$75 . \quad$ F. See, T. Seki, P. J. Psaltis, H. P. Sondermeijer, S. Gronthos, A. C. Zannettino, K. M. Govaert, M. D. Schuster, P. A. Kurlansky, D. J. Kelly, H. Krum, S. Itescu, Therapeutic effects of human STRO-3-selected mesenchymal precursor cells and their soluble factors in experimental myocardial ischemia. J Cell Mol Med 15, 2117 (Oct, 2011).

76. J. M. Duran, C. A. Makarewich, T. E. Sharp, T. Starosta, F. Zhu, N. E. Hoffman, Y. Chiba, M. Madesh, R. M. Berretta, H. Kubo, S. R. Houser, Bone-derived stem cells repair the heart after myocardial infarction through transdifferentiation and paracrine signaling mechanisms. Circulation research 113, 539 (Aug 16, 2013)

77. E. Bassat, Y. E. Mutlak, A. Genzelinakh, I. Y. Shadrin, K. Baruch Umansky, O. Yifa, D. Kain, D. Rajchman, J. Leach, D. Riabov Bassat, Y. Udi, R. Sarig, I. Sagi, J. F. Martin, N. Bursac, S. Cohen, E. Tzahor, The extracellular matrix protein agrin promotes heart regeneration in mice. Nature 547, 179 (Jul 13, 2017).

78. M. Hammadah, I. Al Mheid, K. Wilmot, R. Ramadan, N. Abdelhadi, A. Alkhoder, M. Obideen, P. M. Pimple, O. Levantsevych, H. M. 
Kelli, A. Shah, Y. V. Sun, B. Pearce, M. Kutner, Q. Long, L. Ward, Y. A. Ko, K. Hosny Mohammed, J. Lin, J. Zhao, J. D. Bremner, J. Kim, E. K. Waller, P. Raggi, D. Sheps, A. A Quyyumi, V. Vaccarino, Telomere shortening, regenerative capacity, and cardiovascular outcomes. Circulation research 120, 1130 (Mar 31, 2017).

79. S. Sahoo, D. W. Losordo, Exosomes and cardiac repair after myocardial infarction. Circulation research 114, 333 (Jan 17, 2014).

80. S. L. Beeres, F. M. Bengel, J. Bartunek, D. E. Atsma, J. M. Hill, M. Vanderheyden, M. Penicka, M. J. Schalij, W. Wijns, J. J. Bax, Role of imaging in cardiac stem cell therapy. Journal of the American College of Cardiology 49, 1137 (Mar 20, 2007).

81. A. A. Kocher, M. D. Schuster, M. J. Szabolcs, S. Takuma, D. Burkhoff, J. Wang, S. Homma, N. M. Edwards, S. Itescu, Neovascularization of ischemic myocardium by human bone-marrowderived angioblasts prevents cardiomyocyte apoptosis, reduces remodeling and improves cardiac function. Nature medicine 7, 430 (Apr, 2001).

82. N. Smart, P. R. Riley, The stem cell movement. Circulation research 102, 1155 (May 23, 2008).

83. K. Urbanek, M. Rota, S. Cascapera, C. Bearzi, A. Nascimbene, A. De Angelis, T. Hosoda, S. Chimenti, M. Baker, F. Limana, D. Nurzynska, D. Torella, F. Rotatori, R. Rastaldo, E. Musso, F. Quaini, A. Leri, J. Kajstura, P. Anversa, Cardiac stem cells possess growth factor-receptor systems that after activation regenerate the infarcted myocardium, improving ventricular function and long-term survival. Circulation research 97, 663 (Sep 30, 2005).

84. V. Schachinger, S. Erbs, A. Elsasser, W. Haberbosch, R. Hambrecht, H. Holschermann, J. Yu, R. Corti, D. G. Mathey, C. W. Hamm, T. Suselbeck, B. Assmus, T. Tonn, S. Dimmeler, A. M. Zeiher, R.-A. Investigators, Intracoronary bone marrow-derived progenitor cells in acute myocardial infarction. $N$ Engl J Med 355, 1210 (Sep 21, 2006).

85. M. Gyongyosi, W. Wojakowski, P. Lemarchand, K. Lunde, M. Tendera, J. Bartunek, E. Marban, B. Assmus, T. D. Henry, J. H. Traverse, L. A. Moye, D. Surder, R. Corti, H. Huikuri, J. Miettinen, J. Wohrle, S. Obradovic, J. Roncalli, K. Malliaras, E. Pokushalov, A. Romanov, J. Kastrup, M. W. Bergmann, D. E. Atsma, A. Diederichsen, I. Edes, I. Benedek, T. Benedek, H. Pejkov, N. Nyolczas, N. Pavo, J. Bergler-Klein, I. J. Pavo, C. Sylven, S. Berti, E. P. Navarese, G. Maurer, A. Investigators, Meta-Analysis of Cellbased CaRdiac stUdiEs (ACCRUE) in patients with acute myocardial infarction based on individual patient data. Circulation research 116, 1346 (Apr 10, 2015).

86. B. O. Roep, M. Atkinson, M. von Herrath, Satisfaction (not) guaranteed: re-evaluating the use of animal models of type 1 diabetes. Nature reviews. Immunology 4, 989 (Dec, 2004).

87. B. O. Roep, Are insights gained from NOD mice sufficient to guide clinical translation? Another inconvenient truth. Annals of the New York Academy of Sciences 1103, 1 (Apr, 2007).

88. B. O. Roep, J. Buckner, S. Sawcer, R. Toes, F. Zipp, The problems and promises of research into human immunology and autoimmune disease. Nature medicine 18, 48 (Jan 6, 2012).
D. A. Baidal, C. Ricordi, D. M. Berman, A. Alvarez, N. Padilla, G. Ciancio, E. Linetsky, A. Pileggi, R. Alejandro, Bioengineering of an intraabdominal endocrine pancreas. $N$ Engl $J$ Med 376, 1887 (May 11, 2017). Thiene, L. Fabris, E. Ancona, S. Schiaffino, S. Ausoni, E. Cozzi, Hybrid cardiomyocytes derived by cell fusion in heterotopic cardiac xenografts. FASEB journal : official publication of the Federation of American Societies for Experimental Biology 20, 2534 (Dec, 2006).

1. N. Yamanaka, C. J. Wong, M. Gertsenstein, R. F. Casper, A. Nagy, I. M. Rogers, Bone marrow transplantation results in human donor blood cells acquiring and displaying mouse recipient class I MHC and CD45 antigens on their surface. PloS one 4, e8489 (Dec 31, 2009).

2. A. A. Ramkisoensing, A. A. De Vries, M. J. Schalij, D. E. Atsma, D. A. Pijnappels, Brief report: Misinterpretation of coculture differentiation experiments by unintended labeling of cardiomyocytes through secondary transduction: delusions and solutions. Stem cells 30, 2830 (Dec, 2012).

A. Hafezi-Moghadam, T. Simoncini, Z. Yang, F. P. Limbourg, J. C. Plumier, M. C. Rebsamen, C. M. Hsieh, D. S. Chui, K. L. Thomas, A. J. Prorock, V. E. Laubach, M. A. Moskowitz, B. A. French, K. Ley, J. K. Liao, Acute cardiovascular protective effects of corticosteroids are mediated by non-transcriptional activation of endothelial nitric oxide synthase. Nature medicine 8, 473 (May, 2002).

94. M. Debrunner, E. Schuiki, E. Minder, E. Straumann, B. Naegeli, R. Mury, O. Bertel, J. Frielingsdorf, Proinflammatory cytokines in acute myocardial infarction with and without cardiogenic shock. Clinical research in cardiology : official journal of the German Cardiac Society 97, 298 (May, 2008).

95. P. M. Ridker, B. M. Everett, T. Thuren, J. G. MacFadyen, W. H. Chang, C. Ballantyne, F. Fonseca, J. Nicolau, W. Koenig, S. D. Anker, J. J. P. Kastelein, J. H. Cornel, P. Pais, D. Pella, J. Genest, R. Cifkova, A. Lorenzatti, T. Forster, Z. Kobalava, L. Vida-Simiti, M. Flather, H. Shimokawa, H. Ogawa, M. Dellborg, P. R. F. Rossi, R. P. T. Troquay, P. Libby, R. J. Glynn, C. T. Group, Antiinflammatory therapy with canakinumab for atherosclerotic disease. $N \mathrm{Engl}$ J Med 377, 1119 (Sep 21, 2017).

96. F. van den Akker, J. C. Deddens, P. A. Doevendans, J. P. Sluijter, Cardiac stem cell therapy to modulate inflammation upon myocardial infarction. Biochimica et biophysica acta 1830, 2449 (Feb, 2013).

97. F. Crea, G. Liuzzo, Anti-inflammatory treatment of acute coronary syndromes: the need for precision medicine. European heart journal 37, 2414 (Aug 7, 2016).

98. S. Subramanian, H. Emami, E. Vucic, P. Singh, J. Vijayakumar, K. M. Fifer, A. Alon, S. S. Shankar, M. Farkouh, J. H. F. Rudd, Z. A. Fayad, T. E. Van Dyke, A. Tawakol, High-dose atorvastatin reduces periodontal inflammation: a novel pleiotropic effect of statins. Journal of the American College of Cardiology 62, 2382 (Dec 24, 2013).

99 B. M. Everett, A. D. Pradhan, D. H. Solomon, N. Paynter, J. Macfadyen, E. Zaharris, M. Gupta, M. Clearfield, P. Libby, A. A. Hasan, R. J. Glynn, 
P. M. Ridker, Rationale and design of the Cardiovascular Inflammation Reduction Trial: a test of the inflammatory hypothesis of atherothrombosis. American heart journal 166, 199 (Aug, 2013).

100. M. Honczarenko, Y. Le, M. Swierkowski, I. Ghiran, A. M. Glodek, L. E. Silberstein, Human bone marrow stromal cells express a distinct set of biologically functional chemokine receptors. Stem cells 24, 1030 (Apr, 2006).

101. D. Orlic, J. Kajstura, S. Chimenti, I. Jakoniuk, S. M. Anderson, B. Li, J. Pickel, R. McKay, B. Nadal-Ginard, D. M. Bodine, A. Leri, P. Anversa, Bone marrow cells regenerate infarcted myocardium. Nature 410, 701 (Apr 5, 2001).

102. V. K. Ramiya, M. Maraist, K. E. Arfors, D. A. Schatz, A. B. Peck, J. G. Cornelius, Reversal of insulin-dependent diabetes using islets generated in vitro from pancreatic stem cells. Nature medicine 6, 278 (Mar, 2000).

103. J. Leor, S. Aboulafia-Etzion, A. Dar, L. Shapiro, I. M. Barbash, A. Battler, Y. Granot, S. Cohen, Bioengineered cardiac grafts: A new approach to repair the infarcted myocardium? Circulation 102, III56 (Nov 7, 2000).

104. O. Caspi, I. Huber, I. Kehat, M. Habib, G. Arbel, A. Gepstein, L. Yankelson, D. Aronson, R. Beyar, L. Gepstein, Transplantation of human embryonic stem cell-derived cardiomyocytes improves myocardial performance in infarcted rat hearts. Journal of the American College of Cardiology 50, 1884 (Nov 6, 2007).

105. J. Leor, S. Gerecht, S. Cohen, L. Miller, R. Holbova, A. Ziskind, M. Shachar, M. S. Feinberg, E. Guetta, J. Itskovitz-Eldor, Human embryonic stem cell transplantation to repair the infarcted myocardium. Heart 93, 1278 (Oct, 2007).

106. J. Yu, K. T. Du, Q. Fang, Y. Gu, S. S. Mihardja, R. E. Sievers, J. C. Wu, R. J. Lee, The use of human mesenchymal stem cells encapsulated in RGD modified alginate microspheres in the repair of myocardial infarction in the rat. Biomaterials 31, 7012 (Sep, 2010).

107. H. S. O'Neill, J. O'Sullivan, N. Porteous, E. RuizHernandez, H. M. Kelly, F. J. O'Brien, G. P. Duffy, A collagen cardiac patch incorporating alginate microparticles permits the controlled release of hepatocyte growth factor and insulinlike growth factor-1 to enhance cardiac stem cell migration and proliferation. Journal of tissue engineering and regenerative medicine, (Dec 12, 2016).

108. N. Frey, A. Linke, T. Suselbeck, J. MullerEhmsen, P. Vermeersch, D. Schoors, M Rosenberg, F. Bea, S. Tuvia, J. Leor, Intracoronary delivery of injectable bioabsorbable scaffold (IK-5001) to treat left ventricular remodeling after ST-elevation myocardial infarction: a first-in-man study. Circulation. Cardiovascular interventions 7, 806 (Dec, 2014).

109. K. L. Christman, A. J. Vardanian, Q. Fang, R. E. Sievers, H. H. Fok, R. J. Lee, Injectable fibrin scaffold improves cell transplant survival, reduces infarct expansion, and induces neovasculature formation in ischemic myocardium. Journal of the American College of Cardiology 44, 654 (Aug 4, 2004).

110. K. L. Christman, H. H. Fok, R. E. Sievers, Q. Fang, R. J. Lee, Fibrin glue alone and skeletal myoblasts in a fibrin scaffold preserve cardiac function after myocardial infarction. Tissue engineering 10, 403 (Mar-Apr, 2004).

111. X. Zhang, H. Wang, X. Ma, A. Adila, B. Wang, F. Liu, B. Chen, C. Wang, Y. Ma, Preservation of the cardiac function in infarcted rat hearts by the transplantation of adipose-derived stem cells with injectable fibrin scaffolds. Experimental biology and medicine 235, 1505 (Dec, 2010).

112. L. Ye, Y. H. Chang, Q. Xiong, P. Zhang, L. Zhang, P. Somasundaram, M. Lepley, C. Swingen, L. Su, J. S. Wendel, J. Guo, A. Jang, D. Rosenbush, L. Greder, J. R. Dutton, J. Zhang, T. J. Kamp, D. S. Kaufman, Y. Ge, J. Zhang, Cardiac repair in a porcine model of acute myocardial infarction with human induced pluripotent stem cell-derived cardiovascular cells. Cell stem cell 15, 750 (Dec 4, 2014).

113. E. Blondiaux, L. Pidial, G. Autret, G. Rahmi, D. Balvay, E. Audureau, C. Wilhelm, C. L. Guerin, P. Bruneval, J. S. Silvestre, P. Menasche, O. Clement, Bone marrow-derived mesenchymal stem cell-loaded fibrin patches act as a reservoir of paracrine factors in chronic myocardial infarction. Journal of tissue engineering and regenerative medicine 11, 3417 (Dec, 2017).

114. J. Tang, A. Vandergriff, Z. Wang, M. T. Hensley, J. Cores, T. A. Allen, P. U. Dinh, J. Zhang, T. G. Caranasos, K. Cheng, A regenerative cardiac patch formed by spray painting of biomaterials onto the heart. Tissue engineering. Part $C$, Methods 23, 146 (Mar, 2017).

115. Q. Ke, Y. Yang, J. S. Rana, Y. Chen, J. P. Morgan, Y. F. Xiao, Embryonic stem cells cultured in biodegradable scaffold repair infarcted myocardium in mice. Sheng li xue bao: [Acta physiologica Sinica] 57, 673 (Dec 25, 2005).

116. Y. Wang, X. C. Liu, J. Zhao, X. R. Kong, R. F. Shi, X. B. Zhao, C. X. Song, T. J. Liu, F. Lu, Degradable PLGA scaffolds with basic fibroblast growth factor: experimental studies in myocardial revascularization. Texas Heart Institute journal 36, 89 (2009).

117. J. R. Fitzpatrick, 3rd, J. R. Frederick, R. C. McCormick, D. A. Harris, A. Y. Kim, J. R. Muenzer, A. J. Gambogi, J. P. Liu, E. C. Paulson, Y. J. Woo, Tissue-engineered pro-angiogenic fibroblast scaffold improves myocardial perfusion and function and limits ventricular remodeling after infarction. J Thorac Cardiovasc Surg 140, 667 (Sep, 2010).

118. J. Jin, S. I. Jeong, Y. M. Shin, K. S. Lim, H. Shin, Y. M. Lee, H. C. Koh, K. S. Kim, Transplantation of mesenchymal stem cells within a poly(lactideco-epsilon-caprolactone) scaffold improves cardiac function in a rat myocardial infarction model. European journal of heart failure 11, 147 (Feb, 2009).

119. A. D'Amore, T. Yoshizumi, S. K. Luketich, M. T. Wolf, X. Gu, M. Cammarata, R. Hoff, S. F. Badylak, W. R. Wagner, Bi-layered polyurethane - Extracellular matrix cardiac patch improves ischemic ventricular wall remodeling in a rat model. Biomaterials 107, 1 (Nov, 2016).

120. R. Hashizume, K. L. Fujimoto, Y. Hong, J. Guan, C. Toma, K. Tobita, W. R. Wagner, Biodegradable elastic patch plasty ameliorates left ventricular adverse remodeling after ischemia-reperfusion injury: a preclinical study of a porous polyurethane material in a porcine model. J Thorac Cardiovasc Surg 146, 391 (Aug, 2013). 
121. K. Athanassiadi, E. Apostolakis, G. Kalavrouziotis, C. Charitos, E. Karamichali, D Kakavos, C. Lolas, Surgical repair of postinfarction ventricular septal defect: 10-year experience. World J Surg 23, 64 (Jan, 1999).

122. S. B. Seif-Naraghi, J. M. Singelyn, M. A. Salvatore, K. G. Osborn, J. J. Wang, U. Sampat, O. L. Kwan, G. M. Strachan, J. Wong, P. J. Schup-Magoffin, R. L. Braden, K. Bartels, J. A. DeQuach, M. Preul, A. M. Kinsey, A. N. DeMaria, N. Dib, K. L. Christman, Safety and efficacy of an injectable extracellular matrix hydrogel for treating myocardial infarction. Science translational medicine 5, 173ra25 (Feb 20, 2013).

123. N. Li, R. Huang, X. Zhang, Y. Xin, J. Li, Y Huang, W. Cui, J. F. Stoltz, Y. Zhou, Q. Kong, Stem cells cardiac patch from decellularized umbilical artery improved heart function after myocardium infarction. Bio-medical materials and engineering 28, S87 (2017).

124. C. H. Chen, H. J. Wei, W. W. Lin, I. Chiu, S. M. Hwang, C. C. Wang, W. Y. Lee, Y. Chang, H. W. Sung, Porous tissue grafts sandwiched with multilayered mesenchymal stromal cell sheets induce tissue regeneration for cardiac repair. Cardiovascular research 80, 88 (Oct 1, 2008).

125. P. V. Kochupura, E. U. Azeloglu, D. J. Kelly, S. V. Doronin, S. F. Badylak, I. B. Krukenkamp, I. S. Cohen, G. R. Gaudette, Tissue-engineered myocardial patch derived from extracellular matrix provides regional mechanical function. Circulation 112, I144 (Aug 30, 2005).

126. R. S. Kellar, B. R. Shepherd, D. F. Larson, G. K. Naughton, S. K. Williams, Cardiac patch constructed from human fibroblasts attenuates reduction in cardiac function after acute infarct. Tissue engineering 11, 1678 (Nov-Dec, 2005).

127. A. F. Godier-Furnemont, T. P. Martens, M. S. Koeckert, L. Wan, J. Parks, K. Arai, G. Zhang, B. Hudson, S. Homma, G. Vunjak-Novakovic, Composite scaffold provides a cell delivery platform for cardiovascular repair. Proceedings of the National Academy of Sciences of the United States of America 108, 7974 (May 10, 2011).

128. L. Wang, E. M. Meier, S. Tian, I. Lei, L. Liu, S. Xian, M. T. Lam, Z. Wang, Transplantation of Isl1(+) cardiac progenitor cells in small intestinal submucosa improves infarcted heart function. Stem cell research \& therapy 8, 230 (Oct 16, 2017).

129. M. Izadifar, D. Chapman, P. Babyn, X. Chen, M. E. Kelly, UV-Assisted 3D bioprinting of nanoreinforced hybrid cardiac patch for myocardial tissue engineering. Tissue engineering. Part C, Methods 24, 74 (Feb, 2018).

130. C. A. Holladay, A. M. Duffy, X. Chen, M. V. Sefton, T. D. O'Brien, A. S. Pandit, Recovery of cardiac function mediated by MSC and interleukin-10 plasmid functionalised scaffold. Biomaterials 33, 1303 (Feb, 2012).

131. Z. Xiang, R. Liao, M. S. Kelly, M. Spector, Collagen-GAG scaffolds grafted onto myocardial infarcts in a rat model: a delivery vehicle for mesenchymal stem cells. Tissue engineering 12, 2467 (Sep, 2006)

132. J. C. Chachques, J. C. Trainini, N. Lago, M. Cortes-Morichetti, O. Schussler, A. Carpentier, Myocardial Assistance by Grafting a New Bioartificial Upgraded Myocardium (MAGNUM trial): clinical feasibility study. The Annals of thoracic surgery 85, 901 (Mar, 2008).
133. V. A. Puig-Sanvicens, C. E. Semino, N. I. Zur Nieden, Cardiac differentiation potential of human induced pluripotent stem cells in a 3D self-assembling peptide scaffold. Differentiation; research in biological diversity 90, 101 (Nov-Dec, 2015).

134. M. Tokunaga, M. L. Liu, T. Nagai, K. Iwanaga, K. Matsuura, T. Takahashi, M. Kanda, N. Kondo, P. Wang, A. T. Naito, I. Komuro, Implantation of cardiac progenitor cells using self-assembling peptide improves cardiac function after myocardial infarction. Journal of molecular and cellular cardiology 49, 972 (Dec, 2010).

135. S. Miyagawa, Y. Sawa, S. Sakakida, S. Taketani, H. Kondoh, I. A. Memon, Y. Imanishi, T. Shimizu, T. Okano, H. Matsuda, Tissue cardiomyoplasty using bioengineered contractile cardiomyocyte sheets to repair damaged myocardium: their integration with recipient myocardium. Transplantation 80, 1586 (Dec 15, 2005).

136. K. Sakaguchi, T. Shimizu, T. Okano, Construction of three-dimensional vascularized cardiac tissue with cell sheet engineering. Journal of controlled release : official journal of the Controlled Release Society 205, 83 (May 10, 2015).

137. R. Feiner, L. Engel, S. Fleischer, M. Malki, I. Gal, A. Shapira, Y. Shacham-Diamand, T. Dvir, Engineered hybrid cardiac patches with multifunctional electronics for online monitoring and regulation of tissue function. Nature materials 15, 679 (Jun, 2016).

138. Y. Miyagi, F. Zeng, X. P. Huang, W. D. Foltz, J. Wu, A. Mihic, T. M. Yau, R. D. Weisel, R. K. Li, Surgical ventricular restoration with a cell- and cytokine-seeded biodegradable scaffold. Biomaterials 31, 7684 (Oct, 2010).

139. L. Gao, M. E. Kupfer, J. P. Jung, L. Yang, P. Zhang, Y. Da Sie, Q. Tran, V. Ajeti, B. T. Freeman, V. G. Fast, P. J. Campagnola, B. M. Ogle, J. Zhang, Myocardial tissue engineering with cells derived from human-induced pluripotent stem cells and a native-like, highresolution, 3-dimensionally printed scaffold. Circulation research 120, 1318 (Apr 14, 2017).

140. G. Marchioli, L. van Gurp, P. P. van Krieken, D. Stamatialis, M. Engelse, C. A. van Blitterswijk, M. B. Karperien, E. de Koning, J. Alblas, L. Moroni, A. A. van Apeldoorn, Fabrication of three-dimensional bioplotted hydrogel scaffolds for islets of Langerhans transplantation. Biofabrication 7, 025009 (May 28, 2015).

141. T. M. Suszynski, E. S. Avgoustiniatos, S. A. Stein, E. J. Falde, B. E. Hammer, K. K. Papas, Assessment of tissue-engineered islet graft viability by fluorine magnetic resonance spectroscopy. Transplantation proceedings $\mathbf{4 3}$, 3221 (Nov, 2011).

142. A. Schaschkow, C. Mura, W. Bietiger, C. Peronet, A. Langlois, F. Bodin, C. Dissaux, C. Bruant-Rodier, M. Pinget, N. Jeandidier, M. T. Juszczak, S. Sigrist, E. Maillard, Impact of an autologous oxygenating matrix culture system on rat islet transplantation outcome. Biomaterials 52, 180 (Jun, 2015).

143. T. Kheradmand, S. Wang, R. F. Gibly, X. Zhang, S. Holland, J. Tasch, J. G. Graham, D. B. Kaufman, S. D. Miller, L. D. Shea, X. Luo, Permanent protection of PLG scaffold transplanted allogeneic islet grafts in diabetic 
mice treated with ECDI-fixed donor splenocyte infusions. Biomaterials 32, 4517 (Jul, 2011).

144. S. Kodama, K. Kojima, S. Furuta, M. Chambers, A. C. Paz, C. A. Vacanti, Engineering functional islets from cultured cells. Tissue Eng Part A $\mathbf{1 5}$, 3321 (Nov, 2009).

145. D. M. Berman, J. J. O'Neil, L. C. Coffey, P. C. Chaffanjon, N. M. Kenyon, P. Ruiz, Jr., A. Pileggi, C. Ricordi, N. S. Kenyon, Long-term survival of nonhuman primate islets implanted in an omental pouch on a biodegradable scaffold. American journal of transplantation : official journal of the American Society of Transplantation and the American Society of Transplant Surgeons 9, 91 (Jan, 2009).

146. K. A. Hlavaty, R. F. Gibly, X. Zhang, C. B. Rives, J. G. Graham, W. L. Lowe, Jr., X. Luo, L. D. Shea, Enhancing human islet transplantation by localized release of trophic factors from PLG scaffolds. American journal of transplantation : official journal of the American Society of Transplantation and the American Society of Transplant Surgeons 14, 1523 (Jul, 2014).

147. E. De Carlo, S. Baiguera, M. T. Conconi, S. Vigolo, C. Grandi, S. Lora, C. Martini, P. Maffei, G. Tamagno, R. Vettor, N. Sicolo, P. P. Parnigotto, Pancreatic acellular matrix supports islet survival and function in a synthetic tubular device: in vitro and in vivo studies. International journal of molecular medicine 25, 195 (Feb, 2010).

148. S. H. Mirmalek-Sani, G. Orlando, J. P. McQuilling, R. Pareta, D. L. Mack, M. Salvatori, A. C. Farney, R. J. Stratta, A. Atala, E. C. Opara, S. Soker, Porcine pancreas extracellular matrix as a platform for endocrine pancreas bioengineering. Biomaterials 34, 5488 (Jul, 2013).

149. R. B. Jalili, A. Moeen Rezakhanlou, A. HosseiniTabatabaei, Z. Ao, G. L. Warnock, A. Ghahary, Fibroblast populated collagen matrix promotes islet survival and reduces the number of islets required for diabetes reversal. Journal of cellular physiology 226, 1813 (Jul, 2011).

150. C. Aloy-Reverte, J. L. Moreno-Amador, M. Nacher, E. Montanya, C. E. Semino, Use of RGDfunctionalized sandwich cultures to promote redifferentiation of human pancreatic beta cells after in vitro expansion. Tissue Eng Part A 24, 394 (Mar, 2018).

151. J. Liu, S. Liu, Y. Chen, X. Zhao, Y. Lu, J. Cheng, Functionalized self-assembling peptide improves INS-1 beta-cell function and proliferation via the integrin/FAK/ERK/cyclin pathway. International journal of nanomedicine 10, 3519 (2015).

152. T. Saito, K. Ohashi, R. Utoh, H. Shimizu, K. Ise, H. Suzuki, M. Yamato, T. Okano, M. Gotoh, Reversal of diabetes by the creation of neo-islet tissues into a subcutaneous site using islet cell sheets. Transplantation 92, 1231 (Dec 15, 2011).

153. S. Muthyala, R. R. Bhonde, P. D. Nair, Cytocompatibility studies of mouse pancreatic islets on gelatin--PVP semi IPN scaffolds in vitro: potential implication towards pancreatic tissue engineering. Islets 2, 357 (Nov-Dec, 2010).

154. S. Giwa, J. K. Lewis, L. Alvarez, R. Langer, A. E. Roth, G. M. Church, J. F. Markmann, D. H Sachs, A. Chandraker, J. A. Wertheim, M. Rothblatt, E. S. Boyden, E. Eidbo, W. P. A. Lee, B. Pomahac, G. Brandacher, D. M. Weinstock, G. Elliott, D. Nelson, J. P. Acker, K. Uygun, B. Schmalz, B. P. Weegman, A. Tocchio, G. M.
Fahy, K. B. Storey, B. Rubinsky, J. Bischof, J. A. W. Elliott, T. K. Woodruff, G. J. Morris, U. Demirci, K. G. M. Brockbank, E. J. Woods, R. N. Ben, J. G. Baust, D. Gao, B. Fuller, Y. Rabin, D. C. Kravitz, M. J. Taylor, M. Toner, The promise of organ and tissue preservation to transform medicine. Nature biotechnology 35, 530 (Jun 7, 2017).

155. Y. Bayon, A. A. Vertes, V. Ronfard, E. CulmeSeymour, C. Mason, P. Stroemer, M. Najimi, E. Sokal, C. Wilson, J. Barone, R. Aras, A. Chiesi, Turning regenerative medicine breakthrough ideas and innovations into commercial products. Tissue engineering. Part B, Reviews 21, 560 (Dec, 2015).

156. S. J. Lee, S. Joffe, A. S. Artz, R. E. Champlin, S. M. Davies, M. Jagasia, N. A. Kernan, F. R. Loberiza, Jr., R. J. Soiffer, M. Eapen, Individual physician practice variation in hematopoietic cell transplantation. Journal of clinical oncology : official journal of the American Society of Clinical Oncology 26, 2162 (May 01, 2008).

157. S. Llufriu, M. Sepulveda, Y. Blanco, P. Marin, B. Moreno, J. Berenguer, I. Gabilondo, E. MartinezHeras, N. Sola-Valls, J. A. Arnaiz, E. J. Andreu, B. Fernandez, S. Bullich, B. Sanchez-Dalmau, F. Graus, P. Villoslada, A. Saiz, Randomized placebo-controlled phase II trial of autologous mesenchymal stem cells in multiple sclerosis. PloS one 9, e113936 (2014).

158. J. Cai, Z. Wu, X. Xu, L. Liao, J. Chen, L. Huang, W. Wu, F. Luo, C. Wu, A. Pugliese, A. Pileggi, C. Ricordi, J. Tan, Umbilical cord mesenchymal stromal cell with autologous bone marrow cell transplantation in established type 1 diabetes: A pilot randomized controlled open-label clinical study to assess safety and impact on insulin secretion. Diabetes Care 39, 149 (Jan, 2016).

159. A. C. Davison, Brave pioneers or clinical cowboys? Cell stem cell 6, 504 (Jun 04, 2010).

160. D. Sipp, The unregulated commercialization of stem cell treatments: a global perspective. Frontiers of medicine 5, 348 (Dec, 2011).

161. N. Amariglio, A. Hirshberg, B. W. Scheithauer, Y. Cohen, R. Loewenthal, L. Trakhtenbrot, N. Paz, M. Koren-Michowitz, D. Waldman, L. Leider-Trejo, A. Toren, S. Constantini, G. Rechavi, Donor-derived brain tumor following neural stem cell transplantation in an ataxia telangiectasia patient. PLoS medicine 6, e1000029 (Feb 17, 2009).

162. J. K. Kirklin, D. C. Naftel, R. L. Kormos, L. W. Stevenson, F. D. Pagani, M. A. Miller, J. T. Baldwin, J. B. Young, The Fourth INTERMACS Annual Report: 4,000 implants and counting. The Journal of heart and lung transplantation: the official publication of the International Society for Heart Transplantation 31, 117 (Feb, 2012).

163. A. M. Shapiro, J. R. Lakey, E. A. Ryan, G. S. Korbutt, E. Toth, G. L. Warnock, N. M. Kneteman, R. V. Rajotte, Islet transplantation in seven patients with type 1 diabetes mellitus using a glucocorticoid-free immunosuppressive regimen. $N$ Engl J Med 343, 230 (Jul 27, 2000).

164. T. N. McAllister, D. Audley, N. L'Heureux, Autologous cell therapies: challenges in US FDA regulation. Regenerative medicine 7, 94 (Nov, 2012).

165. T. N. McAllister, N. Dusserre, M. Maruszewski, N. L'Heureux, Cell-based therapeutics from an economic perspective: primed for a commercial 
success or a research sinkhole? Regenerative medicine 3, 925 (Nov, 2008).

166. R. R. Nadig, Stem cell therapy - Hype or hope? A review. Journal of conservative dentistry : JCD 12, 131 (Oct, 2009).

167. N. Scolding, Stem-cell therapy: hope and hype. Lancet 365, 2073 (Jun 18-24, 2005).

168. G. D. Prestwich, K. E. Healy, Why regenerative medicine needs an extracellular matrix. Expert opinion on biological therapy 15, 3 (Jan, 2015).

169. R. M. Bergenstal, S. Garg, S. A. Weinzimer, B. A. Buckingham, B. W. Bode, W. V. Tamborlane, F. R. Kaufman, Safety of a hybrid closed-loop insulin delivery system in patients with type 1 diabetes. Jama 316, 1407 (Oct 04, 2016).

170. D. Jacobs-Tulleneers-Thevissen, M. Chintinne, Z. Ling, P. Gillard, L. Schoonjans, G. Delvaux, B. L. Strand, F. Gorus, B. Keymeulen, D. Pipeleers, E.-F. Beta Cell Therapy Consortium, Sustained function of alginate-encapsulated human islet cell implants in the peritoneal cavity of mice leading to a pilot study in a type 1 diabetic patient. Diabetologia 56, 1605 (Jul, 2013).

171. A. A. Giannopoulos, D. Mitsouras, S. J. Yoo, P. P. Liu, Y. S. Chatzizisis, F. J. Rybicki, Applications of 3D printing in cardiovascular diseases. Nature reviews. Cardiology 13, 701 (Dec, 2016).

172. R. Barrangou, C. Fremaux, H. Deveau, M. Richards, P. Boyaval, S. Moineau, D. A. Romero, P. Horvath, CRISPR provides acquired resistance against viruses in prokaryotes. Science 315, 1709 (Mar 23, 2007).

173. H. Ebina, N. Misawa, Y. Kanemura, Y. Koyanagi, Harnessing the CRISPR/Cas9 system to disrupt latent HIV-1 provirus. Scientific reports 3, 2510 (2013).

174. M. Tabebordbar, K. Zhu, J. K. W. Cheng, W. L. Chew, J. J. Widrick, W. X. Yan, C. Maesner, E. Y. Wu, R. Xiao, F. A. Ran, L. Cong, F. Zhang, L. H. Vandenberghe, G. M. Church, A. J. Wagers, In vivo gene editing in dystrophic mouse muscle and muscle stem cells. Science 351, 407 (Jan 22, 2016).

175. D. P. Dever, R. O. Bak, A. Reinisch, J Camarena, G. Washington, C. E. Nicolas, M. Pavel-Dinu, N. Saxena, A. B. Wilkens, S. Mantri, N. Uchida, A. Hendel, A. Narla, R. Majeti, K. I. Weinberg, M. H. Porteus, CRISPR/Cas9 betaglobin gene targeting in human haematopoietic stem cells. Nature 539, 384 (Nov 17, 2016).

176. E. Haapaniemi, S. Botla, J. Persson, B. Schmierer, J. Taipale, CRISPR-Cas9 genome editing induces a p53-mediated DNA damage response. Nature medicine, (Jun 11, 2018).

177. R. J. Ihry, K. A. Worringer, M. R. Salick, E. Frias, D. Ho, K. Theriault, S. Kommineni, J. Chen, M. Sondey, C. Ye, R. Randhawa, T. Kulkarni, Z. Yang, G. McAllister, C. Russ, J. Reece-Hoyes, W. Forrester, G. R. Hoffman, R. Dolmetsch, A. Kaykas, p53 inhibits CRISPRCas9 engineering in human pluripotent stem cells. Nature medicine, (Jun 11, 2018).

178. J. Wu, D. Okamura, M. Li, K. Suzuki, C. Luo, L. Ma, Y. He, Z. Li, C. Benner, I. Tamura, M. N. Krause, J. R. Nery, T. Du, Z. Zhang, T. Hishida, Y. Takahashi, E. Aizawa, N. Y. Kim, J. Lajara, P. Guillen, J. M. Campistol, C. R. Esteban, P. J. Ross, A. Saghatelian, B. Ren, J. R. Ecker, J. C. Izpisua Belmonte, An alternative pluripotent state confers interspecies chimaeric competency. Nature 521, 316 (May 21, 2015).
179. J. Wu, A. Platero-Luengo, M. Sakurai, A. Sugawara, M. A. Gil, T. Yamauchi, K. Suzuki, Y. S. Bogliotti, C. Cuello, M. Morales Valencia, D. Okumura, J. Luo, M. Vilarino, I. Parrilla, D. A. Soto, C. A. Martinez, T. Hishida, S. SanchezBautista, M. L. Martinez-Martinez, H. Wang, A. Nohalez, E. Aizawa, P. Martinez-Redondo, A. Ocampo, P. Reddy, J. Roca, E. A. Maga, C. R. Esteban, W. T. Berggren, E. Nunez Delicado, J. Lajara, I. Guillen, P. Guillen, J. M. Campistol, E. A. Martinez, P. J. Ross, J. C. Izpisua Belmonte, Interspecies chimerism with mammalian pluripotent stem cells. Cell 168, 473 (Jan 26, 2017).

180. M. Vilarino, S. T. Rashid, F. P. Suchy, B. R. McNabb, T. van der Meulen, E. J. Fine, S. Ahsan, N. Mursaliyev, V. Sebastiano, S. S. Diab, M. O. Huising, H. Nakauchi, P. J. Ross, CRISPR/Cas9 microinjection in oocytes disables pancreas development in sheep. Scientific reports 7, $17472 \quad$ (Dec 12, 2017). 



\section{Chapter 9}

Summary in English. 


\section{ENGLISH SUMMARY}

Cell-based therapy and bioengineering are relatively novel therapeutic concepts to treat tissue degenerative diseases such as heart failure (HF) and insulin dependent diabetes mellitus (IDDM). In preclinical small and large animal models, the results of such therapeutic interventions have been successful; cardiac function in $\mathrm{HF}$ and glucose control in IDDM could both be reversed in model systems, respectively.

Subsequently, cell-based therapy and bioengineering for $\mathrm{HF}$ and IDDM has been attempted in clinical settings and is being actively pursued in clinical trials. It is presumed and thoroughly tested prior to their use that such cells are functional and will not convert to uncontrolled or neoplastic proliferation.

In the case of $\mathrm{HF}$, (stem) cells were injected, depending on the clinical trial design, either directly into myocardial infarcts, infused directly into blocked coronary arteries, or systemically infused through a venous route. The mechanistic hypotheses were that such cells would migrate/home into the damaged tissue to form new cardiac muscle or new cardiac blood vessels, resulting in improved cardiac function.

In the case of IDDM, isolated pancreatic islets were infused into the portal vein in order to create well vascularized cell pockets inside the hepatic microvasculature that would respond to increasing glucose levels by secreting insulin.

Both aforementioned strategies have been hampered by low allograft cell survival due to 1 ) low local oxygen and low local nutrient supply through the native recipient vasculature, 2) low cell retention due to lack of cell adhesion and retention, and 3) immune rejection of implanted cells, and therefore overall limited long term effects on cardiac function (HF) or glucose control (IDDM). These problems are reviewed in chapter 1, and underlie the motivation for the work that is described in this thesis.

In order to improve the effectiveness of cell transplantation in HF and IDDM, several different cell-based therapy and bioengineering approaches were developed and tested in preclinical models, taking into account 1) the optimal design of a 3D base platform that can be used for the transplantation of different kinds of (stem) cell types, 2) enhancing local cell survival of implanted cells by binding of specific cell surface receptors to local extracellular matrix prosurvival factors, 3) enhancing local cell survival by increasing the local supply of oxygen and nutrients by a patent vasculature, 4) enhancing the effect of biomaterial implantation by exploring different anatomical sites (i.e. intramuscular, subcutaneous, or even intraperitoneal) of implantation, 5) modulating the local cytokine environment pharmacologically in order to improve (stem) cell homing to damaged tissue, and 6) minimizing the immune response that ensues against foreign cells or against foreign materials/tissues/organs upon implantation.

In order to design an optimal "general" base platform suitable for cell transplantation, we evaluated and tested several different biomaterials such as biological blood or protein derived products (i.e. fibrin glue, Matrigel), synthetic materials (i.e. peptide nanofibers, PNIPAAM), and others. Ultimately, we decided the polysaccharide sodium alginate $(\mathrm{NaA})$ to be the most optimal because 1) it is algae-derived, minimizing the risk of pathogen (i.e. prion) transfer, 2) it contains modifiable carboxyl(-COOH) groups (1 per NaA monomer) and thus allows for covalent attachment of prosurvival factors to the NaA polymer, 3) $\mathrm{NaA}$ is cheap, 4) has low toxicity, and 5) has the ability to assume a highly porous $3 \mathrm{D}$ structure that permits vascular ingrowth of arterioles and capillaries using simple and affordable techniques.

Because NaA contains potentially immunogenic contamination, we describe in chapter 2 a novel purification protocol that effectively removes immunogenic contaminants and thus generates a highly biocompatible material. This purified "base" material was subsequently used in all further in vitro and in vivo studies employing covalent modification, growth factor addition, 3D scaffold generation, and cell transplantation.

Chapter 3 describes the generation of covalent modification of previously mentioned purified $\mathrm{NaA}$ using the prosurvival peptide cyclic RGDfK. This peptide binds with high affinity to cell surface integrin receptors and enhances cell survival. Porous 3D scaffolds fabricated using this modified $\mathrm{NaA}$ enhance cell survival, as we show with neonatal rat cardiomyocytes and fibroblasts, and human mesenchymal precursor cells (hMPCs). Such scaffolds could be used to transplant hMPCs as a patch to the left ventricular (LV) scar area of infarcted hearts and improve cardiac function following acute myocardial infarction (AMI).

We also evaluated the 3D scaffold approach to transplant pancreatic islets in models of IDDM. Using a modified protocol, we were able to generate 3D hydrogel scaffolds using cyclic RGDfK modified $\mathrm{NaA}$ loaded with vascular growth factors (vascular endothelial growth factor and platelet derived growth factor-BB) to generate an intramuscular vascular bed that facilitated the implantation of isolated pancreatic islets to cure streptozotocininduced IDDM, as shown in chapters 4 \& $\mathbf{5}$. We could visualize live islets in situ using an islet specific marker and positron emission tomography (PET). The addition of vascular growth factors to the implanted scaffolds preimplantation markedly enhanced the effectiveness of the treatment and normalized glucose control in $100 \%$ of diabetic animals.

Following intravenous injection without scaffolds, (stem) cells need to find their way to damaged tissue in a process called "homing". The identification of specific cytokines and chemokines that are released following tissue injury and that subsequently attract or repel certain specific cell types offers the possibility of manipulating the homing capacity of such cells and direct them to specific sites of tissue injury. We have evaluated the 
modulation of these cytokine and chemokine pathways using direct injection and/or blocking of their receptors in order to "trick" human bone marrow derived hematopoietic CD34 ${ }^{+}$stem cells to find their way to the site of injury and create new blood vessels in the infarcted myocardium. We could show in chapters 6 \& 7 that modulating these pathways in an acute myocardial infarct (AMI) model is beneficial for the recovery of LV function following an AMI injury.

In parallel studies (appendices 1-2), we provide evidence that non-hematopoietic hMPCs upon direct injection into the cardiac muscle following AMI prevent cardiac remodelling by formation of new blood vessels within the infarcted heart. Mechanistically, we showed that effects on cardiac function may be dependent on certain chemokines and cytokines that hMPCs secrete, since intramyocardial injection of a concentrated cocktail of chemokines and cytokines that are secreted by hMPCs following ex vivo culture are sufficient to exert a similar effect on remodelling and cardiac function following MI.

In an alternative T-cell-based immunomodulatory approach (appendix 3) aimed at enhancing the survival of transplanted cells or organs, we show that adoptive transfer of expanded regulatory T-cells (i.e. Tregs) induced hematopoietic bone marrow chimerism (i.e. the co-existence of both donor and recipient hematopoietic stem cells in the bone marrow). It was shown that hematopoietic chimerism could prevent allograft rejection in a non-human primate (NHP) model of bone marrow stem cell and kidney transplantation without the use of any long-term immunosuppression.

In summary, this thesis provides an outline of several specific approaches in small animal models to both improvement of cardiac function following an MI and to achieving normoglycemia in streptozotocin-induced diabetes mellitus using stem cell technology combined with novel types of $\mathrm{NaA}$ scaffolds impregnated with cell survival and angiogenic factors. In NHPs it was shown that further enhancing allograft survival could be facilitated by the adoptive transfer of autologous

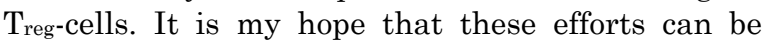
repeated and eventually combined in additional large animal models and human trials facilitated by a close collaboration between academia, clinic and commercial parties. 



\section{Chapter 10 Samenvatting in het Nederlands (Dutch summary).}




\section{NEDERLANDSE SAMENVATTING (DUTCH SUMMARY)}

Celtherapie en bioengineering zijn relatief nieuwe benaderingen om weefseldegeneratieve aandoeningen als hartfalen (HF) en insuline afhankelijke diabetes mellitus (IDDM) te behandelen. De resultaten van deze interventies zijn in proefdiermodellen met kleine én grote proefdieren succesvol gebleken; hartspierfunctie en het reguleren van suikerspiegels in respectievelijk $\mathrm{HF}$ en IDDM kunnen door deze behandelingen vrijwel worden genormaliseerd.

Dientengevolge is getracht interventies gebaseerd op (stam)celtherapie en bioengineering toe passen in klinische settings en deze actief in te zetten in patiëntenstudies, waarbij aangenomen wordt dat grondig geteste (stam)cellen niet zullen uitgroeien tot neoplasmen met ongecontroleerde groei (e.g. kanker).

Afhankelijk van het soort klinische trial worden (stam)cellen in het geval van HF of direct in de hartspier geïnjecteerd, óf door middel van een catheter geïnfundeerd in een verstopte kransslagader, óf met een infuus via een perifeer bloedvat in de circulatie gebracht. Mechanistisch is de hypothese dat deze cellen hun weg vinden in en naar de beschadigde hartspier om daar nieuw hartspierweefsel of nieuwe bloedvaten te vormen, resulterend in verbeterde hartspierfunctie.

In geval van IDDM worden geïsoleerde eilandjes van Langerhans geïnfundeerd in de portale vaten van de lever om zo in de microcirculatie van de lever goed gevasculariseerde "pockets" te creëren die zouden reageren op toename van glucosespiegels door productie van insuline.

Beide strategieën worden in de praktijk gehinderd door beperkte overleving van de geïnjecteerde cellen t.g.v. 1) lage lokale zuurstofspanning en beperkte initiële toevoer van voedingsstoffen door lokaal vaatweefsel, 2) lage celretentie door beperkte aanhechting/verankering van geïnjecteerde cellen en 3) immuunafstoting van de geïnjecteerde cellen. Deze celdood leidt uiteraard tot slechts beperkte positieve lange termijn effecten op hartspierfunctie (HF) en glucosecontrole (IDDM). Deze problemen worden besproken in hoofdstuk 1 , en zijn de onderliggende motivatie geweest voor het werk dat is beschreven in dit proefschrift.

In een poging om de effectiviteit van celtransplantatie in $\mathrm{HF}$ en IDDM te verbeteren worden verschillende hypotheses op basis van (stam)celtransplantatie en bioengineering ontwikkeld en getest in preklinische modellen met kleine en grote proefdieren, waarin continu rekening wordt gehouden met 1) optimaal ontwerp van het 3D biomateriaal platform dat gebruikt kan worden voor de transplantatie van verschillende soorten (stam)cellen, 2) verbetering van lokale overleving van geïmplanteerde cellen door binding van bepaalde oppervlaktereceptoren op de celmembraan met de extracellulaire matrix (ECM), 3) verbetering van lokale overleving van geïmplanteerde cellen door vergroten van de lokale toevoer van zuurstof en voedingsstoffen door functioneel vaatweefsel, 4) verbetering van het effect van (bio)materiaalimplantatie door exploratie van verschillende locaties voor implantatie (intramusculair, subcutaan of zelfs intraperitoneaal), 5) farmacologisch moduleren van het cytokinemilieu om migratie van (stam)cellen naar beschadigd weefsel te vergroten, en 6) modulatie van de immuunrespons die optreedt tegen lichaamsvreemde cellen en/of (bio)materialen/weefsels/organen na implantatie.

Voor het ontwerp van een optimaal "gestandaardiseerd" 3D platform dat geschikt is voor (stam)celtransplantatie worden verschillende biomaterialen getest, waaronder biologische bloedof eiwitproducten (fibrin glue, Matrigel), synthetische biomaterialen (peptide nanofibers, PNIPAAM), en andere. Uiteindelijk is gekozen voor het polysaccharide natrium alginaat $(\mathrm{NaA})$ omdat deze een aantal voordelen heeft ten opzichte van andere biomaterialen: 1) $\mathrm{NaA}$ wordt gewonnen uit algen waardoor het risico op infecties van het gastorganisme met pathogenen (e.g. virussen, prionen) miniem is, 2) de aanwezigheid van carboxyl(-COOH) groepen (1 per $\mathrm{NaA}$ monomeer) maakt NaA polymeren modificeerbaar door impregnantie en/of covalente aanhechting van (groei)factoren met amino(-NH2) groepen via chemische cross-linking, 3) $\mathrm{NaA}$ is goedkoop, 4) heeft lage toxiciteit, en 5) heeft de eigenschap dat het onder milde condities kan worden omgevormd tot hoogporeuze $3 \mathrm{D}$ matrices die vaatingroei (arteriolen, capillairen) mogelijk maakt.

Omdat $\mathrm{NaA}$ potentiële immunogene verontreiniging bevat wordt in hoofdstuk 2 een nieuw gepatenteerd purificatieprotocol omschreven dat effectief het grootste deel van de immunogene contaminatie verwijdert resulterend in een sterk biocompatibel materiaal. Dit gepurificeerde basismateriaal wordt vervolgens gebruikt voor alle in vitro en in vivo studies, inclusief covalente modificatie, groeifactoradditie, 3D materiaal generatie, en celtransplantatie.

Hoofdstuk 3 beschrijft de generatie van covalente modificatie van het eerder genoemde gepurificeerde $\mathrm{NaA}$ met het synthetische celoverlevingspeptide cyclisch RGDfK. Dit peptide bindt met hoge affiniteit aan celoppervlaktereceptoren (integrinen) die op de meeste zoogdiercellen voorkomen, en vergroot hierdoor celoverleving. Hoogporeuze 3D matrices die worden gefabriceerd met behulp van cyclisch RGDfK gemodificeerd $\mathrm{NaA}$ vergroten celoverleving zoals wordt aangetoond met cardiomyocyten en fibroblasten uit neonatale rattenharten, en met menselijke mesenchymale precursor beenmergcellen (hMPC's). Deze 3D matrices zijn vervolgens toegepast voor de transplantatie van hMPCs als levende "pleister" op geïnfarceerde linkerhartspier (LV) na acuut myocardinfarct (MI) waardoor hartspierfunctie significant verbetert.

Met een aangepast protocol is het mogelijk om van hetzelfde cyclisch RGDfK-gemodificeerde $\mathrm{NaA}$ 3D hydrogels te fabriceren die worden geladen 
met vasculaire groeifactoren (vascular endothelial growth factor en platelet derived growth factor-BB) waarmee een intramusculair vaatbed kan worden gegenereerd, waarin vervolgens geïsoleerde eilandjes van Langerhans worden geïnjecteerd en streptozotocin-geinduceerde (STZ) IDDM is genezen, zoals beschreven in hoofdstukken 4 \& 5 . De levende eilandjes kunnen vervolgens worden gevisualiseerd met een specifieke merker door middel van positron emission tomography (PET). Het toevoegen van vasculaire groeifactoren vergroot de effectiviteit van de geïmplanteerde eilandjes op glucosecontrole naar $100 \%$ van de behandelde proefdieren.

Stamcellen die intraveneus worden geïnjecteerd zónder gebruik te maken van een drager(bio)materiaal moeten hun weg vinden naar beschadigd weefsel door middel van een proces dat "homing" wordt genoemd. De identificatie van specifieke cytokinen en chemokinen die vrijkomen na weefselbeschadiging en vervolgens bepaalde celtypen aantrekken of afstoten biedt de mogelijkheid tot manipulatie van de homing capaciteit van zulke cellen om ze naar specifieke locaties te dirigeren. Modulatie van verscheidene interacties van cytokines en chemokines met menselijke $\quad \mathrm{CD}_{4}{ }^{+}$hematopoietische beenmergstamcellen wordt geëvalueerd in een model voor hartfalen door middel van directe injectie van cytokines of blokkade van cytokinereceptoren om (stam)cellen zo te "foppen" dat ze hun weg naar beschadigd hartspierweefsel (in plaats van beenmerg) kunnen vinden. In hoofdstukken 6 \& 7 wordt aangetoond dat het moduleren van specifieke cyto-en chemokines een voordelig effect heeft op vaatgroei en het herstel van hartspierfunctie na MI.

In parallelle studies (appendices 1-2) wordt bewijs geleverd dat niet-hematopoietische hMPC's na directe injectie in de geïnfarceerde hartspier remodeling van het hart verbeteren door het vormen van nieuwe bloedvaten. Mechanistisch wordt aangetoond dat zulke effecten op zijn minst afhankelijk zijn van de cytokinen en chemokinen die lokaal worden uitgescheiden door hMPC's, aangezien directe injectie van een ex vivo door hMPC geproduceerde en geconcentreerde cytokinecocktail in de geïnfarceerde hartspier vergelijkbare effecten heeft op de functie van het geïnfarceerde hart.

In aanvullende studies (appendix 3) met een focus op immunomodulatie wordt in nonhumane primaten aangetoond dat acceptatie van getransplanteerd lichaamsvreemd beenmerg in combinatie met een niertransplantatie kan worden verbeterd door intraveneuze infusie van ex vivo geëxpandeerde lichaamseigen immunosuppressieve regulatoire T-cellen (zgn. Tregs). Hierdoor ontstaat zgn. hematopoietisch chimerisme (het naast elkaar bestaan in het beenmerg van zowel donor als ontvanger hematopoietisch stamcelllen) en kunnen zowel beenmerg- als nier-afstoting worden voorkomen, zónder lange termijn gebruik van immunosuppressiva.

Samenvattend verschaft dit proefschrift concepten voor specifieke benaderingen voor de verbetering van hartfunctie na infarct en voor behandeling van STZ-geïnduceerde IDDM in kleine proefdieren, gebruik makend van (stam)celtransplantatie gecombineerd met nieuwe gemodificeerde typen van $\mathrm{NaA}$ geïmpregneerd met celoverlevings- en proangiogene factoren. Verdere acceptatie en overleving van lichaamsvreemde cellen, weefsels en/of organen na implantatie kan worden bewerkstelligd door co-infusie met lichaamseigen $\mathrm{T}_{\text {reg }}$ cellen. In de toekomst is de hoop dat deze strategieën kunnen worden gecombineerd in aanvullende modellen voor grote proefdieren en/of in klinische trials, in goede samenwerking tussen academische, klinische en commerciële partijen. 
Part IV

Addenda. 


\section{Appendix 1}

Mesenchymal lineage precursor cells induce vascular network formation in ischemic myocardium.

Nature Clinical Practice Cardiovascular Medicine, March 2006, Volume 3, Supplement 1.

Timothy P Martens, Fiona See, Michael D Schuster, Hugo P Sondermeijer, Marco M Hefti, Andrew Zannettino, Stan Gronthos, Tetsunori Seki and Silviu Itescu. 


\section{ABSTRACT}

Mesenchymal lineage precursors can be reproducibly isolated from adult mammalian bone marrow and grown in culture. Immunoselection with monoclonal antibodies against STRO-1 and vascular-cell-adhesion molecule 1 (VCAM1/CD106) prior to expansion results in a 1,000-fold enrichment of mesenchymal precursors compared to standard isolation techniques. Intramyocardial injection of human STRO-1-selected precursors in an athymic rat model of acute myocardial infarction results in induction of vascular network formation and arteriogenesis coupled with global functional cardiac recovery.

\section{INTRODUCTION}

In the prenatal period, definitive vascular network formation to sustain embryonic organogenesis is dependent on influx of mesenchymal lineage cells from the dorsal aorta and neural crest (1-3) to form the vascular supporting mural cells such as vascular smooth muscle cells and pericytes. Mesenchymal lineage precursor cells have been identified to be present in the postnatal mammalian bone marrow, and can be reproducibly isolated and grown in culture by prospective immunoselection (47). These cells are anatomically located in perivascular niches in the bone marrow and throughout the body, and demonstrate phenotypic and genetic identity to vascular pericytes (8).

Freshly isolated multipotent human adult bone marrow mesenchymal lineage stem cells have been extensively characterized for a long list of surface markers (4-7). The combined use of monoclonal antibodies against the antigens STRO-1 and VCAM1/CD106 results in up to 1,000-fold enrichment of mesenchymal precursors capable of giving rise to colony-forming units of the fibroblastoid type relative to their incidence in unseparated bone marrow (7). At a clonal level, cells positive for STRO-1 $1^{\text {bright }}$ and vascular-cell-adhesion molecule 1 (VCAM-1) demonstrate multipotential capability, differentiating to smooth muscle, bone, cartilage, and adipose tissue. Since vascular network formation supports endogenous cardiac regenerative capacity and long-term survival of cardiomyocyte precursors $(9,10)$, we investigated whether mesenchymal lineage precursors could enhance both cardiac neovascularization and myogenesis. Here we show that injection of immunoselected human adult bone marrow mesenchymal precursor cells expressing a STRObright VCAM1-positive phenotype results in induction of arteriogenesis in various tissues, including ischemic myocardium, and in sustained improvement in both global systolic and diastolic parameters of cardiac function.

\section{METHODS AND RESULTS}

Human mesenchymal precursor cells were isolated to greater than $99 \%$ purity from donor bone marrow by dual immunoselection using monoclonal antibodies against STRO-1 and VCAM-1. Following ex vivo cellular culture and expansion for over six passages, phenotypic analysis of the cells demonstrated continued high-level expression of STRO- 1 by $25-40 \%$ of the cultured cells, and these cells were immunoselected a second time using STRO-1 monoclonal antibody. To evaluate whether these cells were capable of inducing vascular network formation in vivo, $0.5 \times 10^{6}$ cultureexpanded STRO-1 $1^{\text {bright }}$ cells were directly injected into a rat glioblastoma tumor that produced high amounts of vascular endothelial growth factor and had been placed 2 weeks earlier in the subcutaneous tissue of an athymic nude rat (Figure 1). Seven days later, the animals were killed and the glioblastoma tissue was evaluated by immunohistochemistry for evidence of vascular network formation. As shown in Figure 1, human mesenchymal precursor cells persisted in large numbers at 2 weeks in rat tissue, as defined by a monoclonal antibody with specificity for human mitochondrial structures, and were found adjacent to and surrounding vascular structures. Marked induction of arteriogenesis was noted at the sites of mesenchymal precursor cell injection, as defined by over eightfold greater numbers of large-caliber vessels (20-100um diameter) dually staining with monoclonal antibodies against the endothelial marker von Willebrand's factor (vWF) and asmooth-muscle-actin (a-SMA), compared with saline-treated controls. Arteriogenesis was limited to the injection site and was not observed distal to the site.

To investigate whether similar induction of arteriogenesis could occur in the acutely ischemic myocardium, culture-expanded STRO-1 ${ }^{\text {bright }}$ cells $\left(0.2 \times 10^{6}\right.$ cells or $1 \times 10^{6}$ cells $), 1 \times 10^{6}$ bone marrow cells depleted of STRO-1 $1^{\text {bright }}$ cells, or saline was injected into the myocardium of athymic nude rats $48 \mathrm{~h}$ after ligation of the left anterior descending coronary artery. Arterioles were quantitated by identifying structures coexpressing an outer layer of a-SMA-positive cells and an inner layer of vWFpositive cells. As shown in Figure 2, animals injected with STRO-1 ${ }^{\text {bright }}$ cells demonstrated a dose dependent increase in arteriolar induction in the ischemic heart, with the highest dose inducing threefold greater numbers of arterioles than salinetreated controls $(\mathrm{P}<0.01)$.

Finally, cardiac function at 2 and 6 weeks was assessed by echocardiography (Figure 3) and measurement of hemodynamic parameters, and correlated with cardiac histology and immunohistochemistry. Animals receiving $1 \times 10^{6}$ STRO- $1^{\text {bright }}$ cells demonstrated mean improvement in ejection fraction of $50 \%$ and $75 \%$ at 2 and 6 weeks, respectively, relative to baseline values 2 

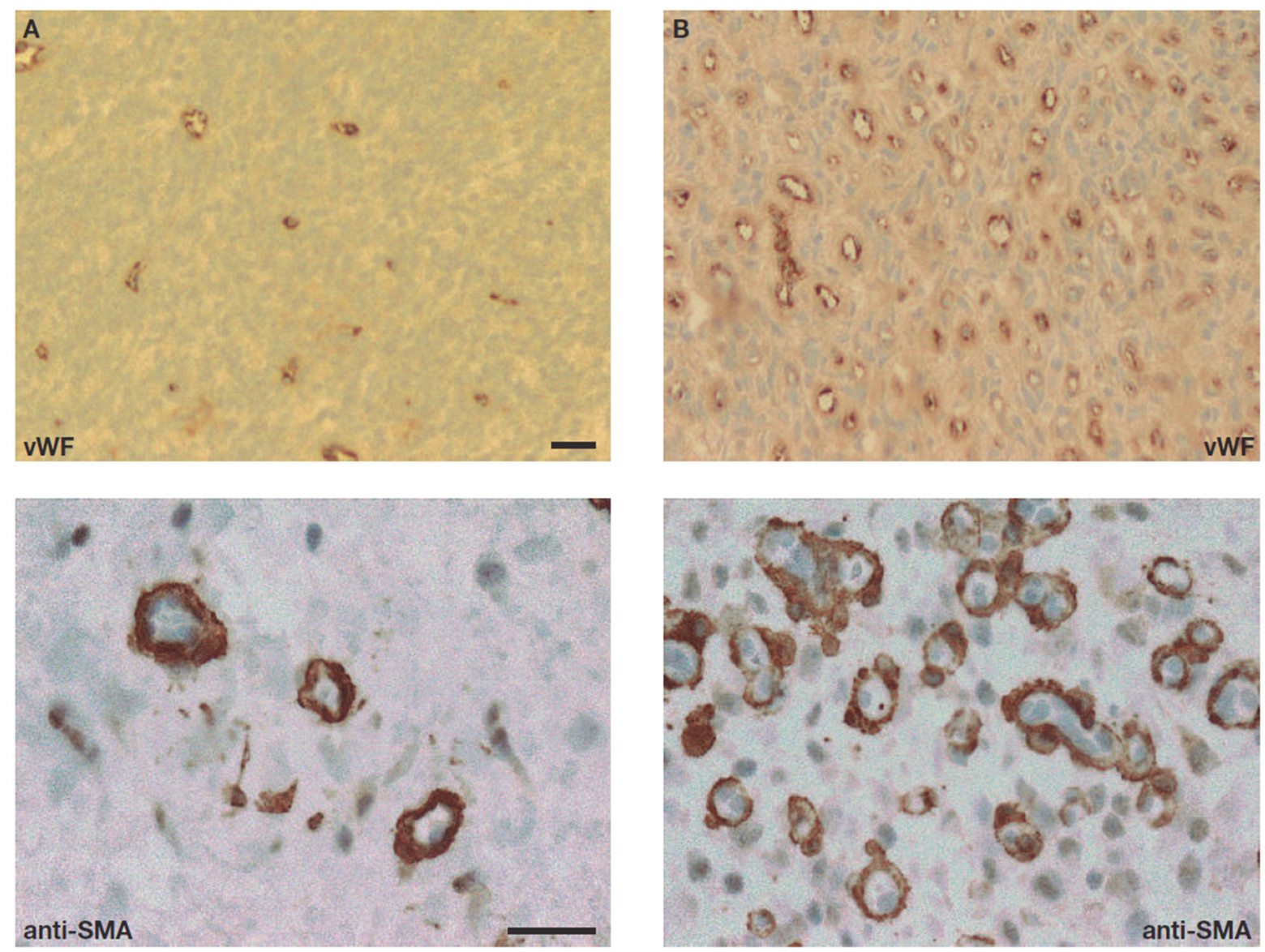

Figure1. Figure 1 Induction of tumor neovascularization (angiogenesis and arteriogenesis) by human STRO-1 ${ }^{\text {bright }}$ cells. Athymic nude rats were irradiated with 6 Gy for $5 \mathrm{~min}$ to remove residual natural killer function, then injected subcutaneously in the flank with $1 \times 10^{6}$ rat glioblastoma cells. Two weeks after implantation, the glioblastoma tumors were directly injected with either (A) saline or (B) $0.5 \times 10^{6}$ STRO$1^{\text {bright }}$ cells, and animals were killed 7 days later. In consecutive sections of the tumor tissue stained by the immunoperoxidase method using monoclonal antibodies directed, respectively, against von Willebrand's factor (vWF) and anti-smooth muscle actin (anti-SMA), animals injected with STRO-1 $1^{\text {bright }}$ cells demonstrated significantly greater numbers of capillaries and arterioles (defined, respectively, by $\mathrm{vWF}$ staining alone and combined expression of $\mathrm{vWF}$ and anti-SMA) than animals injected with saline.

days after ligation of the left anterior descending coronary artery. In stark contrast, saline-treated animals showed only 5\% mean improvement in ejection fraction by 6 weeks $(\mathrm{P}<0.01)$, and animals treated with STRO-1depleted bone marrow mononuclear cells demonstrated no difference from those receiving saline.

Injection of $1 \times 10^{6}$ STRO- $1^{\text {bright }}$ cells resulted in similar dramatic improvement in fractional shortening (mean improvement of $70 \%$ and $90 \%$ at 2 and 6 weeks, respectively). STRO-1depleted bone marrow mononuclear cells again had no effect, while modest improvement was seen after injection of $0.2 \times 10^{6}$ STRO- $1^{\text {bright }}$ cells. Finally, injection of $1 \times 10^{6}$ STRO- $1^{\text {bright }}$ cells resulted in significant improvement in left ventricular compliance compared with saline-treated controls.

\section{DISCUSSION}

In this study, we have shown that intramyocardial injection of human STRO-1 ${ }^{\text {bright }}$ mesenchymal precursor cells results in dose-dependent induction of arteriogenesis and vascular network formation in various tissues, including ischemic myocardium. In the mature vascular system, the endothelium is supported by mural cells, with the smallest capillaries partially covered by solitary pericytes, and arteries and veins surrounded by single or multiple layers of vascular smooth muscle cells. Pericytes coexpress a-SMA and STRO-1 surface markers, consistent with a shared lineage identity with stromal/mesenchymal progenitors (8). The perivascular in vivo location of human mesenchymal lineage precursors, together with their coexpression of markers of both endothelial and smooth muscle lineage cells and their multipotential capabilities, raise the intriguing possibility that mesenchymal lineage precursors may be true progenitors of the vascular tree.

The intimate proximity of human perivascular mesenchymal lineage precursors to vascular endothelium suggests that each cell type influences the biology of the other. Migration of mesenchymal lineage precursors and formation of a pericyte coating in physical continuity with the 
A
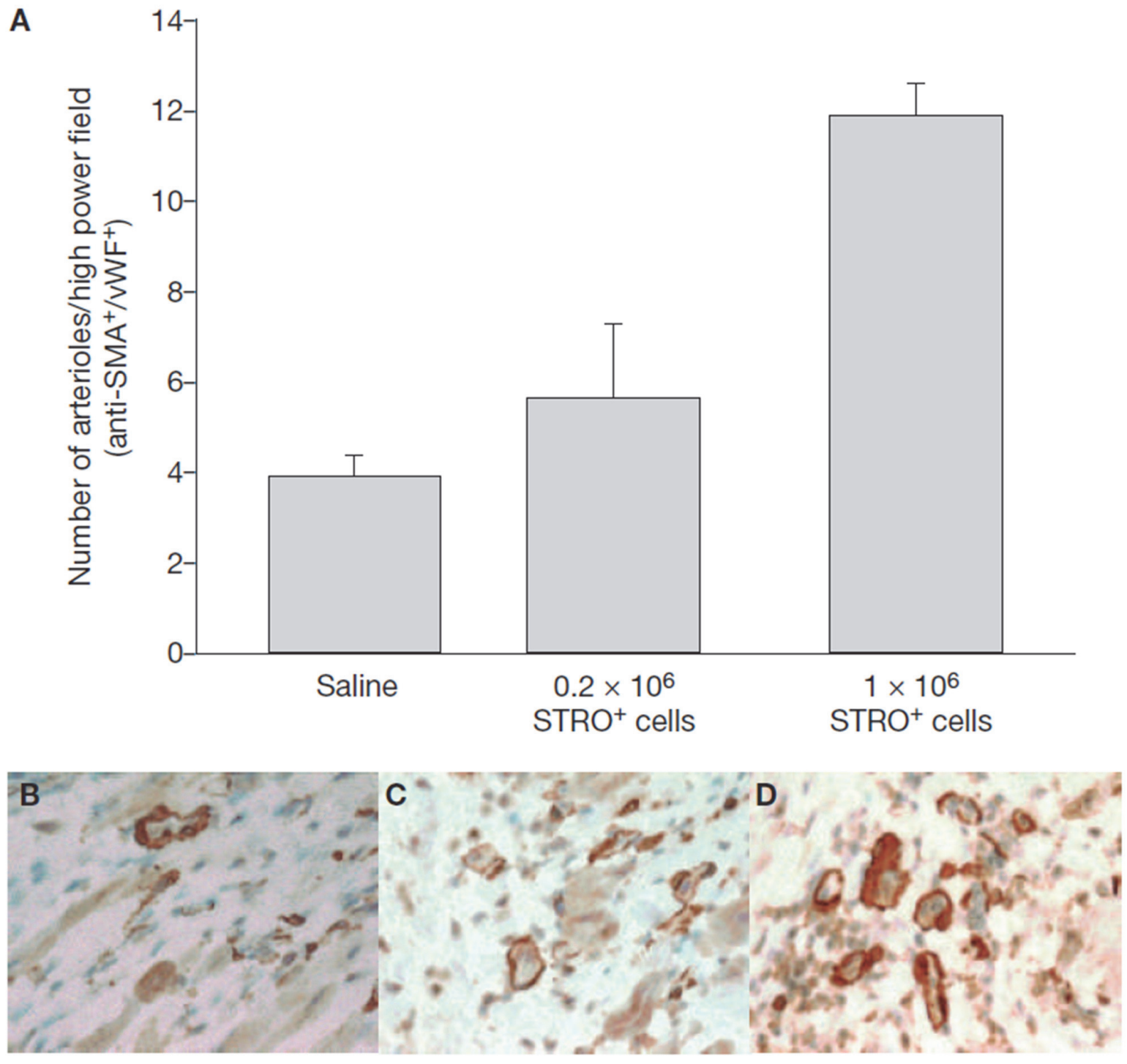

Saline

\section{$0.2 \times 10^{6}$ $\mathrm{STRO}^{+}$cells}

\section{$1 \times 10^{6}$ \\ $\mathrm{STRO}^{+}$cells}

Figure 2. Dose-dependent effect of STRO-1 $1^{\text {bright }}$ cells on myocardial neovascularization. To examine whether induction of angiogenesis and arteriogenesis could be extended to other tissues, and was associated with biological significance, cultured progeny of STRO-1-selected cells were injected by direct intramyocardial injection into the peri-infarct regions of the ischemic hearts in athymic nude rats who had undergone ligation of the left anterior descending coronary artery 2 days earlier. Animals injected with $1 \times 10^{6}$ STRO- $1^{\text {bright }}$ cells (D) demonstrated threefold greater numbers of arterioles at the peri-infarct region than animals injected with saline $(\mathrm{B} ; \mathrm{P}<0.01)$. In contrast, animals injected with only $0.2 \times 10^{6} \mathrm{STRO}-1^{\text {bright }}$ cells (C), delivered in a total of $1 \times 10^{6}$ unfractionated cultured progeny of STRO-1-selected cells, induced only $50 \%$ greater numbers of arterioles at the peri-infarct region than saline $(\mathrm{P}<0.05)$, indicating that STRO$1^{\text {bright }}$ cells have a dose-dependent effect on arteriolar induction in the ischemic heart. Anti-SMA, antismooth-muscle-actin; vWF, von Willebrand's factor.

nascent vascular network is dependent on production of endothelial growth factor and plateletderived growth factor $B$ by nascent endothelial tubes (9). Conversely, maintenance of vessel integrity, stabilization, and prevention of vessel pruning is dependent on pericyte coating of the microvessel (9).

A major limitation to successful cellular therapy in animal models of myocardial damage has been the inability of the introduced donor cells to survive in their host environment because of the lack of a sufficient vascular supply. Recent studies have shown that development of thin-walled capillaries in ischemic myocardium following transplantation of hematopoietic lineage endothelial precursors enhances survival of endogenous cardiomyocytes $(10,11)$. Moreover, transplanting cultured embryonic cardiomyocytes that incorporate vascular structures in vivo results in significantly greater cell survival and protection against apoptosis (12). Finally, in situations where 

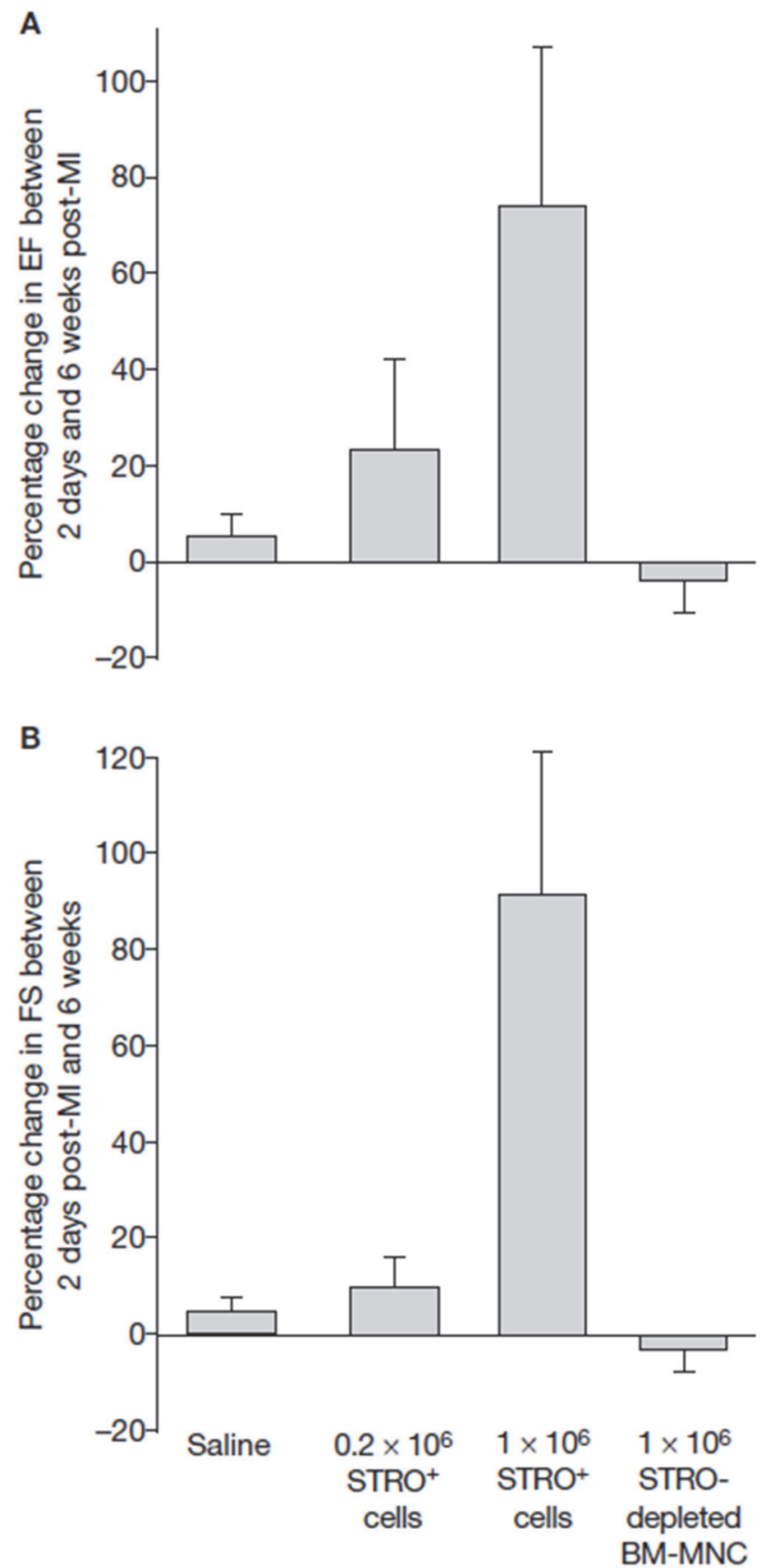

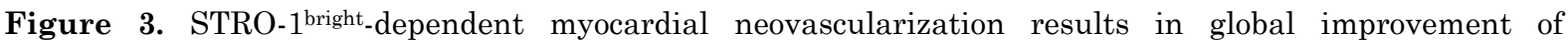
parameters of myocardial function. Injection of $0.2 \times 10^{6}$ and $1 \times 10^{6}$ STRO- $1^{\text {bright }}$ cells resulted in dosedependent improvement in (A) ejection fraction (EF) and (B) fractional shortening (FS) at 2 and 6 weeks, as measured by echocardiography performed and analyzed by a technician blinded to the treatments, compared with saline-treated animals $(\mathrm{P}<0.01)$ and animals treated with STRO-1-depleted fresh bone marrow mononuclear cells $(\mathrm{P}<0.01)$. BM-MNC, bone marrow mononuclear cells; MI, myocardial infarction. 
transplanted cardiomyocyte precursors contained an admixture of cells also giving rise to vascular structures, survival and function of the newly formed cardiomyocytes have been significantly augmented (13)

In the present study, we showed that implantation of STRO-1 ${ }^{\text {bright }}$ mesenchymal precursors into the acutely ischemic myocardium was accompanied not only by arteriogenesis, but also by sustained improvement in both global systolic and global diastolic parameters of cardiac function. While not directly examined, these results suggest a direct effect on regeneration of endogenous, mature cardiomyocytes and/or on survival or differentiation of cardiomyocyte precursors. Alternatively, both the functional improvement witnessed and the regeneration of cardiomyocytes may depend on paracrine secretion rather than direct cell-to-cell interactions. While assessment of global function using echocardiography is somewhat limited, further studies using invasive hemodynamic measures may shed additional light on the mechanism of systolic and diastolic recovery.

\section{CONCLUSION}

Cellular therapies for the treatment of ischemic cardiomyopathy will probably need to address two interdependent processes: first, a renewable source of proliferating, functional cardiomyocytes, and, secondly, the development of a network of capillaries and larger-size blood vessels for supply of oxygen and nutrients to both the chronically ischemic, endogenous myocardium and to the newly implanted cardiomyocytes. To achieve these end points, a common cellular source for regenerating cardiomyocytes, vascular structures, and supporting cells such as pericytes and smooth muscle cells would be ideal. The mesenchymal lineage precursor cell may be an appropriate candidate for such a cellular source.

\section{REFERENCES}

1. C. J. Drake, J. E. Hungerford, C. D. Little, Morphogenesis of the first blood vessels. Annals of the New York Academy of Sciences 857, 155 (1998/10, 1998).

2. J. Hungerford, C. Little, Developmental biology of the vascular smooth muscle cell: Building a multilayered vessel wall. Journal of Vascular Research 36, 2 (1999).

3. M. Bergwerff, M. E. Verberne, M. C. DeRuiter, R. E. Poelmann, A. C. Gittenberger-de-Groot, Neural crest cell contribution to the developing circulatory System : Implications for vascular morphology? Circulation research 82, 221 (1998/02/09, 1998).

4. P. J. Simmons, S. Gronthos, A. Zannettino, S. Ohta, S. Graves, Isolation, characterization and functional activity of human marrow stromal progenitors in hemopoiesis. Progress in clinical and biological research 389, 271 (1994).

5. R. J. A. Filshie, A. C. W. Zannettino, V Makrynikola, S. Gronthos, A. J. Henniker, L. J. Bendall, D. J. Gottlieb, P. J. Simmons, K. F. Bradstock, MUC18, a member of the immunoglobulin superfamily, is expressed on bone marrow fibroblasts and a subset of hematological malignancies. Leukemia 12, 414 (1998/03, 1998).

6. S. Gronthos, M. Mankani, J. Brahim, P. G. Robey, S. Shi, Postnatal human dental pulp stem cells (DPSCs) in vitro and in vivo. Proceedings of the National Academy of Sciences 97, 13625 (2000/11/21, 2000).

7. S. Gronthos, Molecular and cellular characterisation of highly purified stromal stem cells derived from human bone marrow. Journal of cell science 116, 1827 (2003/03/18, 2003).

8. S. Shi, S. Gronthos, Perivascular niche of postnatal mesenchymal stem cells in human bone marrow and dental pulp. Journal of Bone and Mineral Research 18, 696 (2003/04/01, 2003).

$9 . \quad$ L. E. Benjamin, I. Hemo, E. Keshet, A plasticity window for blood vessel remodelling is defined by pericyte coverage of the preformed endothelial network and is regulated by PDGF-B and VEGF. Development 125, 1591 (May, 1998).

10. A. A. Kocher, M. D. Schuster, M. J. Szabolcs, S. Takuma, D. Burkhoff, J. Wang, S. Homma, N. M. Edwards, S. Itescu, Neovascularization of ischemic myocardium by human bone-marrowderived angioblasts prevents cardiomyocyte apoptosis, reduces remodeling and improves cardiac function. Nature medicine 7, 430 (2001/04, 2001).

11. M. D. Schuster, A. A. Kocher, T. Seki, T. P. Martens, G. Xiang, S. Homma, S. Itescu, Myocardial neovascularization by bone marrow angioblasts results in cardiomyocyte regeneration. American Journal of PhysiologyHeart and Circulatory Physiology 287, H525 (2004/08, 2004).

12. M. G. Klug, M. H. Soonpaa, G. Y. Koh, L. J. Field, Genetically selected cardiomyocytes from differentiating embronic stem cells form stable intracardiac grafts. Journal of Clinical Investigation 98, 216 (1996/07/01, 1996).

13. J. Hescheler, B. K. Fleischmann, M. Wartenberg, W. Bloch, E. Kolossov, G. Ji, K. Addicks, H. Sauer, Establishment of ionic channels and signalling cascades in the embryonic stem cellderived primitive endoderm and cardiovascular system. Cells Tissues Organs 165, 153 (1999). 


\section{Appendix 2}

Therapeutic effects of human STRO-3selected mesenchymal precursor cells and their soluble factors in experimental myocardial ischemia.

Journal of Cellular and Molecular Medicine. 2011 Oct; 15(10):211729.

Fiona See, Tetsunori Seki, Peter J. Psaltis, Hugo P. Sondermeijer, Stan Gronthos, Andrew C.W. Zannettino, Klaas M. Govaert, Michael D. Schuster, Paul A. Kurlansky, Darren J. Kelly, Henry Krum, Silviu Itescu. 


\section{ABSTRACT}

Stromal precursor antigen (STRO)-3 has previously been shown to identify a subset of adult human bone marrow (BM)-derived mesenchymal lineage precursors, which may have cardioprotective potential. We sought to characterize STRO-3-immunoselected and culture-expanded mesenchymal precursor cells (MPCs) with respect to their biology and therapeutic potential in myocardial ischemia. Immunoselection of STRO- $3^{+}$MPCs enriched for fibroblastic colony forming units from unfractionated BM mononuclear cells (MNCs). Compared to mesenchymal stem cells conventionally isolated by plastic adherence, MPCs demonstrated increased proliferative capacity during culture expansion, expressed higher levels of early 'stem cell' markers and various proangiogenic and cardioprotective cytokines, and exhibited greater trilineage developmental efficiency. Intramyocardial injection of MPCs into a rat model of myocardial infarction (MI) promoted left ventricular recovery and inhibited left ventricular dilatation. These beneficial effects were associated with cardioprotective and pro-angiogenic effects at the tissue level, despite poor engraftment of cells. Treatment of MI rats with MPC-conditioned medium (CM) preserved left ventricular function and dimensions, reduced myocyte apoptosis and fibrosis, and augmented neovascularization, involving both resident vascular cells and circulating endothelial progenitor cells (EPCs). Profiling of CM revealed various cardioprotective and pro-angiogenic factors, which had biological activity in cultures of myocytes, tissue-resident vascular cells and EPCs. Prospective immunoselection of STRO- $3^{+}$MPCs from BM MNCs conferred advantage in maintaining a population of immature MPCs during ex vivo expansion. Transplantation of culture-expanded MPCs into the post-MI heart resulted in therapeutic benefit, attributable at least in part to paracrine mechanisms of action. Thus, MPCs represent a promising therapy for myocardial ischemia.

\section{INTRODUCTION}

Mesenchymal stem/progenitor cells (MSCs), derived from adult human bone marrow (BM), represent a leading strategy in the development of cell-based therapies for ischemic heart disease. The salutary effects of MSC administration in animal models of myocardial infarction (MI) include recovery of left ventricular function and attenuation of left ventricular remodelling, associated with augmentation of endogenous cardioprotective processes, such as neovascularization, myocyte survival and activation of resident cardiac progenitor cells (1-3). MSC differentiation into cardiomyocyte and endothelial lineage cell types are unlikely to contribute significantly to these therapeutic benefits, given the infrequency of this phenomenon and the typically low engraftment rates of transplanted cells (4-6). Growing evidence indicates that the cardioprotective and proangiogenic effects of MSC therapy may be attributed, at least in part, to paracrine-based mechanisms of action $(7,8)$. Clinical application of MSC therapy is favoured by the ready availability of source tissue, the ease of isolation and culture expansion of cells to therapeutically relevant numbers and their ability to evade immune recognition and response (9).

Conventional methods to isolate MSCs from BM mononuclear cells (MNCs) entail initial selection by plastic adherence. This approach yields a starting population of cells heterogeneous in morphology, immunophenotype and biological activity, including fibroblastic colony forming unit (CFU-f), developmental and proliferative efficiencies (10). Culture expansion of MSCs is associated with down-regulation of stem cell markers, decline of proliferative and differentiation capacities and ultimately cell senescence $(11,12)$. An alternative approach to MSC isolation involves prospective immunoselection of MSCs on the basis of a specific cell surface antigen, with the goal of isolating a more homogenous cell set with respect to biology and function. This strategy may be advantageous in maintaining the population of precursor cells of interest during culture expansion, and may in turn enhance therapeutic outcome (13). Antigenic definition of MSCs typically relies upon a panel of surface molecules, including co-expression of CD105, CD73 and CD90, and simultaneous negativity for CD45, CD34, CD14/CD11b, CD79a/CD19 and HLA-DR, despite these markers individually being non-specific for $\operatorname{MSCs}(14,15)$.

A number of novel candidate markers have been investigated as targets for direct selection of MSCs, including stromal precursor antigen (STRO)1, STRO-3, CD49a and vascular cell adhesion marker (VCAM)-1(13, 16-18). Growing evidence suggests that STRO-1 marks an immature precursor cell type, which resides in the perivascular niche of human $\operatorname{BM}(16,19)$. STRO-1 expression correlates with various stem cell characteristics including fibroblastic clonogenicity, multipotentiality, telomerase expression and proliferative capacity $(11,16)$. In the context of 
myocardial ischemia, STRO- $1^{\text {bright }}$ cells may represent a candidate cell type for therapy because intramyocardial delivery of these cells to nude rats post-MI dose-dependently augmented left ventricular functional recovery and arteriolar density, compared to treatment with STRO-1depleted MNCs (2). These beneficial effects after MI may be attributable, at least in part, to soluble factors secreted by STRO-1 $1^{\text {bright }}$ cells since a recent report demonstrated STRO-1 expression to be a determinant of cardioprotective and pro-angiogenic paracrine activity (13). Therefore, strategies to select for STRO-1 ${ }^{\text {bright }}$ cells may represent an important step forward in the development of STRO-1-based therapy.

The recently described STRO-3 monoclonal antibody, which reacts with a novel epitope of human tissue non-specific alkaline phosphatase, has been shown to identify a subset of STRO-1 $1^{\text {bright }}$ BM MNCs, designated 'mesenchymal precursor cells' (MPCs) (17). Freshly isolated STRO$1^{\text {bright} / S T R O}-3^{+}$MPCs comprise virtually all CFU-f in $\mathrm{BM}$ MNC and demonstrate trilineage developmental potential in in vitro and in vivo assays (17). However, given the low incidence of MPCs, development of these cells for potential therapy after MI necessitates culture expansion to clinically relevant numbers.

Based on this previous body of work, we hypothesized that culture-expanded MPCs would demonstrate a cardioprotective phenotype. Accordingly, we examined the biological characteristics of culture-expanded MPCs in vitro, and we evaluated the therapeutic potential and mechanisms of action of MPCs in a nude rat model of MI.

\section{MATERIALS AND METHODS}

Full details are provided in the Supporting Information section.

\subsection{IN VITRO BIOLOGICAL CHARACTERIZATION OF MSC AND MPCS}

The MNC fraction from human BM aspirates was used to prepare (1) MSCs by conventional, plasticadherence isolation (10) and (2) MPCs by STRO-3based prospective immunoselection by magnetic activated cell sorting (17). Following the establishment of CFU-f, passage (P) 0 MSCs and MPCs were plated as single cell suspensions for $e x$ vivo expansion. P4 MSCs and MPCs were compared for: (i) CFU-f efficiency; (ii) in vitro expansion potential; (iii) immunophenotypic profile; (iv) genetic expression of stem cell-related transcripts and (v) developmental capacities under osteogenic, chondrogenic and adipogenic inductive conditions.

\subsection{ANIMAL STUDIES}

Figure S1 illustrates the three animal experiments performed in this study. An athymic nude rat model of MI induced by permanent coronary artery ligation was used in each experiment. In the 14 day MPC study, animals received either MPCs $\left(1 \times 10^{6}\right)$ suspended in saline $(\mathrm{N}=10)$ or saline as vehicle control $(\mathrm{N}=12)$ by intramyocardial injection at $48 \mathrm{~h}$ after MI. In the 7 day conditioned medium (CM) studies, animals were treated with intramyocardial injections of either concentrated CM derived from $1 \times 10^{6} \mathrm{MPCs}$ (P5) cultured in serum-free (SF) Minimum Essential Medium alpha medium (aMEM) $(\mathrm{N}=12)$ or control SF-aMEM $(\mathrm{N}=10)$ at $48 \mathrm{~h}$ after MI. In the endothelial progenitor cell (EPC) homing study, $1 \times 10^{6}$ human EPCs suspended in saline were delivered by intracardiac injection into the left ventricles of rats at $48 \mathrm{~h}$ after MI. EPCs were allowed to circulate for $15 \mathrm{~min}$. prior to intramyocardial injections of $\mathrm{CM}$ or control medium ( $\mathrm{N}=12$ /group).

\subsection{CYTOKINE PROFILING AND IN VITRO BIOLOGICAL ACTIVITY OF MPC-CM}

Soluble factors present in CM were profiled using a membrane-based antibody array. Concentrations of interleukin (IL)-6, VEGF and monocyte chemotactic protein (MCP)-1 were determined using a spectral bead-based immunoassay. The direct effects of CM on neonatal rat cardiac myocytes, human umbilical vein endothelial cells (HUVECs), A7r5 rat vascular smooth muscle cells (rVSMCs) and EPCs were examined in cell culture experiments, in the presence or absence of neutralizing antibodies raised against IL-6, MCP-1 or VEGF.

\section{RESULTS}

\subsection{BIOLOGICAL CHARACTERIZATION OF STRO-3-IMMUNOSELECTED AND CULTURE EXPANDED MPCS}

STRO- $3^{+}$cells were immunoselected from the MNC fraction of adult human BM aspirate. Although CFU-f were detected in unfractionated MNCs, STRO-3-immunoselection resulted in an 8-fold enrichment of CFU-f (unfractionated versus STRO- $\left.3^{+}, \mathrm{P}<0.05\right)$. The STRO-3-depeleted fraction of MNCs was negative for CFU-f (STRO- $3^{+}$versus STRO-3 $^{-}, \quad \mathrm{P}<0.05$ ) (Fig. $1 \mathrm{~A}$ ). Cultures of immunoselected STRO- $3^{+}$MPCs and MSCs isolated from MNCs by plastic adherence were expanded up to nine passages. In comparison to MSCs, population doublings in cultures of STRO- $3^{+}$MPCs tended to be higher over passages $1-6$, and were significantly increased from passages 7-9 $(\mathrm{P}<0.05)$ (Fig. 1B). At passage 4, cell surface expression of STRO-1 and STRO-3 each tended to be higher in MPCs compared with MSCs (Fig. 1C). Culture-expanded MPCs demonstrated increased gene expression of a range of stem cell markers, Twist transcription factor-1 (TWIST-1), DERMO-1 (TWIST-2), Msx2, core-binding factor (CBFA)-1 and telomerase reverse transcriptase (TERT), relative to MSCs (Fig. 1D). Levels of transcripts for stromal cell-derived factor (SDF)-1, hepatocyte growth factor (HGF)-1, insulin-like growth factor (IGF)-1, VEGF and IL-6, were also elevated in passaged MPCs above MSCs (Fig. 1E). Culture-expanded MPCs exhibited a greater capacity to undergo osteogenic $(\mathrm{P}<0.05)$ (Fig. 1F), adipogenic $(\mathrm{P}<0.05)$ (Fig. $1 \mathrm{G})$ and chondrogenic $(\mathrm{P}<0.05)$ (Fig. $1 \mathrm{H})$ differentiation. 

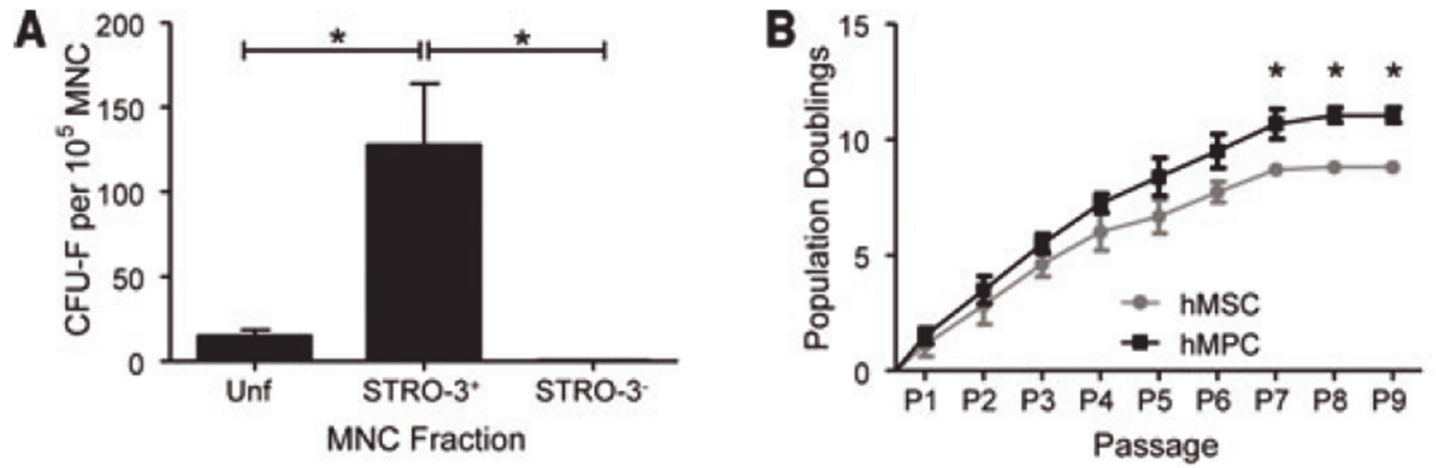

C
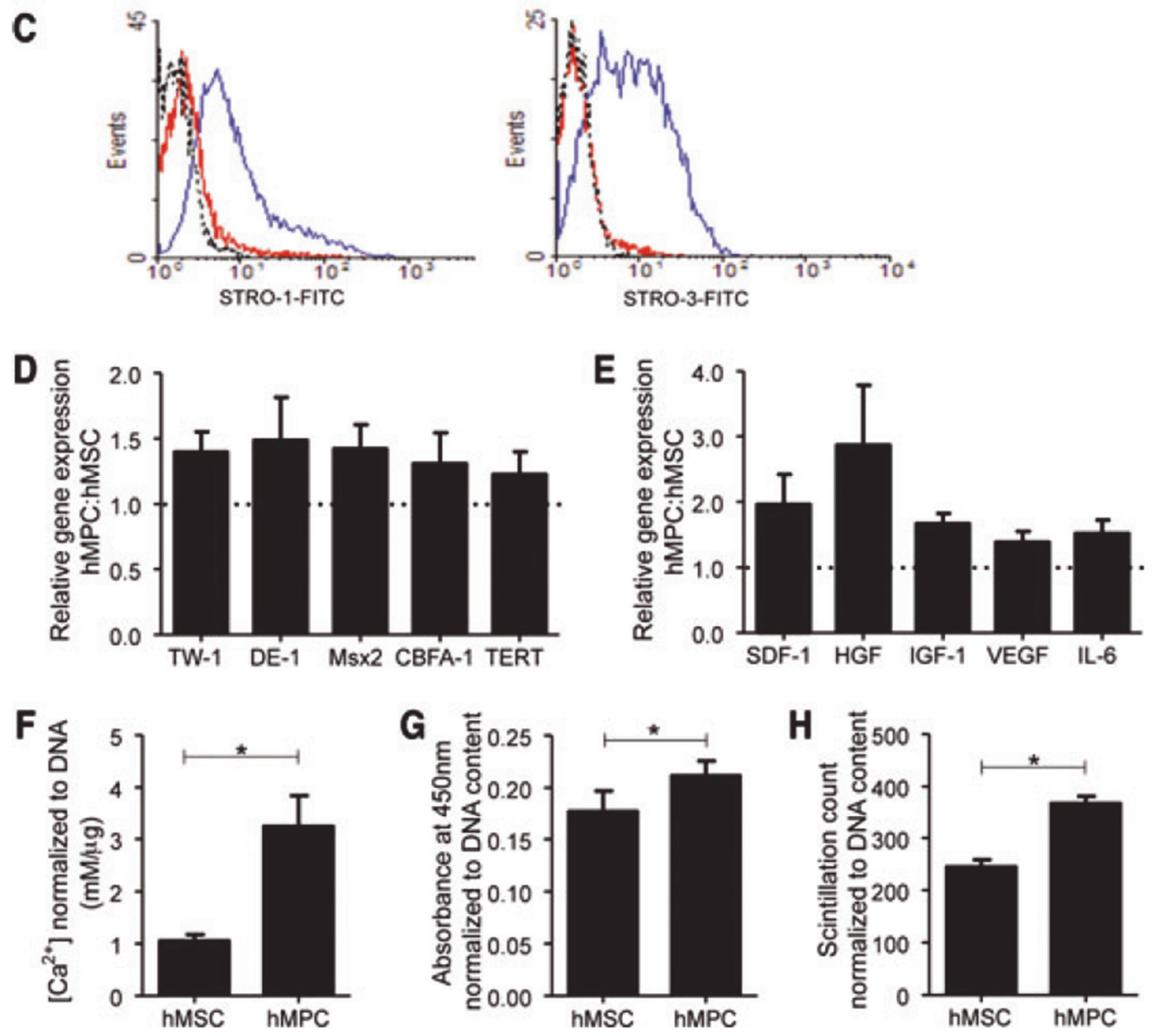

Figure 1. Biological comparisons between MSCs and MPCs. (A) The clonogenic efficiency of each MNC fraction. Results shown are the mean \pm S.E.M. number of CFU-f per $10^{5}$ cells plated for unfractionated (Unf), STRO- $3^{+}$and STRO-3-depleted (STRO-3 ${ }^{-}$) MNC ( ${ }^{*} \mathrm{P}<0.001$, average of five donor experiments). (B) Mean number of population doublings ( \pm S.E.M.) of MSCs and MPCs during ex vivo culture from P0 to senescence $\left({ }^{*} \mathrm{P}<0.05\right.$, average of three donor experiments). (C) Examples of flow cytometric histograms comparing MPCs and MSCs from the same donor, for surface STRO-1 and STRO-3 expression at P4. Dotted line: isotype control. Red line: MSCs. Blue line: MPCs. P4 MPCs gene expression of various immature 'stem cell' markers (D) and cytokines (E). Results are presented as mean ratio \pm S.E.M. of gene expression in MPC relative to MSC (average of three donor experiments). P4 MSC and MPC differentiation capacity for mineralization $(\mathrm{F})$, adipogenesis $(\mathrm{G})$ and glycosaminoglycan synthesis $(\mathrm{H})$, under the respective in vitro inductive conditions. Data are presented as mean \pm S.E.M. ( ${ }^{*} \mathrm{P}<0.05$, average of three donor experiments). 
A

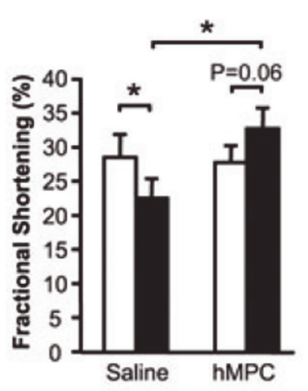

$24 \mathrm{~h}$ post-MI

2 weeks post-MI

D

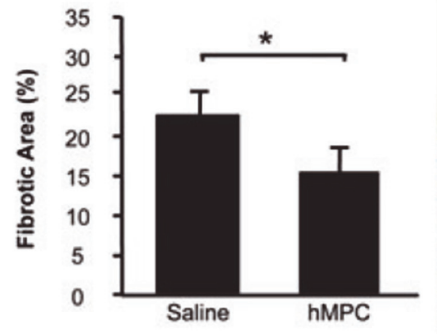

B
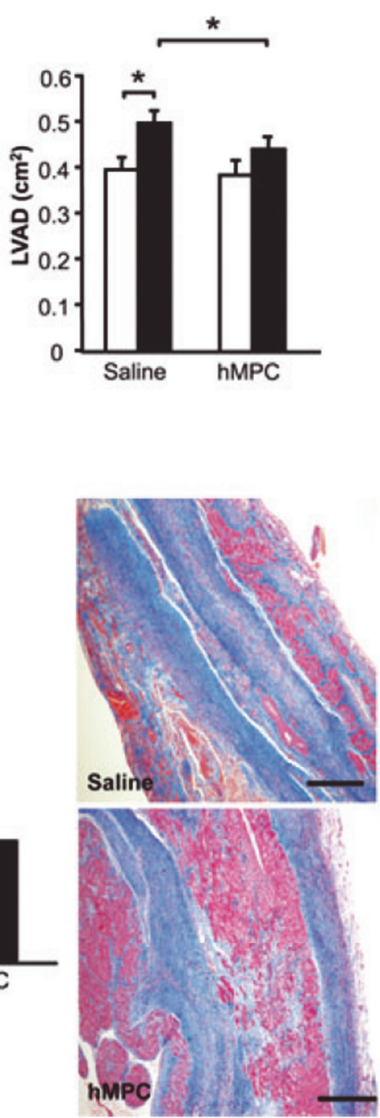

C

E
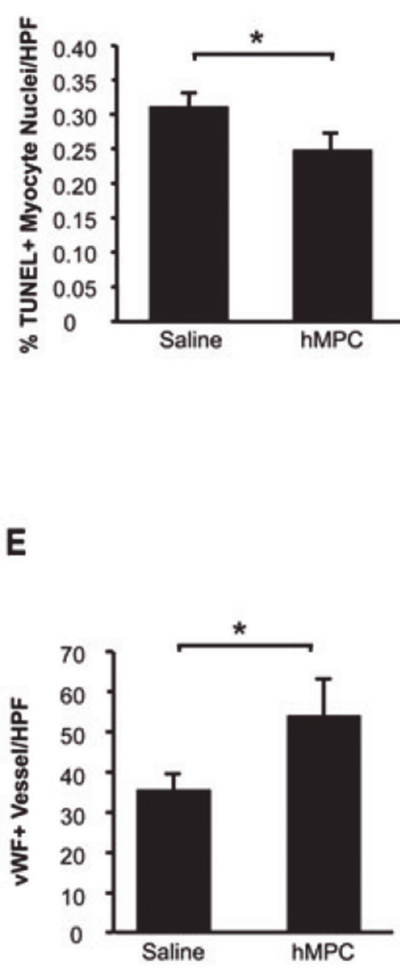
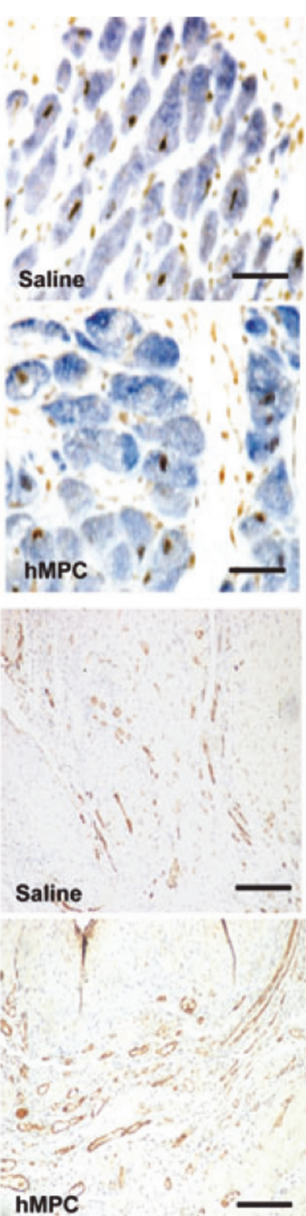

Figure 2. Intramyocardial injection of MPCs after MI attenuates left ventricular dysfunction and remodelling. Echocardiography was performed to assess FS (A) and LVAD (B). Myocardial sections were stained to count TUNEL ${ }^{+}$apoptotic myocytes (C). Masson's Trichrome-stained sections were examined for myocardial fibrosis (D). vWF+vessels per high power field were quantified (E). For (A)-(E), data are represented as mean \pm S.E.M. $\mathrm{N}=10$-12/group. ${ }^{*} \mathrm{P}<0.05$.

\subsection{INTRAMYOCARDIAL INJECTION OF MPCS AFTER MI IN NUDE RATS ATTENUATES LEFT VENTRICULAR DYSFUNCTION AND REMODELLING}

The therapeutic potential of culture-expanded MPCs was examined in a nude rat model of MI. Echocardiographic measurements of fractional shortening (FS) and left ventricular diastolic area (LVAD) obtained at $24 \mathrm{~h}$ post-MI indicated that rats randomized to the two study groups were well matched prior to treatment (Fig. 2A, B). Left ventricular function declined following saline injections $(-19 \%, 24 \mathrm{~h}$ versus 2 weeks, $\mathrm{P}<0.05)$ (Fig. 2A). In contrast, FS was preserved in MPC-treated rats $(+20 \%, 24 \mathrm{~h}$ versus 2 weeks, $\mathrm{P}=0.06)$ and was higher compared to saline-treated controls at the end of the 2 week study (MPC versus saline, $\mathrm{P}<0.05)$. MPC-treatment after MI also attenuated left ventricular dilatation $(+17 \%, 24 \mathrm{~h}$ versus 2 weeks, $\mathrm{P}=\mathrm{NS})$ compared to saline treatment $(+27 \%$, $24 \mathrm{~h}$ versus 2 weeks, $\mathrm{P}<0.05$ ), and resulted in significantly reduced $\mathrm{LVAD}$ at the end of the study period (MPC versus saline, $\mathrm{P}<0.05$ ) (Fig. 2B). At the tissue level, MPC-treated hearts exhibited fewer apoptotic myocyte nuclei at the infarct border compared with saline treated hearts $(\mathrm{P}<0.05)$ (Fig. $2 \mathrm{C})$, as well as less extensive areas of fibrosis $(\mathrm{P}<0.05)$ (Fig. 2D) and augmentation of peri-infarct capillary density $(\mathrm{P}<0.05)$ (Fig. $2 \mathrm{E})$.

MPC engraftment in myocardial tissue at 2 weeks following transplantation was examined by immunostaining for human mitochondrial protein. However, analysis of stained tissues was confounded by the presence of false positive signals in vehicle-treated MI hearts. These signals were likely attributable to inflammatory cells, given their localization in the infarct region and granular staining pattern (data not shown). As an alternative approach to assessing MPC engraftment, we employed PCR to detect human-specific ribosomal protein L32 (hRPL32) in DNA extracts from rat MI hearts at $24 \mathrm{~h}(\mathrm{~N}=2)$ and 7 days $(\mathrm{N}=2)$ following intramyocardial injection of MPCs. MPCs were positive for hRPL32, with band intensities corresponding with cell number (Fig. 3). DNA from saline-treated rat heart was negative for RPL32. Only weak signals for hRPL32 were detected in MPC-treated hearts at $24 \mathrm{~h}$ and 7 days following 


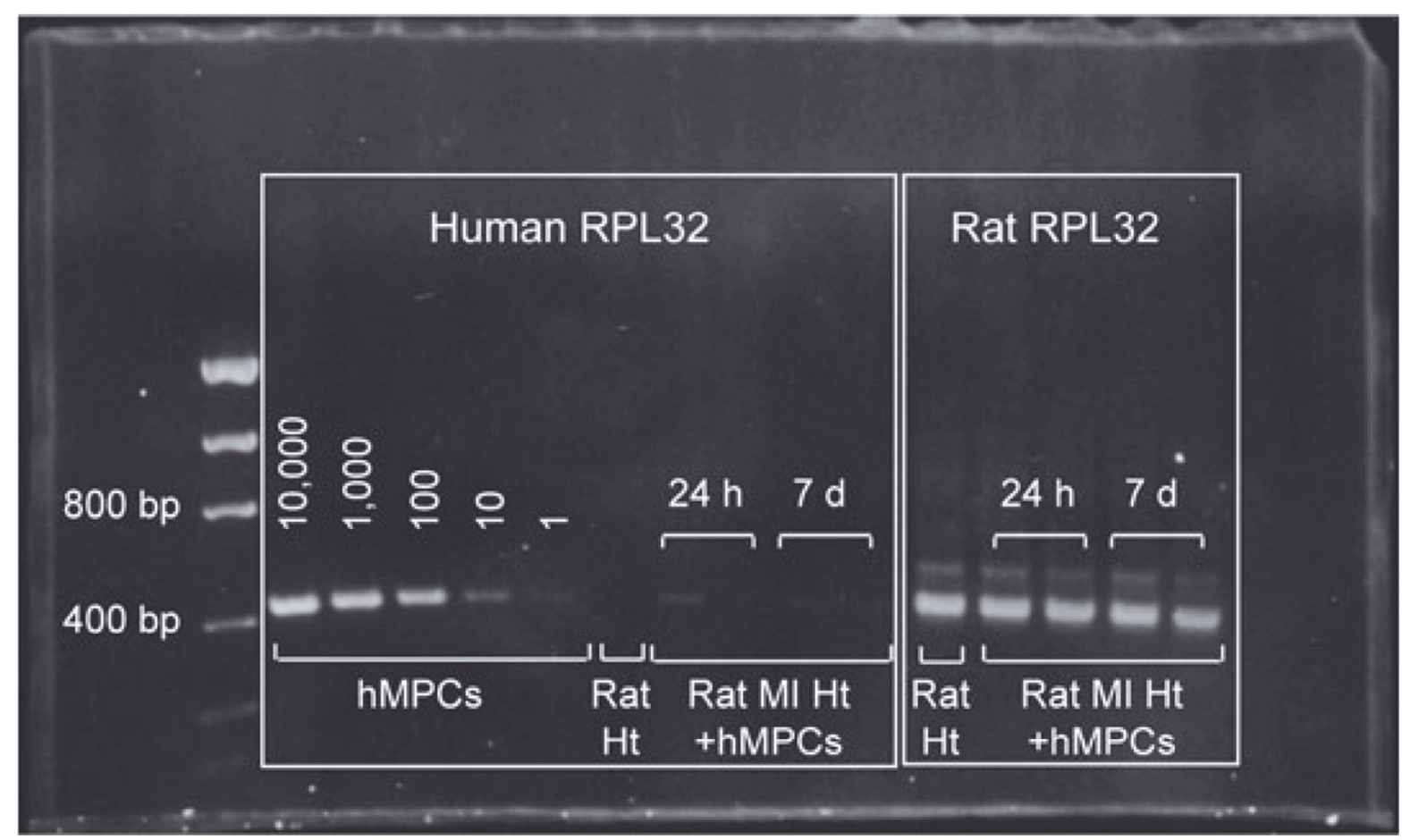

Figure 3. Human MPCs engraft poorly in rat ischemic myocardium. Human-specific RPL32 expression (384bp) in DNA extracts from known numbers of MPCs, untreated control rat heart (ht) and human MPC treated MI hearts harvested at $24 \mathrm{~h}(\mathrm{~N}=2)$ and 7 days $(\mathrm{N}=2)$ following intramyocardial injection, was determined by PCR. Rat-specific RPL32 was used as loading control.

injection, despite equal loading of samples indicated by comparable levels of rat-specific RPL32. These data indicate that rapid loss of MPCs occurs following direct intramyocardial injection at $48 \mathrm{~h}$ after MI.

\subsection{INTRAMYOCARDIAL INJECTION OF MPC-DERIVED CM AFTER MI PRESERVES LEFT VENTRICULAR FUNCTION AND STRUCTURE AND PROMOTES CARDIOPROTECTION AND NEOVASCULARIATION}

We went on to hypothesize that MPC-derived paracrine factors may augment endogenous repair mechanisms in the ischemic heart. MI rats received intramyocardial injections of MPC-conditioned medium (CM) or control medium at $48 \mathrm{~h}$ after MI. FS was similar in both groups prior to treatment, but declined following control medium treatment $(-16 \%, 24 \mathrm{~h}$ versus 1 week, $\mathrm{P}<0.05)$ (Fig. 4A). In contrast left ventricular function was preserved in MI rats treated with $\mathrm{CM}$, such that FS was higher in this group compared to controls at 1 week (CM versus control, $\mathrm{P}=0.05$ ). $\mathrm{LVAD}$ was also similar in both treatment groups at baseline (Fig. 4B). Although LVAD increased by $43 \%$ in control medium-treated rats $(24 \mathrm{~h}$ versus 1 week, $\mathrm{P}<0.05)$, left ventricular dilatation was attenuated in CM-treated animals $(+26 \%, 24 \mathrm{~h}$ versus 1 week, $\mathrm{P}<0.05$ ), which demonstrated significantly smaller left ventricular cavities at the end of the study ( $\mathrm{P}<0.05$ versus saline)

The benefits of $\mathrm{CM}$ on left ventricular function and remodelling over control were associated with reduced myocyte apoptosis in the peri-infarct region $(\mathrm{P}<0.05) \quad$ (Fig. $4 \mathrm{C})$, increased cross-sectional areas of surviving myocytes $(\mathrm{P}<0.05)$ (Fig. 4D) and reduced myocardial fibrosis $(\mathrm{P}<0.05)$ (Fig. 4E). CM-treatment after MI also resulted in enhanced myocardial neovascularization, associated with increased proliferation of resident vascular cells compared with control medium. Von Willebrand Factor (vWF)-positive vessel counts were higher in the peri-infarct region of CM-treated hearts compared with control medium treated counterparts $(\mathrm{P}<0.05)$ (Fig. 5A).

More specifically, CM-treated hearts demonstrated a higher proportion of $\mathrm{vWF}^{+}$vessels co-expressing rat-specific Ki67, a nuclear antigen expressed by proliferating cells, compared with controls $(\mathrm{P}<0.05) \quad$ (Fig. 5B). Intramyocardial injection of CM after MI also resulted in increases in both the density of a-smooth muscle actin (aSMA)-positive arterioles in the peri-infarct region $(\mathrm{P}<0.05)$ (Fig. 5C), as well as the proportion of $\mathrm{aSMA}^{+}$vessels co-expressing Ki67 $(\mathrm{P}=0.06)$ (Fig. 5D).

\subsection{MPC-CM AUGMENTS EPC MOBILIZATION AND HOMING AFTER MI}

To address the question of whether CM promotes endogenous EPC mobilization, peripheral blood was collected from MI rats in both treatment groups at the end of the 1 week study period. The concentration of circulating MNCs was increased following intramyocardial CM injection compared to control-medium treatment $(\mathrm{P}<0.05)$ (Fig. 6A). Counts of acLDL ${ }^{+}$lectin ${ }^{+}$EPCs derived from MNCs 
A

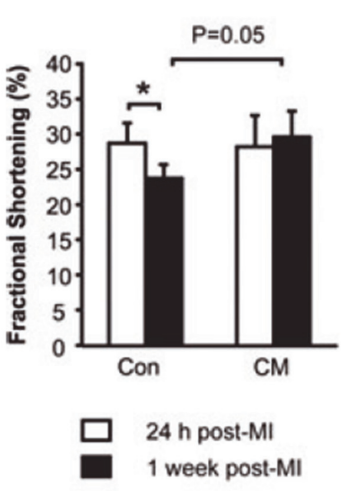

B

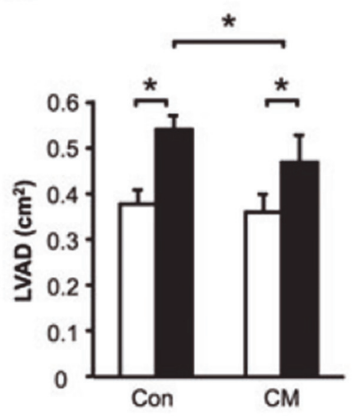

C


D

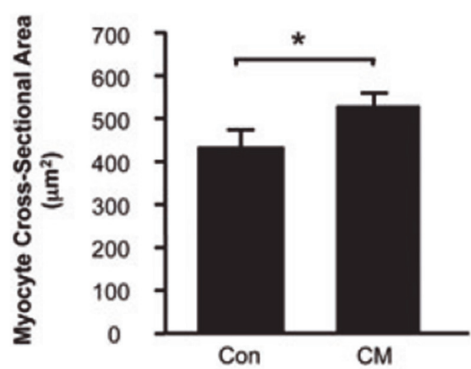

E

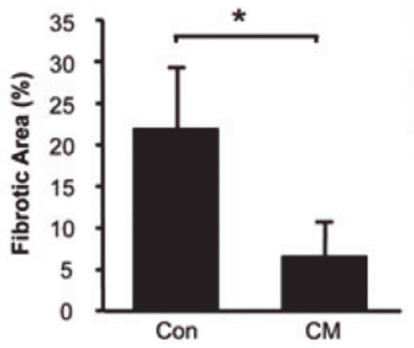

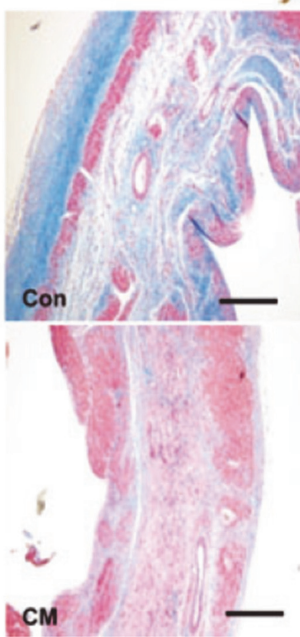

Figure 4. Intramyocardial injection of CM after MI attenuates left ventricular dysfunction and remodelling. Echocardiography was performed to assess FS (A) and LVAD (B). Myocardial sections were stained to count TUNEL $^{+}$apoptotic myocytes (C). Masson's Trichrome-stained sections were assessed for myocyte crosssectional areas (D) and myocardial fibrosis (E). Data are presented as mean \pm S.E.M. N=10-12/group.

of CM-treated MI rats were higher compared with those derived from control-treated counterparts $(\mathrm{P}<0.05)$ (Fig. 6B).

An additional study was undertaken to investigate the effects of CM on EPC homing to the ischemic heart. MI rats received intracardiac injections of $\mathrm{DiI}^{+}$human EPCs, which were allowed to circulate for $15 \mathrm{~min}$ prior to intramyocardial delivery of $\mathrm{CM}$ or control medium. At 5 days following injections, $\mathrm{DiI}^{+}$cells were found in the peri-infarct region of myocardial sections taken from both treatment groups. However CM-treated hearts demonstrated significantly higher numbers of $\mathrm{DiI}^{+}$cells compared to control medium-treated hearts (Fig. 6C). The increased presence of DiI ${ }^{+}$cells in CM-treated hearts was associated with increased capillary density ( $\mathrm{P}<0.05$, versus saline) (Fig. 6D).

\subsection{MPC-CM CONTAINS \\ CARDIOPROTECTIVE AND PRO- ANGIOGENIC FACTORS}

The cytokine profile of CM samples generated under serum-free culture conditions was determined using a membrane-based antibody array system. Detectable signals were semi-quantified by densitometric analysis and expressed relative to control medium. IL-6, VEGF and MCP-1 were among the factors expressed by MPCs at 2-fold or greater levels above control medium. The concentrations of these factors in $\mathrm{CM}$ were quantified: IL-6: $118.04 \pm 0.27 \mathrm{pg} / \mathrm{ml}$; MCP-1: $521.89 \pm 1.48 \mathrm{pg} / \mathrm{ml}$; VEGF: $33.95 \pm 2.98 \mathrm{pg} / \mathrm{ml}$.

The direct effects of CM on cardiac myocytes were examined in vitro. Hypoxic conditions induced apoptosis in myocytes cultured in ischemia-mimetic medium, as indicated by terminal deoxynucleotidyl transferase dUTP nick end labelling (TUNEL) (Fig. 7A). Myocyte apoptosis was reduced in cells pre-treated with $\mathrm{CM}+$ mouse IgG isotype control ( $\mathrm{CM}+\mathrm{mIgG}$ versus control, $\mathrm{P}<0.05)$. This protective effect of $\mathrm{CM}$ was partially abrogated by blockade of IL- 6 activity (CM+aIL-6 $\mathrm{MAb}$ versus $\mathrm{CM}+\mathrm{mIgG}, \mathrm{P}<0.05)$, though the number of $\mathrm{TUNEL}^{+}$cells in co-treated cultures remained lower than control medium-treated cells (CM+aIL-6 MAb versus control, $\mathrm{P}<0.05$ ).

CM stimulated hypertrophic growth of myocytes, as demonstrated by a marked increase in total cellular protein content, without significant change in DNA content $(\mathrm{CM}+\mathrm{mIgG}$ versus control, $\mathrm{P}<0.05$ ) (Fig. 7B). Neutralization of IL-6 attenuated the growth-promoting effect of CM (CM+aIL-6 MAb 
A

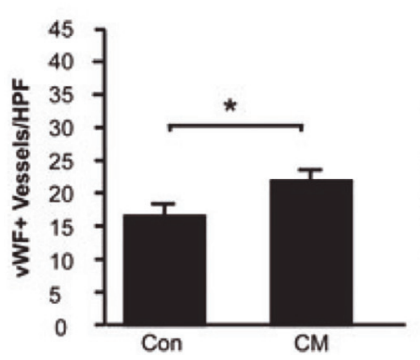

C

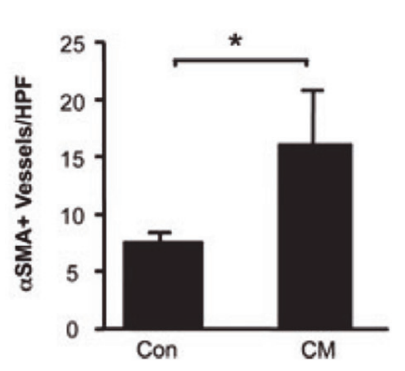

B
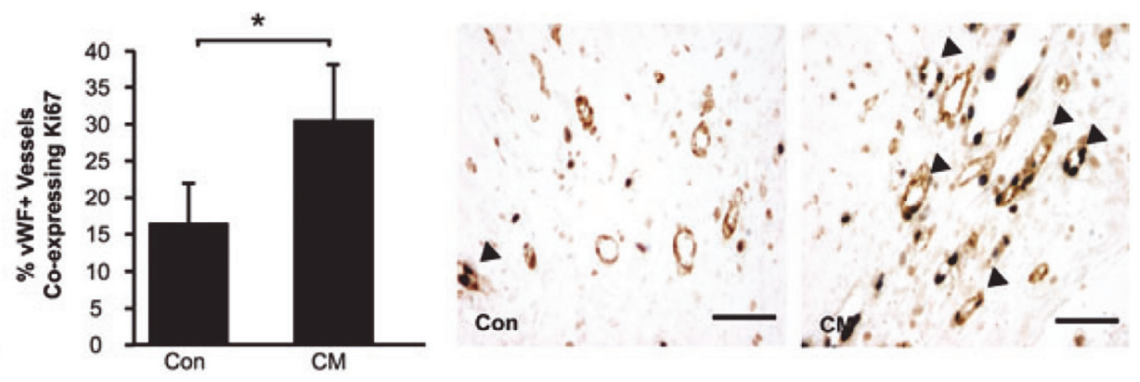

D

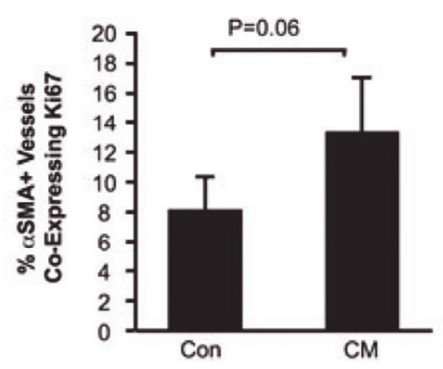

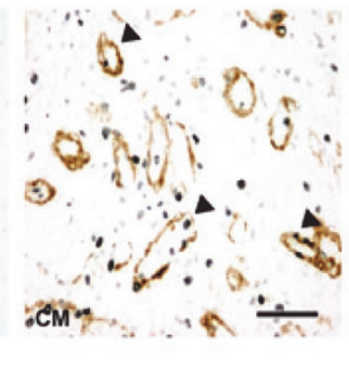

Figure 5. Intramyocardial injection of $\mathrm{CM}$ after $\mathrm{MI}$ promotes neovascularization of the ischemic myocardium. Myocardial sections were immunostained to identify capillaries and arterioles. $\mathrm{vWF}^{+}$vessels were counted (A). Proliferating $\mathrm{vWF}^{+}$vessels were identified by co-expression of the proliferating cell nuclear antigen Ki67 (arrow heads) (B). Arterioles were immunostained with aSMA (C). Serial sections were double stained for aSMA and Ki67 (arrow heads) (D). Data are presented as mean \pm S.E.M. N=1012/group. ${ }^{*} \mathrm{P}<0.05$.

versus $\mathrm{CM}+\mathrm{mIgG}, \mathrm{P}<0.05)$. However protein content in myocyte cultures treated with $\mathrm{CM}+\alpha \mathrm{IL}-6 \mathrm{MAb}$ remained greater than that in control-treated cells $(\mathrm{CM}+\alpha \mathrm{IL}-6 \mathrm{MAb}$ versus control, $\mathrm{P}<0.05)$. Consistent with these findings, phalloidin staining of myocytes treated with $\mathrm{CM}+\mathrm{mIgG}$ for $72 \mathrm{~h}$ demonstrated increased size and obvious striation and organization of the contractile protein, actin, into sarcomeric units (Fig. 7C). These morphological features were less pronounced in myocytes treated with CM+aIL-6 MAb. Cellular proliferation was increased in HUVECs treated with $\mathrm{CM}+\mathrm{mIgG}$ compared with control medium $(\mathrm{P}<0.05)$ (Fig. 8A). Blockade of VEGF activity partially inhibited this effect $(\mathrm{CM}+\alpha \mathrm{VEGF} \mathrm{MAb}$ versus $\mathrm{CM}+\mathrm{mIgG}, \mathrm{P}<0.05$; $\mathrm{CM}+\mathrm{aVEGF} \mathrm{MAb}$ versus control, $\mathrm{P}<0.05)$. Incomparison to control treatment, CM stimulated HUVEC migration (CM+mIgG versus control, $\mathrm{P}<0.05$ ), which was attenuated by an anti-VEGF antibody (CM+aVEGF MAb versus $\mathrm{CM}+\mathrm{mIgG}$, $\mathrm{P}<0.05$; $\mathrm{CM}+\alpha$ VEGF MAb versus control, $\mathrm{P}<0.05$ ) (Fig. 8B). CM also promoted HUVEC cord formation on growth factor-reduced Matrigel substrate (Fig. $8 \mathrm{C}$ and D). Neutralization of VEGF activity in CM disrupted the formation of these cord-like structures $(\mathrm{CM}+\alpha$ VEGF $\mathrm{MAb}$ versus $\mathrm{CM}+\mathrm{mIgG}, \mathrm{P}<0.05)$. $\mathrm{CM}$ increased rVSMC proliferation above controls $(\mathrm{CM}+\mathrm{mIgG}$ versus control, $\mathrm{P}<0.05) \quad$ (Fig. 8E). Anti-MCP-1 antibody partially reduced the proliferative effects of $\mathrm{CM} \quad(\mathrm{CM}+\alpha \mathrm{MCP}-1 \mathrm{MAb}$ versus $\mathrm{CM}+\mathrm{mIgG}, \quad \mathrm{P}<0.05 ; \quad \mathrm{CM}+\alpha \mathrm{MCP}-1 \quad \mathrm{MAb}$ versus control, $\mathrm{P}<0.05)$. In comparison to control medium, CM stimulated increased rVSMC chemotaxis $(\mathrm{CM}+\mathrm{mIgG}$ versus control, $\mathrm{P}<0.05)$ (Fig. $8 \mathrm{~F})$. Inhibition of MCP-1 activity attenuated this chemotactic effect (CM+aMCP-1 MAb versus $\mathrm{CM}+\mathrm{mIgG}, \quad \mathrm{P}<0.05)$. EPC proliferation was increased in cultures treated with $\mathrm{CM}$, above levels observed in unstimulated controls (CM+mIgG versus control, $\mathrm{P}<0.05$ ) (Fig. 9A). Neutralization of VEGF tended to inhibit this effect $(\mathrm{CM}+\mathrm{mIgG}$ versus $\mathrm{CM}+\mathrm{aVEGF} \mathrm{MAb}, \mathrm{P}<0.05)$. $\mathrm{CM}$ also exhibited chemotactic effects on EPCs $(\mathrm{CM}+\mathrm{mIgG}$ versus control, $\mathrm{P}<0.05$ ) (Fig. $9 \mathrm{~B}$ ), which were partly attenuated in $\mathrm{CM}+\alpha$ VEGF MAb $(\mathrm{CM}+\alpha \mathrm{VEGF} \mathrm{MAb}$ versus $\mathrm{CM}+\mathrm{mIgG}, \quad \mathrm{P}<0.05 ; \quad \mathrm{CM}+\alpha \mathrm{VEGF} \mathrm{MAb}$ versus control, $\mathrm{P}<0.05)$. $\mathrm{CM}$ increased survival of EPCs cultured under hypoxic conditions $(\mathrm{CM}+\mathrm{mIgG}$ versus control, $\mathrm{P}<0.05$ ) (Fig. 9C). This protective effect was reduced by blockade of VEGF $(\mathrm{CM}+\alpha$ VEGF $\mathrm{MAb}$ versus $\mathrm{CM}+\mathrm{mIgG}, \mathrm{P}<0.05) . \mathrm{CM}$ stimulated formation of cord-like structures in EPCs grown on Matrigel substrate (Fig. 9D). Blockade of VEGF inhibited formation of these structures $(\mathrm{CM}+\alpha$ VEGF MAb versus $\mathrm{CM}+\mathrm{mIgG}$, $\mathrm{P}<0.05)$.

\section{DISCUSSION}

In the present study, we examined the biological characteristics of the culture-expanded progeny of STRO-3-immunoselected MPCs and their therapeutic potential after MI. The key findings of this study are: (1) ex vivo-grown MPCs exhibited increased proliferative capacity, gene expression for various early stem cell markers and cytokines, and differentiation efficiency compared with 
A

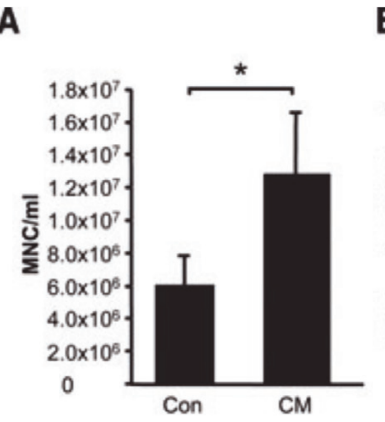

B

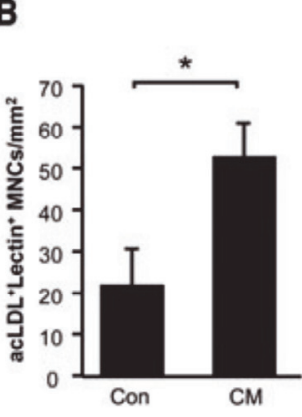

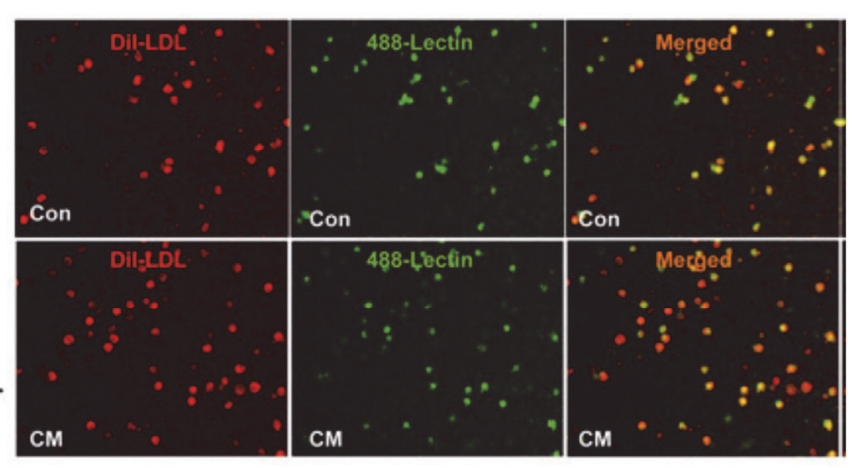

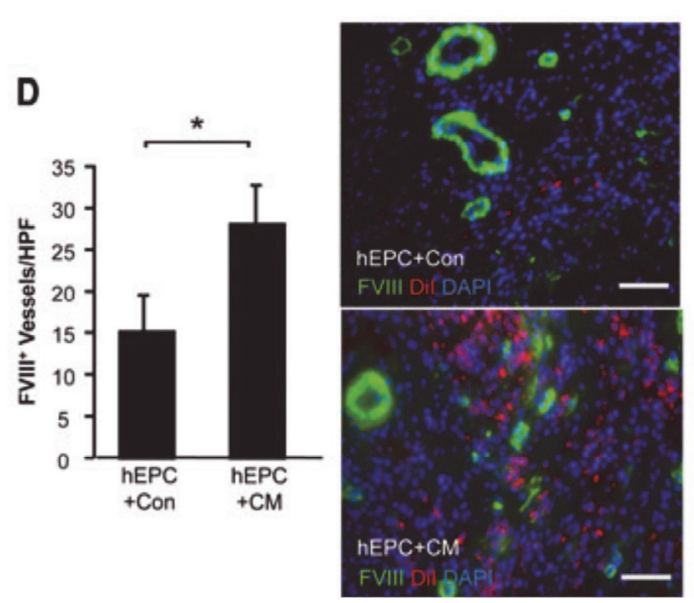

Figure 6. CM augments mobilization and homing of EPCs to the post-MI heart. To examine the effect of CM treatment on EPC mobilization, peripheral blood was sampled from rats at the end of the 1 week study and total MNC were counted (A). acLDL ${ }^{+}$lectin ${ }^{+}$EPCs cultured from the MNC fraction were counted (B). In a separate experiment, the effects of control medium or $\mathrm{CM}$ on $\mathrm{DiI}^{+} \mathrm{EPC}$ homing to the ischemic rat heart were examined. At 1 week after MI myocardial sections were examined for the presence of $\mathrm{DiI}^{+}$cells (C). Myocardial sections were stained to identify Factor VIII (FVIII+) vessels co-localized with DiI+ EPCs (D). Data are presented as mean \pm S.E.M. $\mathrm{N}=10-12$ /group. ${ }^{*} \mathrm{P}<0.05$.

conventionally prepared MSCs; (2) intramyocardial injection of MPCs into rats after MI attenuated left ventricular dysfunction and remodelling, reduced myocyte apoptosis and augmented myocardial neovascularization, despite poor engraftment of transplanted cells; (3) administration of MPC-CM to the MI heart also mitigated left ventricular dysfunction and dilatation, promoted myocyte survival and hypertrophy and increased vascular density and (4) MPC-CM contained soluble factors with biological activity in cultures of cardiac myocytes, vascular cells and peripheral blood-derived EPCs. The recently described STRO-3 monoclonal antibody has previously been shown to enrich for a subset of STRO- $1^{\text {bright }}$ MNCs, which is clonogenic and multipotential (17). Co-expression of high levels of STRO-1 suggests that STRO-3 ${ }^{+}$MPCs may be a relatively immature precursor cell type with cardioprotective potential $(2,16)$. The present findings extend on existing data by demonstrating that the culture-expanded progeny of STRO-3-selected MPCs remain proliferative and multipotential following culture expansion over several passages. These functional characteristics were associated with cell-surface expression of STRO-1, and gene expression of a panel of early 'stem cell' markers, which are implicated in the regulation of progenitor cell cycle progression and differentiation $(12,20-22)$. Culture-expanded MPCs also expressed transcripts of various cytokines, reflective of the native function of mesenchymal lineage cells in supporting the population of naive haematopoietic progenitors in BM. Notably, proliferative and developmental potentials and stem cell marker and cytokine expression levels were augmented in cultures initiated by STRO- $3^{+}$MPCs above that observed in cultures of MSCs established by conventional methods. In sum, our data suggest that prospective immunoselection of STRO- $3^{+}$MPCs enriches for CFU-f, and may be advantageous in maintaining a population of immature MPCs during culture expansion, compared with preliminary isolation of MSCs by plastic-adherence alone. Further, these data support the possibility of generating therapeutically relevant numbers of precursor cells by ex vivo expansion for clinical application.

Our in vivo studies are the first to demonstrate the cardioprotective and pro-angiogenic properties of STRO-3-selected and culture-expanded human MPCs in a rat model of MI. Intramyocardial transplantation of $1 \times 10^{6} \mathrm{MPCs}$ to rats at $48 \mathrm{~h}$ after MI resulted in improved left ventricular function, reduced dilatation, increased 
A

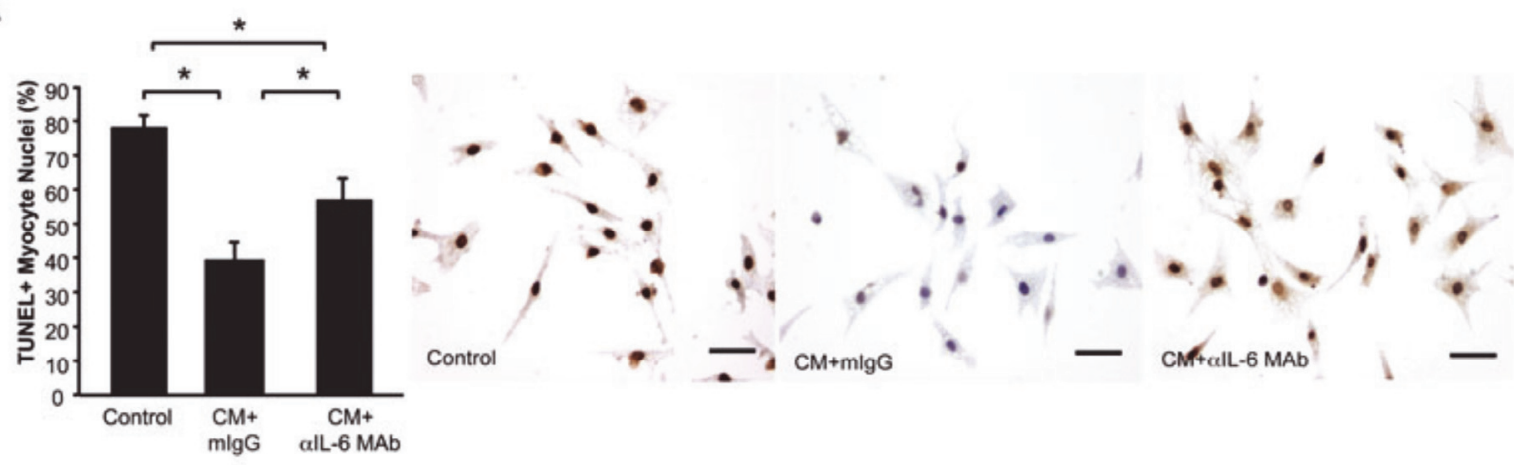

B

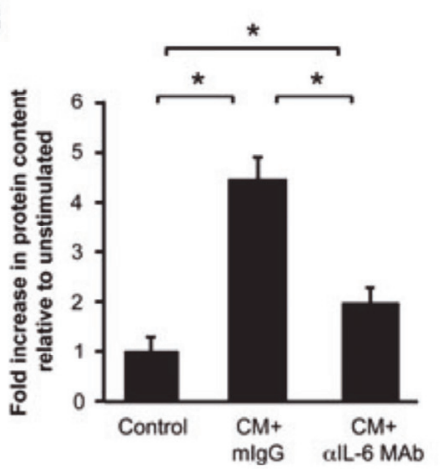

C

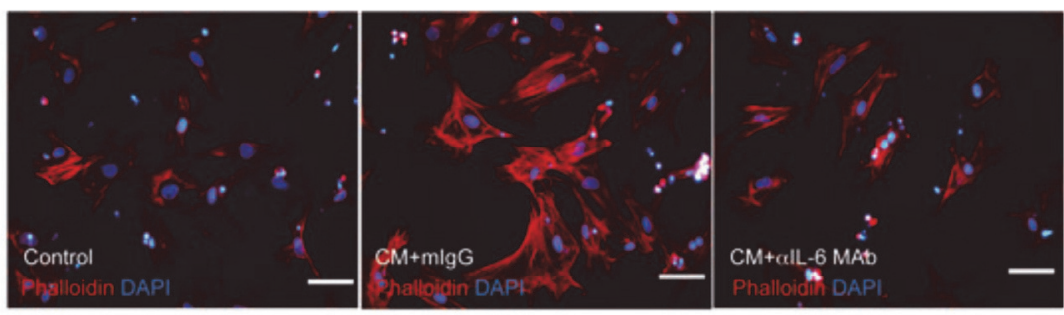

Figure 7. CM protects cardiac myocytes from apoptotic death and promotes myocyte hypertrophy. The direct effects of control medium, $\mathrm{CM}+$ mouse IgG isotype control (mIgG) or CM+aIL-6 MAb on neonatal rat cardiac myocytes were examined. (A) Hypoxia-induced apoptosis was determined by TUNEL (brown). Blue: viable nuclei. Myocyte hypertrophy was determined by measuring total protein content, relative to DNA content (B) and phalloidin staining of fixed cells (C). Data are represented as mean \pm S.E.M. Each condition was represented in triplicate. $\mathrm{N}=3$ experiments. ${ }^{*} \mathrm{P}<0.05$.

myocyte survival and capillary density associated with reduced fibrosis, compared with saline control at 2 weeks. The dose, route and timing of administration of MPCs were selected based on our previous work, which demonstrated the efficacy of $1 \times 10^{6}$ STRO $^{+}{ }^{+}$culture-expanded MPCs in a rat model of MI (2). The present findings echo our earlier observations of functional recovery and arteriogenesis in the ischemic heart following treatment with STRO-1+ ${ }^{+}$MPCs (2). Similarly, recent reports have demonstrated that in a sheep model of myocardial ischemia, allogeneic transplantation of STRO-3-selected, ex vivo-cultured ovine MPCs attenuated infarct expansion, accompanied by increased vascular density, in a dose-dependent manner, associated with modulation of matrix remodelling $(23,24)$. Together, these data suggest that the STRO-3 antibody may be employed to select a subset of BM mesenchymal lineage cells, which exhibit a cardioprotective phenotype following culture expansion.

Interestingly, we found that the beneficial effects of MPC therapy after MI in rats occurred despite poor engraftment of cells. Specifically, the numbers of MPCs present in the post-MI heart at $24 \mathrm{~h}$ and 7 days following injection were dramatically diminished compared to the number injected, and were negligible by 2 weeks. Our observations are similar to reports in the literature of rapid and progressive attrition of MSCs following intramyocardial transplantation under both syngeneic and xenogeneic conditions $(5,25)$. In the acute phase after MI, transplanted cells are likely to be beset by dynamic processes including inflammation, cellular necrosis, fibrosis and metabolic and mechanical disturbances, which may impair engraftment. Our data suggest that under the present study conditions, mechanisms which depend on cell engraftment in the ischemic myocardium, such as MPC differentiation or fusion, are unlikely to account significantly for the observed effects of MPC administration post-MI.

Instead, our observations fall in line with a current working hypothesis that the therapeutic benefits observed following MSC administration to the ischemic heart occur, at least in part, via paracrine-mediated mechanisms of action. Various studies have demonstrated beneficial effects of MSC therapy without long-term engraftment, and a link between donor cell-derived factors and left ventricular recovery following MSC transplantation (26-28). Moreover, injection of MSC-derived factors to the post-MI heart has been shown to rapidly promote angiogenesis and cardioprotection $(7,29$ 31). Consistent with this body of work, intramyocardial injection of MPC-derived soluble factors after MI resulted in therapeutic benefits, which mirrored the outcome observed following treatment of MI rats with MPCs. Profiling of CM revealed the presence of a range of multifunctional 
A

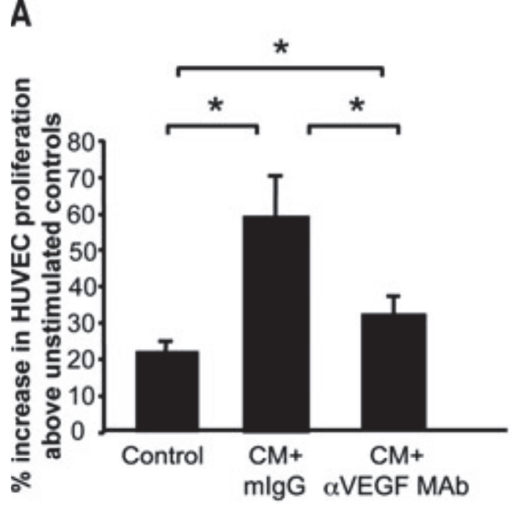

B

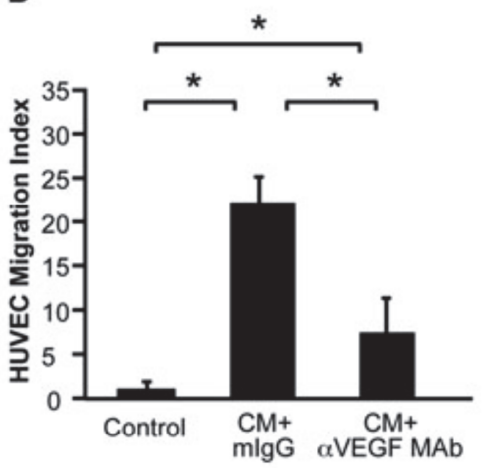

C

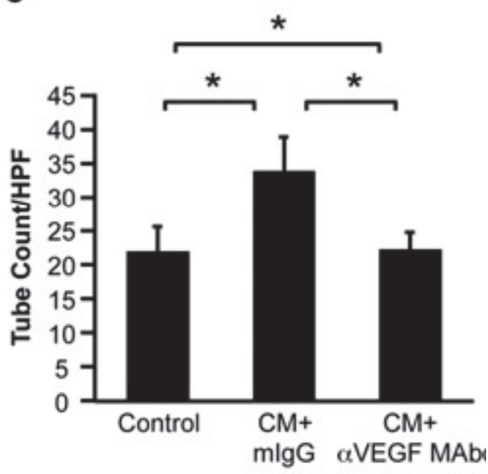

D
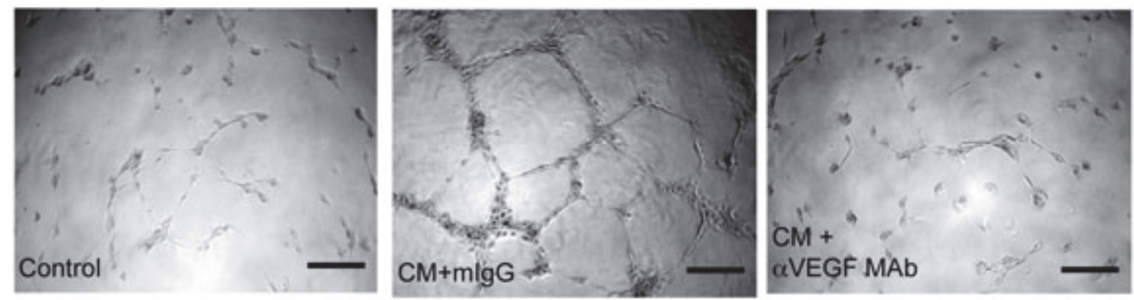

E

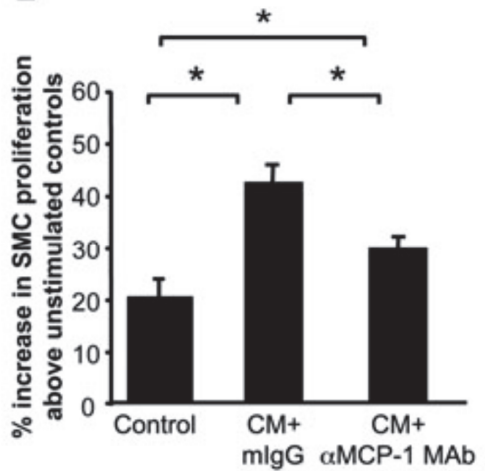

$\mathbf{F}$

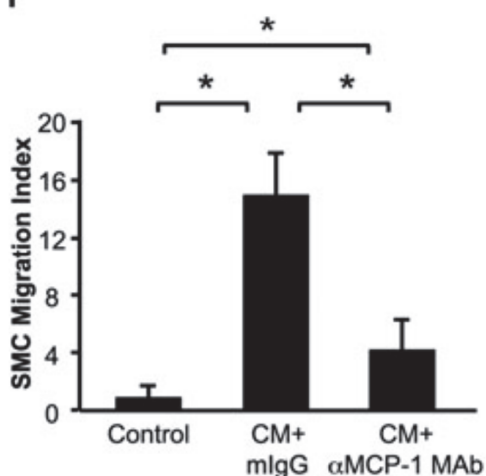

Figure 8. CM promotes vascular cell proliferation, migration, survival and cord formation. The direct effects of control medium, CM+mouse IgG isotype control (mIgG) or CM+aMCP-1 MAb on cultures of HUVECs were examined in assays for proliferation (A), migration (B) and cord formation (C). Representative images of cord formation in HUVEC cultures (D). The effects of control medium, CM+mouse IgG isotype control (mIgG) or $\mathrm{CM}+\alpha \mathrm{MCP}-1 \mathrm{MAb}$ on rat A7r5 smooth muscle cells were examined with respect to proliferation (E) and migration $(\mathrm{F})$. Data are represented as mean \pm S.E.M. Each condition was represented in triplicate. $\mathrm{N}=3$ experiments. ${ }^{*} \mathrm{P}<0.05$.

soluble factors. Our in vitro studies evidence the contribution of IL-6, VEGF and MCP-1 present in $\mathrm{CM}$ to its direct actions on myocytes, HUVECs, rVSMCs and EPCs, and suggest possible mechanistic underpinnings for the effects of $\mathrm{CM}$ in the post-MI heart. It remains to be determined whether resident cardiac progenitors cells are activated in response to CM treatment, and whether other mechanisms of tissue repair may be involved in the attenuation of left ventricular dysfunction. However, together, the present data from our CM studies support the notion that MPCs may exert paracrine-mediated actions when transplanted into the ischemic myocardium.

Interestingly we found that MPC- or CM-treatment after MI resulted in myocyte hypertrophy both in vivo and in vitro. Although better function is often coupled with attenuation of myocyte enlargement, hypertrophy of the residual myocardium occurs in the acute phase after MI as a compensatory response to the loss of tissue at the site of infarct to maintain left ventricular contractile function. Previous studies support the hypothesis that insufficient compensatory hypertrophy after MI may contribute to left ventricular dilatation and heart failure disease progression (32). Given the improvements in left ventricular function observed in our study, we speculate that administration of MPCs or CM at 48h after MI may augment an early compensatory response, which may contribute to their salutary effects in this context.

Treatment of MI rats with either MPCs or $\mathrm{CM}$ also attenuated myocardial fibrosis at the site of infarct. In a previous report, the anti-fibrotic and infarct-limiting effects of allogeneic transplantation of STRO-3-derived MPCs into an ovine model of myocardial ischemia were associated with increased indices of collagen degradation (24). However, the 
A

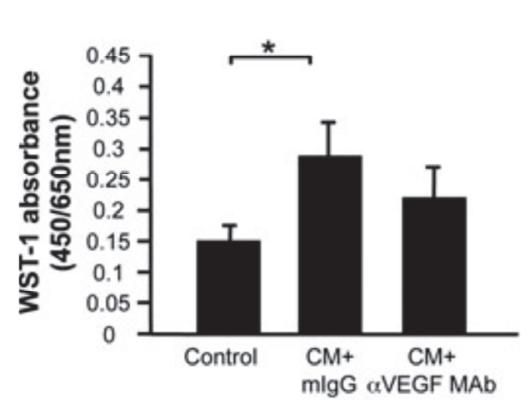

B

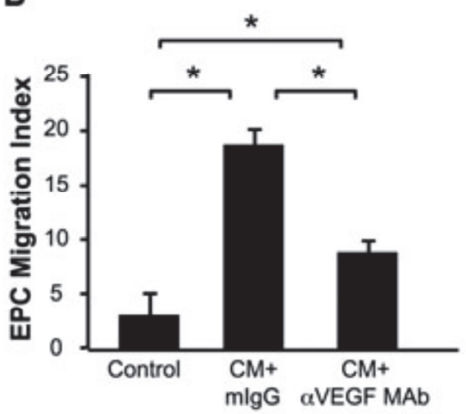

C

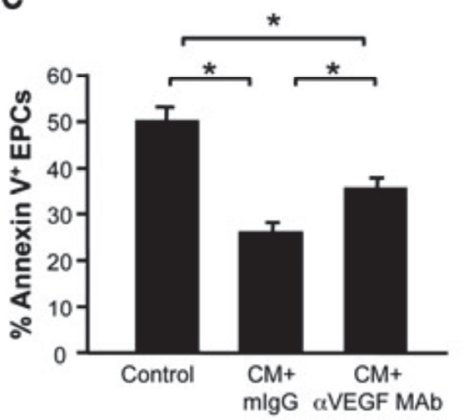

D

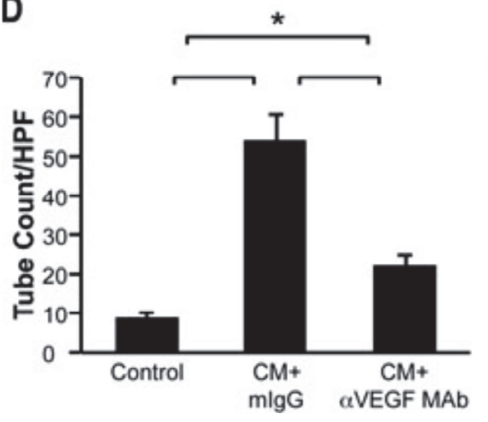

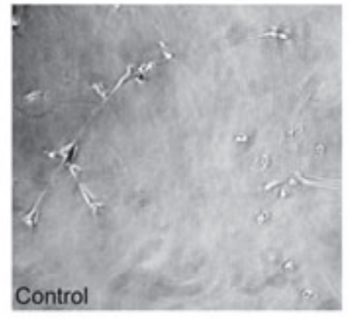
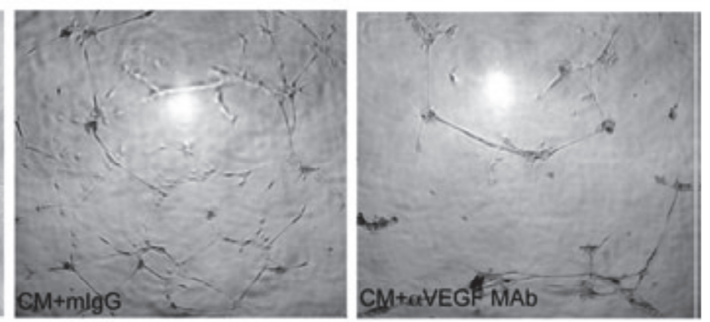

Figure 9. CM promotes EPC proliferation, migration, survival, and cord formation. The direct effects of control medium, CM+mouse IgG isotype control (mIgG) or CM+aVEGF MAb on isolated EPCs were examined in assays for proliferation (A), migration (B), apoptosis (C) and cord formation (D). Data are represented as mean \pm S.E.M. Each condition was represented in triplicate. $\mathrm{N}=3$ experiments. ${ }^{*} \mathrm{P}<0.05$.

direct actions of MPCs on myocardial collagen turnover remain to be determined. Alongside the concomitant reduction in myocyte apoptosis in the same hearts, our data may instead suggest that reduced tissue fibrosis in the infarcted region is secondary to augmentation of myocyte survival. Alternatively, reductions in infarct size and tissue fibrosis following cell therapy in animal models of MI may be attributable to partial regeneration of the necrotic myocardium (33). In light of poor engraftment of MPCs in the post-MI rat heart, our data support a paracrine mechanism of action for these cells in this setting. However, our data do not preclude the possibility that MPCs may have the capacity for cardiogenesis, and the potential of MPCs for cardiac development and to activate resident cardiac progenitors or myocytes remains a subject for future investigation.

Our CM studies cast light on a possible paracrine-based mechanism of action of MPC therapy after MI, though we acknowledge that the data does not provide direct documentation of a paracrine action of MPCs transplanted into the ischemic myocardium. However, our data may provide some insight into the biology of ex vivo grown MPCs. From this perspective, it is important to emphasize that MPC-CM was generated under serum-free and normoxic culture conditions. Thus, our data demonstrate that the constitutive secretome of culture-expanded MPCs includes pro-angiogenic and cardioprotective factors with biological activity both in vitro and in vivo. The profile of cytokines identified in this study overlaps qualitatively with that previously detected in MSC-CM, and similarly produced pro-angiogenic effects in cultures of HUVECs (8). Interestingly, MPC-CM also promoted myocyte survival under ischemia-mimetic culture conditions and attenuated left ventricular remodelling and dysfunction after MI, without need for potentiation of MPCs via transfection of survival genes and/or hypoxic culture, which was previously found to be necessary to generate MSC-CM with similar effects (7). The reasons for these differences in cardioprotective potential between MPC-CM and MSC-CM require further investigation, though we note that in the present study, transcripts for various pro-angiogenic and cardioprotective cytokines were more abundant in MPCs compared with MSCs prepared by conventional methods. Similarly, Psaltis and colleagues recently reported that CM generated by STRO-1-immunoselected cells demonstrated enhanced cardioprotective and pro-angiogenic activity compared to MSC-CM (13). Clearly, the functional consequences of these differences remain to be examined. However, the present data suggest that prospective immunoselection and culture expansion of STRO- $3^{+}$ MPCs may enrich for a population of cells, which intrinsically expresses a profile of factors that is both qualitatively and quantitatively sufficient to yield therapeutic benefit in myocardial ischemia.

Speculatively, these observations point to the intriguing possibility of MPC-derived soluble factors as therapy per se. To this end, the sufficiency of CM generated under serum-free 
conditions to produce beneficial effects in the ischemic myocardium, and the persistence of these effects at 7 days after MI, are encouraging. Further investigations might include examination of MPC-CM therapy alone, with animals followed to later time-points to determine whether the effects of $\mathrm{CM}$ after MI are sustained. MPC-CM might also be administered in combination with cells types, including EPCs, given the potential synergy between MPC-CM and circulating EPCs observed in this study. In looking ahead toward the possible clinical application of MPCs or CM for post-MI therapy, further efforts are required to optimize these approaches to ensure full exploitation of their respective therapeutic potentials. For example, our data indicate a need for strategies that enhance persistence of MPCs in the ischemic myocardium, because previous studies have shown cell engraftment to correlate positively with therapeutic outcome (34). Additional experiments, such as a head-to-head comparison of the efficacy of MPC versus CM injections, would also inform evaluation of the most promising way to translate MPC-based therapy for myocardial ischemia into the clinical setting.

The present data support the potential utility of STRO-3 as a marker for a subset of mesenchymal lineage precursors present in adult BM MNCs. Prospective immunoselection of STRO- $3^{+}$MPCs may be advantageous in maintaining an immature mesenchymal precursor population during ex vivo expansion. The culture-expanded progeny of STRO- $3^{+}$MPCs demonstrated therapeutic potential in the post-MI heart, attributable at least in part, to the secretion of pro-angiogenic and cardioprotective factors. These characteristics endow MPCs with clinical relevance and promise as therapy for ischemic heart disease.

\section{ACKNOWLEDGMENTS}

We acknowledge the technical assistance of Geping Zhang. Grant support for this study was provided by the NIH/NHLBI (P50HL077096) and by the Miami Heart Research Institute.

\section{DISCLOSURES}

Silviu Itescu is Director, Scientific Founder, Chief Scientist, Chairman of Scientific Advisory Board and equity holder of Angioblast Systems, Inc., New York, NY; Director and Chief Scientific Adviser of Mesoblast Ltd., Melbourne, Australia. Michael Schuster is a co-founder and Vice President of Operations of Angioblast Systems, Inc., New York, NY. Henry Krum is a member of the Scientific Advisory Board of Mesoblast Ltd., Melbourne, Australia.

\section{ADDITIONAL SUPPORTING INFORMATION}

Additional Supporting Information may be found in the online version of this article:

Fig. S1 Study design of animal experiments. Animal studies were performed to examine the effects of intramyocardial (IM) delivery of MPCs (A) and CM (B) post-MI and of CM on EPC homing to the infarcted heart (C). IC: intracardiac.

Table S1 Cytokines detected in MPC-CM cultured under serum free conditions.

\section{REFERENCES}

1. L. C. Amado, A. P. Saliaris, K. H. Schuleri, M. St. John, J. S. Xie, S. Cattaneo, D. J. Durand, T. Fitton, J. Q. Kuang, G. Stewart, S. Lehrke, W. W. Baumgartner, B. J. Martin, A. W. Heldman, J. M. Hare, Cardiac repair with intramyocardial injection of allogeneic mesenchymal stem cells after myocardial infarction. Proceedings of the National Academy of Sciences 102, 11474 (2005/08/01, 2005).

$2 . \quad$ T. P. Martens, F. See, M. D. Schuster, H. P. Sondermeijer, M. M. Hefti, A. Zannettino, S. Gronthos, T. Seki, S. Itescu, Mesenchymal lineage precursor cells induce vascular network formation in ischemic myocardium. Nature Clinical Practice Cardiovascular Medicine 3, S18 (2006/03, 2006).

3. C. Nakanishi, M. Yamagishi, K. Yamahara, I. Hagino, H. Mori, Y. Sawa, T. Yagihara, S. Kitamura, N. Nagaya, Activation of cardiac progenitor cells through paracrine effects of mesenchymal stem cells. Biochemical and Biophysical Research Communications 374, 11 (2008/09, 2008).

$4 . \quad$ G. V. Silva, S. Litovsky, J. A. Assad, A. L. Sousa, B. J. Martin, D. Vela, S. C. Coulter, J. Lin, J. Ober, W. K. Vaughn, R. V. Branco, E. M. Oliveira, R. He, Y. J. Geng, J. T. Willerson, E. C. Perin, Mesenchymal stem cells differentiate into an endothelial phenotype, enhance vascular density, and improve heart function in a canine chronic ischemia model. Circulation 111, 150 (Jan 18, 2005).

$5 . \quad J$. Terrovitis, M. Stuber, A. Youssef, S. Preece, M. Leppo, E. Kizana, M. Schar, G. Gerstenblith, R. G. Weiss, E. Marban, M. R. Abraham, Magnetic resonance imaging overestimates ferumoxide-labeled stem cell survival after transplantation in the heart. Circulation 117, $1555(2008 / 03 / 10,2008)$.

6. C. Toma, Human mesenchymal stem cells differentiate to a cardiomyocyte phenotype in the adult murine heart. Circulation 105, 93 (2002/01/01, 2002).

7. M. Gnecchi, H. He, N. Noiseux, O. D. Liang, L. Zhang, F. Morello, H. Mu, L. G. Melo, R. E. Pratt, J. S. Ingwall, V. J. Dzau, Evidence supporting paracrine hypothesis for Aktmodified mesenchymal stem cell-mediated cardiac protection and functional improvement. The FASEB Journal 20, 661 (2006/04, 2006).

8. S.-C. Hung, R. R. Pochampally, S.-C. Chen, S.-C. Hsu, D. J. Prockop, Angiogenic effects of human multipotent stromal cell conditioned medium activate the PI3K-Akt pathway in hypoxic endothelial cells to inhibit apoptosis, increase survival, and stimulate angiogenesis. Stem cells 25, $2363(2007 / 09,2007)$.

9. S. Aggarwal, M. F. Pittenger, Human mesenchymal stem cells modulate allogeneic immune cell responses. Blood 105, 1815 (Feb 15, 2005).

10. M. F. Pittenger, A. M. Mackay, S. C. Beck, R. K. Jaiswal, R. Douglas, J. D. Mosca, M. A. 
Moorman, D. W. Simonetti, S. Craig, D. R. Marshak, Multilineage potential of adult human mesenchymal stem cells. Science 284, 143 (Apr 2, 1999).

11. S. Shi, S. Gronthos, S. Chen, A. Reddi, C. M. Counter, P. G. Robey, C.-Y. Wang, Bone formation by human postnatal bone marrow stromal stem cells is enhanced by telomerase expression. Nature Biotechnology 20, 587 (2002/06, 2002).

12. J. L. Simonsen, C. Rosada, N. Serakinci, J. Justesen, K. Stenderup, S. I. S. Rattan, T. G. Jensen, M. Kassem, Telomerase expression extends the proliferative life-span and maintains the osteogenic potential of human bone marrow stromal cells. Nature Biotechnology 20, 592 (2002/06, 2002).

13. P. J. Psaltis, S. Paton, F. See, A. Arthur, S. Martin, S. Itescu, S. G. Worthley, S. Gronthos, A C. W. Zannettino, Enrichment for STRO-1 expression enhances the cardiovascular paracrine activity of human bone marrowderived mesenchymal cell populations. Journal of Cellular Physiology, n/a (2010).

14. M. Dominici, K. Le Blanc, I. Mueller, I. SlaperCortenbach, F. C. Marini, D. S. Krause, R. J. Deans, A. Keating, D. J. Prockop, E. M. Horwitz, Minimal criteria for defining multipotent mesenchymal stromal cells. The International Society for Cellular Therapy position statement. Cytotherapy 8, 315 (2006)

15. F. Sabatini, L. Petecchia, M. Tavian, V. J. de Villeroché, G. A. Rossi, D. Brouty-Boyé, Human bronchial fibroblasts exhibit a mesenchymal stem cell phenotype and multilineage differentiating potentialities. Laboratory Investigation 85, 962 (2005/05/30, 2005)

16. S. Gronthos, A. C. Zannettino, S. J. Hay, S. Shi, S. E. Graves, A. Kortesidis, P. J. Simmons, Molecular and cellular characterisation of highly purified stromal stem cells derived from human bone marrow. Journal of cell science 116, 1827 (May 1, 2003).

17. S. Gronthos, S. Fitter, P. Diamond, P. J. Simmons, S. Itescu, A. C. W. Zannettino, A novel monoclonal antibody (STRO-3) identifies an isoform of tissue nonspecific alkaline phosphatase expressed by multipotent bone marrow stromal stem cells. Stem cells and development 16, 953 (2007/12, 2007).

18. F. Gindraux, Z. Selmani, L. Obert, S. Davani, P. Tiberghien, P. Hervé, F. Deschaseaux, Human and rodent bone marrow mesenchymal stem cells that express primitive stem cell markers can be directly enriched by using the CD49a molecule. Cell and Tissue Research 327, 471 (2006/11/16, 2006).

19. S. Shi, S. Gronthos, Perivascular niche of postnatal mesenchymal stem cells in human bone marrow and dental pulp. Journal of Bone and Mineral Research 18, 696 (2003/04/01, 2003).

$20 . \quad$ G. Hu, H. Lee, S. M. Price, M. M. Shen, C. AbateShen, Msx homeobox genes inhibit differentiation through upregulation of cyclin D1. Development 128, 2373 (Jun, 2001).

21. S. Isenmann, A. Arthur, A. C. W. Zannettino, J. L. Turner, S. Shi, C. A. Glackin, S. Gronthos, TWIST family of basic helix-loop-helix transcription factors mediate human mesenchymal stem cell growth and commitment. Stem cells 27, 2457 (2009/10, 2009).
C. Shui, T. C. Spelsberg, B. L. Riggs, S. Khosla, Changes in Runx2/Cbfa1 expression and activity during osteoblastic differentiation of human bone marrow stromal cells. Journal of Bone and Mineral Research 18, 213 (2003/02/01, 2003).

23. H. Hamamoto, J. H. Gorman, L. P. Ryan, R. Hinmon, T. P. Martens, M. D. Schuster, T. Plappert, M. Kiupel, M. G. St. John-Sutton, S. Itescu, R. C. Gorman, Allogeneic mesenchymal precursor cell therapy to limit remodeling after myocardial infarction: The effect of cell dosage. The Annals of thoracic surgery 87, 794 (2009/03, 2009).

24. J. A. Dixon, R. C. Gorman, R. E. Stroud, S. Bouges, H. Hirotsugu, J. H. Gorman, T. P. Martens, S. Itescu, M. D. Schuster, T. Plappert, M. G. St John-Sutton, F. G. Spinale, Mesenchymal cell transplantation and myocardial remodeling after myocardial infarction. Circulation 120, S220 (2009/09/14, 2009).

25. J. Müller-Ehmsen, B. Krausgrill, V. Burst, K. Schenk, U. C. Neisen, J. W. U. Fries, B. K. Fleischmann, J. Hescheler, R. H. G. Schwinger, Effective engraftment but poor mid-term persistence of mononuclear and mesenchymal bone marrow cells in acute and chronic rat myocardial infarction. Journal of molecular and cellular cardiology 41, 876 (2006/11, 2006).

26. M. Zhang, N. Mal, M. Kiedrowski, M. Chacko, A. T. Askari, Z. B. Popovic, O. N. Koc, M. S. Penn, SDF-1 expression by mesenchymal stem cells results in trophic support of cardiac myocytes after myocardial infarction. The FASEB Journal 21, 3197 (2007/10, 2007).

27. Y. Iso, J. L. Spees, C. Serrano, B. Bakondi, R. Pochampally, Y.-H. Song, B. E. Sobel, P. Delafontaine, D. J. Prockop, Multipotent human stromal cells improve cardiac function after myocardial infarction in mice without long-term engraftment. Biochemical and Biophysical Research Communications 354, 700 (2007/03, 2007).

28. M. Mirotsou, Z. Zhang, A. Deb, L. Zhang, M. Gnecchi, N. Noiseux, H. Mu, A. Pachori, V. Dzau, Secreted frizzled related protein 2 (Sfrp2) is the key Akt-mesenchymal stem cell-released paracrine factor mediating myocardial survival and repair. Proceedings of the National Academy of Sciences 104, 1643 (2007/01/24, 2007).

29. M. Gnecchi, H. He, O. D. Liang, L. G. Melo, F. Morello, H. Mu, N. Noiseux, L. Zhang, R. E. Pratt, J. S. Ingwall, V. J. Dzau, Paracrine action accounts for marked protection of ischemic heart by Akt-modified mesenchymal stem cells. Nature medicine 11, 367 (2005/04, 2005).

30. W. Dai, S. L. Hale, R. A. Kloner, Role of a paracrine action of mesenchymal stem cells in the improvement of left ventricular function after coronary artery occlusion in rats. Regenerative medicine 2, 63 (2007/01, 2007).

31. L. Timmers, S. K. Lim, F. Arslan, J. S. Armstrong, I. E. Hoefer, P. A. Doevendans, J. J. Piek, R. M. El Oakley, A. Choo, C. N. Lee, G. Pasterkamp, D. P. V. de Kleijn, Reduction of myocardial infarct size by human mesenchymal stem cell conditioned medium. Stem Cell Research 1, 129 (2008/06, 2008).

32. S. E. Litwin, T. E. Raya, P. G. Anderson, C. M. Litwin, R. Bressler, S. Goldman, Induction of myocardial hypertrophy after coronary ligation in rats decreases ventricular dilatation and 
Appendix 2 - Therapeutic effects of human STRO-3-selected MPCs.

improves systolic function. Circulation 84, 1819 (1991/10/01, 1991).

33. D. Orlic, J. Kajstura, S. Chimenti, I. Jakoniuk, S. M. Anderson, B. Li, J. Pickel, R. McKay, B. Nadal-Ginard, D. M. Bodine, A. Leri, P. Anversa, Bone marrow cells regenerate infarcted myocardium. Nature 410, 701 (2001/04/05, 2001).
34. J. Huang, Z. Zhang, J. Guo, A. Ni, A. Deb, L. Zhang, M. Mirotsou, R. E. Pratt, V. J. Dzau, Genetic modification of mesenchymal stem cells overexpressing CCR1 increases cell viability, migration, engraftment, and capillary density in the injured myocardium. Circulation research 106, $1753(2010 / 04 / 08,2010)$. 



\section{Appendix 3}

\section{Effect of ex vivo-expanded recipient regulatory $T$ cells on hematopoietic chimerism and kidney allograft tolerance across MHC barriers in cynomolgus macaques.}

Transplantation. 2017 Feb;101(2):274-283.

Raimon Duran-Struuck", Hugo P. Sondermeijer", Leo Bühler, Paula Alonso-Guallart, Jonah Zitsman, Yojiro Kato, Anette Wu, Alicia N. McMurchy, David Woodland, Adam Griesemer, Mercedes Martinez, Svetlan Boskovic, Tatsuo Kawai, Benedict Cosimi, Cheng-Shie Wuu, Andrea Slate, Markus Y. Mapara, Sam Baker, Rafal Tokarz, Vivette D'Agati, Scott Hammer, Marcus Pereira, W. Ian Lipkin, ThomasWekerle, Megan K. Levings, and Megan Sykes. $\left({ }^{\#}\right.$ contributed equally).

Awarded the ESOT/AST Exchange Grant Award (2011) (HPS). Awarded the TTS Leslie Brent Award (2018) (HPS, RDS). 


\section{ABSTRACT}

Background: Infusion of recipient regulatory $\mathrm{T}$ ( $\mathrm{T}_{\mathrm{reg}}$ ) cells promotes durable mixed hematopoietic chimerism and allograft tolerance in mice receiving allogeneic bone marrow transplant (BMT) with minimal conditioning. We applied this strategy in a Cynomolgus macaque model. Methods: $\mathrm{CD} 4^{+} \mathrm{CD} 25^{\text {high }} \mathrm{T}_{\text {reg }}$ cells that were polyclonally expanded in culture were highly suppressive in vitro and maintained high expression of FoxP3. Eight monkeys underwent nonmyeloablative conditioning and major histocompatibility complex mismatched BMT with or without $\mathrm{T}_{\text {reg }}$ cell infusion. Renal transplantation (from the same BMT donor) was performed 4 months post-BMT without immunosuppression to assess for robust donor-specific tolerance. Results: Transient mixed chimerism, without significant $\mathrm{T}$ cell chimerism, was achieved in the animals that received BMT without $\mathrm{T}_{\text {reg cells }}(\mathrm{N}=3)$. In contrast, 2 of 5 recipients of $\mathrm{T}_{\text {reg }}$ cell+BMT that were evaluable displayed chimerism in all lineages, including $\mathrm{T}$ cells, for up to 335 days post-BMT. Importantly, in the animal that survived long-term, greater than $90 \%$ of donor $\mathrm{T}$ cells were CD45RA ${ }^{+} \mathrm{CD} 31^{+}$, suggesting they were new thymic emigrants. In this animal, the delayed (to 4 months) donor kidney graft was accepted more than 294 days without immunosuppression, whereas non-Treg cell BMT recipients rejected delayed donor kidneys within 3 to 4 weeks. Early CMV reactivation and treatment was associated with early failure of chimerism, regardless of $\mathrm{T}_{\text {reg }}$ cell administration. Conclusions: Our studies provide proof-of-principle that, in the absence of early CMV reactivation (and BM-toxic antiviral therapy), cotransplantation of host $\mathrm{T}_{\text {reg }}$ cell can promote prolonged and high levels of multilineage allogeneic chimerism and robust tolerance to the donor.

\section{INTRODUCTION}

$\mathrm{CD}^{+}{ }^{+} \mathrm{FoxP}^{+}$regulatory $\mathrm{T}\left(\mathrm{T}_{\text {reg }}\right)$ cells modulate autoimmune and alloimmune responses (1-5). Induction of kidney allograft tolerance, via transient mixed hematopoietic chimerism and nonmyeloablative conditioning, has been achieved in large animal models (6) and humans (7). However, kidney allograft tolerance was achieved in only $60 \%$ to $70 \%$ of cynomolgus monkeys (cynos) and humans, and tolerance could not be readily extended to islet, heart or lung allografts in monkeys (8-10). Although durable mixed chimerism has been achieved with total lymphoid radiation, antithymocyte globulin and donor kidney transplantation in the HLA-identical transplant setting, this approach has not yet succeeded in achieving durable chimerism or tolerance across HLA barriers (11-14). Another approach achieves renal allograft tolerance with development of full donor chimerism across extensive HLA barriers (15, 16), but the full donor chimerism likely reflects the more rigorous and potentially toxic host conditioning and/or graft-versus-host reactivity of the infused donor $\mathrm{T}$ cells, which eliminates recipient hematopoiesis, and high rates of opportunistic infection were observed (17). Mixed chimerism, in contrast, provides a steady supply of recipientderived antigen presenting cells (APCs), conferring superior ability to mount cytotoxic $\mathrm{T}$ cell responses that clear viral infections compared to full chimeras (17-20). Thus, the reliable achievement of durable mixed chimerism across HLA barriers, with its potential to induce tolerance to any type of donor organ and to cure congenital hematologic disorders, remains an important and elusive goal in humans $(21,22)$.

In mice, adoptive transfer of recipient blood-derived natural $\mathrm{T}_{\text {reg }}$ cells at the time of bone marrow transplant (BMT) with minimal conditioning regimen permitted the establishment of permanent hematopoietic mixed chimerism and skin allograft tolerance (23-26). We have adapted the use of $\mathrm{T}_{\text {reg }}$ cells for the abovementioned cyno model that otherwise achieves only transient mixed hematopoietic chimerism and which has been extensively characterized (8-10). We tested the hypothesis that the addition of expanded recipient $\mathrm{T}_{\text {reg cells to the "standard" conditioning protocol }}$ would promote durable chimerism and allow acceptance of a donor kidney after a marked delay of 4 months, when donor kidneys are uniformly rejected by transient chimeras prepared with this protocol (27).

\section{MATERIALS AND METHODS}

\subsection{ANIMALS}

Male adult cynos (Charles River Primates, Wilmington, MA and Sanofi-Synthelabo, Bridgewater, NJ) were used. All procedures were approved by the IACUC of Columbia University and Massachusetts General Hospital (MGH). Both are AAALAC international accredited institutions.

\subsection{CYNOMOLGUS MAJOR HISTOCOMPATIBILITY COMPLEX GENOTYPING}

Peripheral blood mononuclear cell (PBMCs) were genotyped at the University of Wisconsin Primate 


\begin{tabular}{|c|c|c|c|c|}
\hline Recipient & Treg cells & $\begin{array}{c}\text { CIMV } \\
\text { (serology) }\end{array}$ & $\begin{array}{l}\text { Mismatch } \\
\text { in MHC-I }\end{array}$ & $\begin{array}{l}\text { Mismatch } \\
\text { in MHC-II }\end{array}$ \\
\hline $90-47$ & No & + & 2 haplotype & 1 haplotype \\
\hline $90-1$ & No & - & 2 haplotype & 1 haplotype \\
\hline $90-7$ & No & + & 2 haplotype & 1 haplotype \\
\hline M5210 & Yes & $+^{*}$ & 2 haplotype & 1 haplotype \\
\hline $90-39$ & Yes & - & 1 haplotype & 2 haplotype \\
\hline $90-15$ & Yes & + & 1 haplotype & 1 haplotype \\
\hline $6 c 64$ & Yes & + & 1 haplotype & 2 haplotype \\
\hline $6 c 1$ & Yes & + & 1 haplotype & 1 haplotype \\
\hline
\end{tabular}

All recipients had donors with 1 or both MHC-I and II alleles mismatched.

${ }^{*}$ Animal M5210 was not tested but assumed to be positive.

Table 1. Donor: recipient MHC mismatches (refer to Supplemental Figure 1). All recipients had donors with 1 or both MHC-I and II alleles mismatched. *Animal M5210 was not tested but assumed to be positive.

Research Center Laboratory http://www.primate.wisc.edu/wprc/services/genetics. html (28-31).

\subsection{CONDITIONING REGIMEN}

Recipients of major histocompatibility complex (MHC) mismatched donor BMT (Table 1 and Figure S1, SDC, http://links.lww.com/TP/B373) underwent the "standard" conditioning regimen as previously described $(6,32) \quad+/-\mathrm{T}_{\text {reg }}$ cells (Figure 1A). Cyclosporine levels were maintained between 200$400 \mathrm{ng} / \mathrm{mL}$.

\subsection{TREG CELL SORTING AND EXPANSION}

The $1.0 \%$ of $\mathrm{CD}^{+} \mathrm{T}$ cells expressing the highest levels of CD25 were sorted (FACSAria or Influx, BD Biosciences, Billerica, MA) and plated $\left(1 \times 10^{5}\right.$ cells $\left./ \mathrm{cm}^{2}\right)$ on fibroblasts (L929) $\left(10 \times 10^{5}\right.$ cells $\left./ \mathrm{cm}^{2}\right)$ expressing human CD32 (FcR), CD58 (LFA-3) and CD80 $(33,34)$ (referred as artificial APCs [aAPC]) in combination with human recombinant IL-2 (200U/mL), anti-CD3 (SP-34) 100ng/mL, and rapamycin $100 \mu \mathrm{g} / \mathrm{mL}$ (Sigma-Aldrich, St Louis, MO) for 7 days. Growth medium consisted of RPMl-1640 (Gibco), fetal calf serum (Gibco), L-glutamine, penicillin/streptomycin, and nonessential amino acids. After 7 days, cells were replated with irradiated donor PBMCs (1 PBMC to $1 \mathrm{~T}_{\text {reg }}$ cell) and IL-2 (200U/mL), anti-CD3 (SP-34) $1 \mu \mathrm{g} / \mathrm{mL}$ or alternatively in combination with aAPCs $\left(3 \times 10^{5}\right.$ to $5 \times 10^{5}$ cells per $\mathrm{cm}^{2}$ ) (Table 2 ). Cells were cultured for another 7 days, then split and cultured for another 7 days. When irradiated aAPCs were used, $\mathrm{T}_{\text {reg }}$ cells were cultured for an additional 5 days in the presence of rapamycin $100 \mathrm{ng} / \mathrm{mL}$ (Table 2). After expansion, cells were cryopreserved in fetal calf serum (Gibco) with 5\% dimethyl sulfoxide for future use.

\subsection{BMT}

Bone marrow (BM) was harvested aseptically from donor iliac bones by multiple percutaneous aspirations or surgically from the vertebrae. BM cells $\left(1.3-3.0 \times 10^{8}\right.$ mononuclear cells $\left./ \mathrm{kg}\right)$ were infused intravenously. CD34 ${ }^{+}$content was $1 \%(+/-$ $0.4 \%$ ), as determined by flow cytometry.

\subsection{KIDNEY TRANSPLANTATION}

The details of the kidney transplant procedure were reported previously (35). Kidneys were transplanted between days 119 and 134 post-BMT. Recipients underwent unilateral native nephrectomy and ligation of the contralateral ureter on the day of transplant. The remaining native kidney was removed $\sim 100$ days after transplantation.

\subsection{FLOW CYTOMETRIC ANALYSES, DETECTION OF CHIMERISM, AND CELL SORTING}

Whole blood was lysed and labeled with a combination of the following mAbs: CD3

PerCPCy5.5 (SP34.2), CD4-APC (L200), CD4-PE (L200), CD8-APC (SK1), CD11b-PE (ICRF44). CD20-PE (2H7), CD25-PE (BC96), CD31-PE (WM59), CD56-PE (MY31), pan-MHC A.B.C-PE (W6/32), FOXP3-PE (236A/E7). For chimerism analysis, we used H38 (anti-BW6; One Lambda, Inc., Canoga Park, CA). The recipient and donor pairs were chosen based on their MHC haplotypes and H38 expression. The fluorescence of the stained samples was analyzed using FACS Calibur and FlowJo software. 
A
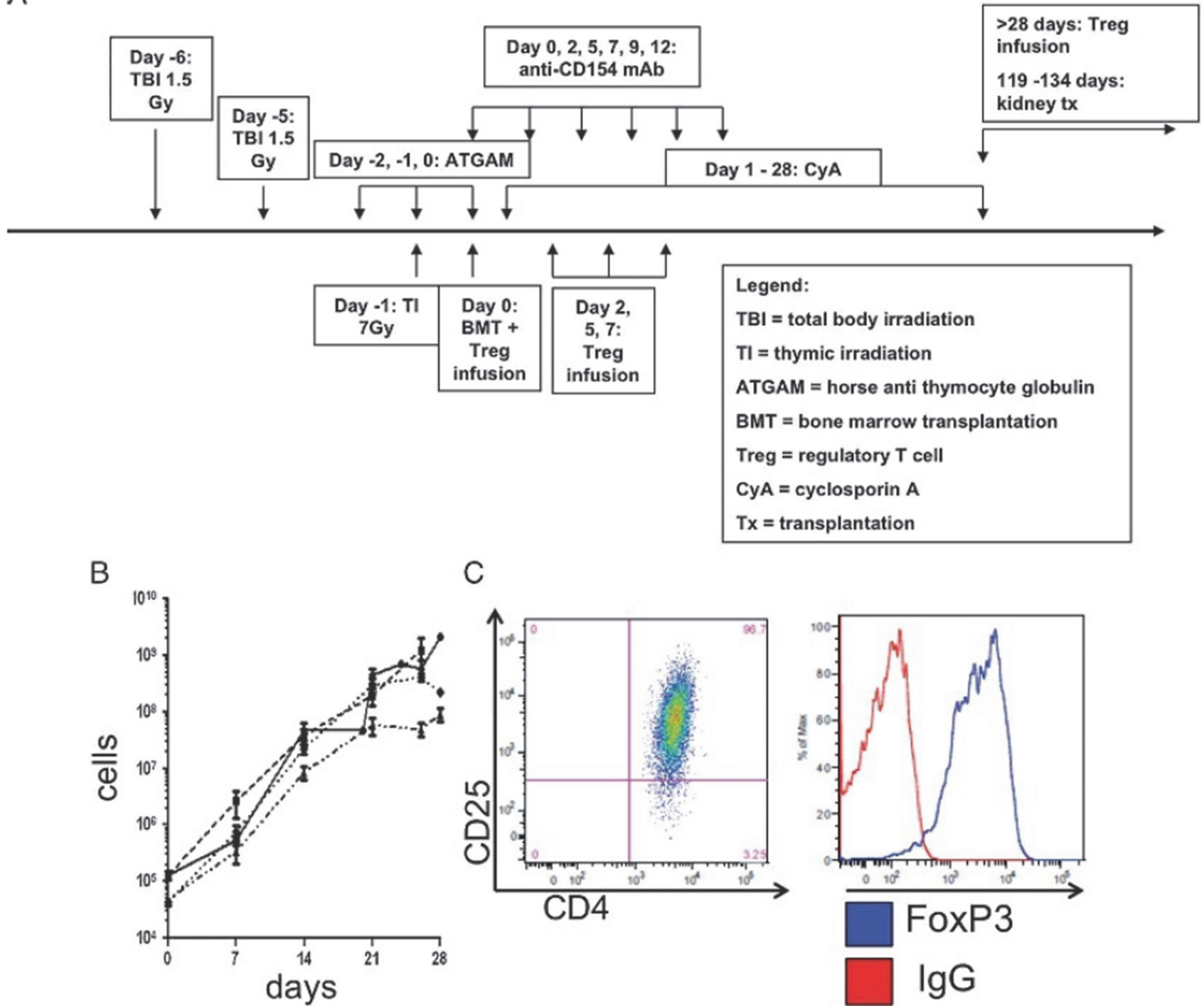

C
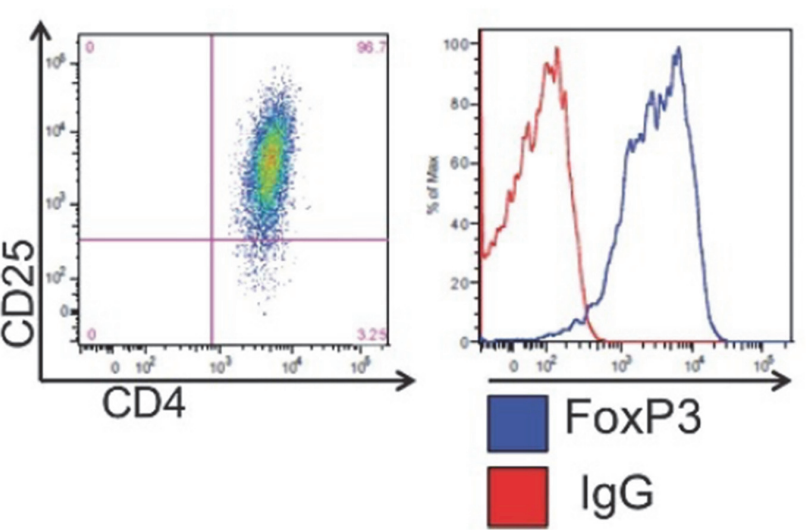

Figure 1. Transplant scheme and $\mathrm{T}_{\text {reg }}$ expansion. (A) Transplant protocol. (B). Expansion of $\mathrm{T}_{\text {reg }}$ lines from 4 animals over 4 weeks. The average number of cells for each animal at each expansion time point is graphed (SEM) (bars). (C) A representative phenotype of $\mathrm{T}_{\text {reg }}$ at the end of culture, with high levels of CD25 and of FoxP3.

\subsection{MIXED LYMPHOCYTE REACTIONS AND TREG CELL SUPPRESSION ASSAYS}

Mixed lymphocyte reactions (MLRs) were performed as previously described (6). In addition, Treg cells were titrated for their specificity in suppressing host anti-donor versus third party and donor antihost versus third party responses. Donor or host PBMC responders were stimulated with irradiated host, donor, or third-party PBMCs. Host nonirradiated $\mathrm{T}_{\text {reg }}$ cells were added to the culture and pulsed with tritiated thymidine 4 days after initiation of culture and read in a beta counter as previously described (6). Treg cells were also tested for suppression of anti-CD2-, anti-CD3-, and antiCD28-coated NHP activation bead-mediated activation (Miltenyi Biotec) at 1 bead to every 2 PBMCs.

\section{RESULTS}

\subsection{EXPANSION, PHENOTYPE, AND SUPPRESSION OF CYNO CD4 ${ }^{+}$CD25 ${ }^{\mathrm{HIGH}}$}

An average of $118,907 \pm 9,588 \mathrm{CD} 4^{+} \mathrm{CD} 25^{\text {high }}$ cells were sorted from each blood draw. Usually a 10- to 100 -fold expansion was achieved within the first 7 $\left(0.695 \times 10^{6} \pm 0.175 \times 10^{6}\right)$ to $14\left(22.47 \times 10^{6} \pm 4.3 \times 10^{6}\right)$ days of culture (Figure 1B, representative lines). At the end of culture, $\mathrm{T}_{\text {reg }}$ cells were analyzed for phenotype (Figure 1C) and function (Figures 2A, B) before cryopreservation.

Infused $\mathrm{T}_{\text {reg }}$ cell expressed high levels of FoxP3 and CD25 (Figure 1C) (Table S1, SDC, http://links.lww.com/TP/B373). Inhibition of the proliferation of bead- (anti-CD2/CD3/CD28) stimulated autologous (cryopreserved pretransplant) PBMCs generally revealed greater than $95 \%$ suppression at a $1: 1$ ratio of $\mathrm{PBMCs} / \mathrm{T}_{\text {reg }}$ cell (Figures $2 \mathrm{~A}$ and $\mathrm{B}$ ). The infused $\mathrm{T}_{\text {reg }}$ cells varied in suppressive potency but all achieved 50\% suppression at or above a1:2 $\mathrm{T}_{\text {reg }}$ cell/PBMC ratio (Figures 2A and B) (Table S1, SDC, http://links.lww.com/TP/B373).

We aimed to generate polyclonal, nonspecifically suppressive $\mathrm{T}_{\text {reg }}$ cell lines with our expansion protocol. While donor PBMCs were added 
A

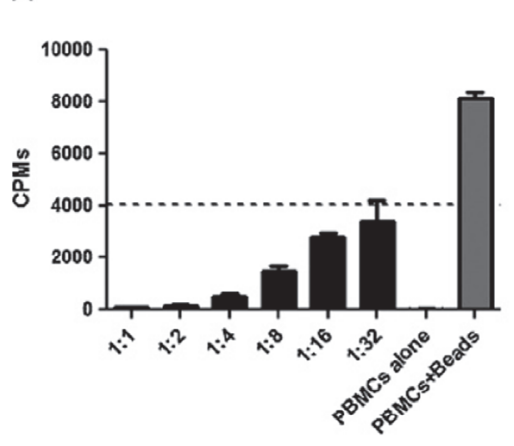

D

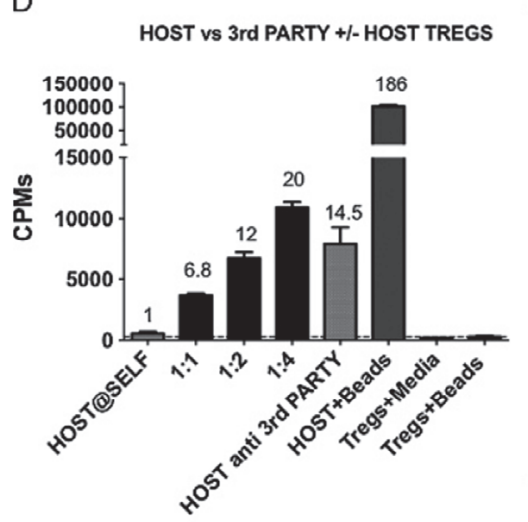

B

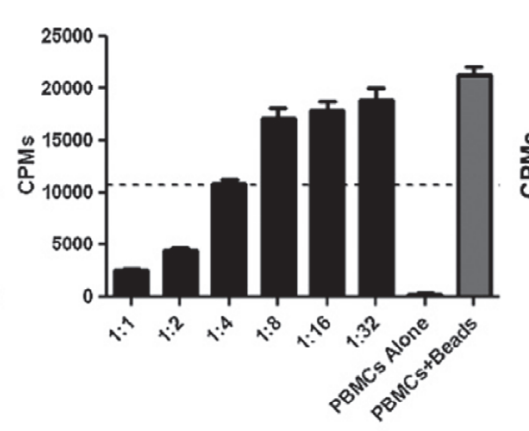

$E$

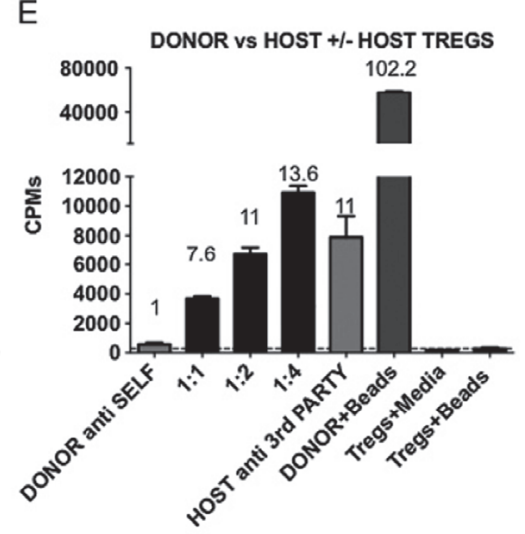

C

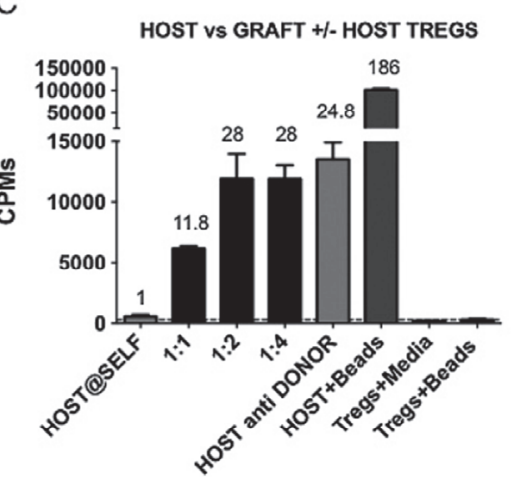

$\mathrm{F}$

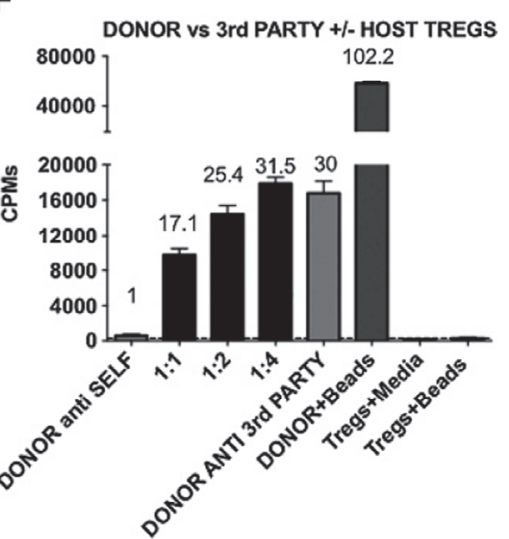

Figure 2. Culture of cynomolgus regulatory $\mathrm{T}$ cells. (A) Highest quality $\mathrm{T}_{\text {reg }}$ suppressed over $50 \%$ the proliferation of bead stimulated (anti-CD2CD3CD28) PBMCs at 1:32 $\mathrm{T}_{\text {reg: }} \mathrm{PBMC}$ ratio. (B) All $\mathrm{T}_{\text {reg }}$ lines achieved at least 50\% suppression of proliferation at a 1:2 Treg:PBMC ratio. Microsuppression assays shown. (C-F) MLRs assessing the specificity of host $\mathrm{T}_{\text {reg. }}$. Host (C, D) and donor (E, F) PBMC responders were plated with either host, donor or third party stimulators. Host Treg were added to the cultures at the indicated PBMC:T $T_{\text {reg }}$ ratios (1:1, 1:2 and 1:4) and assessed for suppressive activity. All data points represent means of triplicates. Error bars indicate SE. Similar results were obtained in a repeat experiment (not shown).

during the expansion period as a source of APCs, specificity studies on 2 different $\mathrm{T}_{\text {reg }}$ cell lines (Figures 2C-F) revealed similar suppression of host antidonor, host anti-third-party, antihost, and donor anti-third-party responses.

\subsection{PROOF OF CONCEPT THAT TREG CELL INFUSION CAN PROLONG MULTILINEAGE DONOR CELL CHIMERISM}

We tested whether polyclonal $\mathrm{T}_{\text {reg }}$ cells could prolong donor hematopoietic chimerism compared to controls, which historically achieved transient (3060 days) chimerism (6). Three control animals were treated as previously described (6), except they did not receive a donor kidney graft on Day 0. Five animals received the same treatment plus $\mathrm{T}_{\text {reg }}$ cell infusions posttransplant. These 5 animals (M5210, 90-39, 6c64, 6c1, 90-15) received expanded polyclonal autologous $\mathrm{T}_{\text {reg }}$ cells $\left(15-53 \times 10^{6}\right.$ per infusion) during the first week posttransplant (days $0,2,5,7$ ) and on day +50 (Table S1, SDC, http://links.lww.com/TP/B373). Total dose was 88$96 \times 10^{6} / \mathrm{kg}$. Two Treg cell recipients, M5210 and 9039, developed significant multilineage chimerism (Figure 3, top row). Although M5210 survived longterm, animal 90-39 died of cytomegalovirus (CMV) disease on day 43 with significant donor chimerism in all lineages (Figure 3). The chimerism in M5210 (Figure 3, top left panel) persisted longer than ever observed in this model, remaining detectable in the lymphoid, monocyte and granulocyte lineages until days 292,224 , and 335 , respectively.

We monitored CMV viremia, and when it exceeded 10,000 copies $/ \mathrm{mL}$ (initially) or 1,000 copies $/ \mathrm{mL}$ (after our experience in the first few animals), we treated animals with ganciclovir and/or foscarnet. Animal 6c64 was given antiviral prophylaxis to prevent CMV reactivation and developed only low and short-lived chimerism (Figure 3) with prolonged pancytopenia, suggesting that BM-toxic effects of the antiviral treatment may have impaired both donor and recipient hematopoiesis. Two additional $\mathrm{T}_{\text {reg }}$ cell recipients, 6c1 and 90-15, experienced CMV reactivation with high viral loads and required treatment with antivirals at high doses within the first week posttransplant. These animals developed only shortlived and low levels of chimerism (6c64, 6c1, 90-15 shown in Figure 3, middle row) in association with protracted cytopenias, often requiring transfusions. These results suggest that CMV reactivation and/or the bone marrow toxic effects of early antiviral 


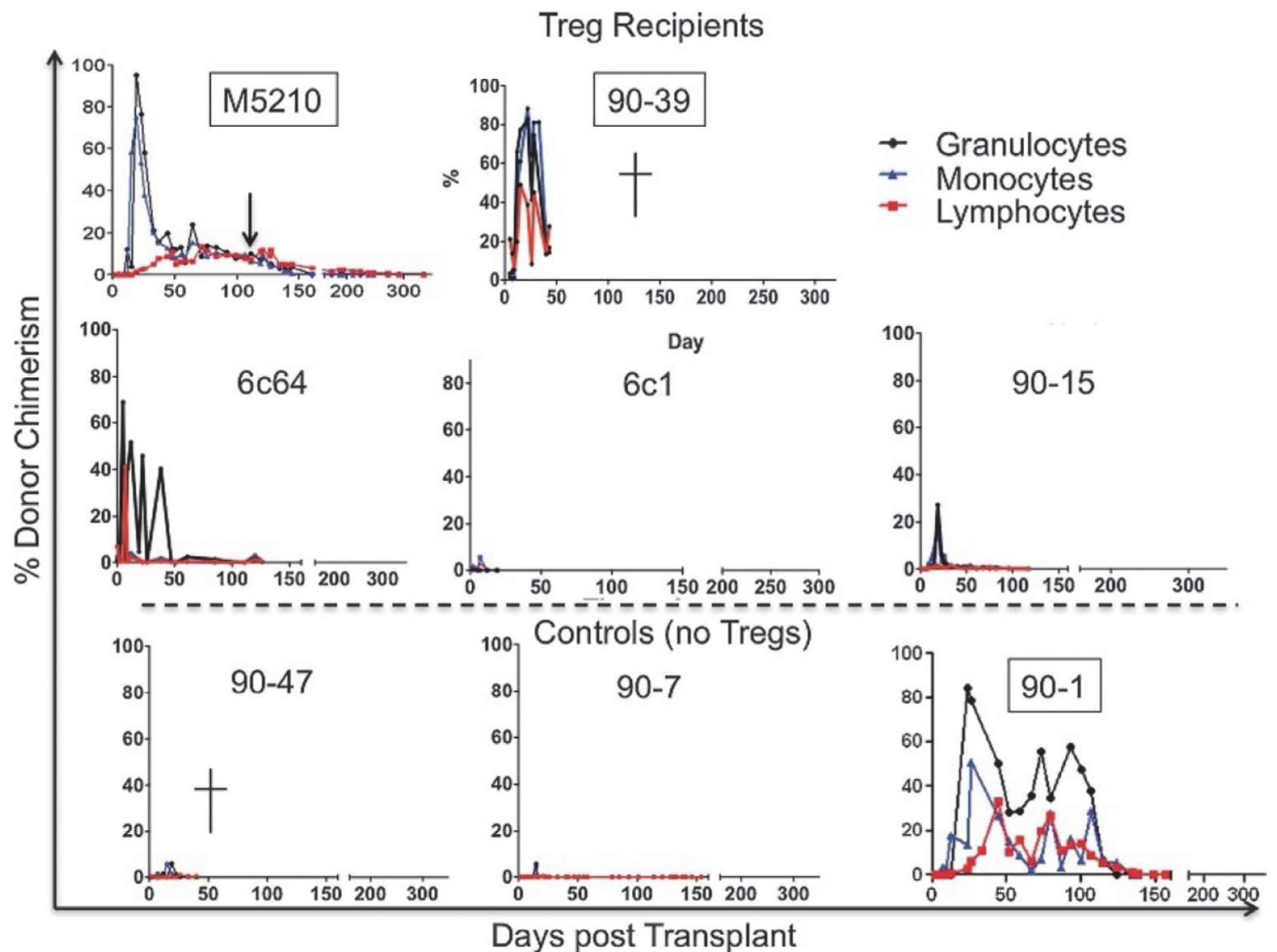

Figure 3. Summary of percent donor chimerism. Granulocyte (black circles), monocyte (blue triangles) and lymphocyte (red squares) lineages of each animal are shown. Animals with boxed identification numbers (M5210, 90-39, and 90-1) received no antiviral treatments. Animals whose figures have a cross died or were euthanized due to untreated or unmanageable CMV disease. Animal 90-47 was serologically CMV-pre-Tx, but developed CMV following BMT from a CMV+ donor that had been serologically negative on initial screen. Animal 90-1, who was CMV- pre-Tx and received a BMT from a CMV- donor, never developed CMV. The 5 animals shown on the top part of the figure received BMT+ $\mathrm{T}_{\text {reg, }}$, while the 3 below the dotted line received BMT without $\mathrm{T}_{\text {reg. }}$

therapy may have potentially interfered with initial engraftment of the donor marrow.

Of the 3 control animals $(90-47,90-7,90-1)$ receiving BMT without $\mathrm{T}_{\text {reg }}$ cell infusion, 1 (animal 90-47) died of CMV before the development and implementation of the CMV surveillance and treatment protocol, without showing any significant chimerism (Figure 3, bottom row, left panel). The 2 other controls survived long term. Animal 90-7 also developed low-level, short-lived chimerism. The third control animal, 90-1, was unique in that both recipient, M5210, had only a very low level CMV viremia $(<1,000$ copies $/ \mathrm{mL})$ and exhibited the longest documented donor chimerism ever seen with this or related protocols over a period of more than twenty years.

\subsection{ONLY TREG CELL RECIPIENTS}

\section{DEVELOPED T CELL CHIMERISM}

The 3 evaluable (i.e., that were not treated early with antivirals) animals that had measurable lymphoid chimerism included $\mathrm{T}_{\text {reg }}$ cell recipients it and the donor were CMV-negative and chimerism lasted over 100 days before disappearing $(6,32)$.

In summary, recipients that reactivated CMV, regardless of $\mathrm{T}_{\text {reg }}$ cell infusion, succumbed to disease if not treated promptly with antivirals. Early CMV reactivation and its treatment or prophylaxis were associated with very short-lived chimerism. Only 2 animals survived without antiviral treatment $\left(1 \mathrm{~T}_{\text {reg }}\right.$ cell recipient and 1 CMV-negative non- $\mathrm{T}_{\text {reg }}$ cell control.). The $\mathrm{T}_{\text {reg }}$ cell

M5210 and 90-39 and CMV(-) control recipient 90-1 (Figure 4).

However, in the non- $\mathrm{T}_{\text {reg }}$ cell recipient 90-1 (the control animal in which donor and recipient were CMV negative), lymphoid chimerism included NK cells (data not shown) and B cells (e.g., Figure $4 \mathrm{~B}$, left), but did not include significant donor $\mathrm{T}$ cell chimerism. In contrast, both evaluable $\mathrm{T}_{\text {reg }}$ cell recipients had not only $\mathrm{B}$ cell and NK cell chimerism, but also significant CD4 and CD8 T cell chimerism (Figures $4 \mathrm{~B}$, center and $\mathrm{C}$, right). In M5210, the long-lived $\mathrm{T}_{\text {reg }}$ cell recipient, $\mathrm{T}$ cell 
A

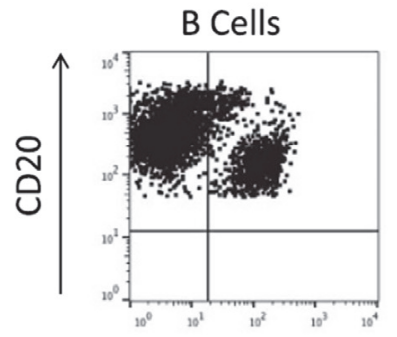

T Cells

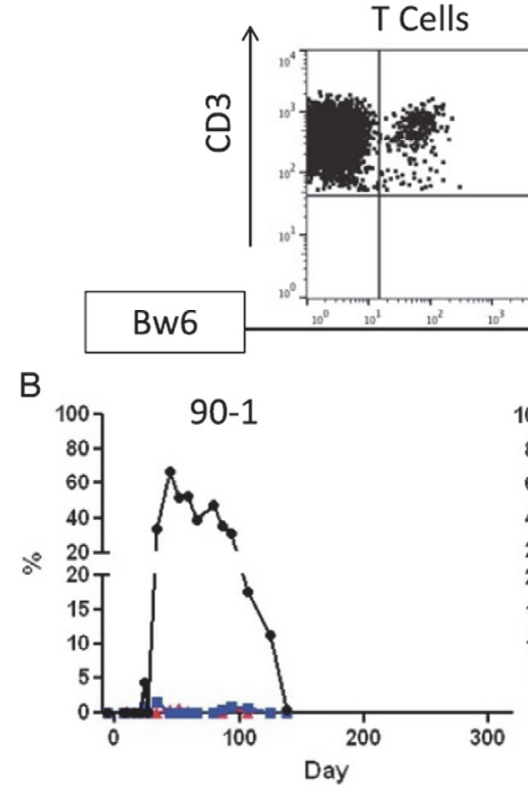

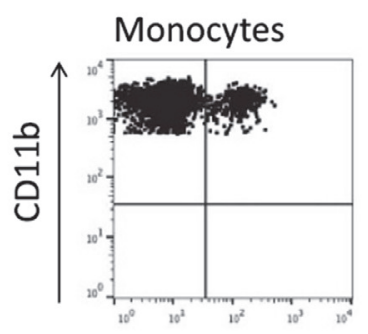

CD4+CD8- T Cells
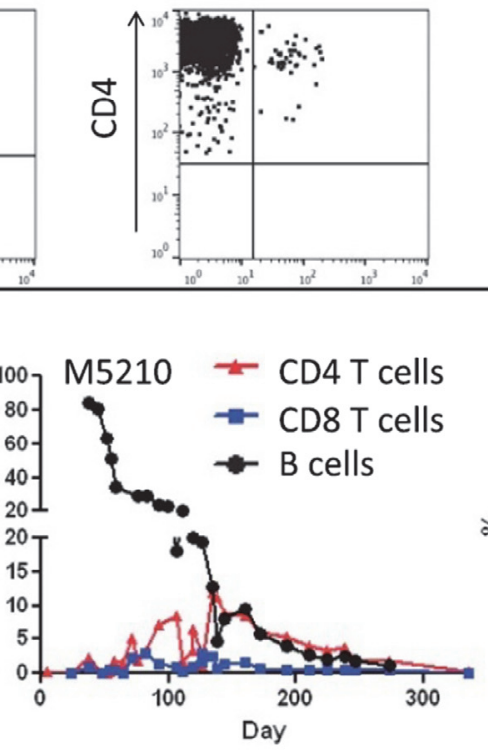

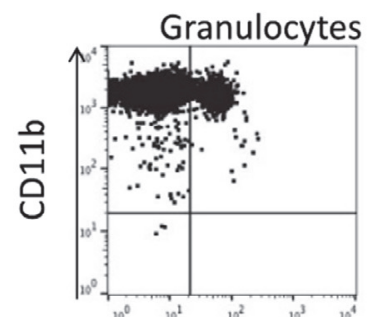

CD4-CD8+T Cells

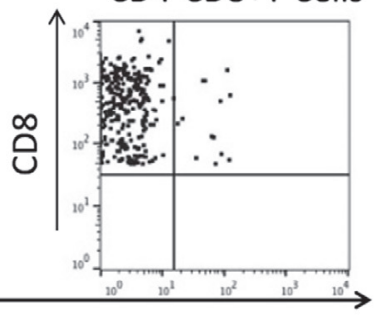

Figure 4. Chimerism analysis of BMT recipients. (A) Representative flow cytometry of animal M5210 on day +99 post BMT. Donor chimerism is measured with the $\mathrm{Bw6}^{+}$(MHC-I) marker. B cell $\left(\mathrm{CD} 20^{+}\right)$, monocyte $\left(\mathrm{CD} 11 \mathrm{~b}^{+}\right)$and T cell (CD3, CD4 and CD8) chimerism measured among cells with low/medium forward and side scatter (not shown). Granulocytes $\left(\mathrm{CD} 11 \mathrm{~b}^{+}\right.$) were analyzed among cells with high forward and side scatter (not shown). (B) B Cell (black circle), CD4 (red triangle) and CD8 (blue square) T cell chimerism in the 3 animals with the highest and most prolonged chimerism. CMV- control animal 90-1 developed high levels $\mathrm{B}$ cell chimerism, but no $\mathrm{T}$ cell chimerism and chimerism declined after discontinuation of immunosuppression and was completely lost by day 110. Treg recipient M5210 developed high B cells chimerism and delayed, prolonged T cell chimerism in both CD4 and CD8 T cell lineages. Chimerism lasted

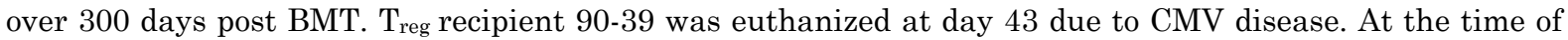
euthanasia B cell and CD4 T cell chimerism was detectable in the peripheral blood.

chimerism first appeared 45 days post-BMT $(2.5$ weeks after cyclosporine had been discontinued) and increased significantly on day +60 post-BMT. Similarly, Treg cell recipient 90-39 (which died of CMV on day +43) had a spike in donor $\mathrm{T}$ cell chimerism in the peripheral blood 1 month after BMT (at the time immunosuppression was discontinued) (Figure 4B, right) and still had peripheral blood $\mathrm{T}$ cell chimerism (5\%, mostly in $\mathrm{CD} 4 \mathrm{~T}$ cells) on the day of euthanasia. These results represent the first time that $\mathrm{T}$ cell chimerism has been observed using this nonmyeloablative monkey BMT model and suggest that $\mathrm{T}_{\text {reg }}$ cells promote $\mathrm{T}$ cell chimerism.

We then investigated, in the only long-lived $\mathrm{T}_{\text {reg }}$ cell recipient chimera, the phenotype of host and donor $\mathrm{T}$ cells, including CD31, a marker expressed on new thymic emigrants (36) and CD45RA, a marker of naïve $\mathrm{T}$ cells, among both donor and recipient $\mathrm{T}$ cells (Figure 5). Almost all donor CD4 and CD8 T cells in M5210 expressed CD31 throughout followup (Figures 5A and B). Consistent with de novo origin in the recipient thymus, the expression of CD45RA was also very high on donor CD4+ T cells Figure $5 \mathrm{C}$ ), peaking close to $90 \%$. For recipient $\mathrm{T}$ cells, expression of CD31 in both CD4 and CD8 cell populations was significantly less. However, CD31 expression increased markedly in host $\mathrm{T}$ cells (80\%) early after the transplant (Figures 5A-B), suggesting that a wave of new host T-cells was released from the thymus after transplant. The percentage of host-derived CD31 ${ }^{+} \mathrm{T}$ cells slowly decreased from day \pm 20 until day +50 . CD45RA expression on recipient $\mathrm{CD} 4^{+} \mathrm{T}$ cells peaked at $50 \%$ at about 1 month posttransplant. The expression of CD31 and CD45RA was lower in animals that did not develop donor $\mathrm{T}$ cell chimerism, as shown in Figures 5A to $\mathrm{C}$ (bottom rows) for animal 90-7, a control BMT recipient that did not receive $\mathrm{T}_{\text {reg }}$ cells. In summary, donor $\mathrm{T}$ cells exhibited high levels of 


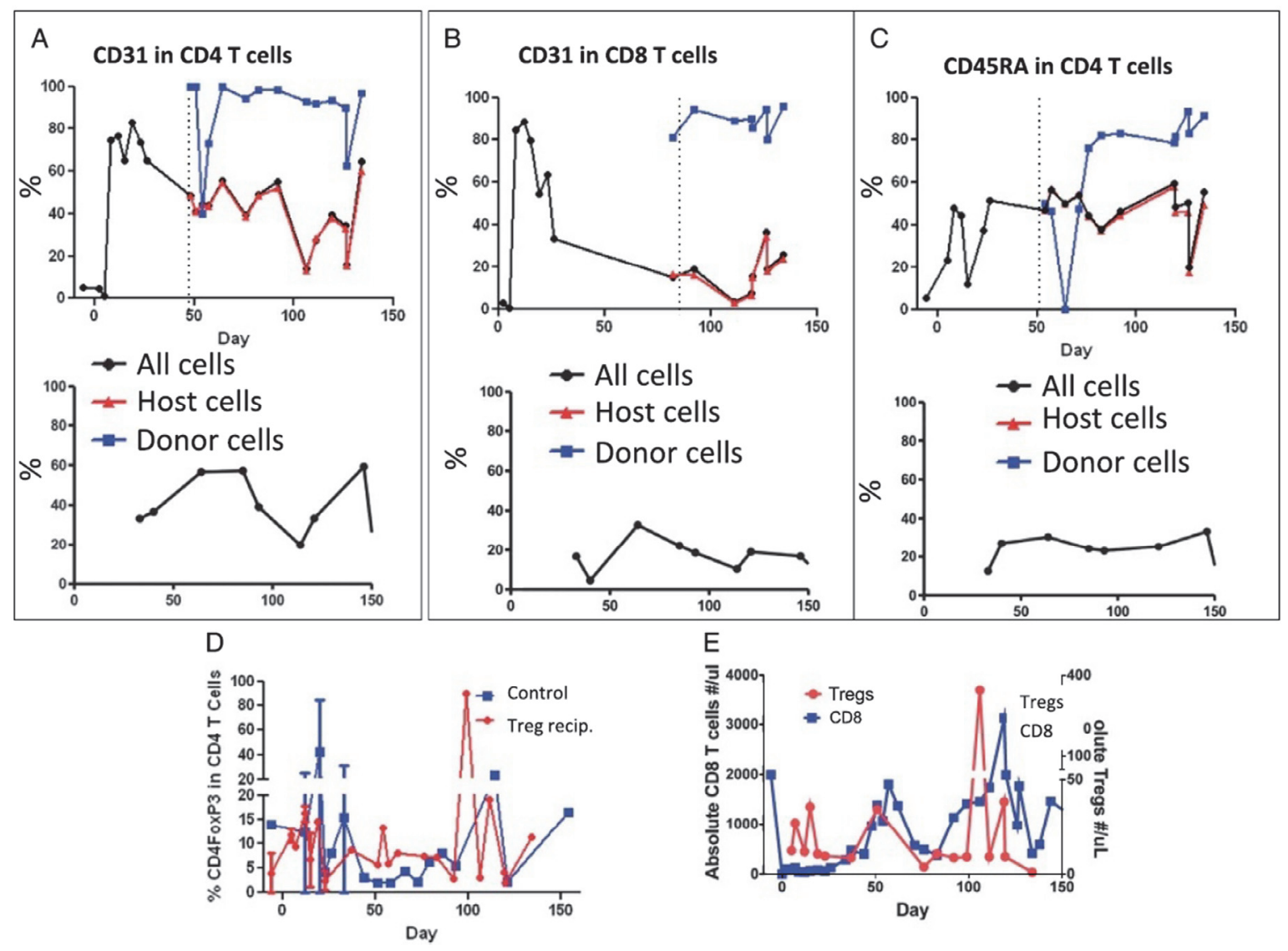

Figure 5. Immune reconstitution of animal M5210 Post BMT (+ $\mathrm{T}_{\text {reg }}$ ) and 90-7 (control). (A-C top row M5210 and bottom row 90-7 control). Dotted lines indicate first detection of donor chimerism in CD4 or CD8 T cells. (A-top) Total CD4 T cells (black circle) expressed CD31 at increased levels posttransplant. Donor CD4 T cells (blue squares) maintained high CD31expression. Recipient-derived CD4 $\mathrm{T}$ cells (red triangles) expressed lower levels of CD31. (B-top) Total CD8 T cells expressed high CD31 levels following transplant (black circle). CD31 expression in host CD8 T cells (red triangles) decreased, however donor-derived cells (blue squares) maintained high CD31 expression long after transplant. (C-top) Donor-derived CD4 T cells (blue squares) expressed higher levels of CD45RA compared to recipient CD4 T cells (red triangles). In contrast animal 90-7 never exhibited any donor chimerism (A-C bottom row) and the levels of CD31 and CD45 were lower than those observed in M5210 donor (blue) T cell populations. (D) Average percentage of CD4 T cells expressing FoxP3 after transplant in $\mathrm{T}_{\text {reg }}$ recipients (red triangles) ( $\mathrm{n}=2$ animals) compared to control animals (blue squares) $(\mathrm{n}=3)$. (E) Animal M5210 absolute Treg numbers (red triangles) compared to the absolute number of CD8 T cells (blue squares).

CD45RA and CD31, suggesting de novo development from the thymus in animal M5210.

\subsection{KINETICS OF $\mathrm{CD}^{+}{ }^{+} \mathrm{CD}^{+}{ }^{+} \mathrm{FOXP}^{+}{ }^{+}$CELLS IN THE CIRCULATION AFTER INFUSION}

Peripheral $\mathrm{T}_{\text {reg }}$ cell counts and percentages were similar in the 3 controls and the 2 evaluable $\mathrm{T}_{\text {reg }}$ cell recipients that developed high levels of chimerism (M5210 and 90-39) (Figure 5D). Treg cells were largely of recipient origin (Figure S2, SDC, http://links.lww.com/TP/B373). A peak was observed on day +50 in M5210 after the infusion of 28 million $\mathrm{T}_{\mathrm{reg}} / \mathrm{kg}$, which was given in an effort to reverse a sudden increase in the absolute number of $\mathrm{CD}^{+}{ }^{+} \mathrm{CD}^{2} 8^{-}$effector CD8 $\mathrm{T}$ cells (Figure $5 \mathrm{E}$ ) of mostly recipient origin (Figure $4 \mathrm{~B}$, middle panel) 20 days after the discontinuation of cyclosporine $\mathrm{A}$ (levels on day +48 were subtherapeutic at $118 \mathrm{ng} / \mathrm{mL}$ and low on day +53 at $35 \mathrm{ng} / \mathrm{mL}$ ). CD8 T cell counts declined after the infusion of $\mathrm{T}_{\text {reg }}$ cells on day +50 (Figure $5 \mathrm{E}$ ). Both the $\mathrm{T}$ cell chimerism (Figure 4B) and the myeloid chimerism (Figure 3, top left panel) increased shortly after the $\mathrm{T}_{\text {reg }}$ cell infusion and remained stable for an additional 80 days (Figure 3, top left). Of note, on day 80 postBMT, there was a second increase in the absolute CD8 $\mathrm{T}$ cell count that was followed by a subsequent spontaneous $\mathrm{T}_{\text {reg }}$ cell increase, after which CD8 counts normalized (Figure 5E).

In summary, infusion of $\mathrm{T}_{\text {reg }}$ cells was associated with the development of $\mathrm{T}$ cell chimerism, prolonged multilineage chimerism, and reversal of increasing recipient effector $\mathrm{CD}^{+} \mathrm{T}$ cell counts in animal M5210. 
A

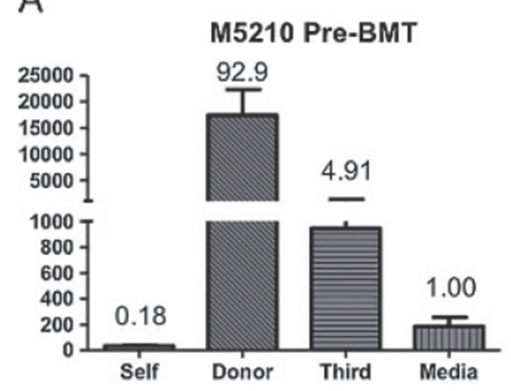

C
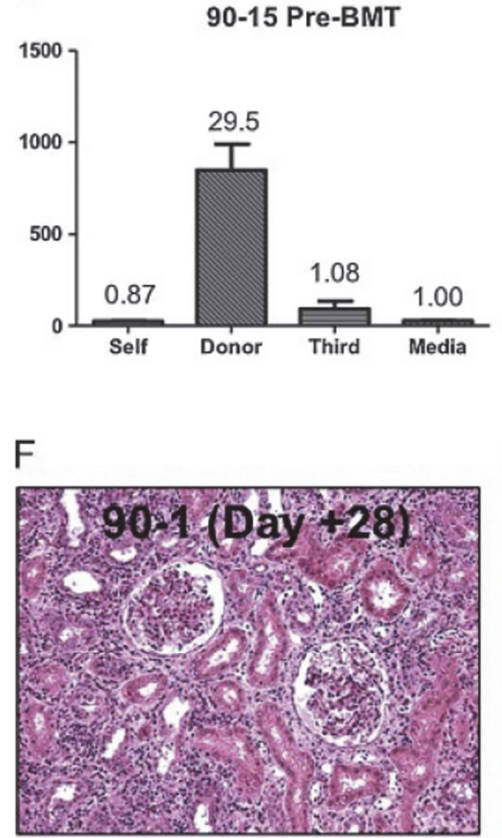

B

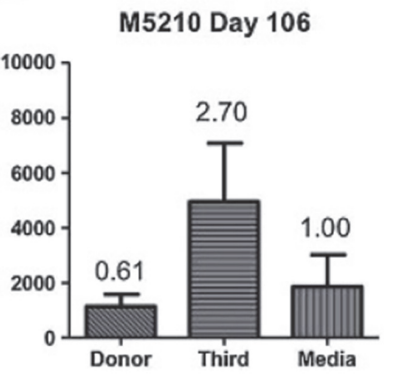

D

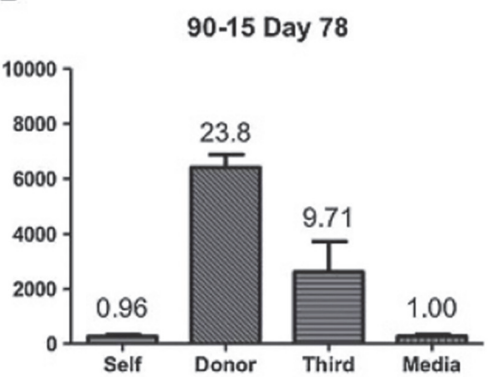

E

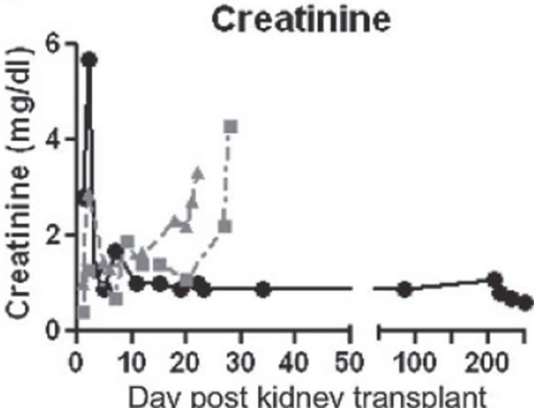

G

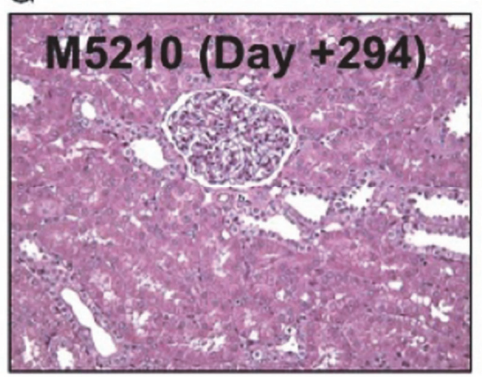

* Treg Recipient

-... Control Animal 1

- Control Animal 2

Day post kidney transplant

Figure 6. Tolerance to the donor in M5210 $\mathrm{T}_{\text {reg }}$ recipient but not in control. (A) Pre-transplant MLR in animal M5210 demonstrates strong proliferative responses to donor (diagonal stripes) and weaker response to third party (horizontal stripes). (B) Day 106 Post-Tx MLR (before kidney allograft from the same BM donor). Proliferation is maintained to third party but not to donor. (C) Animals that lost chimerism never became tolerant nor showed decreased anti-donor proliferation. An example is shown in (C) pretransplant and (D) posttransplant day 78. (E) Following kidney transplant, creatinine levels in M5210 (black circle) stayed in the normal range while that in 2 control (non- $\mathrm{T}_{\text {reg }}$ ) animals (dashed grey lines) showed increases 2 3 weeks following kidney transplant. (F, G) Kidney histopathology. Biopsies were taken from transplanted donor kidneys at the time of euthanasia. Shown is day +28 and day +294 (day of euthanasia) post kidney transplant in animals 90-1 (F) (control, left) and M5210 (G) (+Treg, right) respectively. 90-1 had extensive lymphocyte infiltrates scored as a Banff grade 3 rejection, while M5210 showed no signs of rejection. 


\subsection{PROOF OF PRINCIPLE: PERSISTENT CHIMERISM INDUCED BY TREG CELL TREATMENT WAS ASSOCIATED WITH IN VITRO DONOR-SPECIFIC HYPORESPONSIVENESS AND ALLOGRAFT TOLERANCE}

M5210 showed donor-specific unresponsiveness in MLR at day 106, before kidney transplantation was performed (Figure 6B), whereas strong proliferative responses to the donor were present pre-BMT (Figure 6A). Similar responses to third party were observed posttransplantation. pretransplantation and

Animals were challenged with a solid organ allograft (a kidney from the same BMT donor) 4 months after the original BMT, without immunosuppression. Only $1 \mathrm{~T}_{\text {reg }}$ cell recipient (M5210) was evaluable at the 4-month timepoint. At the time of kidney transplant, M5210 remained chimeric in all lineages (Figures 3 and 4). The recipient's contralateral ureter was ligated on day 0 and on day 100 post kidney transplant the recipient's contralateral kidney was removed. Serum creatinine levels (Figure 6E) remained normal and stable until the day of euthanasia 293 days postkidney transplant, demonstrating tolerance to the donor kidney. Histopathology on day +294 postkidney transplant showed no evidence for rejection in M5210 (Figure 6F).Two control animals that underwent the same protocol (without $\mathrm{T}_{\text {reg }}$ cells) were also grafted with a kidney from their same BM donor 4 months post-BMT. In contrast to M5210, the 2 controls rejected their donor kidneys within a month (Figure 6E), in line with previous results (27). The donor kidneys in nonchimeric control animals showed Banff grade 3 rejection (Figures 6F and $\mathrm{G}$ ) at the time of euthanasia. Nonchimeric $\mathrm{T}_{\text {reg }}$ cell recipients (i.e., animals that received $\mathrm{T}_{\text {reg }}$ cells but had short-lived hematopoietic chimerism in association with early CMV reactivation and treatment) retained antidonor proliferative responses (Figures 6C and D) and rejected donor kidneys on day +120 post-BMT $(n=2)$, similar to controls (data not shown). These results are proof of concept and suggestive of the importance of mixed chimerism in tolerance induction in this model. No or minimal antidonor alloantibody was detected in animals that rejected their donor kidneys (Figure S3, SDC, http://links.lww.com/TP/B373).

In summary, control recipients rejected the donor kidneys uniformly, whereas the only evaluable long-term surviving $\mathrm{T}_{\text {reg }}$ cell recipient M5210 maintained normal kidney function until termination of the experiment. This result provides proof-of-principle that prolongation of chimerism using expanded $\mathrm{T}_{\text {reg }}$ cells can promote more robust tolerance than that achieved in previous studies using this model $(6,27,32)$.

\section{DISCUSSION}

Our studies provide proof-of-concept that expanded recipient-derived polyclonal $\mathrm{T}_{\text {reg }}$ cells can increase and extend donor hematopoietic chimerism and promote robust allograft tolerance across MHC barriers in a NHP nonmyeloablative BMT model without an increased risk of GVHD. Infusion of $\mathrm{T}_{\mathrm{reg}}$ cell is an attractive approach to overcoming $\mathrm{HvG}$ responses, because it may further reduce the risk of GVHD (37) rather than increasing this risk or the overall toxicity of the conditioning regimen like most other approaches.

Phase I clinical trials using $\mathrm{T}_{\text {reg }}$ cells have shown safety (38), but efficacy remains to be proven. Both induced and natural $\mathrm{T}_{\text {reg }}$ cell promoted engraftment, stable mixed chimerism and tolerance in mice under a minimal conditioning protocol in which the $\mathrm{BM}$ is otherwise rejected $(24,26)$. We demonstrate in a monkey model that host $\mathrm{T}_{\text {reg }}$ cells improved the level and duration of chimerism, extending it to the $\mathrm{T}$ cells. Moreover, robust donorspecific tolerance was achieved in 1 evaluable animal such that a donor kidney grafted at 4 months post-transplant was accepted without immunosuppression. Previous studies using this protocol without $\mathrm{T}_{\text {reg }}$ cells, in which donor $\mathrm{BM}$ and kidney were co-transplanted on day 0 , were associated with long-term kidney graft survival in about $60 \%$ of animals $(6,39)$ and donor hematopoietic chimerism (in some animals reaching $\pm 85 \%$ ) consistently disappeared by day 60 post-BMT (32). A delay in grafting a donor kidney to more than 3 months post-BMT was always associated with rejection of the donor graft (27).

Previous work in NHPs (rhesus macaques) using a nonmyeloablative BMT regimen with costimulatory blockade achieved prolonged levels of donor chimerism as long as basiliximab and belatacept were infused. Chimerism was lost after discontinuation of this treatment (40) and allograft tolerance was not achieved. In contrast, an animal in our study retained chimerism to 335 days and accepted a donor kidney grafted at 4 months, despite stopping immunosuppressive monotherapy at 28 days post-BMT.

In mice, we have shown that the presence of $\mathrm{T}$ cell chimerism is associated with early and long-term deletional tolerance, because thymic engraftment of donor $\mathrm{T}$ cell progenitors reflects successful ablation of intrathymic alloreactivity, permitting intrathymic engraftment of both thymocyte progenitors and donor APCs that contribute to negative selection of donor-reactive $\mathrm{T}$ cells $(22,41-43)$. For the first time in the more than 20 years using this monkey nonmyeloablative BMT regimen, we have obtained evidence of de novo donor thymopoiesis, with $\mathrm{T}$ cell chimerism consisting of recent thymic emigrants in the peripheral blood. CD45RA and CD31 expressions suggested that almost all donor cells were newlydeveloped, whereas recipient $\mathrm{T}$ cells were a mix of new thymic emigrants and naive or memory $\mathrm{T}$ cells that evaded host conditioning.

CMV reactivation presented a major impediment to achieving the goals of our studies. Although this complication has not been described in previous studies using the model we adopted, uniform CMV reactivation has been reported in 
cynomolgus monkeys receiving thymoglobulin (44). CMV reactivation was not directly caused by the infusion of $\mathrm{T}_{\text {reg }}$ cells because control animals had a similar rate of reactivation. Only 1 animal, M5210, was able to control CMV without antiviral treatment. Because CMV itself can directly affect $\mathrm{BM}$ function (45-47) and antiviral treatments are known to be BM toxic, modifications to the protocol are needed. The increased duration and level of chimerism observed in the $1 \mathrm{CMV}$-negative (non$\mathrm{T}_{\text {reg }}$ cell recipient) transplant (albeit without $\mathrm{T}$ cell chimerism or tolerance) supports a direct role for $\mathrm{CMV}$ and/or its treatment in limiting hematopoietic engraftment. We are currently exploring substitution of the mTOR inhibitor rapamycin for CSA to better control CMV reactivation and enhance $\mathrm{T}_{\text {reg }}$ cell function, expansion, and survival $(24,48)$.

In summary, we provide proof-of-concept that BM plus expanded cryopreserved polyclonal recipient $\mathrm{T}_{\text {reg }}$ cell can prolong donor chimerism, promote $\mathrm{T}$ cell chimerism and induce robust tolerance without an increase of toxic conditioning intensity or GVHD risk in a preclinical monkey model. Successful refinement of this protocol has the potential to be translated to the clinic.

\section{ACKNOWLEDGMENTS}

The authors thank Dr. Remi Creusot for the critical review of the article.

\section{REFERENCES}

1. S. Hori, Control of regulatory T cell Development by the transcription factor Foxp3. Science 299, 1057 (2003/01/09, 2003).

2. S. M. Kang, Q. Tang, J. A. Bluestone, CD4+CD25+Regulatory $\mathrm{T}$ cells in transplantation: Progress, challenges and prospects. American Journal of Transplantation 7, 1457 (2007/06, 2007).

3. S. Sakaguchi, D. A. A. Vignali, A. Y. Rudensky, R. E. Niec, H. Waldmann, The plasticity and stability of regulatory T cells. Nature Reviews Immunology 13, 461 (2013/05/17, 2013).

4. S. M. Krummey, M. L. Ford, Braking bad: Novel mechanisms of CTLA-4 inhibition of $\mathrm{T}$ cell responses. American Journal of Transplantation 14, $2685(2014 / 11 / 11,2014)$

$5 . \quad$ S. Amarnath, C. W. Mangus, J. C. M. Wang, F. Wei, A. He, V. Kapoor, J. E. Foley, P. R. Massey, T. C. Felizardo, J. L. Riley, B. L. Levine, C. H. June, J. A. Medin, D. H. Fowler, The PDL1-PD1 axis converts human TH1 cells into regulatory T cells. Science translational medicine 3 , 111ra120 (2011/11/30, 2011)

6. T. Kawai, A. B. Cosimi, R. B. Colvin, J. Powelson, J. Eason, T. Kozlowski, M. Sykes, R. Monroy, M. Tanaka, D. H. Sachs, Mixed allogeneic chimerism and renal allograft tolerance in cynomolgus monkeys. Transplantation 59, $256(1995 / 01,1995)$.

7. T. Kawai, A. B. Cosimi, T. R. Spitzer, N. TolkoffRubin, M. Suthanthiran, S. L. Saidman, J. Shaffer, F. I. Preffer, R. Ding, V. Sharma, J. A. Fishman, B. Dey, D. S. Ko, M. Hertl, N. B. Goes, W. Wong, W. W. Williams, Jr., R. B. Colvin, M. Sykes, D. H. Sachs, HLA-mismatched renal transplantation without maintenance immunosuppression. $N$ Engl $J$ Med 358, 353 (Jan 24, 2008).

8. T. Kawai, H. Sogawa, M. Koulmanda, R. N. Smith, J. J. O'Neil, S. L. Wee, S. Boskovic, M. Sykes, R. B. Colvin, D. H. Sachs, H. Auchincloss, Jr., A. B. Cosimi, C. K. DS, Long-term islet allograft function in the absence of chronic immunosuppression: a case report of a nonhuman primate previously made tolerant to a renal allograft from the same donor. Transplantation 72, 351 (Jul 27, 2001).

$9 . \quad$ T. Kawai, A. B. Cosimi, S. L. Wee, S. Houser, D. Andrews, H. Sogawa, J. Phelan, S. Boskovic, O. Nadazdin, G. Abrahamian, R. B. Colvin, D. H. Sach, J. C. Madsen, Effect of mixed hematopoietic chimerism on cardiac allograft survival in cynomolgus monkeys. Transplantation 73, 1757 (Jun 15, 2002).

10. A. Aoyama, C. Y. Ng, T. M. Millington, S. Boskovic, T. Murakami, J. C. Wain, S. L. Houser, J. C. Madsen, T. Kawai, J. S. Allan, Comparison of lung and kidney allografts in induction of tolerance by a mixed-chimerism approach in cynomolgus monkeys. Transplantation Proceedings 41, 429 (2009/01, 2009).

11. J. D. Scandling, S. Busque, S. Dejbakhsh-Jones, C. Benike, M. T. Millan, J. A. Shizuru, R. T. Hoppe, R. Lowsky, E. G. Engleman, S. Strober, Tolerance and chimerism after renal and hematopoietic-cell transplantation. New England Journal of Medicine 358, 362 (2008/01/24, 2008).

12. J. D. Scandling, S. Busque, S. Dejbakhsh-Jones, C. Benike, M. Sarwal, M. T. Millan, J. A. Shizuru, R. Lowsky, E. G. Engleman, S. Strober, Tolerance and withdrawal of immunosuppressive drugs in patients given kidney and hematopoietic cell transplants. American Journal of Transplantation 12, 1133 (2012/03/08, 2012).

13. J. D. Scandling, S. Busque, J. A. Shizuru, E. G. Engleman, S. Strober, Induced immune tolerance for kidney transplantation. New England Journal of Medicine 365, 1359 (2011/10/06, 2011).

14. M. T. Millan, J. A. Shizuru, P. Hoffmann, S. Dejbakhsh-Jones, J. D. Scandling, F. Carl Grumet, J. C. Tan, O. Salvatierra, R. T. Hoppe, Strober, Samuel, Mixed chimerism and immunosuppressive drug withdrawal after hlamismatched kidney and hematopoietic progenitor transplantation1. Transplantation 73, $1386(2002 / 05,2002)$.

15. J. Leventhal, M. Abecassis, J. Miller, L. Gallon, K. Ravindra, D. J. Tollerud, B. King, M. J. Elliott, G. Herzig, R. Herzig, S. T. Ildstad, Chimerism and tolerance without GVHD or engraftment syndrome in HLA-mismatched combined kidney and hematopoietic stem cell transplantation. Science translational medicine 4, 124ra28 (2012/03/07, 2012).

16. J. Leventhal, M. Abecassis, J. Miller, L. Gallon, D. Tollerud, M. J. Elliott, L. D. Bozulic, C. Houston, N. Sustento-Reodica, S. T. Ildstad, Tolerance induction in HLA disparate living donor kidney transplantation by donor stem cell infusion. Transplantation Journal 95, 169 (2013/01, 2013).

17. J. R. Leventhal, M. J. Elliott, E. S. Yolcu, L. D. Bozulic, D. J. Tollerud, J. M. Mathew, I. Konieczna, M. G. Ison, J. Galvin, J. Mehta, M. D. Badder, M. M. I. Abecassis, J. Miller, L. Gallon, S. T. Ildstad, Immune 
reconstitution/immunocompetence in recipients of kidney plus hematopoietic stem/facilitating cell transplants. Transplantation 99, 288 (2015/02, 2015)

18. E. Rüedi, M. Sykes, S. T. Ildstad, C. H. Chester, A. Althage, H. Hengartner, D. H. Sachs, R. M. Zinkernagel, Antiviral T cell competence and restriction specificity of mixed allogeneic $(\mathrm{P} 1+$ P2 $\rightarrow$ P1) irradiation chimeras. Cellular Immunology 121, 185 (1989/06, 1989).

19. S. T. Ildstad, Characterization of mixed allogeneic chimeras. Immunocompetence, in vitro reactivity, and genetic specificity of tolerance. Journal of Experimental Medicine 162, $231(1985 / 07 / 01,1985)$.

20. R. M. Zinkernagel, A. Althage, G. Callahan, R. M. Welsh, Jr., On the immunocompetence of $\mathrm{H}-2$ incompatible irradiation bone marrow chimeras. Journal of immunology 124, 2356 (May, 1980).

21. Y. Sharabi, D. H. Sachs, Mixed chimerism and permanent specific transplantation tolerance induced by a nonlethal preparative regimen. $J$ Exp Med 169, 493 (Feb 1, 1989)

22. Y. Tomita, A. Khan, M. Sykes, Role of intrathymic clonal deletion and peripheral anergy in transplantation tolerance induced by bone marrow transplantation in mice conditioned with a nonmyeloablative regimen. Journal of immunology 153, 1087 (Aug 1, 1994).

23. N. Pilat, T. Wekerle, Mechanistic and therapeutic role of regulatory $\mathrm{T}$ cells in tolerance through mixed chimerism. Current Opinion in Organ Transplantation 15, 725 (2010/12, 2010).

24. N. Pilat, U. Baranyi, C. Klaus, E. Jaeckel, N. Mpofu, F. Wrba, D. Golshayan, F. Muehlbacher, T. Wekerle, Treg-therapy allows mixed chimerism and transplantation tolerance without cytoreductive conditioning. American Journal of Transplantation 10, 751 (2010/04, 2010)

25. N. Pilat, A. M. Farkas, B. Mahr, C. Schwarz, L. Unger, K. Hock, R. Oberhuber, K. Aumayr, F. Wrba, T. Wekerle, T-regulatory cell treatment prevents chronic rejection of heart allografts in a murine mixed chimerism model. The Journal of Heart and Lung Transplantation 33, 429 (2014/04, 2014)

26. N. Pilat, C. Klaus, K. Hock, U. Baranyi, L. Unger, B. Mahr, A. M. Farkas, F. Wrba, T. Wekerle, Polyclonal recipient nTregs are superior to donor or third-party Tregs in the induction of transplantation tolerance. Journal of Immunology Research 2015, 1 (2015).

27. T. Kawai, A. Poncelet, D. H. Sachs, S. Mauiyyedi, S. Boskovic, S. L. Wee, D. S. Ko, A. Bartholomew, M. Kimikawa, H. Z. Hong, G. Abrahamian, R. B. Colvin, A. B. Cosimi, Longterm outcome and alloantibody production in a non-myeloablative regimen for induction of renal allograft tolerance. Transplantation 68, 1767 (Dec 15, 1999).

$28 . \quad$ K. J. Campbell, A. M. Detmer, J. A. Karl, R. W. Wiseman, A. J. Blasky, A. L. Hughes, B. N. Bimber, S. L. O'Connor, D. H. O'Connor, Characterization of $47 \mathrm{MHC}$ class I sequences in Filipino cynomolgus macaques. Immunogenetics 61, 177 (2008/12/24, 2008)

29. S. L. O'Connor, A. J. Blasky, C. J. Pendley, E. A Becker, R. W. Wiseman, J. A. Karl, A. L. Hughes, D. H. O'Connor, Comprehensive characterization of MHC class II haplotypes in Mauritian cynomolgus macaques. Immunogenetics 59, 449 (2007/03/24, 2007).

30. C. J. Pendley, E. A. Becker, J. A. Karl, A. J. Blasky, R. W. Wiseman, A. L. Hughes, S. L. O'Connor, D. H. O'Connor, MHC class I characterization of Indonesian cynomolgus macaques. Immunogenetics 60, 339 (2008/05/27, 2008)

31. R. W. Wiseman, J. A. Karl, B. N. Bimber, C. E. O'Leary, S. M. Lank, J. J. Tuscher, A. M. Detmer, P. Bouffard, N. Levenkova, C. L. Turcotte, E. Szekeres, C. Wright, T. Harkins, D. H. O'Connor, Major histocompatibility complex genotyping with massively parallel pyrosequencing. Nature medicine $\mathbf{1 5}, 1322$ (2009/10/11, 2009)

32. T. Kawai, H. Sogawa, S. Boskovic, G. Abrahamian, R.-N. Smith, S.-L. Wee, D. Andrews, O. Nadazdin, I. Koyama, M. Sykes, H. J. Winn, R. B. Colvin, D. H. Sachs, A. B. Cosimi, CD154 blockade for induction of mixed chimerism and prolonged renal allograft survival in nonhuman primates. American Journal of Transplantation 4, 1391 (2004/09, 2004).

33. R. De Waal Malefyt, S. Verma, M.-T. Bejarano, M. Ranes-Goldberg, M. Hill, H. Spits, CD2/LFA3 or LFA-1/ICAM-1 but not CD28/B7 interactions can augment cytotoxicity by virus-specific $\mathrm{CD} 8^{+}$ cytotoxic T lymphocytes. European Journal of Immunology 23, 418 (1993/02, 1993).

34. M. K. Levings, R. Sangregorio, F. Galbiati, S. Squadrone, R. de Waal Malefyt, M. G. Roncarolo, IFN- and IL-10 induce the differentiation of human type $1 \mathrm{~T}$ regulatory cells. The Journal of Immunology 166, 5530 (2001/05/01, 2001).

35. A. B. Cosimi, F. L. Delmonico, J. K. Wright, S. L. Wee, F. I. Preffer, L. K. Jolliffe, R. B. Colvin, Prolonged survival of nonhuman primate renal allograft recipients treated only with anti-CD4 monoclonal antibody. Surgery 108, 406 (Aug, 1990).

36. S. Kimmig, G. K. Przybylski, C. A. Schmidt, K. Laurisch, B. Möwes, A. Radbruch, A. Thiel, Two subsets of naive $\mathrm{T}$ helper cells with distinct $\mathrm{T}$ cell receptor excision circle content in human adult peripheral blood. The Journal of Experimental Medicine 195, 789 (2002/03/18, 2002).

37. B. Sawitzki, C. Brunstein, C. Meisel, J. Schumann, K. Vogt, C. Appelt, J. M. Curtsinger, M. R. Verneris, J. S. Miller, J. E. Wagner, B. R. Blazar, Prevention of graft-versus-host disease by adoptive $\mathrm{T}$ regulatory therapy is associated with active repression of peripheral blood Tolllike receptor 5 mRNA expression. Biology of Blood and Marrow Transplantation 20, 173 (2014/02, 2014).

38. Q. Tang, J. A. Bluestone, Regulatory T-cell therapy in transplantation: Moving to the clinic. Cold Spring Harbor Perspectives in Medicine 3, a015552 (2013/11/01, 2013).

39. M. Kimikawa, D. H. Sachs, R. B. Colvin, A. Bartholomew, T. Kawai, A. B. Cosimi, Modifications of the conditioning regimen for achieving mixed chimerism and donor-specific tolerance in cynomolgus monkeys. Transplantation 64, 709 (Sep 15, 1997).

40. L. S. Kean, A. B. Adams, E. Strobert, R. Hendrix, S. Gangappa, T. R. Jones, N. Shirasugi, M. R. Rigby, K. Hamby, J. Jiang, H. Bello, D. Anderson, K. Cardona, M. M. Durham, T. C. Pearson, C. P. Larsen, Induction of chimerism in rhesus macaques through stem cell transplant 
and costimulation blockade-based immunosuppression. American Journal of Transplantation 7, 320 (2007/02, 2007).

41. Y. Tomita, A. Khan, M. Sykes, Mechanism by which additional monoclonal antibody $(\mathrm{mAB})$ injections overcome the requirement for thymic irradiation to achieve mixed chimerism in mice receiving bone marrow transplantation after conditioning with anti-T cell mABs and 3-Gy whole body irradiation. Transplantation 61, 477 (Feb 15, 1996).

42. Y. Tomita, D. H. Sachs, A. Khan, M. Sykes, Additional monoclonal antibody (mAB) injections can replace thymic irradiation to allow induction of mixed chimerism and tolerance in mice receiving bone marrow transplantation after conditioning with anti-T cell $\mathrm{mABs}$ and 3-Gy whole body irradiation. Transplantation 61, 469 (Feb 15, 1996).

43. B. Nikolic, A. Khan, M. Sykes, Induction of tolerance by mixed chimerism with nonmyeloblative host conditioning: The importance of overcoming intrathymic alloresistance. Biology of Blood and Marrow Transplantation 7, $144(2001 / 03,2001)$.

44. D. Han, D. M. Berman, M. Willman, P. Buchwald, D. Rothen, N. M. Kenyon, N. S.
Kenyon, Choice of immunosuppression influences cytomegalovirus DNAemia in cynomolgus monkey (Macaca fascicularis) islet allograft recipients. Cell Transplantation 19, 1547 (2010/12, 2010).

45. H. P. Steffens, J. Podlech, S. Kurz, P. Angele, D. Dreis, M. J. Reddehase, Cytomegalovirus inhibits the engraftment of donor bone marrow cells by downregulation of hemopoietin gene expression in recipient stroma. Journal of virology 72, 5006 (Jun, 1998).

46. T. Paulin, O. Ringden, B. Lonnqvist, Faster immunological recovery after bone marrow transplantation in patients without cytomegalovirus infection. Transplantation $\mathbf{3 9}$, 377 (Apr, 1985).

47. B. C. Fries, D. Khaira, M. S. Pepe, B. TorokStorb, Declining lymphocyte counts following cytomegalovirus (CMV) infection are associated with fatal CMV disease in bone marrow transplant patients. Exp Hematol 21, 1387 (Sep, 1993).

48. M. Battaglia, A. Stabilini, M. G. Roncarolo, Rapamycin selectively expands $\mathrm{CD} 4^{+} \mathrm{CD} 25^{+} \mathrm{FoxP}_{3}+$ regulatory T cells. Blood 105 , 4743 (Jun 15, 2005). 



\section{Appendix 4}

Valorization addendum \& patent. 


\section{VALORIZATION}

Novelty and non-obviousness are most important aspects for an idea that may have potential commercial application. Subsequently, nondisclosure is a major factor, as disclosure voids the idea of novelty. Hence, an enthusiastic scientist that shares his novel ideas at a scientific conference may subsequently encounter problems obtaining patent/intellectual property (IP) protection at a later stage. The United States Patent and Trademark Office (USPTO) has clear guidelines on what is novel and non-obvious, and will thoroughly investigate every invention for patentability (1).

The emphasis on valorization is perceived by some to be associated with adverse impact on the research environment, creating "science hypes, premature implementation or translation of research results, loss of public trust in the university research enterprise, research policy conflicts and confusion, and damage to the longterm contributions of university research" (2). On the other hand, the individual career and/or financial rewards for spending the better part of one's productive (often frugal!) years in the laboratory can be a welcome addition to the scientific and intellectual prestige.

Recently, there has been some controversy surrounding the patentability of stem cells (3). In line with the decision of unpatentability of natural genes such as in the BRCA1 case (4), naturally occurring stem cells that are isolated from an organism would not be patentable. However, synthetic stem cells would be patentable, under the same law.

Shinya Yamanaka, a former surgeon and the recipient of the 2012 Nobel Prize in Physiology or Medicine is a proponent of stem cell patentability. Since his discovery of iPS cells, he has claimed that "Private sector support is indispensable when it comes to translating our research results into effective treatments or drugs and delivering them to the broader population" (5). Despite the existing legal precedents, the discussion on patentability of biological molecules, cells and tissue is far from over.

Some of the work in the present thesis was submitted and approved for a provisional patent application with the help of Columbia University Science and Technology Ventures and the law office of Wai-Kit Chan, in New York (6). This work was mainly based on the development of purification and modification of alginate with the synthetic RGDfK peptide for the generation of biocompatible $3 \mathrm{D}$ scaffolds (7-10). However, since the cell type that is used within the alginate matrix could be of paramount importance to the eventual effect on disease parameters (i.e. cardiac function after MI), some of the content in this chapter will be dedicated to the use and modification of specific stem cell populations. As mentioned before, it is currently not possible to patent isolated stem cells, however it is possible to generate artificial cells that are protected by intellectual property laws, as is also illustrated in the proposition \#5 of this thesis that quotes Nobel laureate Shinya Yamanaka.

Patents are deemed useful to protect discoveries that are commercially interesting and seem to serve a commercial interest only. Acknowledging that clinically applicable discoveries typically require costly research and testing, it can easily be seen that protection of those discoveries will serve as an incentive to engage in the entire process. The downside of that protection is that initial products will be far more expensive than dictated by their manufacturing costs alone and will therefore be not only available to those (people, nations) who can afford them. This effect is somewhat mitigated by the limited lifetime of a patent. With this perspective, it can be questioned if inventions made with the help of public funding should be patented.

\section{SOCIETAL OR ECONOMIC RELEVANCE}

\subsection{RELEVANCE OF VALORIZATION FOR BIOMATERIALS IN HF AND IDDM}

The growing shortage of organ donors in ageing societies poses a major problem for people with endstage heart failure, insulin dependent diabetes mellitus, and kidney failure requiring dialysis (mean survival rate from start of dialysis is $3-5$ years). Novel approaches need to be explored and cell therapy and tissue engineering potentially add to or constitute these novel approaches. The development of an affordable biocompatible 3D scaffold that could be used off-the-shelf, i.e. ready made without extensive manipulation before implantation, poses an attractive alternative option. A 3D scaffold would also be much less costly, both monetarily and physically, than an organ transplant procedure with all potential complications (surgery, immunosuppression) involved. Of course, an optimal base material needs to be identified and this base material needs to be safe and well tolerated by potential patients. We systematically approached the issues of biocompatibility (i.e. material implantation without cells) and suitability for cell transplantation within an optimal product.

For heart disease, 3D "scaffolds" are clinically used in the form of bioabsorbable vascular 3D PGA tubes, known as stents (11). While not a regenerative medicine approach per se, the materials used for such 3D scaffolds hold promise in other applications such as a (cardiac) muscle regeneration setting. Recently, a scaffold free approach was used in a small clinical trial with cell sheets for cardiomyopathy (12). This approach based on PNIPAAM dissolvable biomaterial seems to be safe, though the actual material in this setting is merely used to facilitate the generation of cell sheets ex vivo and is completely removed before implantation. Instead of a scaffold free approach, a cell free approach developed by the Swiss/Dutch company Xeltis was recently shown for an artificial heart valve, based on a fibrous valvular scaffold, fabricated from a novel supramolecular elastomer, 
that enables endogenous cells to enter and produce matrix in vivo (13). The laboratory of Smadar Cohen and her company BioLineRx has developed a soluble alginate scaffold (BL-1040) that was applied in a phase I/II trial and infused in coronary arteries after myocardial infarction (clinical trial identifier NCT00557531).

For IDDM, the biotechnology company Viacyte has developed a macroencapsulation device (i.e. pouch) that contains ESC derived insulin producing cells (14), which is also used in clinical trials (clinical trial identifier NCT02939118). The device is still in its early development phase but holds promise as a viable approach for the treatment of IDDM.

\subsection{RELEVANCE OF VALORIZATION FOR MODIFIED (STEM) CELLS}

As with biomaterials, modified (stem) cells that could be used to replace damages tissues take a long time to test and develop. Bone marrow transplantation (BMT) is such a therapy, but since bone marrow is a natural product, it is not patentable. Whether this is important is another question, since BMT has been a treatment of choice for the treatment of bone marrow malignancies for several decades. Hence non-patentability may even be desirable when it comes to patient's wellbeing. On the other hand, patents typically expire within 15 years of filing (including R\&D time), making the described and protected technology eventually subject to competition by other producers, presumably leading to price reduction.

Exceptions to such rules are known for certain biological drugs as Humira (adalimumab) and Enbrel (etanercept), both TNFa inhibitors against rheumatic diseases. While Humira went to market in 2003 and hence the patent is about to expire, subtle changes in their formulation have stretched its patent life to more than 20 years (15, 16).

A biomaterial may be patentable as a novel device if loaded with specific (stem) cells for a specific application. Newer developments such as CAR-T cells, which have modified chimeric T-cell receptors that may be artificially designed against a specific target (i.e. a specific cancer cell) may be patentable, though there is still debate in courts about this.

A genetic modification technique such as CRISPR/Cas9 which can cut and paste specific genetic sequences in mammalian (stem) cells is another technique that is now planned for use in clinical trial development. The question remains whether one could patent the sequence that is able to modify the DNA, or the resulting modified cell.

\section{TARGET GROUPS}

\subsection{TARGET GROUPS FOR BIOMATERIALS}

Sodium alginate has been studied in the clinical setting for $\mathrm{HF}$ (17) (clinical trial identifier NCT01226563) and IDDM (18) (clinical trial identifier NCT00940173), as described in Chapter
8 (Section 8, Target Patients) of this thesis. RGD modified alginate such as used in this thesis is further being evaluated in preclinical models, however RGD modified alginate has not yet been tested in clinical trials. Implantation or infusion of such modified alginate may pose some specific hurdles, since modification is done using chemical cross-linkers which could also cause cross-linking of proteins after implantation in vivo, hence there is a need for their sufficient removal from modified scaffolds.

It is not yet clear whether RGD-modified alginate is safe for intracorporal implantation. One approach to overcome this could be to start with the evaluation of RGD-modified alginate in (diabetic) skin wound healing trials; in order to evaluate the pro-angiogeneic properties while obviating the need for explantation in case of a foreign body reaction (FBR).

Apart from suitable target patients such as in HF or IDDM, the methods described in the patent application could be relevant to a number of other applications. They include the use of sodium alginate for wound dressing, dentistry and the food industry, which uses sodium alginate as a beer foam stabilizer, as well as a growth substratum for edible muscle fibers (i.e. cultured meat). Biomaterials companies could employ the conditions used in the purification process to purify their biomaterial of choice while significantly reducing the amount of waste generated. The method used for scaffold generation, i.e. freeze gelation, would also be applicable to other biomaterials in order to create highly porous scaffolds designed for varying uses such as sponges or other fluid absorbing materials. In medicine and surgery, alternative implantation sites and disease applications could lead to new approaches in transplantation and regenerative medicine. Hence, off-label use would be possible with a wide range of applications, from wound dressing to food and beverage technologies.

\subsection{TARGET GROUPS FOR MODIFIED (STEM) CELLS}

In order to replace damaged tissue, modified cells could be employed to enhance their function. For example, mesenchymal stem cells modified with the pro-survival protein AKT could be used in hypoxia driven diseases such as MI. Other cell types could be modified using the same technique, for example cardiac muscle cells. Enhanced survival could lead to enhanced efficacy, however AKT only protects against certain types of cell death, implying that other modifications need to be employed for an optimal product. The optimal combination would need to be determined based on the disease. So, for hypoxic diseases, cells could be rendered less sensitive to hypoxia, while for genetic diseases, the gene of interest would need to be added to the cells to be used in order to replace cells containing lossof-function gene mutations, for example in sicklecell anemia.

\section{ACTIVITIES/PRODUCTS}




\subsection{ACTIVITIES/PRODUCTS FOR BIOMATERIALS/SODIUM ALGINATE}

Alginate is mostly produced in Europe and Asia Pacific (i.e. East Asia, South Asia, Southeast Asia, and Oceania) which therefore have the largest market share in volume. In terms of value however, it is expected that Europe and North America will comprise the most lucrative market in the near future because of high value alginate derivatives.

The market for alginates \& derivatives is projected to reach a value of $\$ 409.2$ million by 2019 growing at a CAGR of $3.8 \%$ from 2014 to 2019. Trends such as increasing demand for natural ingredients, clean-label products, and products that boost health and wellness are driving the global alginates \& derivatives market. The prevalence of inferior grade alginates extracted from different species of brown algae is one of the major challenges alginate suppliers face. The global wound healing market is estimated at $\$ 15$ billion annually, and mostly consists of wound dressings and gauzes (19). Alginate holds about $4 \%$ of this market, i.e. $\$ 600$ million (Figure 1).

\subsection{ACTIVITIES/PRODUCTS FOR MODIFIED (STEM) CELLS}

In the global stem cells market a sizeable proportion of companies are trying to garner investments from organizations based overseas. This is one of the strategies leveraged by them to grow their market share. Further, they are also establishing partnerships with pharmaceutical organizations to potentially increase revenues, since large pharmaceutical companies have resources that allow them to conduct large scale clinical trials using novel therapeutics. The global market for stem cells is expected to register a CAGR of $13.8 \%$ during the period from 2017 to 2025 growing to a value of $\$ 271 \mathrm{bn}$ by 2025 . Depending upon the type of products, the global stem cell market can be divided into adult stem cells, human embryonic stem cells, induced pluripotent stem cells, etc. Of these, the segment of adult stem cells accounts for a leading share in the market. This is related to their ease of controllable expansion, their presumed safety and specific characteristics such as immunomodulation in the case of mesenchymal stem/stromal cells (MSCs) (20). At present, North America dominates the market because of the substantial investments in the field leading to technical progress, wealth, willingness to pay for medical innovations and rising instances of target chronic diseases. As per the TMR report, the market in North America will likely retain its dominant share in the near future to become worth $\$ 167 \mathrm{bn}$ by 2025 .

For HF and IDDM specifically, the clinical stem cell market is limited to experimental research and development phases. While this stimulates economic activity and revenues in the first place, actual reimbursable therapies have to be developed. Most therapeutic stem cell based revenues are made in the bone regeneration field, where approved products are estimated at a value of $\$ 600 \mathrm{~m}$.

\section{INNOVATIONS}

\subsection{INNOVATIONS FOR BIOMATERIALS/SODIUM ALGINATE}

New biomaterials are constantly being developed and optimized for novel clinical applications. Think of coated coronary artery stents with antiproliferative agents such as rapamycin, to new alloys for hip-or other skeletal replacement/support therapies. For alginate specifically, purification is important, as we have shown in this thesis. Also, alginate modification with biological molecules can be ultimately limitless, as new peptides and/or proteins that can be covalently attached to alginate are continuously being discovered and characterized. Since alginate can be covalently modified using peptides or proteins, it is possible to add specific characteristics to alginate, such as proadhesion, pro-survival, or anti-immunogenic. Our patent already describes an improved alginate purification protocol that renders alginate less immunogenic, and the attachment of an adhesion peptide (cyclic RGDfK) that enhances its prosurvival signaling capabilities $(6-8,10)$.

\subsection{INNOVATIONS FOR PRIMARY OR MODIFIED (STEM) CELLS}

Similar to novel biomaterials, new (stem) cell types with potential clinical applications continue to be identified and described. The latest clinically applicable cell therapy is probably CAR-T, i.e. Tcells with modified T-cell receptors against specific targets. In this thesis, we also describe the expansion of rare regulatory $\mathrm{CD} 4^{+}$T-cell types ( $\mathrm{T}_{\text {regs }}$ (Appendix 3), which have immunosuppressive and transplant toleranceinducing capacity. Optimization of such expansion methods/protocols that make them suitable for clinical application is another highly important hurdle that needs to be addressed. In our case, we used a genetically modified murine cell-line that stimulates $\mathrm{T}_{\text {reg-cells }}$ to proliferate. For clinical application, it would be more useful to use a cellfree stimulation system such as modified microbeads. Such systems need to be further optimized for clinical application. We have further described the use of specific cell-surface markers such as CXCR4, the receptor for SDF-1, to redirect $\mathrm{CD}^{+}{ }^{+}$stem cells to damaged tissues. These receptor modulations may be patented separately for additional indications, as was done by one of the autor's previous principle investigators (21). 


\section{Change in Share of Total Wound Management Sales} 2017 to 2026

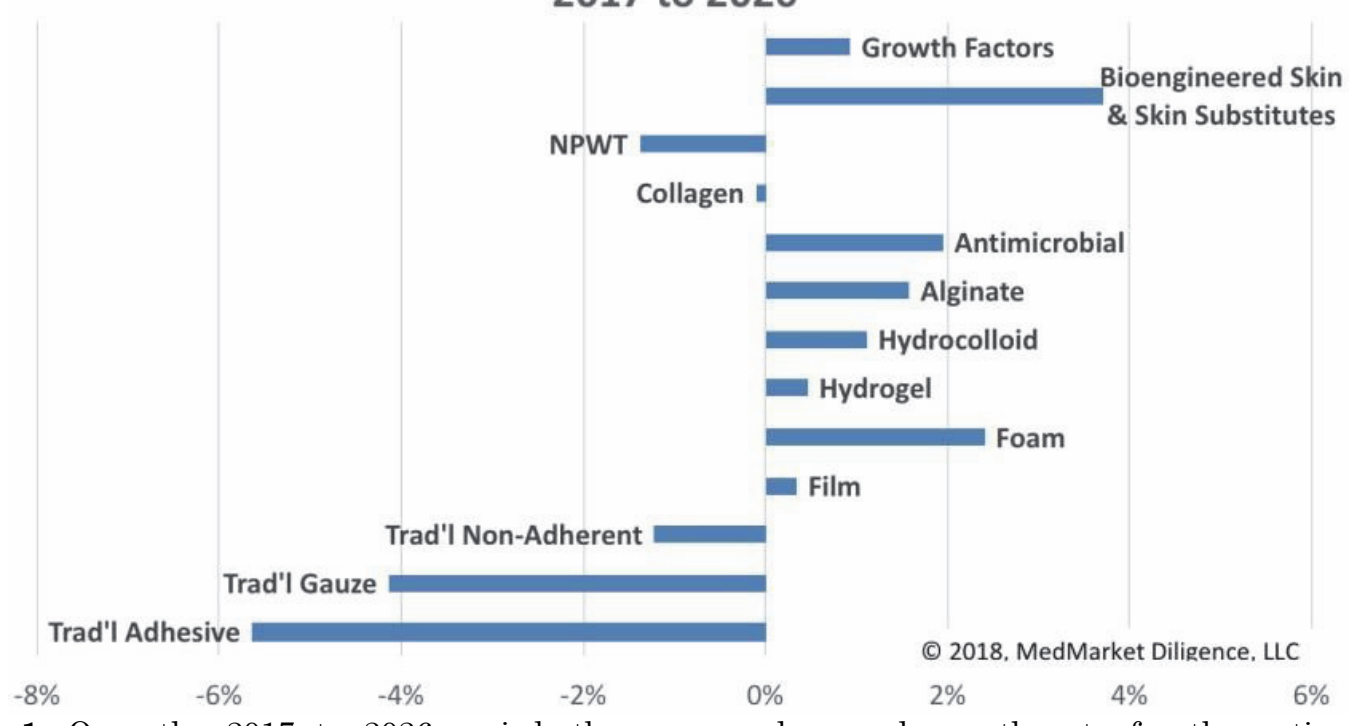

Figure 1. Over the 2017 to 2026 period, the compound annual growth rate for the entire wound management market will approach $6 \%$, a respectable rate of growth for an established market, though not quite high enough to encourage investment in the market as a whole. Of course, the total wound market is comprised of a number of very large, slow-growing segments, like traditional adhesive dressings, gauze dressings, and non-adherent dressings, which have annual sales at $\$ 3.8$ billion, $\$ 3.2$ billion, and $\$ 1.3$ billion, respectively

(19).

\section{PLANNING/REALIZATION}

\subsection{PLANNING/REALIZATION OF BIOMATERIALS/ SODIUM ALGINATE}

In order to bring the sodium alginate technology that was patented in this thesis to market, several steps need to be taken. First, the cost of purification is briefly addressed in chapter 2 . We estimate an additional $\$ 1500 /$ patient for the production of a purified alginate scaffold for any indication. As a comparison, a drug eluting coronary artery stent can cost around $\$ 1500$ per patient, depending on a country's health care and insurance systems. The scaffold price excludes potential cells being prepared to be seeded in or on the scaffold. In addition, alginate has to be prepared in a Good Manufacturing Practice (GMP) environment, which could add to the overall costs, though mass production could significantly lower such expenses. FDA/EMEA would need to be involved, and the design of clinical trials to test a potential product can cost up to US\$100m (around $\$ 60 \mathrm{~m}$ for $\mathrm{HF}$ or IDDM) (Figure 2) (22). Then there is the chemical modification of sodium alginate and other biomaterials, which would add another level of complexity. Authorities have specific guidelines for purity, immunogenicity and other characteristics for biomaterial trials. While intracoronary infusion of calcium alginate matrix has been studied in congestive heart failure (clinical trial identifier NCT01226563), covalently peptide modified alginate has thus far not been evaluated in clinical trials to our knowledge.

In order to address the use of potentially toxic cross-linkers for the fabrication of RGDfK alginate, it is noted that other cross-linked materials are being evaluated in clinical trials, such as an osteoinductive composite called Smartbone consisting of bovine bone matrix, biodegradable polymers and cell nutrients (clinical trial identifier NCT03462823) for anterior cruciate ligament tears, or the Integra bilayer matrix wound dressing, comprised of a porous matrix of cross-linked bovine collagen and glycosaminoglycan and a semipermeable polysiloxane layer for diabetic foot ulcers (clinical trial identifier NCT03476876).

\subsection{PLANNING/REALIZATION OF MODIFIED (STEM) CELLS}

Some of the techniques and cells that are described in this thesis are patented by other investigators, for example Mesoblast Ltd. holds patents on human mesenchymal precursor cell (hMPC) technology. Planning and bringing human stem cell therapy to clinic is a multi-decade process, apart from making it profitable. For cell therapy, there are specific guidelines also that need to be followed, both by the FDA and EMEA. The FDA has recently cracked down on "unscrupulous clinics" selling "so-called cures." The FDA seized materials from one clinic in California, and sent a warning letter to another in Florida (23). The costs involved in culturing and maintaining (stem) cell populations can rise quickly, and efficacy is not always guaranteed (24). In addition, there are challenges lie in the determination of quality and safety. Combining cells with biomaterial scaffolds would create additional challenges. Safety and efficacy testing need to have clearly defined end-points. 


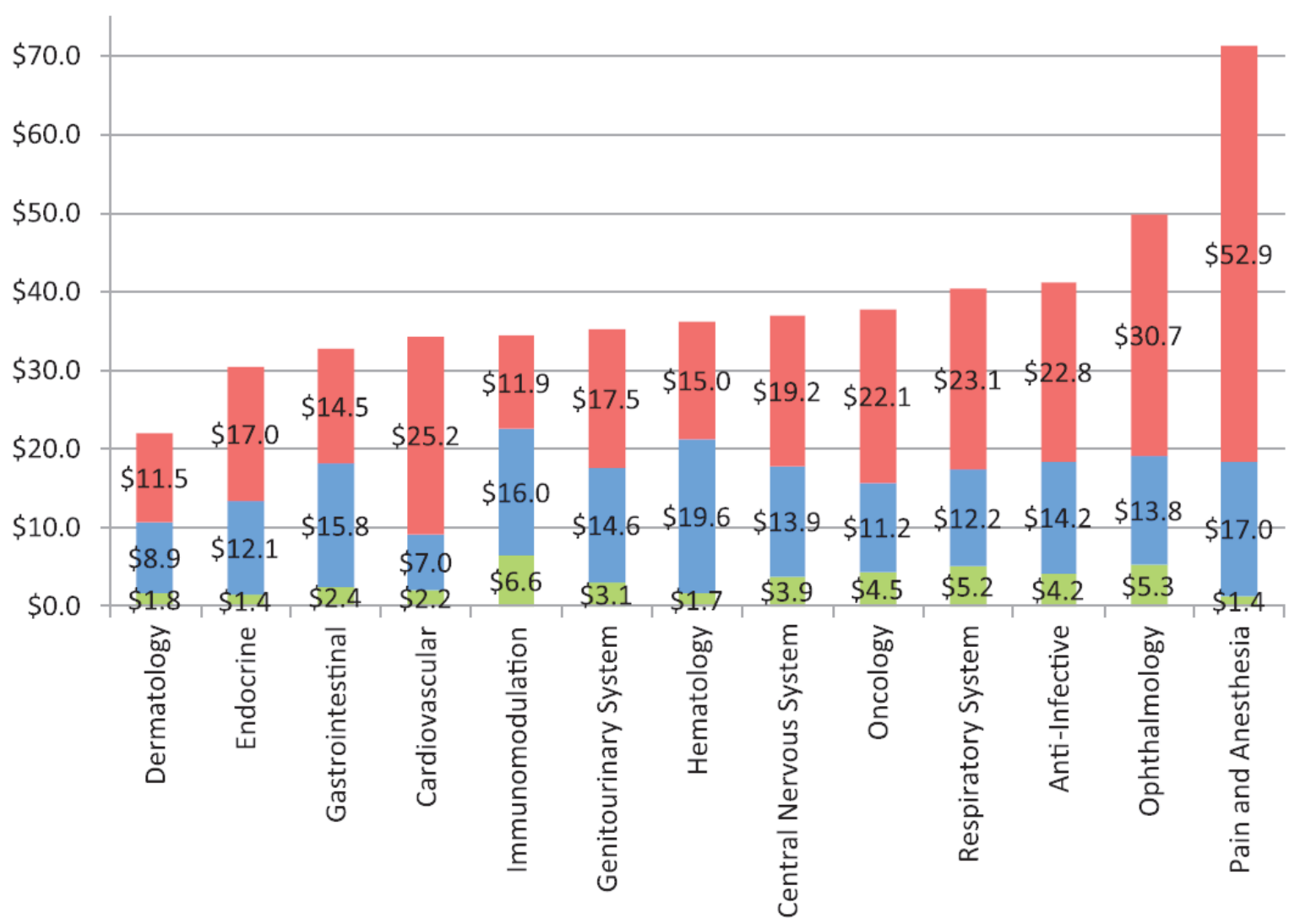

\section{Phase 1 Phase 2 Phase 3}

Figure 2. Total per-study costs (in $\$$ millions), by clinical trial phase and therapeutic area. As can be observed, Phase 2 costs are lower than Phase 3 costs for all but three therapeutic areas: gastrointestinal, hematology, and immunomodulation. This somewhat counterintuitive relationship is due to a variety of factors, including higher data collection costs, administrative staff costs, and site recruitment costs in Phase 2 than in Phase 3 for these therapeutic areas (22).

\section{FINAL WORDS}

Some of the procedures described in this thesis are potentially protected by a provisional patent application. However, the EPO ruled against some parts of the patent due to prior art/lack of novelty. When bringing this technology to market, several challenges lie ahead. Valorization may therefore be risky, however the process of setting up a biotechnology start-up firm based on sound science with or even without intellectual property protection is an invaluable addition to any scientist's experience. As of November 2018, a business plan based on the findings in this thesis is in preparation.

\section{REFERENCES}

1. USPTO, United States patent and Trademark office (USPTO). https://www.uspto.gov/.

2. T. Caulfield, U. Ogbogu, The commercialization of university-based research: Balancing risks and benefits. BMC medical ethics 16, 70 (Oct 14, 2015).

3. S. Davey, N. Davey, Q. Gu, N. Xu, R. Vatsa, S. Devalaraja, P. Harris, S. Gannavaram, R. Dave, A. Chakrabarty, Interfacing of Science, Medicine and Law: The Stem Cell Patent Controversy in the United States and the European Union.
Frontiers in cell and developmental biology 3, 71 (2015).

4. G. Matthijs, I. Huys, G. Van Overwalle, D. Stoppa-Lyonnet, The European BRCA patent oppositions and appeals: coloring inside the lines. Nature biotechnology 31, 704 (Aug, 2013).

5. S. Yamanaka, Using patents to ensure access to pioneering cell technology. WIPO Magazine 4, (August, 2015)

6. H. Sondermeijer, Witkowski, P., Hardy, M.A., (WO/2009/039185) Uses Of Immunologically Modified Scaffold For Tissue Prevascularization And Cell Transplantation. (26 March, 2009).

7. H. P. Sondermeijer, P. Witkowski, D. Woodland, T. Seki, F. J. Aangenendt, A. van der Laarse, S. Itescu, M. A. Hardy, Optimization of alginate purification using polyvinylidene difluoride membrane filtration: Effects on immunogenicity and biocompatibility of three-dimensional alginate scaffolds. Journal of biomaterials applications 31, 510 (Oct, 2016).

8. H. P. Sondermeijer, P. Witkowski, T. Seki, A. van der Laarse, S. Itescu, M. A. Hardy, RGDfKPeptide Modified Alginate Scaffold for Cell Transplantation and Cardiac Neovascularization. Tissue engineering. Part A 24, 740 (May, 2018).

9. M. A. Hardy, P. Witkowski, H. Sondermeijer, P. Harris, The long road to pancreatic islet 
transplantation. World journal of surgery 34,625 (Apr, 2010).

10. P. Witkowski, H. Sondermeijer, M. A. Hardy, D C. Woodland, K. Lee, G. Bhagat, K. Witkowski, F. See, A. Rana, A. Maffei, S. Itescu, P. E Harris, Islet grafting and imaging in a bioengineered intramuscular space. Transplantation 88, 1065 (Nov 15, 2009).

11. D. J. Kereiakes, S. G. Ellis, C. Metzger, R. P. Caputo, D. G. Rizik, P. S. Teirstein, M. R. Litt, A. Kini, A. Kabour, S. O. Marx, J. J. Popma, R McGreevy, Z. Zhang, C. Simonton, G. W. Stone, A. I. Investigators, 3-Year Clinical Outcomes With Everolimus-Eluting Bioresorbable Coronary Scaffolds: The ABSORB III Trial. Journal of the American College of Cardiology 70, 2852 (Dec 12, 2017).

12. S. Miyagawa, K. Domae, Y. Yoshikawa, S. Fukushima, T. Nakamura, A. Saito, Y. Sakata, S. Hamada, K. Toda, K. Pak, M. Takeuchi, Y. Sawa, Phase I Clinical Trial of Autologous Stem Cell-Sheet Transplantation Therapy for Treating Cardiomyopathy. Journal of the American Heart Association 6, (Apr 5, 2017).

13. J. Kluin, H. Talacua, A. I. Smits, M. Y. Emmert, M. C. Brugmans, E. S. Fioretta, P. E. Dijkman, S. H. Sontjens, R. Duijvelshoff, S. Dekker, M. W. Janssen-van den Broek, V. Lintas, A. Vink, S. P. Hoerstrup, H. M. Janssen, P. Y. Dankers, F. P. Baaijens, C. V. Bouten, In situ heart valve tissue engineering using a bioresorbable elastomeric implant - From material design to 12 months follow-up in sheep. Biomaterials 125, 101 (May, 2017).

14. A. D. Agulnick, D. M. Ambruzs, M. A. Moorman, A. Bhoumik, R. M. Cesario, J. K. Payne, J. R. Kelly, C. Haakmeester, R. Srijemac, A. Z Wilson, J. Kerr, M. A. Frazier, E. J. Kroon, K. A. D'Amour, Insulin-Producing Endocrine Cells Differentiated In Vitro From Human Embryonic Stem Cells Function in Macroencapsulation Devices In Vivo. Stem cells translational medicine 4, 1214 (Oct, 2015).

15. U. Storz, Of patents and patent disputes: The TNFalpha patent files. Part 1: Humira. Human antibodies 25, 1 (2017).

16. U. Storz, Of patents and patent disputes - The TNFalpha patent files. Part 2: Enbrel, Remicade,
Cimzia and Simponi. Human antibodies 26, 49 (Feb 5, 2018).

17. S. V. Rao, U. Zeymer, P. S. Douglas, H. AlKhalidi, J. A. White, J. Liu, H. Levy, V. Guetta, C. M. Gibson, J. F. Tanguay, P. Vermeersch, J. Roncalli, J. D. Kasprzak, T. D. Henry, N. Frey, O. Kracoff, J. H. Traverse, D. P. Chew, J. LopezSendon, R. Heyrman, M. W. Krucoff, Bioabsorbable Intracoronary Matrix for Prevention of Ventricular Remodeling After Myocardial Infarction. Journal of the American College of Cardiology 68, 715 (Aug 16, 2016).

18. A. L. Hillberg, K. Kathirgamanathan, J. B. Lam, L. Y. Law, O. Garkavenko, R. B. Elliott, Improving alginate-poly-L-ornithine-alginate capsule biocompatibility through genipin crosslinking. Journal of biomedical materials research. Part B, Applied biomaterials 101, 258 (Feb, 2013).

19. Medical Technology Market Analysis, MedMarket Diligence, LLC; Report \#S254 (publishing Mar. 2018).

20. K. English, A. French, K. J. Wood, Mesenchymal stromal cells: facilitators of successful transplantation? Cell stem cell 7, 431 (Oct 8, 2010).

21. S. Itescu, Use of SDF-1 to improve ischemic myocardial function (US patent \# Patent \# US 9,387,234 B2). (July 12, 2016).

22. A. Sertkaya, H. H. Wong, A. Jessup, T. Beleche, Key cost drivers of pharmaceutical clinical trials in the United States. Clinical trials 13, 117 (Apr, 2016).

23. A. E. Kuriyan, T. A. Albini, J. H. Townsend, M. Rodriguez, H. K. Pandya, R. E. Leonard, 2nd, M. B. Parrott, P. J. Rosenfeld, H. W. Flynn, Jr., J. L. Goldberg, Vision Loss after Intravitreal Injection of Autologous "Stem Cells" for AMD. The New England journal of medicine 376, 1047 (Mar 16, 2017).

24. E. F. Jacobson, E. S. Tzanakakis, Human pluripotent stem cell differentiation to functional pancreatic cells for diabetes therapies: Innovations, challenges and future directions. Journal of biological engineering 11, 21 (2017). 



\section{Appendix 5}

Acknowledgments, list of publications, curriculum vitae. 


\section{ACKNOWLEDGMENTS}

"I am thankful for all of those who said no to me. It's because of them I'm doing it myself." - Albert Einstein

Ph.D. stands for doctor of philosophy, and philosophy stands for rationally critical thinking. Apart from thinking about science, it takes a lot of time and effort to critically think about the people that influence the course of your life journey. Hence, I have decided to attempt to reflect on all the people who played a role, be it big or small, in my life and journeys during the work and the writing of this thesis. In addition, I will highlight the 3 major achievements that I think I got out of this journey.

The thesis is the culmination of a journey that took almost 20 years of my life, from Leiden, the Netherlands to Melbourne, Australia to New York, NY, Boston, MA and Tokyo, Japan. It was written in many locations around the world, from my former office in the relocated Sykes/TBRC laboratories in the Navy Yard in Boston to the lobby of the Marunouchi oazo building (dubbed "mental oasis") opposite Tokyo Central Station.

Without much of a preconceived idea of the path that I was going to travel, as a medical student, it seemed like a good idea to work overseas to get more "life experience", as we say in Dutch. This brought me to the man who seems to know everyone, top clinical pharmacologist and nephrologist Adam Cohen, formerly of the CHDR, who introduced me to clinical pharmacologist and top cardiologist Henry Krum, who was working on heart failure trials (i.e. ValHeFT) in Melbourne, Australia (if instead I would have joined my friend and anesthesiologist Jurjan van Cosburgh in India, this thesis would have probably looked completely different).

Thus, I remember sitting with Henry and Adam in Adam's Leiden office (it must have been in 1999 or 2000) discussing the best places to live in Melbourne (i.e. Toorak, St Kilda). I was lucky that my friend, housemate and colleague Alexander van Marle wanted to join me on this initial trip, and we lived on Louise Street close to the Alfred Hospital, the Department of Epidemiology and Preventive Medicine, and behind the Albert Park F1 racing circuit, where we did some of our work. During our time in Melbourne, we had lots of fun, analyzed lots of heart rate variability data and successfully designed, executed and published in a top cardiology journal a small clinical trial in healthy volunteers.

In Melbourne, I met Fiona See who played another big role in my career path. It was then that my path started to diverge quite dramatically from the path of the "average" Dutch medical graduate. During my clinical internships, I returned to Melbourne on several occasions to conduct further research and performed clinical cardiology and surgery internships at the Alfred Hospital. In order to finish my Biomedical Sciences Master's degree, I needed to conduct a basic research project. Henry's long-time friend and colleague, top rheumatologist and stem cell expert professor Silviu Itescu, was so generous to take me into his laboratory at Melbourne University where I worked on the emerging field of stem cell treatment for heart disease. Here, I learned many lab techniques (left coronary artery ligation in rats, leukapheresis, $\mathrm{CD}^{+}{ }^{+}$cell purification) with Fiona, Andrew Kompa, Andrey Boyle, Kim Connelly, Andrew Wilson, and other members of the team, and got to know Douwe Atsma (cardiology) and Arnoud van der Laarse (clinical chemistry) at Leiden University Medical Center, LUMC) and internist Jouke Tamsma (LUMC) who helped me on the Dutch side.

At the time, Silviu was running a laboratory in New York and asked Fiona and me to join the lab to continue stem cell work, a great opportunity to conduct Ph.D. research. Thanks to Silviu and Michael Schuster, a scientist and later business partner in Silviu's laboratory, I was introduced to the use of biomaterials for cell transplantation by writing an executive summary on this subject, which culminated in this thesis. After the transition to New York City, we met the local team, notably brilliant Tetsunori Seki, Guosheng Xiang, and Timothy Martens. With the help of and special thanks to former postdoctoral fellows and cardiothoracic surgeons Alfred Kocher and Nikolaos Bonaros, who were back in Austria at the time we joined, this team of people assisted us with building the Itescu laboratory.

Big words of thanks go to Xander Wehrens and Stefan Lehnert for fruitful discussions and their generous offer to use Andrew Marks lab's HP/Philips Sonos 5500 small animal ultrasound machine that generated the data for Chapter 3 and Appendix 2 of this thesis. Further thanks go to Gordana Vunjak-Novakovic for her insightful feedback, and Sara Gusik for making my biomaterial patent a reality (Achievement \#1).

Additional big thanks go to 2 Dutch people at Columbia, pharmacist and director of Columbia's Pathology Clinical Pharmacology and Toxicology Laboratory Serge Cremers and top cardiovascular scientist Marit Westerterp of Alan Tall's lab for productive discussions and continuous Dutch support, both inside and outside the lab, i.e. at Upper West Side's Prohibition, soccer cups at Coogan's, etc.

It was then that I also met Nicole SuciuFoca, a prominent immunologist and friend and colleague of Silviu's who shared lab space, and Mark Hardy, who has been one of my closest mentors even today. The latter two played significant roles in my further work in transplantation research. When I started to work on biomaterials, I teamed up with Hardy's research fellow and transplant surgeon, Piotr Witkowski, and became fascinated with transplant immunology and islet transplantation. Our teamwork resulted in a patent and has laid the foundation for $m y$ ambition of setting up a biotechnology business. Following my work with Silviu, I was generously accepted in the lab of Nicole Suciu-Foca, where I 
worked with George Vlad, Zhuoru Liu, Chris Chang, Geo Serban ("Where is the ligand?"), and Hannah Dobrowolska, who taught me everything about transplant immunology and biologicals. It was only for a brief time that I worked on Nicole's ILT3Fc biological. In 2010, based on my observation that ILT3Fc seemed to bind to its unknown receptor on activated T-cells in the presence of $\mathrm{Mn}^{++}$, I hypothesized that the receptor may be an adhesion molecule. Without having sufficient time to prove this, it recently turned out that the receptor is indeed an adhesion molecule, namely CD166/ALCAM (Achievement 2).

At this time, most of the small animal lab work that is presented in this thesis was done, however my curiosity for deep-diving into the field of transplant immunology had only grown. During my time in the laboratory, it was announced that a brilliant immunologist in the transplantation field would join Columbia University Medical Center from Massachusetts General Hospital/Harvard University: Megan Sykes. She was recruited to set up an integrated transplantation immunology program at Columbia University Medical Center, called the Columbia Center for Translational Immunlogy (CCTI). Fortunately, I was accepted for a postdoctoral fellowship in her lab where I worked on $\mathrm{T}_{\text {reg }}$ cell treatment in non-human primates, and spent 6 months at the Transplantation Biology Research Center (TBRC) in Boston/Charlestown to learn the techniques involved. It was a pleasant surprise to receive a copy from one of my Leiden friends' Ph.D. thesis in the New York laboratory of Professor Sykes: Co Bosch, who joined me before at several occasions, i.e. my graduation in medicine, some good times in NYC, and worked in the same MGH/Charlestown area as I did,

In the Sykes labs in Boston and New York, I also met many other new friends, notably Leo Bühler, Yojiro Kato, Anette $\mathbf{W u}$, and Ben Sprangers who helped me with these challenging projects. The primate project culminated in a top research paper (Appendix 3 of this thesis) and 2 major research awards, the ESOT/AST Exchange Award in 2011 and the TTS Leslie Brent Award in 2018. Our results indicated that we could infuse regulatory $\mathrm{T}$ cells $\left(\mathrm{T}_{\text {regs }}\right)$ to induce hematopoietic chimerism and long term tolerance to unrelated donor kidney transplants without any immunosuppression, a feat that had not been achieved in this setting for over 20 years (Achievement \#3).

Following my time in New York, I returned to the Netherlands to finalize the Ph.D. thesis with stem cell pioneer and cardiologist professor Mark Post of Maastricht University Medical Centre, while working in the clinic as a resident cardiologist with the help of Jacques J. Barth and Timo Lenderink. In order to combine my research, clinical and commercial skills, I decided to broaden my horizon and worked at the pharmaceutical company GSK for 1 year, where I met Rudolf van Olden, Judith van Schaik and Rob Bohte, who encouraged me to look into biotechnology firms for a more research and development focused environment, which led me to my current appointment.

Earlier, I had the opportunity to visit the Novartis offices in Toranomon Hills and Chugai/Roche in Tokyo, and got in touch with Beate Heissig, who runs a stem cell lab at Tokyo University, regarding potential collaborations. In the meantime, Maastricht University Medical Center had just recruited Clemens van Blitterswijk to set up the Institute for TechnologyInspired Regenerative Medicine (MERLN). I gladly accepted a role in the lab of Aart van Apeldoorn and spent some time working on a novel medical device to transplant pancreatic islets into humans with IDDM.

Then, the Dutch/Belgian biotechnology firm Galapagos, which has a product portfolio in the fields of antiinflammation and immunogy, got in touch after a previous application, this time for a position where I could combine all my previous skills and venture to expand my experience in clinical development.

On a personal level, I have to thank my loving and kindhearted spouse Moeko and our brilliant son Isaac Stewart for being patient with all my plans. Without their support and understanding, this thesis may not have happened.

Furthermore, my parents, Willem and Ellen, for being supportive of all my endeavors. My brother Wouter and his partner Wanda and their kids Jamie and Tycho. My sister Brigitte and her husband Ryan, their son Alexander and new baby Julian. And of course their extended families. I am sure none had any idea what I'd been up to, since they kept asking me: "What are you actually doing?"

Thanks also go to Gay Wilgus, who was an extremely hospitable landlady during my stay in NYC.

On a special note, I have to humbly thank Arnoud van der Laarse, who introduced me to Mark Post, and Mark Post himself, who believed in me and who took upon himself the role as patient Ph.D. promotor. Of course, Mark Hardy was the catalyst in all this, and Adam Cohen was the ever present co-pilot. I would like to sincerely thank the foundations and funding sources in the Netherlands, the United States and Australia that generously granted financial support to this and other work. Conclusively, I would like to acknowledge each and everyone who contributed and supported me in my journey and the completion of this thesis. I will try to cover your location and institution. I sincerely apologize if your name is not on this list, but you know I appreciate all your help and support.

\section{PH.D. CORE PEOPLE}

\subsection{PROMOTORES}

Mark J. Post, Arnoud van der Laarse.

\subsection{Ph.D.COMMITTEE}


Appendix 5 - Acknowledgments, list of publications, curriculum vitae.

Gerard Bos, Pamela Habibovic, Tilman Hackeng, Marcel Karperien.

\subsection{PARANYMPHS}

Ben Sprangers, Goda Choi.

\section{IMPORTANT PLACES AND PEOPLE}

\subsection{LEIDEN}

Adam Cohen, Arnoud van der Laarse, Douwe Atsma, Jouke Tamsma, Alexander van Marle, Jurjan van Cosburgh, Jacobus (Co) Bosch.

\subsection{MELBOURNE}

\subsubsection{KRUM LAB}

Henry Krum, Fiona See, Andrew Kompa, Marina Skiba.

\subsubsection{ITESCU LAB}

Silviu Itescu, Fiona See, Andrew Boyle, Kim Connelly, Andrew Wilson.

\subsection{NEW YORK}

\subsubsection{ITESCU LAB}

Silviu Itescu, Fiona See, Tetsunori Seki, Guosheng Xiang, Michael Schuster, Tim Martens, Alfred Kocher, Nikolaos Bonaros.

\subsubsection{SUCIU FOCA LAB}

Nicole Suciu-Foca, George Vlad, Zhuoru Liu, Chris Chang, Geo Serban, Hanna Dobrowolska, Haiyan Qin, Rafael Clynes, Raffaello Cortesini, Adriana Colovai, Elena Vasilescu, Erik Ho.

\subsubsection{HARDY LAB}

Mark Hardy, Piotr Witkowski, David Woodland, Abbas Rana.

\subsubsection{SYKES LAB/CCTI}

Megan Sykes, Anette Wu, Yojiro Kato, Ben Sprangers, Brittany Shonts, David Woodland, Adam Griesemer, Tomoaki Kato, Raimon Duran-Struuck, Paula Alonso-Guallart, Mercedes Martinez, Sam Baker, Rafal Tokarz, Vivette D'Agati, Scott Hammer, Marcus Pereira, Ian Lipkin, Thomas Wekerle, Jan Chen, Donna Farber, YongGuang Yang, Remi Crusot, Emmanuel Zorn

\subsubsection{OTHER COLUMBIA}

\section{LABS/DEPARTMENTS}

Marit Westerterp, Serge Cremers, Xander Wehrens, Stefan Lehnart, Gordana Vunjak-Novakovic, Sara Gusik.

\subsection{BOSTON}

\subsubsection{TBRC/MGH}

Leo Bühler, Thomas Wekerle, Svetlan Boskovic, Yohei Yamada, Makoto Tonsho, Zurab Machaidze, Christian Schütz, David Sachs, Tatsuo Kawai, Christian LeGuern, Robert Colvin, Sam Locascio,
Christene Huang, Kazuhiko Yamada, Curtis Cetrulo, Joren Madsen.

\subsection{TOKYO}

\subsubsection{TOKYO UNIVERSITY}

Beate Heissig

\subsection{MAASTRICHT}

3.6.1. MERLN

Aart van Apeldoorn. 


\section{LIST OF PUBLICATIONS}

1. Alonso-Guallart P, Zitsman JS, Stern J, Kofman $\mathrm{SB}$, Woodland D, Ho SH, Sondermeijer HP, Bühler L, Griesemer A, Sykes M, Duran-Struuck R. Characterization, biology, and expansion of regulatory $T$ cells in the Cynomolgus macaque for pre-clinical studies. Am J Transplant. 2019 Feb 15.

2. Sondermeijer HP, Witkowski P, Seki T, van der Laarse A, Itescu S, Hardy MA. RGDfK-Peptide Modified Alginate Scaffold for Cell Transplantation and Cardiac Neovascularization. Tissue Eng Part A. 2018 May;24(9-10):740-751.

3. Kato Y, Griesemer AD, Wu A, Sondermeijer HP, Weiner JI, Duran-Struuck R, Martinez M, Slate AR, Romanov A, Lefkowitch JH, Sykes M, Kato T. Novel H-shunt Venovenous Bypass for Liver Transplantation in Cynomolgus Macaques. Comp Med. 2017 Oct 1;67(5):436-441.

4. Duran-Struuck $R^{*}$, Sondermeijer HP*, Bühler L, Alonso-Guallart P, Zitsman J, Kato Y, Wu A, McMurchy AN, Woodland D, Griesemer A, Martinez M, Boskovic S, Kawai T, Cosimi AB, Wuu CS, Slate A, Mapara MY, Baker S, Tokarz R, D’Agati V, Hammer S, Pereira M, Lipkin WI, Wekerle T, Levings MK, Sykes M. Effect of Ex Vivo-Expanded Recipient Regulatory $T$ Cells on Hematopoietic Chimerism and Kidney Allograft Tolerance Across MHC Barriers in Cynomolgus Macaques. Transplantation. $2017 \quad$ Feb;101(2):274-283. (*Contributed equally).

5. Sondermeijer HP, Witkowski P, Woodland D, Seki T, Aangenendt FJ, van der Laarse A, Itescu S, Hardy MA. Optimization of alginate purification using polyvinylidene difluoride membrane filtration: Effects on immunogenicity and biocompatibility of three-dimensional alginate scaffolds. J Biomater Appl. 2016 Oct;31(4):510-520.

6. Joshua Weiner, Raimon Duran-Struuck, Jonah Zitsman, Leo Buhler, Hugo Sondermeijer, Alicia N. McMurchy, Megan K. Levings, Megan Sykes, Adam Griesemer. Restimulation After Cryopreservation and Thawing Preserves the Phenotype and Function of Expanded Baboon Regulatory T Cells. Transplantation Direct, 2015, 1, 1,1

7. See F, Seki T, Psaltis PJ, Sondermeijer HP, Gronthos S, Zannettino AC, Govaert KM, Schuster MD, Kurlansky PA, Kelly DJ, Krum H, Itescu S. Therapeutic effects of human STRO-3-selected mesenchymal precursor cells and their soluble factors in experimental myocardial ischemia. J Cell Mol Med. 2011 Oct;15(10):2117-29.

8. Bonaros $\mathrm{N}^{*}$, Sondermeijer $\mathbf{H}^{*}$, Wiedemann $\mathrm{D}$, Schlechta B, Schachner T, Schuster M, Seki T, Martens TP, Itescu S, Kocher AA. Downregulation of the CXC chemokine receptor 4/stromal cell- derived factor 1 pathway enhances myocardial neovascularization, cardiomyocyte survival, and functional recovery after myocardial infarction. J Thorac Cardiovasc Surg. 2011 Sep;142(3):687-96, 696. ( ${ }^{*}$ Contributed equally).

9. Hardy MA, Witkowski P, Sondermeijer H, Harris P. The Long Road to Pancreatic Islet Transplantation. World J Surg. World J Surg. 2010 Apr;34(4):625-7.

10. Hugo P Sondermeijer, Piotr Witkowski and Mark A Hardy. Uses of immunologically modified scaffold for tissue prevascularization and cell transplantation.

(http://www.wipo.int/pctdb/en/wo.jsp?WO=20090391 85).

11. Piotr Witkowski, Hugo Sondermeijer, Mark A. Hardy, David C. Woodland, M.D, Keagan Lee, Govind Bhagat, Kajetan Witkowski, Fiona See, Abbas Rana, Antonella Maffei, Silviu Itescu, Paul E. Harris. Islet grafting and imaging in a bioengineered intramuscular space. Transplantation. 2009 Nov 15;88(9):1065-74.

12. Ho EK, Vlad G, Colovai AI, Vasilescu ER, Schwartz J, Sondermeijer H, Burke E, Marboe CC, Itescu S, Suciu-Foca N, Mancini D. Alloantibodies in Heart Transplantation. Human Immunology. 2009 Jun 22.

13. Vlad G, Stokes MB, Liu Z, Chang CC, Sondermeijer H, Vasilescu ER, Colovai AI, Berloco P, D'Agati VD, Ratner L, Cortesini R, SuciuFoca N. Suppression of xenogeneic graft-versus-host disease by treatment with immunoglobulin-like transcript 3-Fc. Human Immunology. 2009 Jun 6.

14. Bonaros $\mathrm{N}^{*}$, Sondermeijer $\mathbf{H}^{*}$, Schuster $\mathrm{M}$, Rauf R, Wang SF, Seki T, Skerrett D, Itescu S, Kocher AA. CCR3- and CXCR4-mediated interactions regulate migration of CD34+ human bone marrow progenitors to ischemic myocardium and subsequent tissue repair. Journal of Thoracic and Cardiovascular Surgery, 2008 Oct;136(4):104453. ( ${ }^{*}$ Contributed equally).

15. Piotr Witkowski, Tetsunori Seki, Guosheng Xiang, Timothy Martens, Hugo Sondermeijer, Fiona See, Govind Bhagat, Michael Schuster, Mark A. Hardy, Silviu Itescu. A DNA enzyme against plasminogen activator inhibitor- type 1 (PAI-1) limits neointima formation after angioplasty in an obese diabetic rodent model. Journal of Cardiovascular Pharmacology, 2007 Dec;50(6):633640.

16. Hugo P. Sondermeijer, Eric C.J. Claas, Jurgen M. Orendi, Jouke Tamsma. Bartonella Quintana prosthetic valve endocarditis detected by blood culture incubation beyond 10 days. European Journal of Internal Medicine, 2006 Oct;17(6):441-3. 
Appendix 5 - Acknowledgments, list of publications, curriculum vitae.

17. Martens TP, See F, Schuster MD, Sondermeijer HP, Hefti MM, Zannettino A, Gronthos S, Seki T, Itescu S. Mesenchymal lineage precursor cells induce vascular network formation in ischemic myocardium. Nature Clinical Practice Cardiovascular Medicine, 2006 Mar;3 Suppl 1:S1822.

18. Kocher AA, Schuster MD, Bonaros N, Lietz K, Xiang G, Martens TP, Kurlansky PA, Sondermeijer H, Witkowski P, Boyle A, Homma S, Wang SF, Itescu S. Myocardial homing and neovascularization by human bone marrow angioblasts is regulated by IL-8/Gro CXC chemokines. Journal of Molecular and Cellular Cardiology, 2006 Apr;40(4):455-464.

19. Xiang G, Seki T, Schuster MD, Witkowski P, Boyle AJ, See F, Martens TP, Kocher A, Sondermeijer H, Krum H, Itescu S. Catalytic degradation of vitamin $D$ up-regulated protein 1 mRNA enhances cardiomyocyte survival and prevents left ventricular remodeling after myocardial ischemia. Journal of Biological Chemistry, 2005 Nov 25;280(47):39394-402.

20. Sondermeijer HP, van Marle AGJ , Kamen P, Krum H. Acute effects of caffeine on heart rate variability. American Journal Of Cardiology, 2002; 90(8):906-7. 


\section{CURRICULUM VITAE}

Family Name: Sondermeijer.

Given Name(s): Hugo Pieter.

Date of Birth and Location: 16 April 1975, Leiderdorp, the Netherlands.

\section{EDUCATION}

Ph.D. (non-resident), Bioengineering of novel 3D scaffolds for cell-based therapy in heart failure and diabetes mellitus. Maastricht University Medical Center, The Netherlands and Columbia University Medical Center, New York, U.S.A. 2014 - 2018.

M.D., Leiden University Medical Center, The Netherlands. 1996 - 2004.

M.Sc., Biomedical Sciences, Leiden University Medical Center, The Netherlands. 1994 - 2005.

\section{RESEARCH EXPERIENCE}

Maastricht University, MERLN Institute for Technology-Inspired Regenerative Medicine, Maastricht, the Netherlands. Postdoctoral Research Scientist. Development of a biocompatible device for pancreatic beta-cell transplantation. A/Professor Aart van Apeldoorn, Ph.D. 2017 2018.

Columbia University, Center for Translational Immunology, New York, U.S.A. Postdoctoral Research Scientist. Regulatory T cells for promotion of durable mixed hematopoietic chimerism and immune tolerance in a nonhuman primate model. Professor Megan Sykes, M.D. 2010 - 2013.

Massachusetts General Hospital/Transplant Biology Research Center, Boston, U.S.A. Visiting Postdoctoral Research Scientist. Regulatory T cells for promotion of durable mixed hematopoietic chimerism and immune tolerance in a nonhuman primate model. Professor Leo Bühler, M.D., Professor Megan Sykes, M.D., Prof. David Sachs, M.D. 2010.

Columbia University, New York, U.S.A. Postdoctoral Research Scientist. Characterization of ILT3-Fc and its effects on islet rejection following transplantation in humanized mice. Mentor: Professor Nicole Suciu-Foca, Ph.D. 2008 - 2010.

Columbia University, New York, U.S.A. Postdoctoral Research Scientist. Significance of antiHLA antibodies detected by solid-phase assay in heart allograft recipients. Mentor: Professor Nicole Suciu-Foca, Ph.D. 2008 - 2010.

Columbia University, New York, U.S.A. Postdoctoral Research Fellow. Development of a tissue engineered RGD-modified 3-dimensional alginate scaffold for adult mesenchymal stem cell and pancreatic islet transplantation in rodent models of heart failure and diabetes. Mentors: Professor Mark Hardy, M.D., Professor Silviu Itescu, M.D. 2004 - 2008.

University of Melbourne/St. Vincent's Hospital, Melbourne, Australia. Master of Science Final Research Project. Transplantation of bone marrow derived CD34 $4^{+}$stem cells in a rodent model of heart failure following myocardial infarction. Mentor: Professor Silviu Itescu, M.D. 2004. 
Appendix 5 - Acknowledgments, list of publications, curriculum vitae.

Monash University NHMRC/CCRE, Melbourne, Australia. Medical Degree Final Research Project. Effects of caffeine on parasympathetic nervous activity using heart rate variability. Mentor: Professor Henry Krum, M.D., Ph D. 2004.

Monash University NHMRC/CCRE, Melbourne, Australia / Novartis Holter Laboratory, Washington, U.S.A. Coordinator Valsartan Heart Failure Trial - Holter Substudy (1). Professor Henry Krum, M.D., Ph D. 2000 - 2004.

\section{CLINICAL MEDICINE \& CLINICAL DEVELOPMENT EXPERIENCE}

Galapagos N.V., Mechelen, Belgium. Associate Medical Director. 2018 -.

GlaxoSmithKline B.V., Zeist, the Netherlands. Medical Scientific Expert Vaccines. 2016 - 2017.

Atrium-Orbis Medical Center, Heerlen, the Netherlands. Cardiology resident physician. 2014 2015 .

Blakeburg Medical Center, Rotterdam, the Netherlands. Cardiology resident physician. 2013 2014.

Monash University/Alfred Hospital, Melbourne, Australia. General medicine/cardiology elective student. 2003 - 2004.

Monash University/Alfred Hospital, Melbourne, Australia. General surgery elective student. 2002 .

Leiden University Medical Center, Leiden, the Netherlands. General clinical internships. 2001 2003.

Monash University, Melbourne, Australia. Assistant Course Coordinator. Drug development \& clinical research methods certificate course. 2001.

Monash University, Department of Epidemiology and Preventive Medicine, Melbourne, Australia. Translator. Prevalence of asthmatic symptoms in 3 regions in the Netherlands. 2001

\section{OTHER EXPERIENCE}

TedX Amsterdam 2013 Short List, 3D scaffold project. Amsterdam, the Netherlands. 2013.

Columbia University, New York, U.S.A., Science and Technology Ventures Fellow. Invention report assessment in field of stem cells and tissue engineering applications. 2008.

\section{GRANT AWARDS}

The Transplantation Society (TTS) Leslie Brent Award. 2018.

European Society of Organ Transplantation (ESOT)/American Society of Transplantation (AST) Joint Research Grant. 2011. 
Leiden University Fund Grant, Dr. Dekker Dutch Heart Foundation Grant, Jo Keur Grant, Schimmel van-Outeren Grant, Saal Swanenburg Grant, Vrijvrouwe Renswoude Grant, Curators Grant. 2003.

Leiden University Lustra Grant. 2002.

Leiden University Fund Grant, Jo Keur Grant, Boehringer-Ingelheim Research Grant, Numico B.V. Research Grant, Sanofi-Synthelabo Research Grant. 2000.

\section{(PROVISIONAL) PATENTS}

Uses of immunologically modified scaffold for tissue prevascularization and cell transplantation. Hugo P Sondermeijer, Piotr Witkowski and Mark A Hardy (http://www.wipo.int/pctdb/en/wo.jsp?WO=2009039185).

\section{REVIEWER}

Human Immunology - ad hoc reviewer.

Transplant International - ad hoc reviewer.

\section{COURSES}

Good Clinical Practice (GCP) Course Certification. 2018.

New York Academy of Sciences. From Idea to IPO: The Technology Venture course. 2007.

Leiden University, the Netherlands. Experimental animal handling course. 2003.

\section{ABSTRACTS - ORAL PRESENTATIONS}

1. Yojiro Kato, Tomoaki Kato, Anette Wu, Adam D Griesemer, Hugo Sondermeijer, Andrea R Slate, David L Ruble, Tatsuo Kawai, Megan Sykes. The Use of Nonhuman Primates for Induction of Allograft Tolerance - a Preclinical Model. AFLAS 2012, Bangkok, Thailand.

2. Hugo P Sondermeijer, Leo Bühler, Alicia McMurchy, Yojiro Kato, Anette Wu, Adam Griesemer, Mercedes Martinez, Svetlan Boskovic, Yohei Yamada, Tatsuo Kawai, A Benedict Cosimi, Gilles Benichou, Neal Rex Smith, Andrea Slate, Thomas Wekerle, Megan Levings,Megan Sykes. Ex vivo recipient expanded regulatory T-cells promote prolonged mixed hematopoietic chimerism and renal allograft tolerance in a non-myeloablative non-human primate bone marrow transplantation model. American Transplant Congress, Boston, MA, 2012.

3. Hugo P Sondermeijer, Fiona See, Tetsunori Seki, Piotr Witkowski, David C Woodland, Mark A Hardy, Silviu Itescu. Biocompatible 3-dimensional RGD-modified alginate scaffold designed to enhance cell transplantation to infarcted myocardium. American Heart Association Scientific Sessions, New Orleans, 2008.

4. Witkowski P, Sondermeijer H, Lee K, Bhagat G, Rana A, Simpson N, Saxena CM , Van Heertum R, See F, Harris P, Itescu S, Hardy MA. Islet grafts into intramuscular space. A preliminary study using a biodegradable scaffold enriched with vascular growth factors. IPITA, IXA, CTS, Minneapolis, 2007. 
5. Piotr Witkowski, Hugo Sondermeijer, Govind Bhagat, Keagan Lee, Jin-Ming Xing, Norman Simpson, Ronald Van Heertum, Fiona See, Abbas Rana, Paul Harris, Silviu Itescu, Mark A. Hardy. Islet grafts into intramuscular space - a preliminary study using a bioscaffold enriched with vascular growth factors. Columbia University Medical Center, Surgical Residents' Competition (Second Prize), New York, 2007.

6. Fiona See, Timothy P Martens, Hugo P Sondermeijer, Tetsunori Seki, Silviu Itescu. Human mesenchymal precursor cells promote cardiomyocyte survival and hypertrophy, and improve cardiac function following acute infarction. American Heart Association Scientific Sessions, Chicago, 2006.

7. Fiona See, Tetsunori Seki, Timothy P Martens, Hugo P Sondermeijer, Silviu Itescu. Human mesenchymal precursor cells secrete paracrine factors which protect cardiac myocytes, prevent LV remodelling, and improve functional cardiac recovery following acute ischemia. American Heart Association Scientific Sessions, Chicago, 2006.

8. Henry Krum, Andrea Mortara, Hugo Sondermeijer. Reduced spectral component of low frequency heart rate variability is an independent predictor of morbidity and mortality in heart failure. Data from Val-HeFT. American Heart Association Scientific Sessions, Chicago, 2006.

9. Mortara, H. Krum, H. Sondermeijer, S. Barlera, R. Maestri, S. Masson, R. Latini, L. Tavazzi. Heart rate variability in the LF band is closely related to BNP levels in heart failure. Data from the multicenter Valsartan Heart Failure Trial (Val-HeFT). World Congress of Cardiology, Barcelona, 2006.

10. Piotr Witkowski, Tetsunori Seki, Guosheng Xiang, Timothy Martens, Hugo Sondermeijer, Fiona See, Michael Schuster, Mark A Hardy, Silviu Itescu. Local inhibition of plasminogen activator inhibitor type I (PAI-1) expression limits neointimal formation and restenosis after balloon angioplasty. Congress of the European Society for Surgical Research, RostockWarnemuende, 2006.

11. Piotr Witkowski, Michael Schuster, Guosheng Xiang, Tetsunori Seki, Timothy Martens, Hugo P Sondermeijer, Fiona C See, Allan W Tulloch Jr, Mark A Hardy, Silviu Itescu. Downregulated arterial expression of plasminogen activator inhibitor-type 1 (PAI-1) limits neointima formation after angioplasty in type 2 diabetic rodents. American Heart Association Scientific Sessions, Dallas, 2005.

12. Sondermeijer HP, M.S. Degree Graduation Lecture. CD34+ bone marrow derived stem cell therapy induces cardiac neovascularization in a model of chronic heart failure. Leiden, The Netherlands, 2005.

13. Sondermeijer HP, van Marle AGJ, Krum H, Kamen P. Caffeine reduces cardiac parasympathetic activity following acute ingestion in man. 3th Leiden International Medical Student's Congress, Leiden, The Netherlands, 2003.

14. Sondermeijer HP, van Marle AGJ, Krum H, Kamen P. Caffeine reduces cardiac parasympathetic activity following acute ingestion in man. World Congress Of Cardiology, Sydney, Australia, 2002. 


\section{ABSTRACTS - POSTER PRESENTATIONS}

1. Hugo Sondermeijer, Mark Hardy, David Woodland, Silviu Itescu, Michael Millis, Piotr Witkowski. Biocompatible, 3-dimensional, cyclic RGD-modified, purified alginate scaffold designed to enhance cell viability, neovascularization and efficacy of cell transplantation. Biomediscasummit, MECC, Maastricht, 2014.

2. Hugo P. Sondermeijer, Eric Ho, Geo Serban, George Vlad, Rodica Vasilescu, Donna Mancini, Adriana Colovai. Significance of anti-HLA antibodies detected by solid-phase assay in heart allograft recipients. ASHI 35 ${ }^{\text {th }}$ Annual Meeting, San Fransisco, 2009 and American Transplant Congress, San Diego, 2010.

3. Hugo Sondermeijer, Mark Hardy, David Woodland, Silviu Itescu, Michael Millis, Piotr Witkowski. Biocompatible, 3-dimensional, cyclic RGD-modified, purified alginate scaffold designed to enhance cell viability, neovascularization and efficacy of extrahepatic islet transplantation. IPITA, IXA, CTS, Venice, 2009, and Cardiovascular Research Initiative (CVRI), Columbia University Medical Center, 2010.

4. Hugo Sondermeijer, Fiona See, Piotr Witkowski, Tetsunori Seki, Mark Hardy, Silviu Itescu. Three dimensional RGD-modified alginate scaffold designed to enhance efficacy of cell transplantation to infarcted myocardium. American College of Cardiology, Orlando, 2009, and Cardiovascular Research Initiative (CVRI), Columbia University Medical Center, 2010.

5. Witkowski P, Sondermeijer H, Woodland, D, Lee K, Rana A, See F, Harris P, Itescu S, Hardy MA. Biodegradable scaffold enriched with vascular growth factors facilitates pancreatic islet engraftment into the intramuscular space. American Transplant Congress, Toronto, 2008.

6. Witkowski P, Sondermeijer H, Lee K, Rana A, See F, Harris P, Itescu S, Hardy MA. Islet grafts into intramuscular space. A preliminary study using a biodegradable scaffold enriched with vascular growth factors. Transplant Summit, Chicago, 2007.

7. Fiona See, Tetsunori Seki, Peter Psaltis, Timothy Martens, Stan Gronthos, Stephen Worthley, Hugo Sondermeijer, Klaas Govaert, Andrew Zannettino, SiIviu Itescu. Human Stro-1 Mesenchymal Precursor Cells Induce Proliferative Effects on Vascular Endotheial Cells and Smooth Muscle Cells via PI3 Kinase Dependent Pathways. American Heart Association, Orlando, 2007.

8. Govaert KM, See F, Sondermeijer HP, Itescu S. Human Bone Marrow Derived Mesenchymal Precursor Cells Secrete Paracrine Factors That Stimulate Vascular Cell Proliferation. Stem Cells Present and Future, Boston, 2007.

9. Sondermeijer HP, van Marle A, Krum H, Kamen P. Caffeine Reduces Cardiac Parasympathetic Activity Following Acute Ingestion in Man. European Student's Conference, Berlin, November, 2002. 